\title{
Development of METHANE de-NOX Reburn Process for Wood Waste and Biomass Fired Stoker Boilers FINAL REPORT
}

\author{
METHANE de-NOX ${ }^{\circledR}$ REBURN COMMERCIAL \\ TECHNOLOGY MANUAL
}

\author{
Prepared by: \\ J. Rabovitser, Bruce Bryan, S. Wohadlo, S. Nester, J. Vaught, M. Tartan \\ Gas Technology Institute \\ 1700 S. Mount Prospect Rd. \\ Des Plaines, IL 60018 \\ and \\ L. Szymanski and R. Glickert \\ ESA-Environmental Solutions \\ One Veterans Way, Suite 204 \\ Pittsburgh, PA 15106
}

GTI Project No. 15301 (61117)

\author{
Prepared for: \\ U.S. Department of Energy \\ Energy Efficiency and Renewable Energy \\ Award No. DE-FC36-99GO10418
}

December 2005 


\section{DISCLAIMER}

LEGAL NOTICE: This report was prepared by Gas Technology Institute (GTI) and ESA-Environmental Solutions (ESA-ES) as an account of work sponsored by the United States Department of Energy (DOE). Neither DOE, GTI, EAS-ES nor any of DOE, GTI or ESA-ES employees, or any person acting on their behalf:

a. Makes any warranty or representation, express or implied with respect to the accuracy, completeness, or usefulness of the information contained in this report, or that the use of any information, apparatus, method, or process disclosed in this report may not infringe privately owned rights; or

b. Assumes any liability with respect to the use of, or for any and all damages resulting from the use of, any information, apparatus, method, or process disclosed in this report. 


\section{Research Summary}

\section{Title METHANE de-NOX ${ }^{\circledR}$ Reburn Commercial Technology Manual}

Contractor Gas Technology Institute (GTI)

DOE Award Number: DE-FC36-99GO10418

Principal

Investigators

J. K. Rabovitser, B. Bryan, S. Wohadlo, S. Nester, J. Vaught, M. Tartan (GTI)

L. Szymanski, R. Glickert (ESA-Environmental Solutions)

Objective The overall objective of this project was to demonstrate the effectiveness of the METHANE de-NOX ${ }^{\circledR}$ (MdN) Reburn process in the Forest Products Industry (FPI) to provide more efficient use of wood and sludge waste (biosolids) combustion for both energy generation and emissions reduction (specifically from nitrogen oxides $\left(\mathrm{NO}_{\mathrm{x}}\right)$ ) and to promote the transfer of the technology to the wide range of wood waste-fired stoker boilers populating the FPI.

This document, MdN Reburn Commercial Technology Manual, was prepared to be a resource to promote technology transfer and commercialization activities of MdN in the industry and to assist potential users understand its application and installation requirements. The Manual includes a compilation of $\mathrm{MdN}$ commercial design data from four different stoker boiler designs that were baseline tested as part of the development effort. Design information in the Manual include boiler CFD model studies, process design protocols, engineering data sheets and commercial installation drawings. Each design package is unique and implemented in a manner to meet specific mill requirements.

Technical Recovering energy from by-product fuels consisting of biomass, Perspective wood wastes and solid residues are important in operating a mill efficiently. Wood waste fuels are typically burned to generate steam in a stoker boiler for process or power production; these boilers are commonly referred as a hog fuel-fired stoker boiler. Combustion of waste fuels can be limited by their low and variable heating value, high moisture content and presence of fuel-bound nitrogen content, however. High moisture wood waste and solid residue fuels are difficult to burn and contribute to poor fuel distribution which results in inefficient combustion and increased emissions of carbon monoxide (CO) and $\mathrm{NO}_{\mathrm{x}}$. Fuels with high nitrogen content such as secondary and tertiary treatment solids also contribute to increased $\mathrm{NO}_{\mathrm{x}}$ emissions, limiting the ability to fire these fuels in boilers operating near their $\mathrm{NO}_{\mathrm{x}}$ permit limit. Cofiring supplemental fuel 
such as natural gas through auxiliary burners helps to improve combustion effectiveness and reduce $\mathrm{NO}_{\mathrm{x}}$ emissions; however, these benefits are typically limited to the fractional input of the cofiring fuel.

Technical In 1988, a research team led by GTI developed a cost-effective $\mathrm{NO}_{\mathrm{x}}$ Approach reduction process for solid fuel-fired stoker applications called METHANE de-NOX (MdN). MdN is a patented reburn technology for reduction of $\mathrm{NO}_{\mathrm{x}}$ emissions solely for stoker furnaces. In this process, a portion of flue gas is recirculated (FGR) and combined with natural gas for injection above the grate combustion zone. Injection of reburn fuel with FGR in the lower furnace provides an oxygen-deficient environment, greater turbulence and mixing, and higher, more uniform temperatures. Less-oxidizing conditions at the grate promote the decomposition of fuel-bound nitrogen compounds to reduce nitrogen oxide formation. Increased temperatures generated above grate also boost the effectiveness of grate combustion. Air distribution between the undergrate and overfire air is also adjusted to reduce oxygen availability in the lower furnace and improve burnout in the upper furnace.

Successful commercial-scale demonstrations were conducted on municipal solid waste (MSW) operations and coal applications in the 1990s. Based on these past technology successes, DOE's Office of Industrial Technologies (OIT) through the Agenda 2020 initiative in 1997 provided support along with GRI, IGT, SMP and industrial partners in development efforts to adopt the MdN technology to applications in the FPI.

Results Field-evaluations (commonly called baseline tests) were conducted at four (4) different hog fuel-fired stoker boilers at pulp and paper mills located in the U.S. (International Falls MN, DeRidder LA; Port Hudson, LA; and Wallula WA). These selected stoker boilers covered a variety of different stoker design configurations; grates consisted of water cooled-vibratory, traveling spreader, and water cooled-stationary pinhole types. Physical dimensions of the furnace ranged from square to rectangular and pneumatic spreader type fuel distributors was common to all systems. Each boiler was equipped to co-fire natural gas from dedicated burners and bark was the major fuel constituent for grate combustion. Other waste fuels fired included waste water treatment sludges and non-condensable gases, both high volume low concentration (HVLC) and low volume high concentration (LVHC) streams.

Baseline Tests collected data about the boiler operation and chemical composition of in-furnace gases through sampling with special water-cooled probes. Analysis of this data provided the basis for: 1) determination of $\mathrm{NO}_{\mathrm{x}}$ formation zones in the furnace; 2) 
assessment of boiler variables impact on $\mathrm{NO}_{\mathrm{x}}$ emissions and 3) estimation of benefits from an MdN Reburn retrofit.

This development effort also included creation of a custom computational fluid dynamic (CFD) wood waste stoker boiler model using Fluent software, specifically to help in technology transfer, application, optimization and commercialization of the MdN process in the FPI.

Demonstration of MdN technology in the FPI was first implemented at a mill located in International Falls, MN. Performance with MdN provided significant benefits such as a 300\% increase in sludge combustion (savings in landfill volume and disposal costs); a 30\% decrease in natural gas usage, a $40 \%$ reduction in $\mathrm{NO}_{\mathrm{x}}$ emissions, and an increase of about $1 \%$ in thermal efficiency. A second MdN boiler retrofit design was commercially installed and successfully commissioned on hog fuel-fired boiler at the Port Hudson, LA mill in 2001. At Port Hudson, a 30-40\% reduction in $\mathrm{NO}_{\mathrm{x}}$ emission was achieved. Presently, both systems are in full-scale, continuous operation

Furthermore, a technology licensing agreement with Energy Systems Associates-Environmental Solutions (EAS-ES) located in of Pittsburgh, PA to market and install MdN reburn technology was successfully negotiated. ESA-ES's staff of engineers is skilled in combustion, boiler operation and emission control technologies.

Project METHANE de-NOX Reburn process applied to wood waste-fired Implications stoker boilers maximizes the use of hard-to burn industry byproducts such as wood waste solids, sludges and biomass through an effective use of natural gas to ease the cost of energy production and reduced emission of gaseous $\mathrm{NO}_{\mathrm{x}}$ in compliance with regulated environmental limits. The technology is cost-effective; relatively easy to retrofit and install.

GTI Project Manager

Stan Wohadlo

Senior Engineer, Power Generation 


\section{Executive Summary}

Pulp and paper companies comprise a highly energy-intensive industry in which production wastes such as bark, hog fuel and clarifier solids (sludge) are routinely used as fuel. Economic pressures are forcing pulping processes to utilize more of the wood fiber and the waste fuels available for steam and power generation. Recent enactment of EPA's cluster rules for the pulp and paper industry is resulting in more non-condensable gas (NCG) streams being generated and which require disposal in an economic and environmentally sound manner. Declining solid fuel quality and increasing combustion of waste gases is increasing dependence on expensive cofiring fuels like oil and natural gas to maintain combustion stability, steaming capacity and emissions limits in the industry's waste-fired boilers. Increasing prices for natural gas put a severe economic strain on the industry and underscore the need to develop more effective and economic combustion methods to recover energy from mill waste streams.

METHANE de-NOX (MdN), a natural gas-based reburn technology developed by GTI in the 1990s and already successfully demonstrated in commercial demonstrations on stoker boilers for power generation using municipal solid waste and coal as fuels provides improved combustion performance, reduction in emissions (specifically $\mathrm{NO}_{\mathrm{x}}$ ), and increased thermal efficiency compared to conventional gas cofiring schemes. As a result of these process benefits, a development project was awarded in 1999 under a DOE Cooperative Agreement DE-FC3699G010418 to extend and demonstrate the technology in applications related to the Forest Products Industry (FPI), specifically on hog fuel-fired stoker boilers found in pulp and paper operations. Later, additional funds were granted to study use of NCGs generated in a pulp and paper mill as replacement for a portion of the reburn fuel used in a conventional MdN retrofit; further reducing natural gas consumption and saving costs.

A major effort in the overall development activity included field evaluations of four (4) hog fuelfired stoker boilers at different pulp and paper mills located in the U.S., out of which then led to two (2) successful commercial-scale MdN installations, currently in continuous operation today. The first commercial-scale installation was for demonstration purposes on a bark and sludgefired stoker boiler rated at 200,000 lb/h MCR (maximum continuous rating) at Boise Cascade's mill in International Falls, MN. With MdN in operation, significant improvements in key boiler performance areas were achieved:

- $\quad$ Reduced emissions of stack $\mathrm{NO}_{\mathrm{x}}$ by over $40 \%$, equivalent to approximately 180 tons/boiler/yr with reburn natural gas injection at $9.5 \%$ of the boiler's thermal input

- Increased grate sludge combustion by a factor of 3, which reduced mill's landfill volume and sludge disposal costs (a \$396,000 reported savings per year)

- Increased boiler thermal efficiency by 1 to $2 \%$

- Decreased unburned carbon in bottom and fly ash by $30 \%$

- Performance of MdN boiler retrofit at International Falls recognized by industry with a 1999 AF\&PA Environmental and Energy Achievement Award 
The second MdN system was a commercial installation at a mill in Port Hudson LA where a 30$40 \%$ reduction in $\mathrm{NO}_{\mathrm{x}}$ emissions was achieved.

In an effort to promote the technology and its commercialization to the variety of hog fuel stoker boiler designs operating in the FPI, GTI developed a custom CFD stoker boiler model to provide basic MdN boiler retrofit design support and a tool for process optimization studies. A licensing agreement was executed with Energy Systems Associates-Environmental Solutions located in Pittsburgh PA to market the technology in North America. And this document, MdN Reburn Commercial Technology Manual, was prepared to serve as a resource to potential users in understanding the application and installation requirements of the technology. 


\section{Table of Contents}

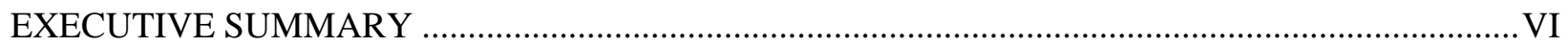

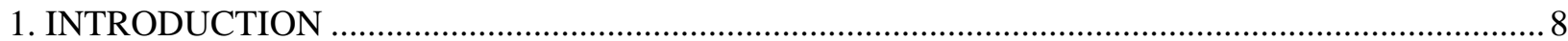

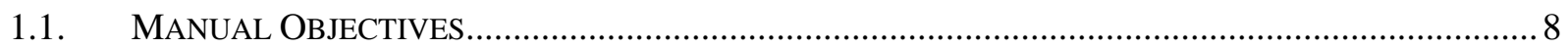

1.2. MdN REBURN PROCESS DEVELOPMENT - HISTORICAL PERSPECTIVE ....................................... 9

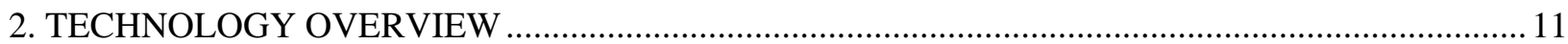

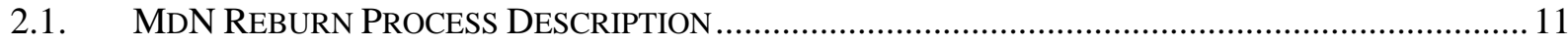

2.2. MDN REBURN PROCESS ELEMENTS ................................................................................... 13

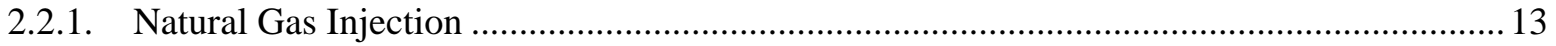

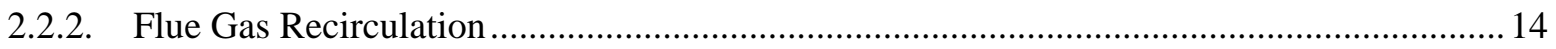

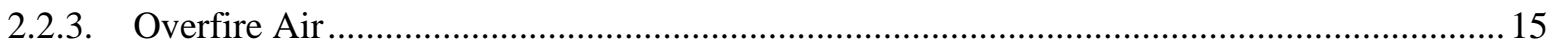

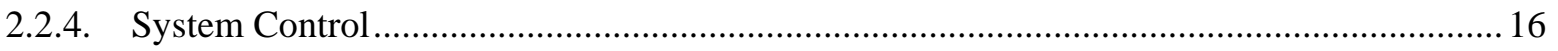

2.3. METHANE DE-NOX PROCESS FEATURES ….................................................................... 17

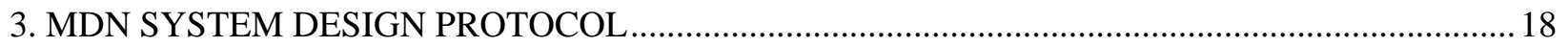

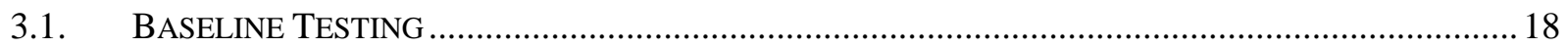

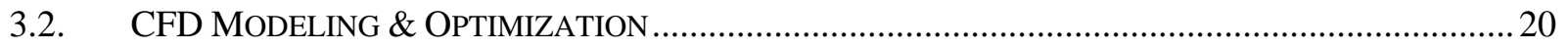

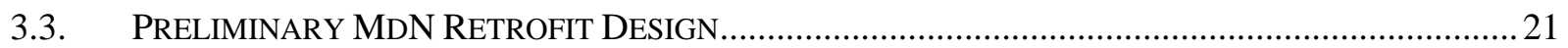

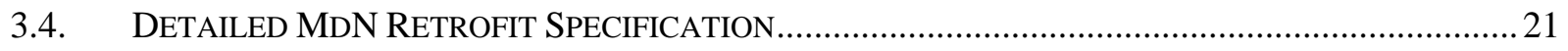

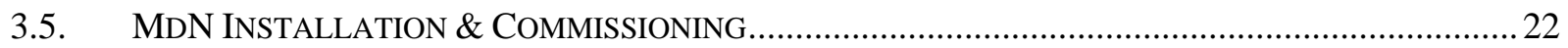

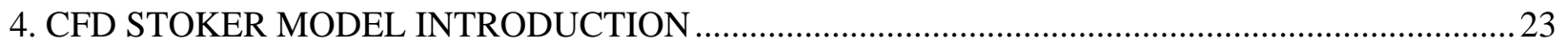

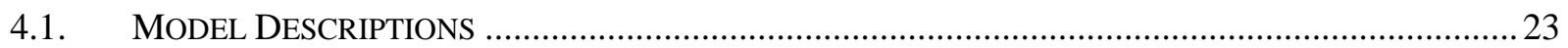

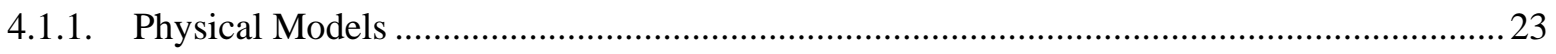

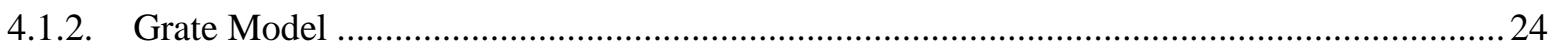

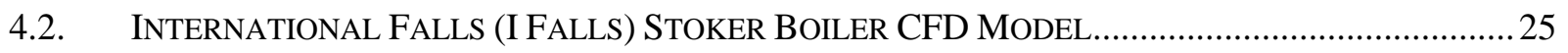

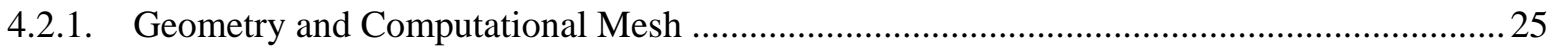

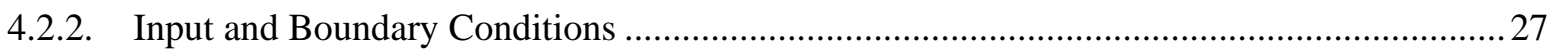

4.2.3. Validation of Stoker Boiler CFD Baseline Model ........................................................29

4.2.4. Comparison of Boiler Performance with CFD: Baseline Boiler Model versus with MdN

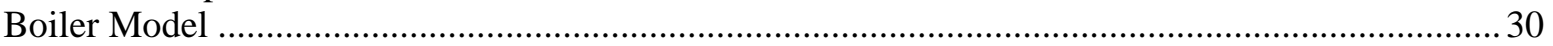

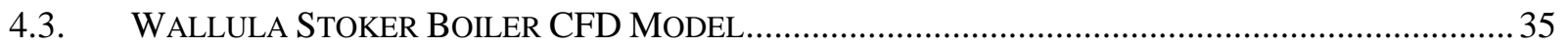

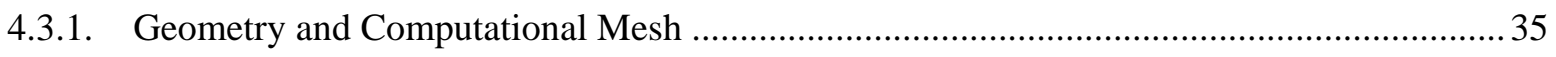

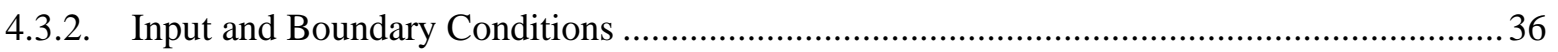

4.3.3. Validation of Stoker Boiler CFD Baseline Model ......................................................... 38

4.3.4. Comparison of Boiler Performance with CFD: Baseline Boiler Model versus Boiler Model

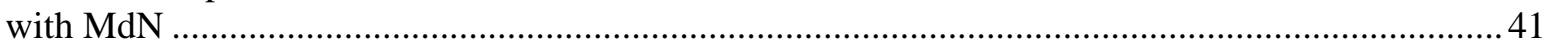

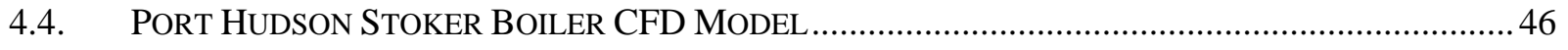

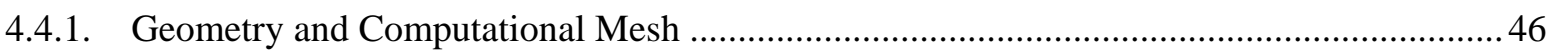

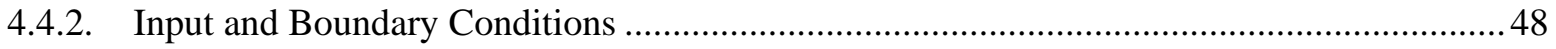

4.4.3. Validation of Stoker Boiler CFD Baseline Model .............................................................. 49

4.4.4. Comparison of Boiler Performance with CFD: Baseline Boiler Model versus Boiler Model

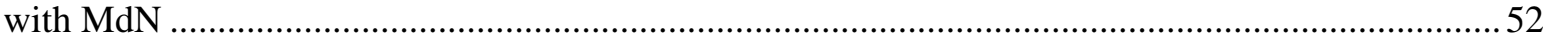

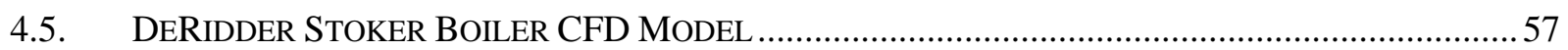


4.5.1. Geometry and Computational Mesh …......................................................................... 57

4.5.2. Input and Boundary Conditions ...................................................................................... 58

4.5.3. Validation of Stoker Boiler CFD Baseline Model ...........................................................60

4.5.4. Comparison of Boiler Performance with CFD: Baseline Boiler Model versus Boiler Model with $\mathrm{MdN}$

4.5.5. CFD Model Studies with Addition of SOG and NCG to MdN Retrofit Boiler ...................67

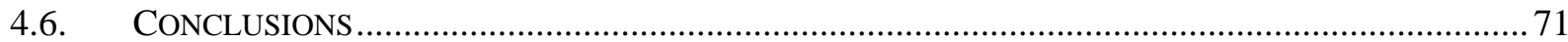

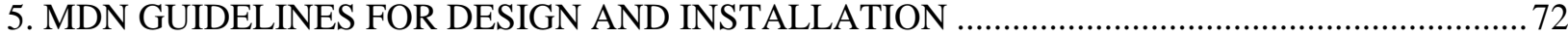

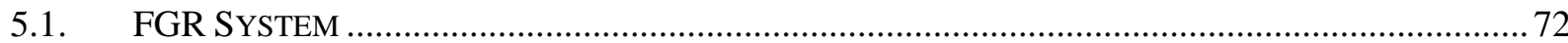

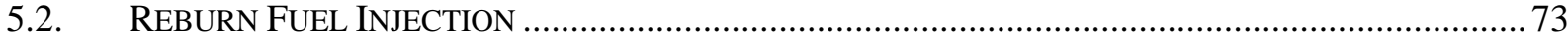

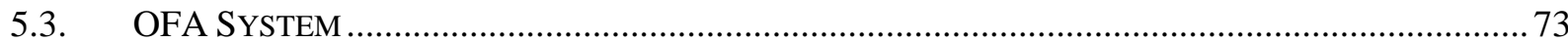

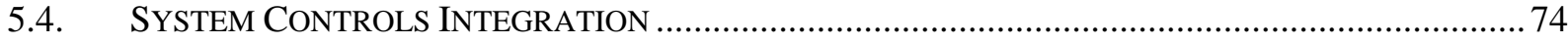

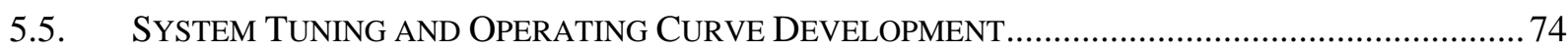

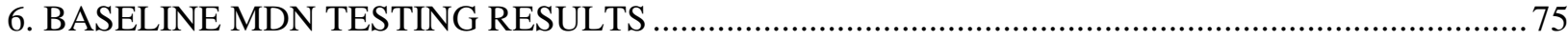

6.1 INTERNATIONAL FALLS MDN BASELINE TESTING.................................................................. 75

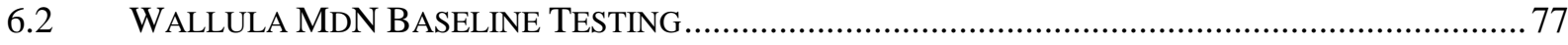

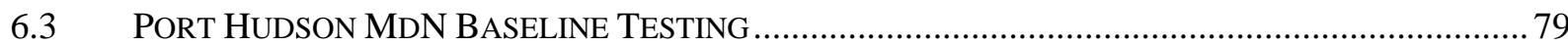

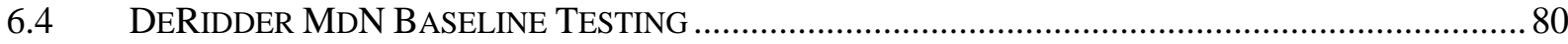

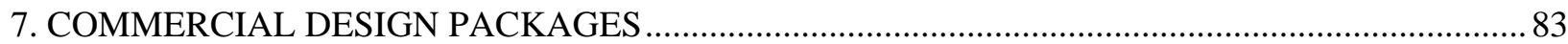

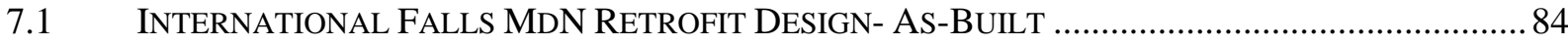

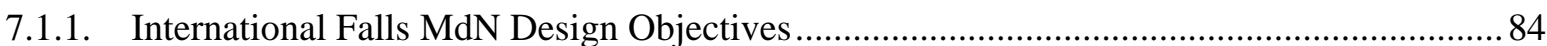

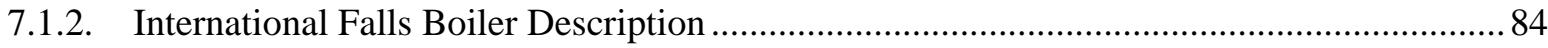

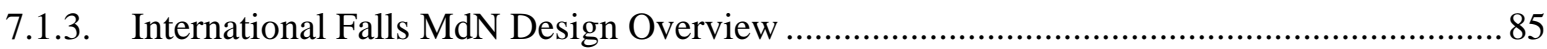

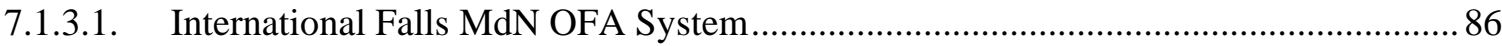

7.1.3.2. International Falls MdN Reburn Fuel Injection System............................................ 86

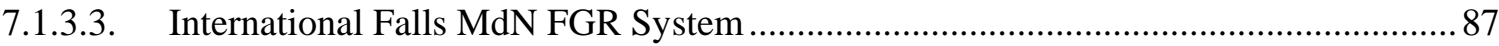

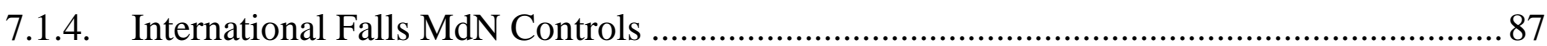

7.1.5. International Falls MdN System installation Cost Estimate.............................................. 88

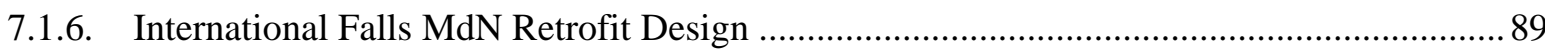

7.1.7. International Falls MdN System Drawings - Preliminary .................................................. 89

7.1.8. International Falls MdN System Equipment Specifications ........................................... 103

7.2. WALLULA Hog FUEL BOILER - PRELIMINARY RETROFIT DESIGN........................................ 136

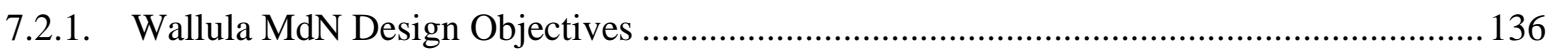

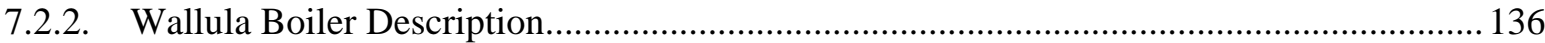

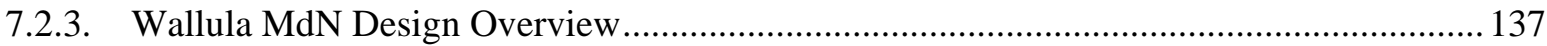

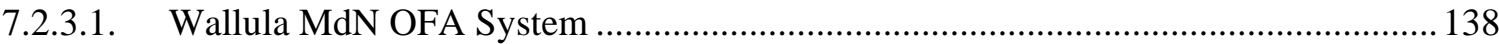

7.2.3.2. Wallula MdN Reburn Fuel Injection System .......................................................... 138

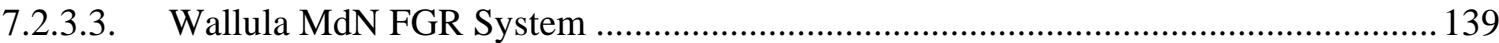

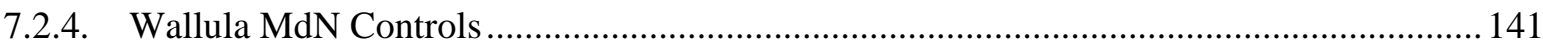

7.2.5. Wallula MdN System installation Cost Estimate ............................................................ 142

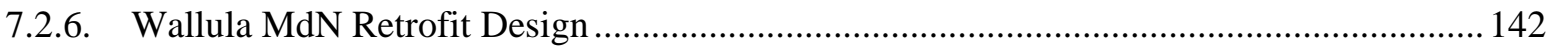

7.2.7. Wallula MdN System Drawings - Preliminary ............................................................... 143 
7.2.8. Wallula MdN System Equipment Specifications ............................................................ 155

7.3. PORT HUDSON MDN RETROFIT DESIGN- PRELIMINARY …................................................. 186

7.3.1. Port Hudson MdN Design Objectives ............................................................................... 186

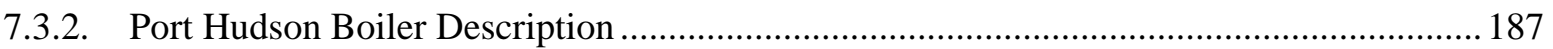

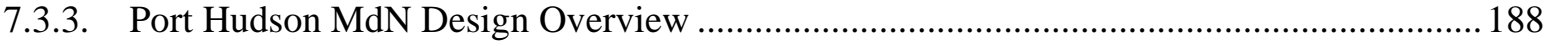

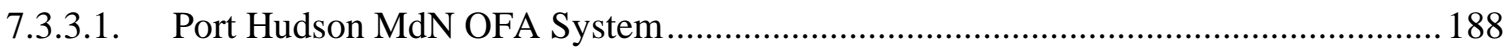

7.3.3.2. Port Hudson MdN Reburn Fuel Injection System ..................................................... 189

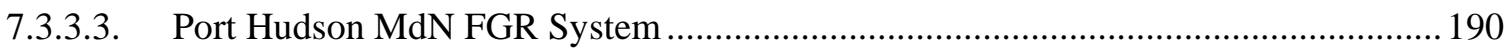

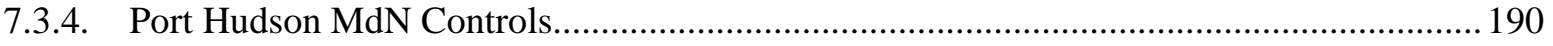

7.3.5. Port Hudson MdN System installation Cost Estimate....................................................... 191

7.3.6. Port Hudson MdN Detailed Retrofit Design .................................................................... 192

7.3.7. Port Hudson MdN System Drawings - Preliminary .......................................................... 192

7.3.8. Port Hudson MdN System Equipment Specifications ….................................................... 209

7.4. DERIDDER POWER BOILER No. 2 - PRELIMINARY RETROFIT DESIGN .................................. 249

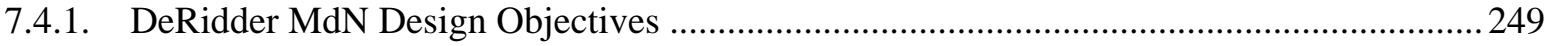

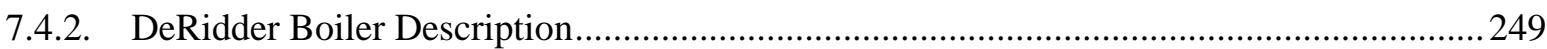

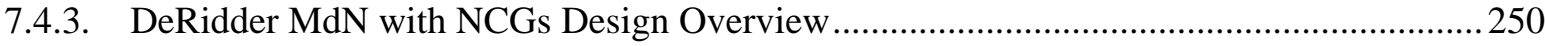

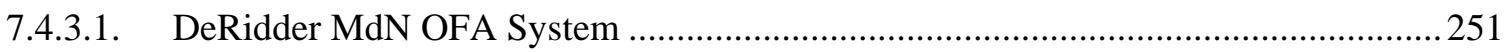

7.4.3.2. DeRidder MdN Reburn Fuel Injection System ...................................................... 251

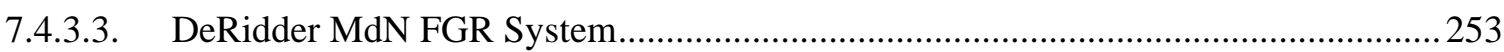

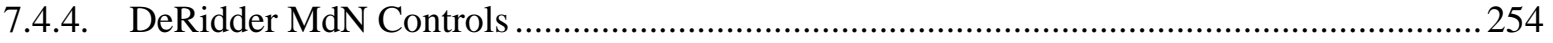

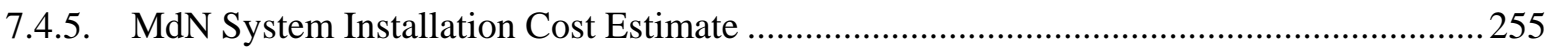

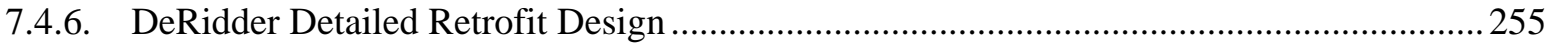

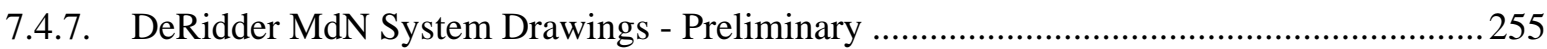

7.4.8. DeRidder MdN System Equipment Specifications ........................................................... 269

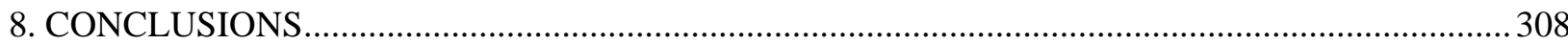

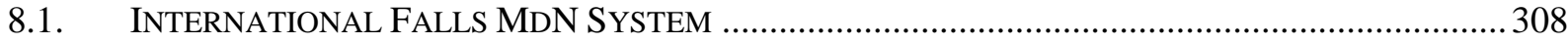

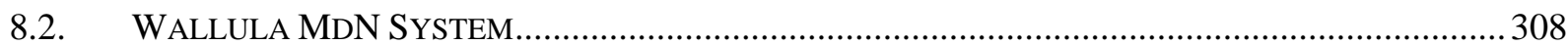

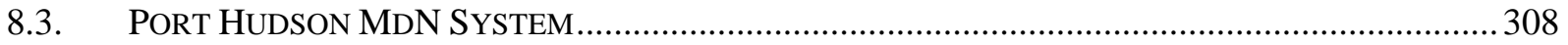

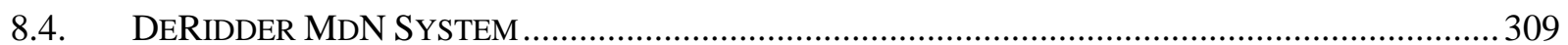




\section{List of Figures}

Figure 1-1 Pilot Scale Stoker Furnace for MdN development

Figure 2-1 MdN Reburn Process Diagram; fuel and air staging provides combustion improvement and reduced $\mathrm{NO}_{\mathrm{x}}$ emissions

Figure 2-2 Illustration of Fundamental MdN Process Elements involved in a Stoker Boiler Retrofit ....... 12

Figure 2-3 SOG and LVHC will be introduced separately into the natural gas/FGR injection headers.....12

Figure 2-4 Nozzle Mix Flow Schematic for MdN natural gas injection.................................................13

Figure 2-5 Premix Flow Schematic for MdN natural gas injection ........................................................ 14

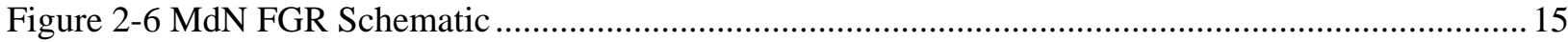

Figure 2-7 MdN New Proprietary OFA Compound Nozzle ............................................................... 16

Figure 3-1 A Typical Stoker Boiler Arrangement with Baseline test gas sample locations identified.......19

Figure 4-1 Small, Medium and Large Particle Trajectories (Blue section shows particle evaporation phase; Green section shows particle combustion phase; Red section shows particle burnout........... 25

Figure 4-2 I Falls Inlet Ports for Boiler Baseline Case ............................................................................ 26

Figure 4-3 I Falls Inlet Ports for Boiler MdN Retrofit Arrangement.....................................................26

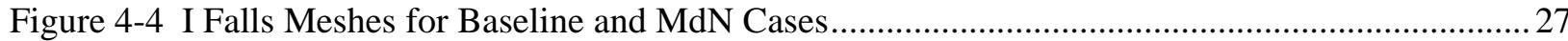

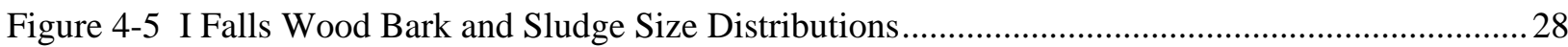

Figure 4-6 I Falls Comparison of $\mathrm{CFD} \mathrm{O}_{2}$ Concentration with Measured $\mathrm{O}_{2}$ (62 inch above grate).........29

Figure 4-7 I Falls Comparison of CFD Temperature with Measured Temperature (170 inch above grate)

Figure 4-8 I Falls Comparison of CFD CO with Measured CO (483 inch for Port7 and 585 inch for Port8

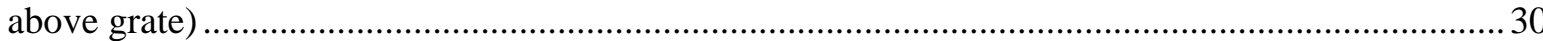

Figure 4-9 I Falls Comparison of Turbulent Kinetic Energy, $300 \mathrm{ft}^{2} / \mathrm{s}^{2}$ Iso-surface for Baseline and MdN

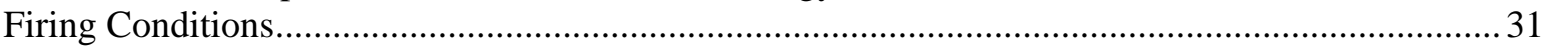

Figure 4-10 I Falls Contours of Temperature $\left({ }^{\circ} \mathrm{F}\right)$ for Baseline and MdN Firing Conditions ................... 31

Figure 4-11 I Falls Contours of Temperature $\left({ }^{\circ} \mathrm{F}\right)$ for Baseline and MdN Firing Conditions .................... 32

Figure 4-12 I Falls Contours of Mole Fraction of O2 (wet) for Baseline and MdN Firing Conditions..... 32

Figure 4-13 I Falls Contours of Mole Fraction of O2 (wet) for Baseline and MdN Firing Conditions..... 33

Figure 4-14 I Falls Contours of Mole Fraction of CO (wet and uncorr.) for Baseline and MdN Firing Conditions

Figure 4-15 I Falls Contours of Mole Fraction of CO (wet and uncorr.) for Baseline and MdN Firing Conditions

Figure 4-16 I Falls Iso-surfaces of CO Mole Fraction (3\% wet) for Baseline and MdN Firing Conditions

Figure 4-17 Wallula Inlet Ports for Boiler Baseline Case................................................................. 35

Figure 4-18 Wallula Inlet Ports for Boiler MdN Retrofit Arrangement ..................................................36

Figure 4-19 Wallula CFD Meshes for Baseline and MdN Cases .......................................................... 36

Figure 4-20 Wallula Wood Bark Size Distributions ............................................................................... 38

Figure 4-21 Wallula Comparison of Computed $\mathrm{O}_{2}$ Concentration with Measured $\mathrm{O}_{2}$ (18 inch above

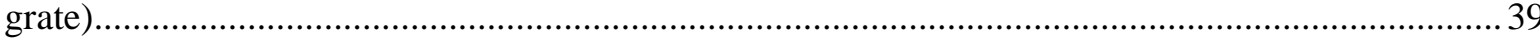

Figure 4-22 Wallula Comparison of Computed $\mathrm{O}_{2}$ Concentration with Measured $\mathrm{O}_{2}$ (83 inch above grate)

Figure 4-23 Wallula Comparison of Computed CO Concentration with Measured CO (18 inch above grate). 
Figure 4-24 Wallula Comparison of Computed CO Concentration with Measured CO (83 inch above grate).

Figure 4-25 Wallula Comparison of Computed $\mathrm{O}_{2}$ Concentration with Measured $\mathrm{O}_{2}$ (24 inch above grate).

Figure 4-26 Wallula Iso-surfaces of Turbulent Kinetic Energy Levels $\left(300 \mathrm{ft}^{2} / \mathrm{s}^{2}\right.$ ) for Baseline and MdN Firing Conditions.

Figure 4-27 Wallula Contours of Temperature (F) for Baseline and MdN Firing Conditions .................. 42

Figure 4-28 Wallula Contours of Temperature (F) for Baseline and MdN Firing Conditions ................. 43

Figure 4-29 Wallula Contours of Mole Fraction of O2 (wet) for Baseline and MdN Firing Conditions .. 43

Figure 4-30 Wallula Contours of Mole Fraction of $\mathrm{O}_{2}$ (wet) for Baseline and MdN Firing Conditions... 44

Figure 4-31 Wallula Contours of Mole Fraction of CO (wet and uncorr.) for Baseline and MdN Firing Conditions

Figure 4-32 Wallula Contours of Mole Fraction of CO (wet and uncorr.) for Baseline and MdN Firing Conditions

Figure 4-33 Wallula Iso-surfaces of CO Mole Fraction (3\% wet) for Baseline and MdN Firing

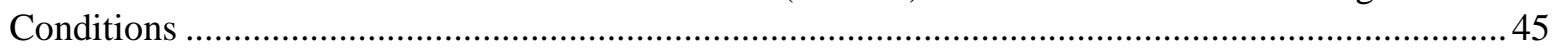

Figure 4-34 Port Hudson Inlet Ports for Boiler Baseline Case ....................................................... 46

Figure 4-35 Port Hudson Inlet Ports for Boiler MdN Retrofit Arrangement.......................................... 47

Figure 4-36 Port Hudson CFD Meshes for Baseline and MdN Cases ................................................... 47

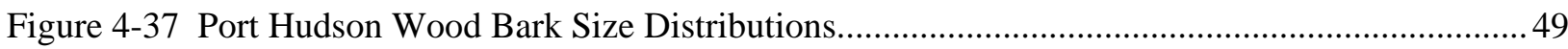

Figure 4-38 Port Hudson Comparison of Computed O2 Concentration with Measured $\mathrm{O}_{2}$ (18 inch above

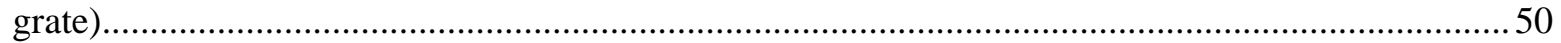

Figure 4-39 Port Hudson Comparison of Computed Temperature with Measured Temperature (18 inch

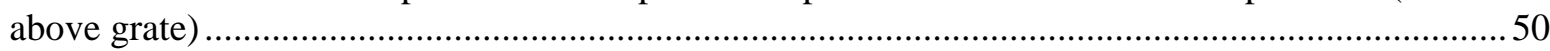

Figure 4-40 Port Hudson Comparison of Computed $\mathrm{O}_{2}$ Concentration with Measured $\mathrm{O}_{2}$ (180 inch

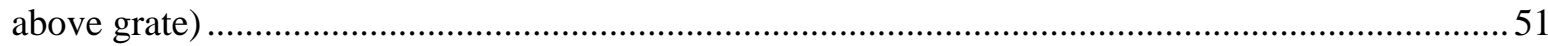

Figure 4-41 Port Hudson Comparison of Computed CO Concentration with Measured CO (180 inch

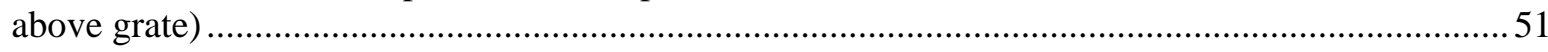

Figure 4-42 Port Hudson Comparison of Turbulent Kinetic Energy, $300 \mathrm{ft}^{2} / \mathrm{s}^{2}$ Iso-surface for Baseline

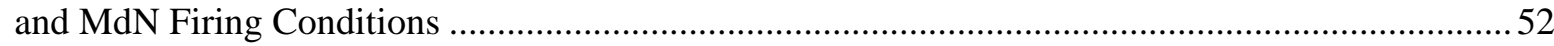

Figure 4-43 Port Hudson Contours of Temperature (F) for Baseline and MdN Firing Conditions........... 53

Figure 4-44 Port Hudson Contours of Temperature (F) for Baseline and MdN Firing Conditions........... 53

Figure 4-45 Port Hudson Contours of Mole Fraction of $\mathrm{O}_{2}$ (wet) for Baseline and MdN Firing Conditions

Figure 4-46 Port Hudson Contours of Mole Fraction of $\mathrm{O}_{2}$ (wet) for Baseline and MdN Firing Conditions

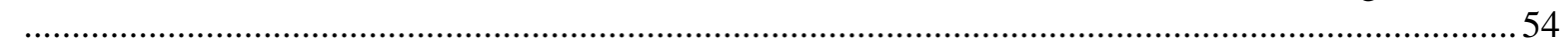

Figure 4-47 Port Hudson Contours of Mole Fraction of CO (wet and uncorr.) for Baseline and MdN

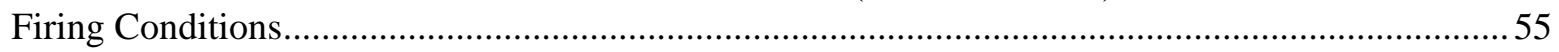

Figure 4-48 Port Hudson Contours of Mole Fraction of CO (wet and uncorr.) for Baseline and MdN

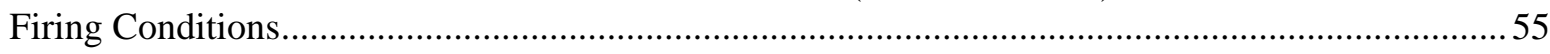

Figure 4-49 Port Hudson Iso-surfaces of CO Mole Fraction (3\% wet) for Baseline and MdN Firing

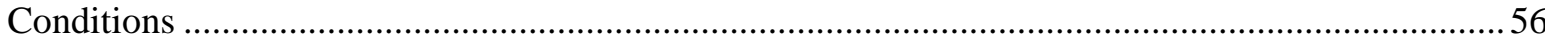

Figure 4-50 DeRidder Inlet Ports for Boiler Baseline Case.................................................................. 57

Figure 4-51 DeRidder Inlet Ports for Boiler MdN Retrofit Arrangement ..............................................57

Figure 4-52 DeRidder Meshes for Baseline and MdN Cases .................................................................. 58 
Figure 4-53 DeRidder Wood Bark Size Distributions ..... 60

Figure 4-54 DeRidder Comparison of Computed $\mathrm{O}_{2}$ Concentration with Measured $\mathrm{O}_{2}$ (12 inch above grate).

Figure 4-55 DeRidder Comparison of Computed O2 Concentration with Measured O2 (216 inch above grate).

Figure 4-56 DeRidder Comparison of Computed $\mathrm{O}_{2}$ Concentration with Measured $\mathrm{O}_{2}$ (459 inch above grate).

Figure 4-57 DeRidder Comparison of Computed CO Concentration with Measured CO (12 inch above grate)

Figure 4-58 DeRidder Comparison of Computed Temperature with Measured Temperature (216 inch above grate)

Figure 4-59 DeRidder Turbulent Kinetic Energy Iso-surfaces, $300 \mathrm{ft}^{2} / \mathrm{s}^{2}$, for Baseline and MdN Firing Conditions

Figure 4-60 DeRidder Contours of Temperature (F) for Baseline and MdN Firing Conditions 64

Figure 4-61 DeRidder Contours of Temperature $\left({ }^{\circ} \mathrm{F}\right)$ for Baseline and MdN Firing Conditions .64

Figure 4-62 DeRidder Contours of Mole Fraction of $\mathrm{O}_{2}$ (wet) for Baseline and MdN Firing Conditions 65

Figure 4-63 DeRidder Contours of Mole Fraction of $\mathrm{O}_{2}$ (wet) for Baseline and MdN Firing Conditions 65 Figure 4-64 DeRidder Contours of Mole Fraction of CO (wet and uncorrected) for Baseline and MdN Firing Conditions.

Figure 4-65 DeRidder Contours of Mole Fraction of CO (wet and uncorrected) for Baseline and MdN

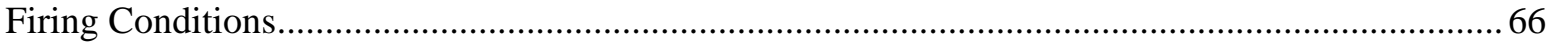

Figure 4-66 DeRidder Iso-surfaces of CO Mole Fraction (3\% wet) for Baseline and MdN Firing Conditions

Figure 4-67 DeRidder Particle Traces Colored by Particle Residence Time (s) for MdN Firing Conditions.

Figure 4-68 DeRidder Contours of Temperature $\left({ }^{\circ} \mathrm{F}\right)$ for MdN with SOG and NCG Addition ................ 70

Figure 4-69 DeRidder Contours of Mole Fraction of $\mathrm{O}_{2}$ (wet) for MdN with SOG and NCG Addition .. 70

Figure 4-70 DeRidder Contours of Mole Fraction of CO (wet and uncorrected) for MdN with SOG and

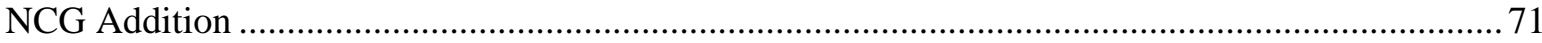

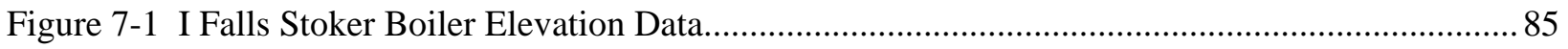

Figure 7-2 Wallula Boiler Elevation Data .................................................................................. 137

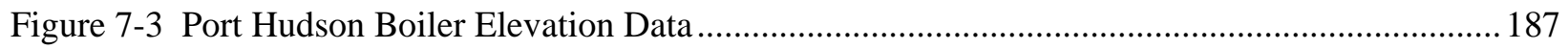

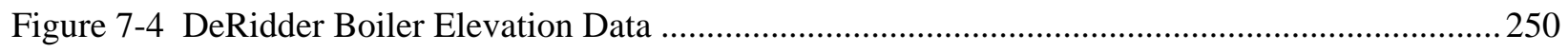




\section{List of Tables}

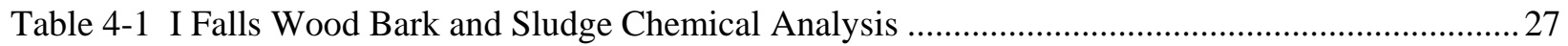

Table 4-2 I Falls Flow Rates of Injected Gas and Solids for Baseline and MdN Cases ...........................28

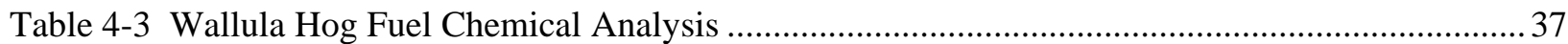

Table 4-4 Wallula Flow Rates of Injected Gas and Solids for Baseline and MdN Cases......................... 38

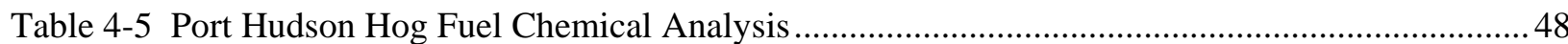

Table 4-6 Port Hudson Flow Rates of Injected Gas and Solids for Baseline and MdN Cases ................. 49

Table 4-7 DeRidder Wood Bark Chemical Analysis ............................................................................ 59

Table 4-8 DeRidder Flow Rates of Injected Gas and Solids for Baseline and MdN Cases...................... 59

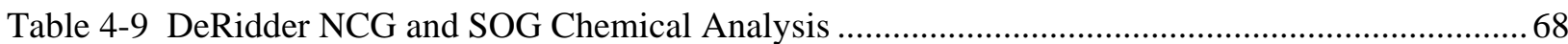

Table 4-10 DeRidder Flow Rates of Injected Gas and Solids for MdN Case with NCG and SOG Injection 69

Table 6-1 I Falls MdN Baseline Conditions for Tests 1-4............................................................. 75

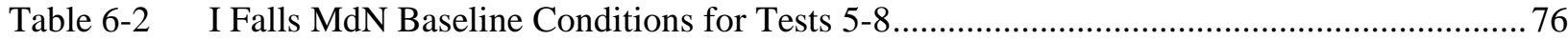

Table 6-3 I Falls MdN Baseline Conditions for Tests 9-12 ............................................................... 76

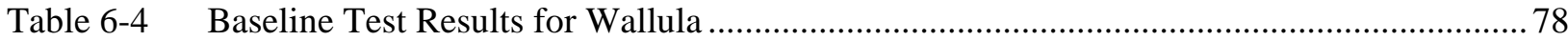

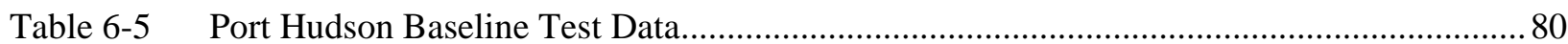

Table 6-6 DeRidder MdN Baseline Boiler Operating Conditions for Tests 1-10 _...........................81

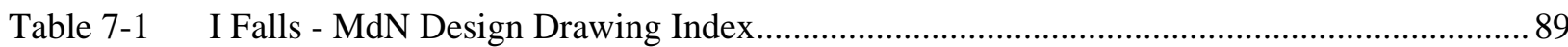

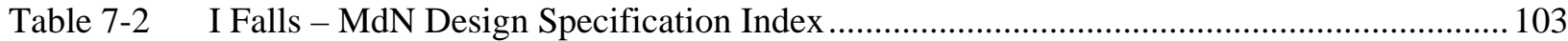

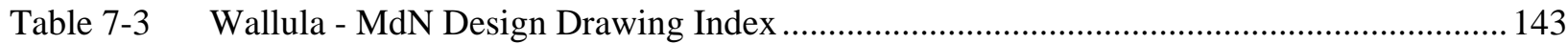

Table 7-4 Boise Wallula - MdN Design Specification Index ….....................................................155

Table 7-5 Port Hudson - MdN Design Drawing Index.................................................................. 192

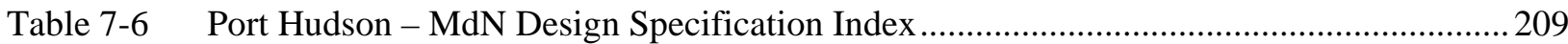

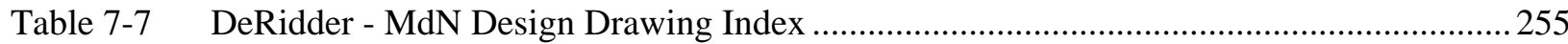

Table 7-8 Boise DeRidder - MdN Design Specification Index ....................................................... 269 


\section{Introduction}

The Gas Technology Institute (GTI) with support from the U.S. Department of Energy (DOE) Office of Energy Efficiency and Renewable Energy Industrial Technologies Program successfully led a team effort in a technology development program (DOE Cooperative Agreement DE-FC36-99GO10418) to extend and demonstrate GTI's METHANE de-NOX (MdN) Reburn technology for applications in the Forest Products Industry (FPI), specifically on hog fuel stoker boilers commonly found in pulp and paper operations. MdN technology was selected because it had shown improved economic, energy and environmental benefits (specifically reduction in $\mathrm{NO}_{\mathrm{x}}$ emissions) compared to conventional cofired schemes with past demonstrations on stokers firing MSW and coal. A baseline trial of a 200,000 lb/h steam (MCR) wood waste stoker boiler at Boise Cascade's International Fall's MN paper mill gave favorable results and became the first commercial-scale demonstration of MdN technology. Construction of this hog fuel-fired stoker boiler included a water-cooled, vibrating grate and windswept pneumatic fuel distributors. With MdN in service, overall boiler performance improvements (discussed later in the document) met all desired objectives of the mill.

Development activities continued to explore application of MdN technology in the FPI and three more baseline field trials of hog fuel stoker boilers were conducted at different U.S. pulp and paper mills to study the impact of MdN performance in stoker boilers with different designs such as a different grate types and furnace configurations. In each instance, analysis of baseline boiler test data showed potential for improved operation with an MdN reburn boiler retrofit as compared to baseline performance.

\subsection{Manual Objectives}

In an effort to promote consideration of the MdN technology in the FPI, GTI along with assistance from Energy Systems Associates-Environmental Solutions (ESA-ES), the technology licensee (Pittsburgh PA), created this MdN Reburn Commercial Technology Manual (Manual). Stoker boilers populating the FPI consist of a wide range of design configurations and potential users giving consideration of implementing the $\mathrm{MdN}$ technology can readily see the adaptability of MdN technology to fit a variety of boiler arrangement as is illustrated in the four commercial design packages presented in this Manual. Process information and design data contained in the Manual is intended to give potential users a review of the technology and a road map or a guide for the installation of an MdN system. This Manual shows the approach in designing and supplying an MdN system from baseline testing and site evaluation to CFD modeling to equipment selection and engineering specifications.

GTI and ESA-ES designed each MdN system to the specific requirements of the mill. The MdN systems installed to date incorporated the key functions of the technology in varying ways. Some systems utilized existing OFA systems, while others have installed MdN OFA systems. Design efforts continually look at novel ways to minimize system and installation costs. Systems have been designed to utilize existing ports and others have required new boiler penetrations. The MdN technology is customized to each boiler to provide improved grate combustion and cost effective $\mathrm{NO}_{\mathrm{x}}$ control. 


\subsection{MdN Reburn Process Development - Historical Perspective}

METHANE de-NOX Reburn is a proven technology, already having been demonstrated in stoker combustion systems firing municipal solid waste (MSW) and coal for power and steam production. GTI technology development activities started in the late 1980's first targeting applications for reduction of $\mathrm{NO}_{\mathrm{x}}$ emissions from MSW mass burn combustors. Laboratory tests were originally conducted in a $0.4 \mathrm{MMBtu} / \mathrm{h}$ test furnace and later process tests conducted in a 3 MMBtu/h pilot-scale stoker (see Figure 1-1) test furnace to show proof of concept of the reburn process.

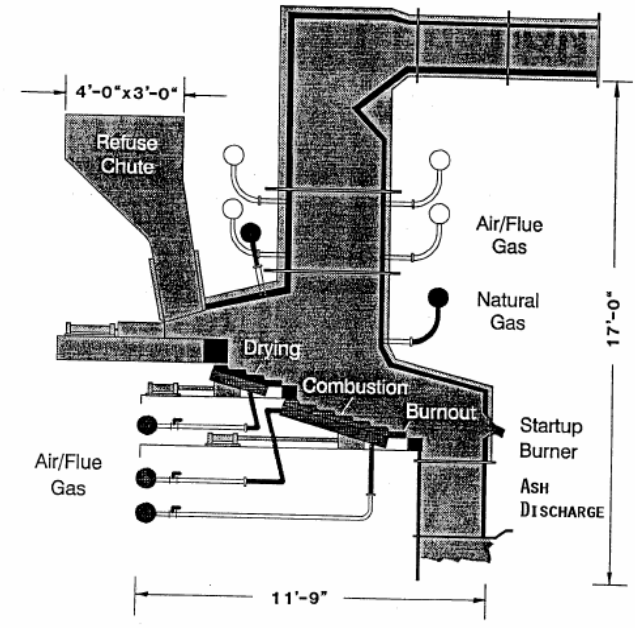

Figure 1-1 Pilot Scale Stoker Furnace for MdN development
The first commercial-scale demonstration of the MdN process was made at Olmsted County Waste-to-Energy facility in Rochester, $\mathrm{MN}$ in 1990 on a 100 ton/day municipal waste combustor (MWC). Operation of the MWC with $\mathrm{MdN}$ installed gave favorable results, confirming the MdN Reburn technology. Emissions of $\mathrm{NO}_{\mathrm{x}}$ were reduced by $50 \%$; emissions of $\mathrm{CO}$ were reduced by $40 \%$ and the boiler thermal efficiency was increased by $2.5 \%$. Commercialization of the technology in MSW applications includes two $\mathrm{MdN}$ installations both located in Japan; one is on a 80 ton/day unit for low calorific value MSW fuel and the other on a 330 ton/day MSW unit in Osaka, Japan.

Later, another development opportunity came about to evaluate MdN on coal-fired stoker applications. In 1996, GTI teamed with Cogentrix, an independent power producer, to install MdN technology on a $360 \mathrm{MMBtu} / \mathrm{h}$ coal-fired stoker boiler at their cogeneration facility in Richmond, Virginia. The MdN technology replaced a problem plagued SNCR system for control of stack $\mathrm{NO}_{\mathrm{x}}$ emissions. With MdN in operation, the coal-fired stoker performance achieved a $70 \%$ reduction in $\mathrm{NO}_{\mathrm{x}}$ while $\mathrm{CO}$ emissions were controlled in compliance with state's regulations. A $1 \%$ increase in boiler thermal efficiency was observed as well. Based on these results, Cogentrix retrofitted the remaining seven boilers at their Richmond, Virginia facility with MdN systems.

Given these positive results with MSW and coal, GTI was awarded additional support to study the application of reburn technology in the FPI. In 1997, GTI teamed with Boise Cascade's International Falls (I Falls) Minnesota pulp and paper mill to install for demonstration purposes a commercial-scale MdN reburn system on its bark and sludge-fired hog fuel stoker, Boiler \#2. The project goal was to show proof of MdN reburn technology impact on applications in the FPI to maximize use of waste materials and biomass that are by-products of the industry for energy generation in an efficient and environmentally sound manner. 


\section{MdN Forest Product Industry Applications}

In December 1999, the I Falls MdN boiler retrofit was commissioned. Specific goals of the mill aimed at reducing the landfill volume requirements for their waste water treatment plant residuals (sludge) by burning more sludge in the mills No. 2 hog fuel stoker boiler. Without MdN, maximum sludge combustion for the boiler was reported at about 1.2 tons per hour and stack $\mathrm{NO}_{\mathrm{x}}$ was within but just below permitted limits. Attempts at increasing sludge combustion were unsuccessful because of stoker grate combustion problems (piling) and stack $\mathrm{NO}_{\mathrm{x}}$ emissions exceeded permitted limits. With MdN, I Fall's No. 2 boiler was able to increase sludge combustion by $200 \%$; reduce emissions of stack $\mathrm{NO}_{\mathrm{x}}$ below permitted limits and increase boiler thermal efficiency by $1.5 \%$. In addition, observations of long term operation showed no signs of internal furnace problems such as from fouling or erosion.

The second baseline trial was conducted at a paper mill in Wallula WA in April 2001 on a hog fuel stoker boiler equipped with a stationary pinhole grate, a square furnace and cinder reinjection. Analyses of baseline data indicated a potential for increased bark combustion and a reduction in natural gas usage as a result of $\mathrm{MdN}$ technology's effective use of natural gas in the reburn process compared to the conventional co-firing scheme. The results created interest, but restricted funds for capital projects at the mill limited further consideration at the time.

The next baseline trial occurred at a pulp and paper mill located in Port Hudson LA in March 2002 and which later became the site of the second commercial installation for MdN Reburn technology. The Port Hudson mill stoker boiler consisted of a traveling grate with a rectangular furnace and injection undergrate of a high volume low concentration (HVLC) waste gas. This mill's main objective was to achieve a steep reduction in emissions of $\mathrm{NO}_{\mathrm{x}}$ while maximizing bark combustion. In this application, the MdN boiler retrofit design included a new overfire air system. The OFA ports, located higher in the furnace, were installed to provide increased furnace volume with which to sustain reburn chemistry reactions. Initial commissioning efforts performed in February 2003 achieved reasonable performance in reduction in $\mathrm{NO}_{\mathrm{x}}$ emissions, however higher levels than normal of $\mathrm{CO}$ were measured in the boiler flue gases. With continued support from the mill, further modification was made to the MdN retrofit that included re-activation of one row of decommissioned OFA ports and the redistribution of recirculated flue gases (FGR) with a portion mixed with overfire air. Subsequent performance tests conducted in May 2004 showed CO levels back to accepted operational levels and a reduction of about $35 \%$ in emissions of $\mathrm{NO}_{\mathrm{x}}$ was achieved.

The last baseline trial was conducted at a pulp and paper mill at DeRidder LA in June of 2002. This mill's hog fuel-fired stoker had a traveling grate, a square furnace and cinder re-injection provisions. Of interest to mill staff was the reduction of boiler $\mathrm{NO}_{\mathrm{x}}$ through an enhanced $\mathrm{MdN}$ boiler retrofit scheme that utilized process generated wastes gases such as off-gases from the mill's foul condensate stripper and non-condensable gases to replace a portion of reburn fuel and consequently reduce consumption of natural while safely disposing of waste gases. Plans to retrofit the mill's boiler were in place; however because of a delays and changes in the mill's business environment, the retrofit was canceled. 


\section{Technology Overview}

\subsection{MdN Reburn Process Description}

\section{Base METHANE de-NOX Technology Background}

The firing of biosolids can be limited by the low heating value and presence of bound nitrogen in these fuels. High moisture fuels result in inefficient combustion due to the latent heat of water vapor that is lost to the stack. High fuel moisture biosolids can also contribute to poor fuel distribution and piling, resulting in poor undergrate air distribution, uneven combustion at the grate, and increased emissions of $\mathrm{CO}$ and $\mathrm{NO}_{\mathrm{x}}$. Fuels with high nitrogen content such as secondary and tertiary treatment solids also contribute to increased $\mathrm{NO}_{\mathrm{x}}$ emissions, limiting the ability to fire these fuels in boilers operating near their NOx permit limit. Cofiring supplemental fuel such as natural gas through auxiliary burners helps to improve combustion effectiveness and to reduce $\mathrm{NO}_{\mathrm{x}}$ emissions. However, these benefits are typically limited to the fractional input of the cofiring fuel.

The MdN reburn process uses both fuel- and air-staging to improve combustion and reduce boiler

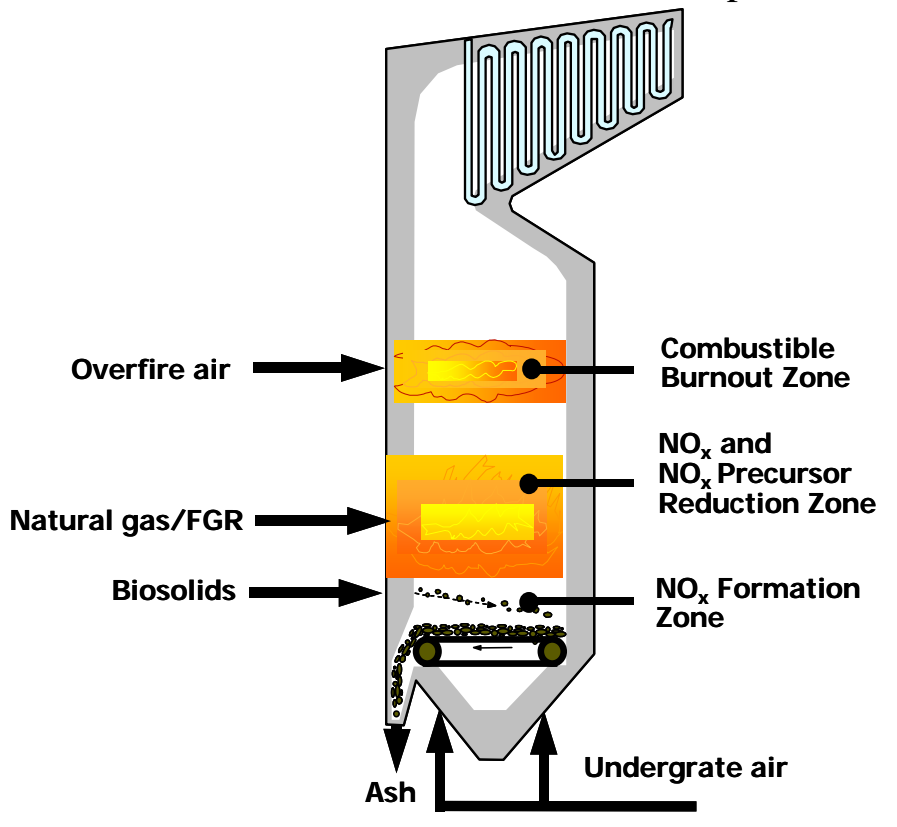

Figure 2-1 MdN Reburn Process Diagram; fuel and air staging provides combustion improvement and reduced $\mathrm{NO}_{\mathrm{x}}$ emissions emissions. A small amount of natural gas (5 - 20\% of the thermal input) and recirculated flue gas (FGR) is injected above the stoker grate to create a well-mixed, oxygen-deficient atmosphere immediately above the primary combustion zone (Figure 2-1). Air distribution between the undergrate and overfire air is also adjusted to reduce oxygen availability in the lower furnace and improve burnout in the upper furnace. Hotter and less-oxidizing conditions at the grate promote the decomposition of fuel-bound nitrogen compounds to reduce nitrogen oxide formation, while deeper air staging improves burnout in the upper furnace and allows operation with lower excess air. The added heat release and gas mixing at the stoker grate also improves combustion of difficult-to-burn wood waste fuels. As a result, more high-moisture waste fuels can be burned, while reducing $\mathrm{NO}_{\mathrm{x}}$ emissions, stabilizing combustion and improving boiler efficiency through reduced carbon losses and operation with lower excess air.

Fundamental elements in an MdN boiler retrofit are shown in Figure 2.2 and consists of a: 1) Natural Gas Injection System; 2) Recirculated Flue Gas System; 3) Overfire Air System (OFA modifications site dependent) and 4) System Control and Integration. 


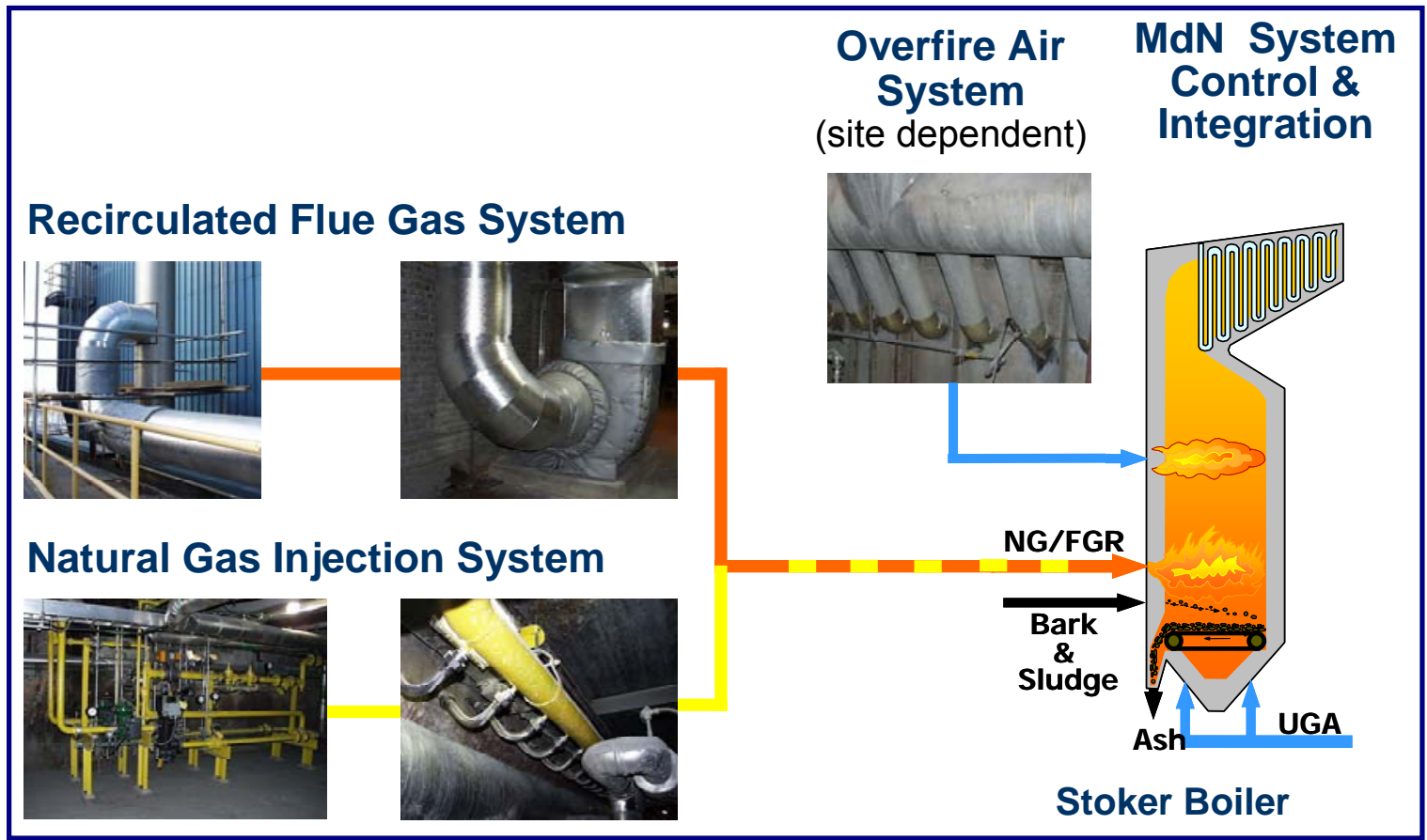

Figure 2-2 Illustration of Fundamental MdN Process Elements involved in a Stoker Boiler Retrofit

Extension of METHANE de-NOX with NCGs Technology Background

An extension to the basic MdN process was introduced after discussions at the Boise DeRidder paper mill introduced the concept of using residual energy content in mill generated waste gases such as from a low volume high concentration non condensable gas (NCG) collection system or from waste gases from a mill Foul Condensate Striping System (SOG) to provide a source of reburn fuel and replace a portion of natural gas usage in the MdN process. With this scheme (Figure 2.3), introduction of LVHC and SOG in the primary combustion zone above the grate, should make the system meet current MACT control requirements and if adequate destruction of NCG is demonstrated, it will be possible to reduce or eliminate the need for firing the auxiliary gas burners. A reduction in natural gas

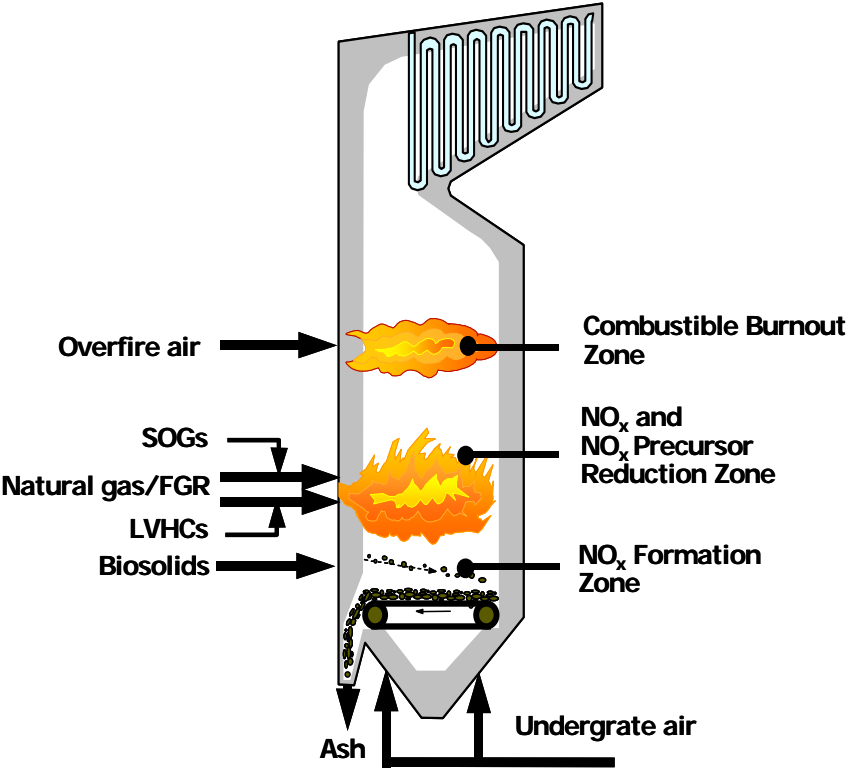

Figure 2-3 SOG and LVHC will be introduced separately into the natural gas/FGR injection headers consumption of $25-30 \%$ is expected as compared with the conventional MdN process demonstrated at I Falls. A planned technology demonstration at the DeRidder mill did not come about due to a changing business climate, however. 


\subsection{MdN Reburn Process Elements}

\subsubsection{Natural Gas Injection}

With MdN technology, the reburn fuel of choice is natural gas because it is clean burning and easily handled. The injection of natural gas assists in creating an oxygen deficient environment as well as combustion radicals, which give support to the reburn reactions. Reburn fuel is combined with FGR and the mixture carried into the furnace through dedicated injection ports strategically aimed at a location a little above the stoker grate. An MdN system design with natural gas for reburn fuel is typically sized to provide fuel based between 5 and $20 \%$ of the total boiler heat input. Other reburn fuels such as propane can be used and are expected to have similar results if used in place of natural gas

Management and control of the reburn fuel is achieved through a dedicated fuel train arrangement, consisting of piping and control hardware as shown in the natural gas injection schematic, Figure 2-4. Figure 2-4 shows a nozzle-mix method of combining natural gas with FGR. In this scheme gas flows through a central tube (called a quill) positioned in the nozzle; an FGR stream flows in the outer space. The quill outlet is recessed in the nozzle to provide some premixing before the FGR/gas mixture enters the furnace. An alternative arrangement referred as a premix method for combining natural gas with FGR is given in Figure 2-5. This scheme utilizes a gas mixer in the FGR duct to make an FGR/gas premix before the OFA header assembly. Both schemes have been used successfully and provided similar performance.

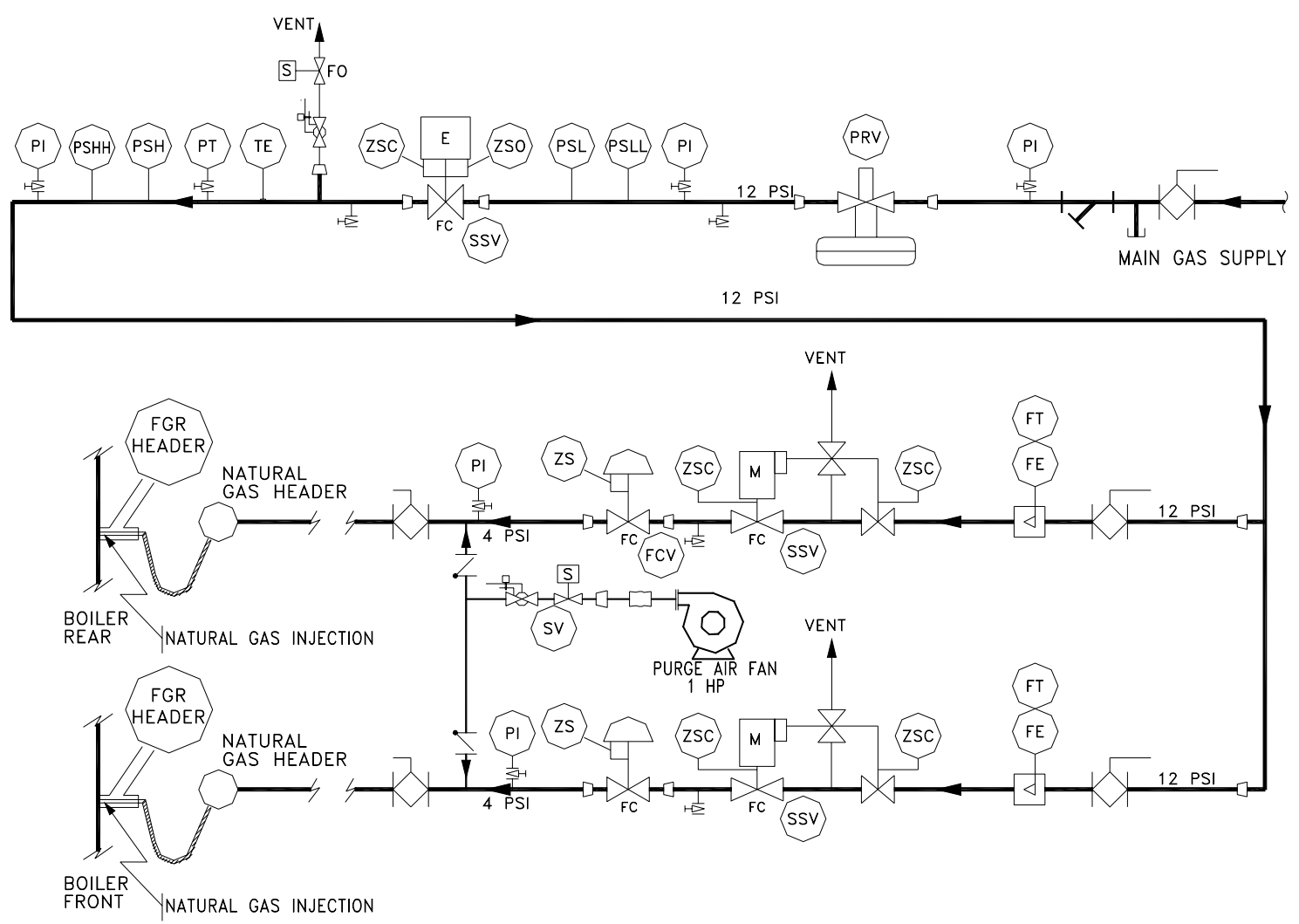

Figure 2-4 Nozzle Mix Flow Schematic for MdN natural gas injection 


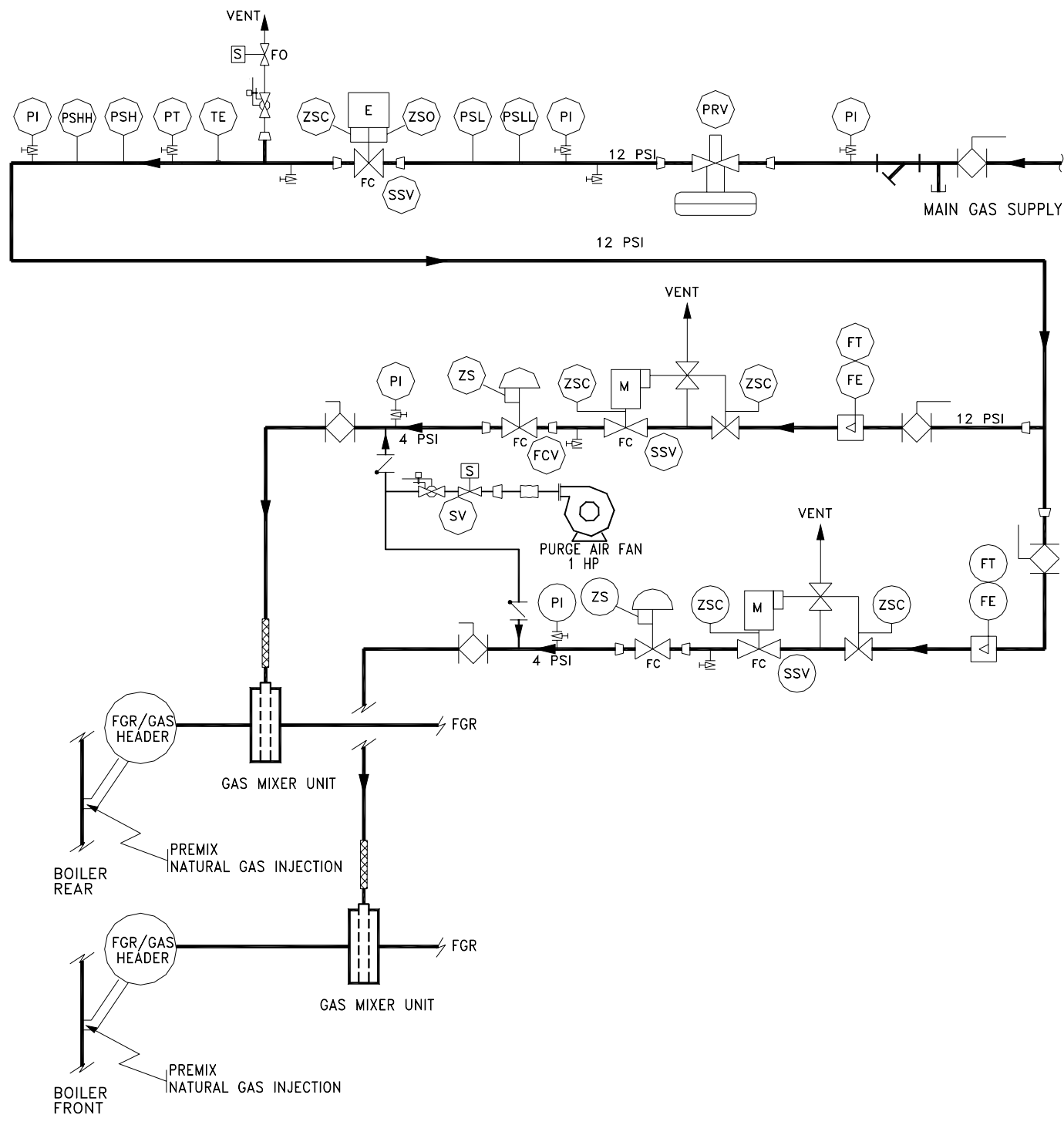

Figure 2-5 Premix Flow Schematic for MdN natural gas injection

The MdN fuel train typically receives natural gas supplied from the mill's main gas header. Gas is reduced in pressure and pressure regulated at about 12 psig before splitting into two separate branches each with dedicated flow meter and flow control stations that regulate reburn fuel flow independently to the boiler front and rear MdN gas injection nozzles. Fast-acting safety shutoff valves are installed on the main supply as well as on the separate branches to safely isolate natural gas from the boiler as directed from system discrete logic. In addition, a purge fan automatically runs to supply a purge stream of air keeping the quill passage or gas mixer holes clean during intervals when the natural gas is shutoff.

\subsubsection{Flue Gas Recirculation}

Recirculated flue gas serves many functions within the MdN process. One function of the FGR is to create turbulence in the lower furnace for the distribution and enhanced mixing of the injected reburn fuel (natural gas). This turbulent mixing improves temperature and combustion gas composition uniformity in the lower furnace region. Average combustion temperature along 
the grate is stabilized (reduced peak temperatures), which improves the combustion of high moisture content fuels like hog fuel and sludges. Another function of the FGR reduces the amount of oxygen present with in the combustion zone. FGR is also frequently used in place of air in the pneumatic fuel distribution systems. For applications with cinder re-injection FGR is recommended to replace some or all of the carrier air in these systems. The FGR can also replace the air injection commonly used on stoker boilers to prevent the flames from impinging on the boiler walls. The total FGR flow for a MdN system may range from 5-15\% of total flue gas flow.

A schematic representation of an MdN FGR arrangement is given in Figure 2-6. Key components include an isolation damper, an FGR fan, oxygen sensor, flowmeter and instrumentation for monitoring fan operation and FGR flowing conditions. The FGR take-off point is site dependent; a preferred location is where the FGR is hot and having minimum particulates such as downstream of an electrostatic precipitator or a mechanical collector.

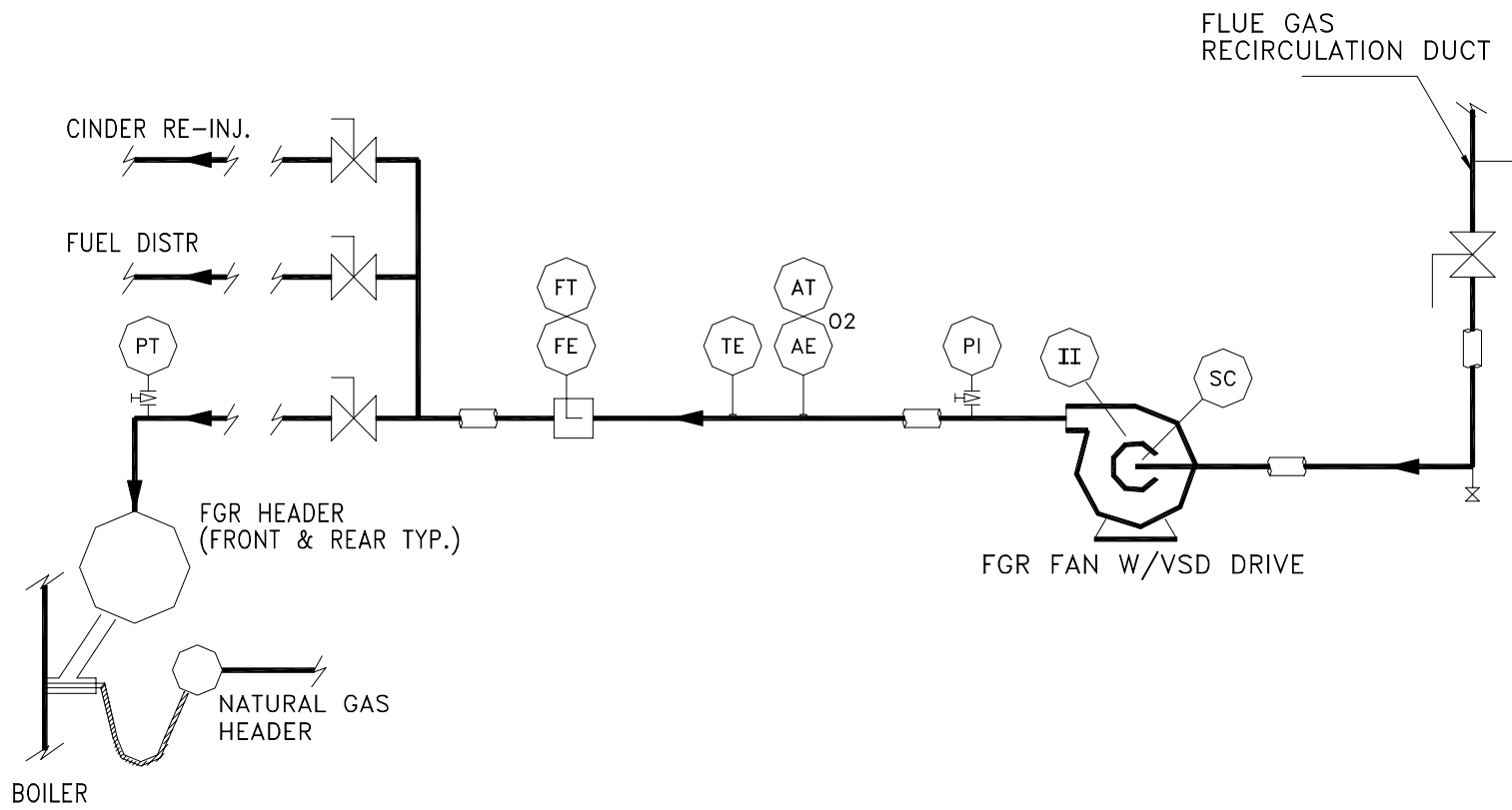

Figure 2-6 MdN FGR Schematic

\subsubsection{Overfire Air}

All hog fuel stoker boilers are equipped with an overfire air system (OFA). OFA systems if properly applied will assist in reduction of $\mathrm{NO}_{\mathrm{x}}$ emissions through staging combustion air. With air staging, less excess air is present at the primary grate combustion zone and with less oxygen available at the grate; less fuel bound nitrogen reacts to form $\mathrm{NO}_{\mathrm{x}}$ during this initial stage of combustion. OFA in the stoker combustion process completes the burnout of combustion gases and solids rising from the grate with addition of combustion air through dedicated OFA ports strategically located to provide adequate mixing. Proper distribution of OFA provides sufficient and satisfactory combustion performance through control of carbon monoxide emissions and minimizing carbon losses in the fly ash. 
In the application of MdN technology, a quality OFA system is considered essential. GTI boiler baseline trials found varying levels of performance from OFA systems tested and through CFD modeling developed a proprietary OFA nozzle arrangement which was successfully tested. GTI's OFA nozzle design consists of a compound array of three injection ports (refer to Figure 2-7) which targeted regions previously overlooked in conventional arrangements. A demonstration of this proprietary design provided improved OFA coverage by a reduction in emission of $\mathrm{CO}$ in the exhaust gases.

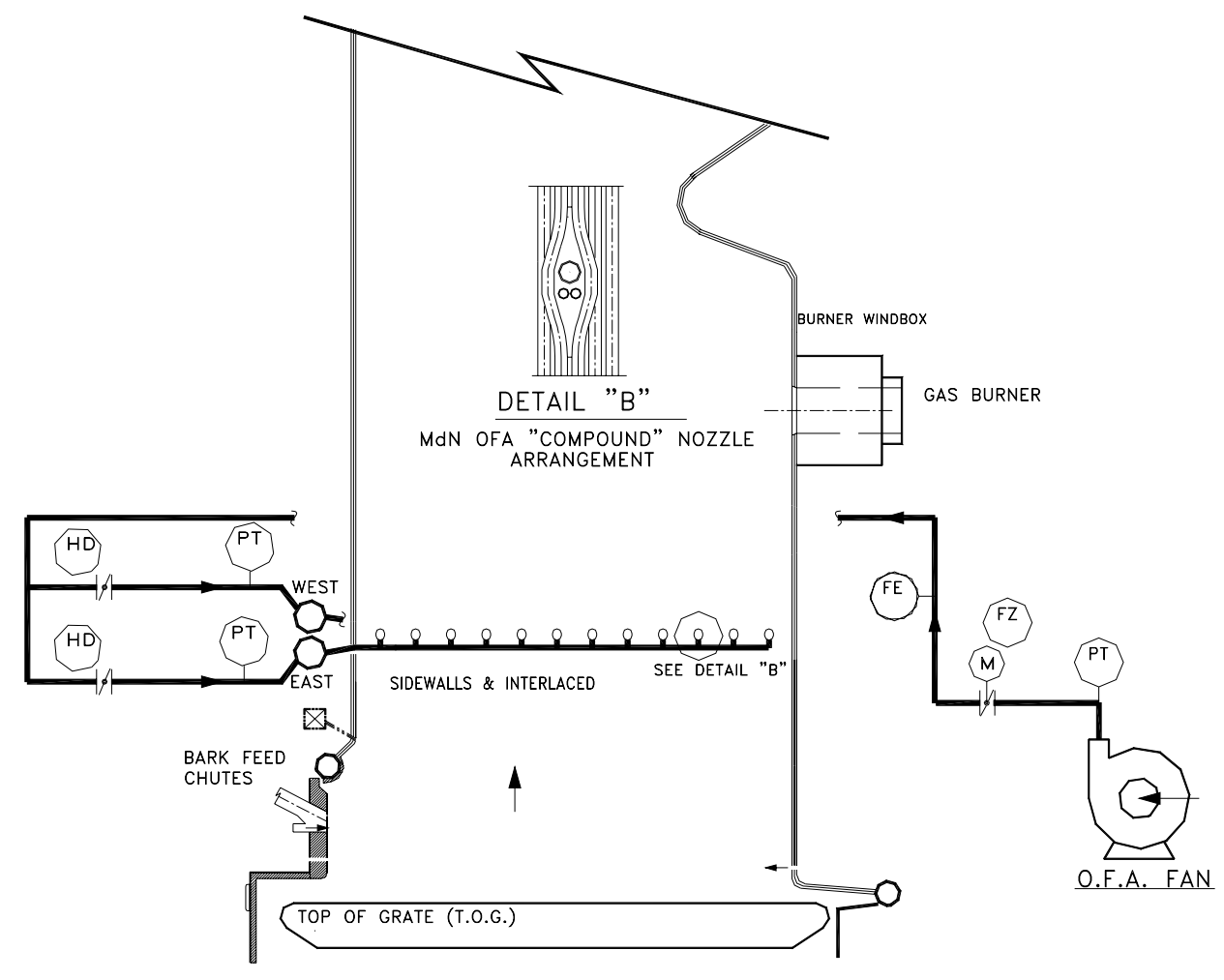

Figure 2-7 MdN New Proprietary OFA Compound Nozzle

\subsubsection{System Control}

An MdN boiler retrofit requires dedicated control hardware and field instrumentation to manage and supervise system start-up, shutdown and normal operation. Control requires both discrete and regulatory functions, which can be implemented in a stand alone microprocessor based control panel or preferably integrated into the existing distributed control system regulating boiler operations. Briefly, on boiler startup, the FGR portion of the MdN system is started during the start of the boiler purge cycle (after the ID fan) to insure that the FGR fan, ductwork and headers are purged of any accumulated combustible gases prior to boiler light off. The Gas Injection system Purge Air fan is also started during the boiler purge cycle after starting the ID fan. This purges any combustible gas remaining in the gas injection header through the gas quills and prevents plugging of the quills during the start of bark firing before gas injection is started. The gas injection system can be started once key system interlocks are satisfied such as boiler bark fuel is on and producing 60\% of boiler MCR steam flow; FGR system is on; FGR oxygen content less than $10 \%$ and both infrared flame scanners register flame on the grate. 


\subsection{METHANE de-NOX Process Features}

Features of the METHANE de-NOX reburn process worthy of consideration are listed below. Actual benefits are site dependent.

- Provides greater $\mathrm{NO}_{\mathrm{x}}$ reduction (up to $75 \%$ ) as compared to similarly priced natural gas based technologies.

- Cost effective; less expensive than SNCR and without associated corrosion, plugging and fouling.

- Increases boiler efficiency through reduced heat loss from the stack.

- Stabilizes combustion on grate

- Reduces carbon losses; decreased LOI found in boiler ash.

- Increases use of hard-to-burn fuels such as waste-water-treatment plant sludges

- Reduces overall consumption of natural gas with shutdown of upper furnace gas burners

- Reduces boiler maintenance

- Increases boiler availability

- Ease of installation, minimum outage time required

- Potential alternative scheme for disposal of mill generated non-condensable waste gases (demonstration test required). 


\section{MdN System Design Protocol}

The design of an MdN system follows an organized procedure developed and adjusted during GTI's demonstration and deployment of the technology in the FPI. The approach consists of five principle tasks; 1) baseline testing; 2) CFD Modeling and Optimization; 3) preliminary MdN Retrofit Design; 4) Detailed MdN Retrofit Specification and 5) MdN Installation and Commissioning. Proper attention in completing these tasks is needed for the successful application of MdN technology; each task activity and objectives are summarized below.

\subsection{Baseline Testing}

The first step in the application of MdN technology is an on-site evaluation, commonly referred to as a baseline trial, of the stoker boiler. A baseline trial comprises a battery of boiler tests with a prescribed test matrix to create a benchmark for stoker combustion performance and to characterize furnace $\mathrm{NO}_{\mathrm{x}}$ production and formation zones. Baseline data consists of; 1) boiler process variables such as system pressures, temperatures and flows; 2) measurement of stoker infurnace gas compositions at selected furnace elevations as well at equipment locations downstream and, 3) a chemical analysis of boiler fuel, as-fired. The first boiler test in this approach is normally carried out with the boiler at its typical or baseline operating condition. Baseline results serve an important function for making performance comparisons. Subsequent boiler tests are organized to study the impact of varying boiler parameters; key stoker boiler parameters include:

- OFA/UGA Ratio

- Grate Combustion Characteristics

- Total Boiler Air

- Steam Flow

- Thermal Input Ratio of Wood Waste/Natural Gas

A boiler test can take approximately 2 to 4 hours depending on the number of furnace gas samples and including time for operators to set boiler operation at test conditions. With this collection of data, expected boiler performance improvements with an MdN retrofit can then be approximated.

During each test, in-furnace gas samples are extracted at key combustion zones dependent on available access ports. Preferred gas sampling locations are shown in Figure 3-2; as indicated by numbers one (1) through seven (7). At each location, furnace gas samples at different furnace depths are collected and analyzed. Based on the measured gas composition, an approximation of combustion performance and $\mathrm{NO}_{\mathrm{x}}$ production from one or a combination of major combustion zones can be evaluated. Specially constructed, water-cooled probes are inserted into the furnace to pull out hot furnace gases; samples are cooled, filtered, dried and directed to analyzers for real time measurement of $\mathrm{O}_{2}, \mathrm{CO}, \mathrm{CO}_{2}$ and $\mathrm{NO}_{\mathrm{x}}$ concentrations. Temperatures are also recorded in each zone using an optical pyrometer.

Grate combustion (location \#1) is of special interest; so sampling at this location is more extensive. The gas sample probe is positioned about 12 to 24" inches above the grate and at different depths; approximately 9 to 12 sample points provide a map of grate combustion conditions and valuable insight about the formation of $\mathrm{NO}_{\mathrm{x}}$. Furnace gas composition data 
collected at locations \#2, \#3 and \#4 provide the effect which OFA, natural gas combustion and upper furnace burnout, respectively, participate in the overall production of $\mathrm{NO}_{\mathrm{x}}$.

In addition, gas analysis is measured at points \#5 through \#7. Gas composition data from the \#5 position provides a check of the boilers in-situ oxygen sensor operation (commonly located after the generating bank) and analysis from \#6 and \#7 provide an indication of possible problems from air in-leakage coming from the furnace roof or the tubular air heater.

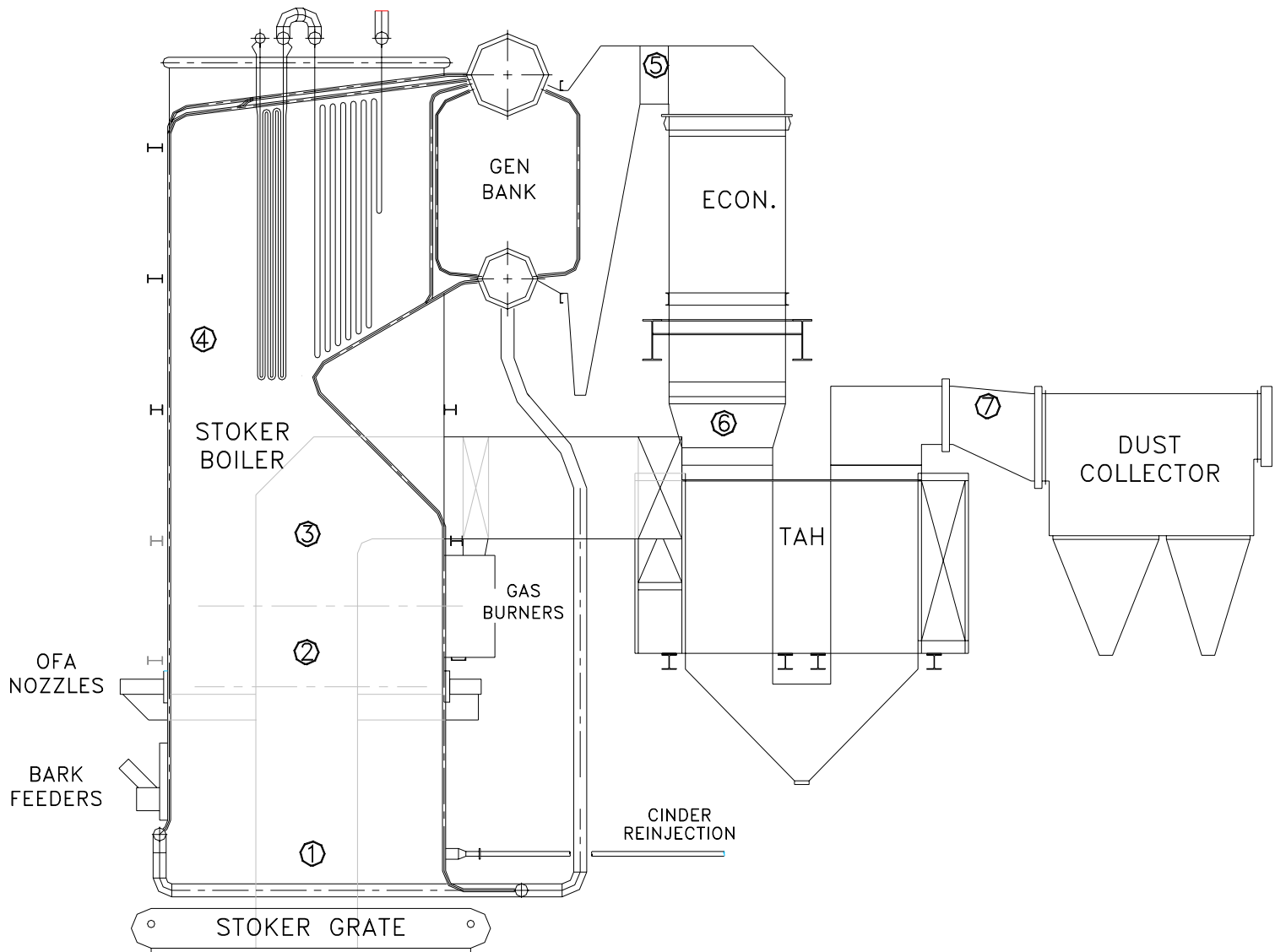

Figure 3-1 A Typical Stoker Boiler Arrangement with Baseline test gas sample locations identified

Boiler process variables such as air flow data are collected for the Forced Draft (FD), Induced Draft (ID), OFA, and cinder re-injection fans to develop an operating curve for each fan. Fan performance is closely monitored to identify any fan capacity issues as well as determining whether or not any existing fans, such as an OFA fan, can be utilized with retrofitted systems. Differential pressure drop measurement are collected for the multiple sections of the boiler; convective sections, economizer, air heater, and dust collection, to calculate the impact of the additional flow from the FGR injection component of MdN systems.

During baseline tests, samples of boiler fuel (i.e. hog fuel, sludge, etc.), bottom ash and cinder re-injection, are collected for analysis of their chemical and physical properties such as moisture content, heating value and carbon content. If one of the objectives of the MdN system is to dispose of waste gas streams, a sample is collected and analyze for chemical content and heating value. Testing for stack particulate emissions may be performed along with stack gas analysis for compounds associated with the disposal of waste gases. In addition to the physical data 
collected during a Baseline trial, boiler operating data is recorded from the mill's DCS historian archive and used in calculations of overall boiler efficiency and analysis of boiler parameters impact on $\mathrm{NO}_{\mathrm{x}}$ formation.

A major item of the baseline testing that can not be quantified from the operating and test data are the visual observations by GTI and ESA-ES personnel. The conditions along the grate are of particular interest to the onsite engineers. The distribution and combustion characteristics along the grate provide useful information in applying MdN technology. The uniformity of fuel distribution is a factor for deciding how the FGR be will utilized in the lower furnace region. The test engineers also advance their understanding of how the unit operates through frequent discussions with operating personnel. Informal conversations with operators can provide valuable information on unit operation. The design goal of GTI and ESA-ES is to supply an MdN system capable providing consistent performance over a wide range of operating conditions.

\section{Baseline Report}

After site-testing the data processing and reporting phase begins. Average, standard deviation, minimum and maximum values of boiler process variables are calculated for each of the different test periods and examined for problems. In-furnace gas composition data is compiled from the different furnace levels and for the different test periods. Chemical and physical analyses from the boiler fuel and ash streams are examined. Based on the aforementioned data, boiler performance calculations are conducted and results studied to characterize the stoker boiler's operation, thermal efficiency and environmental performance. A baseline study report is created and results of the baseline tests are presented along with a determination of projected benefits with addition of an MdN retrofit. Further development actions are dependent on mill approval.

\subsection{CFD Modeling \& Optimization}

Based on favorable findings and mill approval, development work on a computational fluid dynamic (CFD) model begins. Under this development program, a custom CFD model code was configured specifically for stoker boiler applications. GTI’s CFD stoker furnace model simultaneously solves all relevant physics including mass and heat transfer, drying, volatilization, mixed fuel burning, chemical reactions, and radiation. By solving these, the furnace simulation predicts distribution of combustion quantities, primarily, $\mathrm{O}_{2}, \mathrm{CO}, \mathrm{NO}_{\mathrm{x}}$ and temperature as well as particle trajectories at all points in the furnace. Post processing of a working CFD simulation can aid design activities by providing a wide range of visualizations of the flow and combustion patterns in the furnace. A detailed description of the model is described in Section 4 of the Manual.

CFD model work begins by first creating a three-dimensional geometric mesh to duplicate the flow domain of the stoker boiler. This mesh will encompass the furnace from the lower hopper below the blast gate, past the nose, and including the superheater (see Section 4). A working CFD model requires a set of boundary conditions for all mass sources such as under grate air entering through the blast gate, conveying air for the ash re-injection ports, air through existing overfire air ports, and fuel spreader air. 
Using boundary conditions measured during the baseline test, a working CFD Baseline model is created. Model results are then checked and validated through comparisons with as-measured infurnace data for predictions of $\mathrm{O}_{2}, \mathrm{CO}, \mathrm{NO}_{\mathrm{x}}$ and temperature at the different furnace locations sampled. Based on these comparisons, the model boundary conditions may be adjusted to produce a better match. This validation step of the CFD model builds a level of confidence that the model accurately reflects the current operation of the boiler.

\section{CFD Model Study with MdN}

The validated CFD baseline model is then reconfigured; ports for injection of FGR and natural gas are added to the 3D mesh and new boundary conditions are specified. The modified CFD model is then used to simulate MdN system design alternatives. The CFD MdN model is used to test the ratio of FGR and OFA to total boiler air, the flow impact of OFA nozzle size and design, OFA port location, FGR utilization at the various injection locations, and several other variables key to successful MdN systems. The model is also used to compare the effectiveness of the existing OFA system versus the MdN proprietary OFA nozzles offered with MdN systems.

Model results of the multiple case studies are studied and provide the basis for a preliminary MdN system design. The model predictions of flow, temperature, and species in combination with the experience of our engineers will provide guidance in adapting the preliminary MdN design to the specifics of the test boiler.

\subsection{Preliminary MdN Retrofit Design}

At the completion of the CFD modeling phase, a preliminary MdN retrofit design is prepared. The preliminary design includes a significant level of detail and all the general requirements of the system. The target flowrates and injection locations for natural gas, OFA and FGR are reported. The preliminary design contains the requirement for the major components of the MdN system but does not have the details necessary to install and operate the system.

The results of the baseline testing and CFD modeling along with the preliminary design are then presented to the client for evaluation and approval. This proposal summarizes the predicted performance of the system and provides projected targets for environmental goals, boiler efficiency and operating improvements. A budgetary estimate is also given to install the MdN system to assist the client in their decision whether or not to proceed with the MdN installation.

\subsection{Detailed MdN Retrofit Specification}

Upon approval to proceed, ESA-ES, with assistance as needed from GTI, begins the process of developing the final retrofit design. At this stage, ESA-ES, the technology licensee, will work closely with the client to reach an agreement on essential items to the system installation. Some key examples are the placement of physical equipment, the selection of equipment manufacturers, control philosophy, and routing of duct work.

The completed detail design package includes construction-ready details and information to build the MdN system. The design package contains isometric drawings and bill of materials for the installation of all equipment and associated mechanical, piping, electrical, structural, insulation and control requirements. Drawings are prepared for all boiler water wall 
modifications and penetrations that are required for the system. Equipment specification data sheets are provided with manufacturer and model information for procurement. The MdN control logic is finalized in diagram drawings based on SAMA standards. MdN control can be integrated into the existing boiler control platform (DCS) or configured in a stand-alone microprocessor.

\subsection{MdN Installation \& Commissioning}

ESA-ES can provide complete turnkey service as well as work with a client approved list of contractors. ESA-ES can function as the project general contractor and coordinated the installation of all components. ESA-ES can also provided onsite personnel to offer engineering and technical support for plant hired contractors and to insure the proper installation of the MdN system. ESA-ES has experience providing a wide range of services with regard to equipment fabrication and system installation.

A construction schedule is coordinated with the client to minimize the number and duration of boiler outages. At the completion of the equipment installation ESA-ES will begin an exhaustive commissioning of the equipment and control logic scheme. ESA-ES's commissioning plan will check the functionality of the MdN permissive and interlock logic to insure the system operates as designed. This approach is critical when dealing with the injection of natural gas.

After the system commissioning has been completed and all parties are in agreement that the system can operate safely and as designed, ESA-ES will place the MdN system in-service and begin tuning and optimization testing. 


\section{CFD Stoker Model Introduction}

To aid the commercialization of the technology a full-scale 3D Computational Fluid Dynamics (CFD) model of the METHANE de-NOX reburn process for wood waste and sludge-fired stoker boilers has been developed.

GTI owns a full-scale computational fluid dynamics (CFD) model capable of modeling stoker boilers. The model simulates combustion of solid and gaseous fuels in a stoker boiler furnace through a combination of heat, energy, material and momentum balances. The result of these calculations provides detailed information about the temperature distribution, velocities, pressure, and chemical species concentrations inside of the furnace and at the furnace exit. Model simulation results provide important insight on quality of combustion, flame characteristics and effect of furnace arrangements (geometry, injection scheme, fuel composition, etc.) on combustion.

\subsection{Model Descriptions}

\subsubsection{Physical Models}

The combustion CFD model that was utilized here uses a combination of Eulerian and Lagrangian reference frames. The governing equations for gas-phase and particle phase were solved in Eulerian frame and Lagrangian frame respectively.

Flow, temperature and species fields of gas-phase were computed by using the commercial CFD program FLUENT, which solves the Reynolds averaged Navier- Stokes (RANS), turbulent heat and turbulent species transport equations. The steady state solutions were calculated by using first-order discretization for all equations. The standard $k-\varepsilon$ turbulence model was used to close the transport equations. The P-1 radiation model was used to account heat transfer due to radiation. Chemical reactions were modeled by using the Magnussen Eddy Dissipation model. The reaction mechanism was based on a 2-step mechanism for each fuel.

$$
\begin{aligned}
& \text { Fuel }+\mathrm{a} \mathrm{O}_{2} \rightarrow \mathrm{b} \mathrm{CO}+\mathrm{c} \mathrm{H}_{2} \mathrm{O} \\
& \mathrm{CO}+0.5 \mathrm{O}_{2} \rightarrow \mathrm{CO}_{2}
\end{aligned}
$$

The fuel can be wood bark, sludge, volatiles, methane, NCG and SOG.

Discrete Phase Model (DPM) was used to determine the trajectories of fuel particles. The trajectories of particle cloud were calculated by integrating the force balance on the particles in a Lagrangian reference frame after fluid flow solution was computed. Heat and mass transfer to/from particle cloud were also calculated in addition to momentum transfer. The computed source terms for species, momentum, and energy were used in the gas phase equations. Iteration between the gas phase and particle cloud tracking solutions was repeated until a converged solution was reached. The particle-tracking model included laws of inert heating, drying (wet combustion model), devolatilization, and char burnout. Radiation interaction between particles and the furnace environment was enabled. 


\subsubsection{Grate Model}

A special CFD model for wood combustion in a stoker boiler was developed for this project.

The CFD simulation of any solid fuel combustor (e.g. pulverized coal furnace) involves modeling of turbulent fluid flow, particle flow, heat transfer including radiation, homogenous and heterogeneous combustion reactions, heat and mass transfer between solids and gas. In addition, numerous boundary conditions are required to describe entering flows and thermal conditions at the wall, fuel properties. Engineers have been using computational models successfully to simulate combustion in pulverized coal furnaces for more than 15 years.

When simulating a stoker boiler additional challenges arise from modeling the stoker bed on the grate surface. While in pulverized coal furnaces it can be assumed that solid fuel particles can be looked at as individual entities this assumption is not true in a stoker bed. In the stoker bed, particles form a porous layer of solids. Fluid dynamics, radiation, heat and mass transfer between the fuel and the surrounding gas in a bed require a different approach compared to combustion in a suspension. In addition, particle fragmentation, particle lift-off, particle entrainment into the bed become important mechanisms that contribute to the thickness of the bed, fraction of particles burning in suspension and on the bed, amount of fly ash and bottom ash.

A special 'grate-model' has been developed by GTI in collaboration with Fluent, Inc. and Reaction Engineering International for modeling the bed combustion in the boiler. The so-called 'grate model' is based on Lagrangian particle tracking. Here individual particles are tracked through the domain along the particle trajectory. The trajectory of a particle is a result of initial particle conditions and the drag force exerted on the particle by the surrounding gas. The grate model was implemented into CFD code FLUENT through User-Defined-Functions (UDF).

The particle tracking has been modified such that particles on the bed follow the movement of the bed. The heat and mass transfer formulation of the particles that are captured in the bed takes the bed properties into account. The needed UDFs for the grate model were designed with the following features:

- A "grate-zone" can be defined which moves at the same speed as the bed. The velocity of the bed is an input parameter of the model.

- Particles passing through the grate-zone are captured in the bed and continue moving with the bed until they are either discharged into the bottom ash hopper or lift off the bed because they became light enough.

- Undergrate air is entering the furnace through the grate. Particles in the bed may lift off the grate if the lift force is larger than the gravity force.

- Particle fragmentation can occur when the particle porosity reaches a critical porosity. It is assumed that a particle will become a parcel of smaller particles with the same size. Fragmentation parameters are input parameters of the model.

- Evaporation and boiling, devolatilization and surface combustion rates are based on models for transport properties in a bed. Separate Heat and mass transfer equations 
within the bed; rates of devolatilization and char oxidation were solved. Once particles have lifted off the bed standard transport properties are used.

To demonstrate the functionality of the grate-model small, medium size, and large particles have been injected from the bark chute into the furnace. The resulting trajectories are shown in Figure $4-1$.

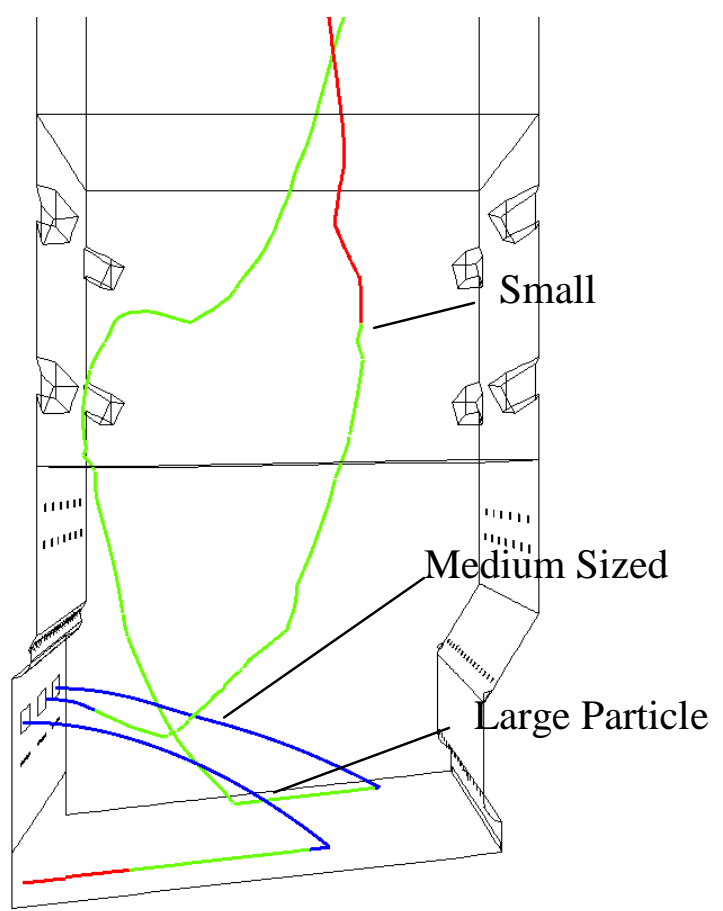

Figure 4-1 Small, Medium and Large Particle Trajectories (Blue section shows particle evaporation phase; Green section shows particle combustion phase; Red section shows particle burnout

The colors of the trajectories represent the current particle state. A blue section of a trajectory indicates that the moisture content in the particles is evaporating. The particle temperature at this stage is at or below boiling temperature of water. The green color means that the particle is combusting either through devolatilization or char burnout. Finally, if the trajectory has a red color the particle is burned out. Only ash is remaining and the particle follows the inert heating law.

The small particle that is shown here is burning in suspension. It never reaches the grate but flies upward with the main gas flow. The medium sized particle is heavy enough to fall onto the grate. It remains on the grate for a while and then lifts-off. Before the particle is lifting off from the grate it has lost mass through combustion and it also has fragmented into smaller pieces. The big particle settles on the grate and stays on the grate until it is discharged into the bottom ash.

\subsection{International Falls (I Falls) Stoker Boiler CFD Model}

\subsubsection{Geometry and Computational Mesh}

The outline and inlet ports of the model for baseline and MdN retrofit arrangement are depicted in Figure 4-2 and Figure 4-3 respectively. A hybrid mesh with approximately 325,000 cells was generated. A tetrahedral mesh was employed around the inlet ports and the grate to allow the cells to grow from the inlets to the interior of the domain. See Figure 4-4, with this 
approach it was possible to resolve all inlet ports that are small compared to the overall size of the domain. The main portion of the domain is filled with an unstructured hexahedral mesh.

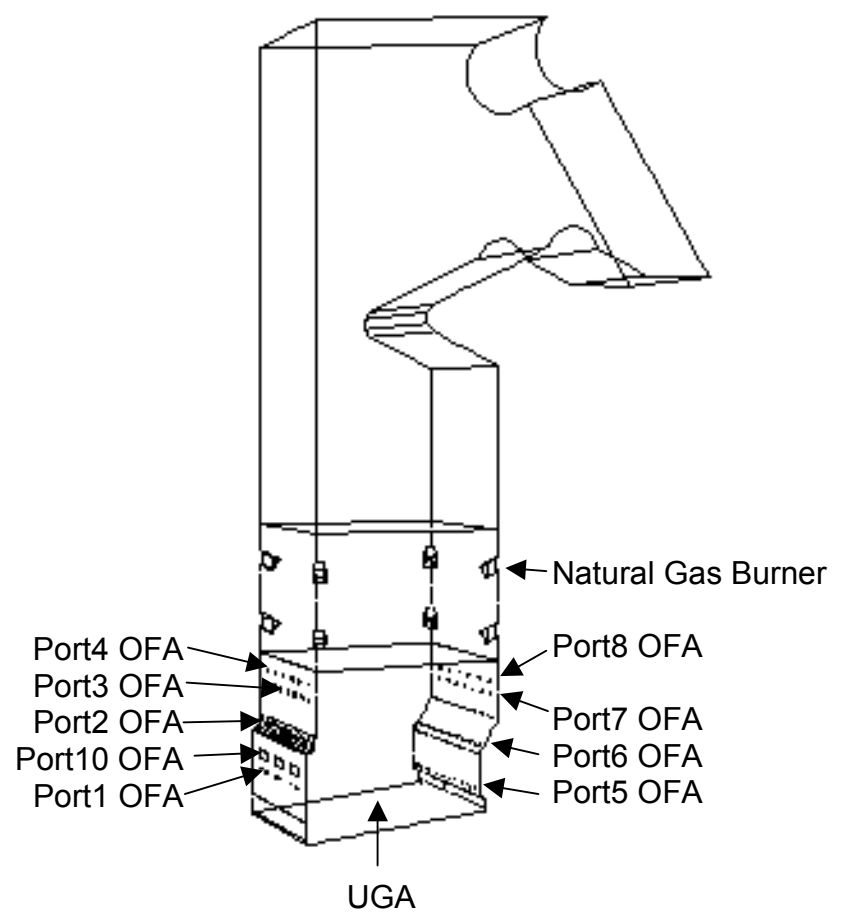

Figure 4-2 I Falls Inlet Ports for Boiler Baseline Case

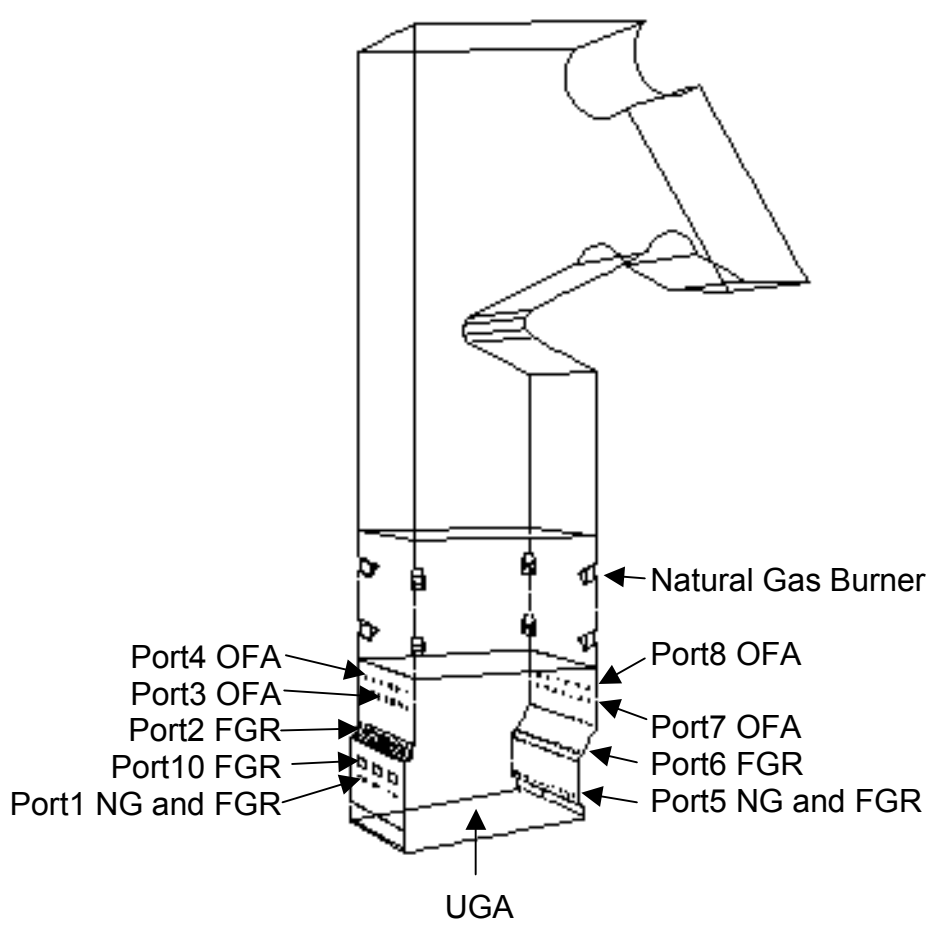

Figure 4-3 I Falls Inlet Ports for Boiler MdN Retrofit Arrangement 


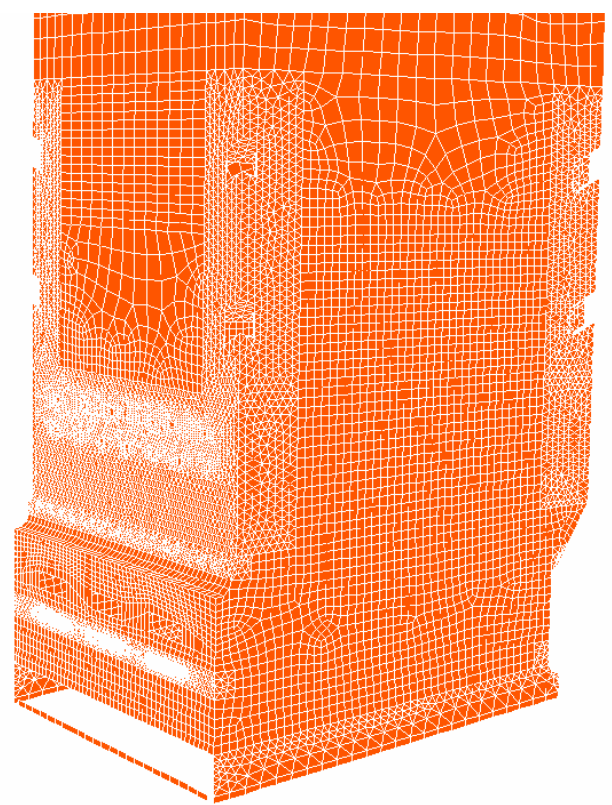

Figure 4-4 I Falls Meshes for Baseline and MdN Cases

\subsubsection{Input and Boundary Conditions}

Fuel properties are summarized in Table 4-1 below. The flow conditions are summarized below in Table 4-2 Compared to the baseline case, the MdN case uses less wood bark, more sludge, FGR, natural gas injection in Port \#1 and Port \#5 instead of the gas burner. The airflow rates were also adjusted to get proper distribution. Sludge and wood barks were introduced to the stoker boiler by DPM injections. Figure 4-5 shows the distributions of particle size injected. The particles were injected from the grate surface in vertical direction with a small velocity. After the first time step, the particles are captured in the bed with a velocity parallel to the grate. The grate velocity is an input parameter of the grate model.

Table 4-1 I Falls Wood Bark and Sludge Chemical Analysis

\begin{tabular}{|c|c|c|c|c|}
\hline FUEL ANALYSIS & \multicolumn{2}{|c|}{ Wood Bark } & \multicolumn{2}{|c|}{ Sludge } \\
\hline & $\begin{array}{l}\%(w / w) \\
\text { As Fired }\end{array}$ & $\begin{array}{c}\%(w / w) \\
\text { Dry }\end{array}$ & $\begin{array}{l}\%(w / w) \\
\text { As Fired }\end{array}$ & $\begin{array}{c}\%(\mathrm{w} / \mathrm{w}) \\
\text { Dry }\end{array}$ \\
\hline \multicolumn{5}{|l|}{ Proximate } \\
\hline & 42.72 & & 78.31 & \\
\hline \multirow{3}{*}{$\begin{array}{r}\text { Ash } \\
\text { Volatile Matter } \\
\text { Fixed Carbon }\end{array}$} & 2.98 & & 8.26 & \\
\hline & 44.69 & & 12.21 & \\
\hline & 9.61 & & 1.22 & \\
\hline \multicolumn{5}{|l|}{ Ultimate } \\
\hline \multirow{6}{*}{$\begin{array}{r}\text { Hydrogen } \\
\text { Carbon } \\
\text { Nitrogen } \\
\text { Sulfur } \\
\text { Oxygen } \\
\text { Ash }\end{array}$} & & 6.06 & & 4.24 \\
\hline & & 50.68 & & 31.49 \\
\hline & & 0.87 & & 1.94 \\
\hline & & 0.07 & & 0.23 \\
\hline & & 37.12 & & 24.02 \\
\hline & & 5.20 & & 38.08 \\
\hline Higher Heating Value [Btu/lb] & 4906 & 8564 & 1144 & 5274 \\
\hline
\end{tabular}


Table 4-2 I Falls Flow Rates of Injected Gas and Solids for Baseline and MdN Cases

\begin{tabular}{|c|c|c|c|c|c|}
\hline & & \multicolumn{2}{|c|}{ Baseline } & \multicolumn{2}{|c|}{ MdN } \\
\hline & & $\begin{array}{l}\text { Flow Rate } \\
\text { [klb/h] }\end{array}$ & $\begin{array}{c}\text { Temperature } \\
{\left[{ }^{\circ} \mathrm{F}\right]}\end{array}$ & $\begin{array}{l}\text { Flow Rate } \\
\text { [klb/h] }\end{array}$ & $\begin{array}{c}\text { Temperature } \\
{\left[{ }^{\circ} \mathrm{F}\right]}\end{array}$ \\
\hline \multicolumn{6}{|l|}{ FUEL } \\
\hline \multirow{3}{*}{\multicolumn{2}{|c|}{$\begin{array}{r}\text { Bark } \\
\text { Sludge } \\
\text { Natural Gas }\end{array}$}} & 65.81 & 80 & 46.05 & 80 \\
\hline & & 2.88 & 80 & 8.42 & 80 \\
\hline & & 1.46 & 509 & 1.00 & 432 \\
\hline \multicolumn{6}{|l|}{ AIR } \\
\hline \multirow{11}{*}{\multicolumn{2}{|c|}{$\begin{array}{l}\text { UGA } \\
\text { OFA Port1 } \\
\text { OFA Port2 } \\
\text { OFA Port5 } \\
\text { OFA Port6 } \\
\text { OFA Port3 } \\
\text { OFA Port4 } \\
\text { OFA Port7 } \\
\text { OFA Port8 } \\
\text { OFA Port10 } \\
\text { Burner Air }\end{array}$}} & 100.71 & 509 & 113.74 & 509 \\
\hline & & 13.72 & 509 & 9.65 & 406 \\
\hline & & 14.63 & 509 & 6.35 & 432 \\
\hline & & 18.60 & 509 & 10.41 & 432 \\
\hline & & 23.17 & 509 & 12.93 & 432 \\
\hline & & 7.66 & 509 & 2.65 & 509 \\
\hline & & 6.68 & 509 & 2.27 & 509 \\
\hline & & 7.09 & 509 & 2.65 & 509 \\
\hline & & 6.52 & 509 & 2.27 & 509 \\
\hline & & 29.72 & 509 & 22.36 & 509 \\
\hline & & 80.45 & 509 & 54.01 & 509 \\
\hline \multicolumn{6}{|l|}{$\overline{F G R}$} \\
\hline \multirow{5}{*}{\multicolumn{2}{|c|}{$\begin{array}{l}\text { FGR Port1 } \\
\text { FGR Port2 } \\
\text { FGR Port5 } \\
\text { FGR Port6 } \\
\text { FGR Port10 }\end{array}$}} & - & - & 2.82 & 406 \\
\hline & & - & - & 1.85 & 432 \\
\hline & & - & - & 3.04 & 432 \\
\hline & & - & - & 3.77 & 432 \\
\hline & & - & - & 6.53 & 509 \\
\hline
\end{tabular}

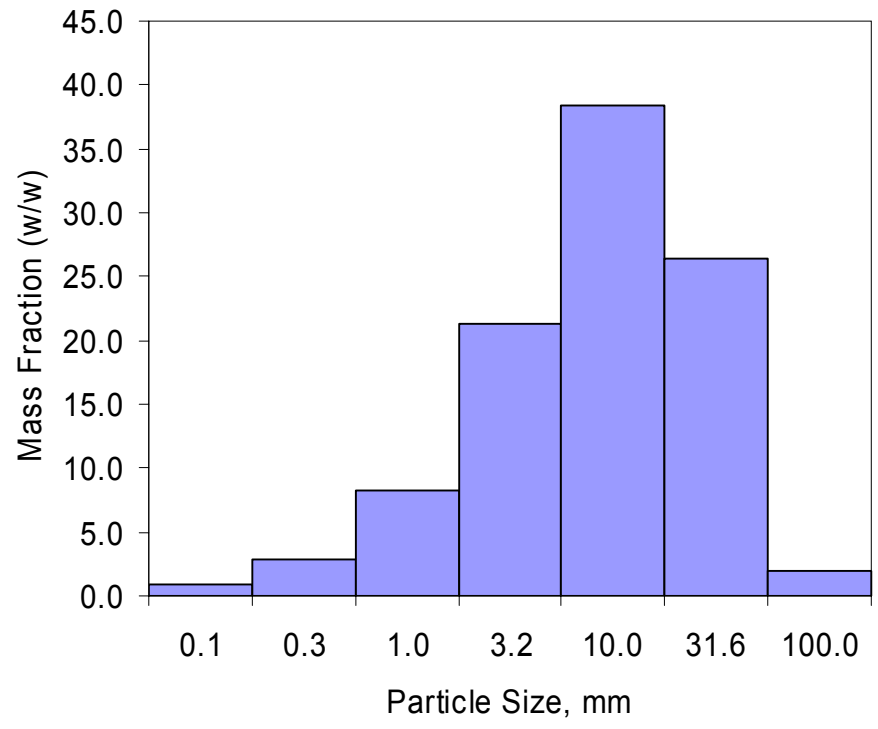

Figure 4-5 I Falls Wood Bark and Sludge Size Distributions 


\subsubsection{Validation of Stoker Boiler CFD Baseline Model}

The CFD model was validated by the test results taken by GTI in Boise Cascade International Falls (I Falls) boiler. The test data taken at different elevations was basically included $\mathrm{O}_{2}, \mathrm{CO}$, $\mathrm{CO}_{2}, \mathrm{NO}_{\mathrm{x}}$ concentrations and temperatures. The comparison of test data and CFD data at the same locations is shown in Figures 4-6 - 4-8. The discrepancies are due to unsteady boundary conditions during total sampling period.

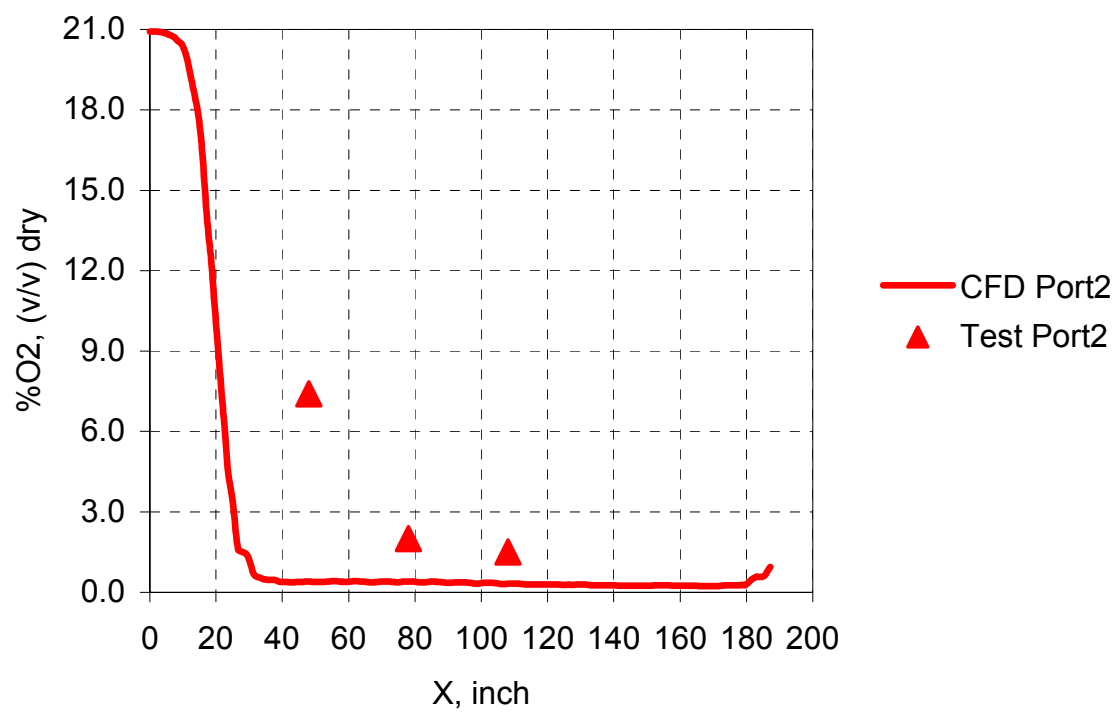

Figure 4-6 I Falls Comparison of CFD $\mathrm{O}_{2}$ Concentration with Measured $\mathrm{O}_{2}$ (62 inch above grate)

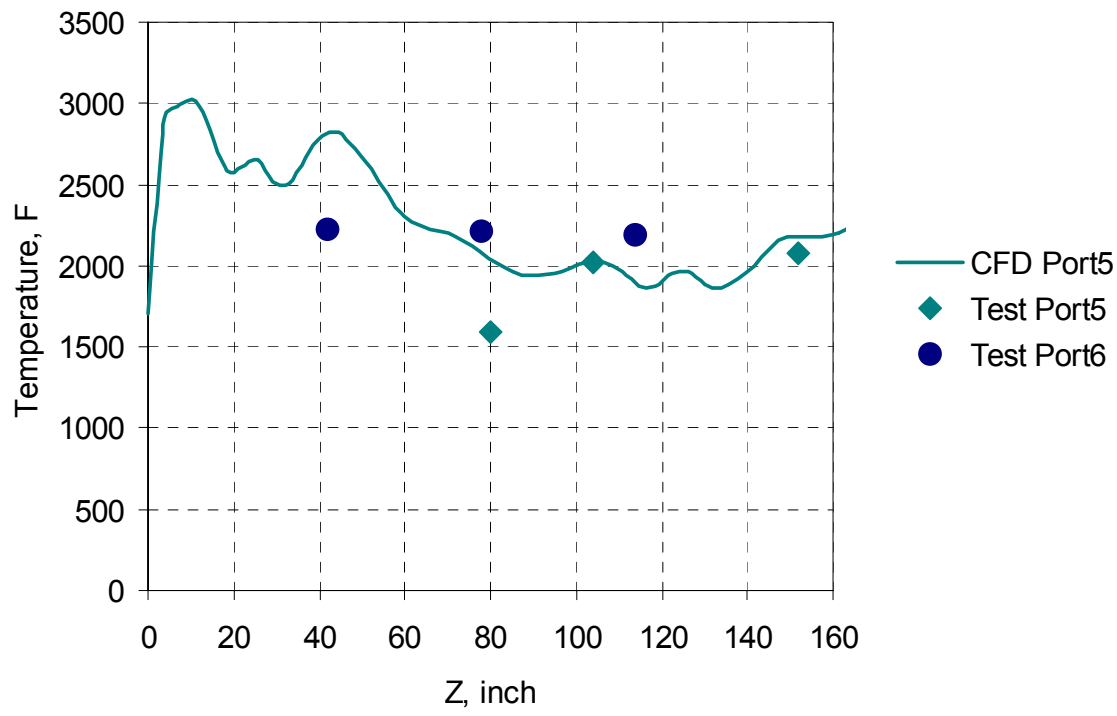

Figure 4-7 I Falls Comparison of CFD Temperature with Measured Temperature (170 inch above grate) 


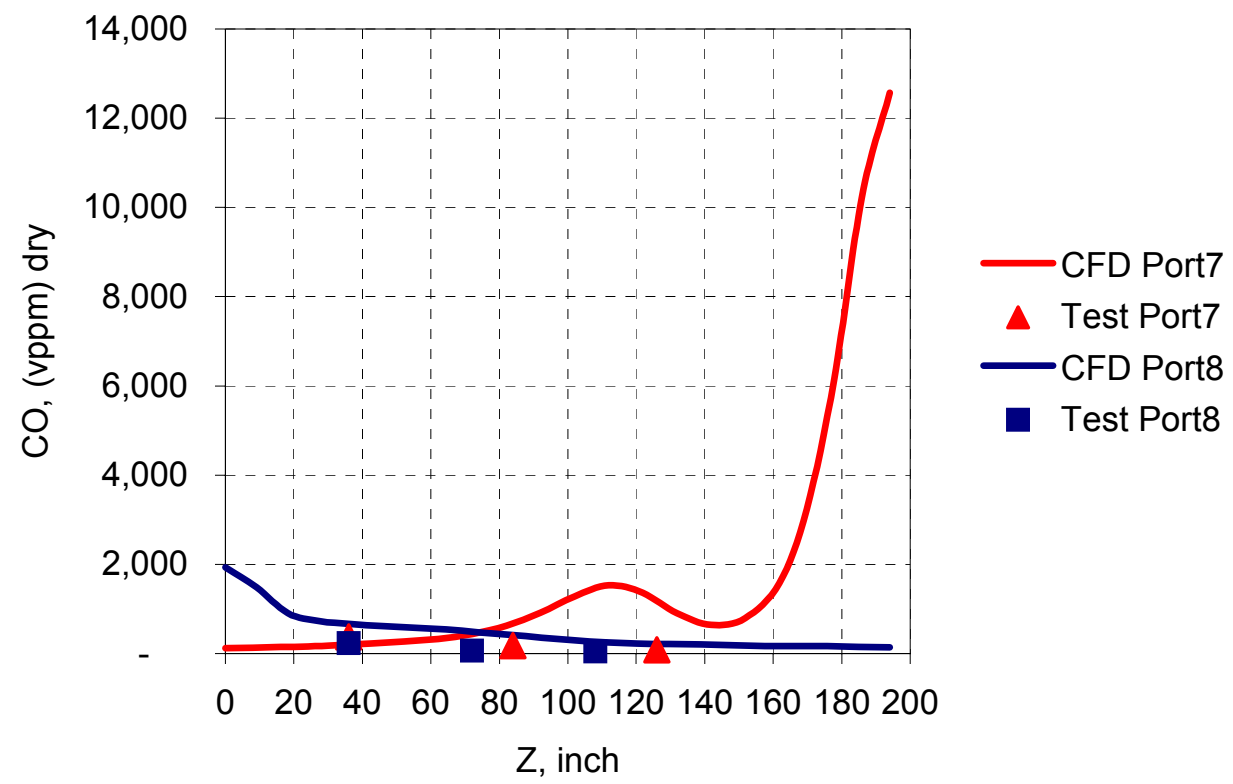

Figure 4-8 I Falls Comparison of CFD CO with Measured CO (483 inch for Port7 and 585 inch for Port8 above grate)

\subsubsection{Comparison of Boiler Performance with CFD: Baseline Boiler Model versus with MdN Boiler Model}

Figure 4-9 shows a comparison of turbulence levels for the baseline and MdN retrofit case. MdN case has better mixing in lower combustion zone.

Figure 4-10 and Figure 4-11 show the temperature distributions in the baseline case and the MdN case respectively. The baseline case has higher temperature and the distribution is less uniform comparing with the MdN case. In the MdN case, because inlets “Gas Burner” input only air and locate higher than the main combustion zone, low temperature regions appear near these inlets. In the baseline case, because inlets “Gas Burner” input $\mathrm{CH}_{4}$ and air, combustion zone goes higher and temperature is also high near inlets.

Figures 4-12 through 4-16 show the contour plots of $\mathrm{O}_{2}$ and $\mathrm{CO}$ for the baseline cases and the $\mathrm{MdN}$ cases. In the $\mathrm{MdN}$ case, there are mainly three combustion zones: The first one is above the grate where volatiles from bark react with air coming from beneath the grate to form $\mathrm{CO}$ and $\mathrm{CO}$ again burns with $\mathrm{O}_{2}$ coming from ports \#1, \#5, and \#6. Also, $\mathrm{CH}_{4}$ from ports \#1 and \#5 burns at the same region to form this combustion zone. The highest temperature can be found in this zone.

The main combustion zone is located above the first one. The zone is much larger and the temperature is very high here. There is another small combustion zone near ports \#7 and \#8. These three zones are quite close to make the temperature distribution more uniform comparing with the baseline case. In the baseline case, there are mainly two combustion zones. The first one is similar to that in the $\mathrm{MdN}$ case. Because in this case, ports \#5 and \#6 only input air, no $\mathrm{CH}_{4}$, the combustion zone is smaller and temperature distribution is less uniform comparing with the MdN case. The main combustion zone is located above the first one. Because in this case, 
inlet "Gas Burners" input $\mathrm{CH}_{4}$, this zone is much larger and located higher (closer to "Gas Burners") comparing with the MdN case. The highest temperature in the baseline case is higher than that in the MdN case. Also because the two combustion zones are rather separated in baseline case, the temperature distribution is not as uniform as in the $\mathrm{MdN}$ case.
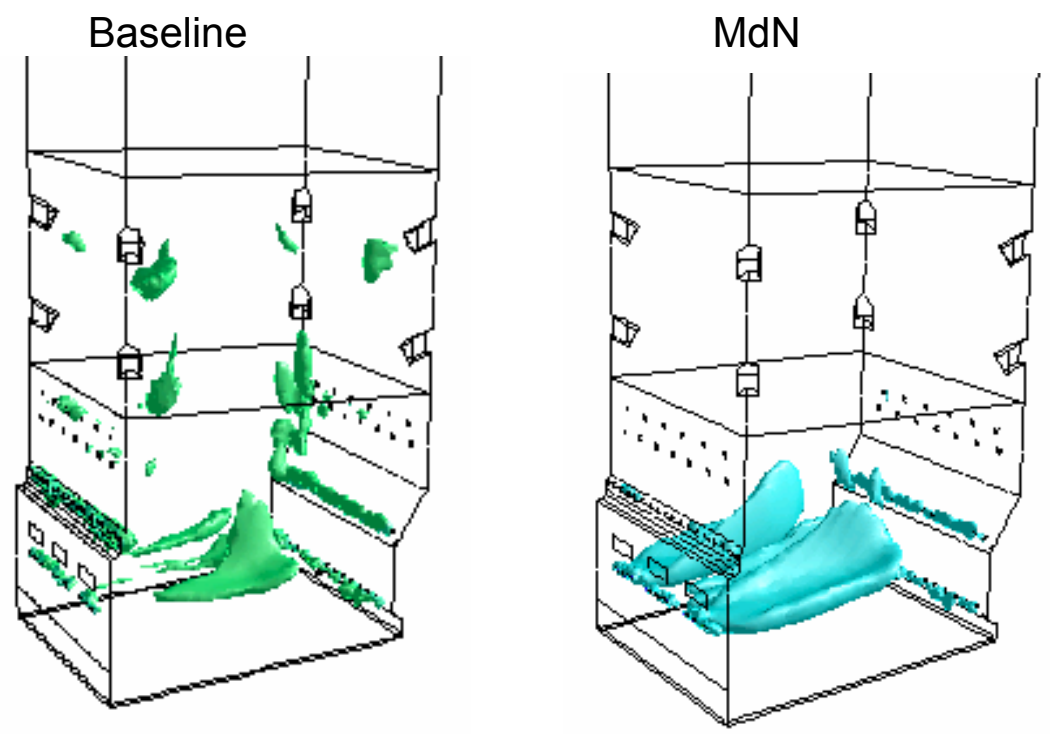

Figure 4-9 I Falls Comparison of Turbulent Kinetic Energy, $300 \mathrm{ft}^{2} / \mathrm{s}^{2}$ Iso-surface for Baseline and MdN Firing Conditions
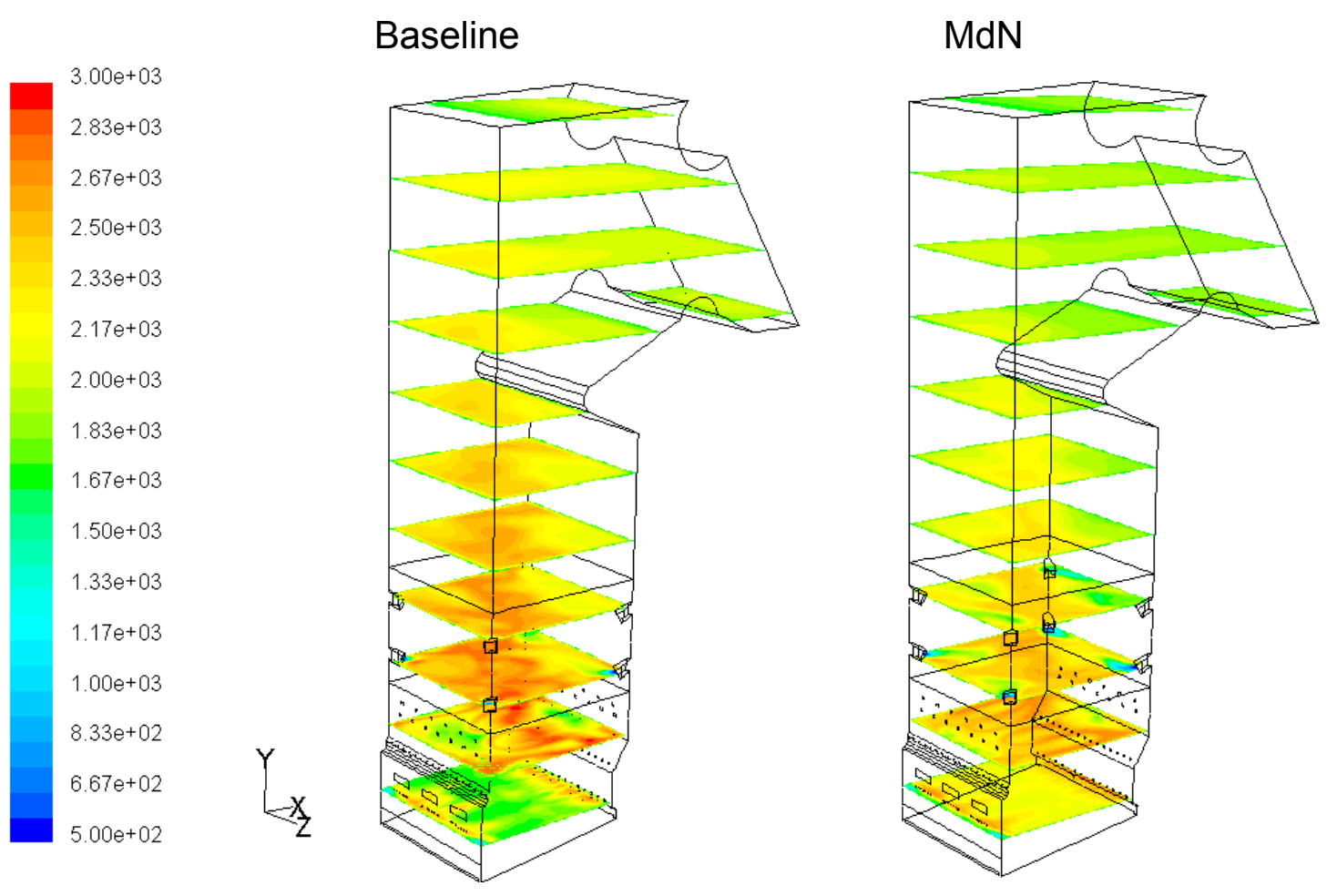

Figure 4-10 I Falls Contours of Temperature $\left({ }^{\circ} \mathrm{F}\right)$ for Baseline and MdN Firing Conditions 


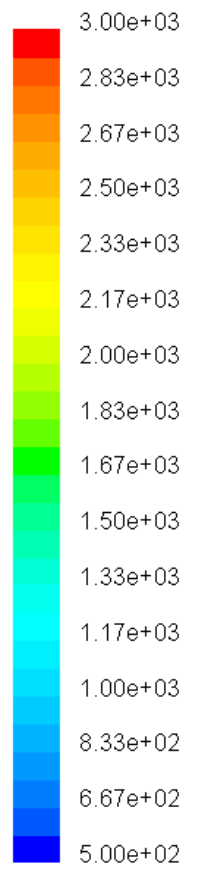

Baseline

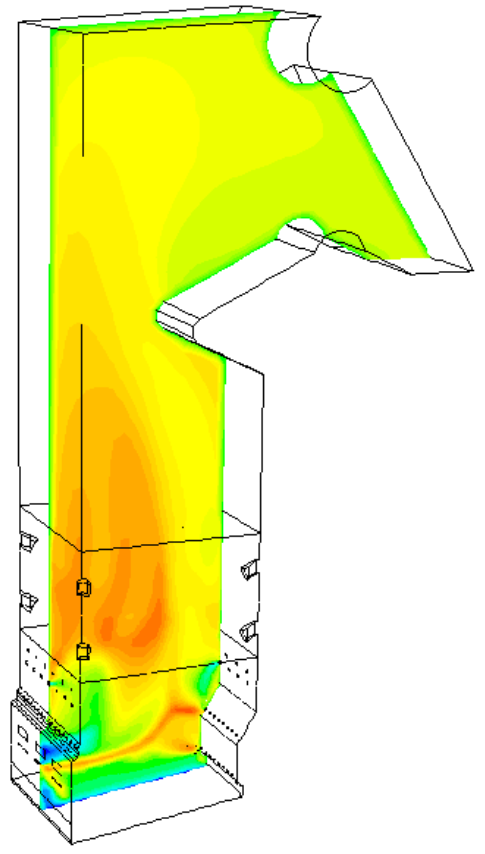

$\mathrm{MdN}$

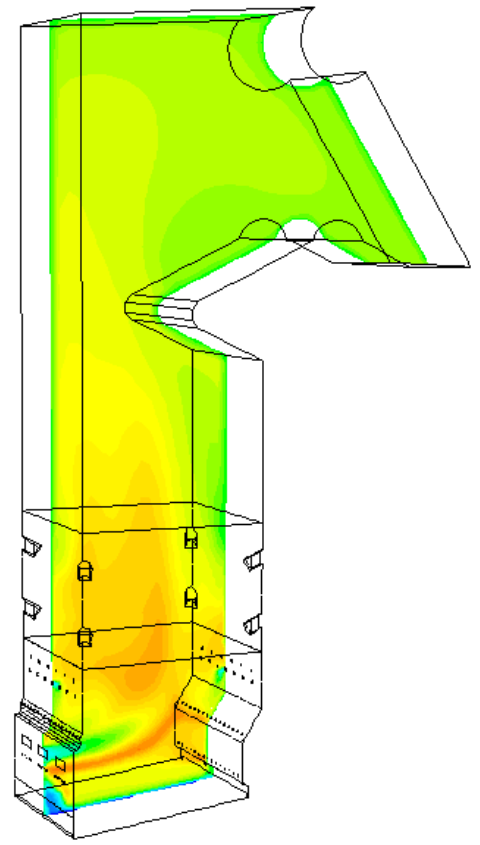

Figure 4-11 I Falls Contours of Temperature $\left({ }^{\circ} \mathrm{F}\right)$ for Baseline and MdN Firing Conditions
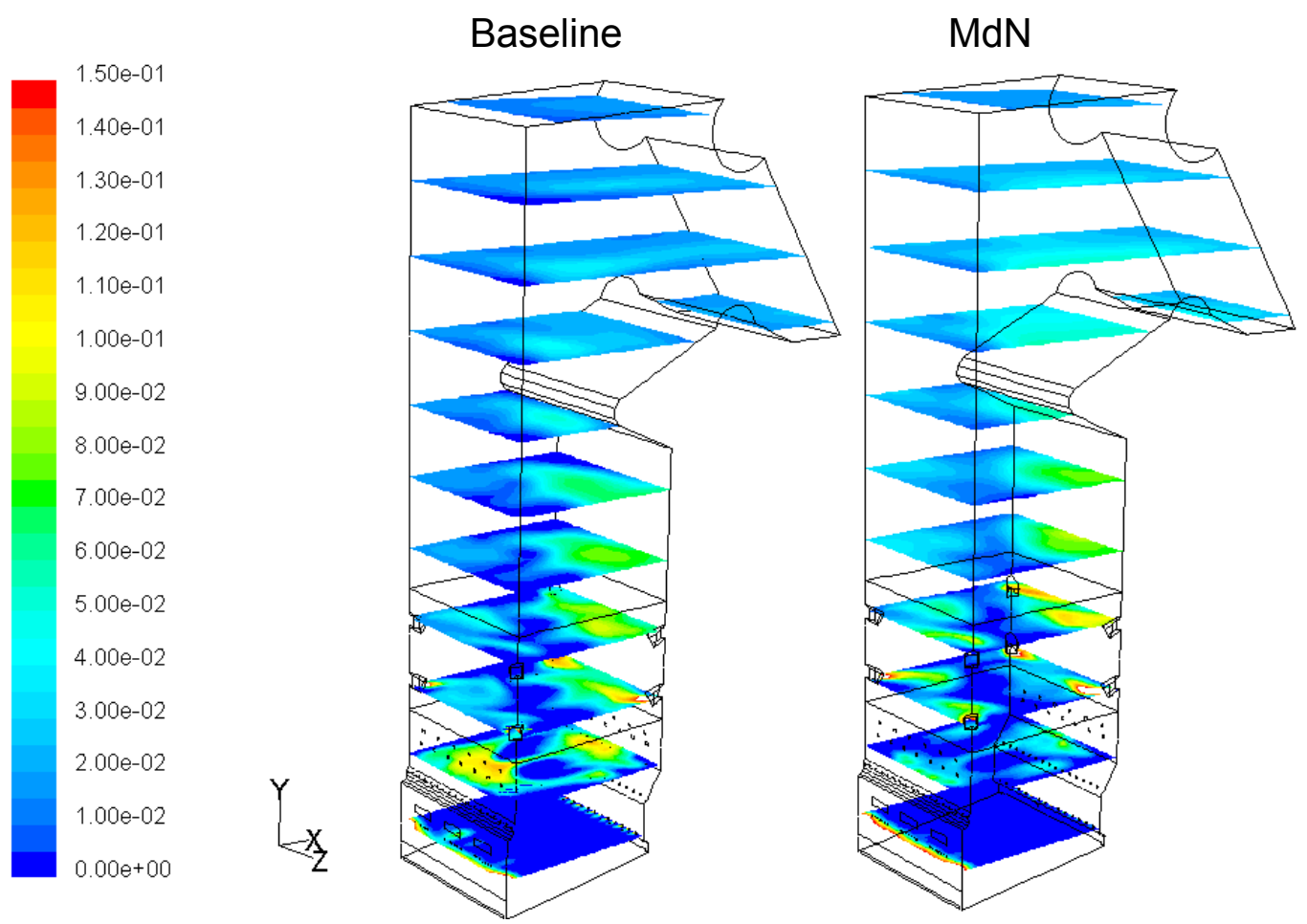

Figure 4-12 I Falls Contours of Mole Fraction of $\mathrm{O} 2$ (wet) for Baseline and MdN Firing Conditions 


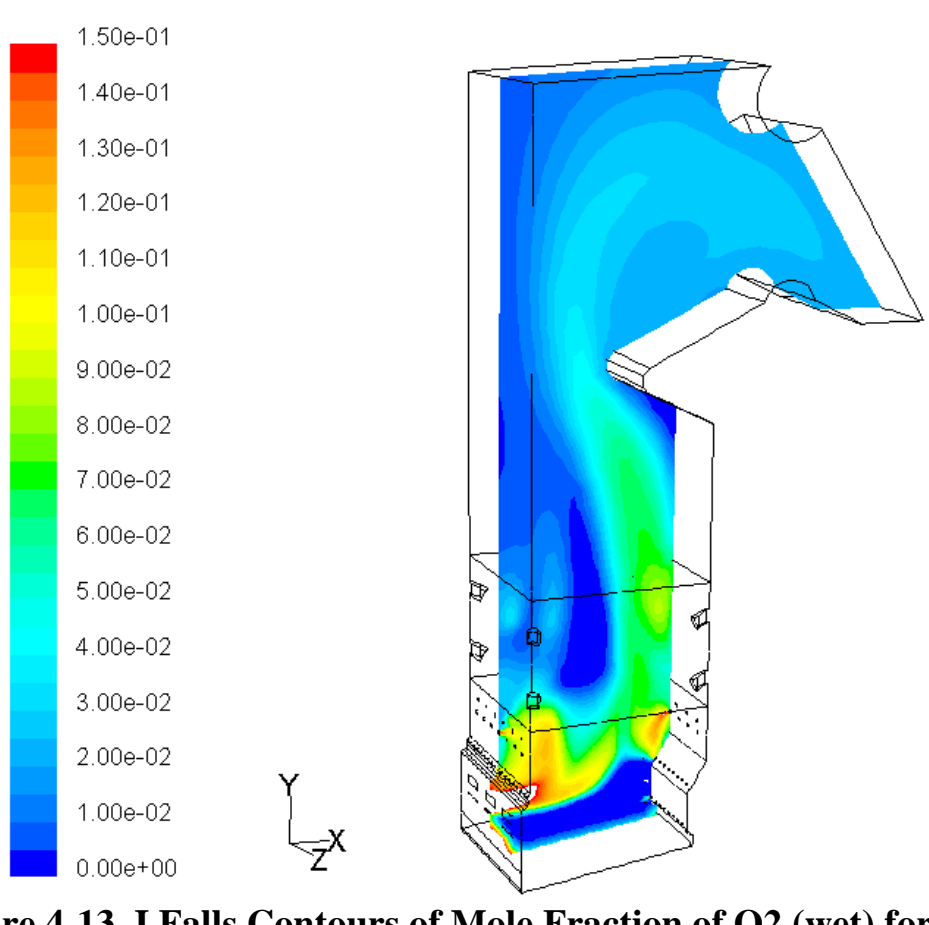

$$
\operatorname{MdN}
$$

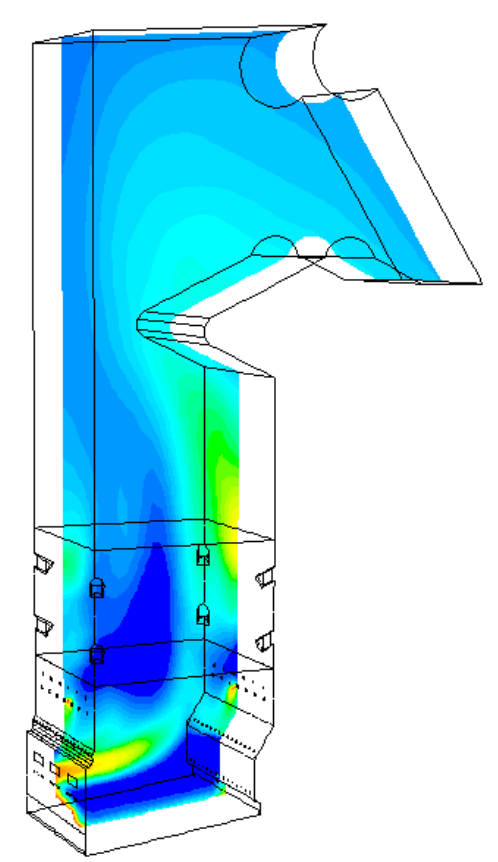

Figure 4-13 I Falls Contours of Mole Fraction of O2 (wet) for Baseline and MdN Firing Conditions

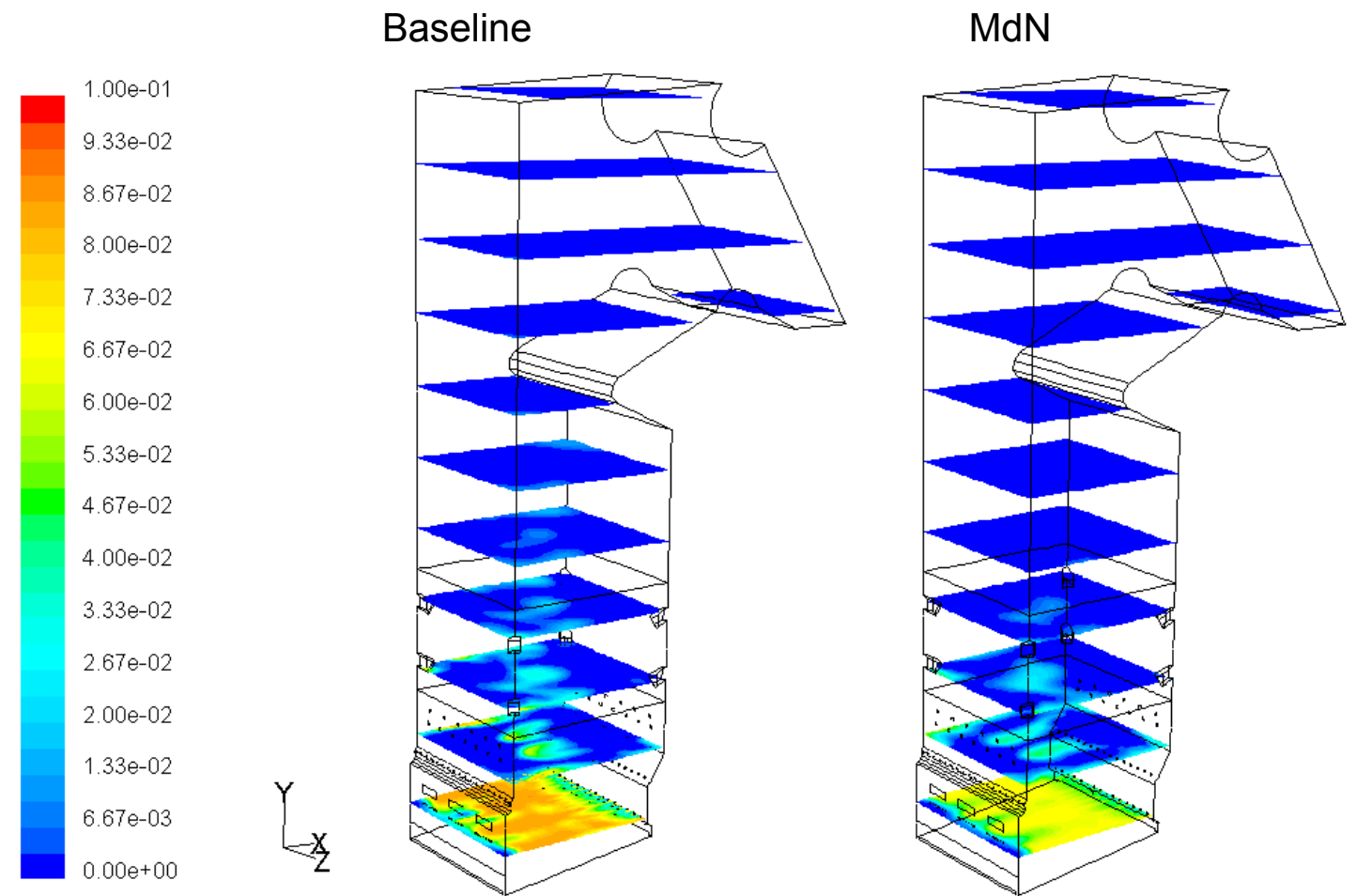

Figure 4-14 I Falls Contours of Mole Fraction of CO (wet and uncorr.) for Baseline and MdN Firing Conditions 


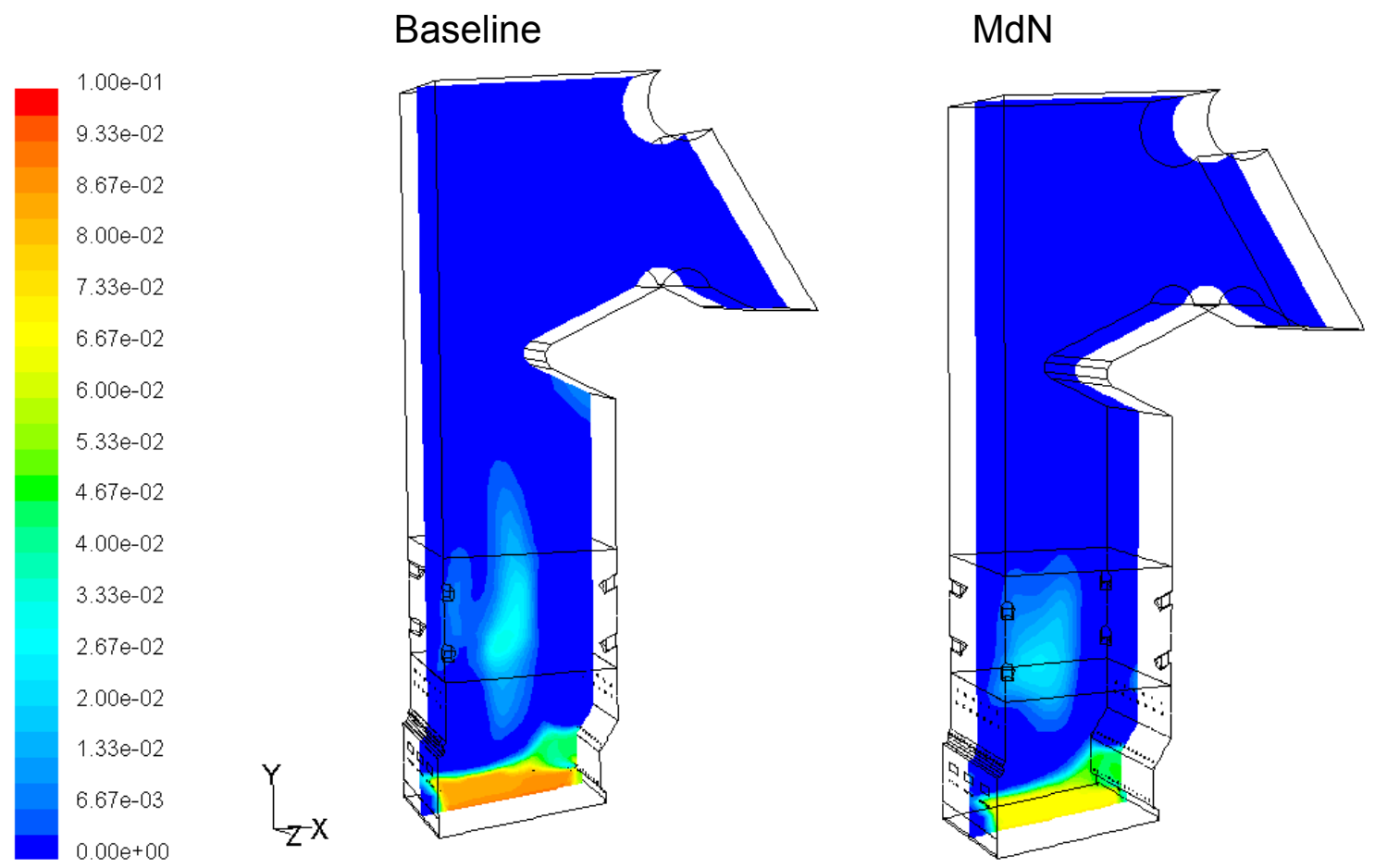

Figure 4-15 I Falls Contours of Mole Fraction of CO (wet and uncorr.) for Baseline and MdN Firing Conditions
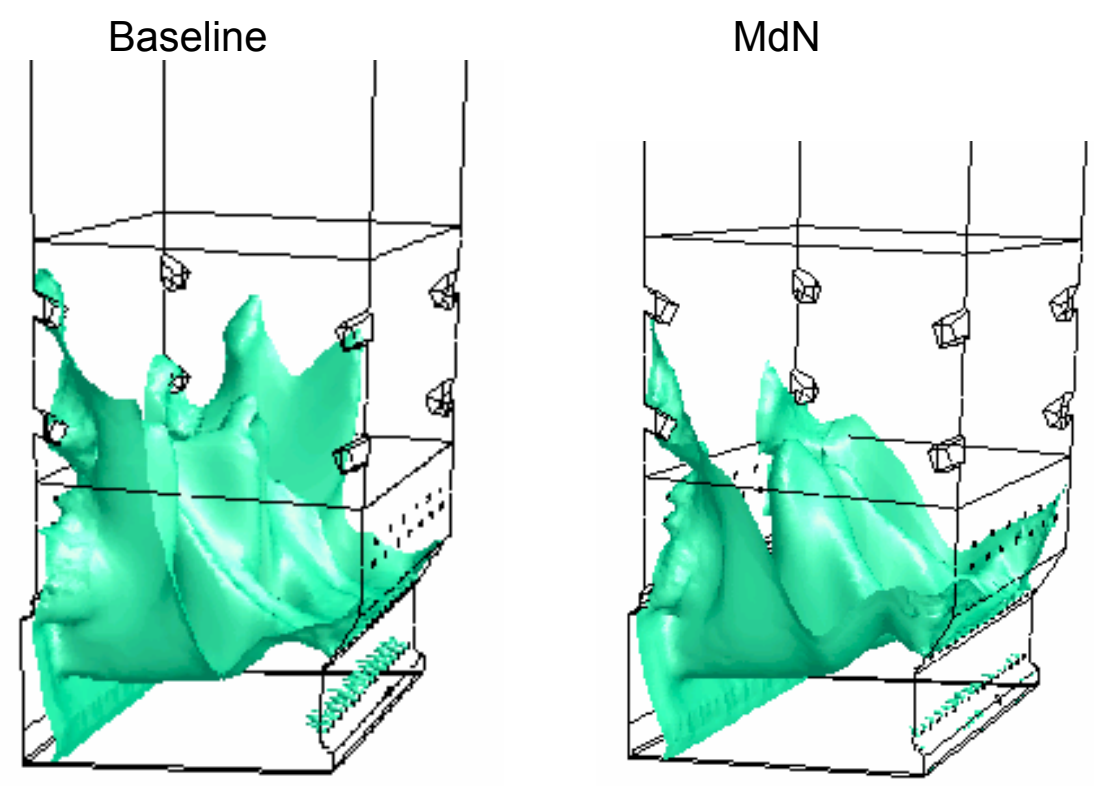

Figure 4-16 I Falls Iso-surfaces of CO Mole Fraction (3\% wet) for Baseline and MdN Firing Conditions 


\subsection{Wallula Stoker Boiler CFD Model}

\subsubsection{Geometry and Computational Mesh}

The outline and the inlet ports for the baseline and the MdN cases were shown in Figure 4-17 and Figure 4-18. Meshes with approximately 350,000 cells were generated for both cases. The computational domain was mostly composed of unstructured hexahedral mesh. As shown in Figure 4-19, refined meshes were used around the inlet ports to allow the cells to grow from the burn out level to the rest of the domain. In this way, it was possible to resolve all inlet ports that were small compared to the overall size of the furnace.

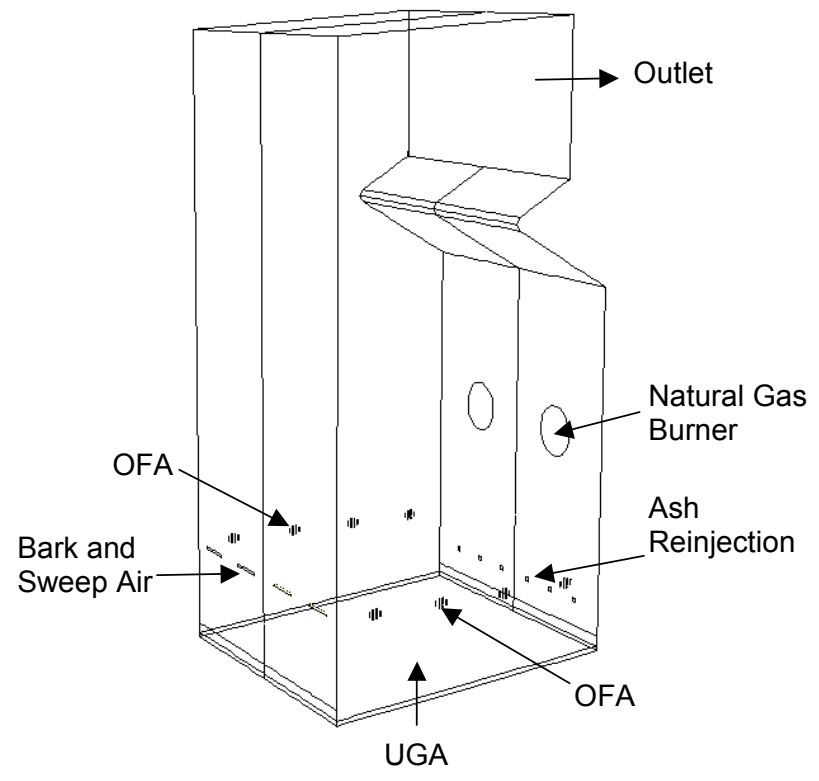

Figure 4-17 Wallula Inlet Ports for Boiler Baseline Case 


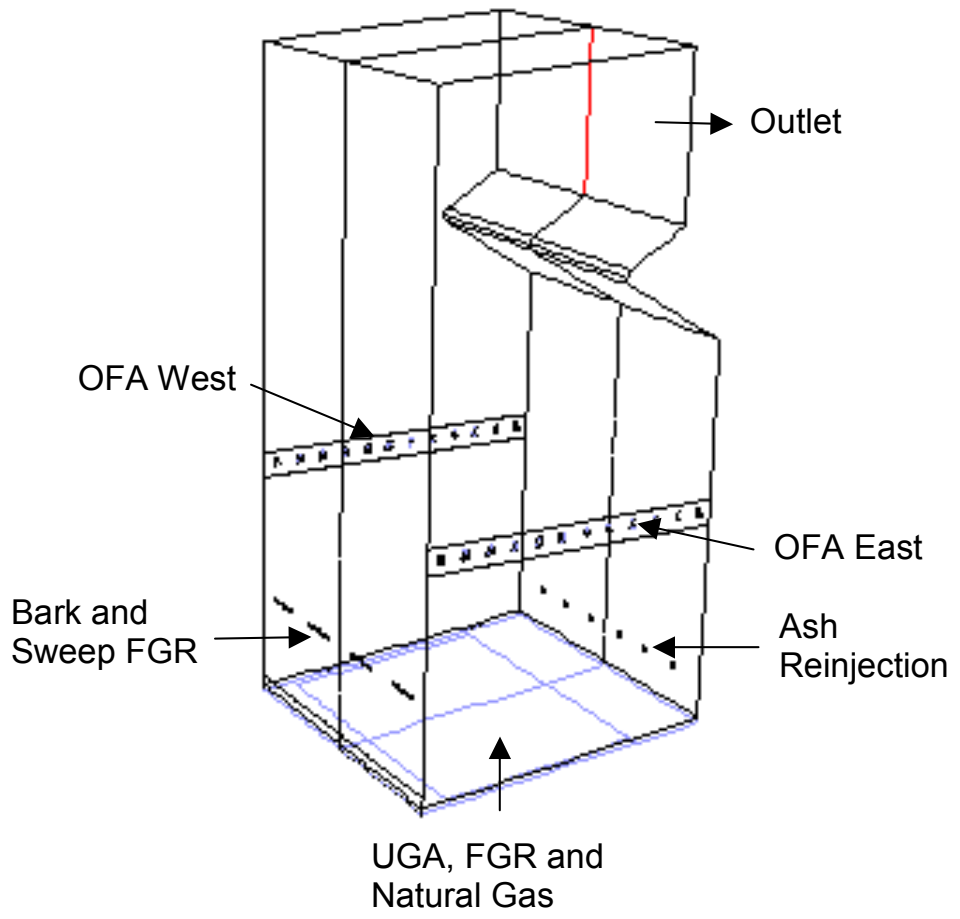

Figure 4-18 Wallula Inlet Ports for Boiler MdN Retrofit Arrangement
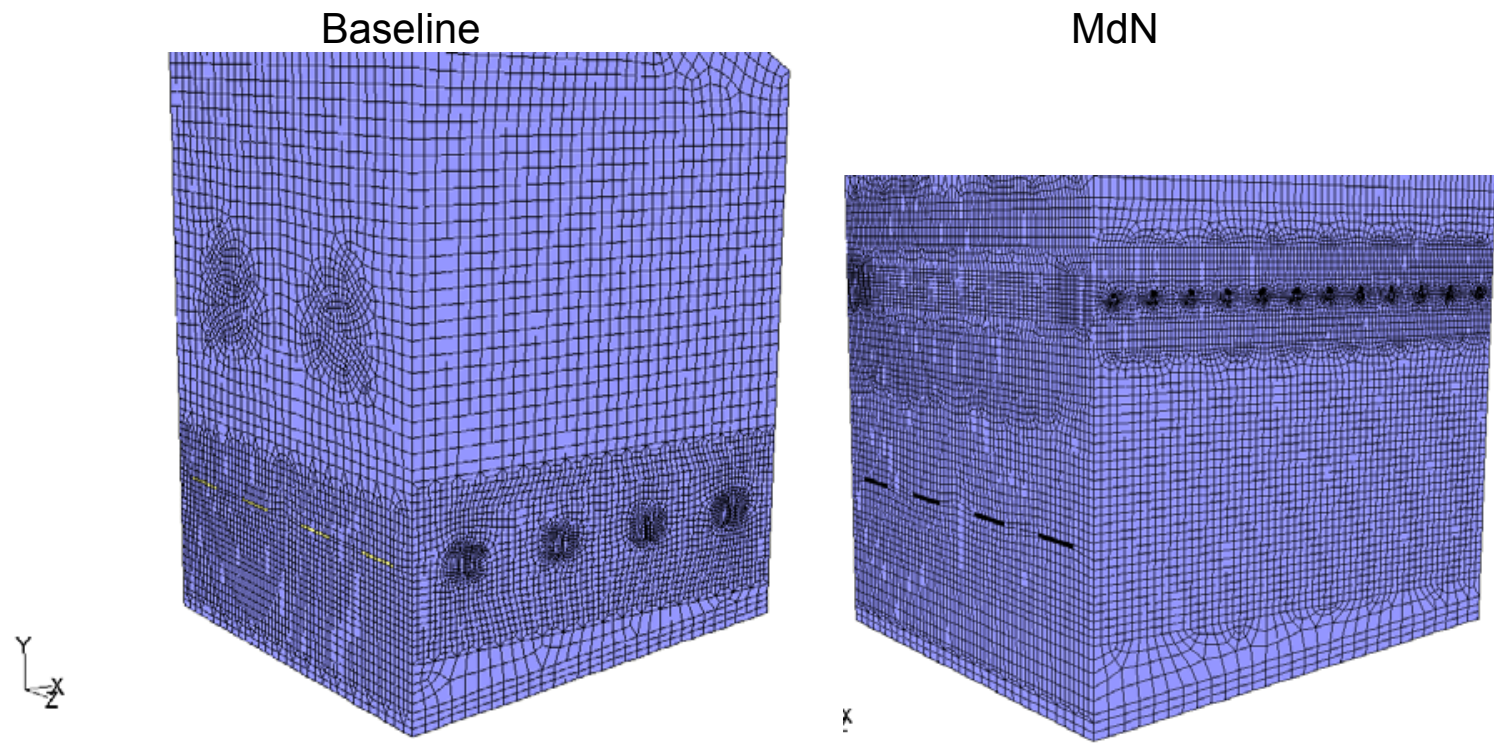

Figure 4-19 Wallula CFD Meshes for Baseline and MdN Cases

\subsubsection{Input and Boundary Conditions}

The boundary conditions for the baseline and MdN cases were set up based on chemical composition of hog fuel, baseline test results and requirement of 5\% exit oxygen. Constant temperature boundary conditions were considered for water walls. Table 4-3 shows the proximate and ultimate analysis of the hog fuel. 
Table 4-4 shows the flow distributions of hog fuel, natural gas, over fire air, under grate air, FGR and recycled ash. In the MdN arrangement of this boiler, the natural gas, FGR and air were injected below grate to lower combustion zone.

Particles were set up with six different particle sizes, which had diameters between $0.1 \mathrm{~mm}$ and $30 \mathrm{~mm}$. The initial condition of hog particles was set up so that they were injected into the furnace uniformly on the grate. Ash particles were injected from the ash re-injection ports 6 degrees upward. Size distribution for hog fuel particles is shown in Figure 4-20.

Table 4-3 Wallula Hog Fuel Chemical Analysis

\begin{tabular}{|c|c|c|}
\hline \multirow[t]{2}{*}{ FUEL ANALYSIS } & & \\
\hline & $\begin{array}{l}\%(w / w) \\
\text { As Fired }\end{array}$ & $\begin{array}{c}\% \text { (w/w) } \\
\text { Dry }\end{array}$ \\
\hline \multicolumn{3}{|l|}{ Proximate } \\
\hline \multirow{4}{*}{$\begin{array}{r}\text { Moisture } \\
\text { Ash } \\
\text { Volatile Matter } \\
\text { Fixed Carbon }\end{array}$} & 43.25 & \\
\hline & 2.08 & \\
\hline & 41.50 & \\
\hline & 13.17 & \\
\hline \multirow{7}{*}{$\begin{array}{r}\text { Hydrogen } \\
\text { Carbon } \\
\text { Nitrogen } \\
\text { Sulfur } \\
\text { Oxygen } \\
\text { Ash }\end{array}$} & & \\
\hline & & 5.87 \\
\hline & & 51.59 \\
\hline & & 0.27 \\
\hline & & 0.05 \\
\hline & & 38.50 \\
\hline & & 3.71 \\
\hline Higher Heating Value [Btu/lb] & & 8816 \\
\hline
\end{tabular}


Table 4-4 Wallula Flow Rates of Injected Gas and Solids for Baseline and MdN Cases

\begin{tabular}{|c|c|c|c|c|c|}
\hline & \multicolumn{2}{|c|}{ Baseline } & \multicolumn{2}{|c|}{ MdN } \\
\hline & & $\begin{array}{l}\text { Flow Rate } \\
{[\mathrm{klb} / \mathrm{h}]}\end{array}$ & $\begin{array}{c}\text { Temperature } \\
\left.{ }^{\circ} \mathrm{F}\right]\end{array}$ & $\begin{array}{l}\text { Flow Rate } \\
\text { [klb/h] }\end{array}$ & $\begin{array}{c}\text { Temperature } \\
{\left[{ }^{\circ} \mathrm{F}\right]}\end{array}$ \\
\hline \multicolumn{6}{|l|}{ FUEL } \\
\hline \multirow{2}{*}{\multicolumn{2}{|c|}{$\begin{array}{l}\text { Bark } \\
\text { Natural Gas }\end{array}$}} & 21.28 & 80 & 36.4 & 80 \\
\hline & & 3.31 & 507 & 0.8 & 548 \\
\hline \multicolumn{6}{|l|}{ AIR } \\
\hline \multirow{6}{*}{\multicolumn{2}{|c|}{$\begin{array}{l}\text { UGA } \\
\text { OFA East } \\
\text { OFA West } \\
\text { Bark Sweep } \\
\text { Ash Re-injection } \\
\text { Burner Air }\end{array}$}} & 115.87 & 548 & 105.2 & 548 \\
\hline & & 17.53 & 548 & 38.3 & 548 \\
\hline & & 17.53 & 548 & 38.3 & 548 \\
\hline & & 24.10 & 80 & - & - \\
\hline & & 15.32 & 548 & - & - \\
\hline & & 75.68 & 507 & - & - \\
\hline \multicolumn{6}{|l|}{ FGR } \\
\hline \multirow{2}{*}{\multicolumn{2}{|c|}{$\begin{array}{l}\text { Sweep FGR } \\
\text { Ash Re-injection }\end{array}$}} & - & - & 24.2 & 80 \\
\hline & & - & - & 12.6 & 260 \\
\hline \multirow[t]{2}{*}{$\mathrm{ASH}$} & \multirow[b]{2}{*}{ Ash Re-injection } & & & & \\
\hline & & 0.56 & 80 & - & - \\
\hline
\end{tabular}

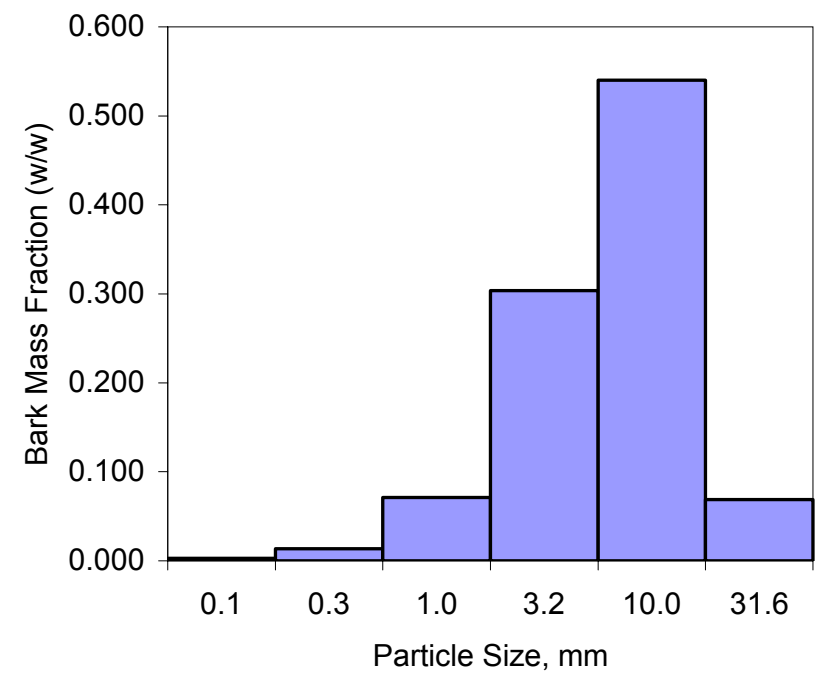

Figure 4-20 Wallula Wood Bark Size Distributions

\subsubsection{Validation of Stoker Boiler CFD Baseline Model}

The CFD model was validated by the test results taken by GTI in Wallula boiler. The comparison of test data and CFD data at the same locations is shown in Figures 4-21 - 4-25. The discrepancies are due to the varying boundary conditions during total sampling period. 


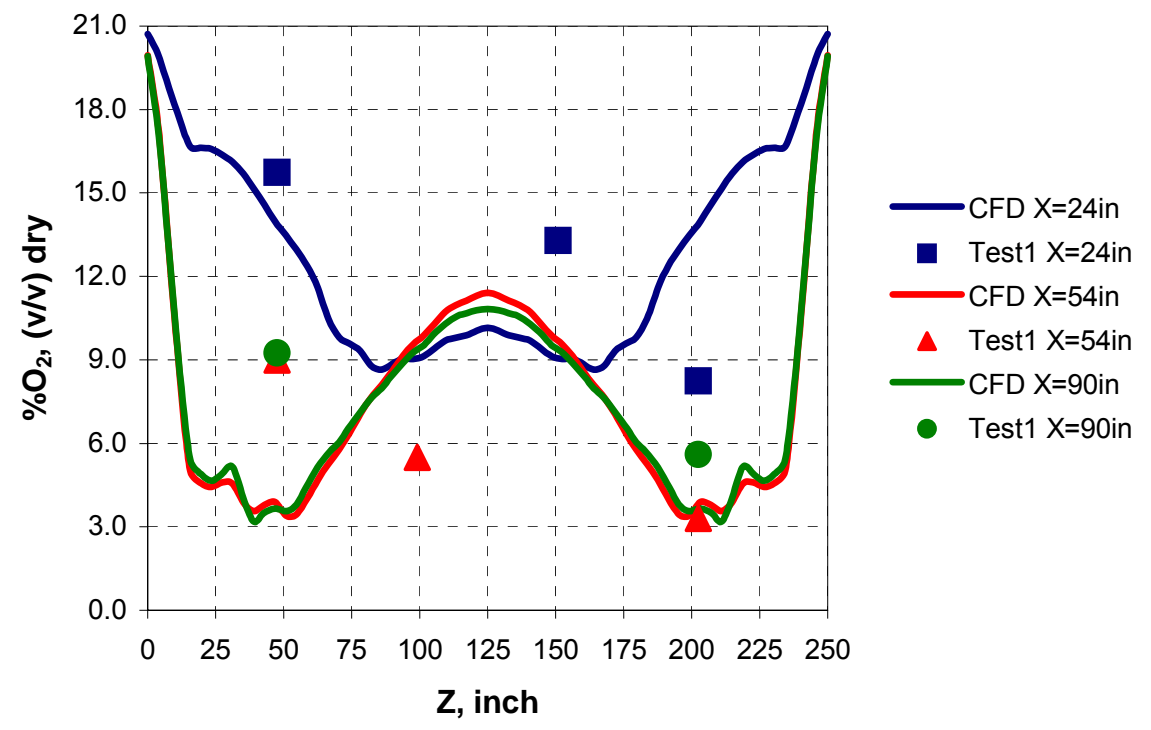

Figure 4-21 Wallula Comparison of Computed $\mathrm{O}_{2}$ Concentration with Measured $\mathrm{O}_{2}$ (18 inch above grate)

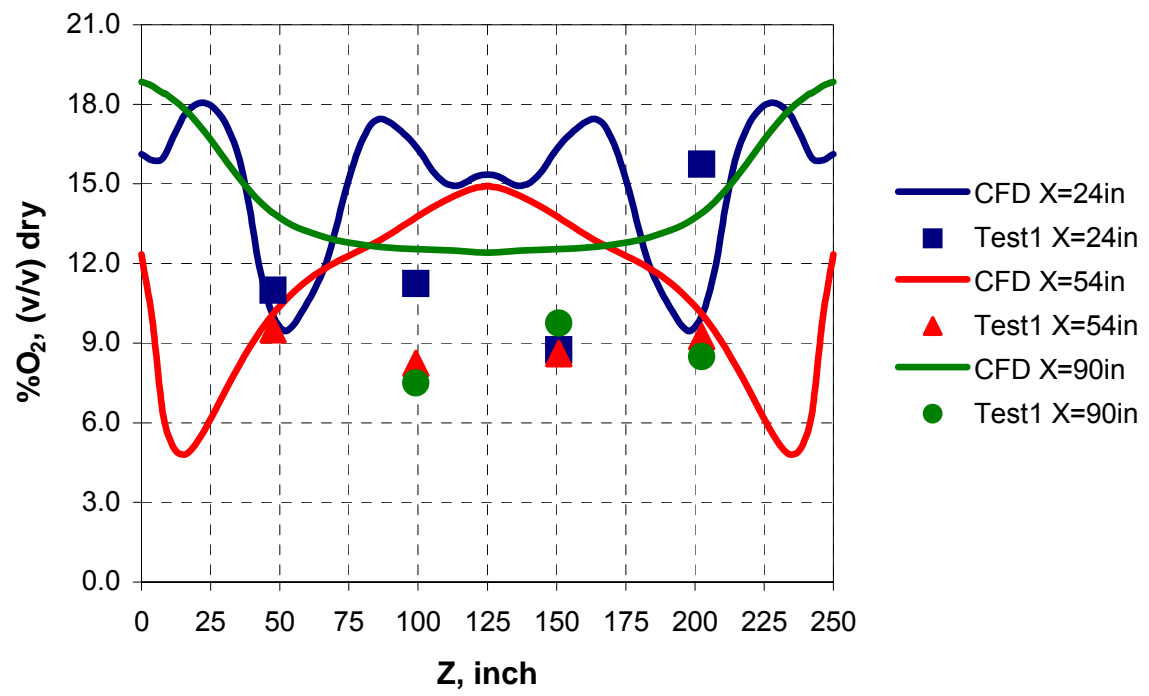

Figure 4-22 Wallula Comparison of Computed $\mathrm{O}_{2}$ Concentration with Measured $\mathrm{O}_{2}$ (83 inch above grate) 


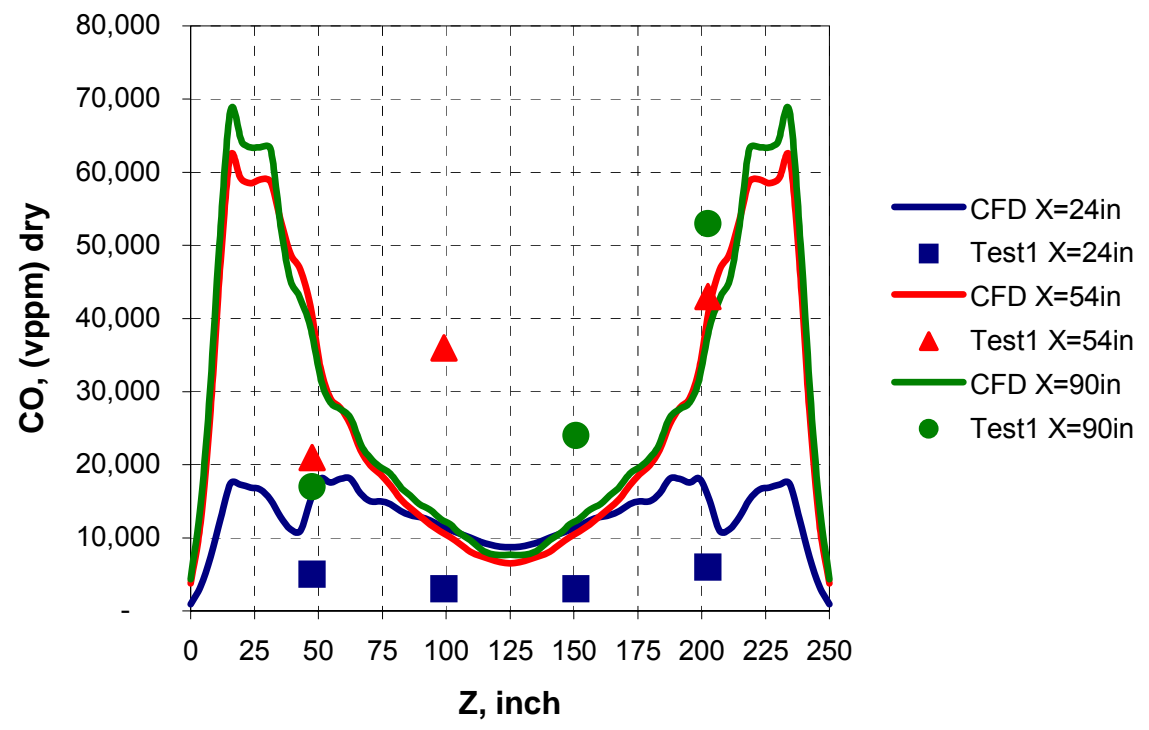

Figure 4-23 Wallula Comparison of Computed CO Concentration with Measured CO (18 inch above grate)

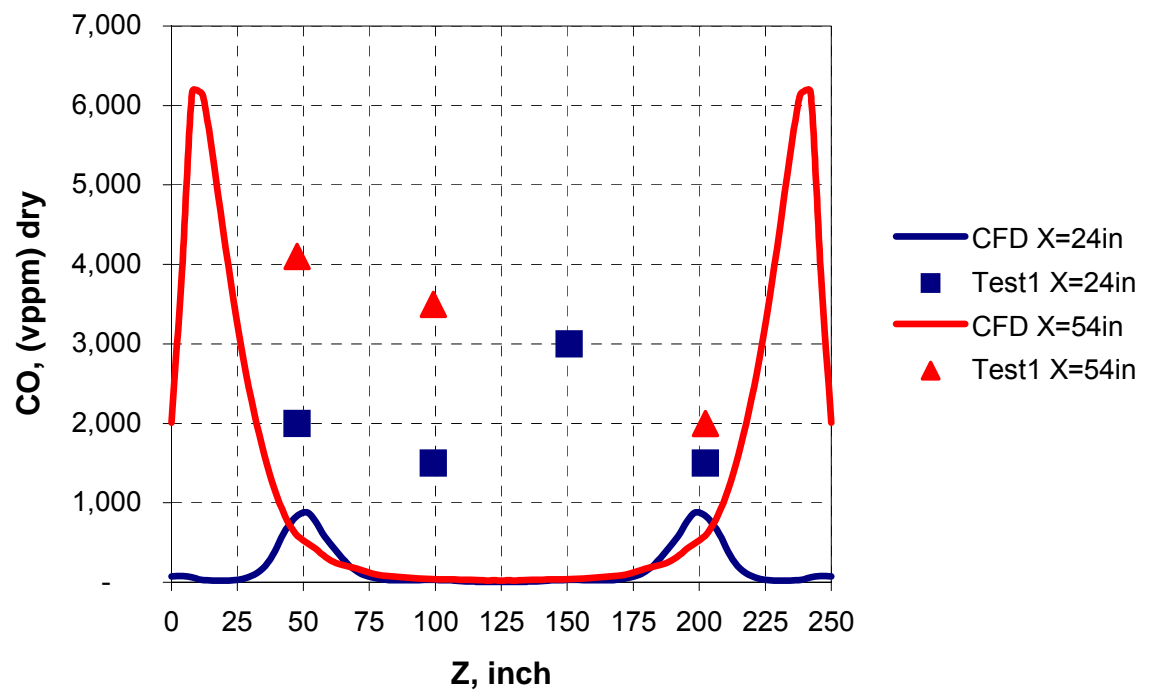

Figure 4-24 Wallula Comparison of Computed CO Concentration with Measured CO (83 inch above grate) 


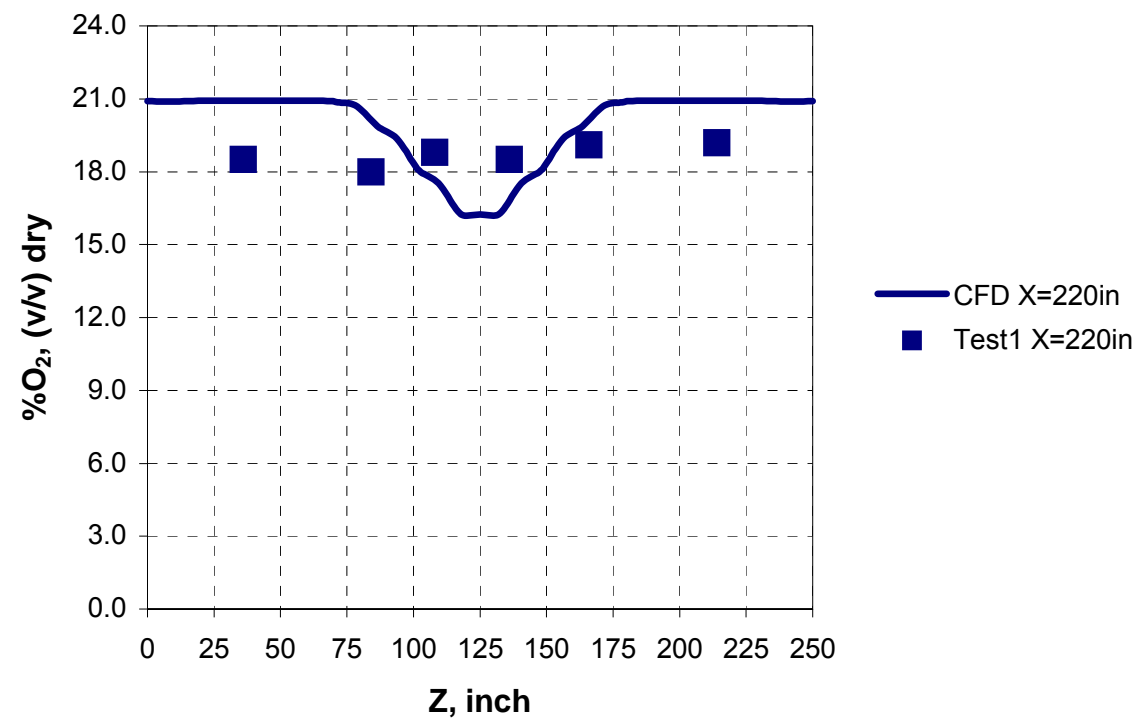

Figure 4-25 Wallula Comparison of Computed $\mathrm{O}_{2}$ Concentration with Measured $\mathrm{O}_{2}$ (24 inch above grate)

\subsubsection{Comparison of Boiler Performance with CFD: Baseline Boiler Model versus Boiler Model with MdN}

Oxygen distribution is controlled in the furnace by OFA jets in the baseline and the MdN cases. Figure 4-26 shows a comparison of turbulence levels for both cases. In MdN retrofit case, small jets from both sides provide stronger mixing in the center.

The temperature distributions in the baseline case and the $\mathrm{MdN}$ case are shown in Figure 4-27 and 4-28, respectively. The distribution in MdN case is more uniform compared to the baseline case. Because methane is introduced from the rear and front walls in the bottom of the furnace, high temperature regions appear in this zone. The combustion zone goes higher and temperature is also high near natural gas burner inlets, in the baseline case.

Figures 4-29 - 4-32 show the contour plots of $\mathrm{O}_{2}$ and $\mathrm{CO}$ for the baseline cases and the $\mathrm{MdN}$ cases. The volatiles from bark as well as methane react with air coming from beneath the grate to form $\mathrm{CO}$ above the grate in the MdN case. Figure 4-33 compares the iso-surfaces of $\mathrm{CO}$ mole fraction in the bottom of the furnace. The highest temperature can be found in this zone. The oxygen coming from OFA ports on the sides of the furnace completes the reaction by burning $\mathrm{CO}$ formed in the lower zone. 

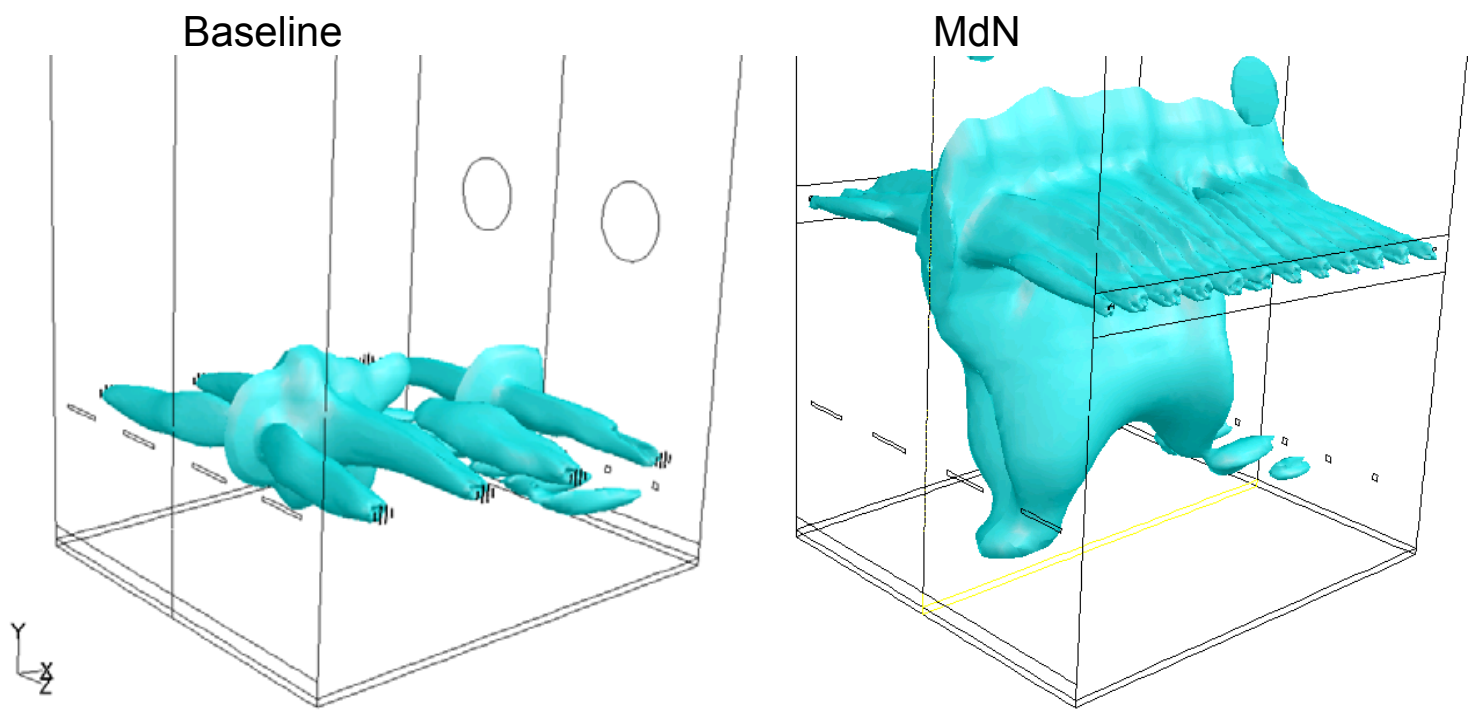

Figure 4-26 Wallula Iso-surfaces of Turbulent Kinetic Energy Levels $\left(300 \mathrm{ft}^{2} / \mathrm{s}^{2}\right)$ for Baseline and MdN Firing Conditions
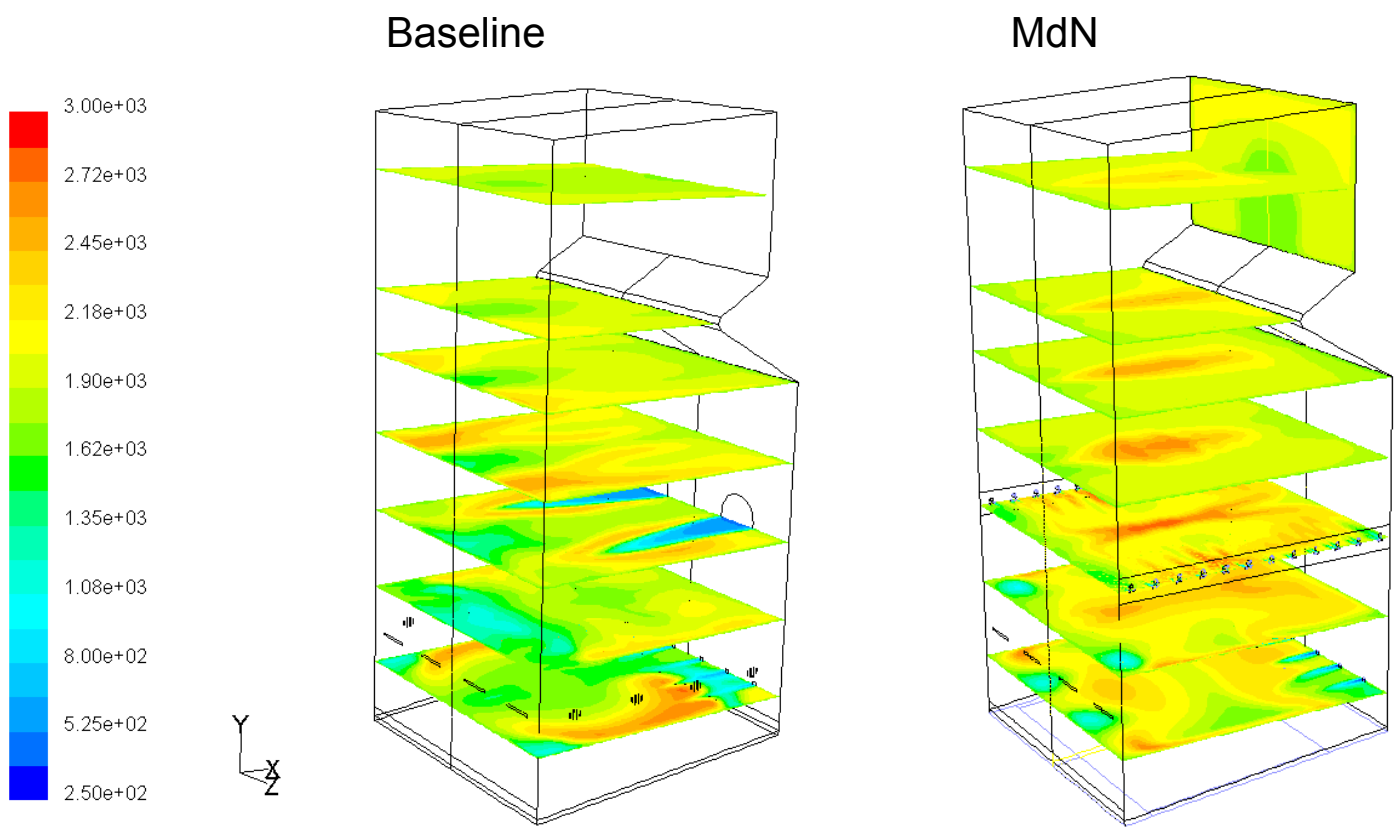

Figure 4-27 Wallula Contours of Temperature (F) for Baseline and MdN Firing Conditions 


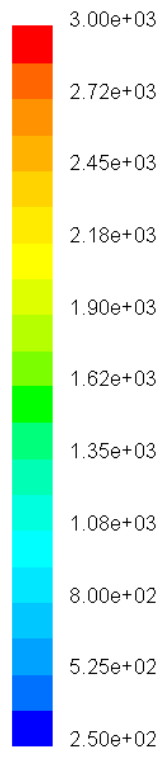

\section{Baseline}

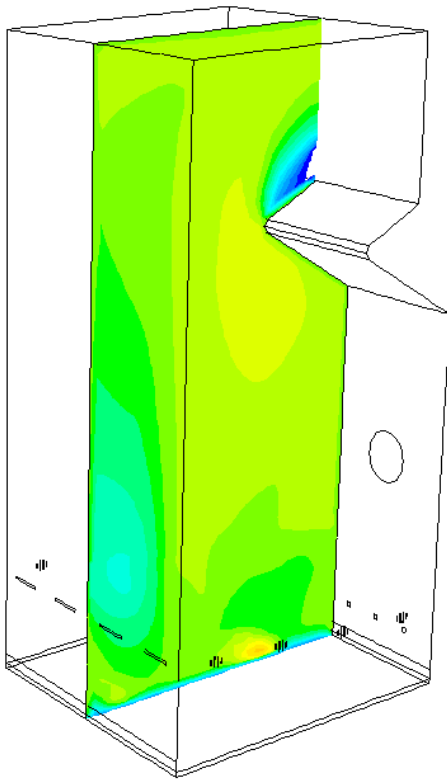

$\mathrm{MdN}$

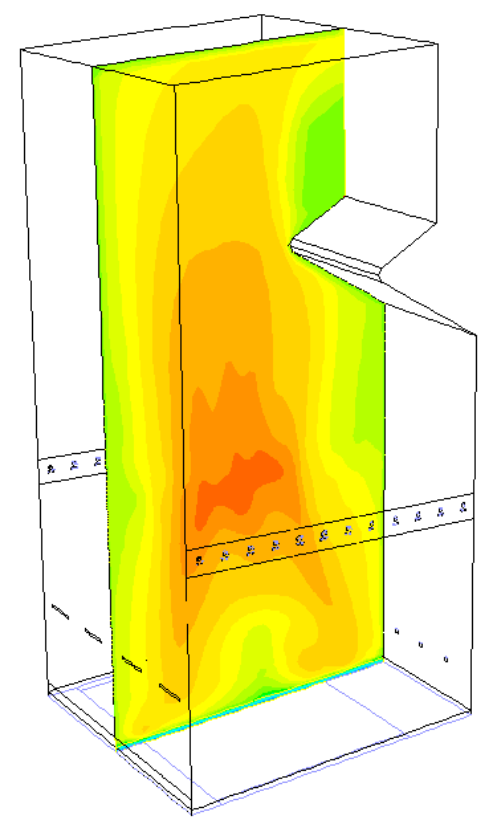

Figure 4-28 Wallula Contours of Temperature (F) for Baseline and MdN Firing Conditions
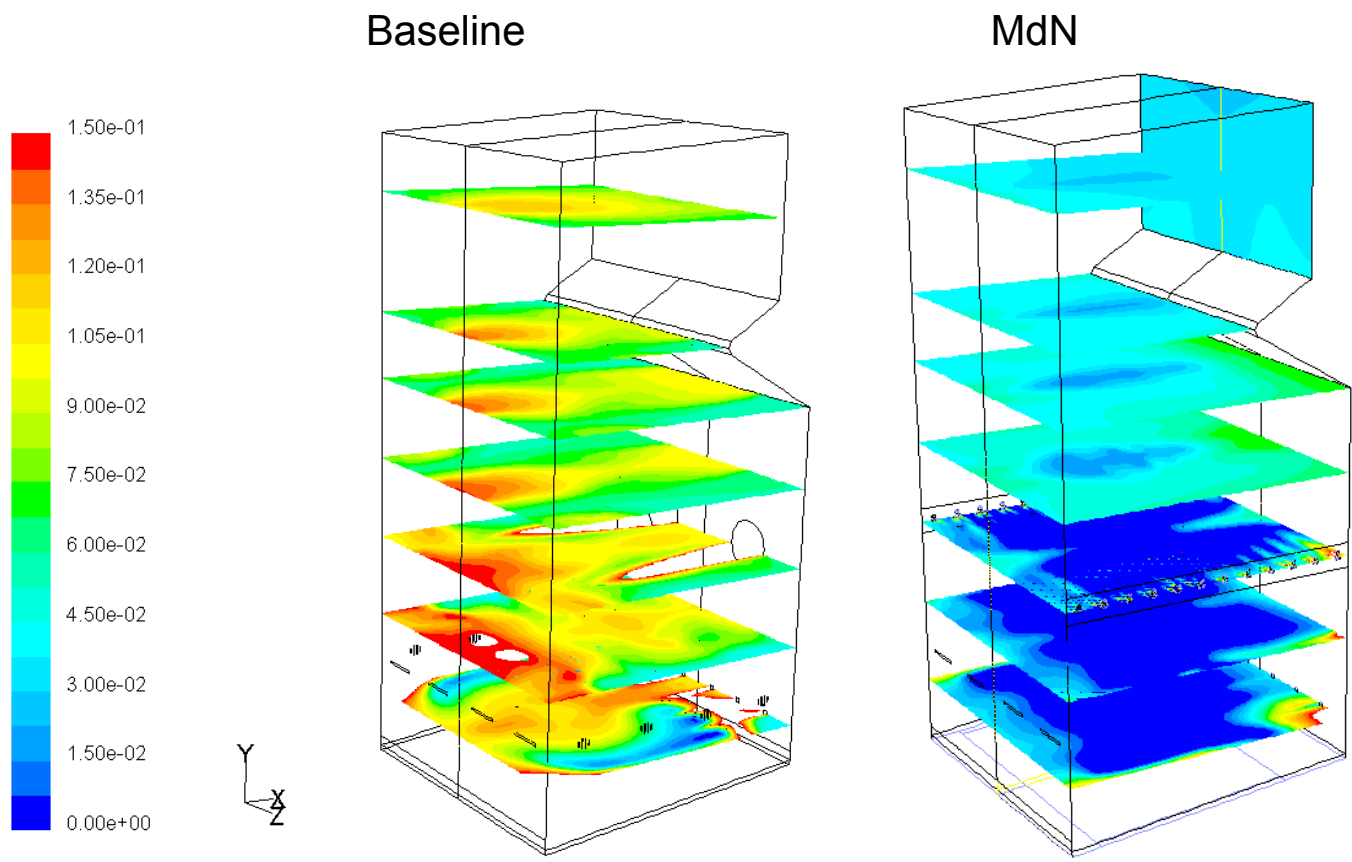

Figure 4-29 Wallula Contours of Mole Fraction of $\mathrm{O} 2$ (wet) for Baseline and MdN Firing Conditions 


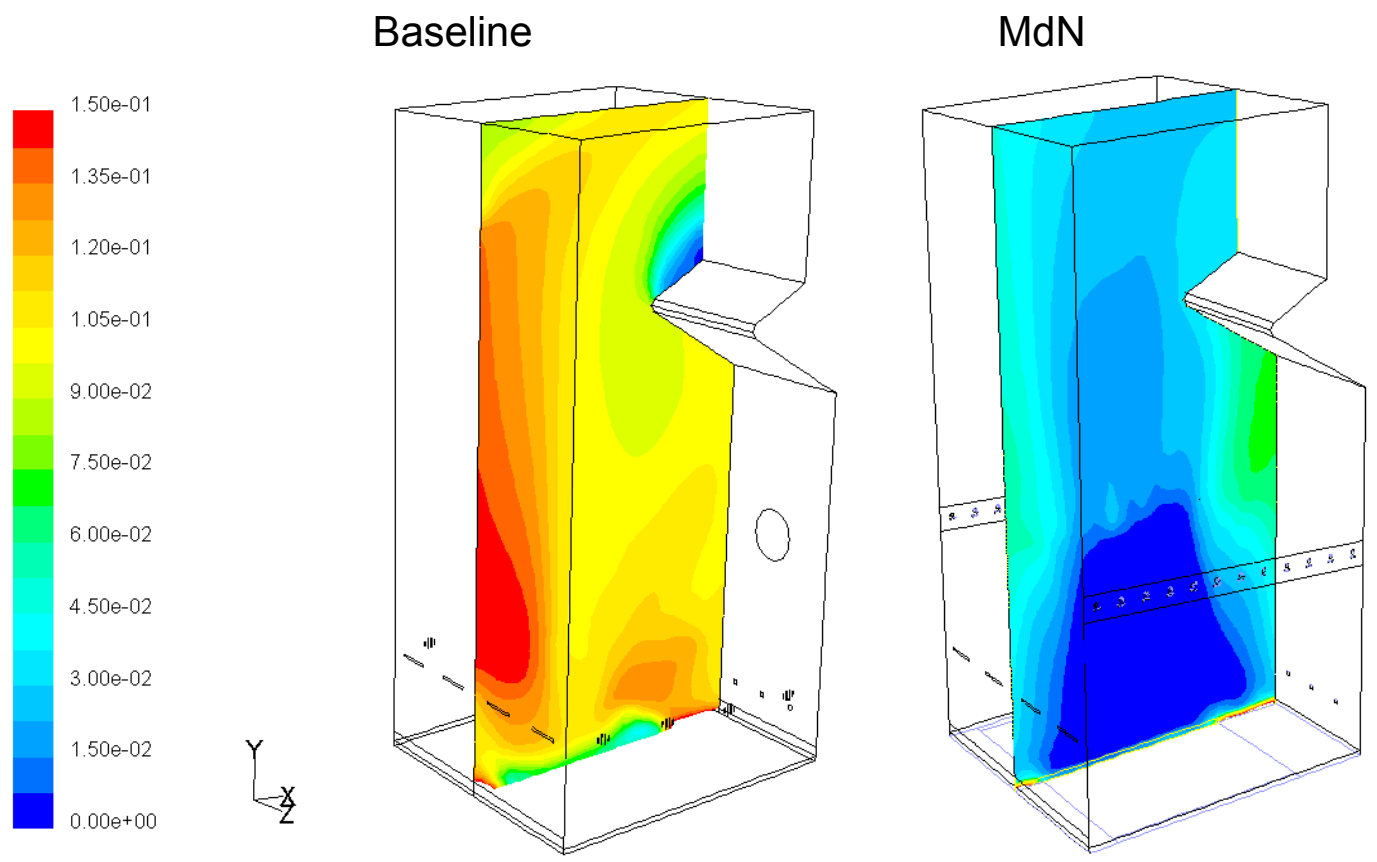

Figure 4-30 Wallula Contours of Mole Fraction of $\mathrm{O}_{2}$ (wet) for Baseline and MdN Firing Conditions

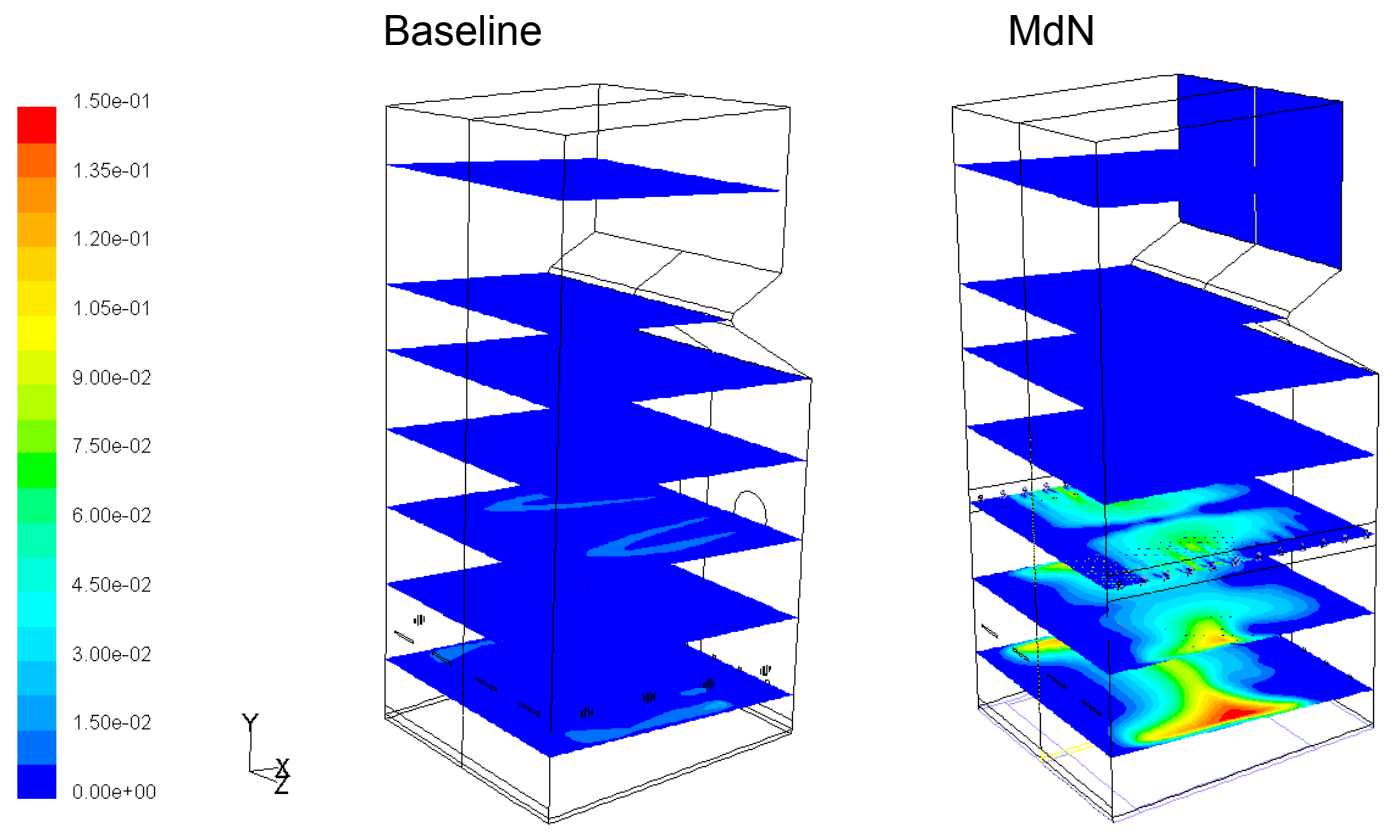

Figure 4-31 Wallula Contours of Mole Fraction of CO (wet and uncorr.) for Baseline and MdN Firing Conditions 


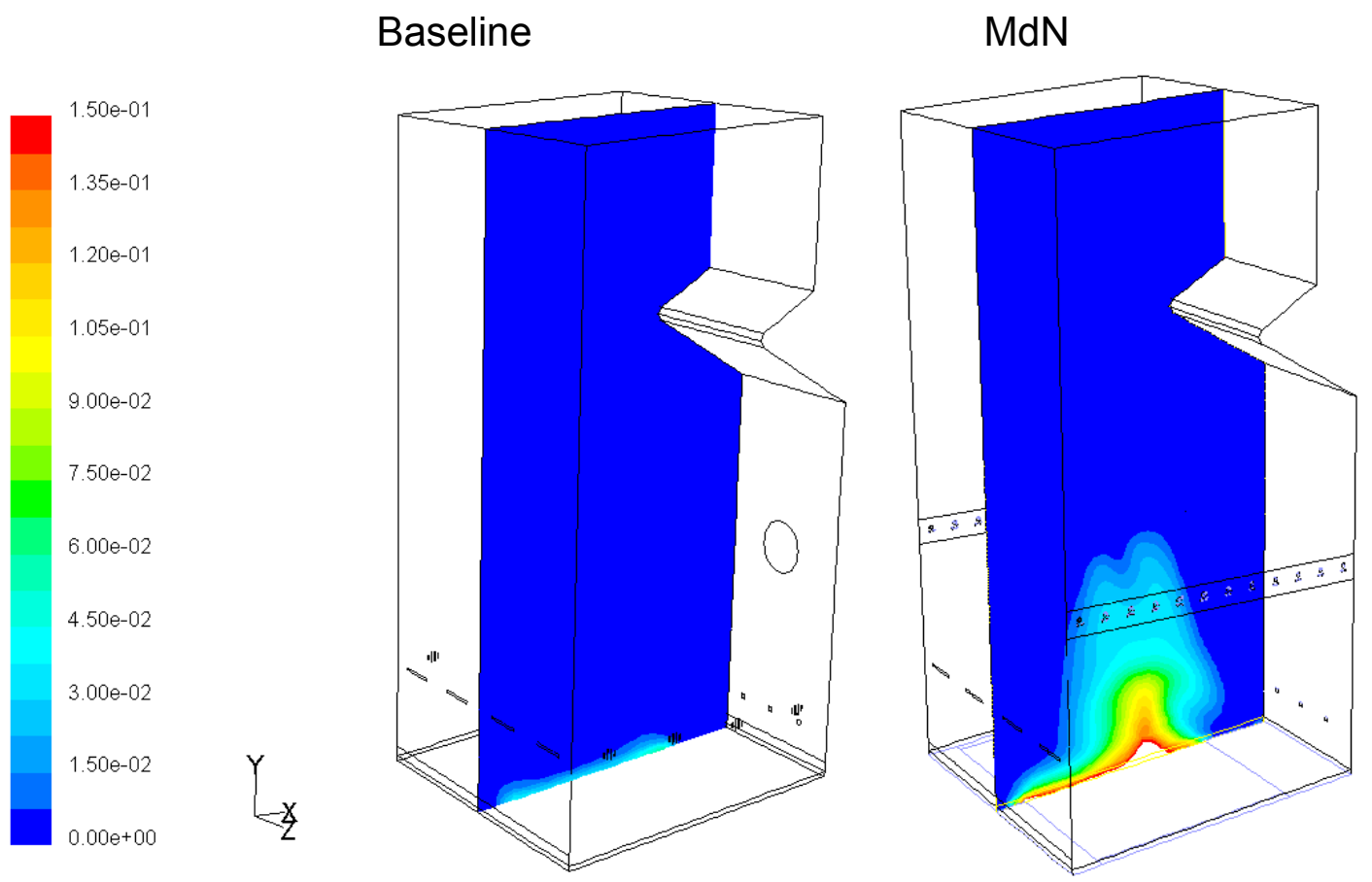

Figure 4-32 Wallula Contours of Mole Fraction of CO (wet and uncorr.) for Baseline and MdN Firing Conditions
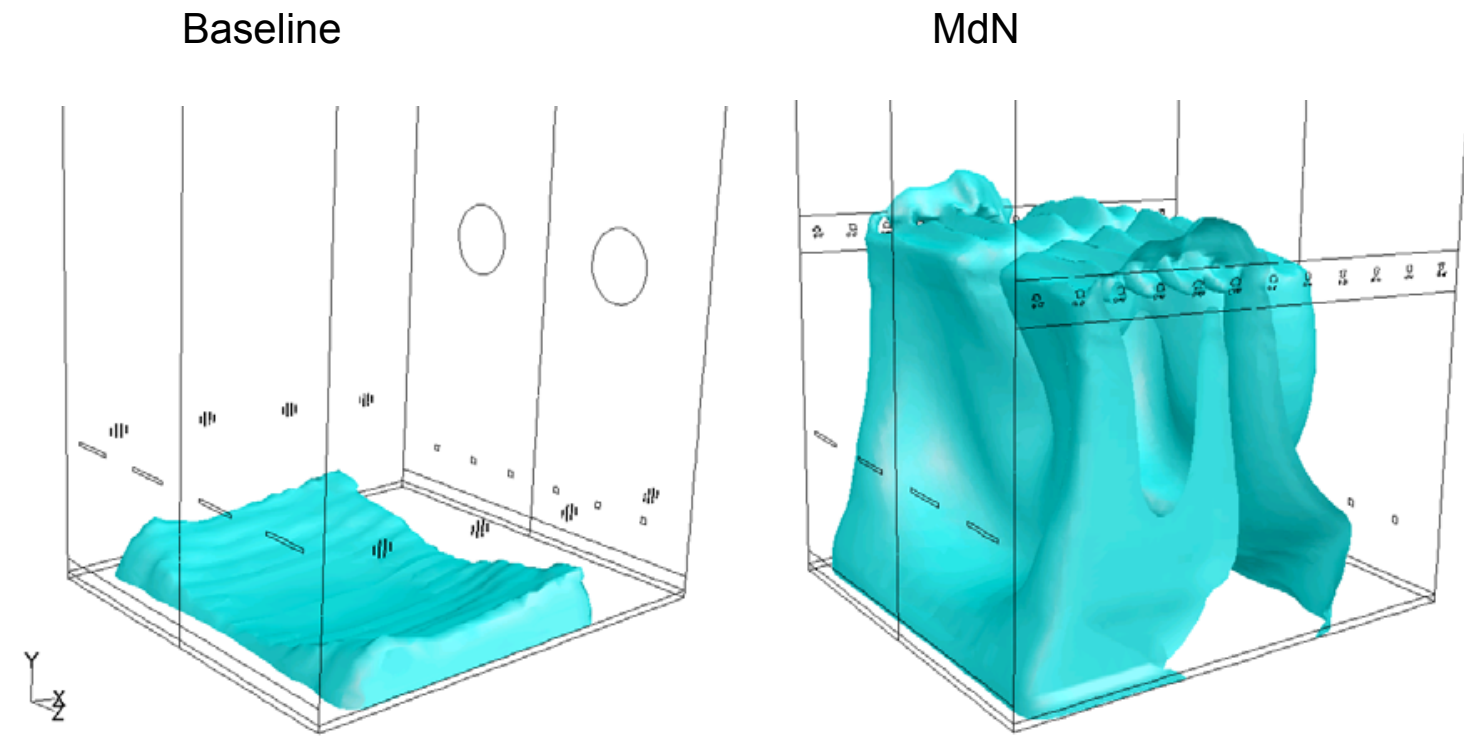

Figure 4-33 Wallula Iso-surfaces of CO Mole Fraction (3\% wet) for Baseline and MdN Firing Conditions 


\subsection{Port Hudson Stoker Boiler CFD Model}

\subsubsection{Geometry and Computational Mesh}

Figure 4-34 and Figure 4-35 show the outline of the furnace as well as the inlet ports of the baseline and the MdN cases. Meshes with approximately 230,000 cells were generated for both cases, as shown in Figure 4-36. The computational domain was filled with unstructured hexahedral meshes. A refined mesh was employed around the inlet ports to allow the cells to grow from the burn out level to the rest of the domain. Hence, it was possible to resolve all inlet ports even though they were small compared to the overall size of the furnace.

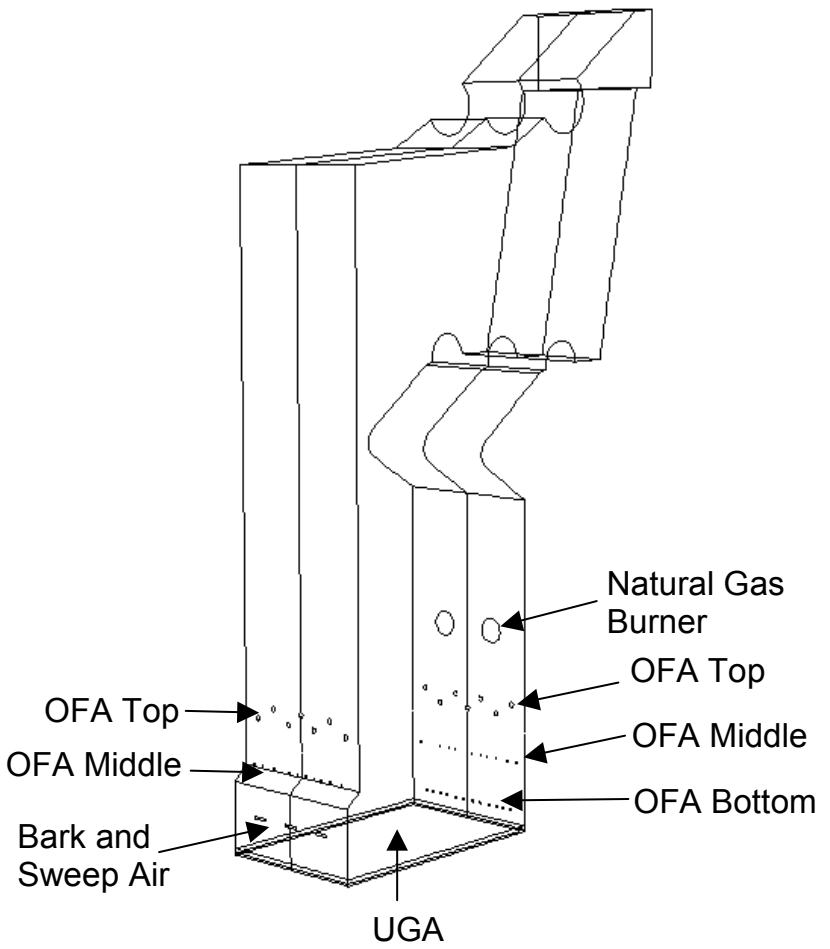

Figure 4-34 Port Hudson Inlet Ports for Boiler Baseline Case 


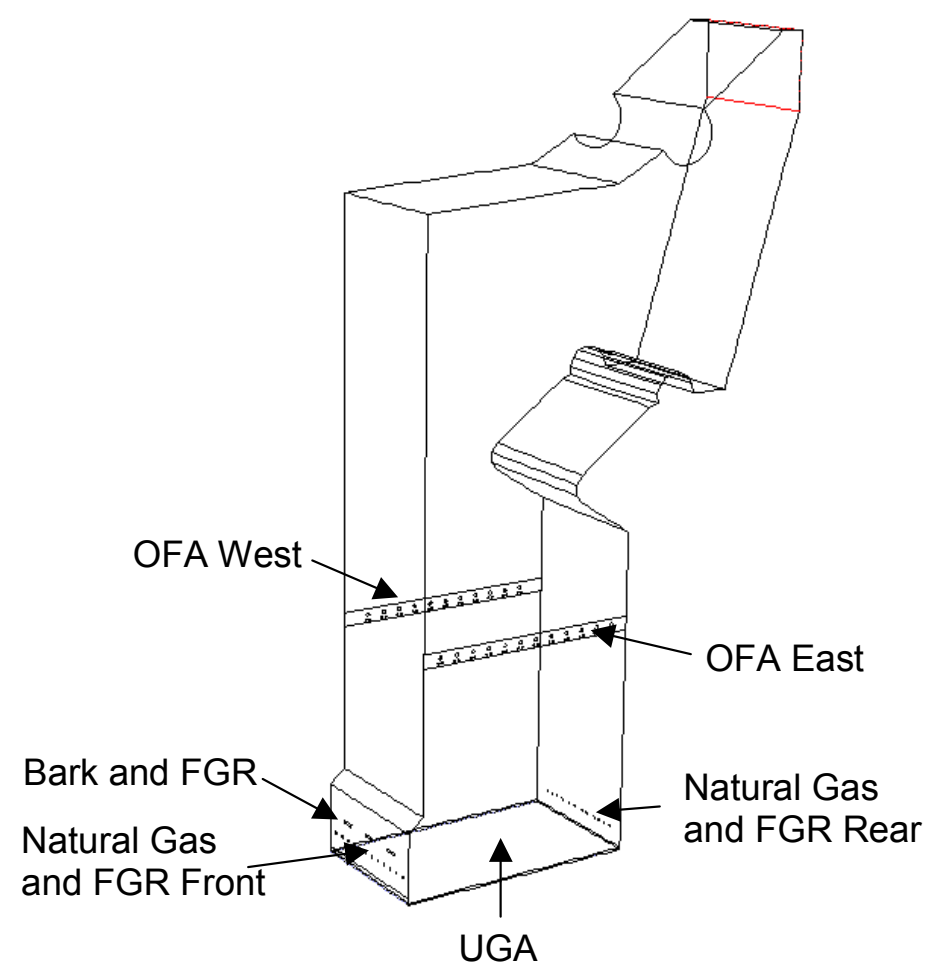

Figure 4-35 Port Hudson Inlet Ports for Boiler MdN Retrofit Arrangement
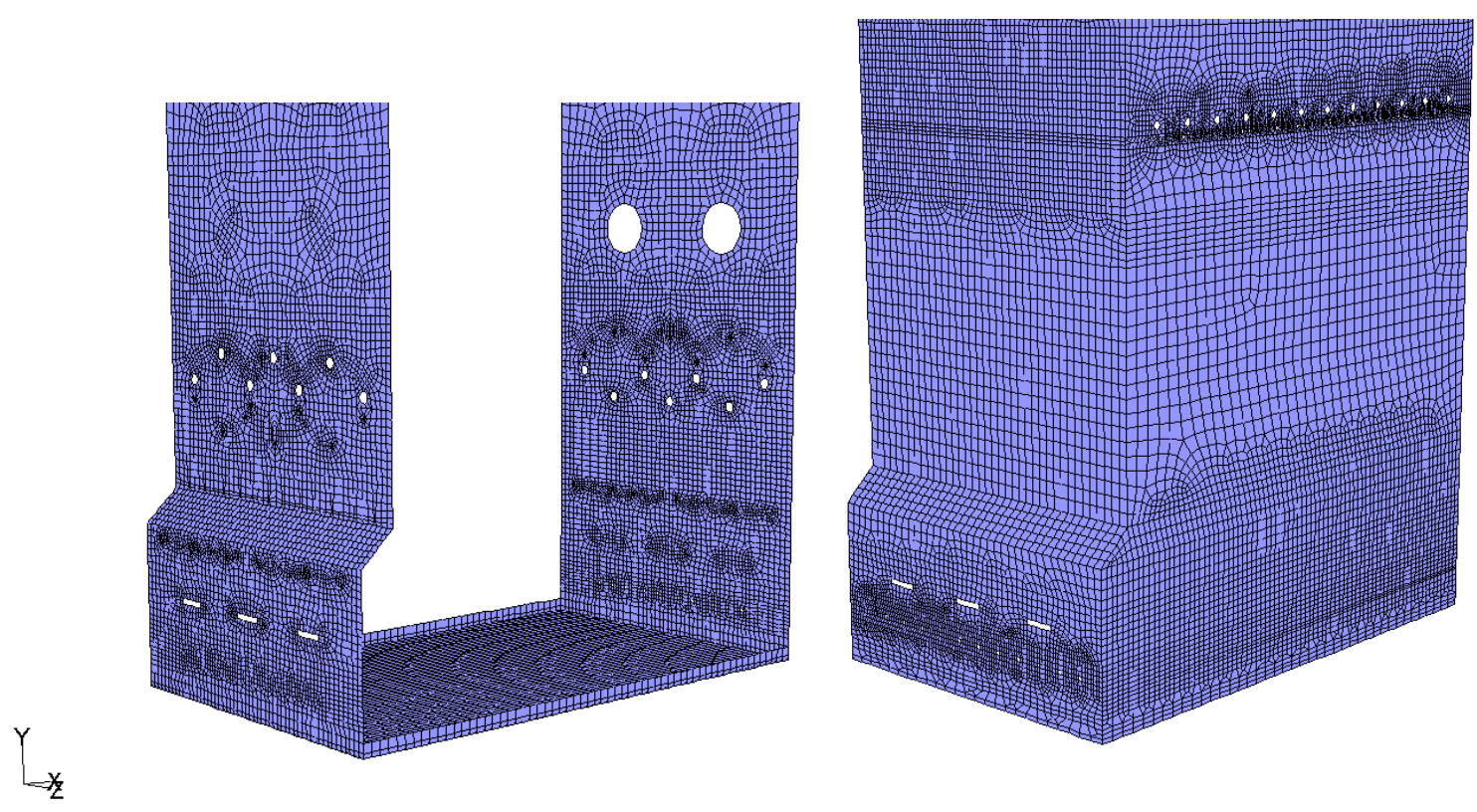

Figure 4-36 Port Hudson CFD Meshes for Baseline and MdN Cases 


\subsubsection{Input and Boundary Conditions}

The boundary conditions for the baseline and MdN cases were set up based on chemical composition of bark fuel and baseline test conditions. Constant temperature boundary conditions were considered for water walls. The ultimate and proximate analysis of the hog fuel is summarized in Table 4-5.

The flow distribution between the boiler injection ports is given in Table 4-6. In MdN case, natural gas flow was twenty percent less than the flow in baseline.

The hog fuel particles were set up with six different particle sizes. The diameters varied between $0.3 \mathrm{~mm}$ and $100 \mathrm{~mm}$. The initial condition of hog particles was arranged so that they were injected into the furnace uniformly on the grate. The size distribution of hog fuel particles is shown in Figure 4-37.

Table 4-5 Port Hudson Hog Fuel Chemical Analysis

\begin{tabular}{|c|c|c|}
\hline \multirow[t]{2}{*}{ FUEL ANALYSIS } & & \\
\hline & $\begin{array}{l}\%(w / w) \\
\text { As Fired }\end{array}$ & $\begin{array}{c}\%(\mathrm{w} / \mathrm{w}) \\
\text { Dry }\end{array}$ \\
\hline \multicolumn{3}{|l|}{ Proximate } \\
\hline \multirow{4}{*}{$\begin{array}{r}\text { Moisture } \\
\text { Ash } \\
\text { Volatile Matter } \\
\text { Fixed Carbon }\end{array}$} & 36.96 & \\
\hline & 2.55 & \\
\hline & 50.82 & \\
\hline & 9.67 & \\
\hline \multicolumn{3}{|l|}{ Ultimate } \\
\hline \multirow{6}{*}{$\begin{array}{r}\text { Hydrogen } \\
\text { Carbon } \\
\text { Nitrogen } \\
\text { Sulfur } \\
\text { Oxygen } \\
\text { Ash }\end{array}$} & & 5.65 \\
\hline & & 49.14 \\
\hline & & 0.11 \\
\hline & & 0.07 \\
\hline & & 40.99 \\
\hline & & 4.04 \\
\hline Higher Heating Value [Btu/lb] & 5239 & 8310 \\
\hline
\end{tabular}


Table 4-6 Port Hudson Flow Rates of Injected Gas and Solids for Baseline and MdN Cases

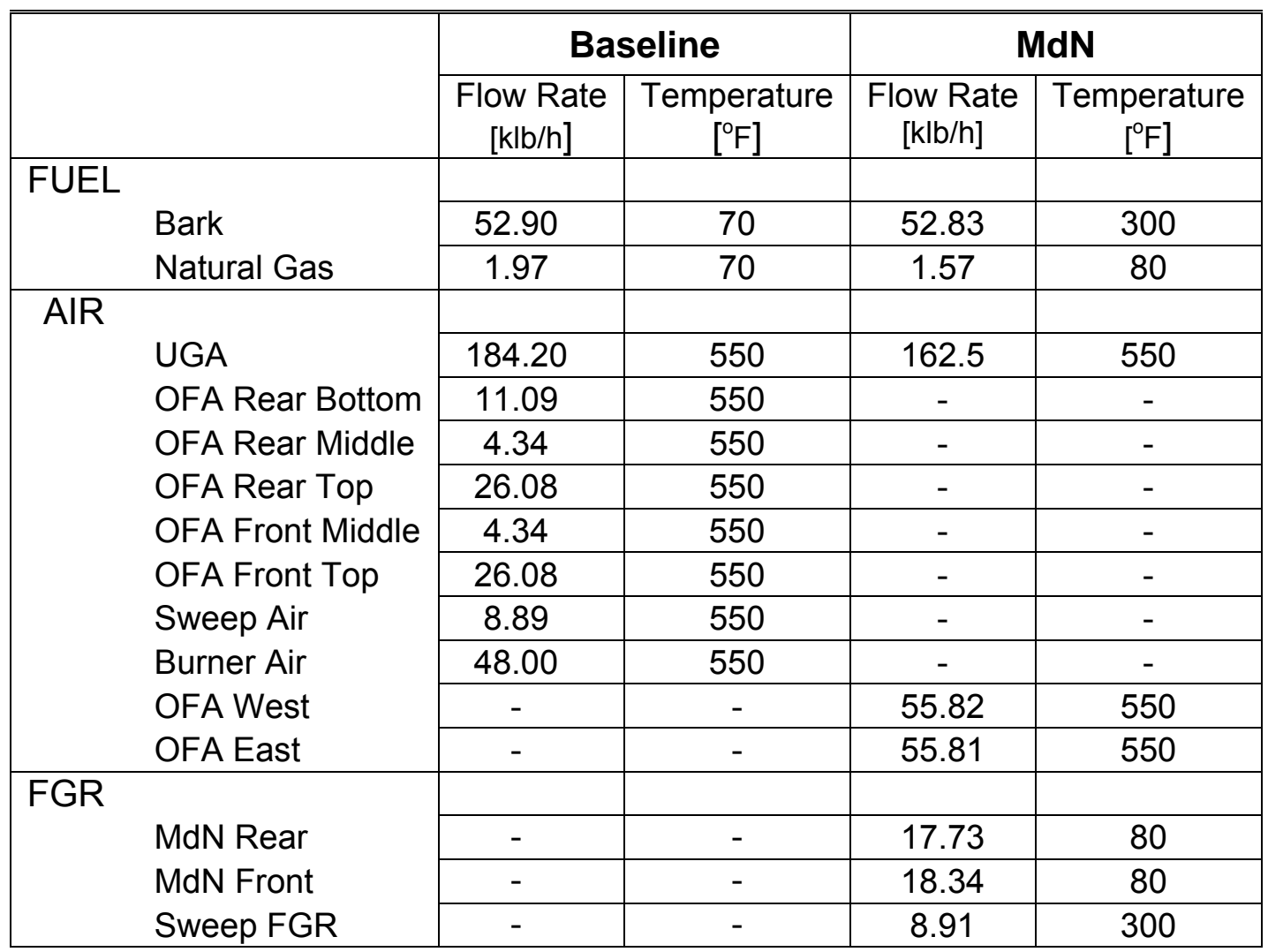

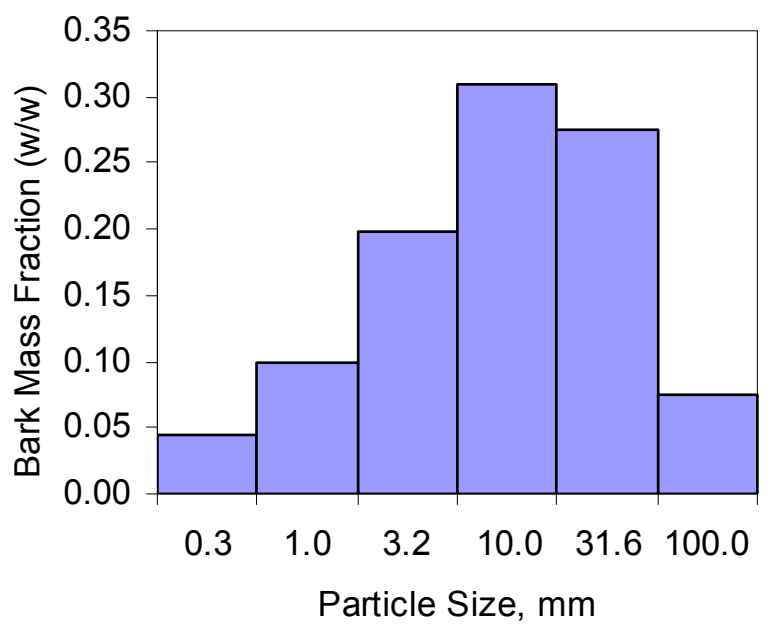

Figure 4-37 Port Hudson Wood Bark Size Distributions

\subsubsection{Validation of Stoker Boiler CFD Baseline Model}

The CFD model was validated by the test results taken by GTI on the Port Hudson boiler. The test data taken at different elevations was basically included $\mathrm{O}_{2}, \mathrm{CO}, \mathrm{CO}_{2}, \mathrm{NO}_{\mathrm{x}}$ concentrations and temperatures. The comparison of test data and CFD data at the same locations is shown in 
Figures 4-38 - 4-41. The discrepancies are due to the changing boundary conditions during total sampling period.

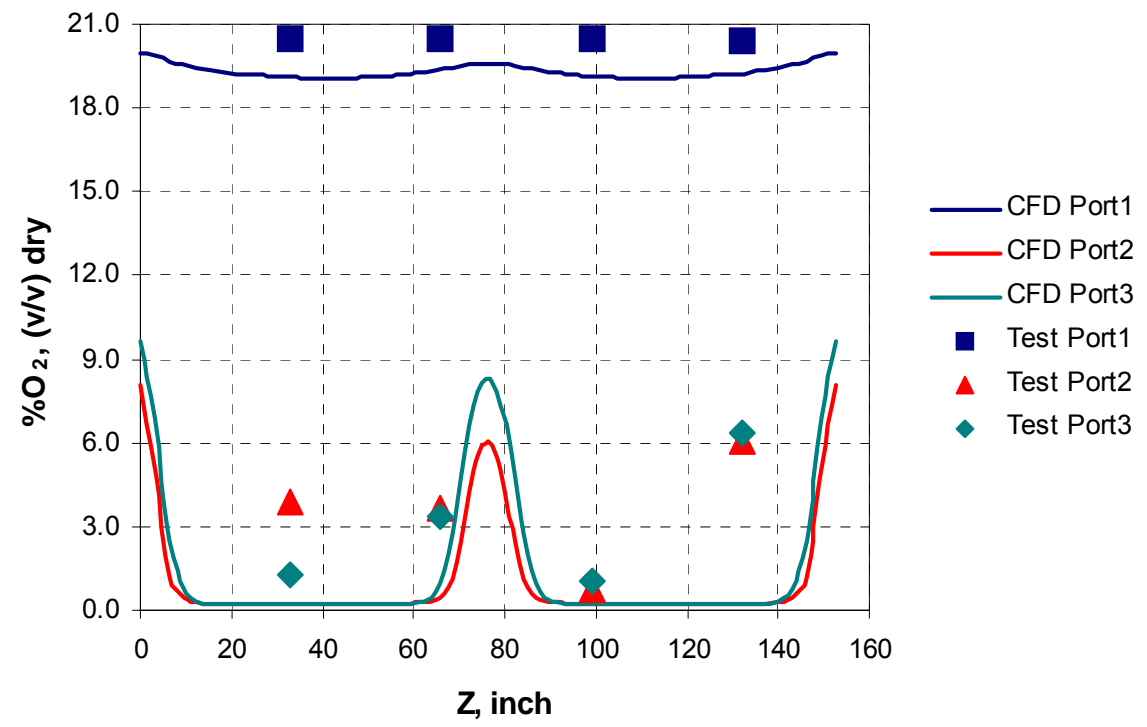

Figure 4-38 Port Hudson Comparison of Computed O2 Concentration with Measured $\mathrm{O}_{2}$ (18 inch above grate)

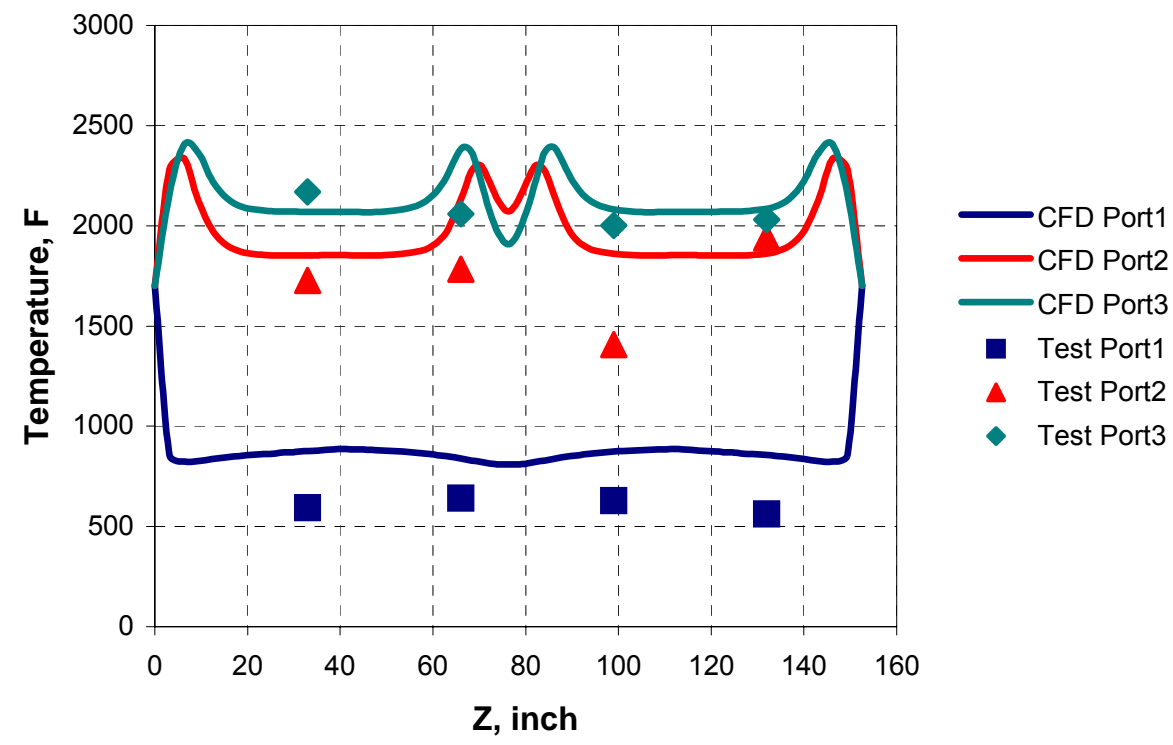

Figure 4-39 Port Hudson Comparison of Computed Temperature with Measured Temperature (18 inch above grate) 


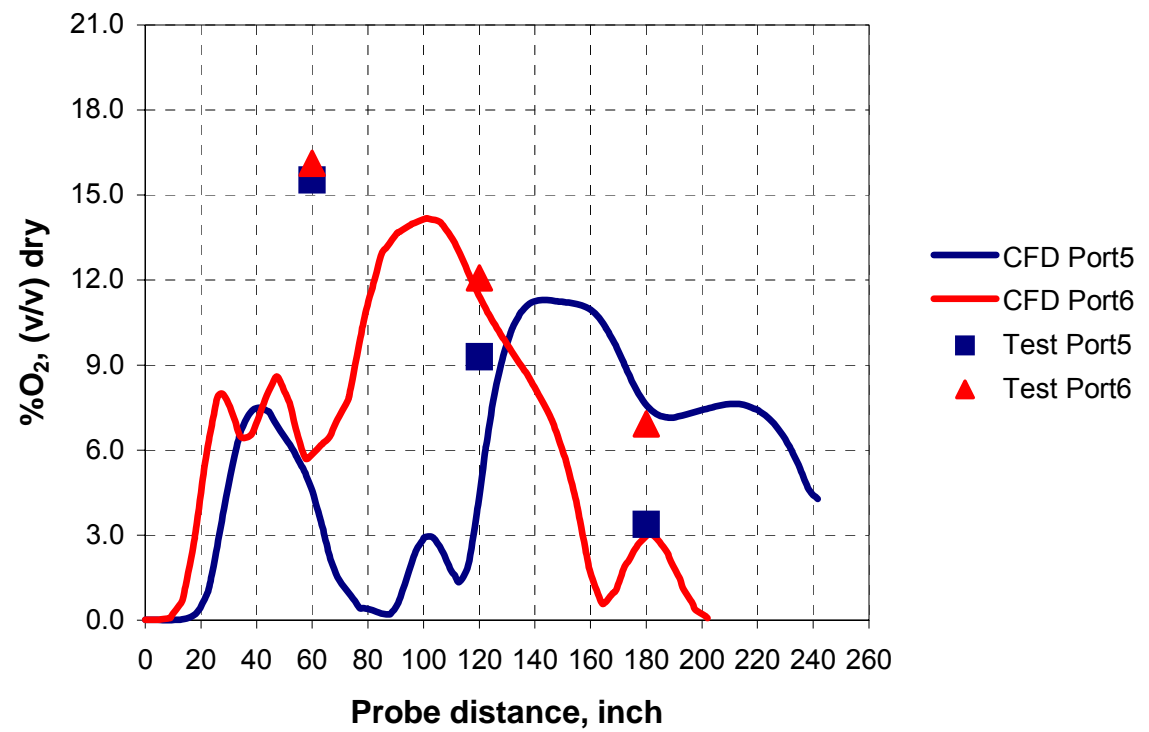

Figure 4-40 Port Hudson Comparison of Computed $\mathrm{O}_{2}$ Concentration with Measured $\mathrm{O}_{2}$ (180 inch above grate)

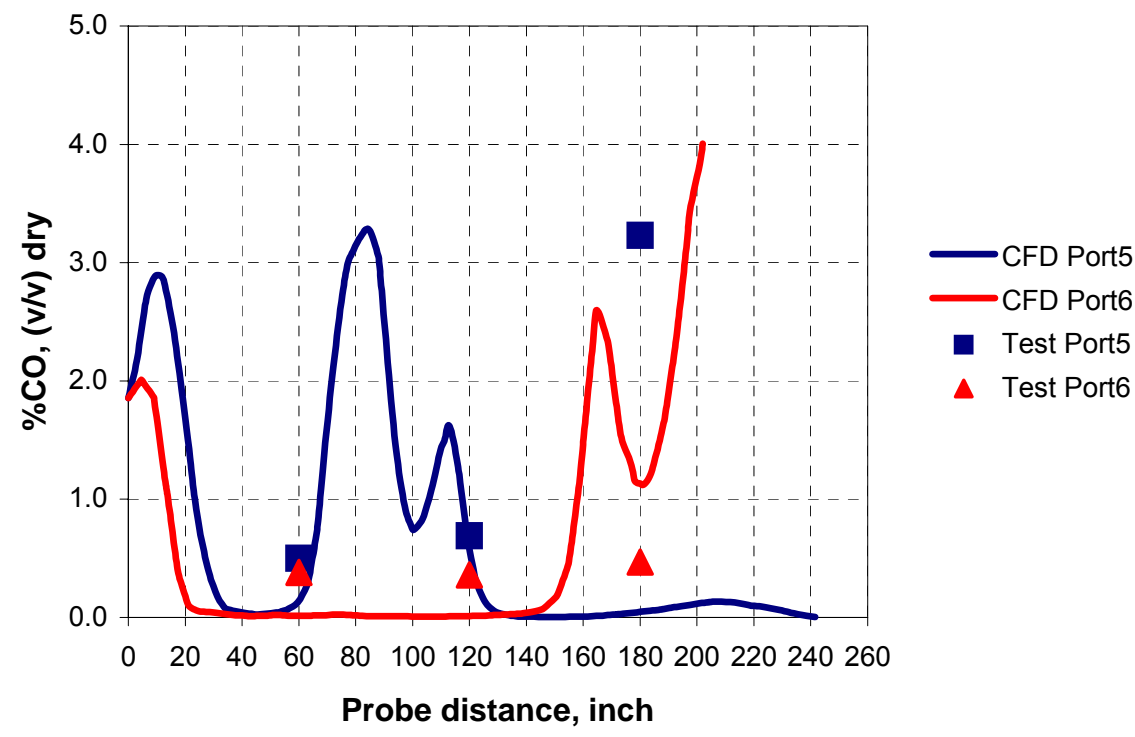

Figure 4-41 Port Hudson Comparison of Computed CO Concentration with Measured CO (180 inch above grate) 


\subsubsection{Comparison of Boiler Performance with CFD: Baseline Boiler Model versus Boiler Model with MdN}

A comparison of turbulence levels for the baseline and the MdN cases is shown in Figure 4-42. In MdN retrofit case, higher OFA velocity jets from both sides provide stronger mixing in the center. OFA jets controls the oxygen distribution in the furnace in both cases.

The temperature distributions in the baseline case and the MdN case are shown in Figure 4-43 and 4-44 respectively. The distribution in $\mathrm{MdN}$ case is more uniform compared to the baseline case. In the $\mathrm{MdN}$ case, high temperature regions appear in the bottom of the furnace because methane is introduced from the rear and front walls in this region. In the baseline case, combustion zone goes higher and temperature is also high near natural gas burner inlets.

Figures 4-45 - 4-48 show the contour plots of $\mathrm{O}_{2}$ and $\mathrm{CO}$ for the baseline cases and the MdN cases. In the $\mathrm{MdN}$ case, volatiles from bark react with air coming from beneath the grate to form $\mathrm{CO}$ above the grate. Also, methane from rear and front ports burns at the same region to form this combustion zone. The highest temperature can be found in this zone. The formed $\mathrm{CO}$ again burns with oxygen coming from OFA ports on the sides of the furnace. Figure 4-49 compares the iso-surfaces of CO mole fraction in the bottom of the furnace.

In the baseline case, the bottom combustion zone is similar to that in the $\mathrm{MdN}$ case. Because in this case, ports in the bottom only input air, no methane, the combustion zone is smaller and temperature distribution is less uniform comparing to the MdN case. The highest temperature in the baseline case can be found near methane inlet zone. The methane inlet ports of baseline case are located higher than those of MdN case. The temperature distribution is not as uniform as in the $\mathrm{MdN}$ case, because the two combustion zones are rather separated in baseline case,

Baseline

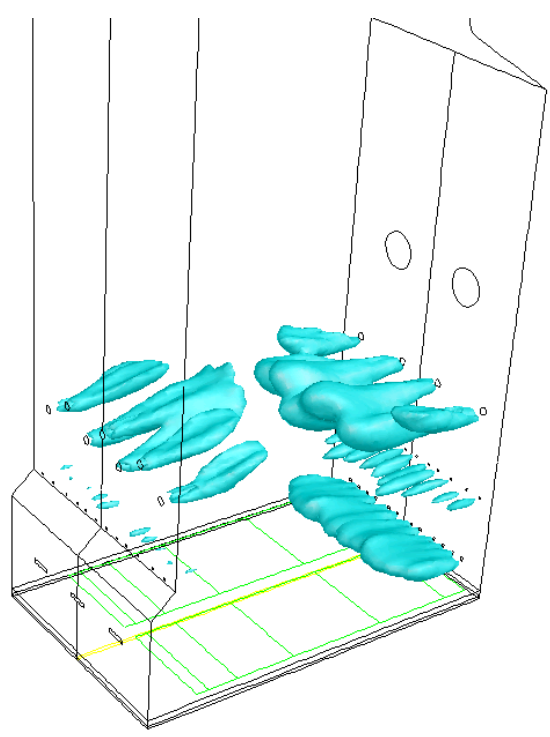

$\mathrm{MdN}$

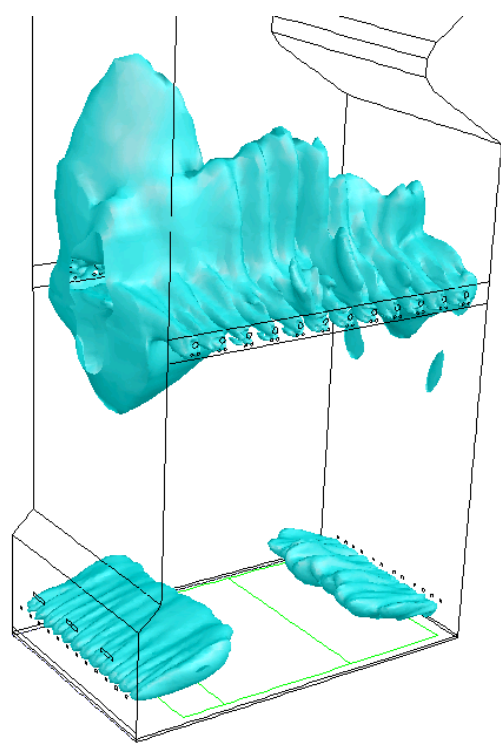

Figure 4-42 Port Hudson Comparison of Turbulent Kinetic Energy, $300 \mathrm{ft}^{2} / \mathrm{s}^{2}$ Iso-surface for Baseline and MdN Firing Conditions 

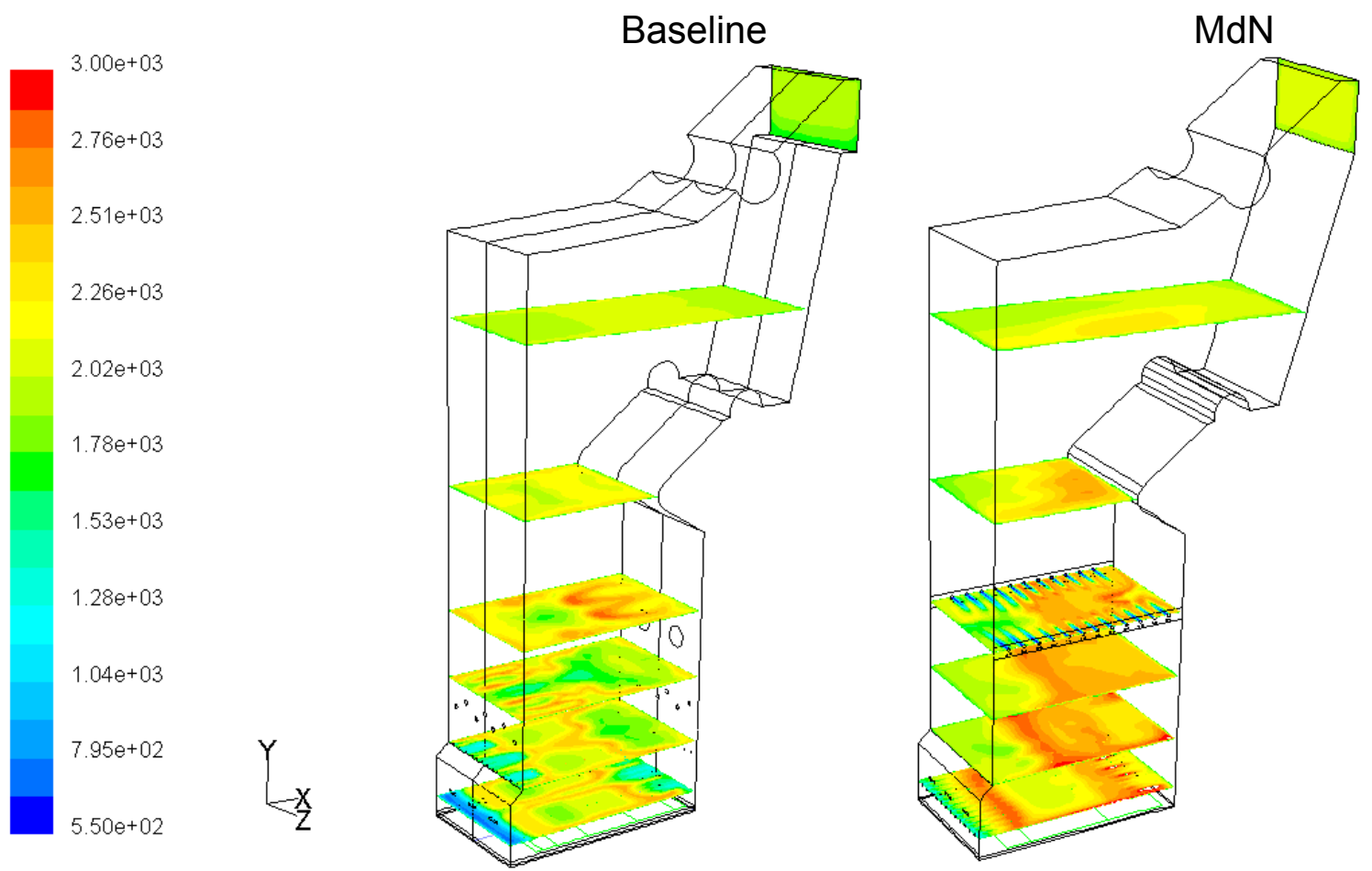

Figure 4-43 Port Hudson Contours of Temperature (F) for Baseline and MdN Firing Conditions
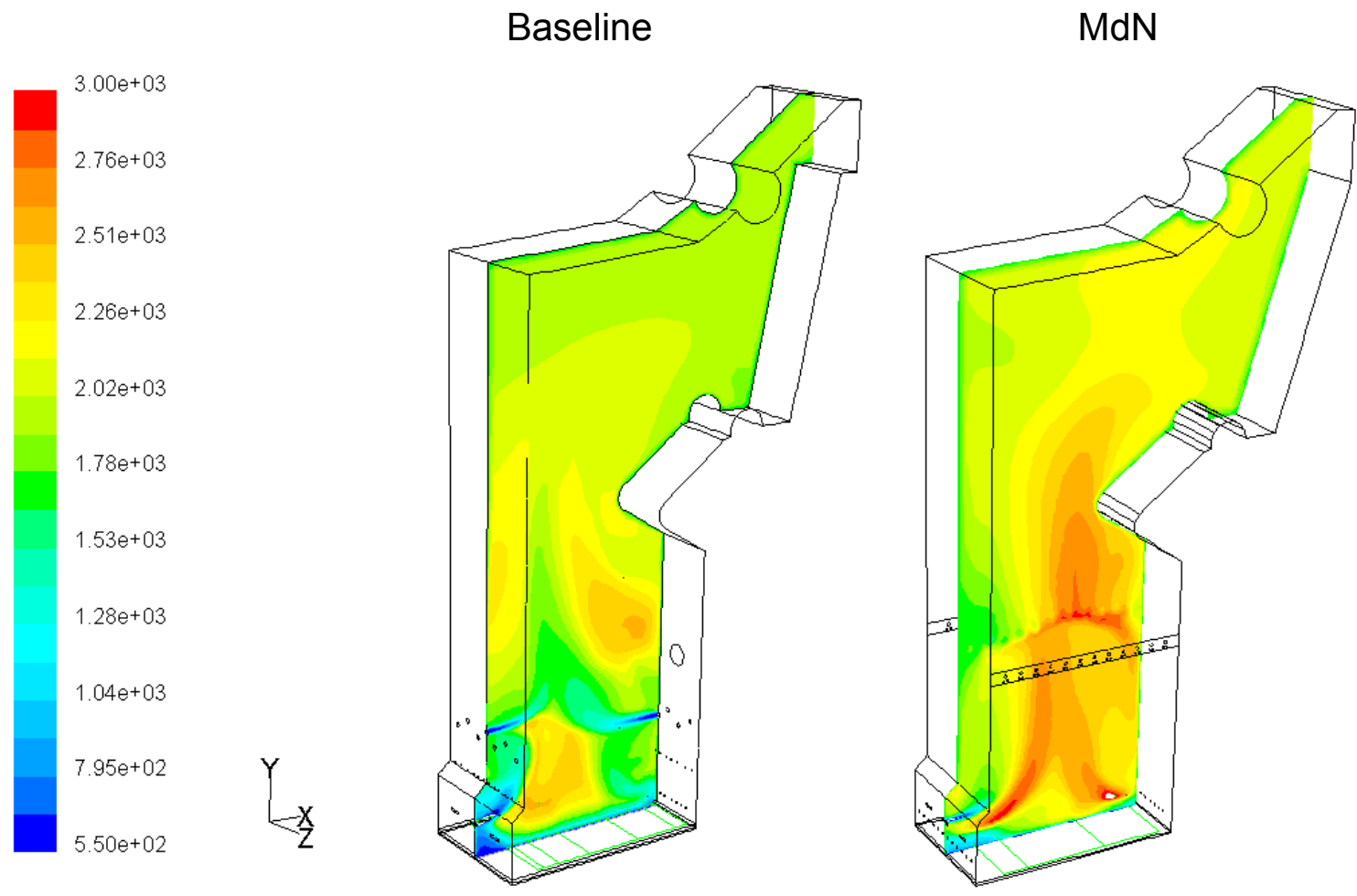

Figure 4-44 Port Hudson Contours of Temperature (F) for Baseline and MdN Firing Conditions 


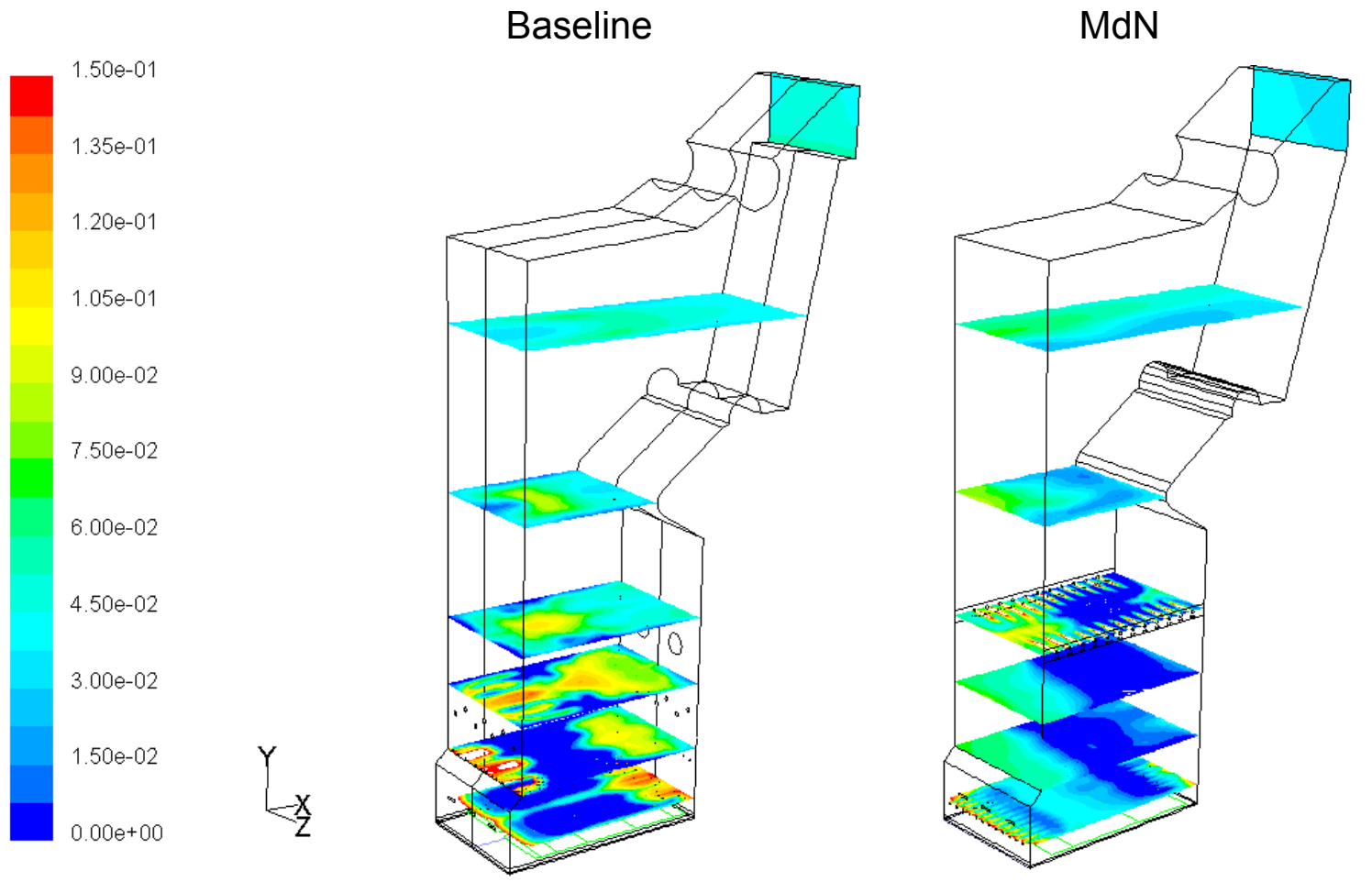

Figure 4-45 Port Hudson Contours of Mole Fraction of $\mathrm{O}_{2}$ (wet) for Baseline and MdN Firing Conditions
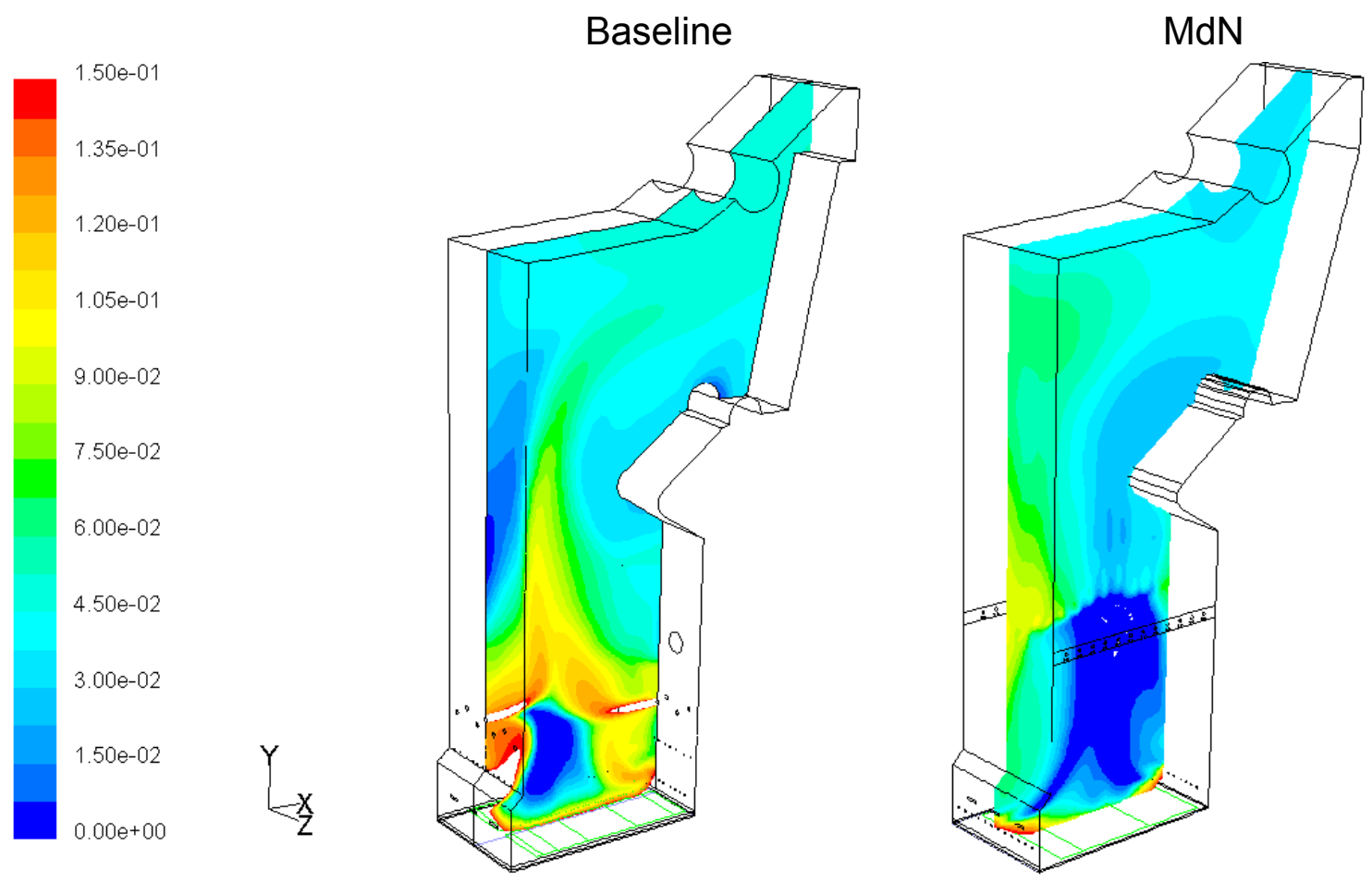

Figure 4-46 Port Hudson Contours of Mole Fraction of $\mathrm{O}_{2}$ (wet) for Baseline and MdN Firing Conditions 

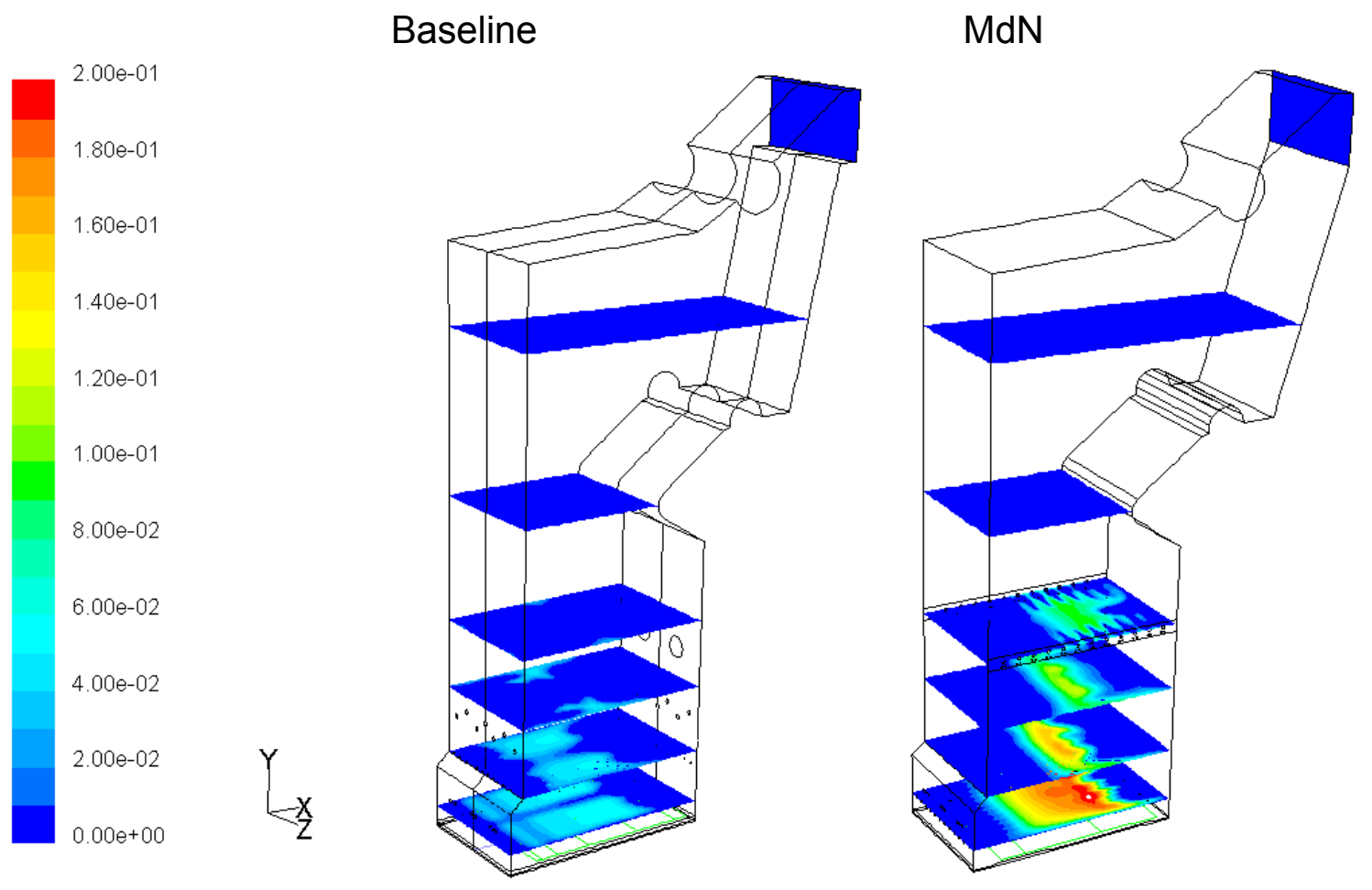

Figure 4-47 Port Hudson Contours of Mole Fraction of CO (wet and uncorr.) for Baseline and MdN Firing Conditions

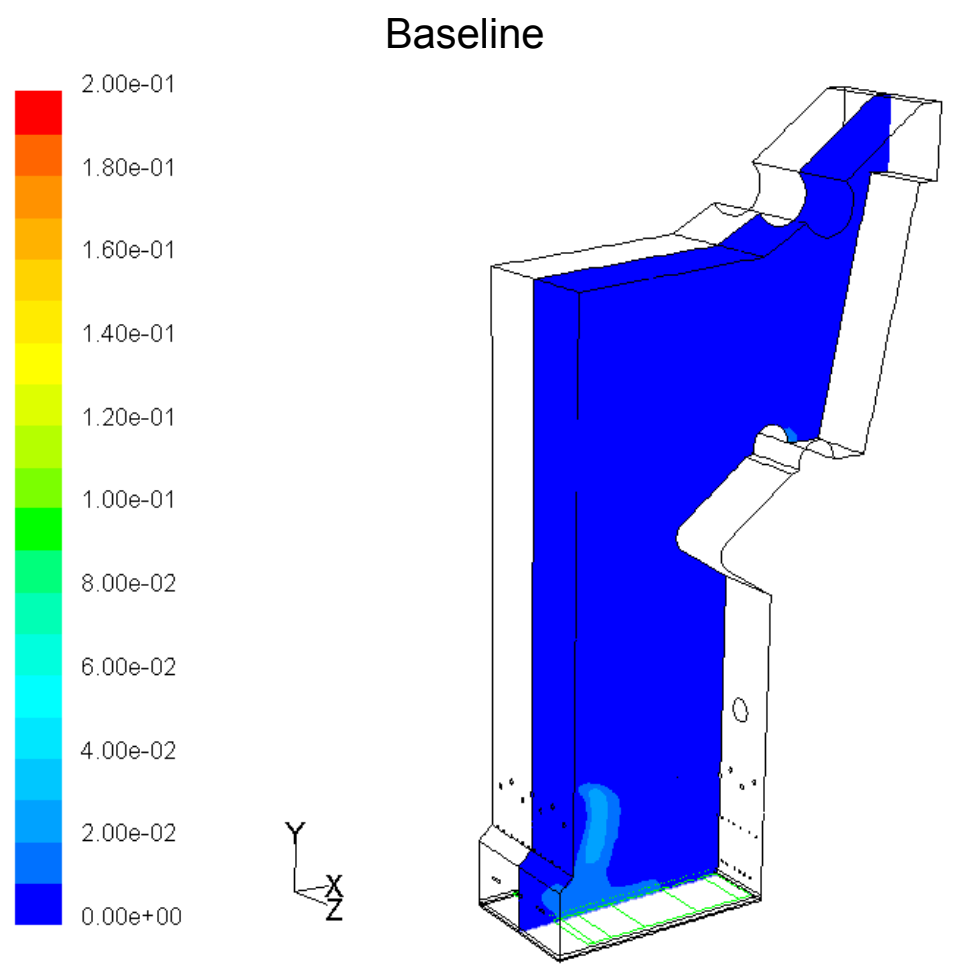

$\operatorname{MdN}$

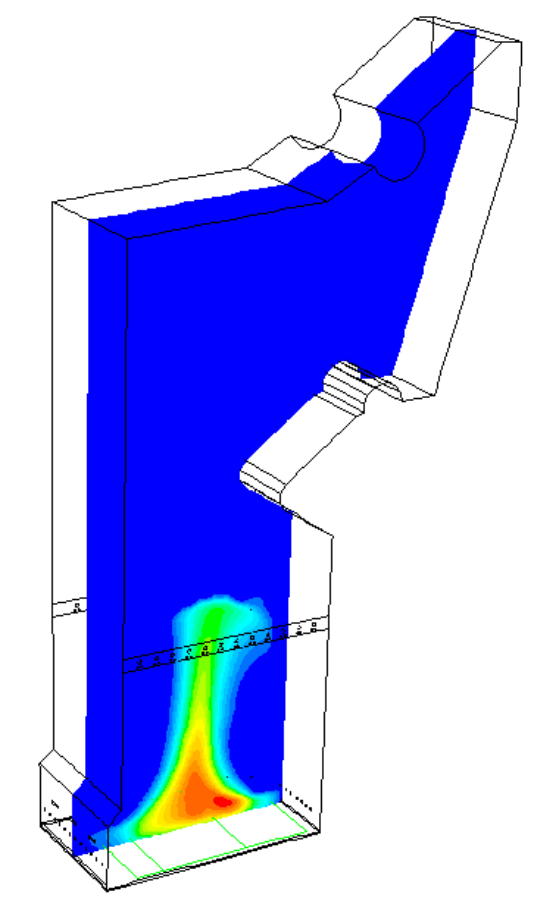

Figure 4-48 Port Hudson Contours of Mole Fraction of CO (wet and uncorr.) for Baseline and MdN Firing Conditions 

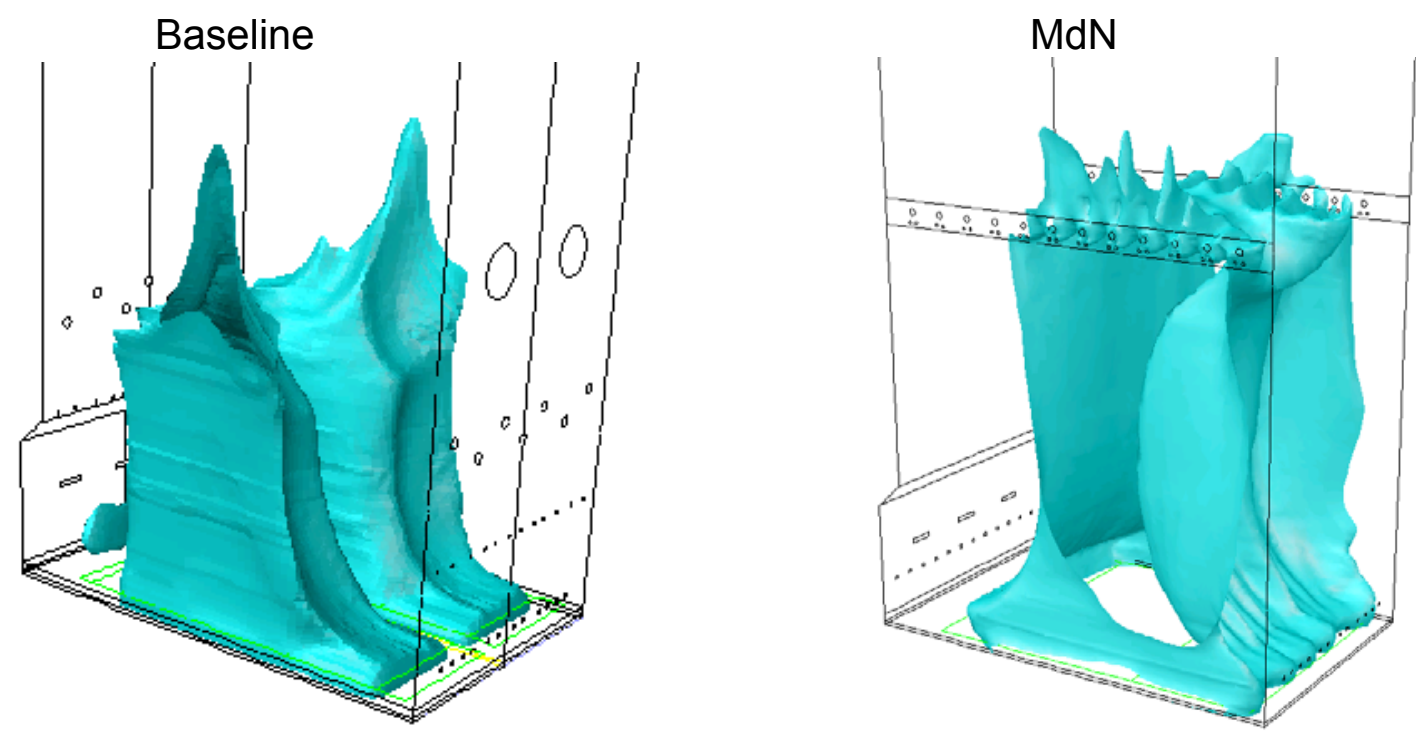

Figure 4-49 Port Hudson Iso-surfaces of CO Mole Fraction (3\% wet) for Baseline and MdN Firing Conditions 


\subsection{DeRidder Stoker Boiler CFD Model}

\subsubsection{Geometry and Computational Mesh}

Figure 4-50 and Figure 4-51 represent the outline and inlet ports of the furnace for baseline and MdN cases. Unstructured hexahedral meshes with approximately 360,000 cells were generated for both cases. The meshes near the inlet ports were refined to obtain proper resolution as seen in Figure 4-52.

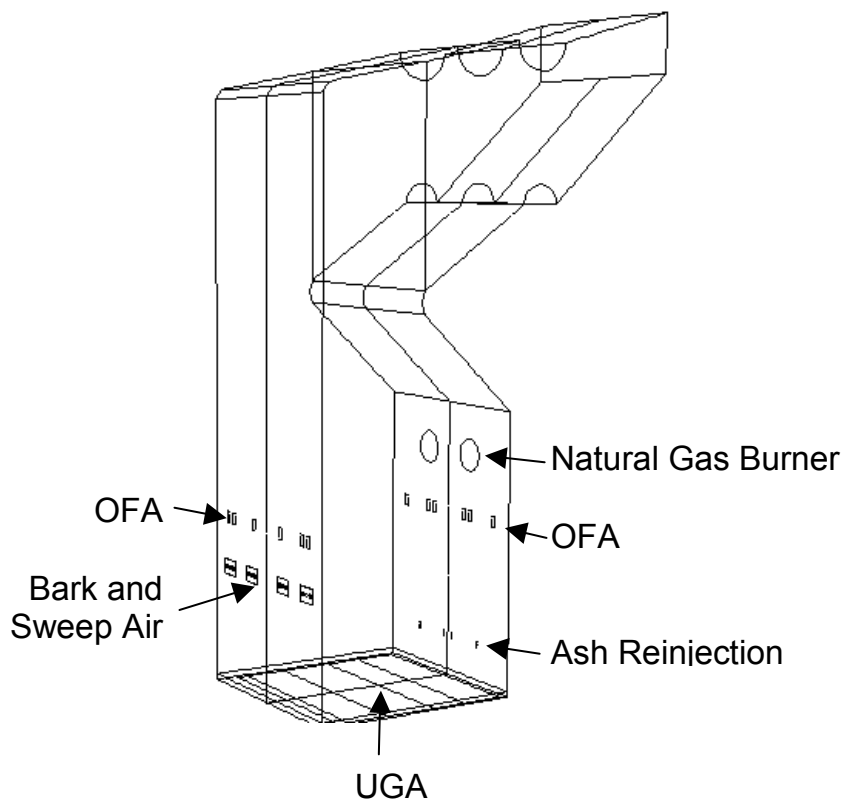

Figure 4-50 DeRidder Inlet Ports for Boiler Baseline Case

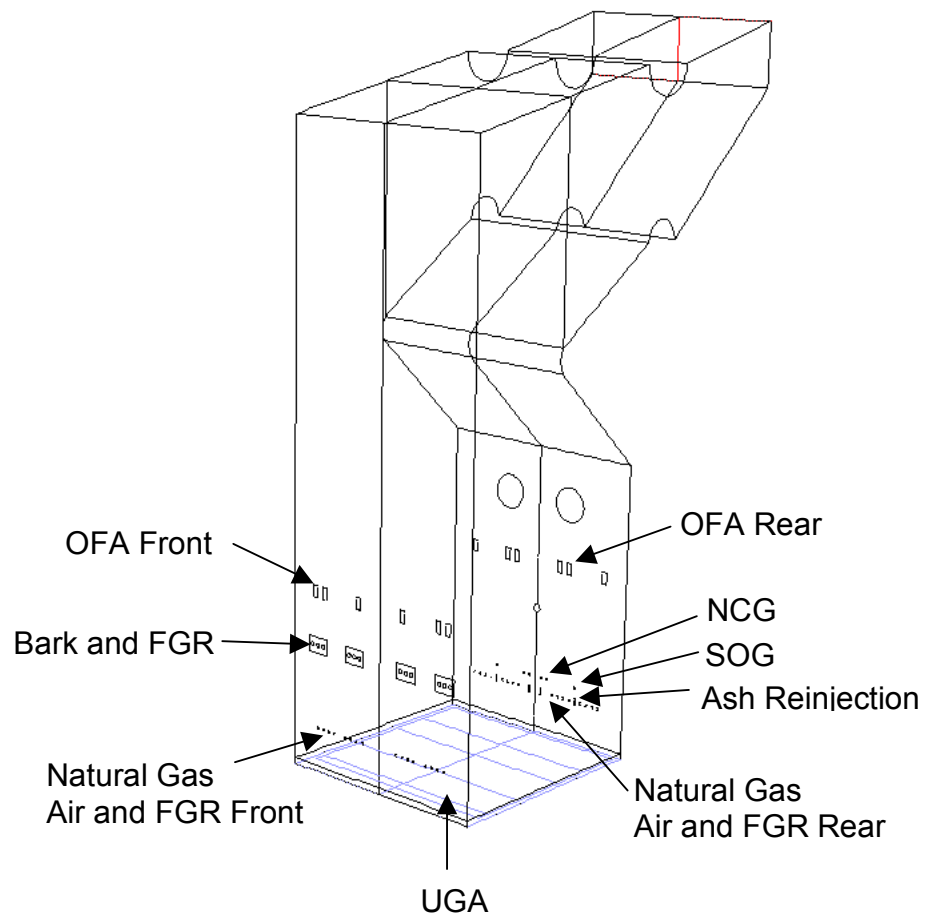

Figure 4-51 DeRidder Inlet Ports for Boiler MdN Retrofit Arrangement 


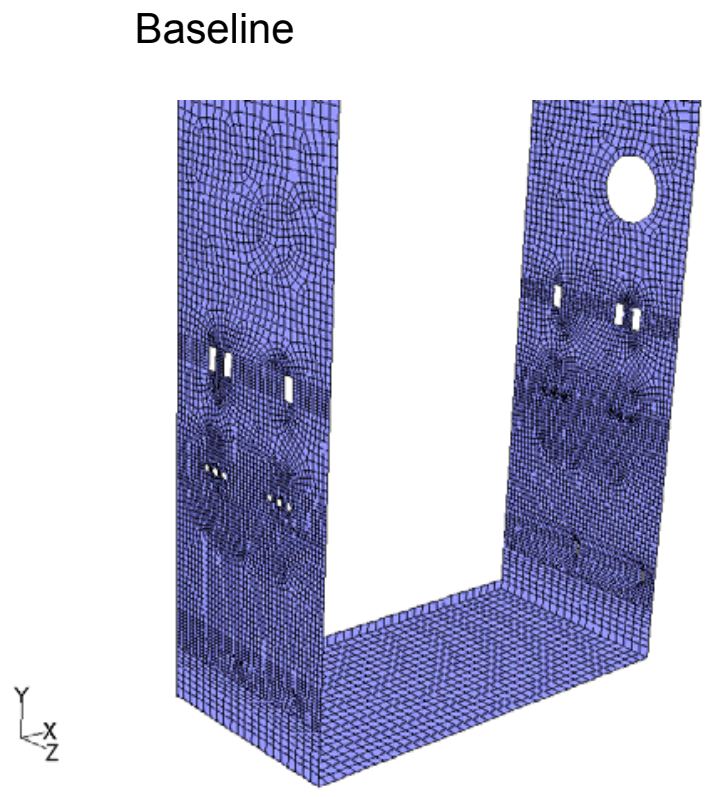

$\mathrm{MdN}$

Figure 4-52 DeRidder Meshes for Baseline and MdN Cases

\subsubsection{Input and Boundary Conditions}

The boundary conditions for the baseline and MdN cases were set up based on chemical composition of bark fuel, baseline test conditions and requirement of $3.5 \%$ (wet) exit oxygen. Constant temperature boundary conditions were considered for water walls. Table 4-7 shows the summary of ultimate and proximate analysis of the bark fuel.

Table 4-8 shows the flow distribution between the boiler injection ports. The under grate airflow was reduced by twenty five percent in the MdN retrofit design.

The diameters of bark fuel particles varied between $0.3 \mathrm{~mm}$ and $100 \mathrm{~mm}$. The fine particles, which had a diameter range of 0.3 to $3.1 \mathrm{~mm}$, were injected from the bark injection port. The rest of the bark particles were arranged so that they were injected into the furnace on the grate. The size distribution of wood bark particles is shown in Figure 4-53. 
Table 4-7 DeRidder Wood Bark Chemical Analysis

\begin{tabular}{|c|c|c|}
\hline \multirow[t]{2}{*}{ FUEL ANALYSIS } & & \\
\hline & $\begin{array}{l}\%(w / w) \\
\text { As Fired }\end{array}$ & $\begin{array}{c}\% \text { (w/w) } \\
\text { Dry }\end{array}$ \\
\hline \multicolumn{3}{|l|}{ Proximate } \\
\hline \multirow{4}{*}{$\begin{array}{r}\text { Moisture } \\
\text { Ash } \\
\text { Volatile Matter } \\
\text { Fixed Carbon }\end{array}$} & 46.99 & \\
\hline & 1.87 & \\
\hline & 39.69 & \\
\hline & 11.45 & \\
\hline \multicolumn{3}{|l|}{ Ultimate } \\
\hline \multirow{6}{*}{$\begin{array}{r}\text { Hydrogen } \\
\text { Carbon } \\
\text { Nitrogen } \\
\text { Sulfur } \\
\text { Oxygen } \\
\text { Ash } \\
\end{array}$} & & 5.65 \\
\hline & & 51.95 \\
\hline & & 0.24 \\
\hline & & 0.03 \\
\hline & & 38.60 \\
\hline & & 3.53 \\
\hline Higher Heating Value [Btu/lb] & 4730 & 8922 \\
\hline
\end{tabular}

Table 4-8 DeRidder Flow Rates of Injected Gas and Solids for Baseline and MdN Cases

\begin{tabular}{|c|c|c|c|c|c|}
\hline & \multicolumn{2}{|c|}{ Baseline } & \multicolumn{2}{|c|}{ MdN } \\
\hline & & $\begin{array}{c}\text { Flow Rate } \\
{[\mathrm{klb} / \mathrm{h}]}\end{array}$ & $\begin{array}{c}\text { Temperature } \\
{\left[{ }^{\circ} \mathrm{F}\right]}\end{array}$ & $\begin{array}{c}\text { Flow Rate } \\
{[\mathrm{klb} / \mathrm{h}]}\end{array}$ & $\begin{array}{c}\text { Temperature } \\
{\left[{ }^{\circ} \mathrm{F}\right]}\end{array}$ \\
\hline FUEL & $\begin{array}{l}\text { Bark } \\
\text { Natural Gas }\end{array}$ & $\begin{array}{c}63.33 \\
2.42\end{array}$ & $\begin{array}{c}80 \\
400\end{array}$ & $\begin{array}{c}62.00 \\
3.10\end{array}$ & $\begin{array}{l}350 \\
352\end{array}$ \\
\hline AIR & $\begin{array}{l}\text { UGA } \\
\text { OFA Rear } \\
\text { OFA Front } \\
\text { Bark Sweep } \\
\text { Ash Re-injection } \\
\text { Burner Air } \\
\text { MdN Rear } \\
\text { MdN Front }\end{array}$ & $\begin{array}{c}209.14 \\
53.59 \\
43.85 \\
17.62 \\
8.30 \\
65.60 \\
- \\
-\end{array}$ & $\begin{array}{c}400 \\
400 \\
400 \\
80 \\
80 \\
400 \\
- \\
- \\
\end{array}$ & $\begin{array}{c}157.00 \\
66.00 \\
66.00 \\
- \\
- \\
20.00 \\
9.00 \\
9.00\end{array}$ & $\begin{array}{c}400 \\
400 \\
400 \\
- \\
- \\
400 \\
352 \\
352 \\
\end{array}$ \\
\hline FGR & $\begin{array}{l}\text { MdN Rear } \\
\text { MdN Front } \\
\text { Bark Sweep } \\
\text { Ash Re-injection } \\
\text { NCG Port } \\
\text { SOG Port }\end{array}$ & $\begin{array}{l}- \\
- \\
- \\
- \\
- \\
-\end{array}$ & $\begin{array}{l}- \\
- \\
- \\
- \\
- \\
-\end{array}$ & $\begin{array}{c}6.00 \\
6.00 \\
19.00 \\
7.00 \\
1.00 \\
1.00 \\
\end{array}$ & $\begin{array}{l}352 \\
352 \\
350 \\
350 \\
350 \\
350 \\
\end{array}$ \\
\hline $\mathrm{ASH}$ & Ash Re-injection & 1.74 & 80 & 1.74 & 350 \\
\hline
\end{tabular}




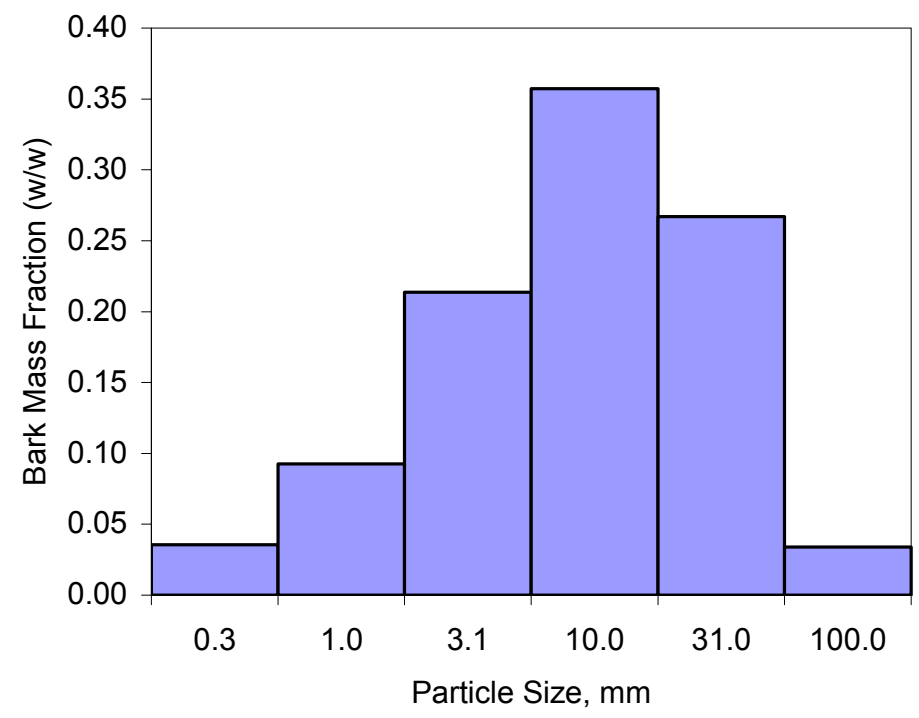

Figure 4-53 DeRidder Wood Bark Size Distributions

\subsubsection{Validation of Stoker Boiler CFD Baseline Model}

The CFD model was validated by the test results taken by GTI in DeRidder boiler. The comparison of test data and CFD data at the same locations is shown in Figures 4-54-4-58. The discrepancies are due to the varying boundary conditions during total sampling period.

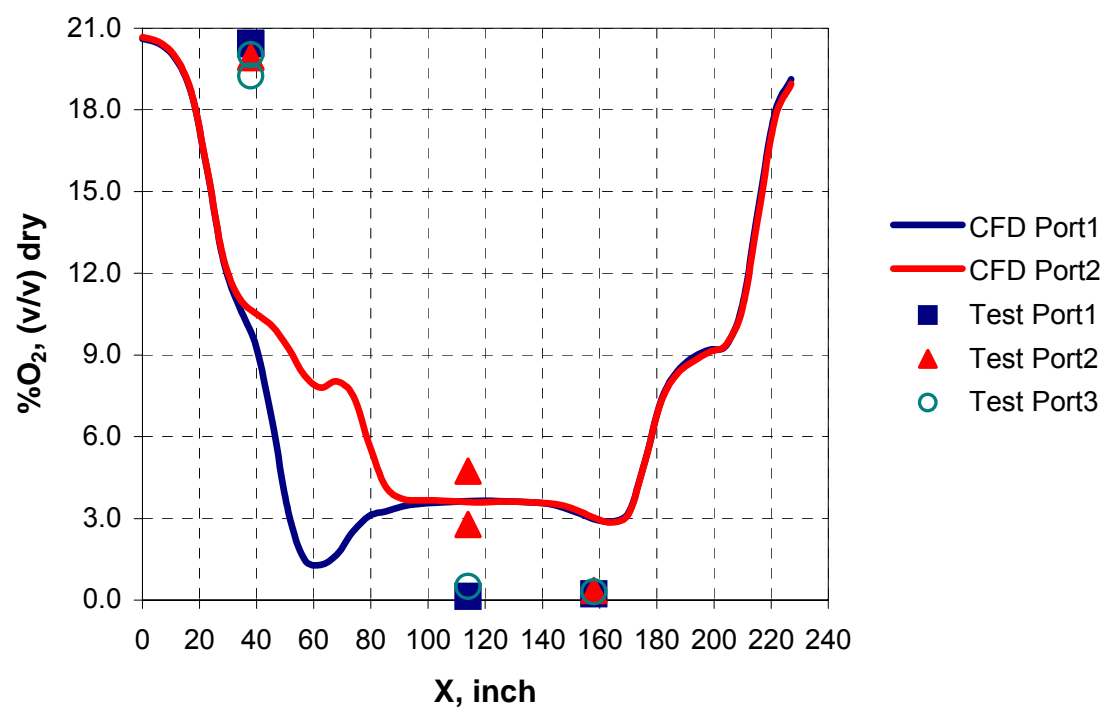

Figure 4-54 DeRidder Comparison of Computed $\mathrm{O}_{2}$ Concentration with Measured $\mathrm{O}_{2}$ (12 inch above grate) 


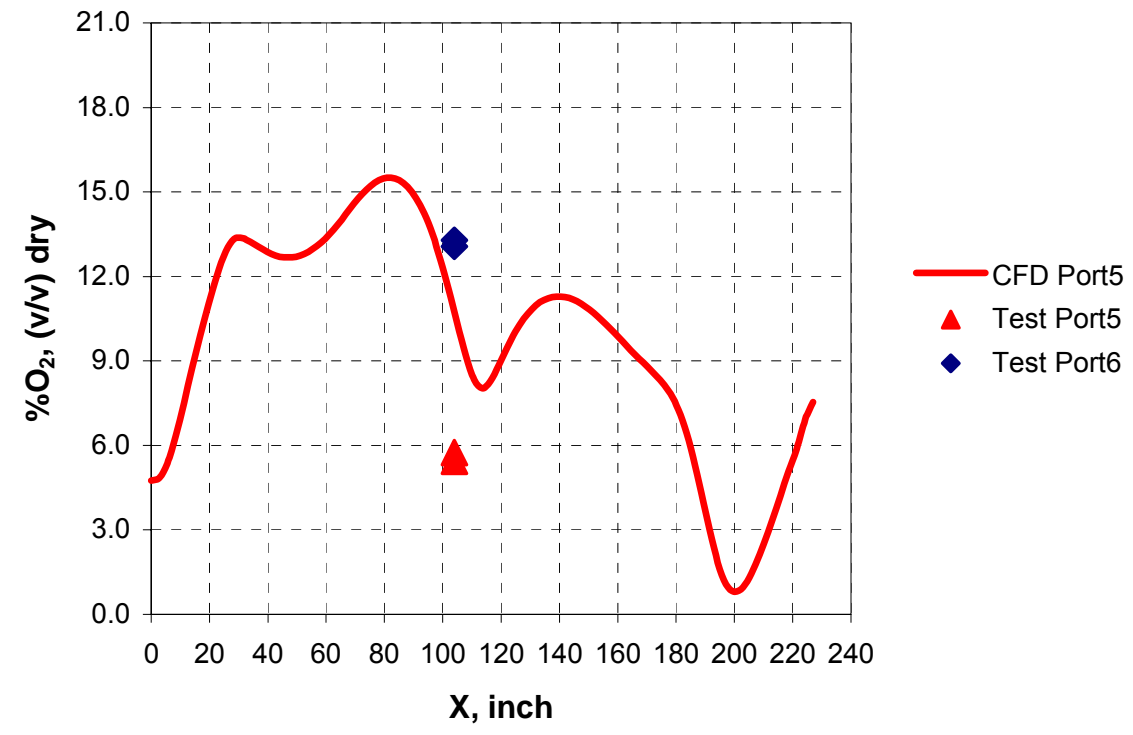

Figure 4-55 DeRidder Comparison of Computed O2 Concentration with Measured 02 (216 inch above grate)

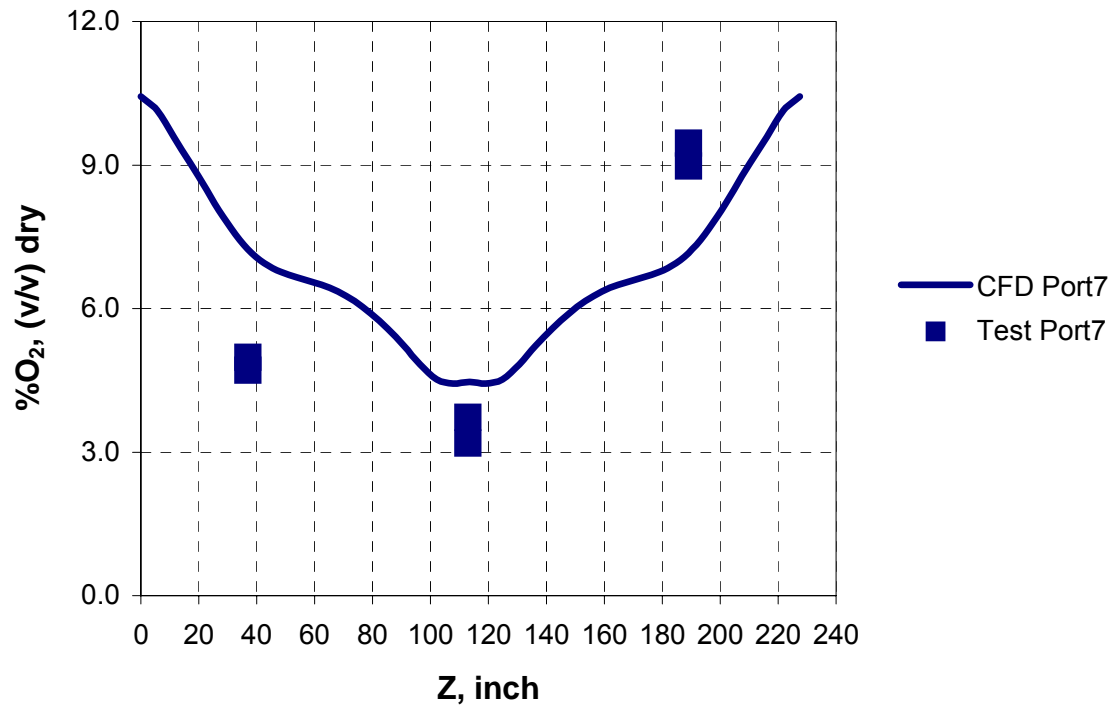

Figure 4-56 DeRidder Comparison of Computed $\mathrm{O}_{2}$ Concentration with Measured $\mathrm{O}_{2}$ (459 inch above grate) 


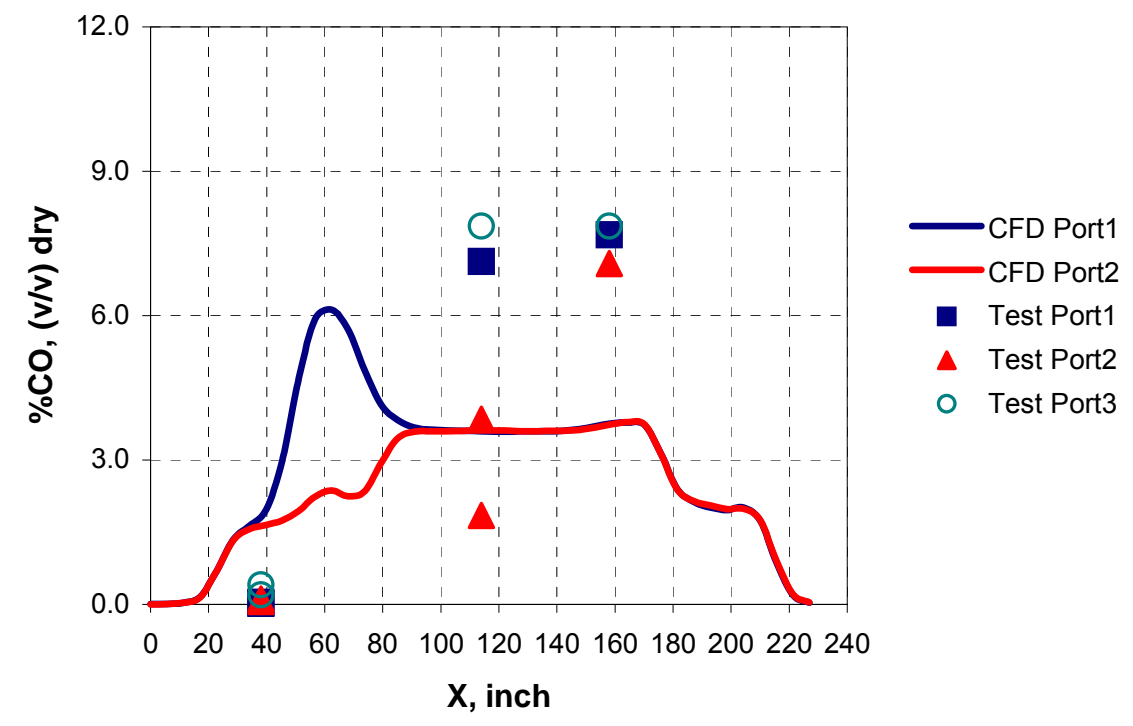

Figure 4-57 DeRidder Comparison of Computed CO Concentration with Measured CO (12 inch above grate)

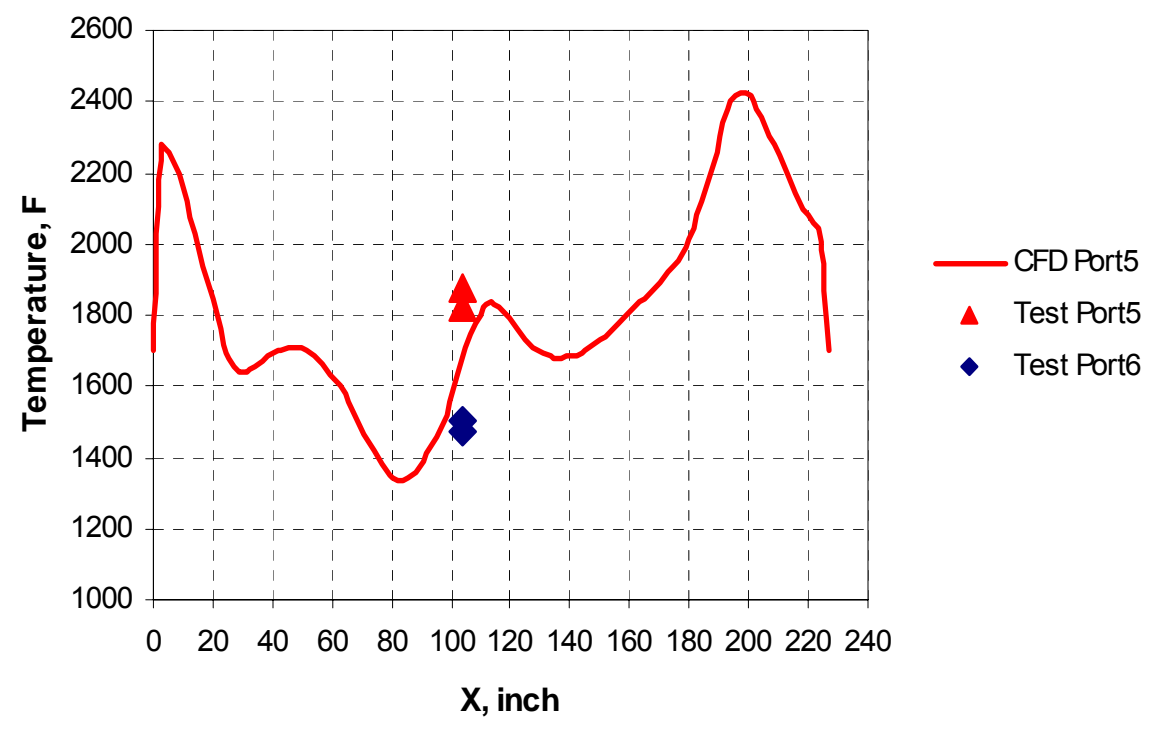

Figure 4-58 DeRidder Comparison of Computed Temperature with Measured Temperature (216 inch above grate)

\subsubsection{Comparison of Boiler Performance with CFD: Baseline Boiler Model versus Boiler Model with MdN}

OFA jets controls the oxygen distribution in the furnace in the baseline and the MdN cases. A comparison of turbulence levels for both cases is shown in Figure 4-59. In MdN retrofit case, higher OFA velocity jets from both sides provide stronger mixing in the center. 
The temperature distributions in the baseline case and the MdN case are shown in Figure 4-60 and 4-61 respectively. In the MdN case, high temperature regions appear in the bottom of the furnace because methane is introduced from the rear and front walls in this region. In the baseline case, combustion zone goes higher and temperature is also high near natural gas burner inlets.

The contour plots of $\mathrm{O}_{2}$ and $\mathrm{CO}$ for the baseline cases and the $\mathrm{MdN}$ cases can be shown in Figures 4-62 - 4-65. Volatiles from bark form CO above the grate with the reaction of air coming from the grate in the MdN case. In addition to that, methane from rear and front ports burns at the same region. Figure 4-66 shows the comparison of CO formation of baseline case with $\mathrm{MdN}$ case in the bottom combustion region. The highest temperature can be found in this zone. The formed $\mathrm{CO}$ again burns with oxygen coming from OFA.

In the baseline case, only air, no methane, is injected at the bottom of the furnace. The highest temperature in the baseline case can be found near methane inlet zone. The methane inlet ports of baseline case are located higher than those of $\mathrm{MdN}$ case.

Figure 4-67 shows the particle path colored by residence time. Typical residence times of fine particles are around 3-4 seconds.

Baseline

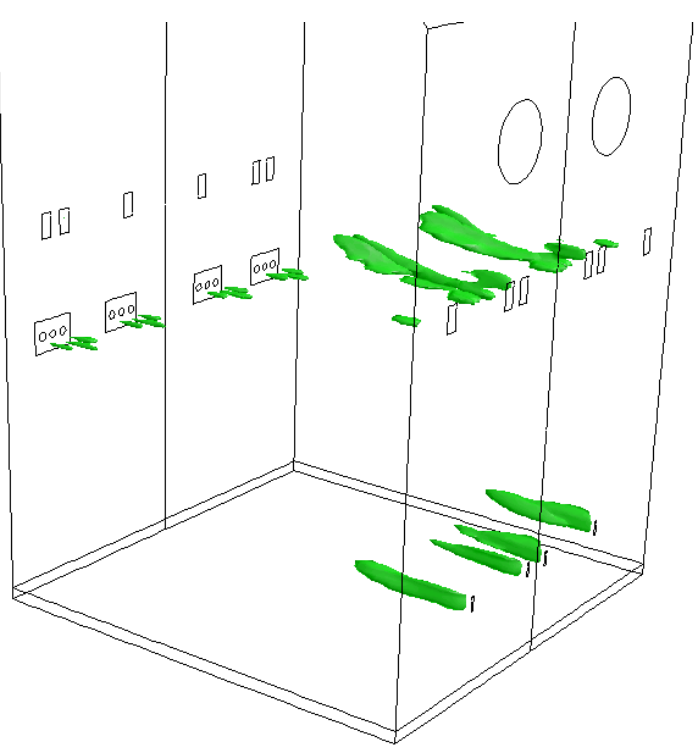

$\mathrm{MdN}$

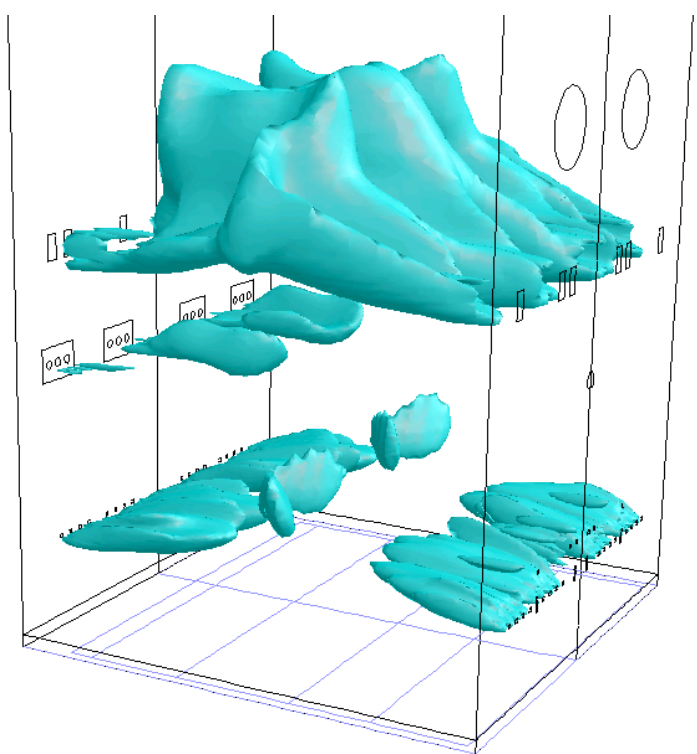

Figure 4-59 DeRidder Turbulent Kinetic Energy Iso-surfaces, $300 \mathrm{ft}^{2} / \mathrm{s}^{2}$, for Baseline and MdN Firing Conditions 


\section{Baseline}

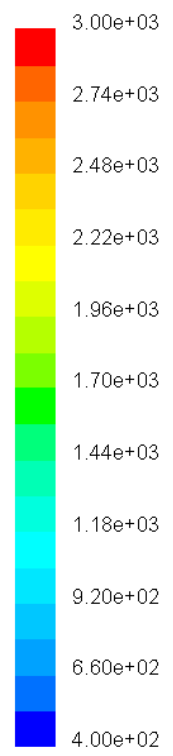

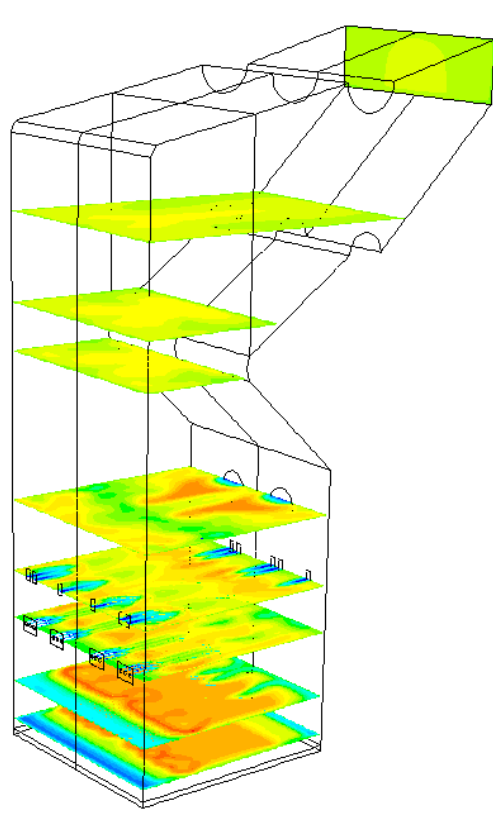

$\mathrm{MdN}$

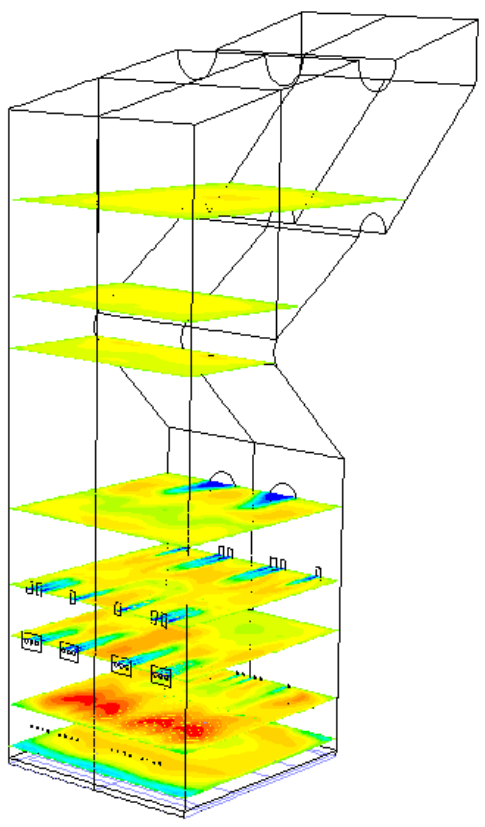

Figure 4-60 DeRidder Contours of Temperature (F) for Baseline and MdN Firing Conditions

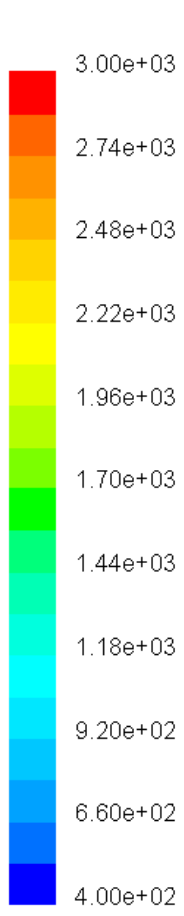

Baseline

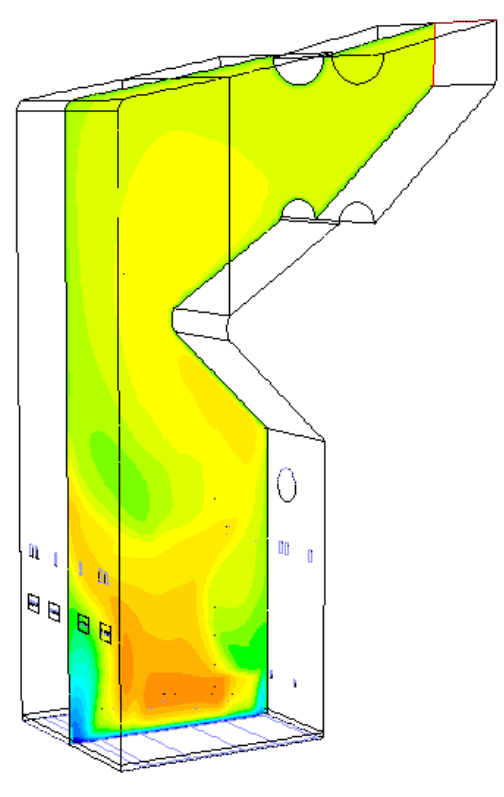

$\mathrm{MdN}$

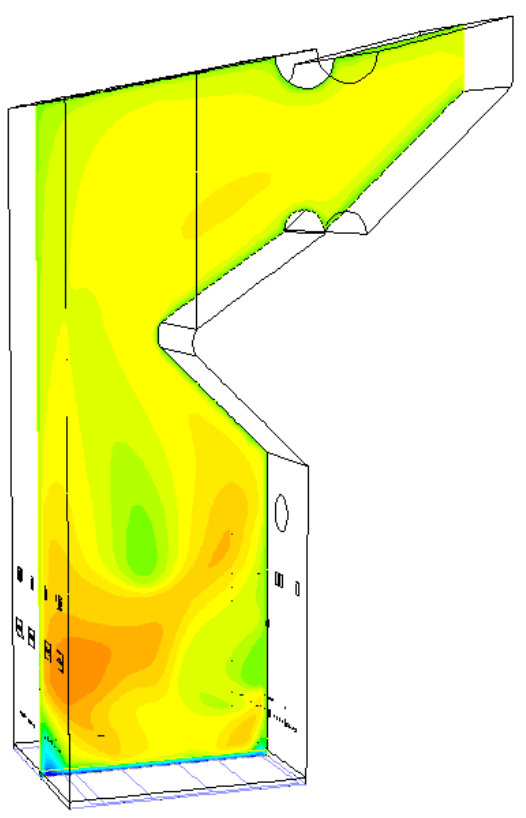

Figure 4-61 DeRidder Contours of Temperature $\left({ }^{\circ}\right.$ F) for Baseline and MdN Firing Conditions 


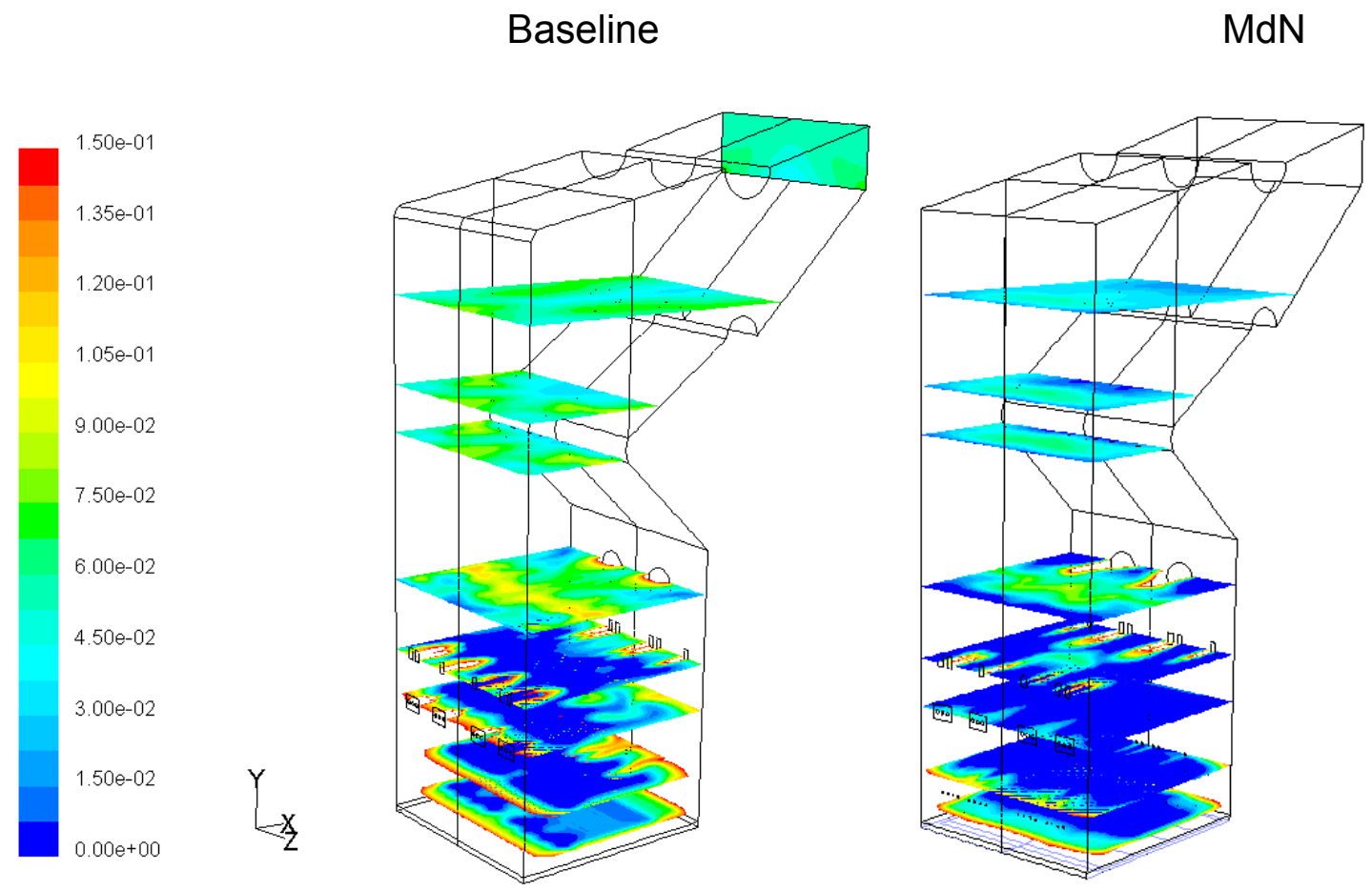

Figure 4-62 DeRidder Contours of Mole Fraction of $\mathrm{O}_{2}$ (wet) for Baseline and MdN Firing Conditions
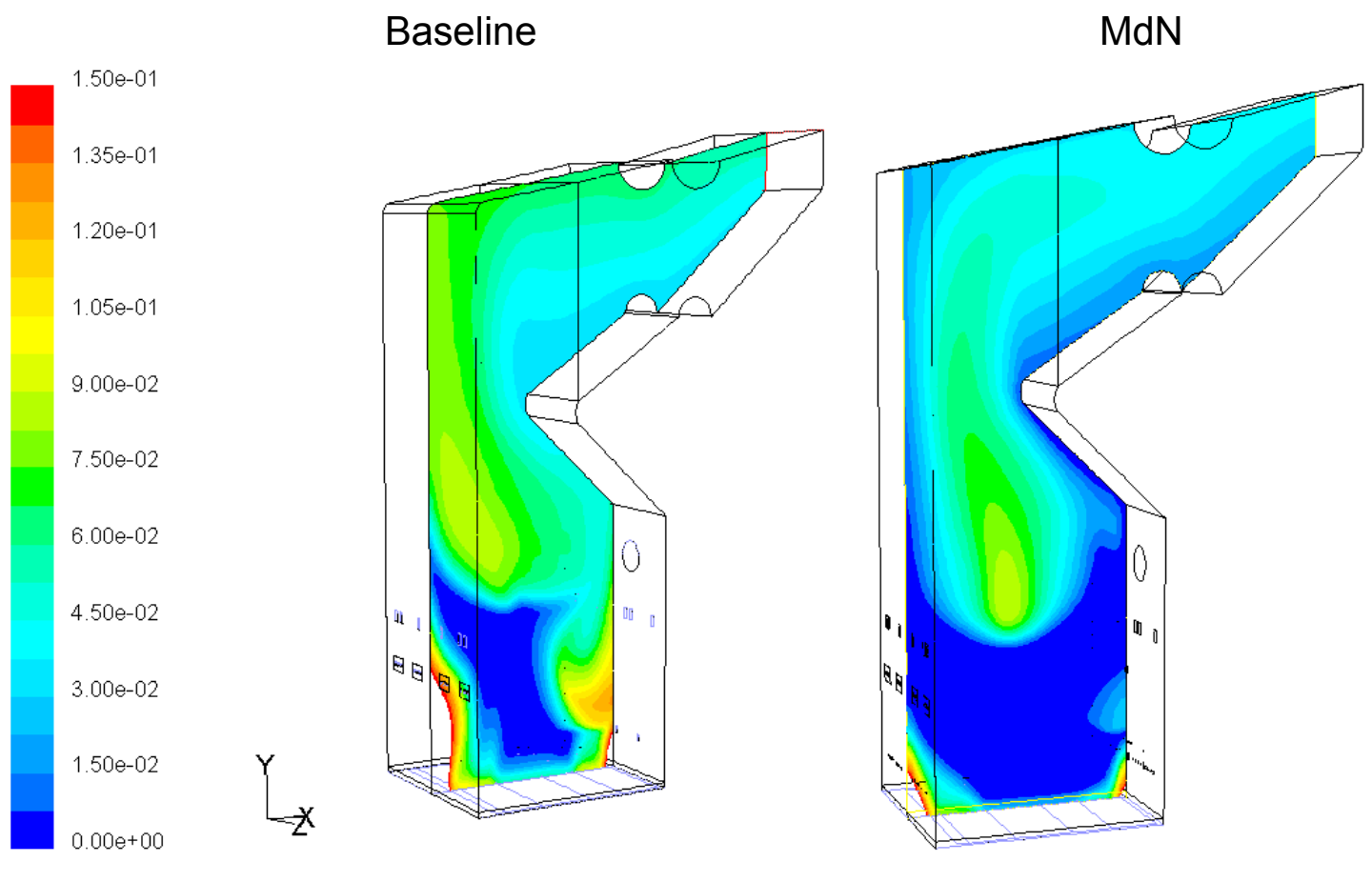

Figure 4-63 DeRidder Contours of Mole Fraction of $\mathrm{O}_{2}$ (wet) for Baseline and MdN Firing Conditions 
Baseline

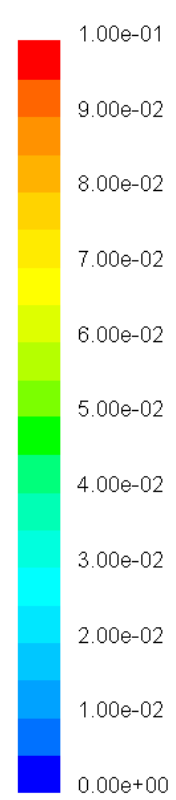

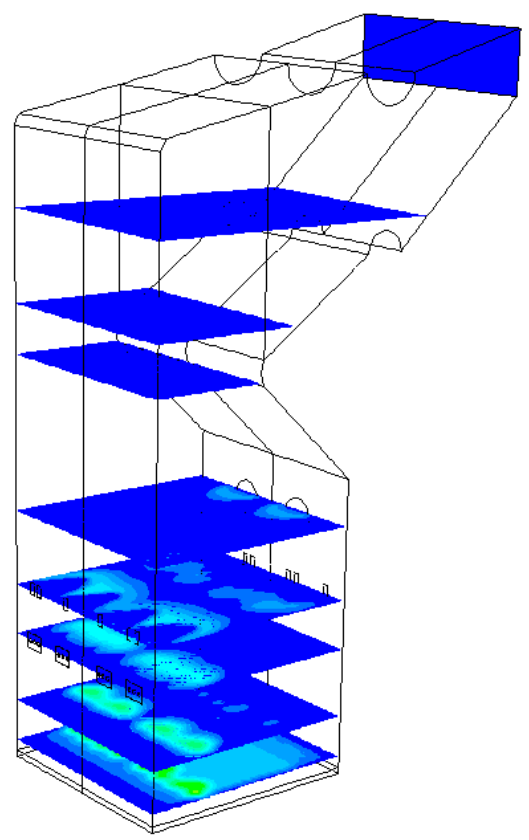

$\mathrm{MdN}$

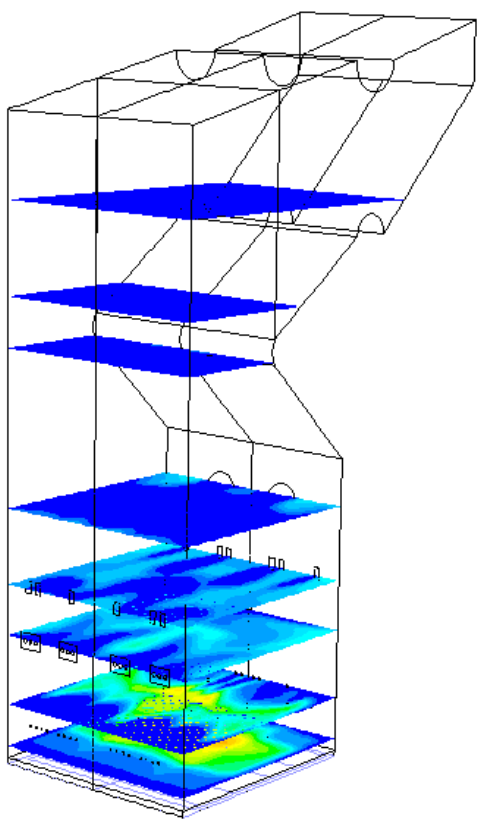

Figure 4-64 DeRidder Contours of Mole Fraction of CO (wet and uncorrected) for Baseline and MdN Firing Conditions
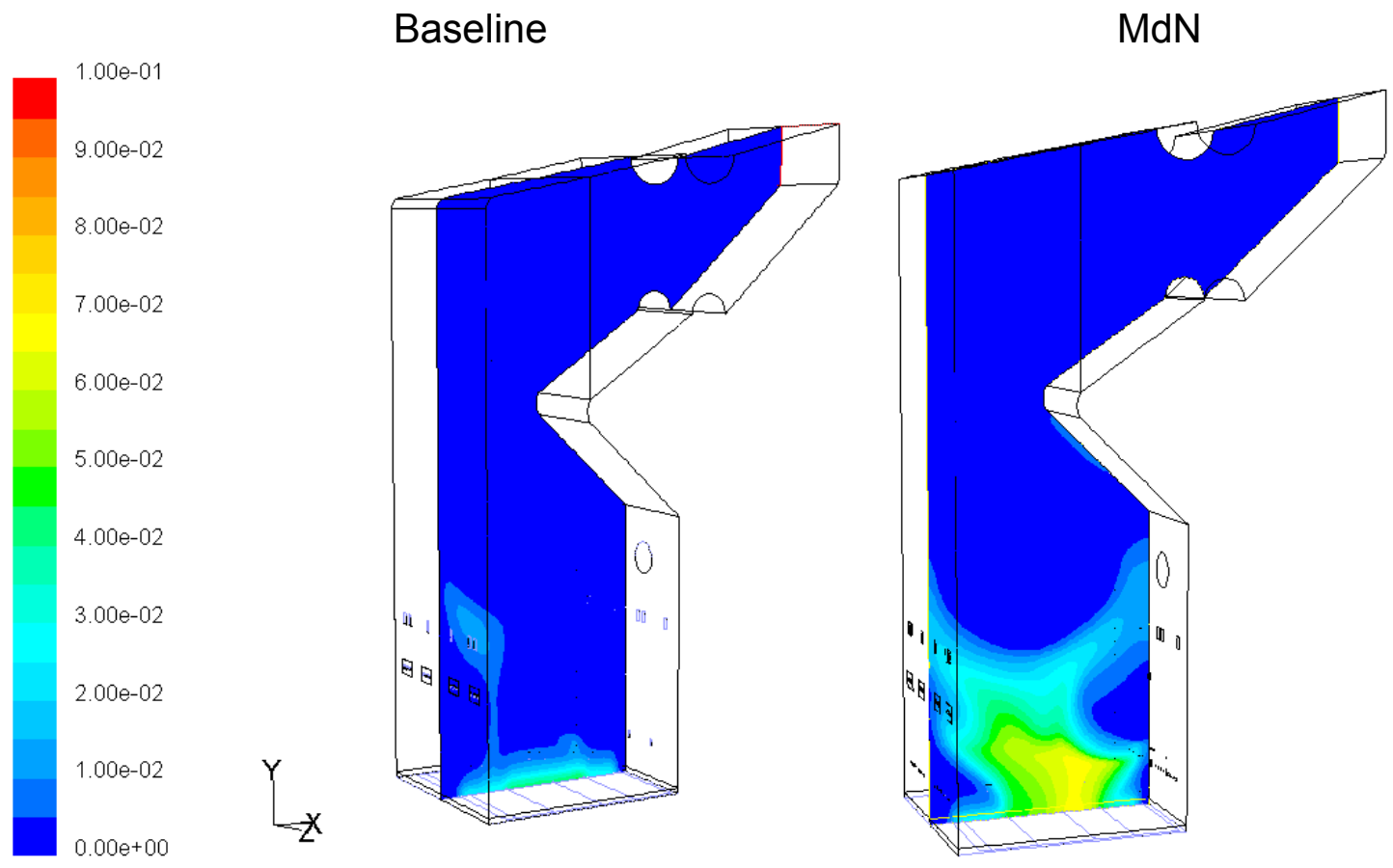

Figure 4-65 DeRidder Contours of Mole Fraction of CO (wet and uncorrected) for Baseline and MdN Firing Conditions 

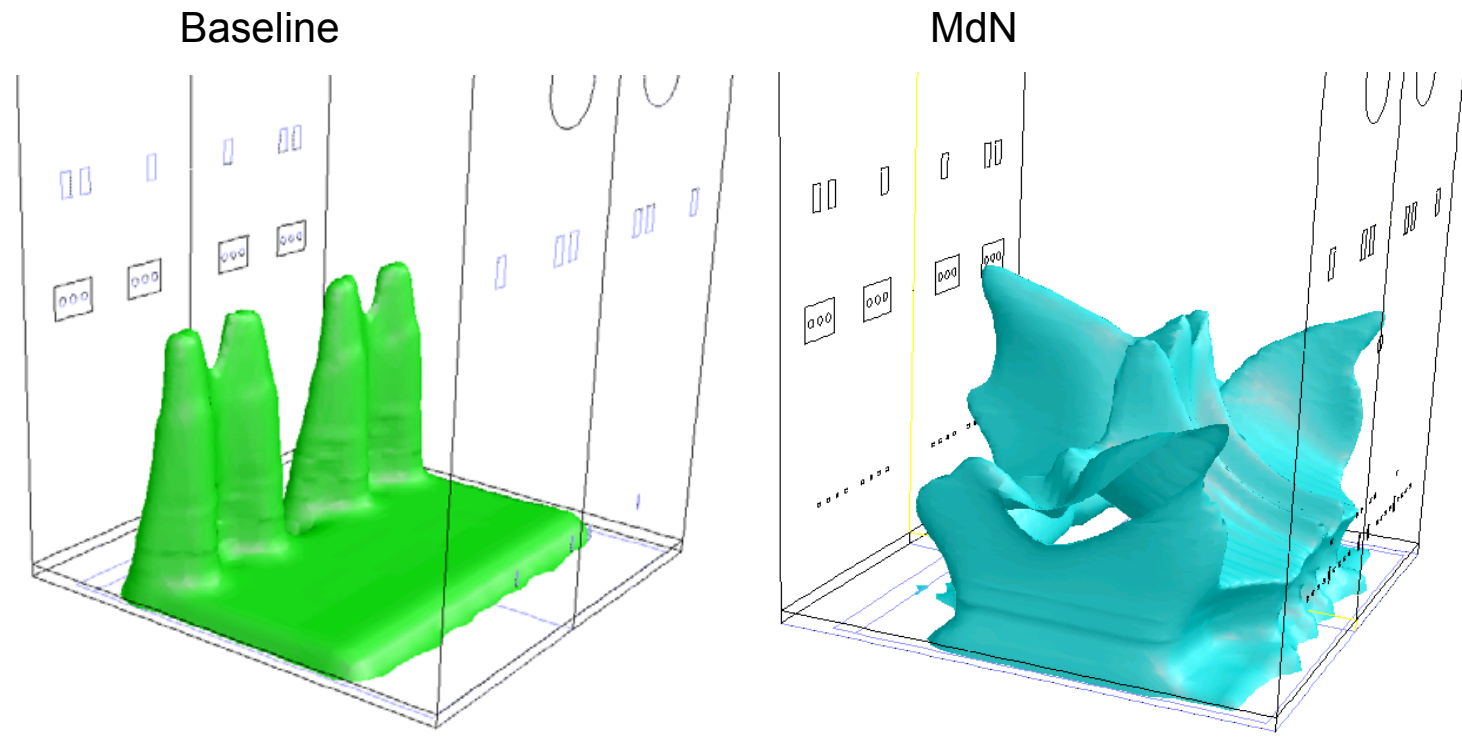

Figure 4-66 DeRidder Iso-surfaces of CO Mole Fraction (3\% wet) for Baseline and MdN Firing Conditions
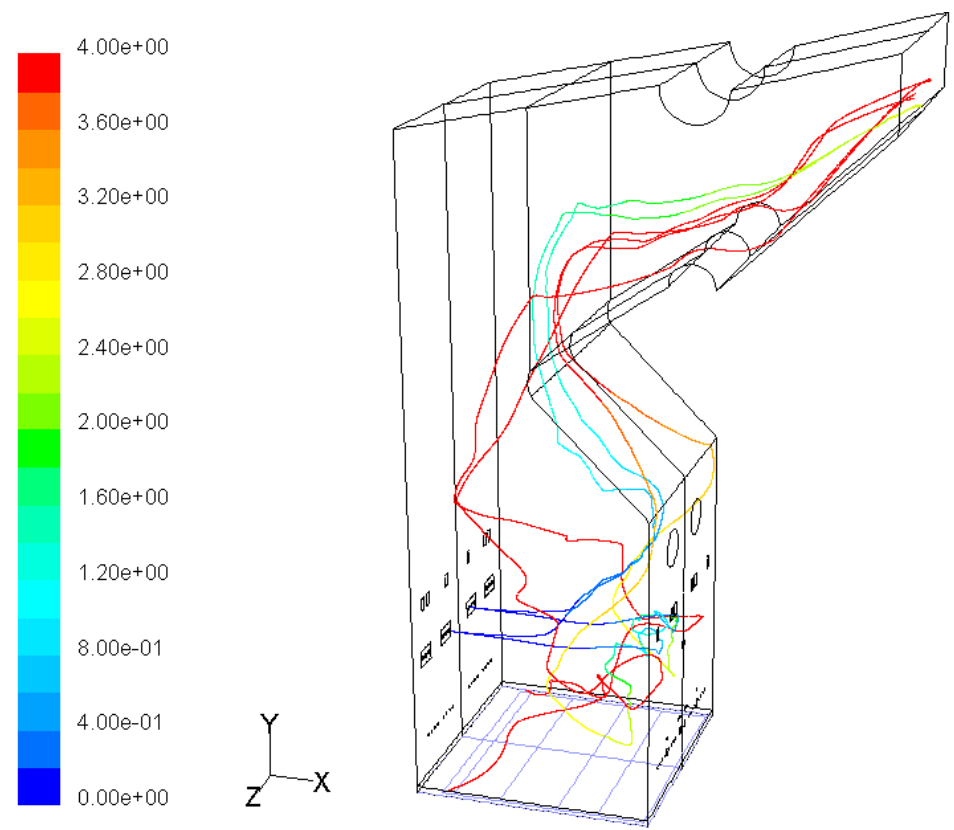

Figure 4-67 DeRidder Particle Traces Colored by Particle Residence Time (s) for MdN Firing Conditions.

\subsubsection{CFD Model Studies with Addition of SOG and NCG to MdN Retrofit Boiler}

The effect of NCG/SOG heat input on the MdN retrofit boiler performance was investigated. This NCG/SOG heat input has the potential to reduce natural gas usage by approximately 0.70 kpph as compared with the natural gas flow specified in the basic MdN configuration. 
SOG stream with a vapor content of $63 \%(\mathrm{v} / \mathrm{v})$ and NCG stream with a vapor content of $66 \%$ (v/v) were injected to the MdN retrofit boiler. Table 4-9 shows the chemical analysis of SOG and NCG used in CFD calculations. The injection ports can be seen in Figure 4-51. The inlet flow conditions are seen in Table 4-10. The flow rates of basic MdN configuration was kept constant except the natural gas flow rate.

Table 4-9 DeRidder NCG and SOG Chemical Analysis

\begin{tabular}{|c|c|}
\hline FUEL & $\begin{array}{c}\% \\
(\mathrm{v} / \mathrm{v})\end{array}$ \\
\hline \multicolumn{2}{|l|}{$\mathrm{NCG}$} \\
\hline Hydrogen & 3.80 \\
\hline Dimethyl Sulfide & 1.36 \\
\hline Dimethyl disulfide & 0.91 \\
\hline Turpentine, C10 & 1.59 \\
\hline Methanol & 4.14 \\
\hline Nitrogen & 83.80 \\
\hline Oxygen & 4.40 \\
\hline \multicolumn{2}{|l|}{ SOG } \\
\hline Methanol & 100.00 \\
\hline
\end{tabular}


Table 4-10 DeRidder Flow Rates of Injected Gas and Solids for MdN Case with NCG and SOG Injection

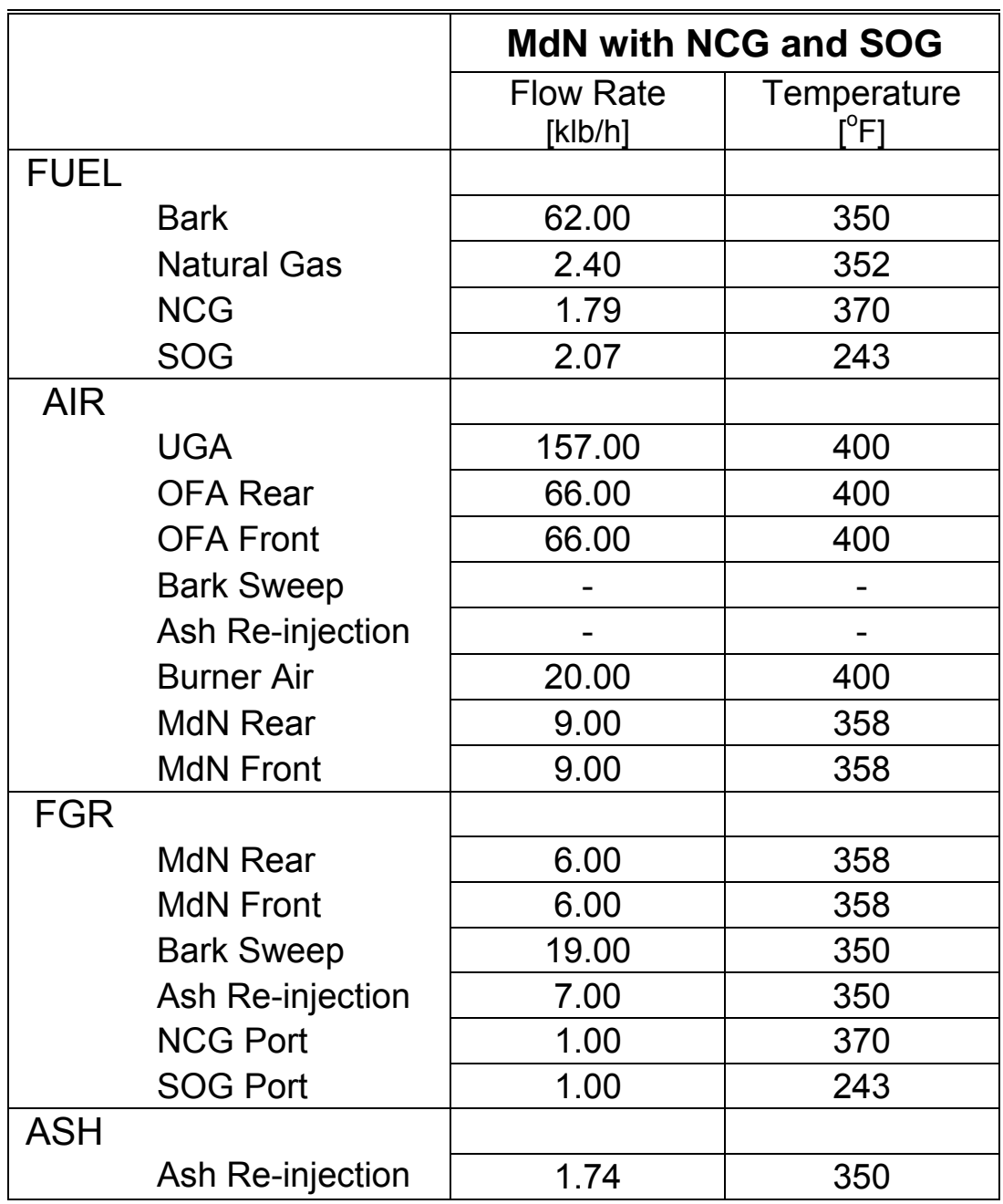

The reactions of individual NCG components were not included in the CFD model. Instead, a compound was defined as NCG with the same chemical and physical properties of NCG constituents. The goal of this first attempt was to investigate the distribution of temperature, oxygen and carbon monoxide throughout the MdN configured boiler. Figures 4-69 - 4-72 show the contours of temperature, oxygen and carbon monoxide. Injection of NCG/SOG to the boiler has no significant negative impact on the boiler performance when both cases, basic MdN and MdN with SOG/NCG, are compared. 


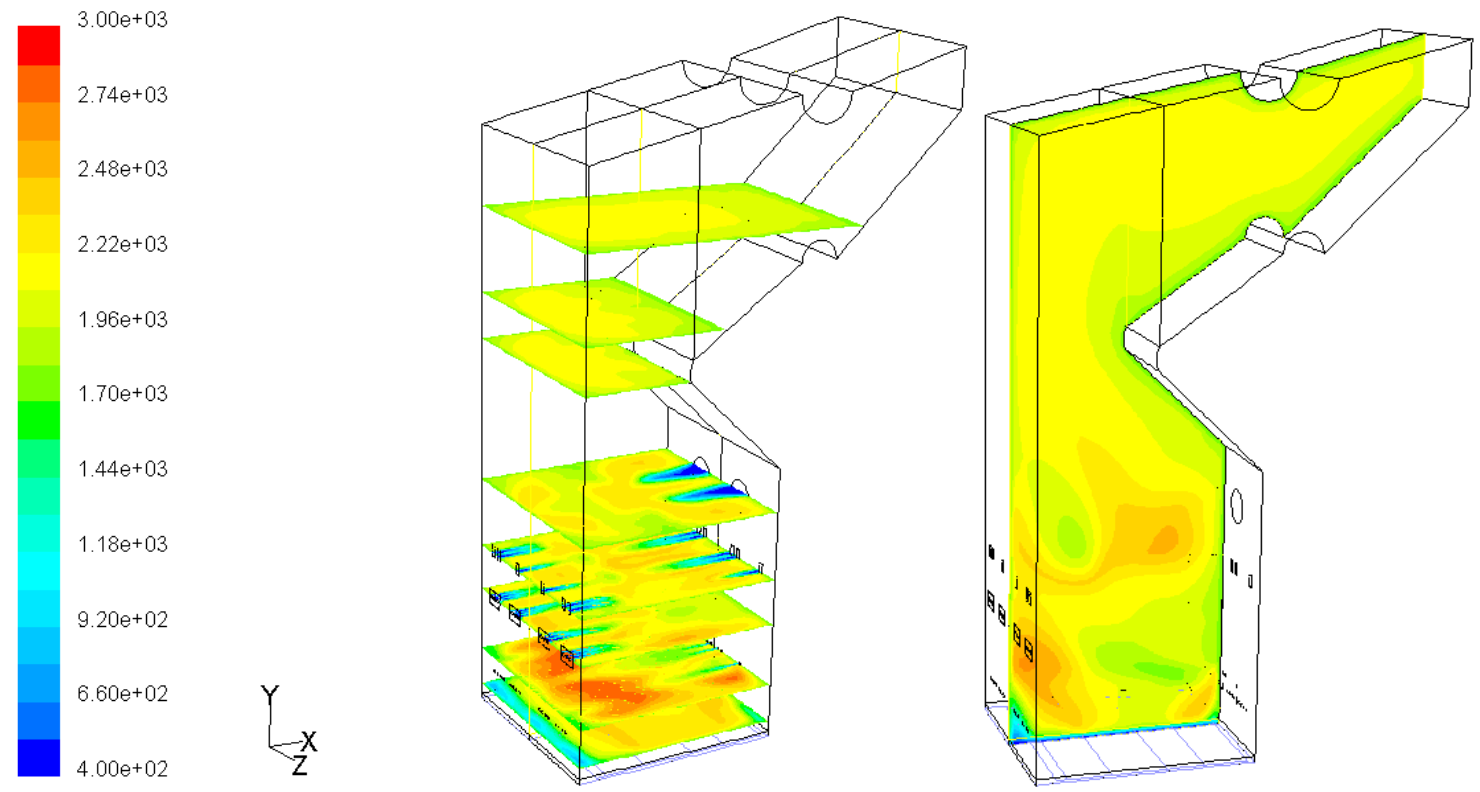

Figure 4-68 DeRidder Contours of Temperature $\left({ }^{\circ} \mathrm{F}\right)$ for $\mathrm{MdN}$ with SOG and NCG Addition
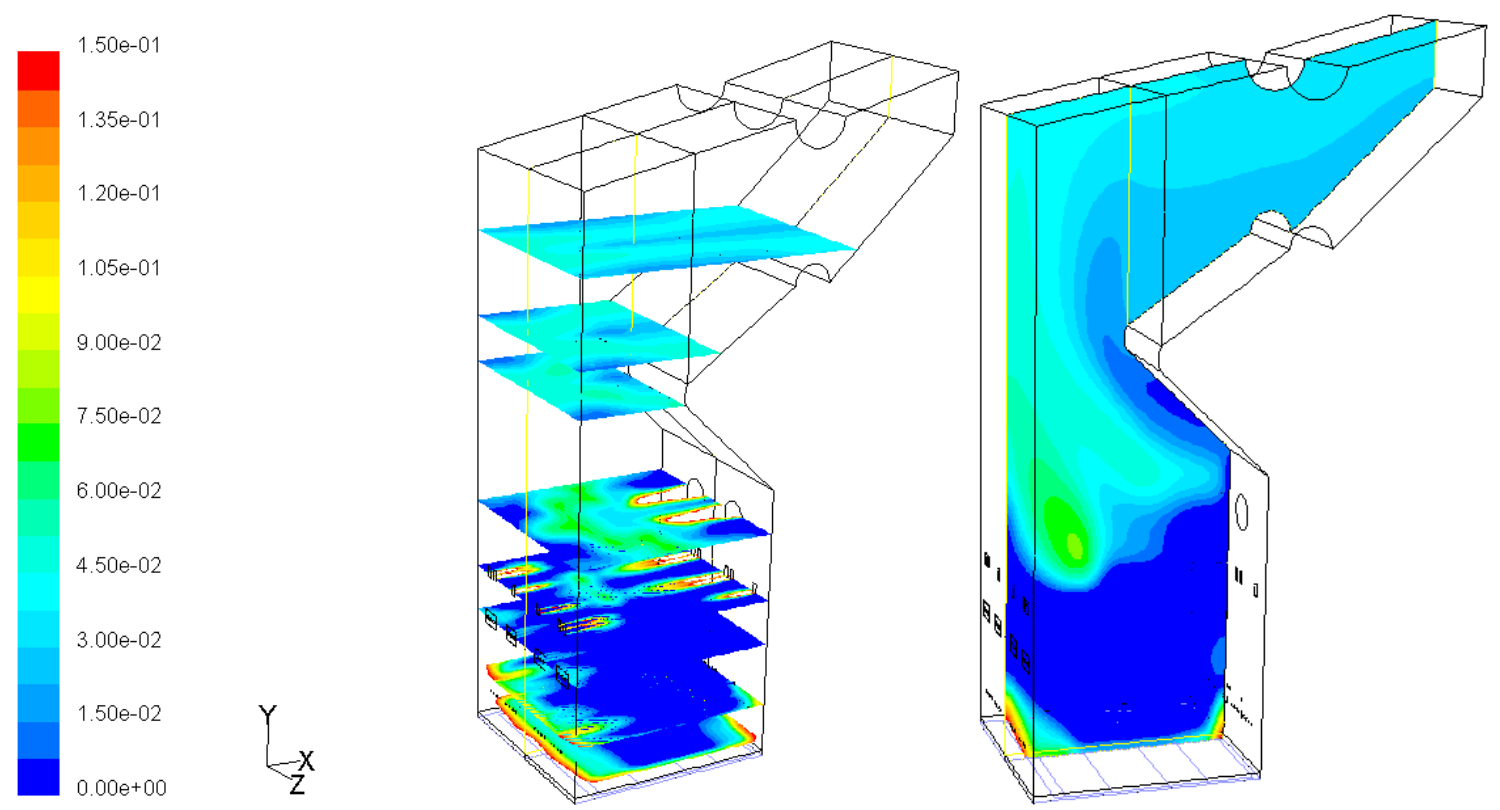

Figure 4-69 DeRidder Contours of Mole Fraction of $\mathrm{O}_{2}$ (wet) for MdN with SOG and NCG Addition 

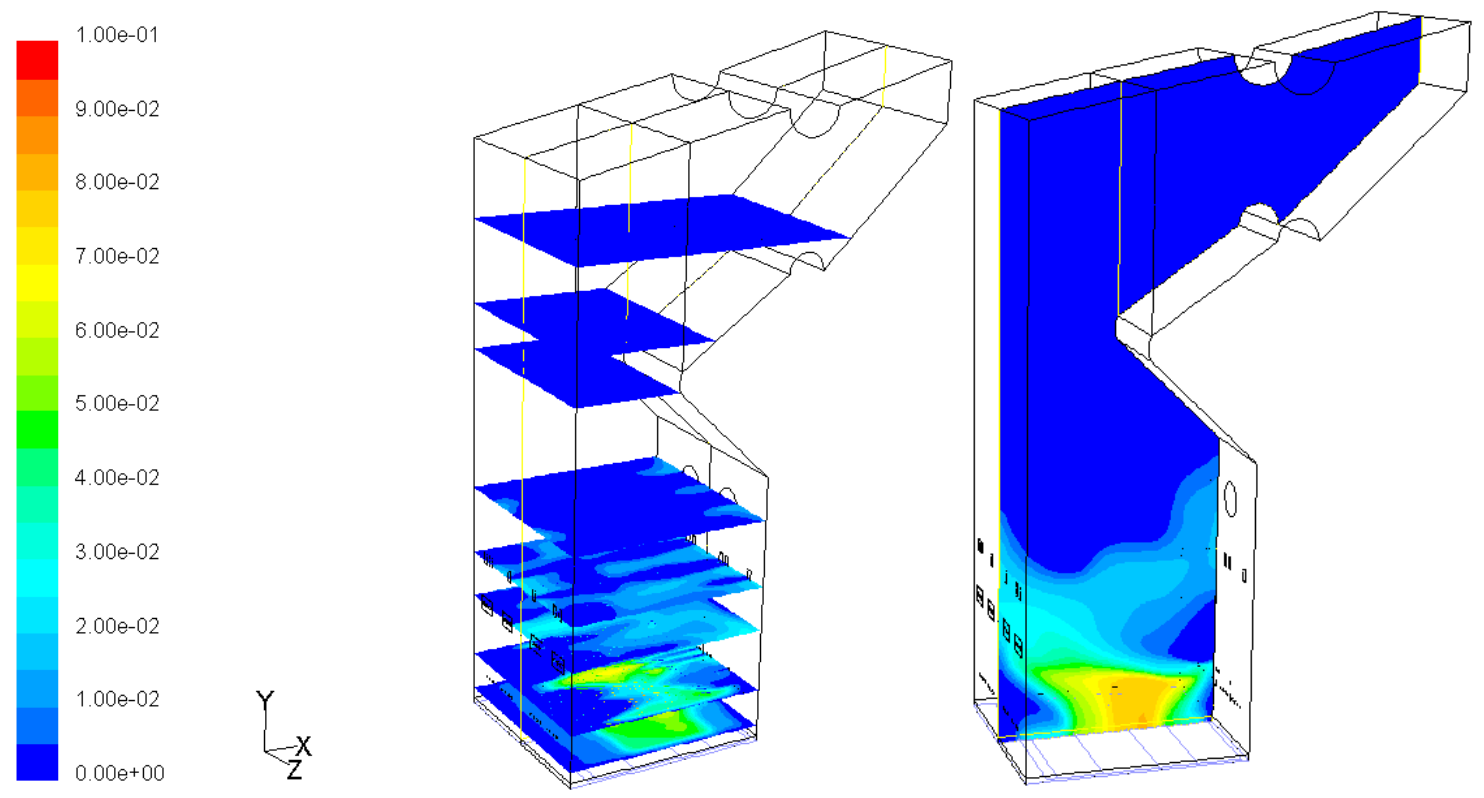

Figure 4-70 DeRidder Contours of Mole Fraction of CO (wet and uncorrected) for MdN with SOG and NCG Addition

\subsection{Conclusions}

A full-scale 3D Computational Fluid Dynamics (CFD) model of the METHANE de-NOX reburn process for wood waste and sludge-fired stoker boilers has been developed to aid the commercialization of the technology. The model is being used for the determination of guidelines for engineering design of the METHANE de-NOX reburn system for stoker boilers.

The CFD model, which GTI owns, calculated combustion of solid and gaseous fuels in four different stoker boiler furnaces. The result of calculations is detailed distribution of temperature, velocities, pressure, and species concentrations inside of the furnace and at the furnace exit. Calculated results were compared with the results from field tests. The validated model helped us to evaluate different $\mathrm{MdN}$ design configurations. The results provided important insight on quality of combustion, flame characteristics and effect of furnace arrangements (geometry, injection scheme, fuel composition, etc.) on combustion. The CFD model results also showed that NCG and SOG use had the potential to further increase gas savings from the reburn system in the boiler due to substitution of NCG and SOG for a portion of the reburn gas. 


\section{MdN Guidelines for Design and Installation}

Many factors are considered when designing a MdN system. The general boiler layout is the starting point for system design. What is the grate type? How high is the furnace? What is the existing OFA design? What is the feedstock quality? Does the ID fan have extra capacity? Where are the auxiliary burners located? How much particulate is in the flue gas? The answer to these questions and many more begins to mold the MdN system.

The first step is to review the boiler layout and support infrastructure. We must visualize where the various components of the MdN system would be located and determine if there are any obstructions. The MdN technology can have many different forms. Each system is designed to the specifics of a given boiler. The basic principles of the technology remain the same but the execution of these principles varies for each boiler.

After reviewing the baseline test data, we have a fundamental understanding of where to locate the various components of the technology. We must review the target areas of the boiler to determine what options are available for the implementation a MdN system.

\subsection{FGR System}

The design process begins by determining where FGR can be utilized to maximize performance. The main objective of the FGR system is to lower the oxygen content within the primary combustion zone and reduce the formation of $\mathrm{NO}_{\mathrm{x}}$. The baseline data on the grate region is analyzed to identify regions along the grate with high oxygen levels.

We start the FGR system design by targeting systems that unnecessarily inject oxygen into the lower furnace region, such as cinder re-injection and feeder sweeps. By replacing the carrier fluid, air, with FGR the oxygen levels near the primary combustion zone are reduced. We also review the grate combustion conditions to determine if a portion of under grate air supply should be replaced with FGR. The FGR to the under grate air supply is primarily used on coal-fired stokers. The under grate FGR has proven to provide little or no improvement on hog fuel-fired stokers.

The other function of the FGR is to provide turbulent mixing within the reburn zone. The FGR is injected with the natural gas to insure adequate mixing and even distribution within the secondary combustion zone. The FGR would also be utilized as a mixing agent for the injection of any waste gas streams.

Once the total FGR flow is known, we decide where to locate the FGR takeoff point. The main consideration for the takeoff location is the capacity of the ID fan. If the ID fan has extra capacity to handle the increased flow from the FGR injection, the FGR fan can be placed after the ID fan. The sizing requirements for the FGR fan placed after the ID fan are much smaller than a fan located before the ID fan.

The last item concerning the FGR system is the level of particulate in the flue gas. A dirty flue gas or flue gas with particulate matter will erode the fan blades and eventually lead to the failure 
of the fan. If the flue gas has higher levels of particulate matter than the FGR fan manage, a mechanical ash collection system must be added to remove the excess matter.

\subsection{Reburn Fuel Injection}

The purpose of the natural gas injection is to create a secondary combustion zone above the grate with conditions conducive to reducing $\mathrm{NO}_{\mathrm{x}}$ and other nitrogen compounds to elemental nitrogen $\left(\mathrm{N}_{2}\right)$. The natural gas system is designed to uniformly cover the grate region with the natural gas and FGR mixture. The typical MdN design has incorporated two natural gas injection zones with one zone located along the front wall and one zone on the rear wall. The injection zones do not have to be located on the front and rear walls, but we have found the front and rear walls usually have existing ports that can be modified for natural gas injection. The project cost can be reduced by utilizing existing boiler penetrations.

The design and quantity of the natural gas nozzle is critical to achieving proper coverage along the grate. The CFD model is an invaluable tool for evaluating the performance for various nozzle sizes and shapes. Through the use of the CFD model our engineers can quantify the penetration and mixing characteristics of various injection nozzles. The CFD model results are used to select what size and shape nozzle to use for the natural gas injection.

The installed MdN systems have incorporated two different approaches to mixing the natural gas with the FGR before injecting the mixture into the boiler. One method has been to mix the natural gas with the FGR at each injection nozzle. The injection system consists of two supply headers, one for natural gas and one for FGR. The two headers supply an injector with inner and outer sleeves. The outside section contains the FGR and the inside section contains the natural gas. The mixing of the natural gas and FGR streams takes place within a few inches of the end of the injector. This methodology has some safety benefits by limiting the mixing of natural gas with an oxygen containing gas. This approach does have additional costs associated with the installation of two supply headers and a more costly injection nozzle.

The second option has been to mix the natural gas and FGR further upstream of the injection location. This method has been utilized when the combination injector was not a feasible alternative. A single header supplies the natural gas and FGR mixture to the injectors. The natural gas and FGR streams are mixed using an inline mixer designed by GTI.

Both GTI's and ESA-ES's personnel have extensive experience with the handling and injection of natural gas into boilers. We are aware of the hazards related natural gas and safety is our first priority. Our systems are designed to meet or exceed all regulations associated with natural gas and boilers. ESA-ES has even assisted the NFPA with incorporating newer reburn technologies into their standards.

\subsection{OFA System}

The goal of any OFA system is to reduce $\mathrm{NO}_{\mathrm{x}}$ emissions. This goal is achieved by staging the combustion of the fuel. A portion of the combustion air necessary to completely burn the fuel is diverted from the primary combustion zone and injected further downstream. The process reduces the quantity of oxygen available in the primary combustion zone available to form $\mathrm{NO}_{\mathrm{x}}$ as well as reducing the amount of thermal $\mathrm{NO}_{\mathrm{x}}$ formed by lower the temperature in the primary combustion zone. 
GTI and ESA-ES begin the OFA system design process by determining how much combustion air can be diverted away from the primary combustion zone while maintaining stable grate conditions. Once the target OFA flowrate is known the CFD model is used to design the OFA nozzle and the layout of the nozzles. Our engineers use the CFD model to test various nozzle sizes and shapes. GTI's proprietary OFA nozzle consists of three (3) individual nozzles. Each of the three nozzles focuses on providing uniform distribution of the overfire air for a specific region near the OFA port. The final OFA system configuration will maintain CO emissions below the permitted level.

The target location for our OFA ports is along the sidewalls at an elevation approximately halfway between the grate and the nose or entrance to the convective section of the boiler. The key design factor for determining the OFA nozzle elevation is CO emissions or carbon burnout. The final nozzle elevation must provide adequate residence time to allow for the combustion of the unreacted carbon. The CFD results from the various OFA nozzle case studies are critical for deciding what elevation provides the maximum NOx reduction with acceptable levels of carbon monoxide.

\subsection{System Controls Integration}

The controls for the MdN system can be installed in several different ways. One option for the MdN controls is to utilize a PLC system designed and supplied by ESA-ES with an operator interface in the control room. Another option is to use the plant DCS by taking advantage of space capacity or adding capacity to the system. The final decision on which control approach should be used comes down to preference of the mill.

\subsection{System Tuning and Operating Curve Development}

At the completion of the MdN installation process, ESA-ES and GTI will begin an extensive testing program to optimize system performance and develop the necessary operating curves for the MdN system. Our test engineers will identify the incremental benefits of each component of the system, FGR, OFA, and natural gas injection, to determine how best to operate the system.

The data collected and analyzed by ESA-ES to tune the MdN systems is similar to the data collected during the baseline test program. ESA will install a temporary sampling matrix at the air preheater inlet to monitor $\mathrm{NO}_{x}, \mathrm{CO}, \mathrm{O}_{2}$, and unreacted hydrocarbons. ESA-ES will use this data to prepare the final operating curves. The control and regulation of the various components will be characterized across the operating range. The final operating curves will be based on boiler load and automatically control injection flowrates and pressures for changes in boiler load. 


\section{Baseline MdN Testing Results}

A brief summary and display of results from four hog fuel fired stoker boiler baseline studies are given for review. A test matrix was developed that ran the boiler at different conditions to characterize the effect major boiler operating parameters contributed to combustion and environmental performance. Evaluation of the field data collected during the baseline testing provided the basis for designing a full-scale commercial METHANE de-NOX system.

\subsection{International Falls MdN Baseline Testing}

The test matrix consisted of twelve (12) tests. In June of 1997, the tests were performed to determine the effects of increased sludge feed and major operating parameters had on furnace gas composition and temperatures at different wood/sludge/natural gas ratios. The flue gas concentrations of $\mathrm{O}_{2}, \mathrm{CO}$, and $\mathrm{NO}_{\mathrm{x}}$ were recorded from in-plant analyzers with a sample port located after the economizer of the boiler. In-furnace gas composition was measured by using water-cooled probes that could be positioned at various measurement points and elevations within the furnace. Data recorded from the water-cooled probes provided a basis for identifying $\mathrm{NO}_{\mathrm{x}}$ formations zones and an approximation of $\mathrm{NO}_{\mathrm{x}}$ produced.

The baseline test conditions are outlined in Table 6-1 for tests 1-4, Table 6-2 for tests 5-8, and Table 6-3 for tests 9-12. The tables contain a summary of the major boiler operating parameters and flue gas concentration for $\mathrm{O}_{2}$ and $\mathrm{NO}_{\mathrm{x}}$ at the economizer exit.

Table 6-1 I Falls MdN Baseline Conditions for Tests 1-4

\begin{tabular}{|l|c|c|c|c|c|}
\hline Major Boiler Parameters & & 100TEA1 & 100TEA2 & 100TEA3 & 100UG/OFA4 \\
\hline Steam Flow Rate & $\mathrm{klb} / \mathrm{h}$ & 210.6 & 221.2 & 205.1 & 197.8 \\
\hline Heat Input & $\mathrm{MMBtu} / \mathrm{h}$ & 306 & 320 & 291 & 280 \\
\hline Bark Input (wet) & $\mathrm{klb} / \mathrm{h}$ & 65.4 & 65.9 & 60.3 & 57.6 \\
\hline Sludge Feed (wet) & $\mathrm{klb} / \mathrm{h}$ & 1.2 & 2.9 & 2.6 & 2.5 \\
\hline Natural Gas Flow Rate & $\mathrm{kscfh}$ & 36.0 & 35.7 & 35.9 & 35.9 \\
\hline UGA Flow Rate & $\mathrm{kscfh}$ & 1131.5 & 1134.6 & 1176.6 & 739.9 \\
\hline OFA Flow Rate & $\mathrm{kscfh}$ & 1131.9 & 1075.2 & 745.7 & 1009.9 \\
\hline Burner Air Flow Rate & $\mathrm{kscfh}$ & 1023.3 & 932.7 & 679.9 & 928.6 \\
\hline Total Air Flow Rate & $\mathrm{kscfh}$ & 3286.7 & 3142.5 & 2601.8 & 2678.0 \\
\hline $\mathrm{O}_{2}$ @ Economizer & $\%$ & 4.8 & 3.5 & 1.6 & 2.5 \\
\hline NO $\mathrm{x}_{\mathrm{x}}$ Emissions & $\mathrm{lb} / \mathrm{MMBtu}$ & 0.32 & 0.32 & 0.23 & 0.26 \\
\hline Bark/Sludge/NG Heat Input & $\% / \% / \%$ & $87 / 0.6 / 11.4$ & $87 / 1.3 / 11.7$ & $86 / 1.2 / 12.8$ & $86 / 1.3 / 12.7$ \\
\hline UGA/OFA Ratio & $\% / \%$ & $50 / 50$ & $51 / 49$ & $61 / 39$ & $42 / 58$ \\
\hline
\end{tabular}


Table 6-2 I Falls MdN Baseline Conditions for Tests 5-8

\begin{tabular}{|l|c|c|c|c|c|}
\hline Major Boiler Parameters & & 100NoHL5 & 100NoHL/LowLL6 & 100SLDG7 & 60TEA8 \\
\hline Steam Flow Rate & $\mathrm{klb} / \mathrm{h}$ & 217 & 214.6 & 214.7 & 169.7 \\
\hline Heat Input & $\mathrm{MMBtu} / \mathrm{h}$ & 312 & 306 & 309 & 243 \\
\hline Bark Input (wet) & $\mathrm{klb} / \mathrm{h}$ & 54.6 & 53.3 & 53.3 & 44.2 \\
\hline Sludge Feed (wet) & $\mathrm{klb} / \mathrm{h}$ & 2.7 & 2.7 & 7.4 & 4.9 \\
\hline Natural Gas Flow Rate & $\mathrm{kscfh}$ & 36 & 36.2 & 34.4 & 17.3 \\
\hline UGA Flow Rate & $\mathrm{kscfh}$ & 1178.3 & 1279.2 & 1297.7 & 1319.5 \\
\hline OFA Flow Rate & $\mathrm{kscfh}$ & 885.1 & 734.0 & 979.5 & 957.7 \\
\hline Burner Air Flow Rate & $\mathrm{kscfh}$ & 1025.8 & 984.2 & 933.1 & 600.8 \\
\hline Total Air Flow Rate & $\mathrm{kscfh}$ & 3089.2 & 2997.3 & 3210.3 & 2878.0 \\
\hline $\mathrm{O}_{2} @$ Economizer & $\%$ & 2.4 & 2.8 & 3.4 & 5.4 \\
\hline NO ${ }_{x}$ Emissions & $\mathrm{lb} / \mathrm{MMBtu}$ & 0.24 & 0.22 & 0.33 & 0.37 \\
\hline Bark/Sludge/NG Heat Input & \%/\%/\% & $87 / 1.6 / 11.4$ & $87 / 1.7 / 11.3$ & $84 / 4.5 / 11.5$ & $89 / 3.8 / 7.2$ \\
\hline UGA/OFA Ratio & \%/\% & $57 / 43$ & $64 / 36$ & $57 / 43$ & $58 / 42$ \\
\hline
\end{tabular}

Table 6-3 I Falls MdN Baseline Conditions for Tests 9-12

\begin{tabular}{|c|c|c|c|c|c|}
\hline Major Boiler Parameters & & 60TEA9 & 100NG10 & 100SLNG11 & BRK/NG12 \\
\hline Steam Flow Rate & $\mathrm{klb} / \mathrm{h}$ & 168.7 & 223.3 & 202.0 & 208.2 \\
\hline Heat Input & MMBtu/h & 240 & 319 & 290 & 298 \\
\hline Bark Input (wet) & $\mathrm{klb} / \mathrm{h}$ & 44.7 & 0.0 & 56.1 & 63.0 \\
\hline Sludge Feed (wet) & $\mathrm{klb} / \mathrm{h}$ & 3.0 & 0.0 & 7.3 & 0.0 \\
\hline Natural Gas Flow Rate & kscfh & 14.9 & 299.7 & 15.0 & 14.9 \\
\hline UGA Flow Rate & kscfh & 967.1 & 264.8 & 1378.2 & 1476.1 \\
\hline OFA Flow Rate & kscfh & 925.2 & 722.7 & 869.0 & 864.1 \\
\hline Burner Air Flow Rate & kscfh & 599.4 & 2022.7 & 729.6 & 729.2 \\
\hline Total Air Flow Rate & kscfh & 2491.7 & 3010.2 & 2976.8 & 3069.5 \\
\hline $\mathrm{O}_{2} @$ Economizer & $\%$ & 4.2 & 3.7 & 3.4 & 3.7 \\
\hline $\mathrm{NO}_{\mathrm{x}}$ Emissions & lb/MMBtu & 0.52 & 0.39 & 0.46 & 0.41 \\
\hline Bark/Sludge/NG Heat Input & $\% / \% / \%$ & $91 / 2.4 / 6.6$ & $0 / 0.0 / 100.0$ & $91 / 3.5 / 5.5$ & $95 / 0 / 5.0$ \\
\hline UGA/OFA Ratio & $\% / \%$ & $51 / 49$ & $27 / 73$ & $61 / 39$ & $63 / 37$ \\
\hline
\end{tabular}

This baseline test data supported several key findings. The $\mathrm{NO}_{\mathrm{x}}$ formation in the furnace was distributed among three combustion zones. The $1^{\text {st }}$ zone was is located along the grate where the wood waste and sludge is combusted. The $2^{\text {nd }}$ zone was located between the lower furnace and the natural gas burners where the OFA is injected to complete the carbon burnout. The $3^{\text {rd }}$ zone was located between the natural gas burners and the furnace exit where the natural gas is combusted. 
The portion of $\mathrm{NO}_{\mathrm{x}}$ formed in each zone at regular conditions ranged from $20-50 \%$ of total $\mathrm{NO}_{\mathrm{x}}$. The specific amount of $\mathrm{NO}_{\mathrm{x}}$ formed for each zone was largely dependent on the stoichiometry between oxygen and the fuels found in each zone.

The $\mathrm{NO}_{\mathrm{x}}$ formation in zone 1 was from the combustion of wood waste and sludge. The sludge feed rate was found to have a measurable impact on $\mathrm{NO}_{\mathrm{x}}$ formation. The $\mathrm{NO}_{\mathrm{x}}$ formation increased approximately $4 \%$ for every $1 \mathrm{ton} / \mathrm{hr}$ of sludge injected in the boiler. The rate of sludge injection appeared to provide no combustion problems along the grate and in the flame. The levels of carbon in the bottom and fly ash were comparable across the feed rate range of sludge. The other major source of $\mathrm{NO}_{\mathrm{x}}$ formation was the UGA flow rate. The UGA was found to increase $\mathrm{NO}_{\mathrm{x}}$ formation by $2 \%$ for every $1 \%$ in UGA flow.

The major contributors to $\mathrm{NO}_{\mathrm{x}}$ formation in Zone 2 were the distribution and flow rate of OFA. The $\mathrm{NO}_{\mathrm{x}}$ concentration decreased in Zone 2 by $2.5 \%$ for a $1 \%$ increase in OFA flow. The $\mathrm{NO}_{\mathrm{x}}$ formation in Zone 3 was linked to the natural gas burners. The $\mathrm{NO}_{\mathrm{x}}$ formed in this zone decreased for $30 \%$ of total $\mathrm{NO}_{\mathrm{x}}$ to $3 \%$ of total $\mathrm{NO}_{\mathrm{x}}$ by reducing the natural gas heat input from $12 \%$ to $5 \%$ of total boiler heat input. The $\mathrm{NO}_{\mathrm{x}}$ formation in Zone 3 characteristics are very favorable for MdN operation since a large portion of the natural gas injected into the Zone 3 region will be relocated to the grate region for the $\mathrm{MdN}$ system.

Outside of the three $\mathrm{NO}_{\mathrm{x}}$ formation zones, the total excess air in the flue gas effected boiler efficiency and $\mathrm{NO}_{\mathrm{x}}$ emissions. The boiler efficiency was improved $1.5 \%$ by reducing the flue gas $\mathrm{O}_{2}$ concentration $2 \%$. The total excess air level also had a significant impact on $\mathrm{NO}_{\mathrm{x}}$ emissions. The $\mathrm{NO}_{\mathrm{x}}$ levels were decreased by $25 \%$ with the lower excess air setting.

During the baseline testing a survey of existing equipment and boiler penetrations showed potential for utilization with an MdN boiler retrofit. The lower level of OFA ports along the front and rear walls could be retrofitted for the natural gas/FGR injection component of the MdN system. The OFA fan that supplies the lower OFA ports could be converted to supply FGR and the outlet duct can be modified to distribute the FGR for the MdN system. The existing natural gas control equipment and piping can be modified to supply natural gas to the MdN injection zones along the grate.

\subsection{Wallula MdN Baseline Testing}

Baseline testing at Wallula was conducted in April 2001 with a total of seven tests. The furnace gases were sampled from fourteen (14) port locations and analyzed for $\mathrm{O}_{2}, \mathrm{CO}, \mathrm{NO}_{\mathrm{x}}, \mathrm{CO}_{2}$, and total hydrocarbons. The operating parameters were obtained from local readings and from the plant data historian (PI) system for boiler performance evaluation. Samples of bark, bottom ash, and fly ash were collected for analysis of each streams chemical composition and higher heating valve.

The main goal of the test matrix was to show the effect major operating parameters had on the hog fuel stoker boiler at normal operation as well as simulated MdN operation. And in response to a mill request, an evaluation of the boiler's FD, ID, and OFA fan performance was made and 
particulate carryover was studied for purposes of maximizing bark feed and minimizing the consumption of natural gas in the auxiliary gas burners.

The furnace region of the boiler was divided into three sections for testing; the grate and near grate zone, the midlevel furnace near the OFA injectors, and the upper furnace near the natural gas burners. The stoichiometric ratio was varied in each of these three zones to determine its affect on $\mathrm{NO}_{\mathrm{x}} / \mathrm{CO}$ formation. The total excess air, UGA/OFA ratio, bark/natural gas heat input, and steam load were varied to study the impact on thermal efficiency and emissions. The baseline testing results can be found in Table 6.4.

Table 6-4 Baseline Test Results for Wallula

\begin{tabular}{|l|c|c|c|c|c|c|c|c|}
\hline Major Boiler Parameters & & \multicolumn{5}{|c|}{ Test \# } \\
\hline & & 1 & 2 & 3 & 4 & 5 & 6 & 7 \\
\hline Steam Flow Rate & $\mathrm{klb} / \mathrm{h}$ & 160.0 & 160.2 & 159.9 & 200.0 & 200.4 & 158.2 & 160.5 \\
\hline Heat Input & MMBtu/h & 210.1 & 219.7 & 216.5 & 271.8 & 273.3 & 212.6 & 217.6 \\
\hline Bark Input (wet) & $\mathrm{klb} / \mathrm{h}$ & 25.0 & 35.7 & 31.4 & 39.6 & 39.0 & 31.0 & 33.4 \\
\hline Natural Gas Flow Rate & $\mathrm{kscfh}$ & 78.2 & 64.4 & 72.8 & 90.9 & 93.2 & 80.5 & 71.0 \\
\hline UGA Flow Rate & $\mathrm{kscfh}$ & 1342.6 & 1449.7 & 1385.4 & 1831.2 & 1876.9 & 1052.6 & 1365.0 \\
\hline OFA Flow Rate & $\mathrm{kscfh}$ & 1121.3 & 1119.0 & 1110.7 & 1081.1 & 1074.0 & 1109.1 & 980.1 \\
\hline Burner Air Flow Rate & $\mathrm{kscfh}$ & 999.4 & 854.8 & 930.8 & 11445.6 & 1173.0 & 914.3 & 911.0 \\
\hline Total Air Flow Rate & $\mathrm{kscfh}$ & 3461.5 & 3421.7 & 3425.0 & 4055.7 & 4121.7 & 3074.3 & 3254.4 \\
\hline $\mathrm{O}_{2}$, Boiler Exit (wet) & $\%$ & 7.0 & 5.8 & 5.7 & 4.8 & 4.8 & 5.2 & 4.9 \\
\hline NO ${ }_{\mathrm{x}}$ Emissions & $\mathrm{lb} / \mathrm{MMBtu}$ & 0.24 & 0.23 & 0.23 & 0.24 & 0.24 & 0.21 & 0.20 \\
\hline Bark/NG Heat Input & $\% / \%$ & $62 / 38$ & $70 / 30$ & $66 / 34$ & $66 / 34$ & $65 / 35$ & $61 / 39$ & $67 / 33$ \\
\hline UGA/OFA Ratio & $\% / \%$ & $55 / 45$ & $56 / 44$ & $56 / 44$ & $63 / 37$ & $64 / 36$ & $49 / 51$ & $58 / 42$ \\
\hline SA/RI/FA (Ratio of OFA) & $\% / \% / \%$ & $44 / 28 / 28$ & $44 / 28 / 28$ & $25 / 46 / 29$ & $43 / 27 / 30$ & $43 / 27 / 30$ & $44 / 28 / 28$ & $15 / 53 / 32$ \\
\hline
\end{tabular}

The $\mathrm{NO}_{\mathrm{x}}$ formation in the bottom or grate zone accounted for $35-50 \%$ of the total $\mathrm{NO}_{\mathrm{x}}$. The major contributing factor in the bottom zone was the bark feed and the stoichiometric ratio of fuel to combustion air. The stoichiometry within the midlevel zone was also the main factor. A $\mathrm{NO}_{\mathrm{x}}$ increase of $3 \%$ was documented for a $1 \%$ increase in the stoichiometric ratio. The $\mathrm{NO}_{\mathrm{x}}$ formation in the upper zone was related to the combustion of natural gas. The high excess air levels exiting the bottom and midlevel zones lowered the flue gas temperature and reduced the natural gas temperature resulting in lower than expected $\mathrm{NO}_{\mathrm{x}}$ formation.

The baseline tests revealed several key operating deficiencies in the boiler. For the reduced load or $80 \%$ steam load condition the boiler operated at $8.2 \% \mathrm{O}_{2}$ or about $60 \%$ excess air. The test data also indicated very high localized levels of $\mathrm{O}_{2}$ along the front and rear walls, 14\% and 18\% respectively. The high excess air level has a negative impact on the thermal efficiency of the boiler. The location of the OFA ports is at the same elevation as the fuel distribution system and creates a high $\mathrm{O}_{2}$ concentration, $10 \%$, in the feeder zone. The OFA system lacks the ability to control total flow through the system at various operating loads and contributes to high excess air levels and poor thermal efficiency. The high oxygen levels produced low CO emissions, 56 vppm, at the boiler exit. The $\mathrm{NO}_{\mathrm{x}}$ emissions were recorded at $0.25 \mathrm{lb} / \mathrm{MMBtu}$ and the majority 
was formed from fuel bound nitrogen. The natural gas usage was found to account for about $38 \%$ of the total heat input to the boiler.

An analysis of the ash revealed very low levels of carbon content in the bottom ash. The carbon levels in the fly ash were also fairly low at 5\%. The ash sample collected from the cinder reinjection system had high levels of carbon, $76 \%$.

Another objective of the baseline testing was to evaluate whether or not any existing boiler penetrations could be utilized for the MdN system and to determine the capacity of the of the FD, ID, and OFA fans. The test data indicated a substantial leak in between the furnace exit and the ID fan inlet. The oxygen level in the flue gas was $20 \%$ higher at the inlet to the ID fan. The air leak was suspected of coming from the tubular airheater.

It was also determined that the existing OFA system lacked the capacity and control necessary to be utilized with an MdN retrofit of the boiler system. The elevation of the existing OFA ports is too low to achieve the combustion staging desired for MdN operation. The existing OFA fan does not meet the specifications for the retrofitted OFA design to be used with the MdN system.

During the baseline testing GTI also reviewed possible alternatives for injecting the natural gas/FGR mixture into the boiler. The pinhole grate requires steam jets to clear the bottom ash from the grate. GTI has determined that the existing steam jets can be utilized for injecting the natural gas/FGR mixture. The cooling properties of the injected mixture will also slow the erosion of the steam jets.

\subsection{Port Hudson MdN Baseline Testing}

In October 2001, six (6) full-scale baseline tests were successfully completed on Boiler No. 1 at the Port Hudson paper mill in Louisiana. The full-scale tests included a full set of in-furnace gas analysis collected with water-cooled probes at multiple elevations within the furnace. The hot gases collected with the water-cooled probes were cooled, dried, filtered, and analyzed for $\mathrm{O}_{2}$, $\mathrm{CO}, \mathrm{CO}_{2}, \mathrm{NO}$, and $\mathrm{NO}_{\mathrm{x}}$ concentrations. The in-furnace sample ports were located near the grate and in the upper furnace. The data from the water-cooled probes was used to determine the fuel/air stoichiometry and $\mathrm{NO}_{\mathrm{x}}$ and $\mathrm{CO}$ formation in the two zones for various test conditions. GTI's test matrix called for varying total excess air, UGA/OFA/burner air distribution, and bark/natural gas heat input to determine the impact in the two furnace zones sampled with the water-cooled probe.

The main goal was similar to previous baseline studies, that is, to obtain data about the stoker boiler for evaluation and use in the design of a boiler retrofit with METHANE de-NOX. The mill's main objective was to achieve the deepest possible reduction in $\mathrm{NO}_{\mathrm{x}}$ emissions while at the same time maximizing bark fuel.

The $\mathrm{NO}_{\mathrm{x}}$ formation in the near grate zone was found to account for $70-85 \%$ of the total $\mathrm{NO}_{\mathrm{x}}$ emissions. The major factors on $\mathrm{NO}_{\mathrm{x}}$ formation in this zone were grate stoichiometric ratio and bark feed. The amount of $\mathrm{NO}_{\mathrm{x}}$ formed in the near grate zone decreased $1 \%$ for $1.5 \%$ decrease in stoichiometric ratio. The bark feed rate was found to in the $\mathrm{NO}_{\mathrm{x}}$ formed by $1 \%$ for an increase of 2 tons/hr in bark feed. 
The upper furnace zone produced $15-30 \%$ of the total $\mathrm{NO}_{\mathrm{x}}$ formation in the furnace with $15 \%$ of the $\mathrm{NO}_{\mathrm{x}}$ linked to the natural gas burners. The excess air level in the upper furnace had the largest effect on $\mathrm{NO}_{\mathrm{x}}$ levels. The $\mathrm{NO}_{\mathrm{x}}$ formation decreased $14 \%$ when the excess $\mathrm{O}_{2}$ level was reduced by $2 \%$. The $\mathrm{CO}$ emissions in the upper zone were within the acceptable ranges for the testing and were seen to decrease with increased bark flow and to increase with deeper combustion staging. A summary of the baseline testing results can be seen in Table 6.5.

Table 6-5 Port Hudson Baseline Test Data

\begin{tabular}{|l|c|c|c|c|c|c|c|}
\hline Major Boiler Parameters & & \multicolumn{7}{|c|}{ Test \# } \\
\hline & & 1 & 2 & 3 & 4 & 5 & 6 \\
\hline Steam Flow Rate & $\mathrm{klb} / \mathrm{h}$ & 195.2 & 194.4 & 195.0 & 205.8 & 204.8 & 201.1 \\
\hline Heat Input & $\mathrm{MMBtu} / \mathrm{h}$ & 306.5 & 303.0 & 303.0 & 318.6 & 318.6 & 312.2 \\
\hline Bark Input, wet & $\mathrm{klb} / \mathrm{h}$ & 54.8 & 54.3 & 54.3 & 57.3 & 57.3 & 58.3 \\
\hline Natural Gas Flow Rate & $\mathrm{kscfh}$ & 46.5 & 45.5 & 45.4 & 46.8 & 46.5 & 35.9 \\
\hline UGA Flow Rate & $\mathrm{kscfh}$ & 2639 & 2190 & 2112 & 1975 & 2298 & 2184 \\
\hline OFA Flow Rate & $\mathrm{kscfh}$ & 1086 & 1120 & 1099 & 1062 & 980 & 971 \\
\hline Burner Air Flow Rate & $\mathrm{kscfh}$ & 598 & 585 & 584 & 893 & 675 & 675 \\
\hline Total Air Flow Rate & $\mathrm{kscfh}$ & 4323 & 3895 & 3796 & 3930 & 3953 & 3830 \\
\hline $\mathrm{O}_{2}$, Boiler Exit & \% (dry) & 8.8 & 6.9 & 6.5 & 6.5 & 7.0 & 7.0 \\
\hline NO $\mathrm{x}_{\mathrm{x}}$ Emissions & $\mathrm{lb} / \mathrm{MMBtu}$ & 0.32 & 0.28 & 0.27 & 0.28 & 0.25 & 0.28 \\
\hline Bark/NG Heat Input & \%/\% & $85 / 15$ & $85 / 15$ & $85 / 15$ & $85 / 15$ & $85 / 15$ & $88 / 12$ \\
\hline UGA/OFA Ratio & \%/\% & $71 / 29$ & $66 / 34$ & $66 / 34$ & $65 / 35$ & $70 / 30$ & $69 / 31$ \\
\hline
\end{tabular}

During the baseline testing the total excess air was found to be higher than optimal boiler operating conditions. The total excess air was about $40 \%$ and produced flue gas $\mathrm{O}_{2}$ levels ranging from $6.0-8.5 \%$. GTI personnel also noticed fuel distribution along the grate was not uniform and led to under utilization of the front grate region. The voids or thinly covered sections of the front grate created oxygen levels near $20 \%$ along the front wall of the furnace.

GTI determined the existing OFA would no be able to provide the combustion staging desired for MdN operation. The existing OFA fan did not have the capacity meet the flow requirements. The mid-level OFA ports are located too close to the grate and do not provide sufficient distribution and mixing for MdN operation. The lower rear OFA nozzles can be converted to injected the natural gas/FGR mixture for the rear wall.

\subsection{DeRidder MdN Baseline Testing}

In June of 2002, a baseline study was completed on Boiler No. 2 at Boise's DeRidder paper mill in Louisiana; ten (10) full-scale tests and fourteen (14) short tests were conducted. The full-scale tests included a full set of in-furnace gas analysis collected with water-cooled probes at multiple elevations within the furnace. The hot gases collected with the water-cooled probes were cooled, 
dried, filtered, and analyzed for $\mathrm{O}_{2}, \mathrm{CO}, \mathrm{CO}_{2}, \mathrm{NO}, \mathrm{NO}_{x}$, and hydrocarbon content. The infurnace sample ports were located above the grate, mid-furnace, and furnace exit. The flue gas temperature was recorded at each location sampled by the water-cooled probes. An optical pyrometer was also used to collect flue gas temperatures at additional sample locations throughout the furnace.

The main goal was similar as other baseline tests and that was to obtain in-furnace gas composition data and boiler operating variables to characterize furnace $\mathrm{NO}_{\mathrm{x}}$ formation and the effect of major boiler parameters on production of $\mathrm{NO}_{\mathrm{x}}$. Of special interest planned at DeRidder was a study targeting the utilization of the mills generated noncondensable waste gas streams, NCGs and stripper off gases (SOG), as supplemental reburn fuel in an enhancement to the basic MdN retrofit scheme. MdN with NCG and SOG provides a reduction in consumption of reburn natural gas and another safe, viable and environmentally sound disposal option of these noncondensable waste gases. A summary of the boiler operating conditions for the baseline test program can be seen in Table 6-6.

Table 6-6 DeRidder MdN Baseline Boiler Operating Conditions for Tests 1-10

\begin{tabular}{|l|c|c|c|c|c|c|c|c|c|c|c|}
\hline Baseline Test No & & $\mathbf{1}$ & $\mathbf{2}$ & $\mathbf{3}$ & $\mathbf{4}$ & $\mathbf{5}$ & $\mathbf{6}$ & $\mathbf{7}$ & $\mathbf{8}$ & $\mathbf{9}$ & $\mathbf{1 0}$ \\
\hline Steam Flow Rate & $\mathrm{klb/h}$ & 228 & 222 & 230 & 218 & 218 & 283 & 218 & 219 & 200 & 242 \\
\hline Heat Input & $\mathrm{MMBtu} / \mathrm{h}$ & 382 & 355 & 365 & 360 & 362 & 450 & 359 & 359 & 343 & 401 \\
\hline Bark Input (wet) & $\mathrm{ton} / \mathrm{h}$ & 38.5 & 23.1 & 24.8 & 34.4 & 34.9 & 29.6 & 30.3 & 31.1 & 36.4 & 35.4 \\
\hline Natural Gas Flow & $\mathrm{kscfh}$ & 59.4 & 156.7 & 154.1 & 71.5 & 69.0 & 198.7 & 103.8 & 96.8 & 37.9 & 103.6 \\
\hline UGA Flow & $\mathrm{kscfh}$ & 2946 & 1777 & 1423 & 1878 & 1894 & 2280 & 1942 & 1926 & 1921 & 2035 \\
\hline OFA Flow & $\mathrm{kscfh}$ & 1616 & 770 & 765 & 773 & 525 & 910 & 646 & 648 & 350 & 828 \\
\hline Burner Air Flow & $\mathrm{kscfh}$ & 735 & 1022 & 1080 & 884 & 1231 & 1398 & 1131 & 1170 & 1385 & 1571 \\
\hline Total Air Flow & $\mathrm{kscfh}$ & 5296 & 3793 & 3483 & 3760 & 3880 & 4821 & 3933 & 3973 & 3874 & 4654 \\
\hline $\mathrm{O}_{2}$, Furnace Exit & \% (dry) & 5.8 & 6.8 & 5.1 & 4.0 & 5.5 & 6.5 & 7.8 & 5.0 & 6.8 & 7.1 \\
\hline NO ${ }_{x}$ Emissions & lb/MMBtu & 0.21 & 0.22 & 0.19 & 0.20 & 0.22 & 0.22 & 0.24 & 0.21 & 0.23 & 0.27 \\
\hline Bark/NG Heat Input & \%/\% & $84 / 16$ & $55 / 45$ & $57 / 43$ & $80 / 20$ & $81 / 19$ & $55 / 45$ & $71 / 29$ & $73 / 27$ & $89 / 11$ & $74 / 26$ \\
\hline UGA/OFA Ratio & \%/\% & $65 / 35$ & $70 / 30$ & $65 / 35$ & $71 / 29$ & $78 / 22$ & $71 / 29$ & $75 / 25$ & $75 / 25$ & $85 / 15$ & $71 / 29$ \\
\hline
\end{tabular}

Flue gas concentrations were also measured at a test grid located at the airheater inlet and in the stack. The stack gas was analyzed for particulate matter and $\mathrm{HCl}$ concentrations. Boiler operating data, such as system flows, pressures, and temperatures were collected from the plant DCS and historian (PI) systems. Field data was also collected for header pressures for OFA, UGA, and the cinder re-injection system. Grab samples of bark, bottom and fly ash, cinder reinjection ash, and SOG and NCG samples were collected and analyzed. The bark and ash samples were tested for moisture content, ash, and elemental analysis. The waste gases, SOG and NCG, were tested for methanol, total nitrogen, total sulfur, and ammonia content.

The baseline testing highlighted the normal operation of the boiler and the effects that change in each of the operating parameters had on the emissions and thermal efficiency of the boiler. 
Stack emissions were typical of a hog fuel-fired stoker boiler with oxygen at 7\%. The average stacks emissions were $0.233 \mathrm{lb} / \mathrm{MMBtu}$ for $\mathrm{NO}_{\mathrm{x}}$ and $0.389 \mathrm{lb} / \mathrm{MMBtu}$ for $\mathrm{CO}$.

The boiler emissions were characterized in two regions of the furnace, the lower and upper. The lower region included the grate and fuel distributors. The upper region consisted of the OFA system and the natural gas burners. The $\mathrm{NO}_{\mathrm{x}}$ formation at the grate accounted for $20-50 \%$ of the total $\mathrm{NO}_{\mathrm{x}}$. The $\mathrm{NO}_{\mathrm{x}}$ formed along the grate was found to increase $2 \%$ for each ton/hr increase in bark feed. The upper furnace accounted for $40-80 \%$ of total $\mathrm{NO}_{\mathrm{x}}$. The OFA system contributed to $25-65 \%$ of the total $\mathrm{NO}_{\mathrm{x}}$. The natural gas burners produced $5-15 \%$ of the total $\mathrm{NO}_{\mathrm{x}}$. The CO emissions varied from 275 to $1375 \mathrm{vppm}$ (corrected to $3 \% \mathrm{O}_{2}$ ) with the highest CO levels observed when the grate stoichiometry was 0.8 or the lowest tested stoichiometry.

The boiler was found to operate normally around 50\% excess air and at an efficiency from 6774\%. The heat input ranged from 330-436 MMBtu/h across the tested range with a grate heat release of 0.5-0.9 MMBtu/ $\mathrm{ft}^{2}$. The average carbon loss in the bottom ash was found to be less than $1 \%$ while the carbon content in the fly ash ranged from $12-35 \%$

During the baseline testing GTI evaluated existing equipment and boiler penetrations for possible utilization with the MdN system. The performance of the FD, ID, and OFA fans were found to have sufficient capacity to meet the requirements of a MdN system. The OFA system, fan and ports, provided adequate mixing and distribution of the OFA and does not require a retrofit for MdN operation. GTI also determined that eight (8) of the ash re-injection ports could be converted and utilized for the natural gas/FGR injection along the rear wall. 


\section{Commercial Design Packages}

Four commercial-scale MdN retrofit design packages are summarized and presented in this manual. These retrofit designs illustrate methods applying MdN technology to hog fuel-fired stoker boilers having a variety of construction features found in the FPI such as noted below.

1. Vibrating Water-Cooled Grate Design and Square furnace with residue from waste water treatment - Boise International Falls Mill

2. Stationary Pinhole Water Cooled Grate Design and square furnace - Boise Wallula Mill

3. Traveling Spreader Grate Design and Rectangular furnace - Port Hudson Mill

4. Traveling Spreader Grate Design and square furnace with Waste Gas Disposal - Boise DeRidder Mill

Each design package is based on respective field data from the hog fuel stoker boiler baseline test. MdN retrofit systems for International Falls and Port Hudson boilers were carried out, installed and placed into full time service at these sites. GTI and EAS-ES, the technology licensee, collaborated in pulling together the data for all boiler designs and in particular development of preliminary MdN process design packages applied to the Wallula and DeRidder boilers. All MdN system design considerations utilized CFD modeling results and ESA-ES engineering experience with $\mathrm{NO}_{\mathrm{x}}$ control technologies. The selection of equipment and component specifications vary depending on existing infrastructure and mill preferences for a given stoker boiler. Construction considerations presented for the Wallula and DeRidder boilers could alter preliminary design features, such as related to availability of a suitable placement for a fan foundation, obstructions, or limitations to the routing and size of the duct work, etc.

All reported MdN retrofit system supply and installation cost estimates were provided by ESAES based on component specifications from ESA-ES's current design philosophy to reflect a common base for comparison of the different MdN retrofit designs. Estimates made for Wallula and DeRidder MdN retrofits were taken from commercial design details developed directly by ESA-ES. Retrofit estimates for I Falls and Port Hudson was also appraised by ESA-ES based on costs for equipment and hardware specifications based on current ESA-ES construction protocols similar to protocols applied at Wallula and DeRidder instead of exactly following the as-built drawing details shown in the overview section. With this approach, the different system estimates developed were based on similar design and construction procedures and best for cost comparison purposes.

ESA-ES utilized their past experience with boiler retrofits and their background in procurement and installation of $\mathrm{NO}_{\mathrm{x}}$ control equipment to develop these estimates. The cost estimates are \pm $30 \%$. Final MdN systems costs are dependent on the final design, equipment specifications, and the local labor rates and regulations. 


\subsection{International Falls MdN Retrofit Design- As-Built}

\subsubsection{International Falls MdN Design Objectives}

The MdN design for the International Falls boiler has several objectives. The primary objective was a reduction in landfill disposal volume required for sludge generated at the mill's waste water treatment plant. The current boiler configuration allows for a portion of the sludge to be burned along with the bark. The remaining sludge must be disposed in a landfill which is environmentally unattractive and has a substantial cost. Attempts to increase sludge combustion resulted in $\mathrm{NO}_{\mathrm{x}}$ emissions exceeding permitted levels, however. And to increase sludge feed to the boiler a reduction in $\mathrm{NO}_{\mathrm{x}}$ emissions was needed. $\mathrm{MdN}$ design projections indicated a reduction of $\mathrm{NO}_{\mathrm{x}}$ emissions of approximately $40 \%$ possible while maintaining carbon monoxide emissions within the current levels. Consequently this MdN system provided a 300\% increase in the sludge feed rate to the boiler. The projected annual savings associated only with sludge disposal is nearly $\$ 400,000$.

The MdN system was also expected to reduce the natural gas total heat input by approximately $25 \%$ from current operating conditions; this reduction in natural gas usage is roughly 12,000 scfh or 100,000 scf per year based on baseline test data. As a result, more bark fuel, a little more than ton per hour, was burned in the stoker and a significant fuel savings realized. The displacement of natural gas from the upper level gas burners to the MdN natural gas injection zone just above the grate will create a more stable combustion environment along the grate and allow for the burning of high moisture content wood waste and water treatment sludge.

Other expected benefits include a reduction in carbon losses in the ash and an overall improvement in boiler thermal efficiency by 1 to $2 \%$ at base load operations.

\subsubsection{International Falls Boiler Description}

International Falls \#2 boiler is hog fuel-fired boiler built by Combustion Engineering in the 1960s. The boiler was retrofitted in 1984 with a water-cooled, vibrating, inclined Hydrograte and three (3) wind swept bark fuel distributors. The boiler can supply 220,000 lb/h of superheated steam at 1290 psig and $835^{\circ} \mathrm{F}$.

The furnace shape is square (16'-2” deep by $16^{\prime}-8$ ” wide) and it is equipped with two zones of OFA injection. Each zone, lower and upper, has a separate OFA fan that provides combustion air through two rows of OFA ports strategically located along the front and rear walls. Above the upper OFA zone are two levels of gas-fired tangential burners designed to augment the bark combustion. The elevation of the main boiler components can be seen in Figure 7-1. 


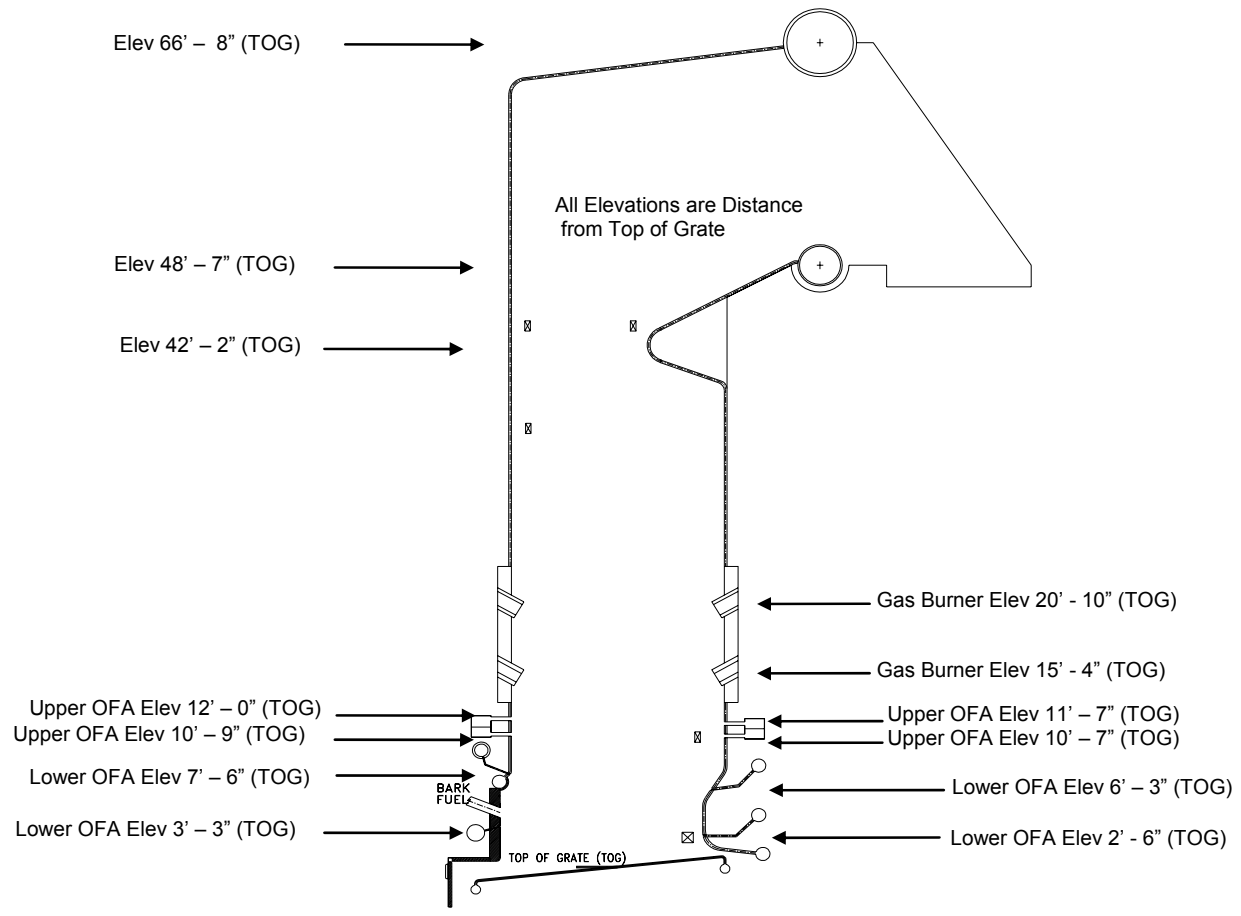

Figure 7-1 I Falls Stoker Boiler Elevation Data

\subsubsection{International Falls MdN Design Overview}

At the time of this first commercial scale demonstration, in 1999, GTI was teamed with Detroit Stoker Company (DSC) out of Monroe Michigan. DSC is a manufacturer of stoker systems and they provided the engineering, detailed design drawings and specifications for International Falls (I. Falls). Mill personnel contributed construction management services and construction supervision to the MdN system installation contractors. The MdN commercial retrofit design for the I. Falls stoker boiler is summarized in a process diagram titled MdN Overview and a detailed piping and instrument diagram, MdN P\&ID. Elements of the design are described in more detail through later system drawings. Drawing descriptions are given below:

\section{International Falls}

MdN OVERVIEW I. Falls No. 2 Boiler system is illustrated along with associated elements with the boiler's MdN retrofit, design guidance and installation details. The MdN retrofit includes the addition of an MdN FGR and MdN reburn fuel (natural gas) systems to the boiler. Natural gas injection is achieved through a revamp of existing lower level OFA air ports at the furnace's front and rear walls. Design flows for the system are designated.

I FALLS P\&ID A detailed piping and instrument diagram used as basis for installation of the MdN retrofit on I. Falls \#2 Boiler is given. MdN instrumentation provisions for the safe handling of FGR and natural gas service are designated. MdN system interlocks for the safe start-up and management of MdN process operation are also listed. 


\subsubsection{International Falls MdN OFA System}

After reviewing the baseline test data and results from the CFD model study (see Section 4), a decision was made to work with and incorporate the existing two zone OFA system of the stoker boiler into the MdN retrofit design. The I. Falls high level upper zone two row OFA ports at about the 11' elevation were shutdown. The displaced high level OFA flow was directed instead to the lower set of burner air registers (located at the corners of the furnace) to complete burnout of grate combustion. This configuration extended the oxygen deficient reburn zone directly above the grate, which gave more furnace volume in support of $\mathrm{NO}_{\mathrm{x}}$ reduction chemistry. In addition, not having to any make water-wall modifications helped control the overall installation costs. The lower OFA system was modified to accept the FGR supply and described later in section 7.1.3.3.

\subsubsection{International Falls MdN Reburn Fuel Injection System}

This system was constructed with two MdN reburn fuel (natural gas) injection zones, one each along the front and rear wall utilizing the bottom row of the existing lower level OFA ports. The front and rear injection zones consisted of 21, 1-1/4" diameter and 15, 2" diameter ports, respectively. Natural gas is distributed to each port through a dedicated 3/8” diameter pipe, referred as a quill, located and secured in the center of each injection nozzle. The natural gas combines with an FGR/OFA mixture in the nozzle before injection and dispersion into the furnace. These MdN gas injection ports will continue to deliver an FGR/OFA mixture even when boiler conditions do not support natural gas injection to maintain a low oxygen environment along the grate. Flow through the top elevation of the existing low level OFA ports can be adjusted depending on furnace conditions and the bottom row of low level OFA ports retrofitted to inject the natural gas / FGR mixture. Design drawings describing the MdN Fuel Injection System are divided into three sections, a brief description of each is given below.

\section{International Falls}

PID-2 MdN natural gas is supplied from the mill's main 75 psig gas header in the boiler house. MdN gas piping tees off this header and is equipped with a manual isolating block valve, pipe strainer and followed by a gas pressure reducing station which includes two pilot-operated pressure reducing regulators in series controlling the MdN gas pressure between 8-12 psig. The second regulator was installed to provide protection from over pressurization of the injection train hardware should the first regulator have a failure such as a ruptured diaphragm. The second regulator will take over pressure control and maintain gas pressure less than 15 psig and within acceptable pressure limits of all installed instrumentation and pipe components. Downstream of the pressure reducing regulators is the main MdN gas safety shutoff valve along with associated instrumentation to monitor flowing gas pressure and temperature. Should an abnormal gas supply condition arise or should a system interlock activate, this shutoff valve will automatically close and remain shut until operations determines and remedies the problem.

In addition, a small blower is installed to purge the natural gas piping during intervals when the natural gas flow has stopped for purposes of preventing the gas quills from plugging with deposits from the grate combustion. 
PID-3 \& 4 Injection of MdN natural gas to the furnace front and rear locations is controlled and managed through two separate fuel injection trains. Each train consists of a manual isolation block valve, a flow metering element, control valve and block and block \& bleed safety shutoff valve assembly. The operation of each station (front and rear) is independent so each station can be started, stopped and their flow set at different rates. The gas flowmeter utilizes a vortex sensor to measure flow; this must be compensated with pressure and temperature to determine the actual mass flow signal.

INJ DETAIL This drawing shows MdN natural gas injection nozzle design. Natural gas flows through a central tube (called a quill). The tube outlet is recessed about 1 inch from the outlet of the injector tube where the gas partially pre-mixes and is carried into the furnace with the FGR/OFA flow in the nozzle.

\subsubsection{International Falls MdN FGR System}

The I. Falls design selected the MdN FGR fan takeoff point after the ID fan and downstream of the precipitator (ESP). The primary reason for choosing this location was the particulate free and hot condition of the flue gas. Flue gas particulates are a issue and a concern because of potential erosion and plugging problems. I Fall's personnel had also requested that FGR system design allow operations the ability to switch the boiler set-up back to operations without FGR. In order to satisfy the mill's request, the injection of FGR was located upstream of the Low Level OFA fan inlet, thereby shutdown of the MdN FGR fan and MdN gas injection put the boiler back to its original configuration. Based on this scheme, the FGR design will require a small boost fan to successfully convey FGR and overcome the pressure at the Low Level OFA fan inlet. The discharge pressure from the lower OFA fan is 25 to $30 \mathrm{inH}_{2} \mathrm{O}$; flow from the fan supplies the OFA headers as well as a branch supply to the stoker's bark feed pneumatic spreader distribution system.

The FGR system duct work was sized and design based on the pressure drop loss through 600 feet of straight pipe with an elevation change of 25 feet from the FGR fan outlet. The actual duct work should be much shorter in length than 600 feet, but the additional length accounts for pressure loss encountered with duct transition sections, elbows, and takeoffs in the installed duct work. A description of the piping and instrument diagram for the FGR system, PID-1 is given below.

\section{International Falls}

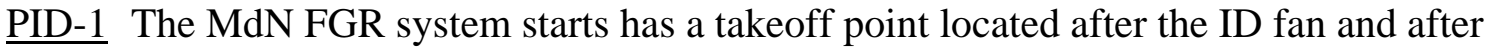
the boiler's ESP. At the take-off is a manual isolation damper and the particulate free FGR is routed through a 20" diameter duct to a new direct drive centrifugal forced draft fan with a 20 hp variable speed motor. The FGR fan discharge flow is metered with an averaging Pitot tube array and temperature compensated; FGR system flow control is implemented by control of fan speed.

\subsubsection{International Falls MdN Controls}

The control philosophy for the MdN system is to minimize the amount of boiler operator interaction necessary to operate the system and provide for the safe start-up and shutdown of the 
MdN process. The control logic is designed to function automatically; it consists of a combination of discrete and regulatory algorithms. System set points for flowrates and pressures are based on boiler steam load and adjusted automatically as change is detected in the boiler operating conditions. Control drawings are described below.

For the purpose of the costing this design, it was assumed the current unit DCS has adequate spare capacity for additional hardware and tag name points associated with the MdN system.

\section{International Falls}

LOGIC-1 A discrete logic control diagram is given that shows MdN system permissives and system interlocks monitoring process limits and operational states of system equipment. The logic's primary function is control and supervision over the safe introduction of the MdN main fuel supply. Discrete states identified as permissives represent conditions that are not compulsory logic elements but are temporary prerequisites which must be satisfied before control permits advancing to another operational state. After reaching the next functional event or state, previous permissive requirements are disabled from system logic and not enforced until a system shutdown resets the logic. Discrete states identified as system interlocks on the other hand represent conditions that are always enforced and compulsory; if not satisfied system control will initiate actions as prescribed in the logic such as a closing the natural gas supply safety shutoff valve. Some examples of key MdN interlocks which must be satisfied to open and keep open the main gas supply are: bark flame detected on grate; boiler steam rate is greater than $40 \%$ MCR and FGR fan is running.

LOGIC-2 This drawing contains the discrete permissives and interlocks for the activation and supervision of natural gas to the front and rear gas injection trains. Each $\mathrm{MdN}$ injection train has a set of permissives and interlocks allowing for independent operation.

LOGIC-3 This drawing contains MdN system regulatory control schemes covering loop requirements for FGR flow control. The drawing shows what instrumentation is linked to the various control valves and the boiler parameter used to characterize the operating curve for each system.

LOGIC-4 \& 5 This drawing shows regulatory control logic for the MdN reburn fuel injection of natural gas to the front and rear zones of the furnace. The control logic includes the calculation for heat input from natural gas injection. The logic is designed to maintain a desired input from the various gas streams and minimizes the quantity of natural gas used. The logic also insure that the maximum allowable heat input from the multiple gas streams is not exceed.

\subsubsection{International Falls MdN System installation Cost Estimate}

The estimated cost to complete final design, procure and install equipment, and test and tune a MdN system for hog fuel boiler at the Boise Cascade International Falls mill is Eight Hundred Fifty Thousand Dollars (\$850,00.00). This estimate is on a plus/minus $30 \%$ basis. The major 
item with regards to uncertainty in the estimate is the cost of local labor and the unknowns related with installation.

The above quoted cost does not include the initial baseline testing, CFD model, and preliminary MdN design. The estimated cost to perform these tasks is One Hundred Seventy Five Thousand Dollars $\mathbf{( \$ 1 7 5 , 0 0 0 )}$.

\subsubsection{International Falls MdN Retrofit Design}

The I. Falls MdN system details shown in this manual were assembled from design data developed in 1999. The installation at that time was completed in a timely manner requiring less than 7 days of outage to complete all system tie-ins. System control requirements were successfully integrated into the boiler's existing Bailey distributed control system and system commissioning/operator training was completed over a two week interval. System cost data presented were estimates from ESA-ES based on the design given in the MdN Overview drawing.

\subsubsection{International Falls MdN System Drawings - Preliminary}

Table 7-1 I Falls - MdN Design Drawing Index

\begin{tabular}{|l|l|}
\hline \multicolumn{1}{|c|}{ Drawing \# } & \multicolumn{1}{c|}{ Description } \\
\hline MdN Overview & MdN System Overview \\
\hline I Falls MdN P\&ID & MdN Overview P\&ID \\
\hline MdN System Elements & Single Line Process Drawing \\
\hline PID-1 & Flue Gas Recirculation Equipment P\&ID \\
\hline PID -2 & Methane Pressure Reducing Equipment P\&ID \\
\hline PID-3 & Front Zone Methane Injection Equipment P\&ID \\
\hline PID-4 & Rear Zone Methane Injection Equipment P\&ID \\
\hline LOGIC-1 & MdN System Interlocks \& Permissives Logic \\
\hline LOGIC-2 & Front \& Rear Zone Interlocks \& Permissives Logic \\
\hline LOGIC-3 & FGR System Control Logic \\
\hline LOGIC-4 & Front Zone Gas Flow Control Logic \\
\hline LOGIC-5 & Rear Zone Gas Flow Control Logic \\
\hline I Falls INJ DETAIL & Methane Injector Detail \\
\hline
\end{tabular}




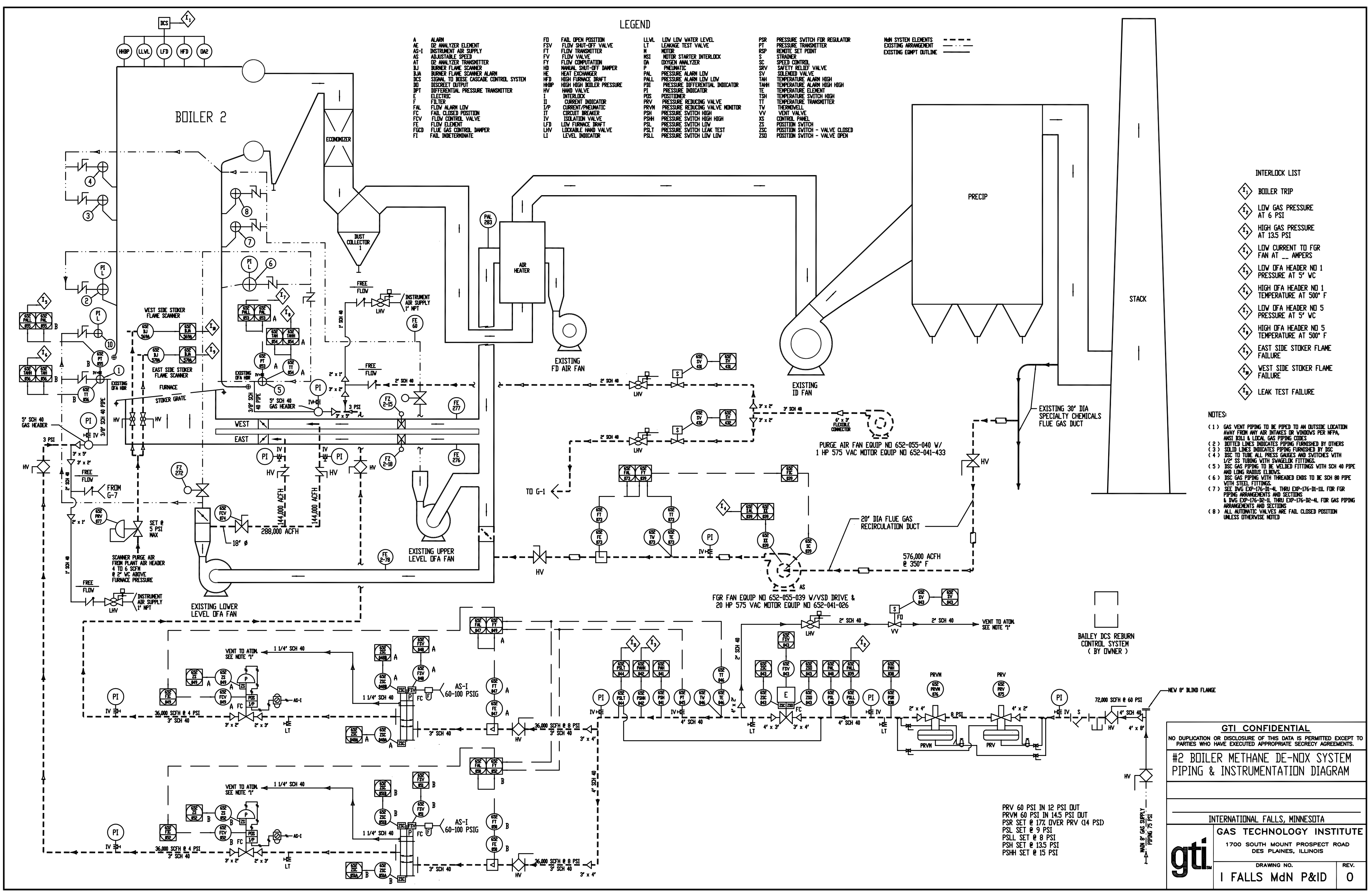




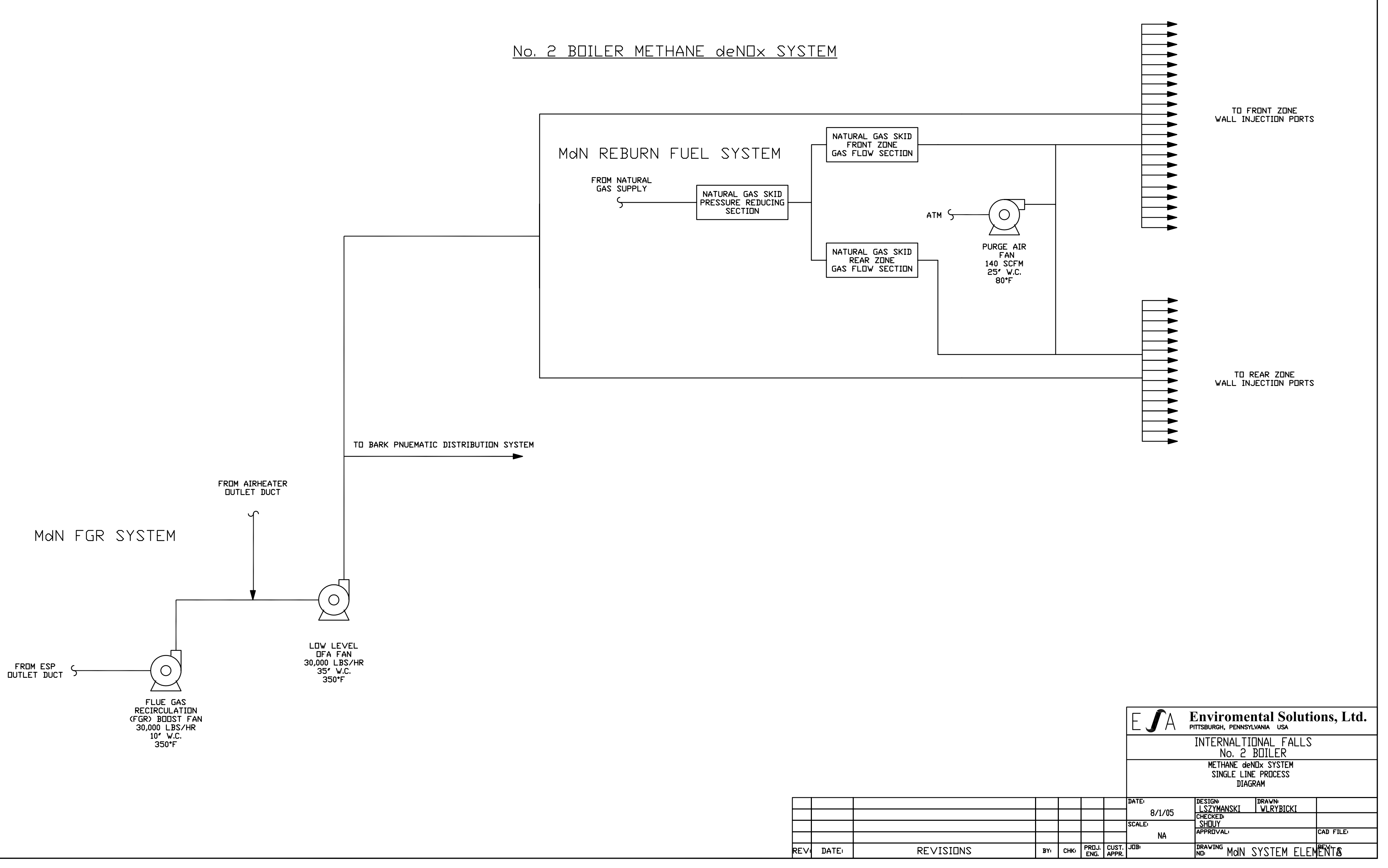




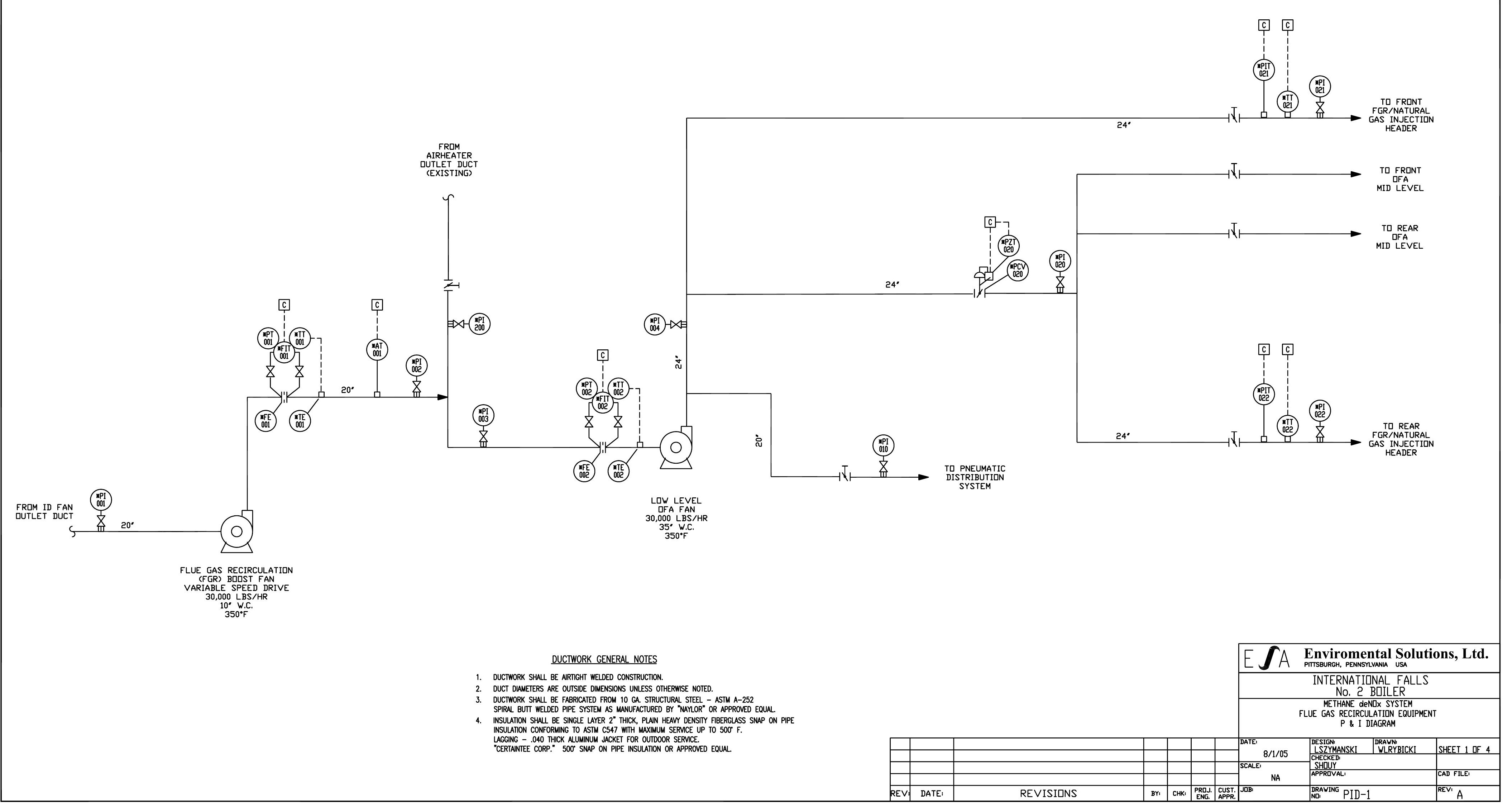




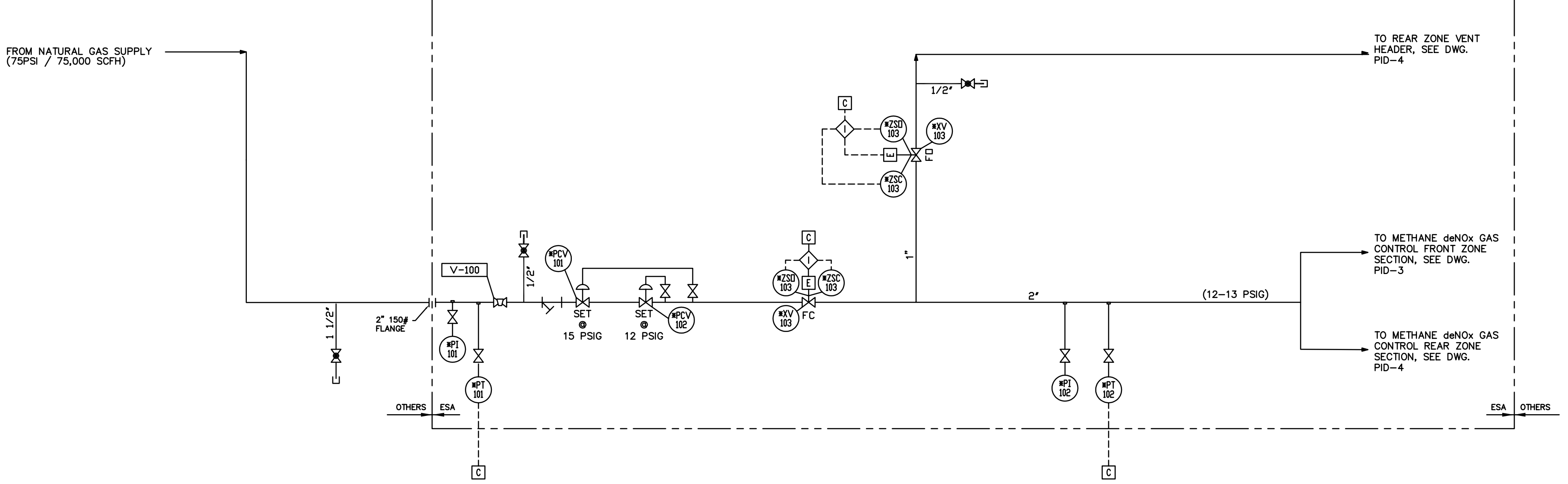

PIPING GENERAL NOTES

1. AL PPMNG PER ASME B31.3 COOE

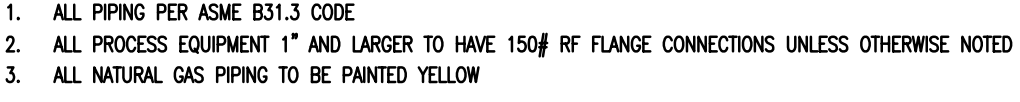

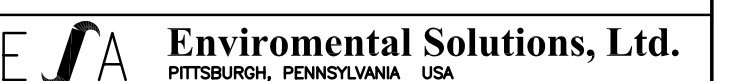
INTERNATIONAL FALLS

No. 2 BDILER
METHANE deNDX SYSTEM

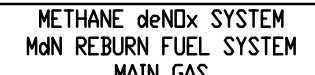

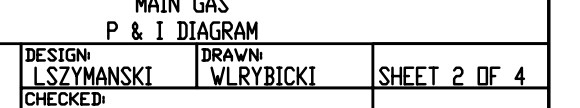

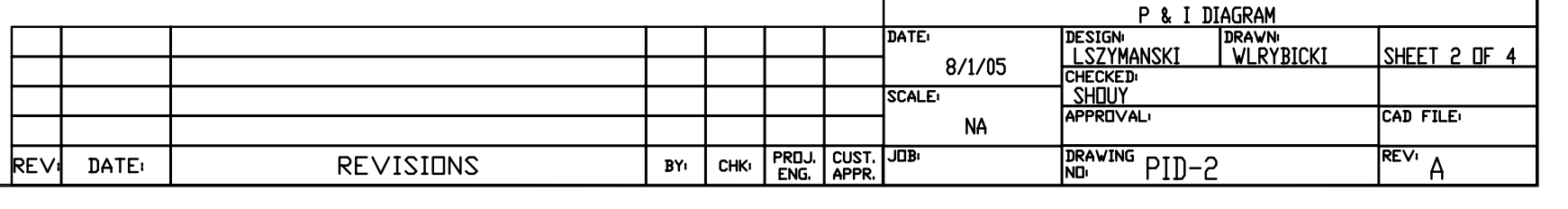




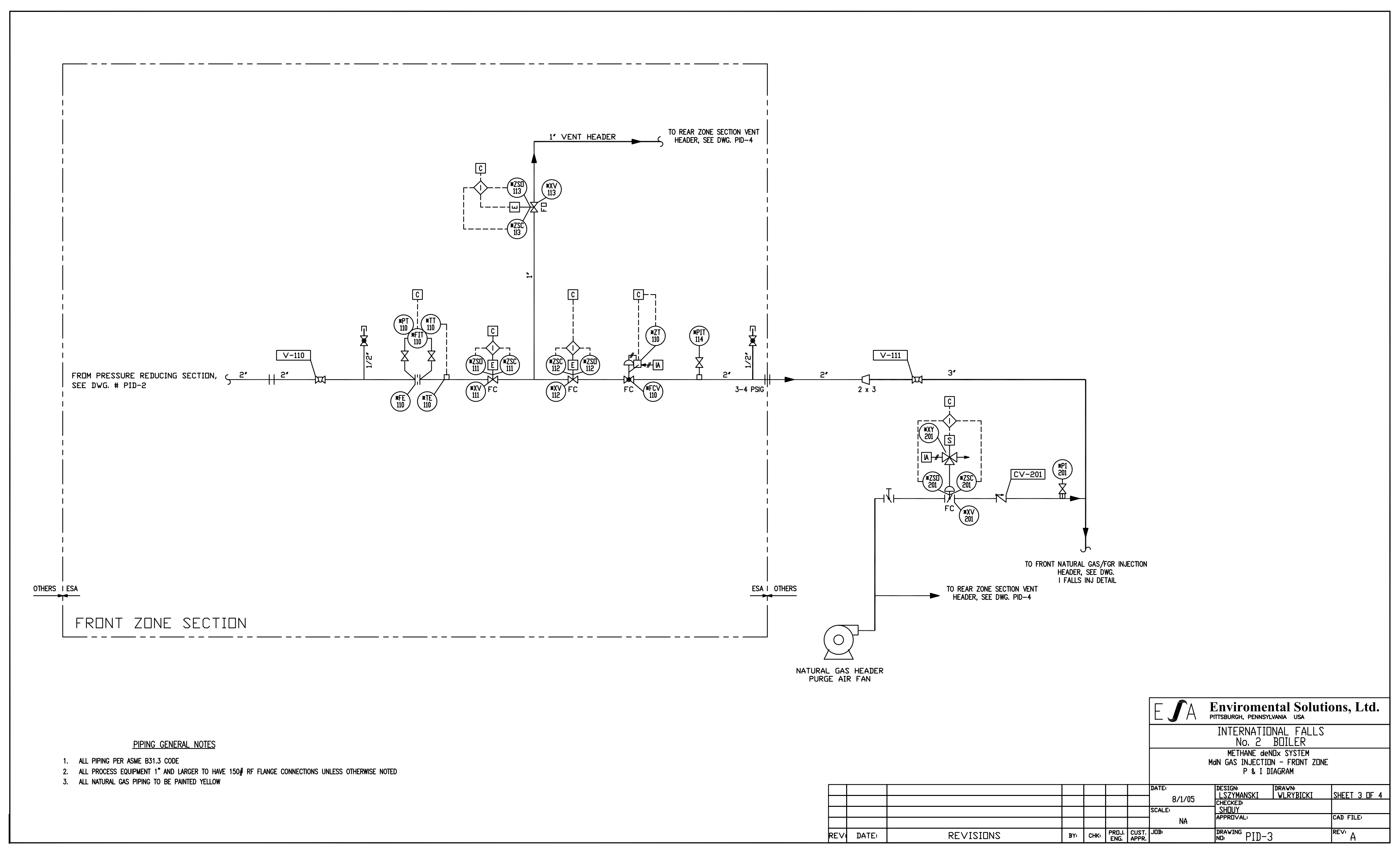




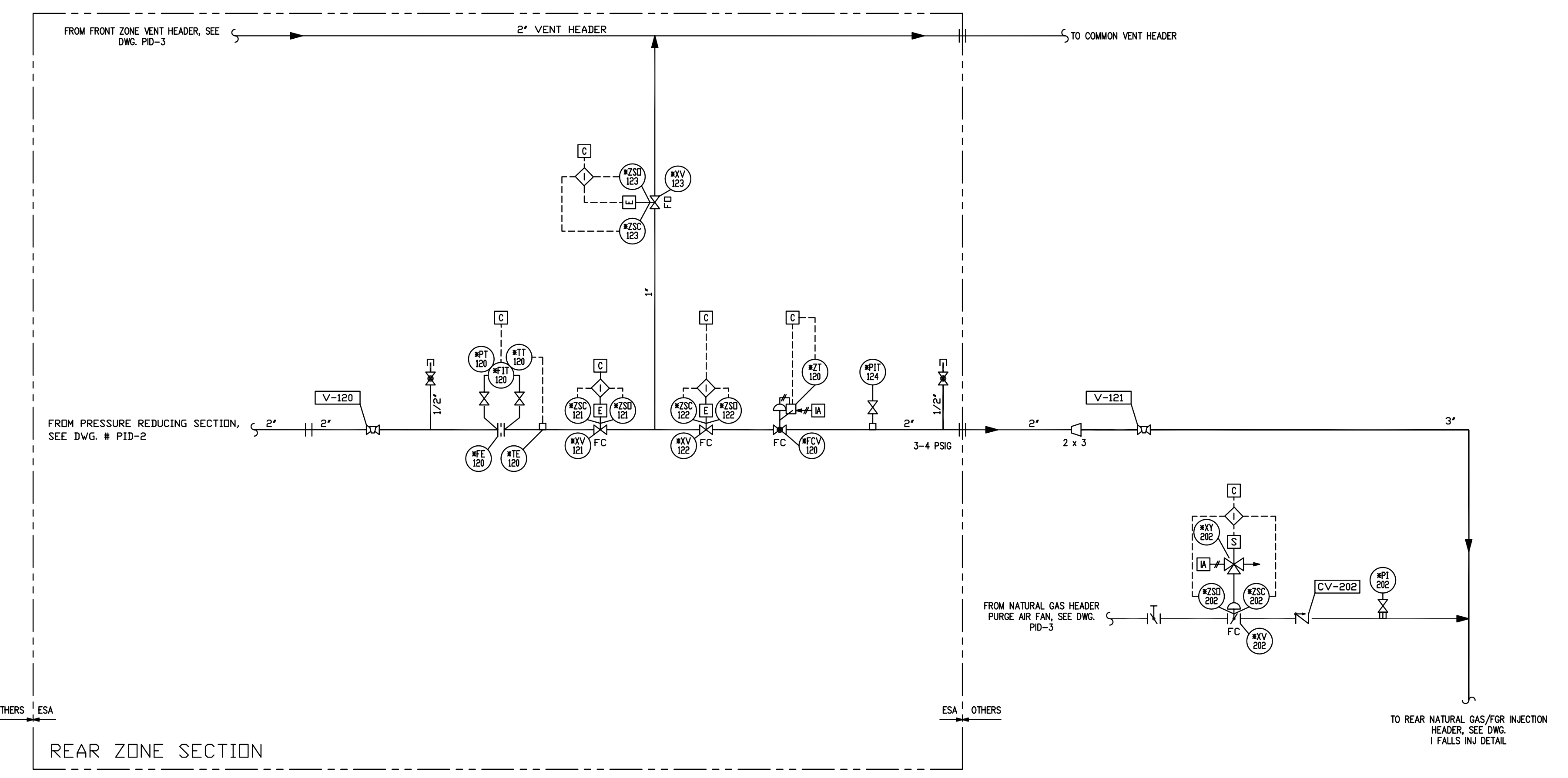

PIPING GENERAL NOTES

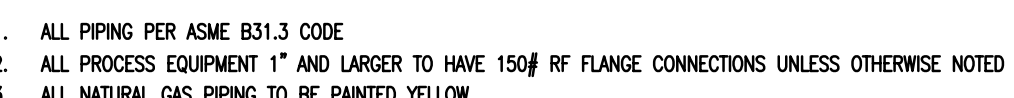

E $\int A$ Anviromental Solutions, Ltd.

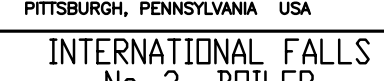

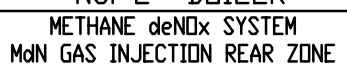
P\& I DIGGRAM

\begin{tabular}{|c|c|c|c|c|c|c|c|c|}
\hline & & & & & & $f^{\text {DATE! }}$ & 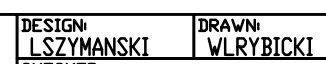 & SHEET 4 OF 4 \\
\hline & & 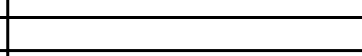 & & & & SCALE! & 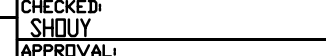 & CAD FIEFE \\
\hline REV & DATE: & REVISIONS & $\mathrm{Br}_{1}$ & \begin{tabular}{|c|c|c|} 
CHKi & $P_{E}$ \\
$E$
\end{tabular} & PROJ. CUST. & & DRAGING PID- 4 & $\frac{R^{2} V_{1}}{A} A$ \\
\hline
\end{tabular}




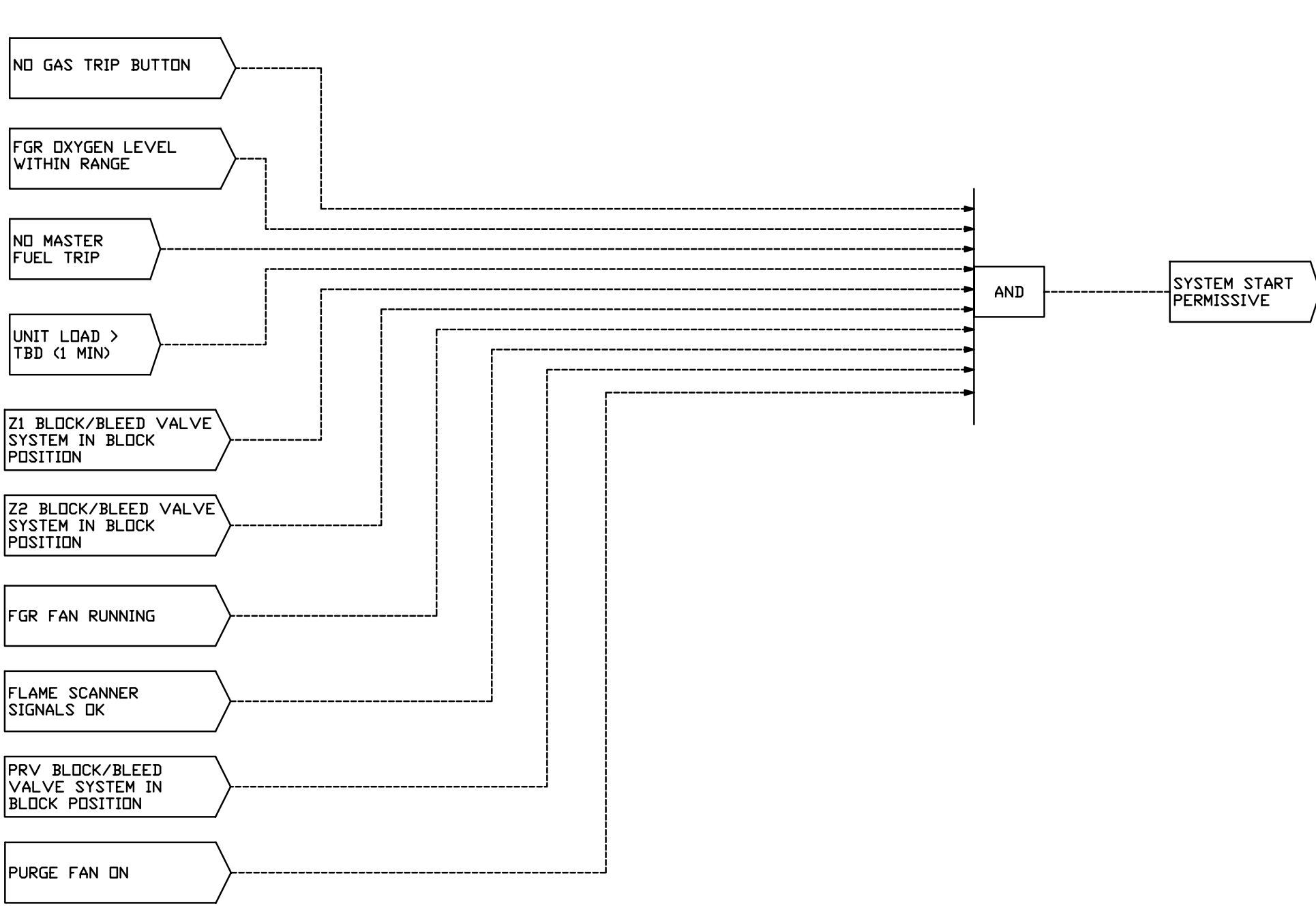

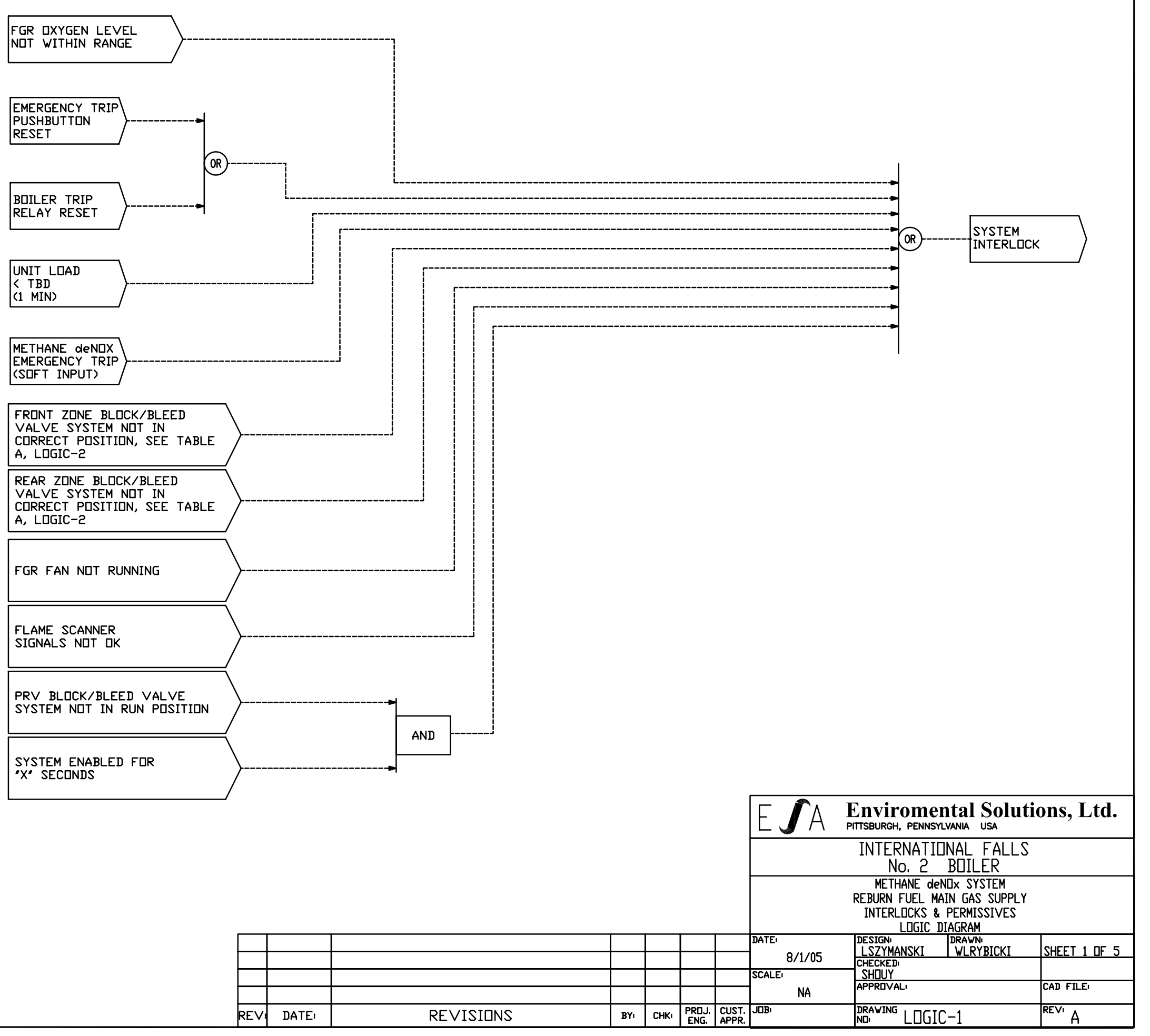



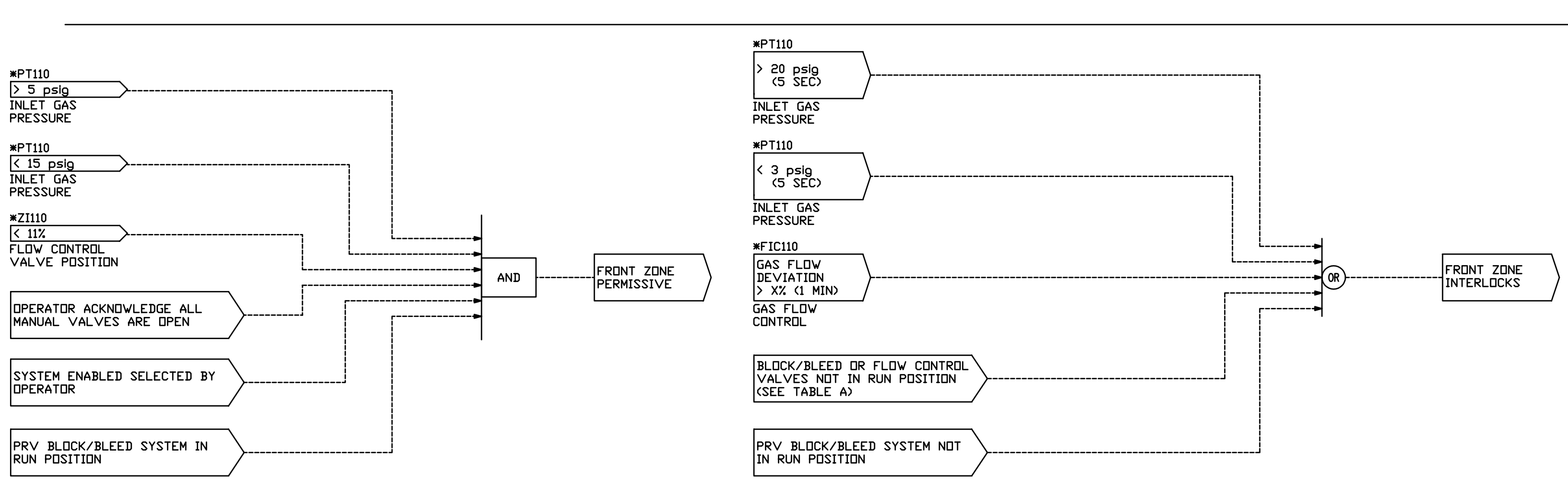

MIELD
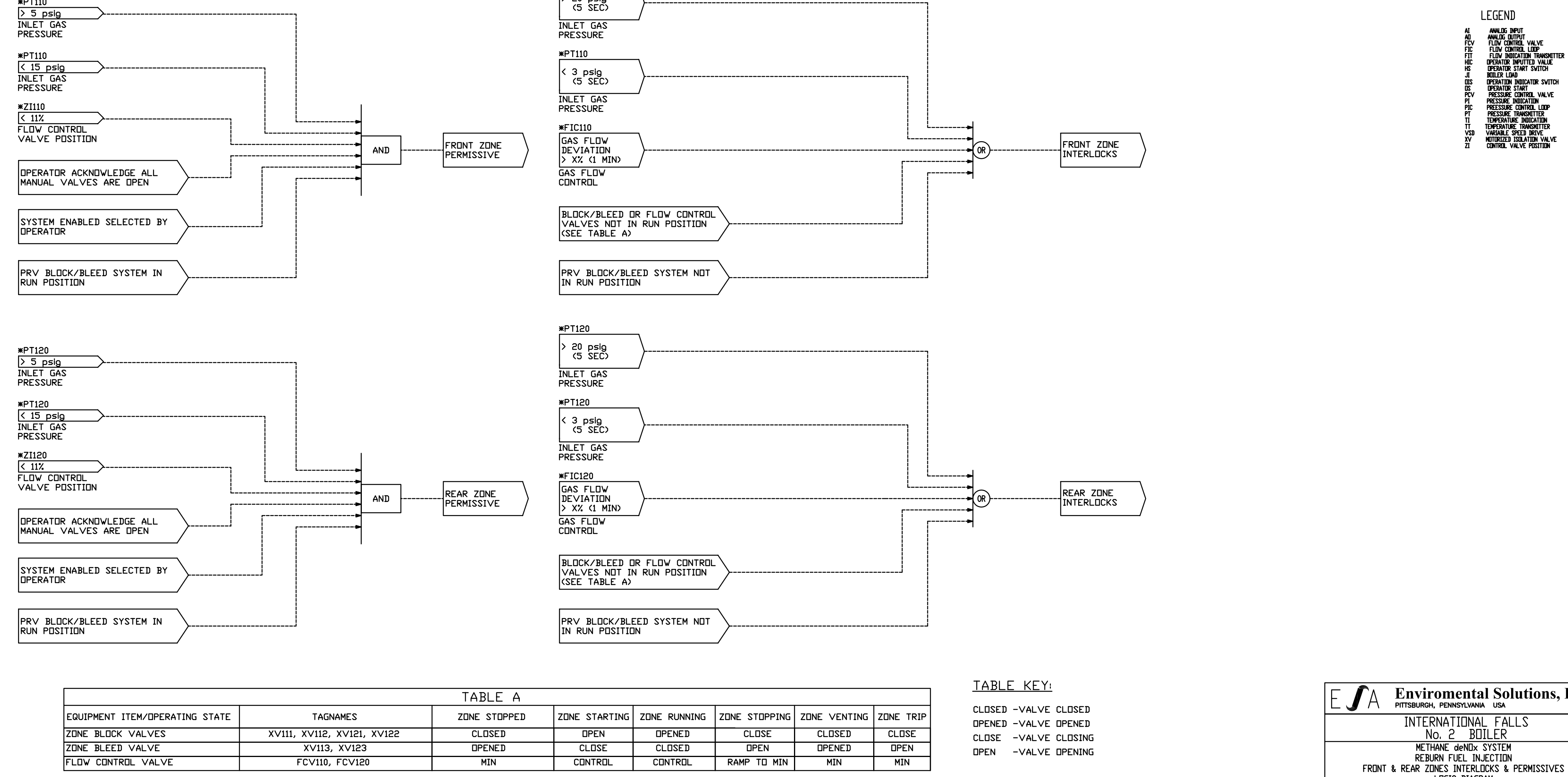

TABLE KEY:

CLOSED -VALVE CLOSED

DPENED - VALVE DPENED

$\begin{array}{ll}\text { CLDSE } & \text {-VALVE CLDSING } \\ \text { DPEN } & \text {-VALVE DPENING }\end{array}$
E $\boldsymbol{\int} A$ Enviromental Solutions, Ltd. INERENATIDNL FALLS METHANE deNDC SSSTEM REBURN FUEL INJECTION
RONT \& REAR ZDNES INTER DOCKS \& PERMISSIVES

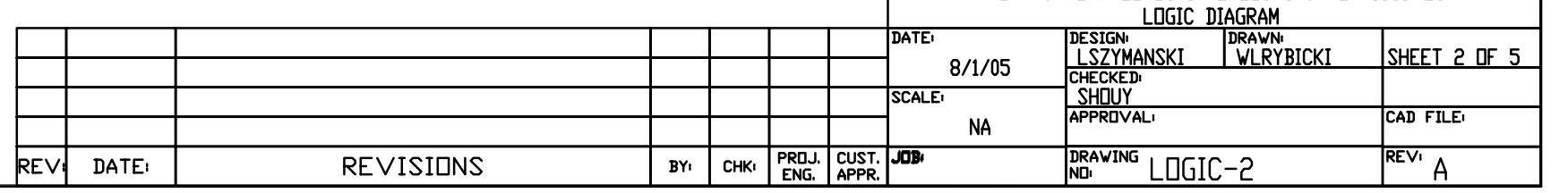




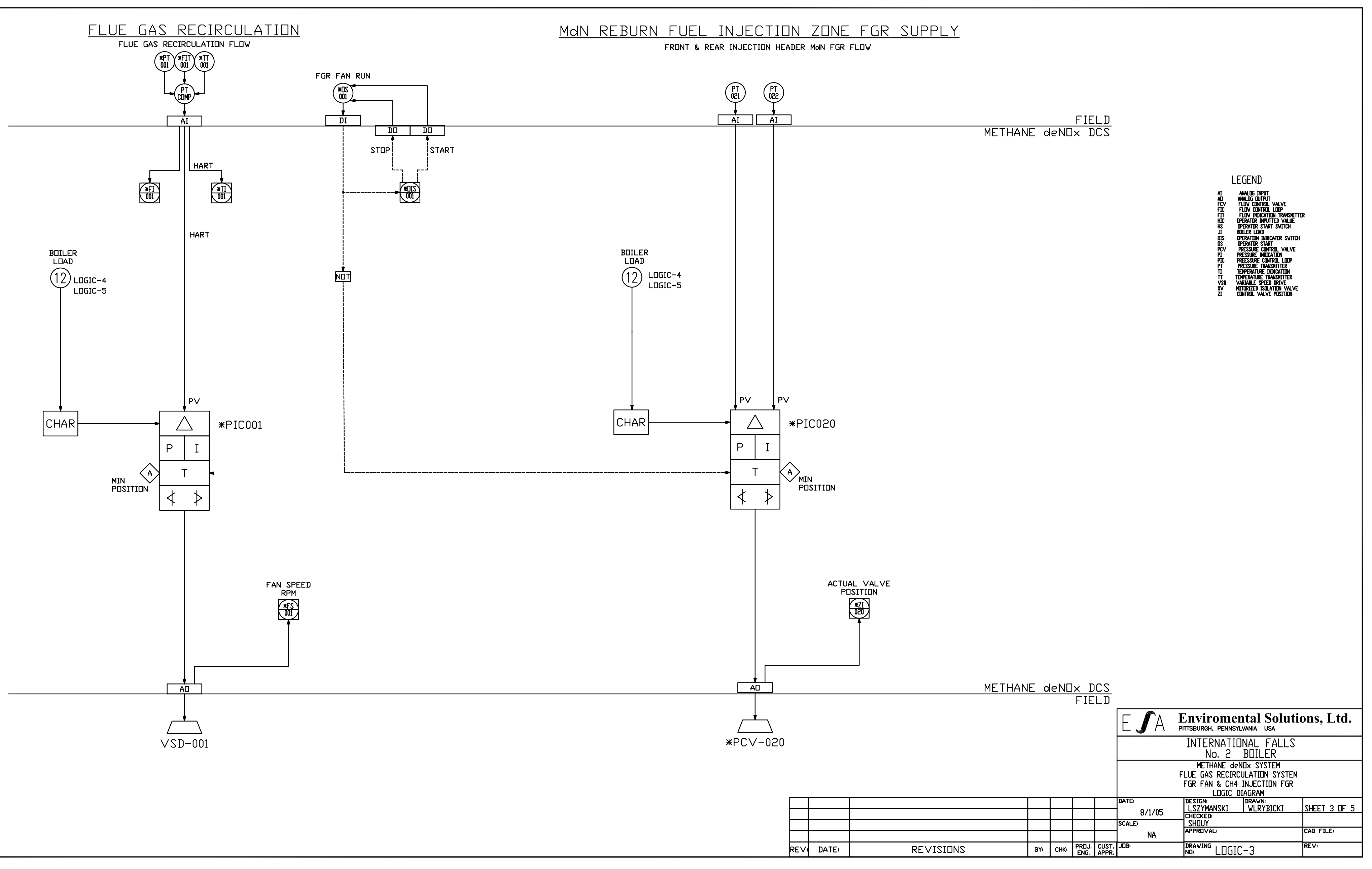




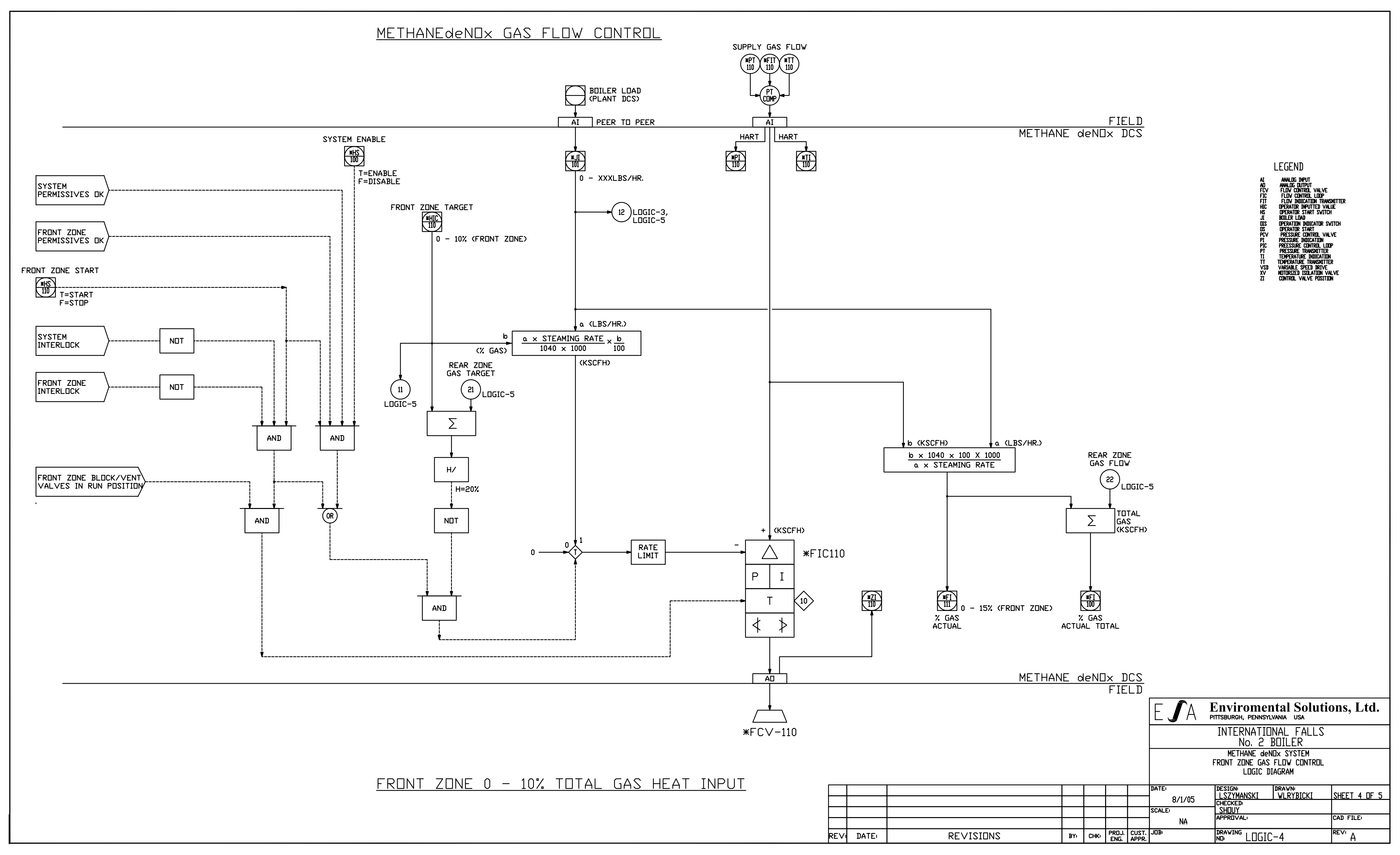




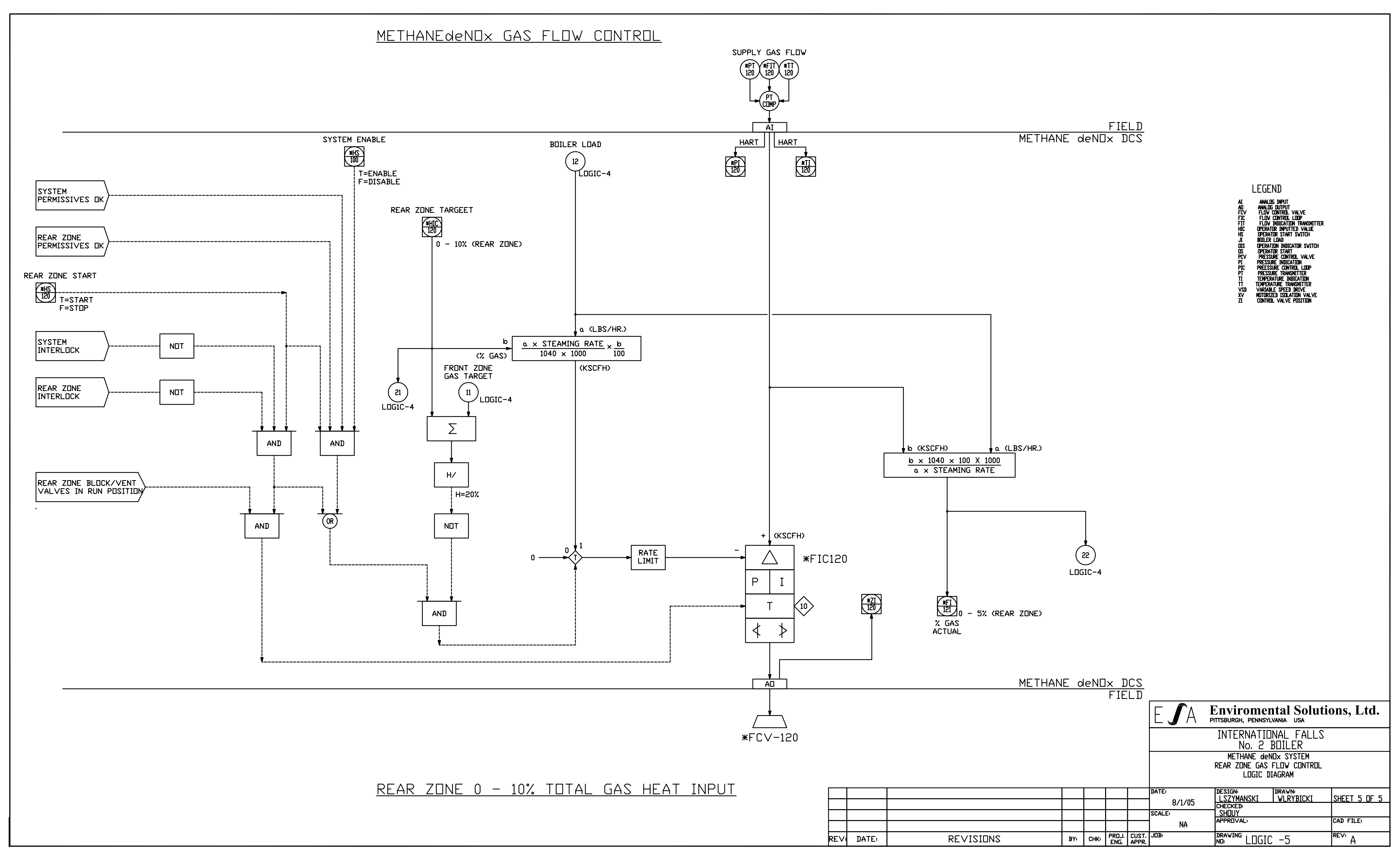




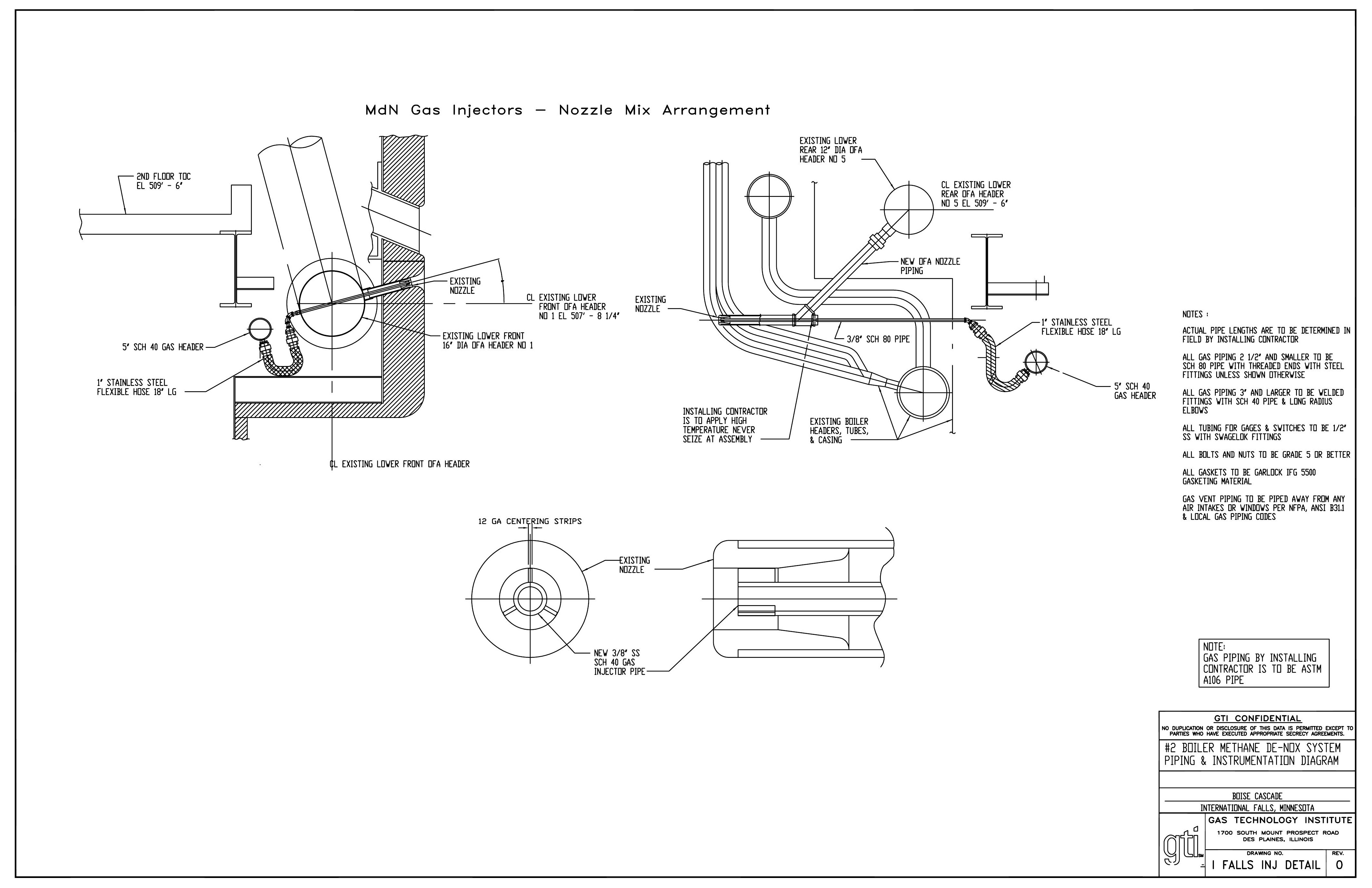




\subsubsection{International Falls MdN System Equipment Specifications}

Table 7-2 I Falls - MdN Design Specification Index

\begin{tabular}{|c|c|}
\hline Specification \# & Specification Description \\
\hline \multicolumn{2}{|l|}{ Rotating Equipment } \\
\hline FGR-FAN & FGR Supply Fan \\
\hline \multicolumn{2}{|l|}{ Instrumentation: Flow Transmitters } \\
\hline FGR-FIT & Mass Flow Transmitters for FGR System \\
\hline CH4-FIT & Flow Transmitters for Methane Supply Zones \\
\hline \multicolumn{2}{|l|}{ Instrumentation: Pressure } \\
\hline FGR-PRESS & Pressure Transmitters for FGR System \\
\hline CH4-PRESS-XMIT & Pressure Transmitters for Methane Supply System \\
\hline FGR-P-GAUGE & Pressure Gauges for FGR System \\
\hline CH4-PRESS & Pressure Gauges for Methane Supply System \\
\hline \multicolumn{2}{|l|}{ Instrumentation: Temperature } \\
\hline FIT-RTD & RTD/Thermowell for FGR Flow Transmitters \\
\hline CH4-RTD & RTD/Thermowell for Methane Flow Transmitters \\
\hline FGR-TEMP & Temperature Transmitters for FGR System \\
\hline FGR-RTD & RTD/Thermowell for Temperature Transmitters \\
\hline \multicolumn{2}{|l|}{ Instrumentation: Control Valves/Drives } \\
\hline VSD-001 & FGR Fan Motor and Variable Speed Drive \\
\hline PCV -020 & FGR Pressure Control Valve for OFA System \\
\hline FCV-110 \& -120 & Flow Control Valves for Methane Supply Zones \\
\hline \multicolumn{2}{|l|}{ Instrumentation: Dampers } \\
\hline DAMPERS & Butterfly Dampers for FGR System \\
\hline \multicolumn{2}{|l|}{ Instrumentation: Isolation Valve } \\
\hline XV-111 \& -112 & Double Block \& Bleed Isolation Valve (Front Zone) \\
\hline$X V-121 \&-122$ & Double Block \& Bleed Isolation Valve (Rear Zone) \\
\hline$X V-201 \&-202$ & Purge Air Isolation Valve \\
\hline XV-101 & Methane Supply Isolation Valve \\
\hline \multicolumn{2}{|l|}{ Instrumentation: Vent Valve } \\
\hline XV-113 \& -123 & Double Block \& Bleed Vent Valve for Zones \\
\hline XV-103 & Methane Supply Vent Valve \\
\hline \multicolumn{2}{|l|}{ Instrumentation: Hand Valve } \\
\hline $\begin{array}{l}\text { PLUG-VLV } \\
\end{array}$ & Manual Plug Valve for Methane Isolation \\
\hline \multicolumn{2}{|l|}{ Instrumentation: Regulator } \\
\hline PRESS-REG & Pressure Regulators for Methane Supply \\
\hline \multirow[t]{3}{*}{ Instrumentation: Misc. } & \\
\hline & Oxygen Analyzer for FGR System \\
\hline & Flame Scanner for MdN System \\
\hline
\end{tabular}




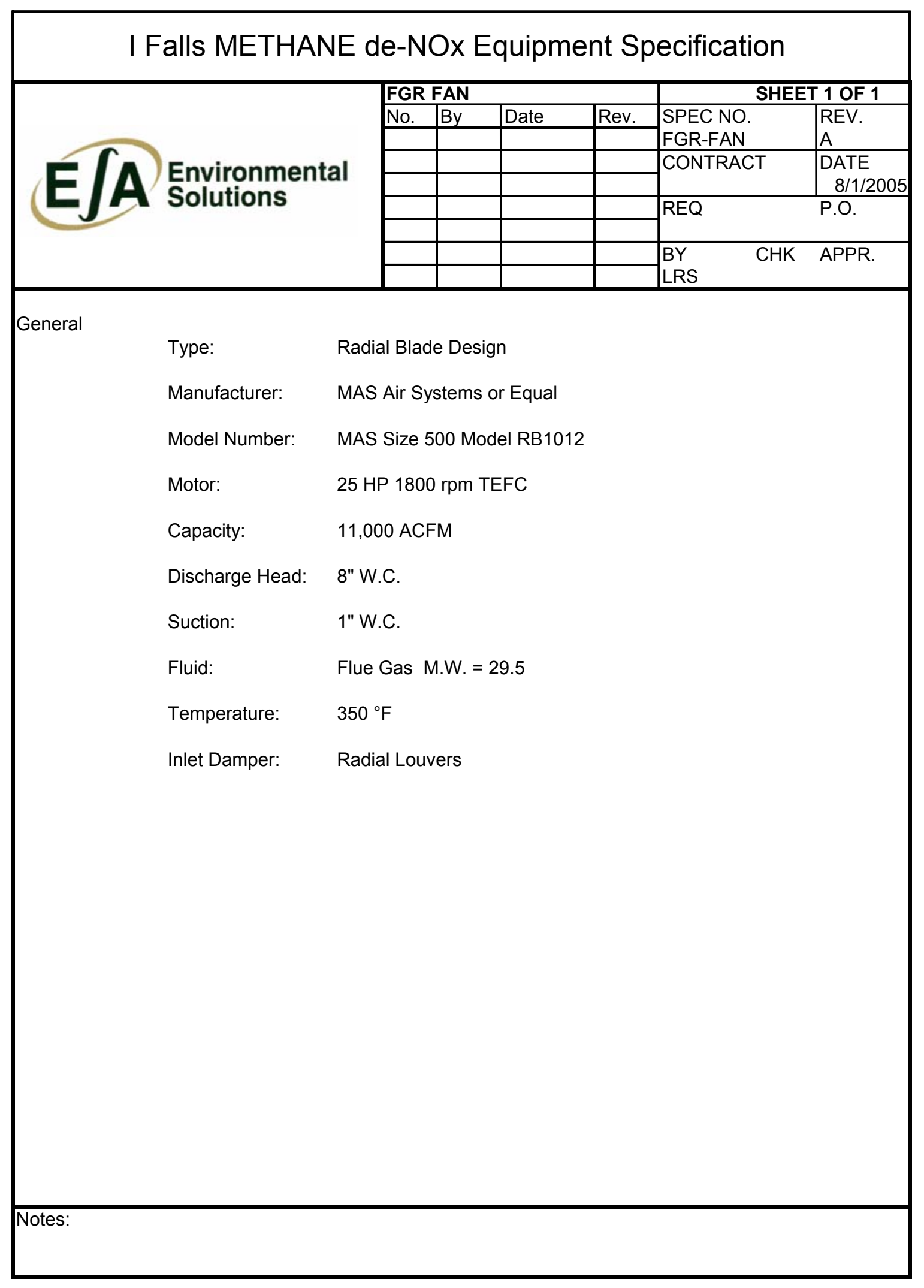




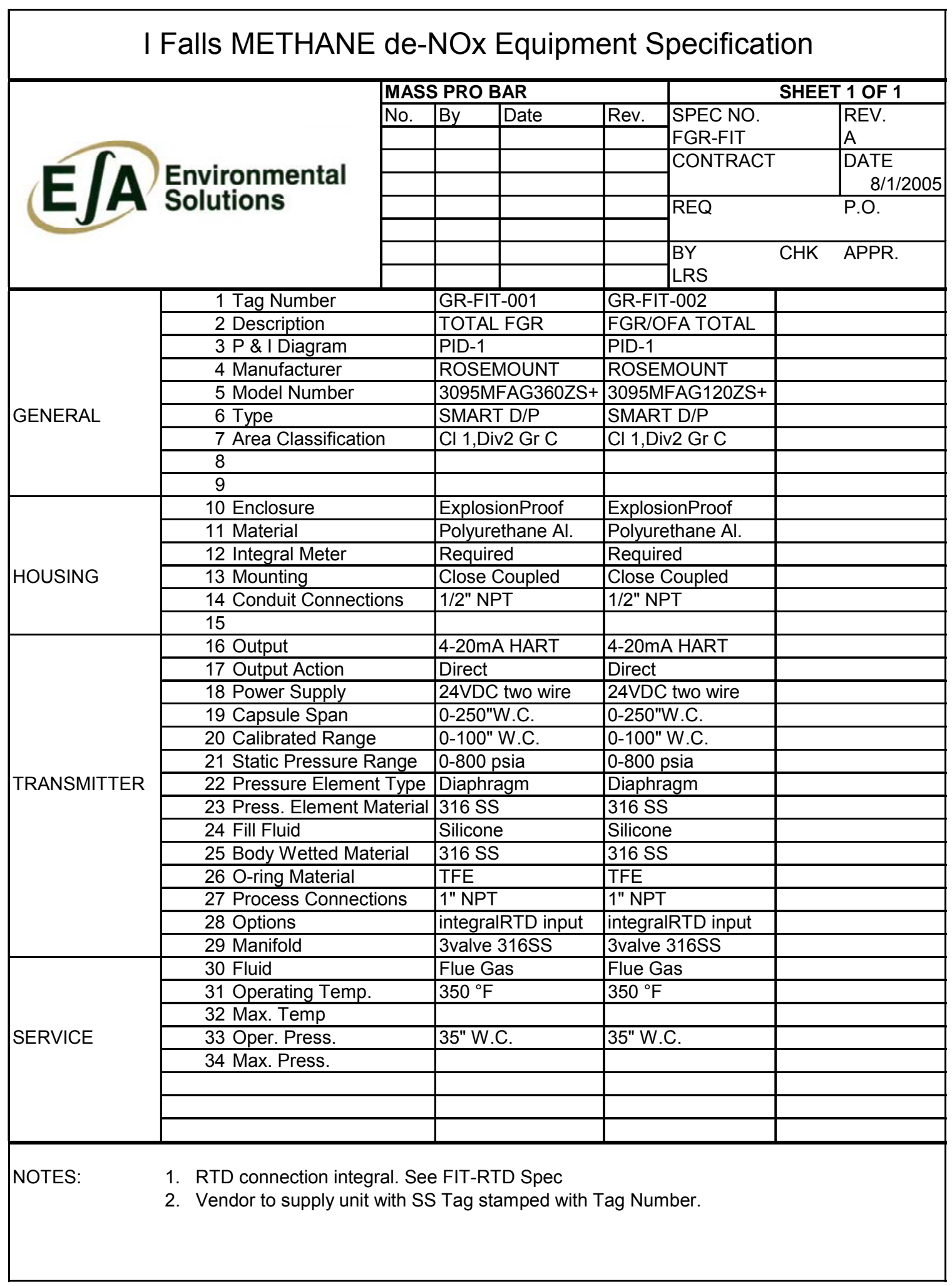




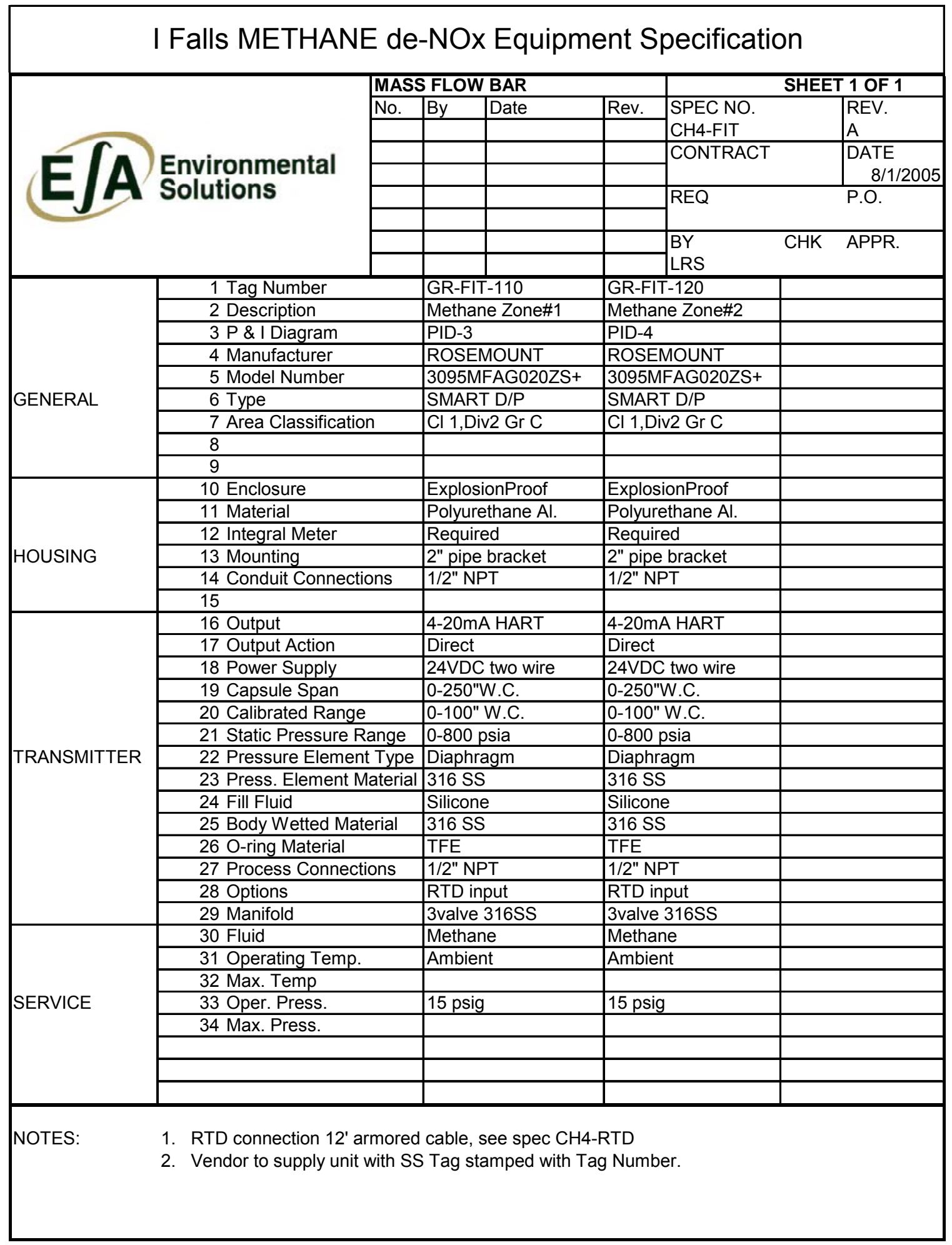




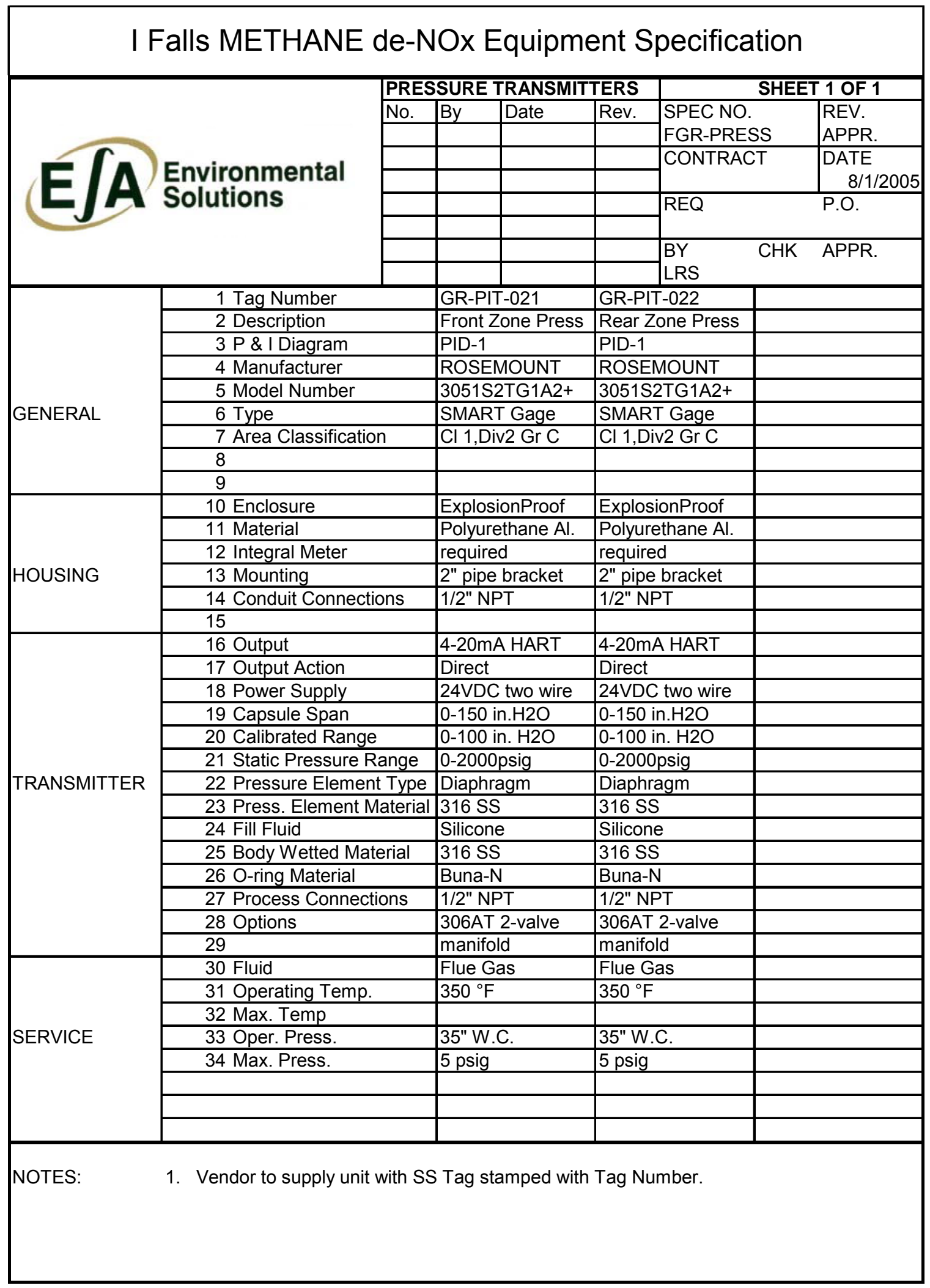




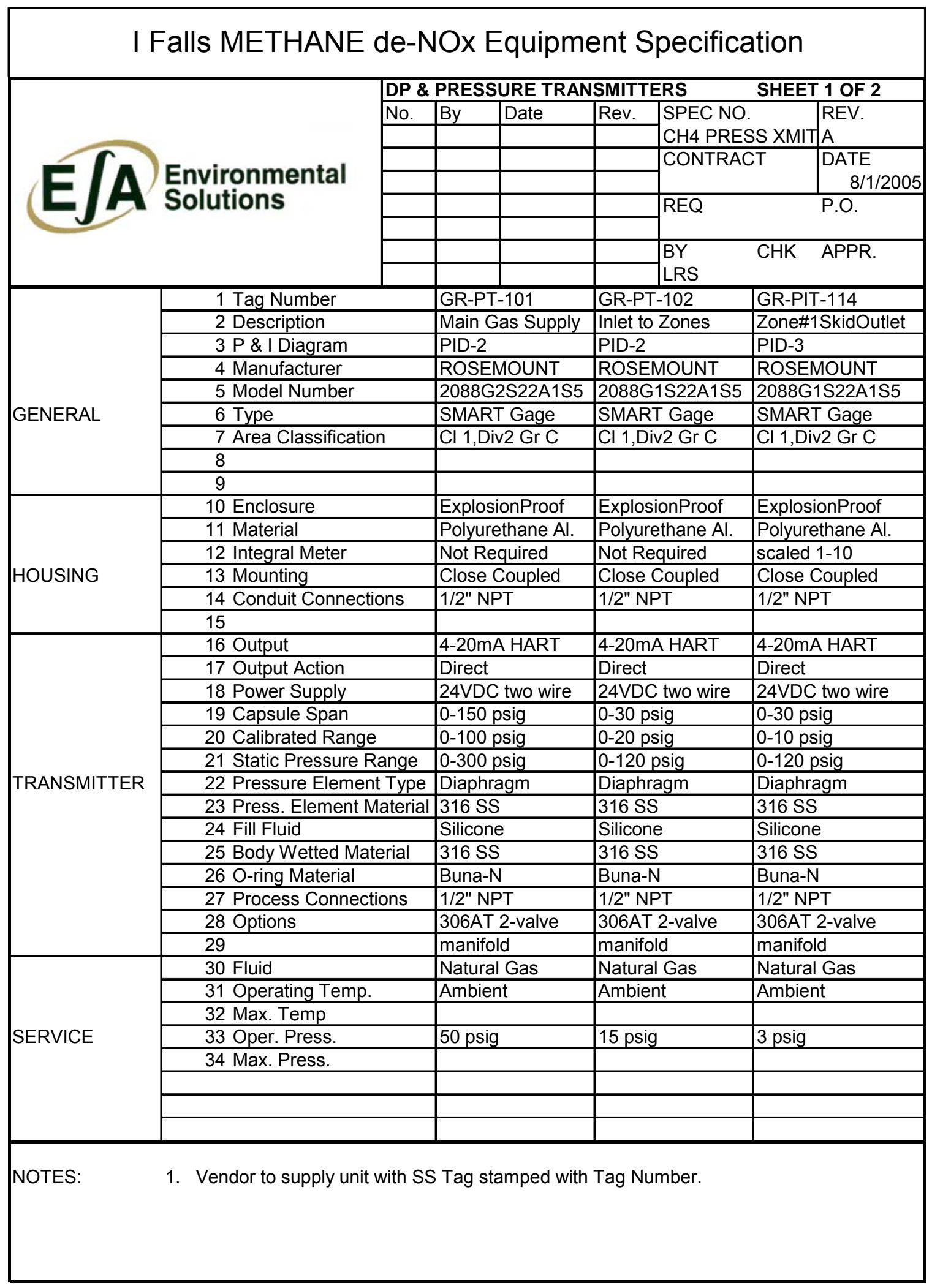




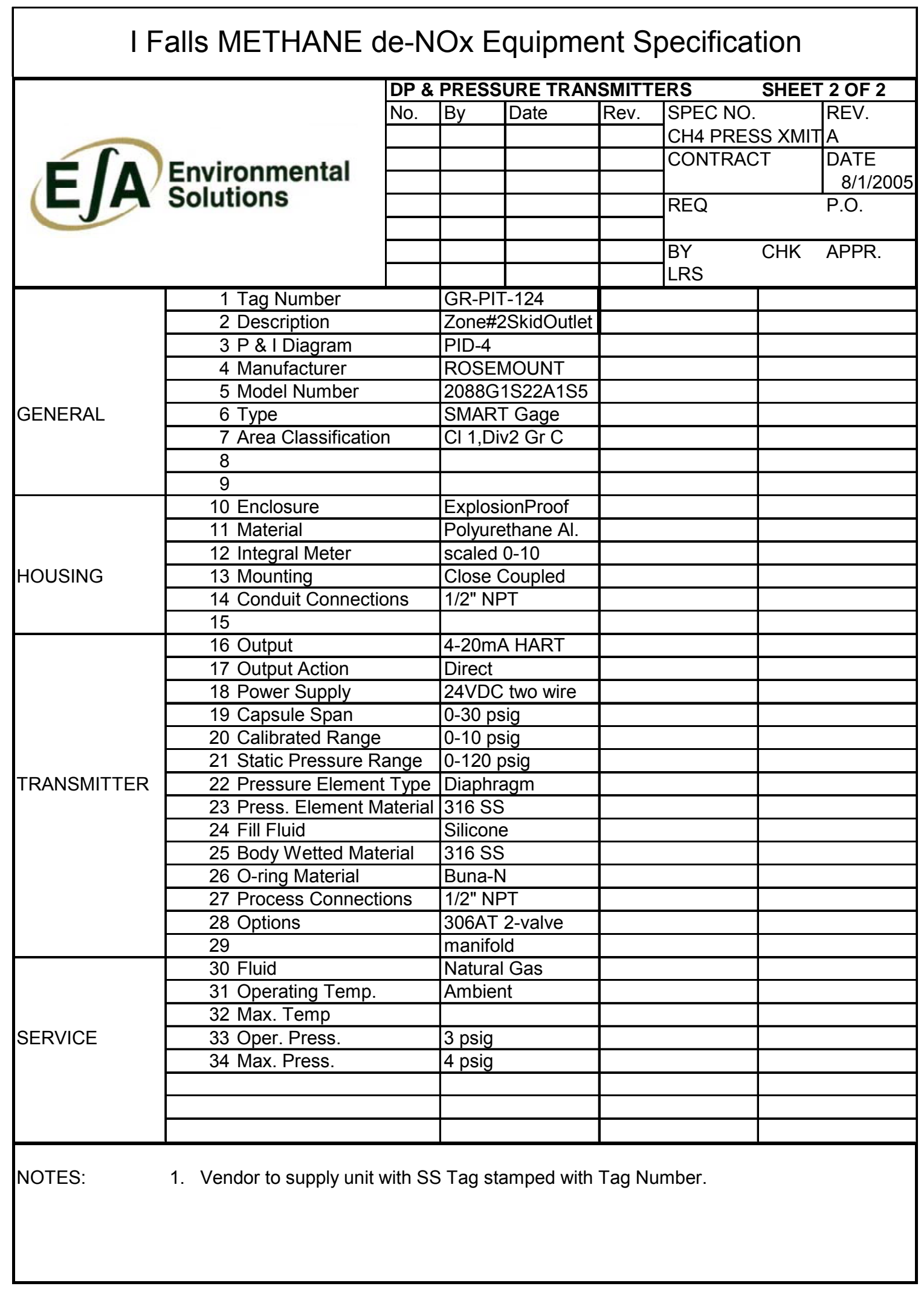




\section{Falls METHANE de-NOx Equipment Specification}

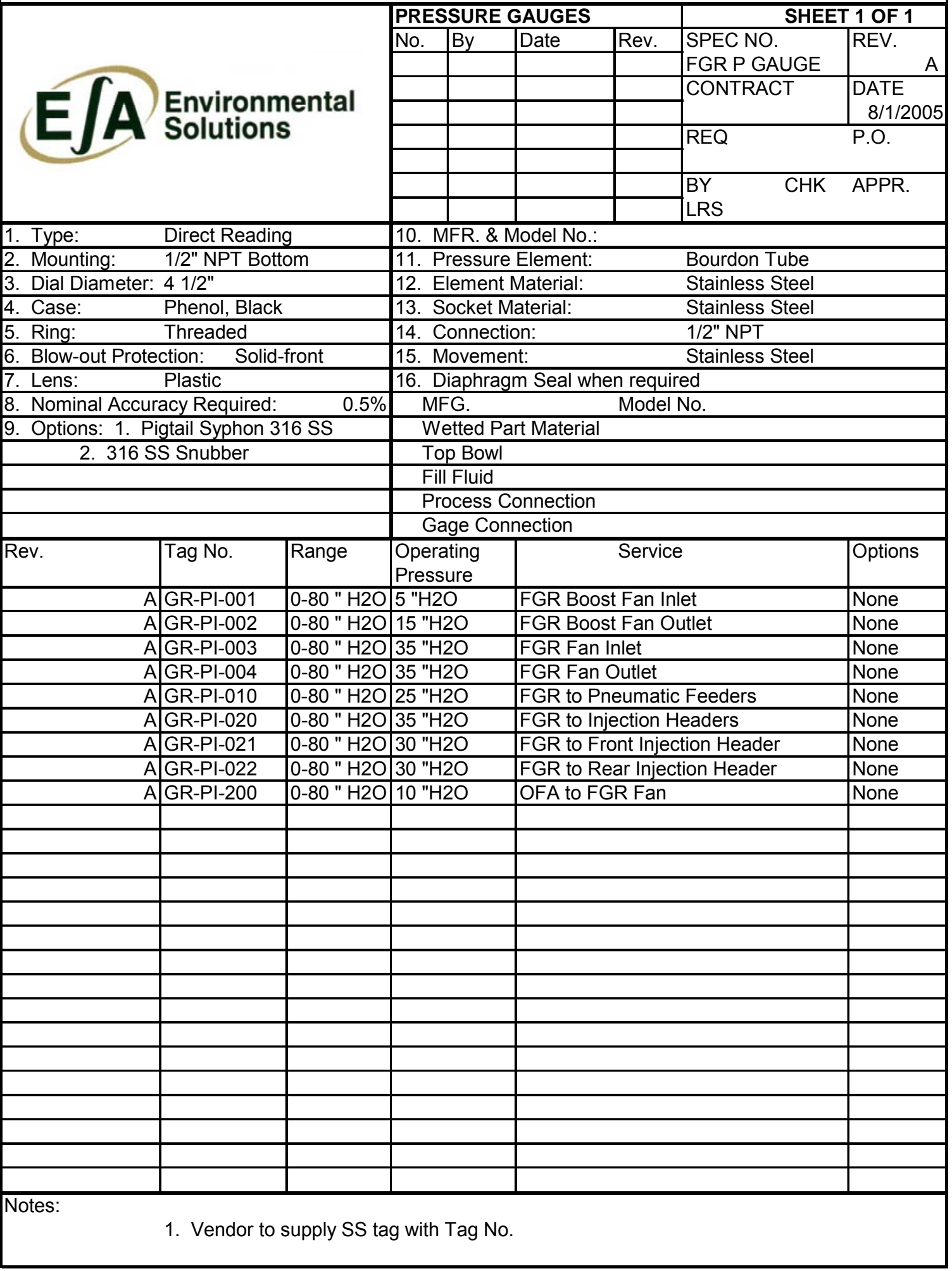




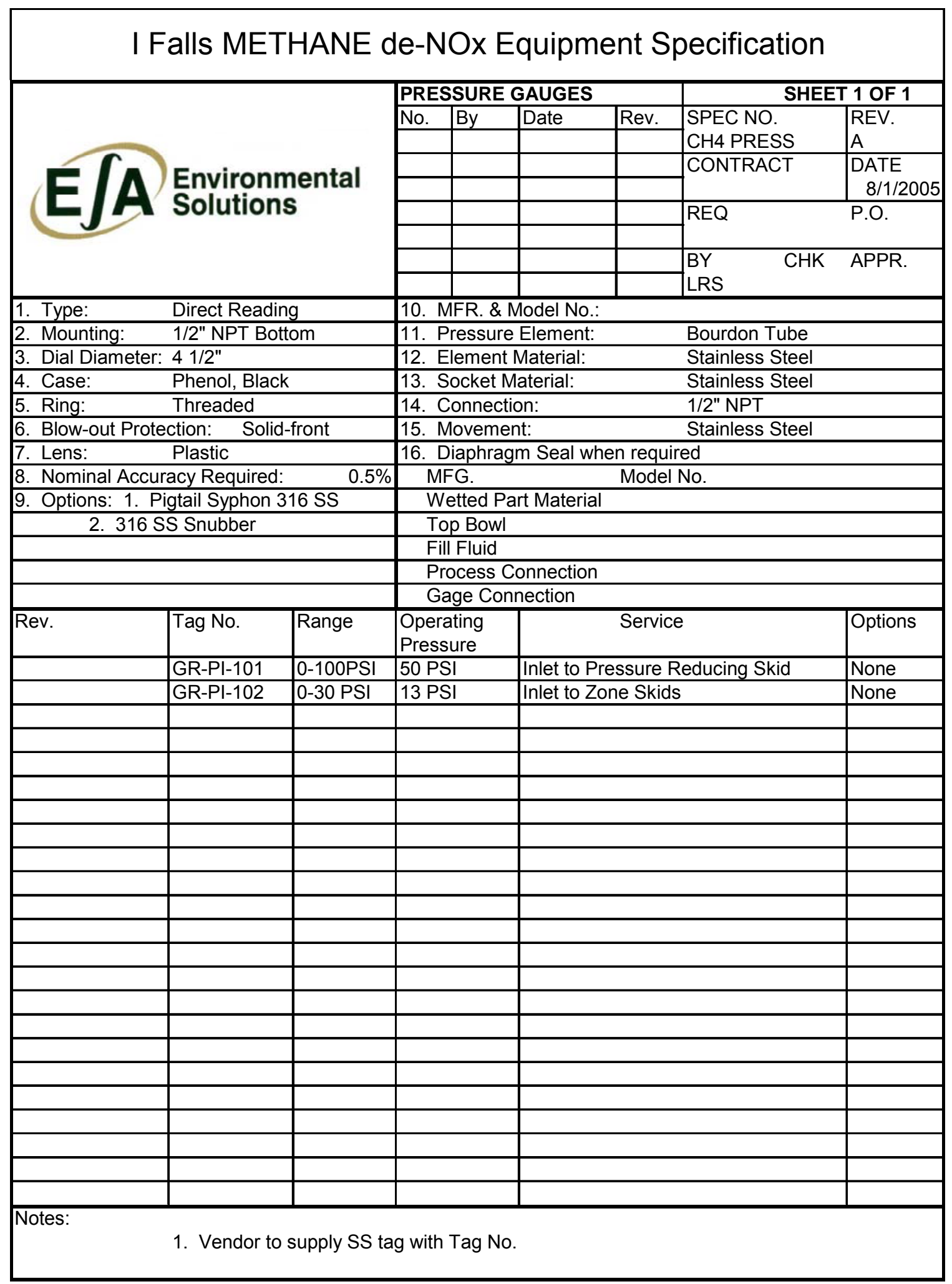




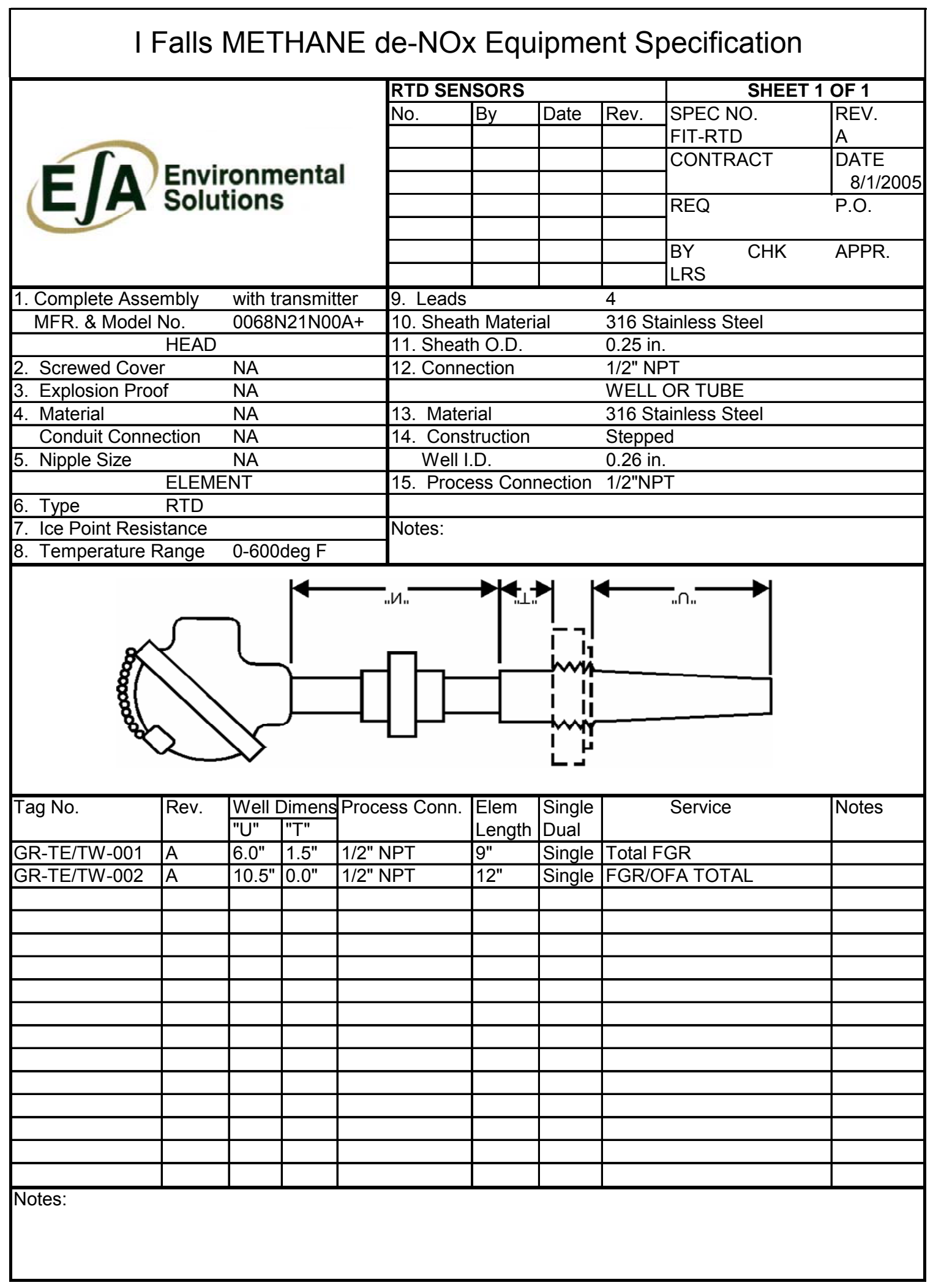




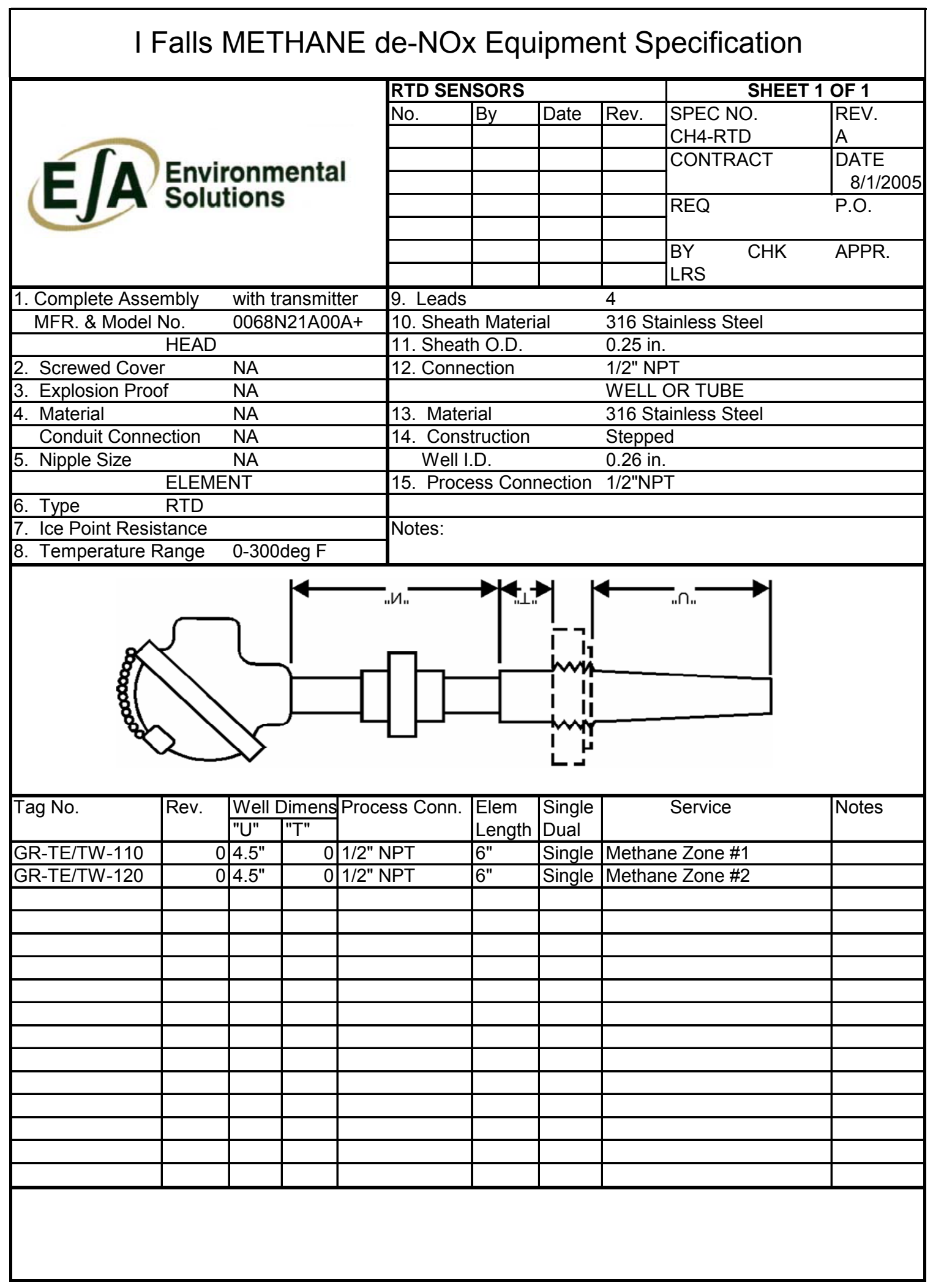




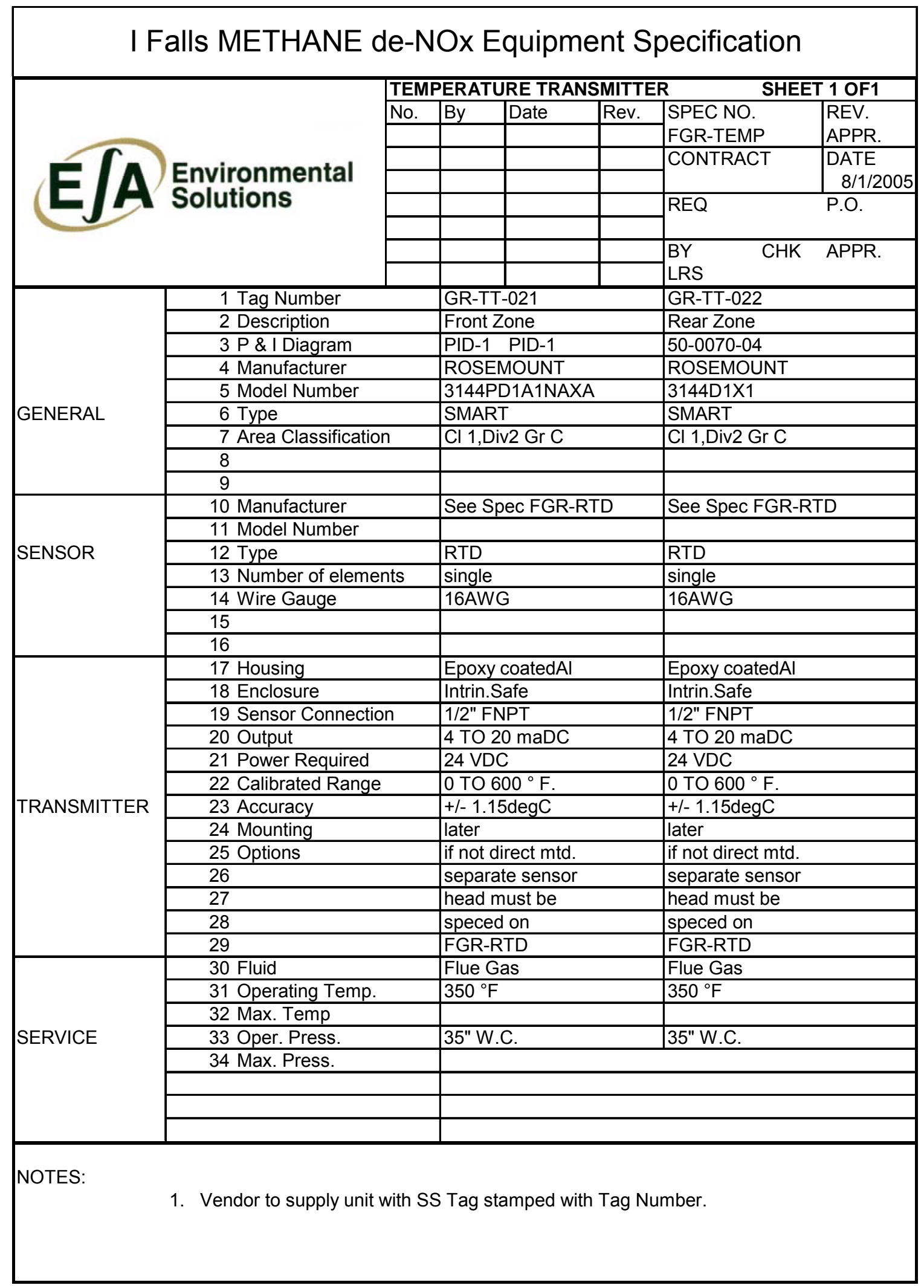




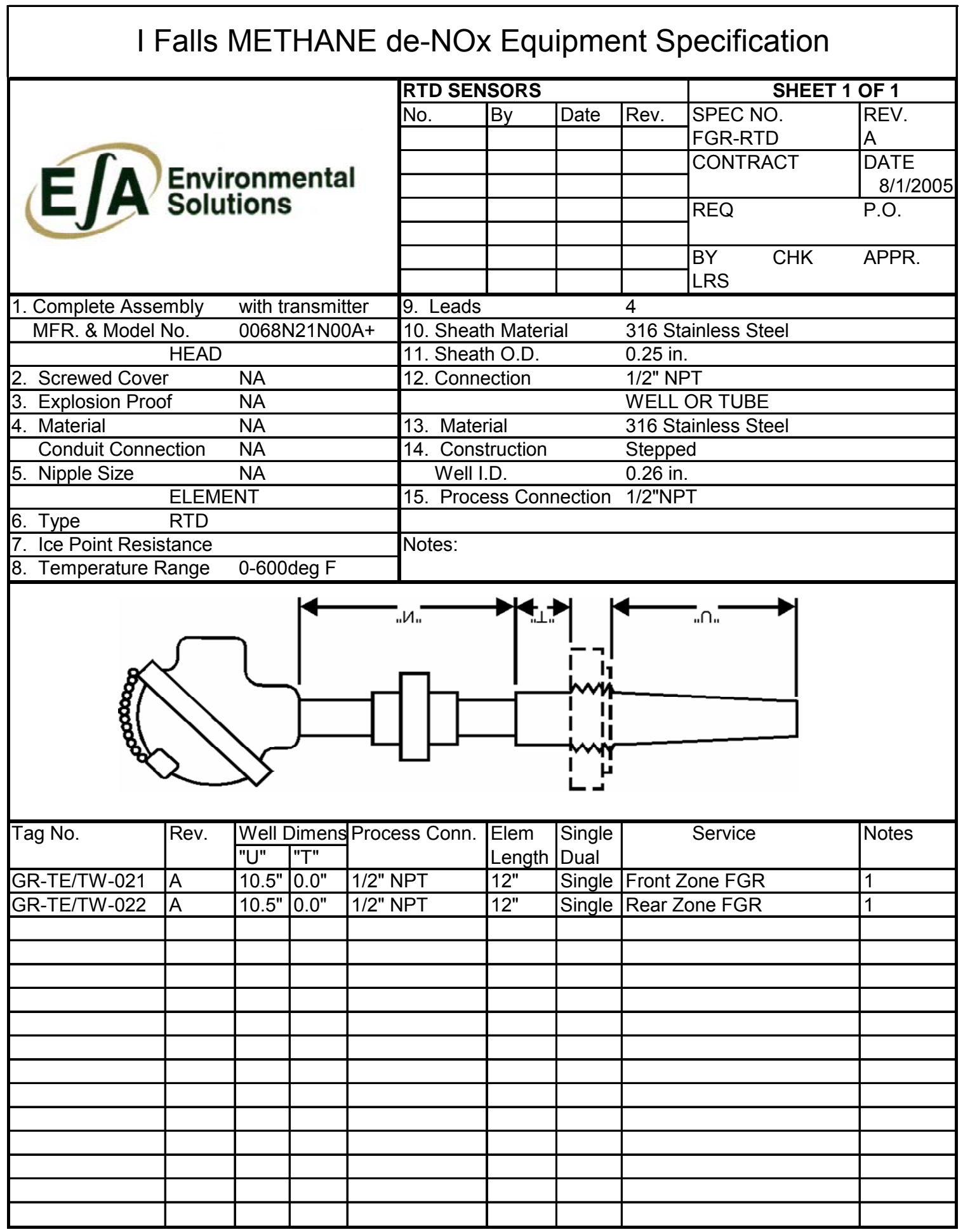




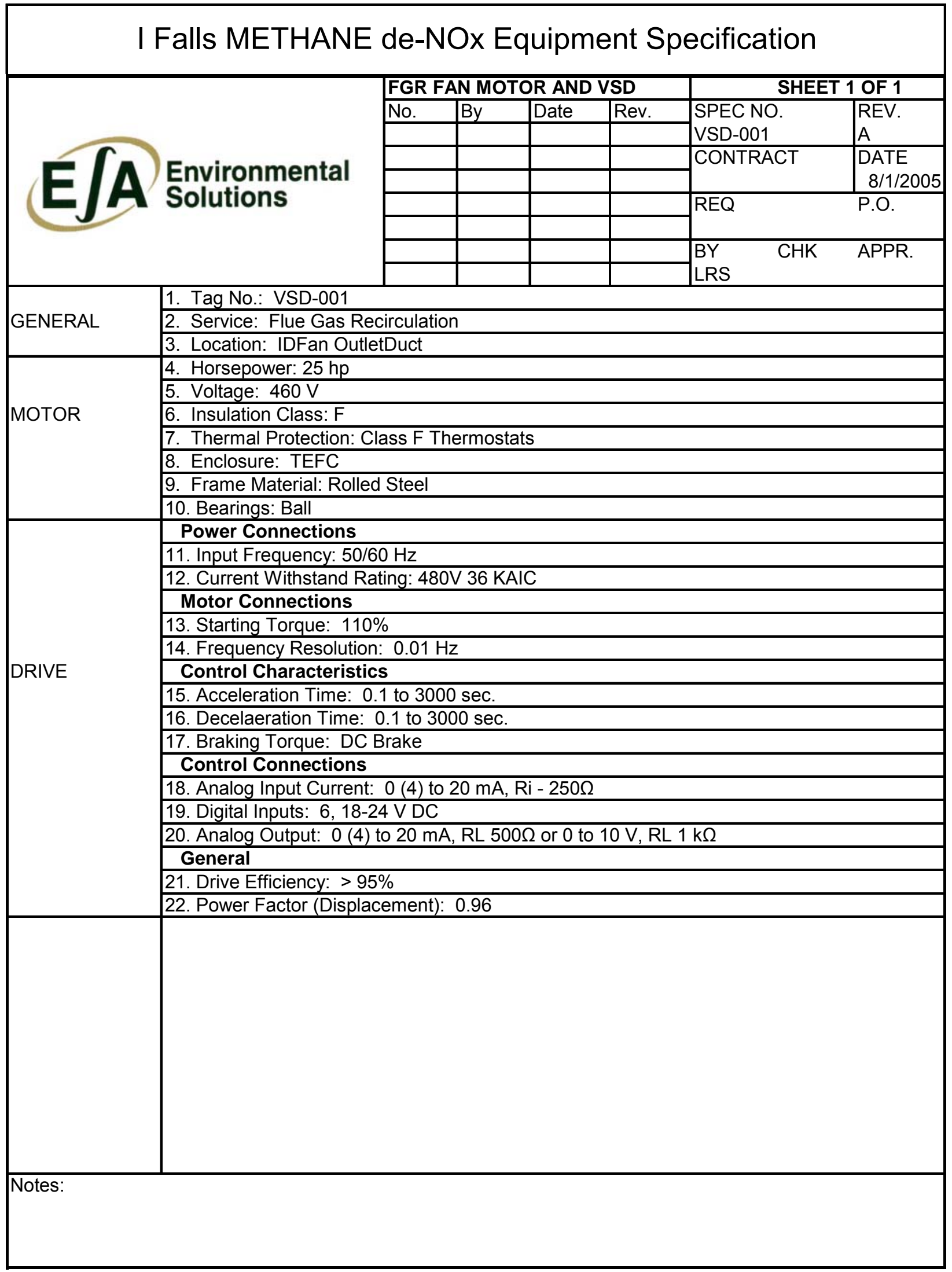




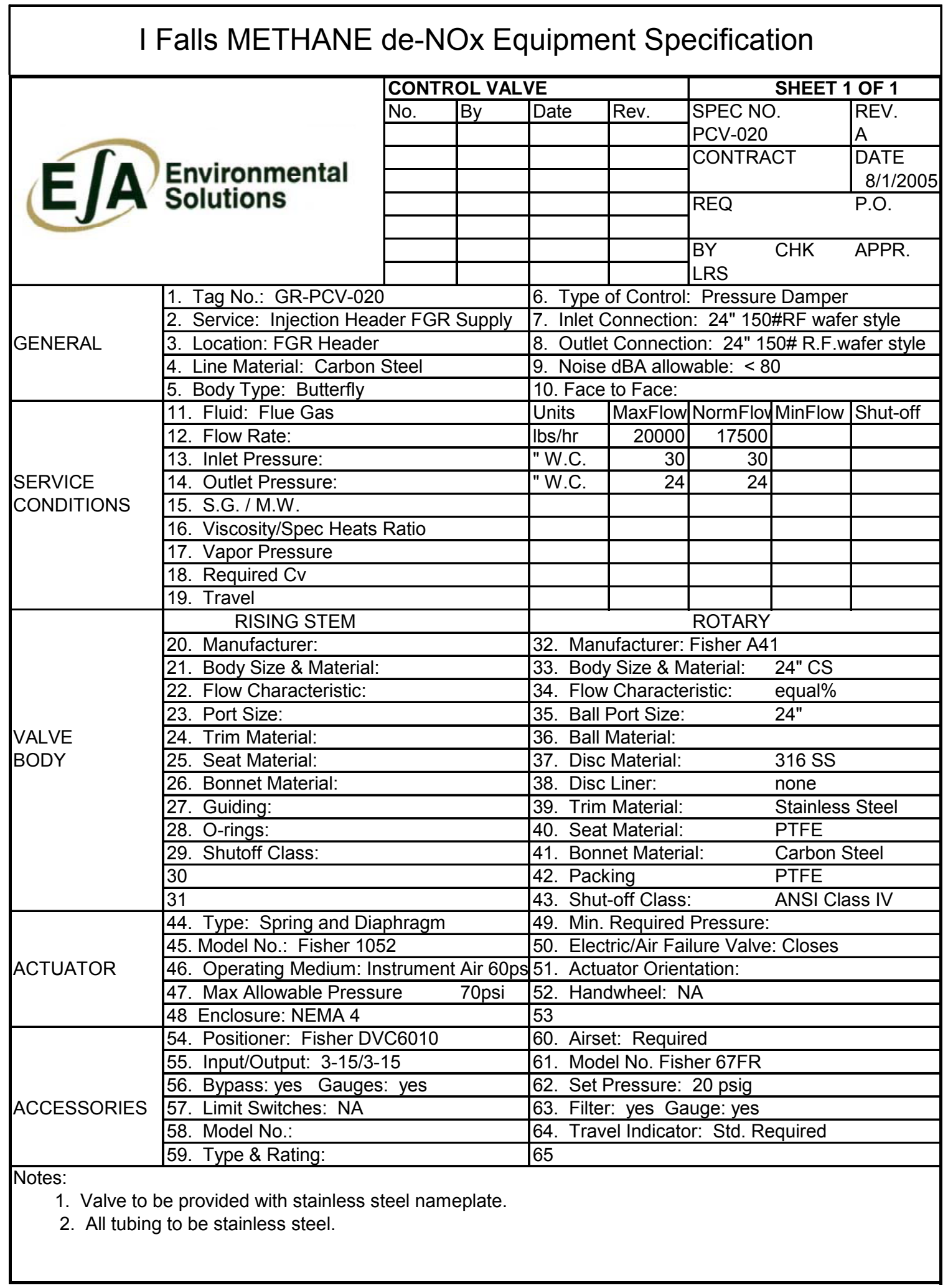




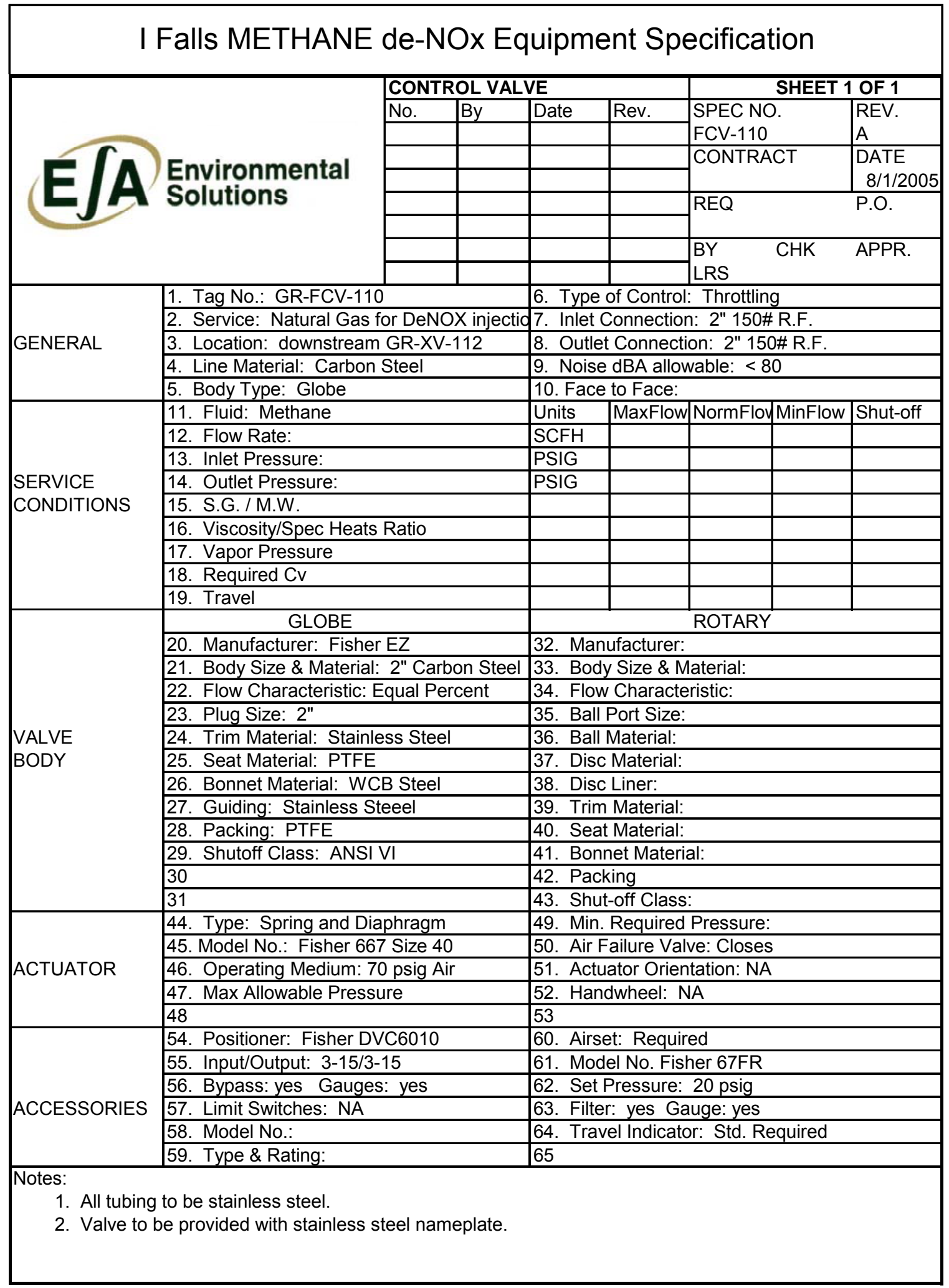




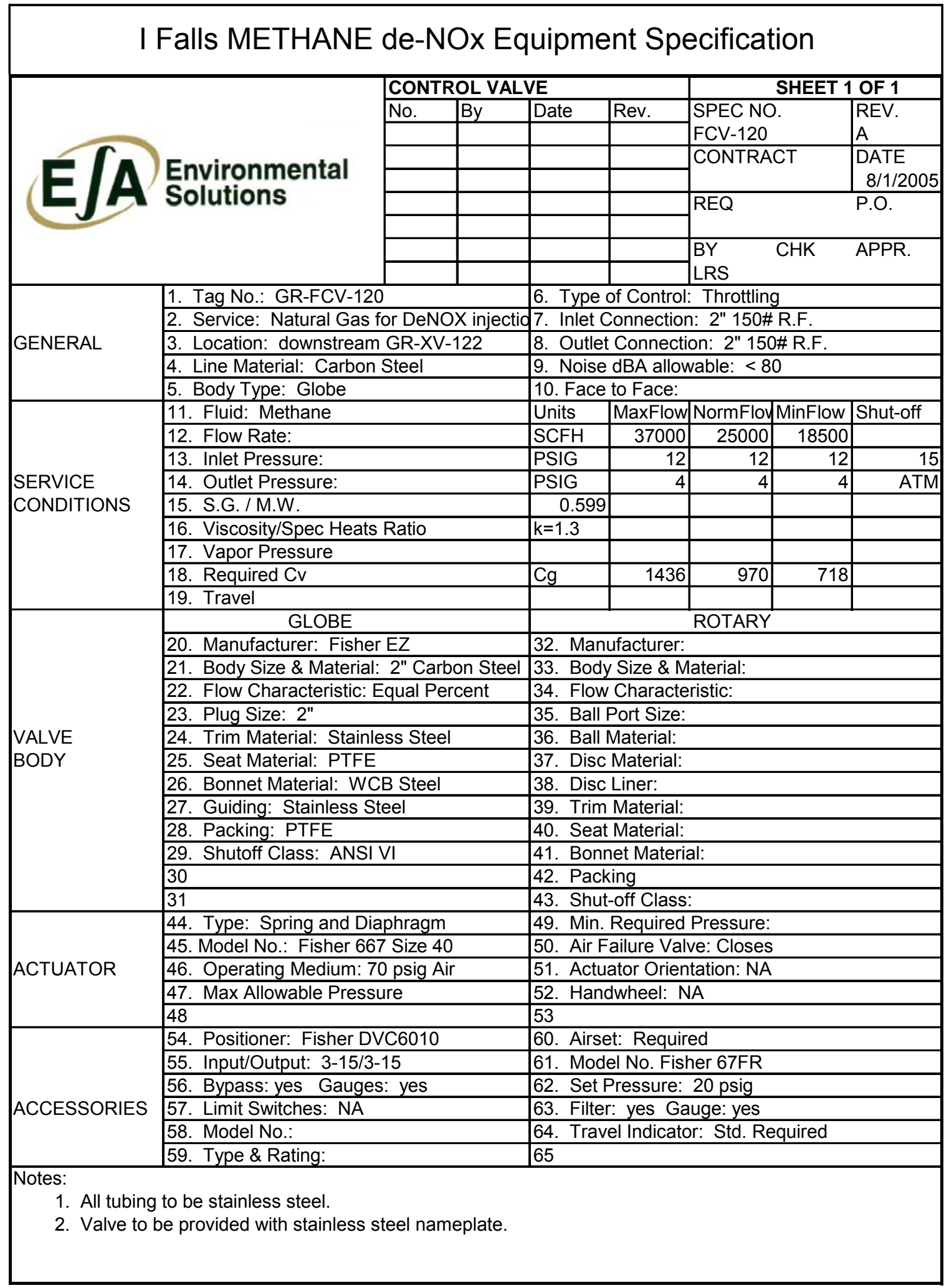




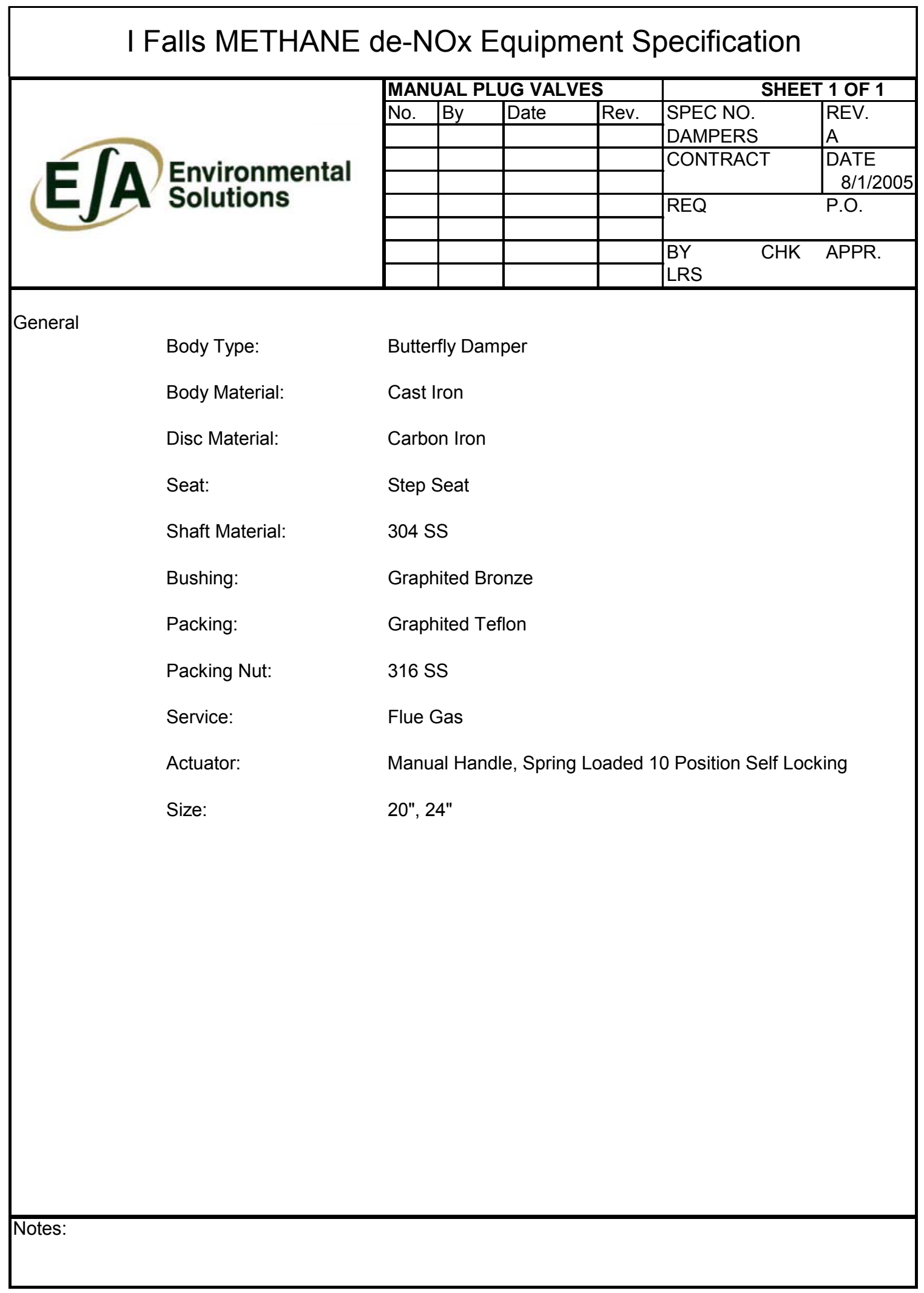




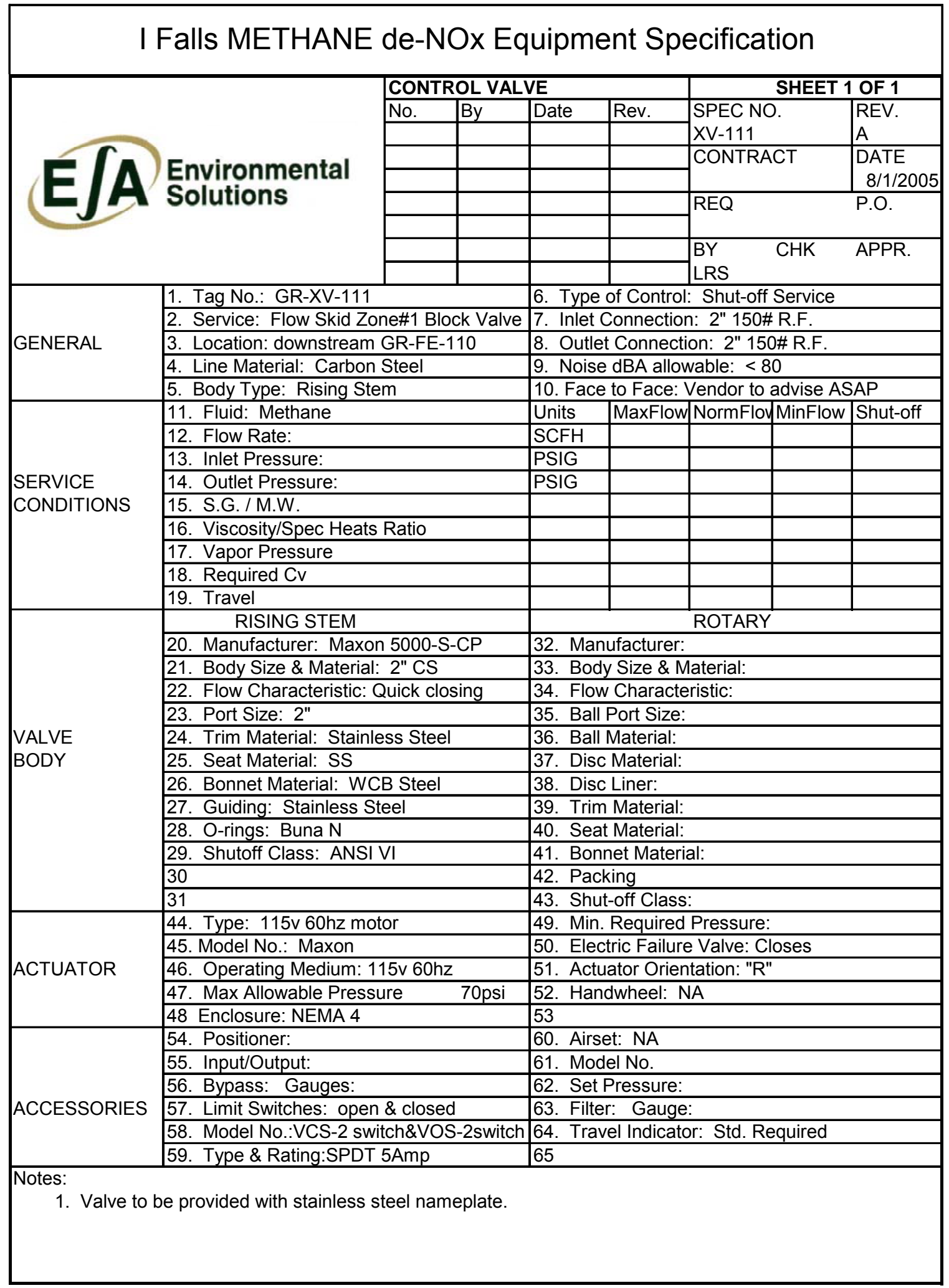




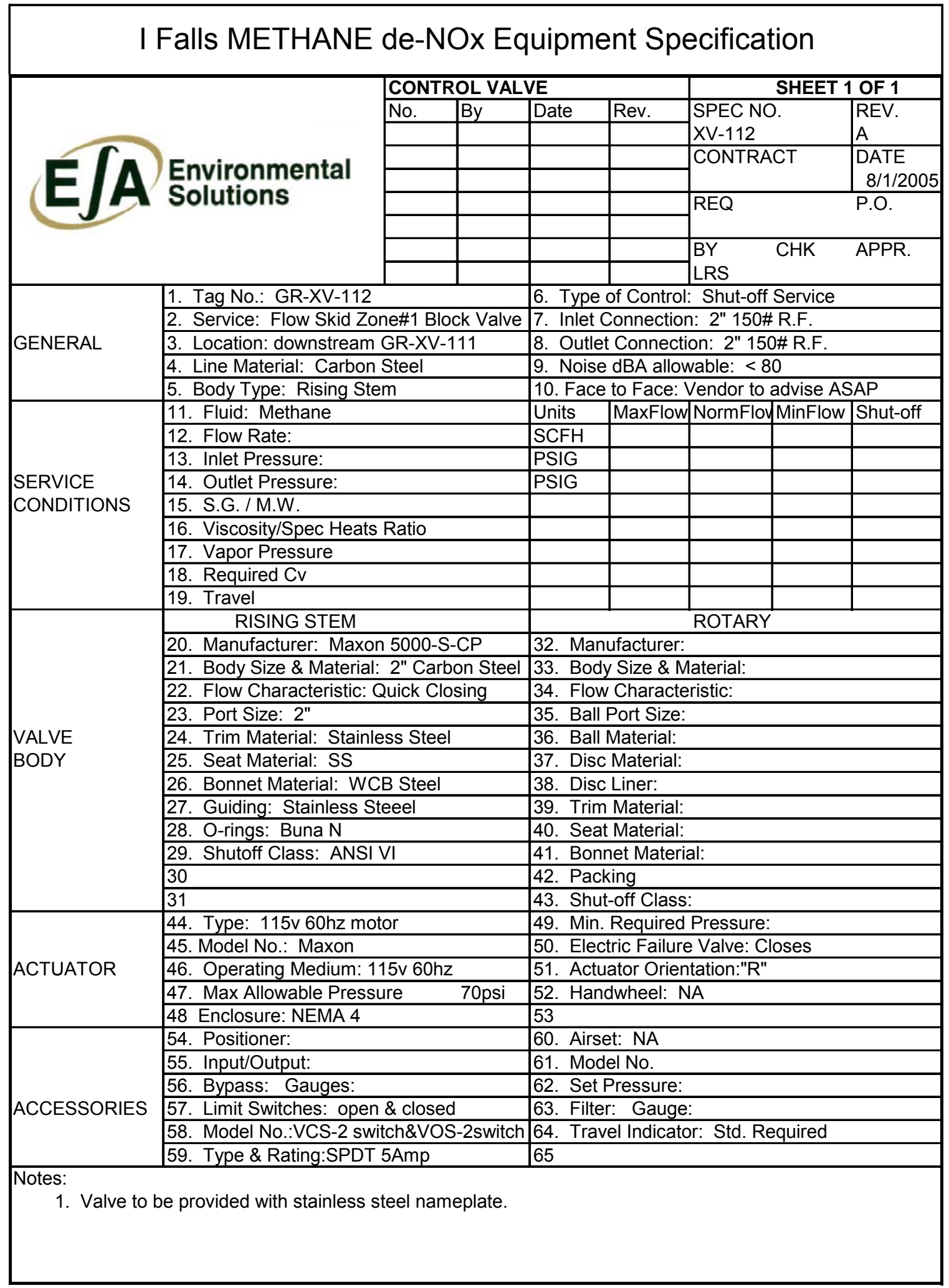




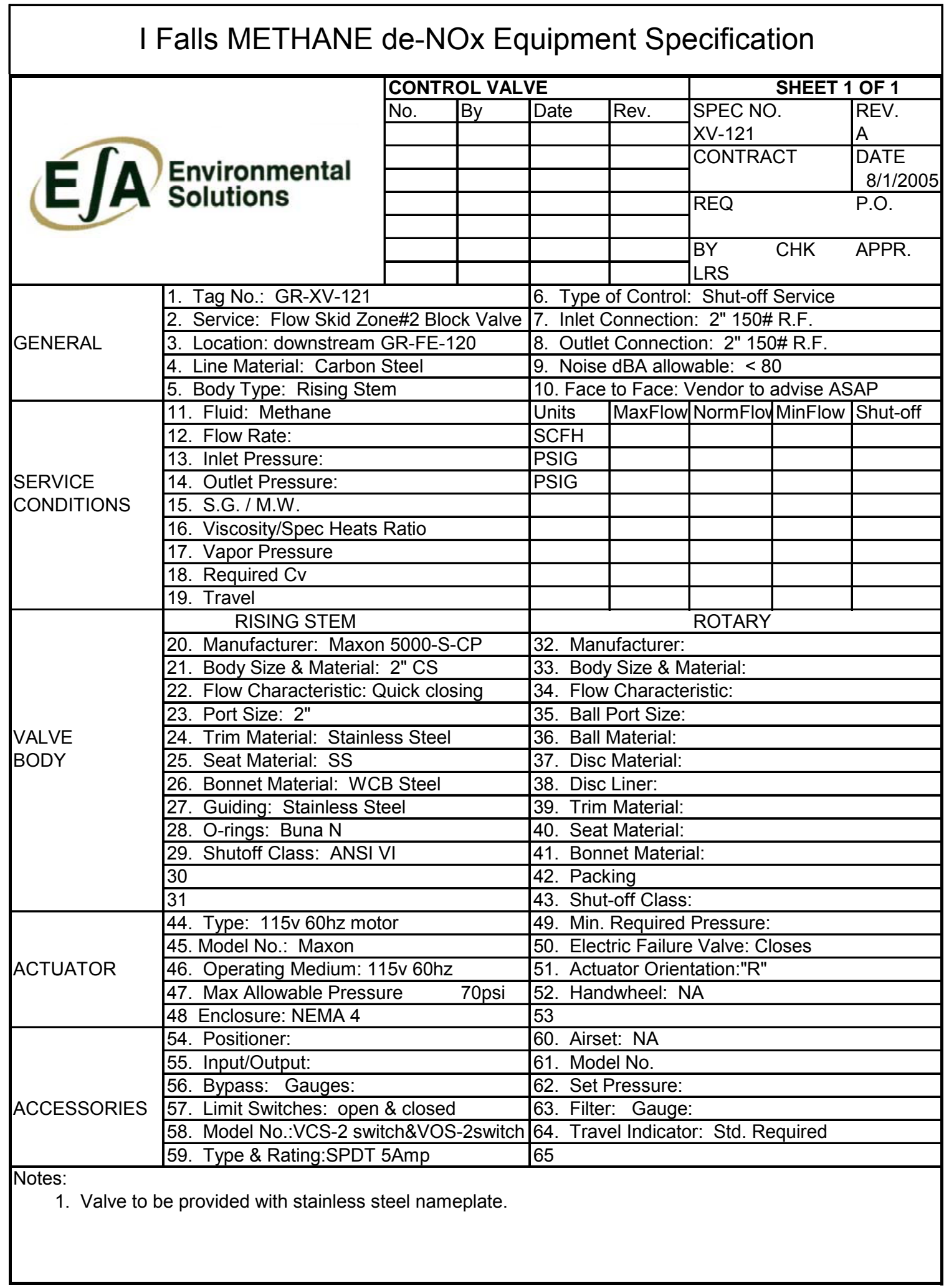




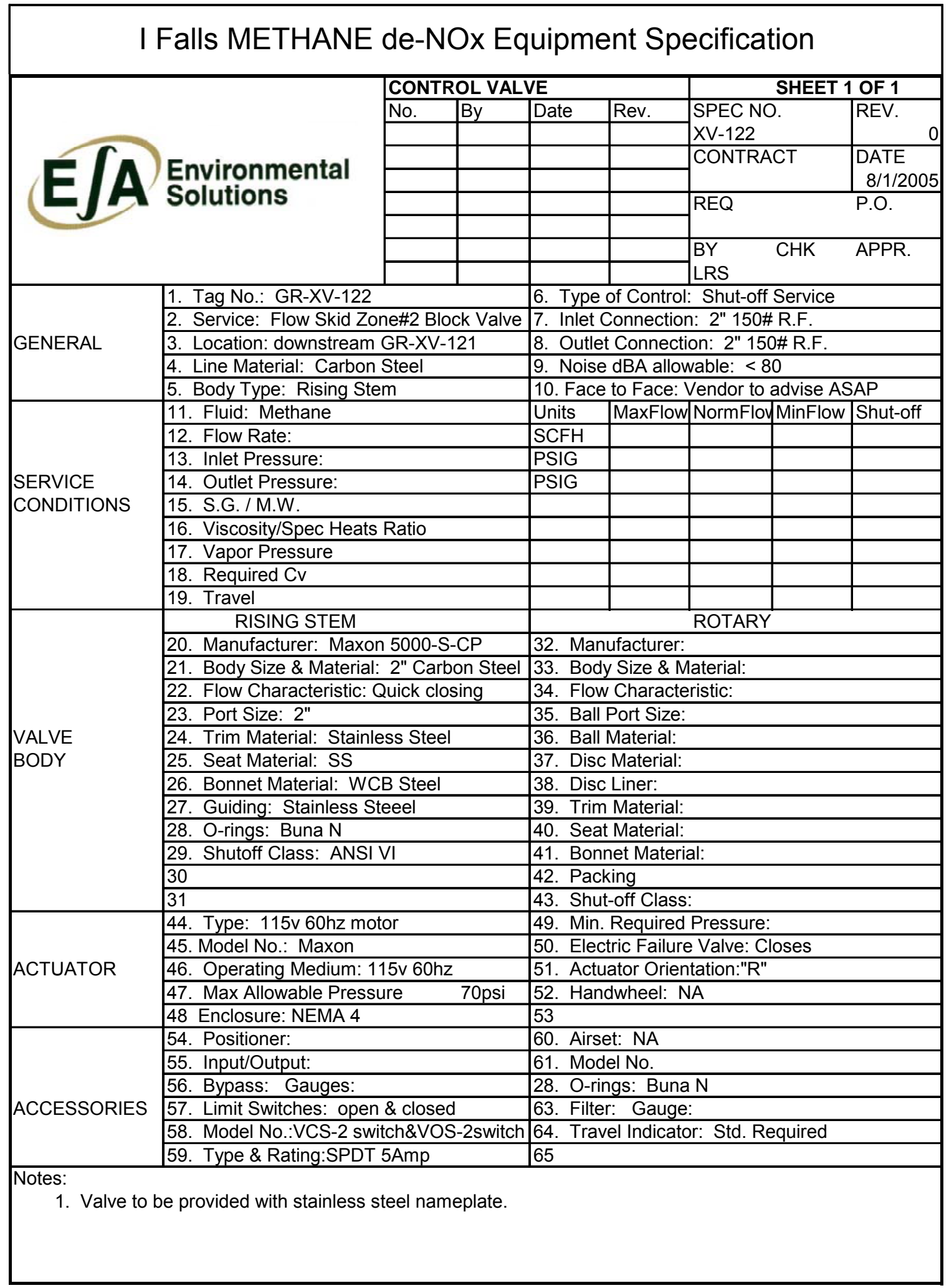




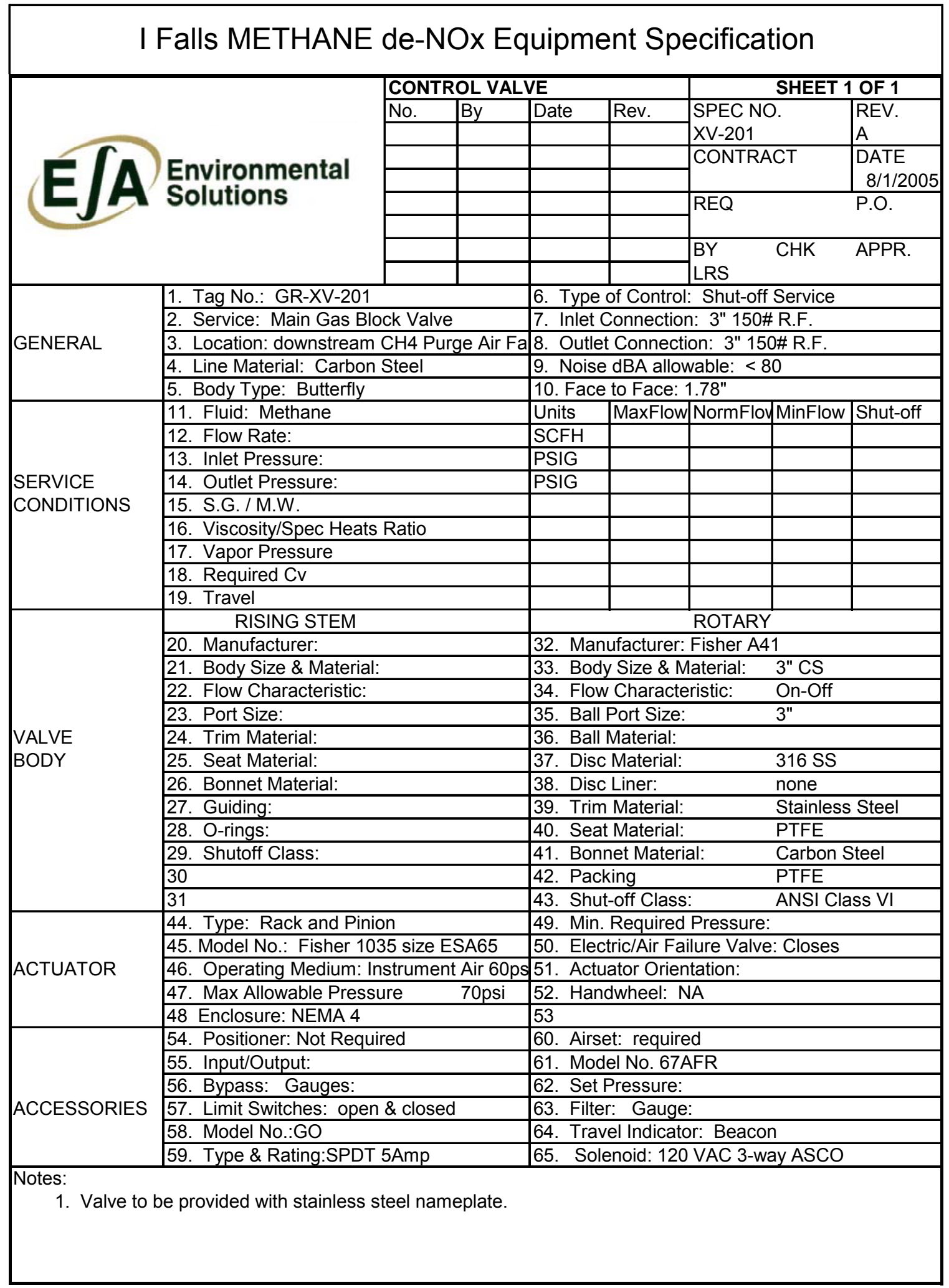




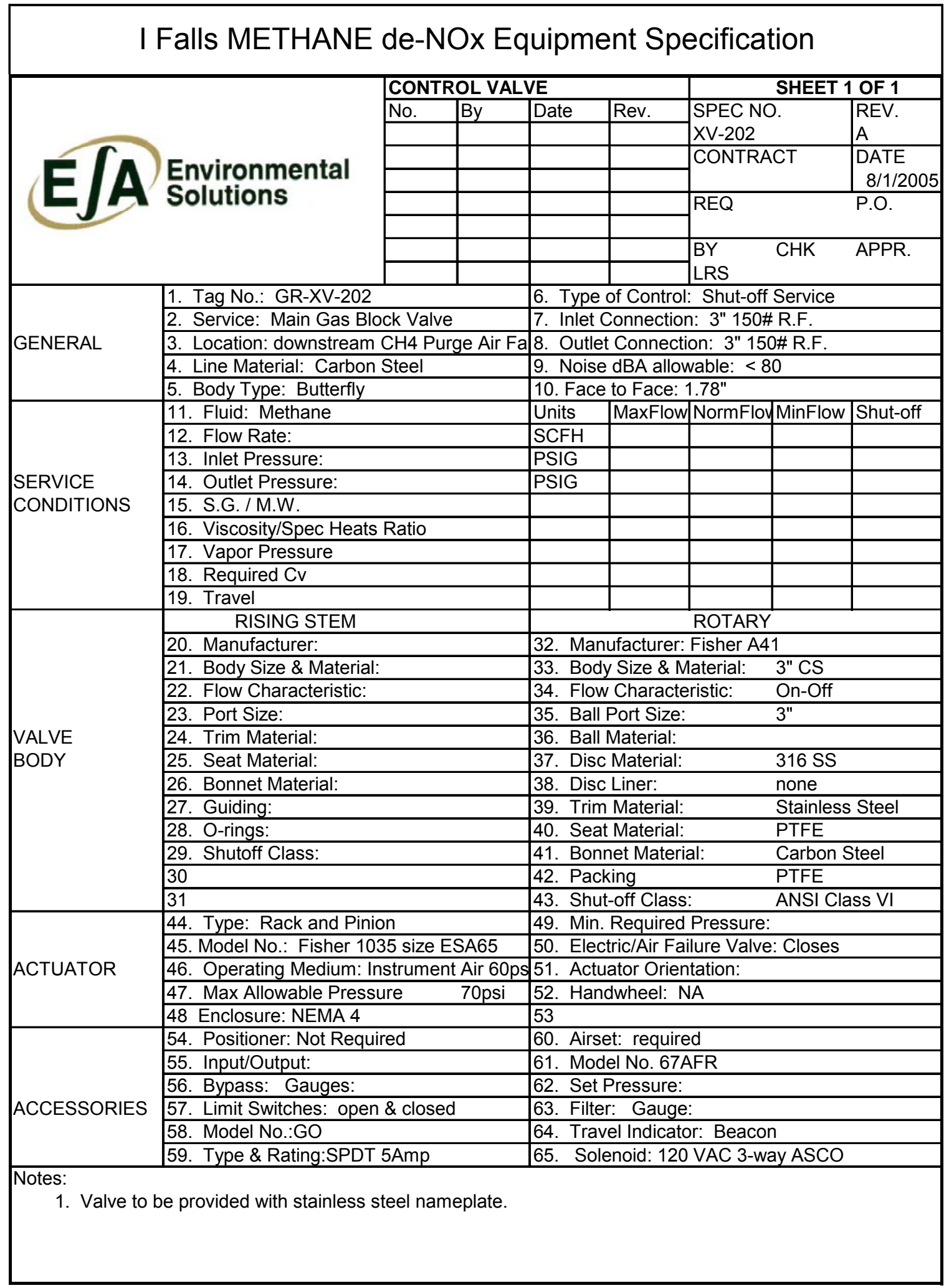




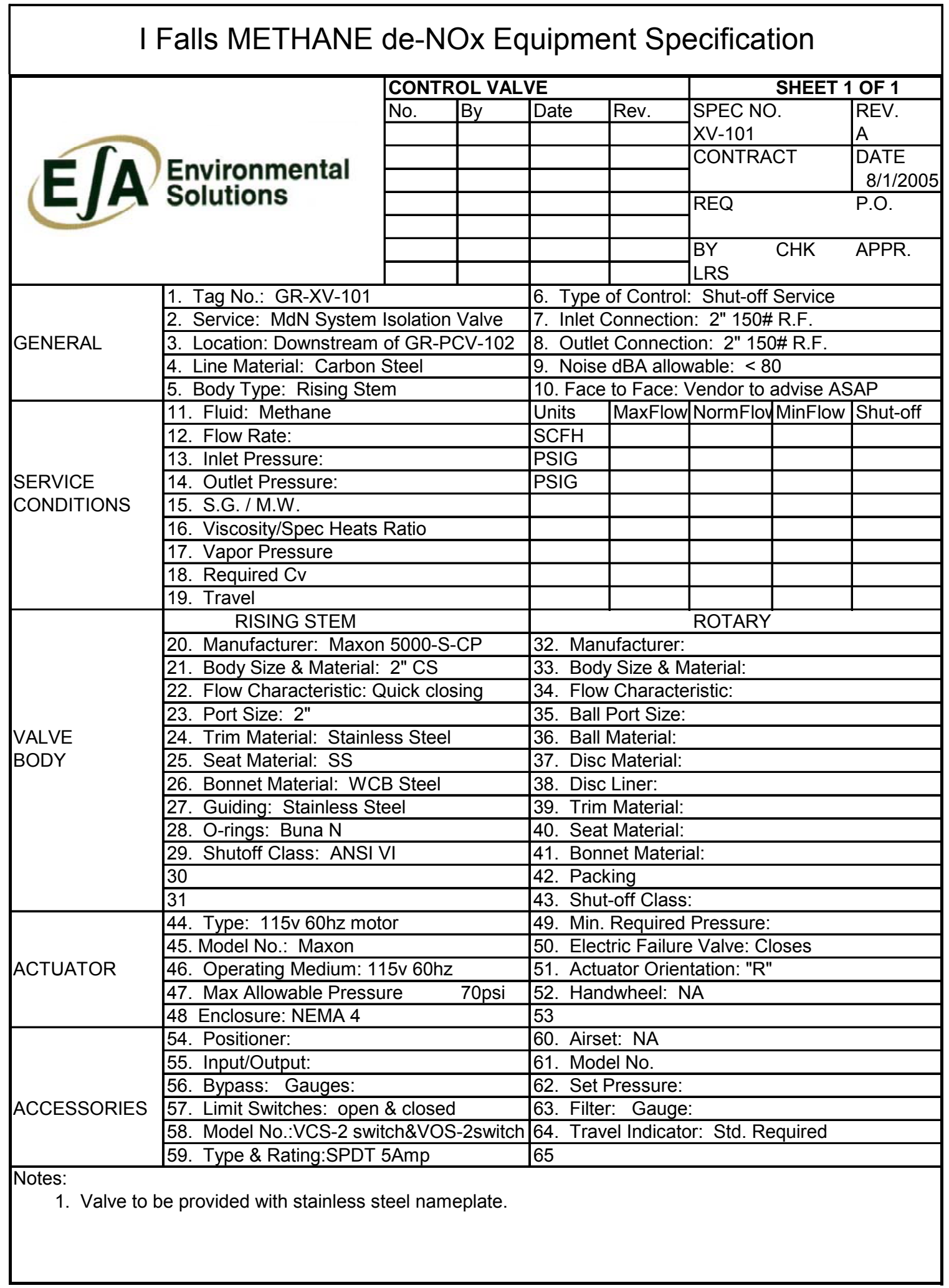




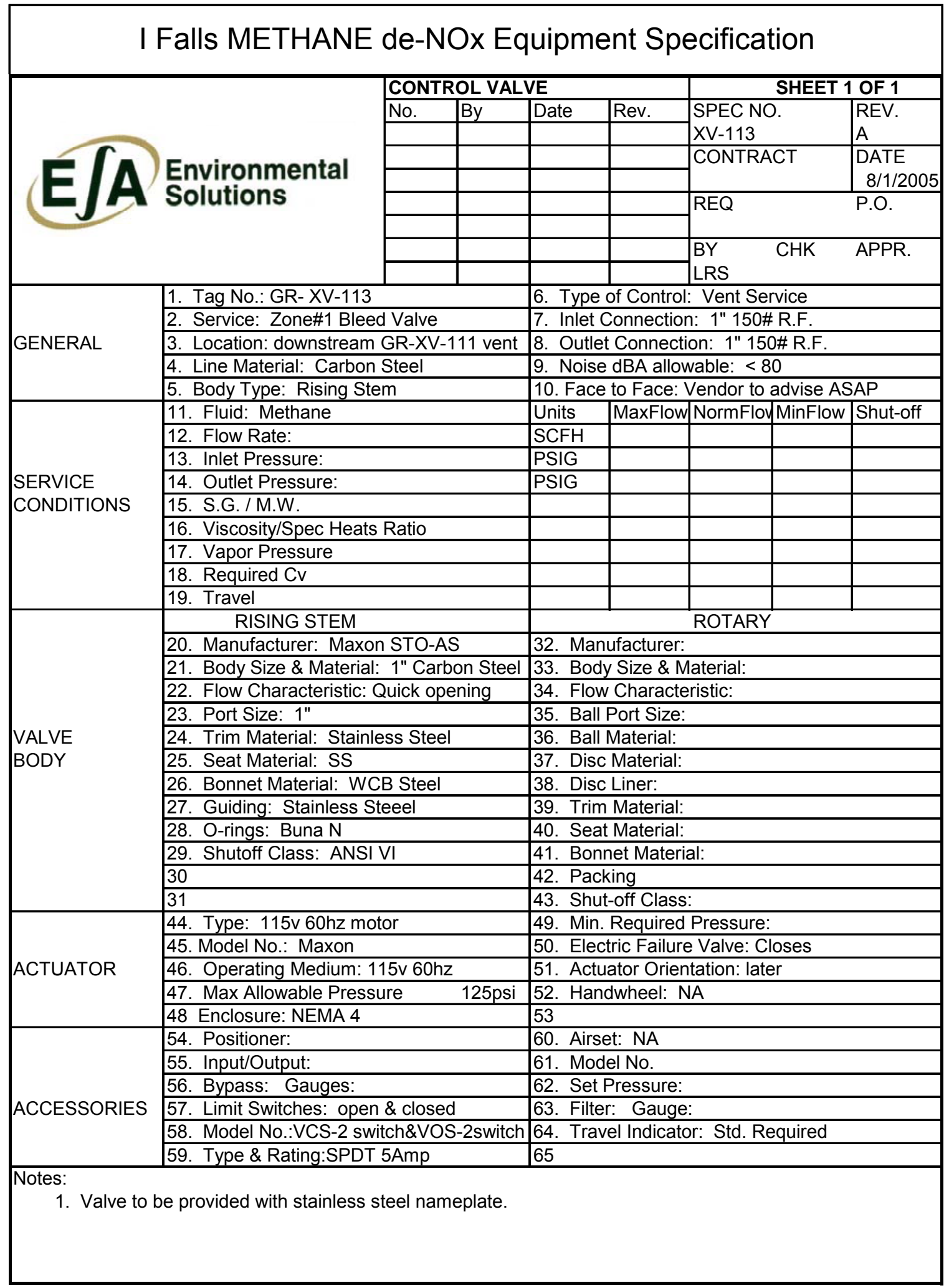




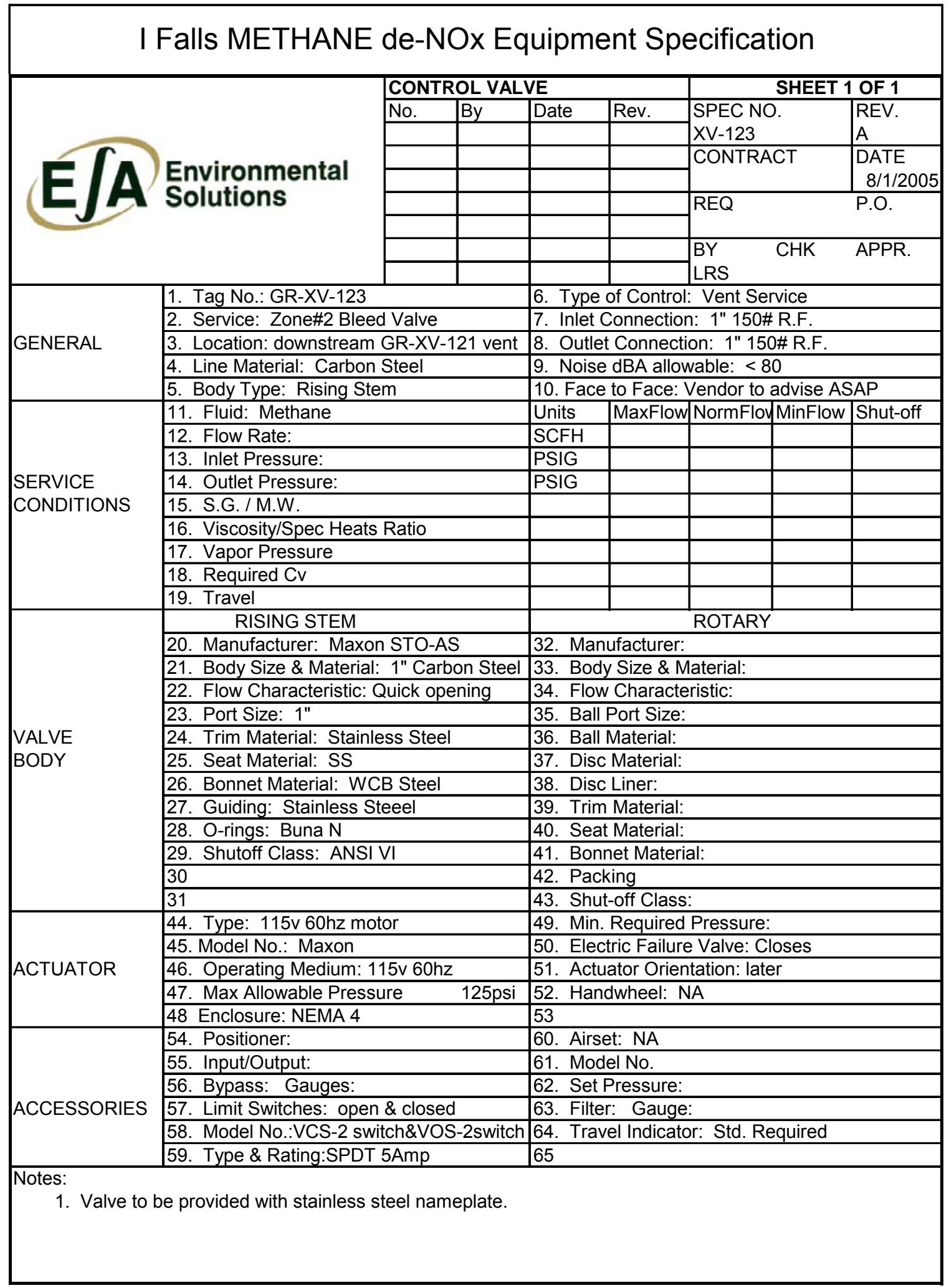




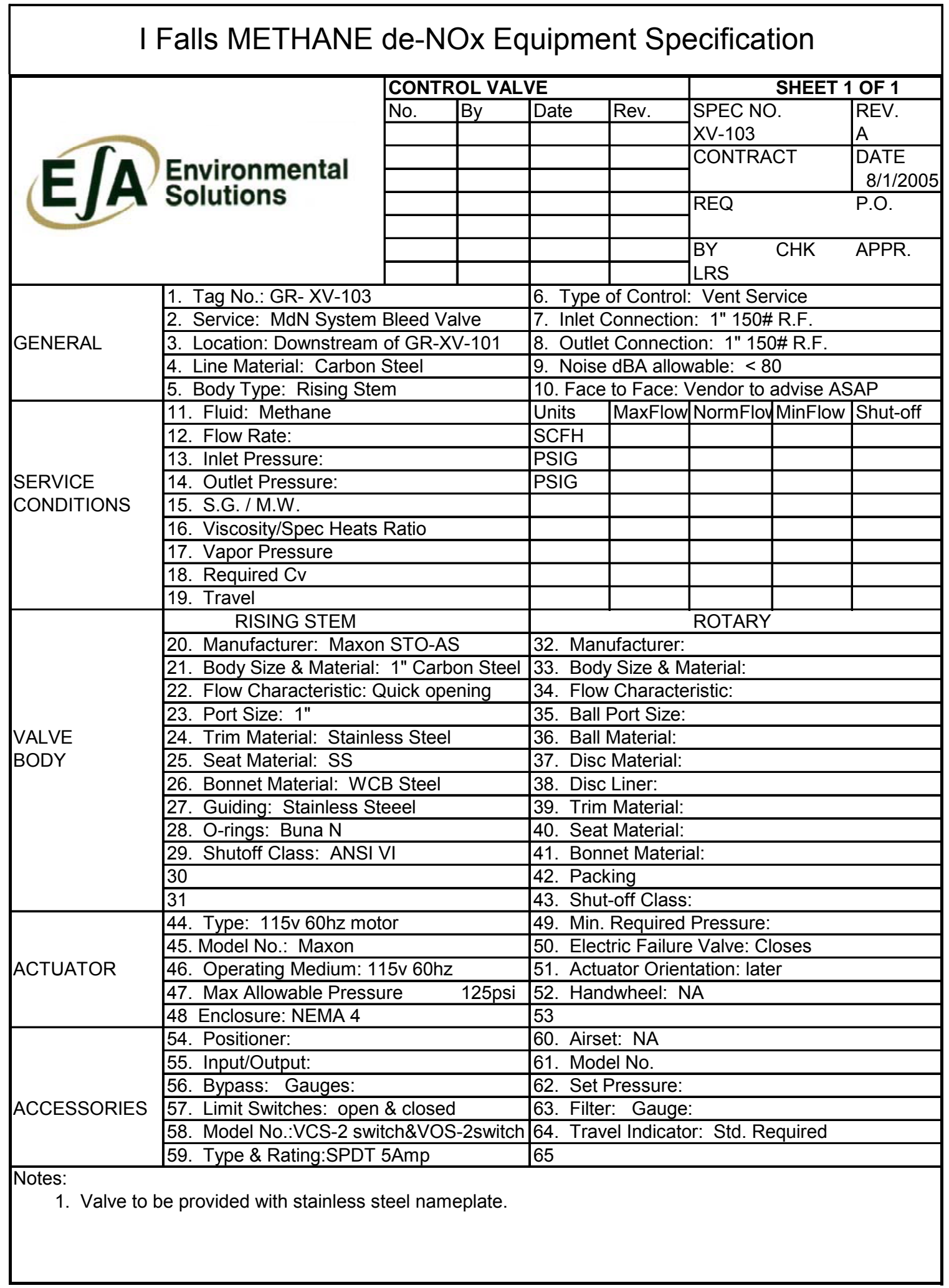




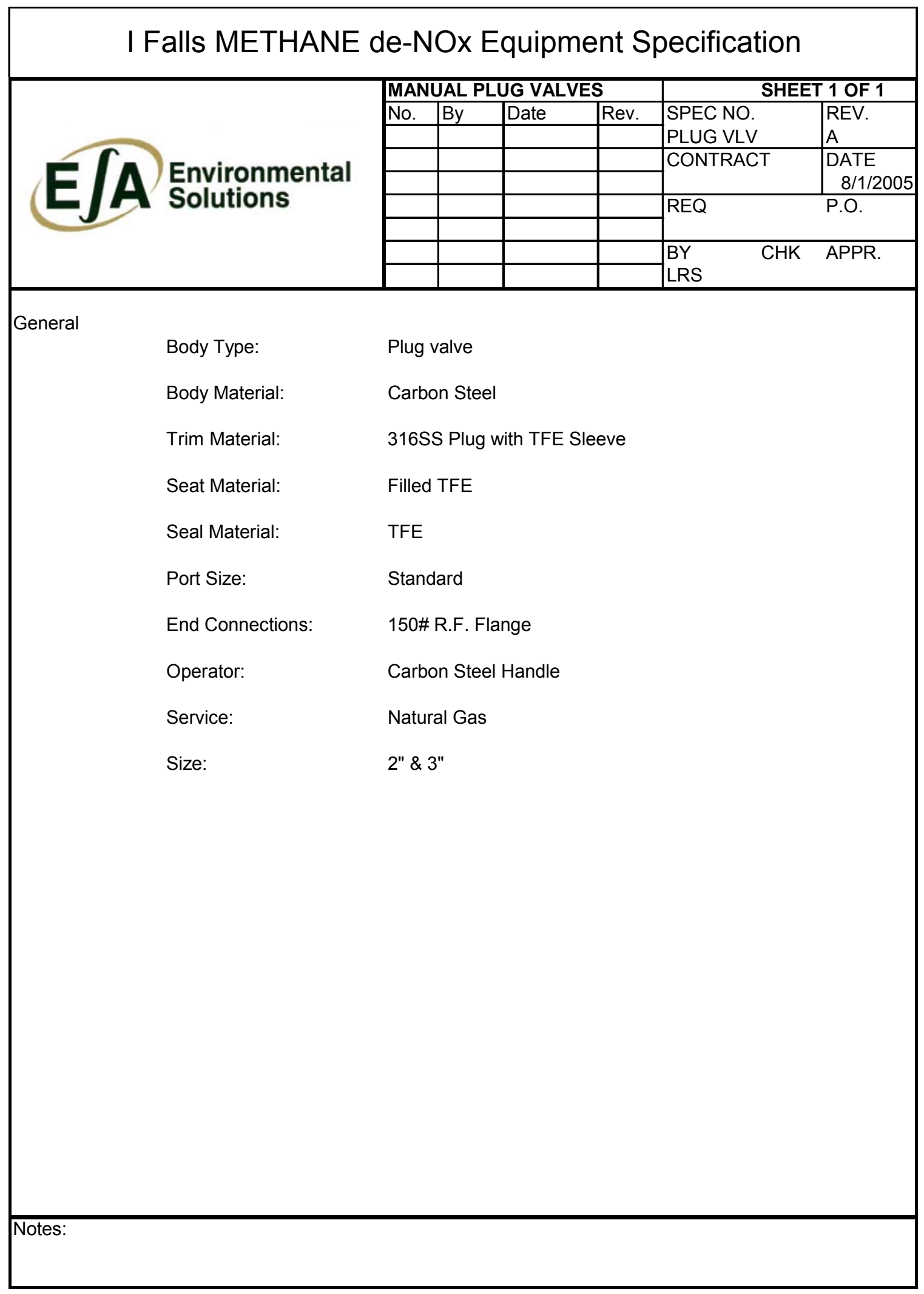




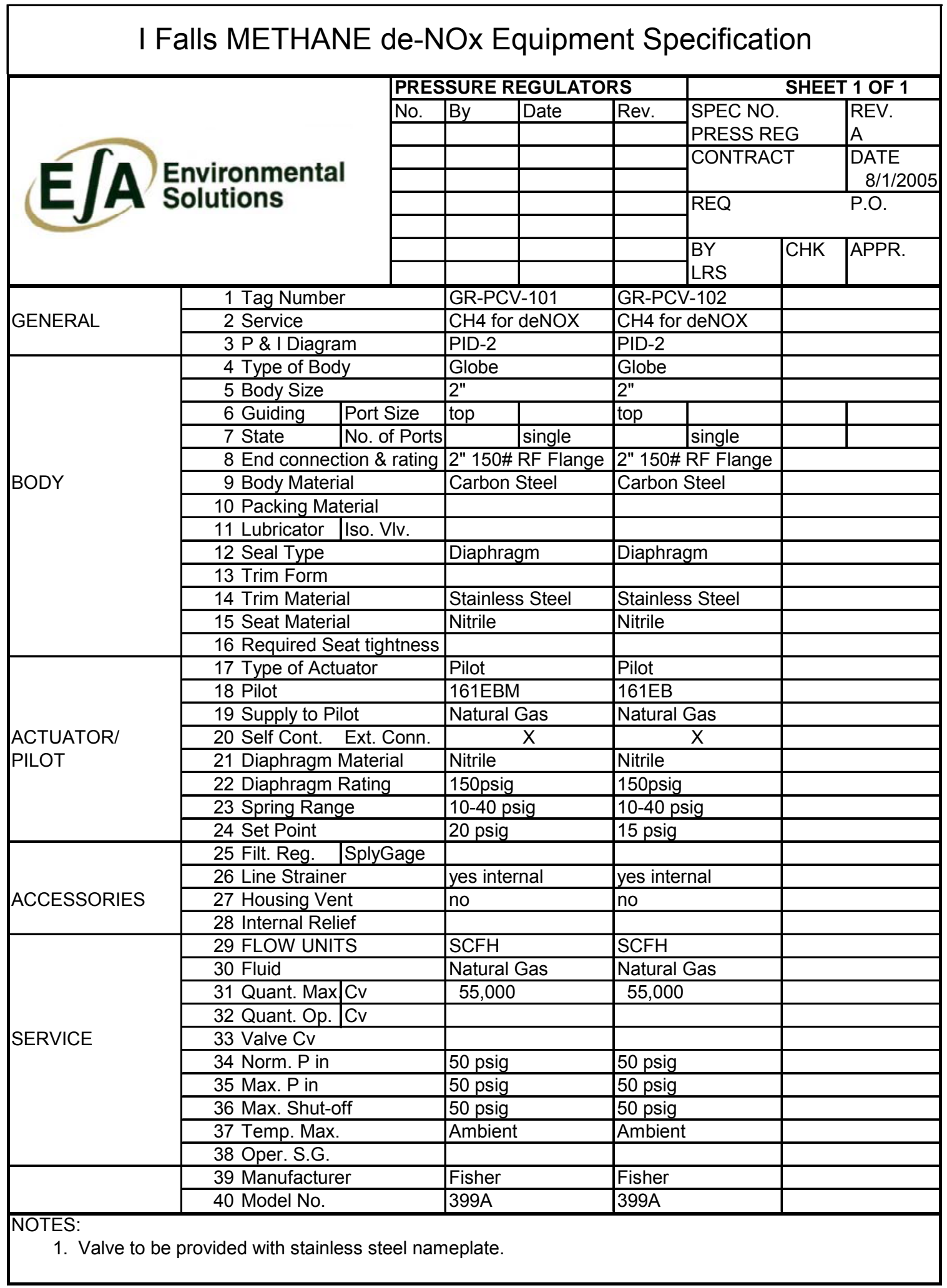




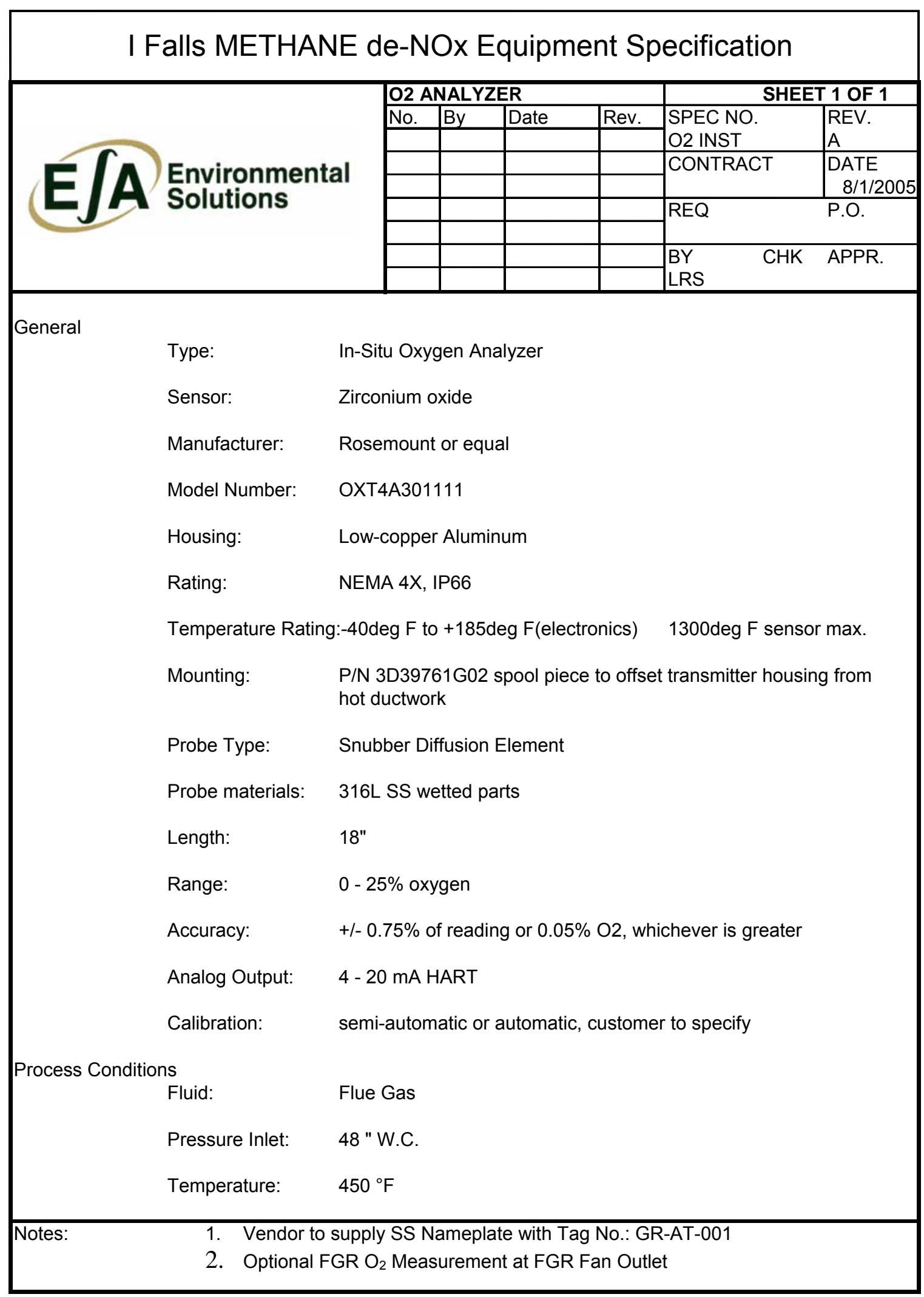




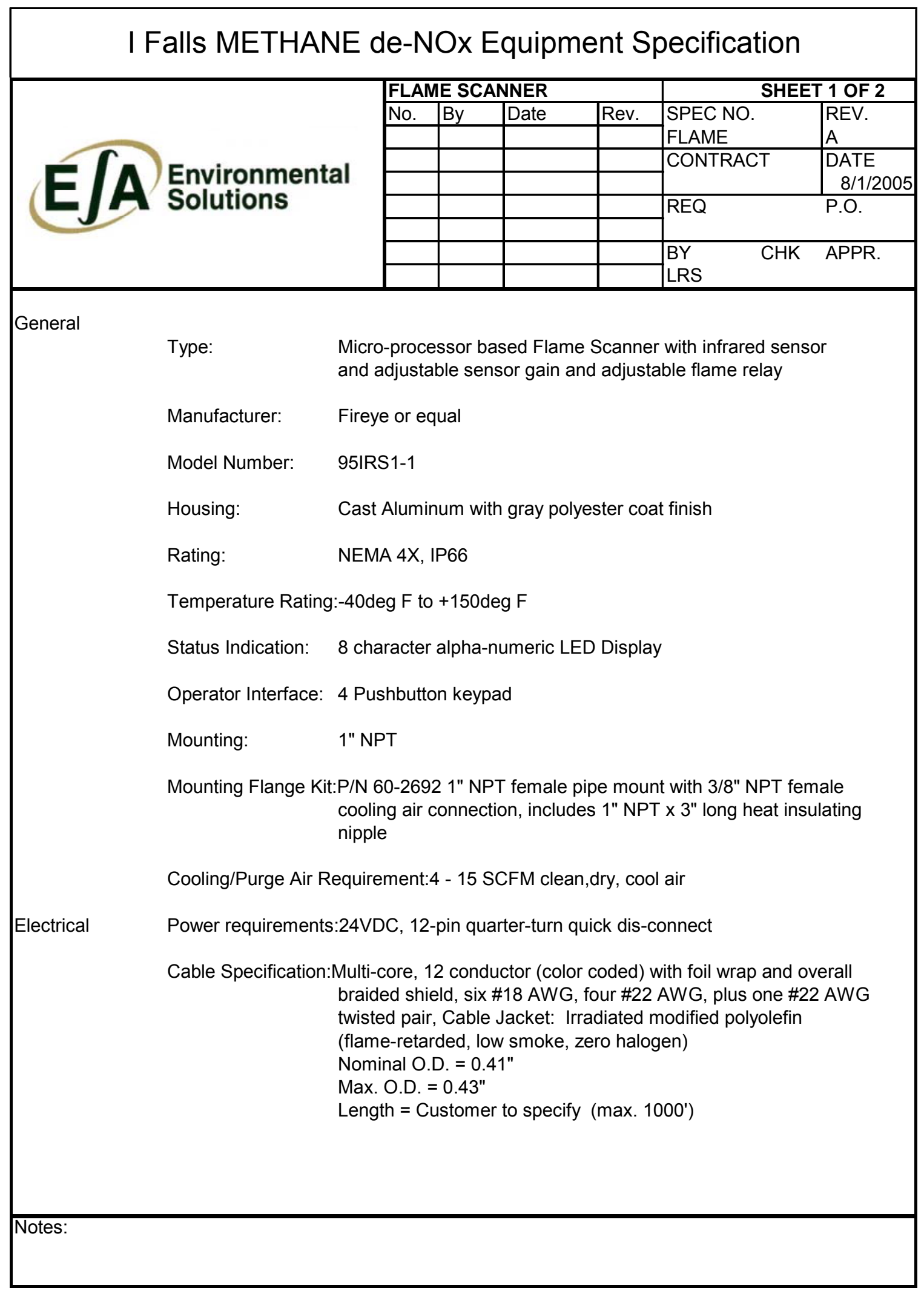




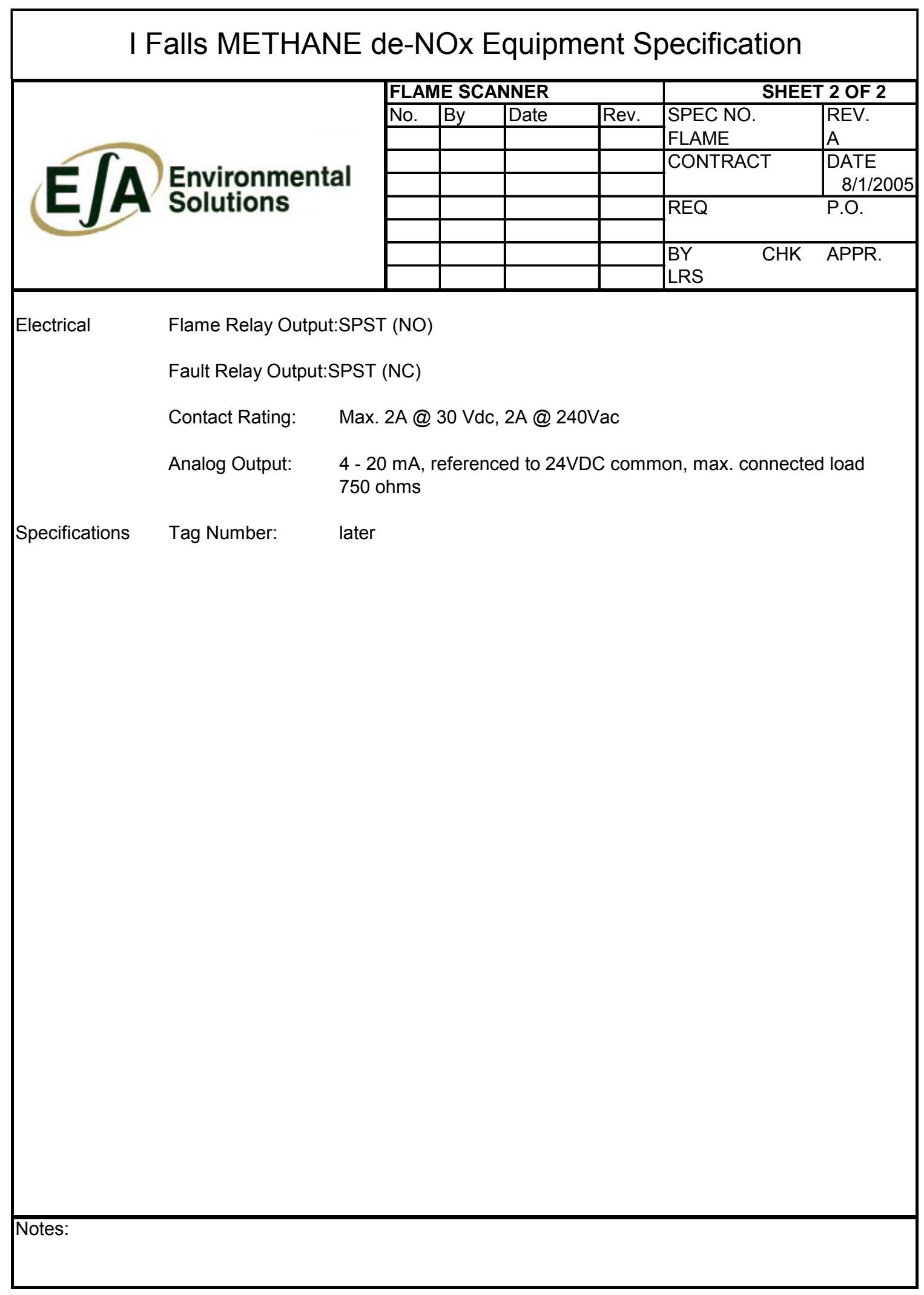




\subsection{Wallula Hog Fuel Boiler - Preliminary Retrofit Design}

\subsubsection{Wallula MdN Design Objectives}

With a MdN retrofit, the Wallula boiler objectives targeted lower emissions of $\mathrm{NO}_{\mathrm{x}}$ and an increase in boiler efficiency by 1 to $2 \%$ at full load operation through a significant reduction in total air flow. CFD model simulations and an analysis of baseline data confirmed a potential to decrease $\mathrm{NO}_{\mathrm{x}}$ emissions down to the $0.20 \mathrm{lb} \mathrm{NO}$ xer million Btu level. Baseline measurements found a moderate level of $\mathrm{NO}_{\mathrm{x}}$ emissions from the current boiler operation at about 0.25 pound $\mathrm{NO}_{x}$ per million Btu corrected at $3 \% \mathrm{O}_{2}$. Carbon monoxide emissions were expected to remain under control and within permitted limits

As is typical with most $\mathrm{MdN}$ system analysis, the boiler was expected to also benefit from a reduction in natural gas consumption at about 5-10\%. Natural gas flow would decrease by 4,000-8,000 scfh compared to baseline performance. The displacement of natural gas from the burners to the grate region would stabilize the grate combustion conditions and reduce the impact of burning high moisture content bark.

\subsubsection{Wallula Boiler Description}

The Wallula boiler is a hog fuel-fired boiler with a water-cooled stationary pinhole grate and four (4) air swept bark distributors. The boiler was installed in 1978 and is a Kipper \& Sons Engineer design. The furnace has a square shape and is equipped with two (2) natural gas-fired burners located at the rear wall and conventionally co-fired to stabilize steam production and augment combustion of wood waste fuel. Flue gas particulates are removed in a mechanical (multiclone) dust collector and collected cinders passed through a sand classifier with the larger size particulates re-injected into the lower furnace. Other boiler system components include a tubular air heater (no economizer) and a high energy wet flue gas scrubber located downstream of the ID fan.

The boiler maximum continuous rating (MCR) is 201,260 pound per hour of 260 psig saturated steam. The unit is equipped with overfire air ports located along the boiler sidewalls. OFA ports consisted of unique 4" and 8" long slots about 5/8" wide cut into the membrane section of the water wall. Figure 7-2 shows a sectional view of the boiler and elevation data of features as measured from the top of grate. 


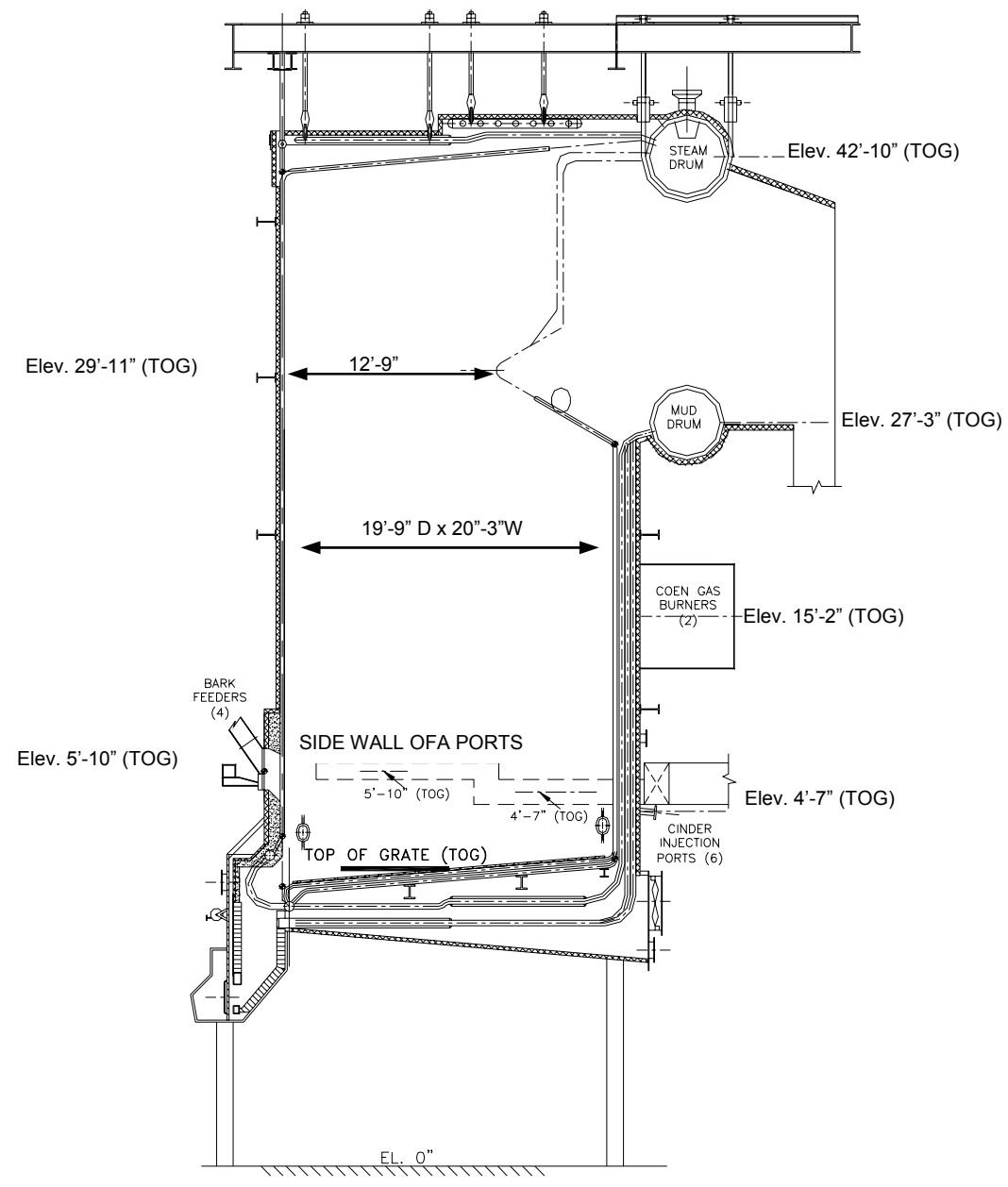

Figure 7-2 Wallula Boiler Elevation Data

\subsubsection{Wallula MdN Design Overview}

The preliminary MdN system design created for Wallula is based on baseline test data, boiler observations during baseline testing, and CFD model results. Certain engineering assumptions were made to develop the preliminary design. A major design consideration assumed the ability to utilize an existing arrangement of grate steam jets to perform a dual role; first to maintain their original function to intermittently remove and clean bottom ash accumulations from the pinhole grate and secondly to provide a scheme for injection of MdN reburn fuel.

\section{Wallula:}

MdN OVERVIEW Design guidance and installation details for the Wallula MdN retrofit are provided. The planned retrofit consists of MdN FGR, MdN Reburn Fuel Injection and a MdN OFA system. FGR take-off was selected upstream of Flue Gas Venturi Scrubber and downstream of the ID Fan; Reburn fuel injection will use natural gas and injection is achieved through an existing arrangement of steam jets installed at the grate for ash removal. Gas injection during grate ash cleaning intervals shall be stopped and resume upon completion of the cleaning cycle. An FGR tie-in was also 
provided to the OFA system; this connection is intended to assist fine tuning overall system performance. A new OFA system was deemed needed to replace the existing port configuration as well as replacement of the OFA Fan. The new OFA Fan would improve air staging and capability for optimization of MdN performance over different load conditions. Boiler equipment is referenced; preliminary placement of the MdN equipment and instrumentation are shown and target parameters for the system, such as injection pressures and flowrates are listed.

MdN SYSTEM ELEMENTS In this drawing, major MdN retrofit system elements are illustrated in a single line schematic for a simplified representation of the retrofit installation for purposes of showing how system components are related and function.

\subsubsection{Wallula MdN OFA System}

The current OFA system has several deficiencies; a major shortcoming is the port elevation. At the current height above the grate, combustion staging and creation of a reducing reburn zone above the grate in support of $\mathrm{MdN}$ technology is not adequate. OFA air distribution does not include the ability to control the flowrate for various boiler load conditions and the existing fan can not supply the desired OFA flowrates for MdN operation. Consequently, the MdN retrofit package incorporated a new OFA system; descriptions of associated design drawings are given below.

Wallula:

PID-1 The MdN OFA system consists of a new 200 hp, 1800 rpm, OFA fan (33,000 cfm @ $30 \mathrm{inH}_{2} \mathrm{O}$ ) and a new OFA port arrangement located at a higher elevation in the furnace. The OFA fan is fed from the air heater outlet duct. The fan discharge is split into two 20" diameter ducts and routed to headers located on both furnace sidewalls. The OFA fan discharge pressure is regulated via an automated inlet damper to maintain a specified pressure in the OFA supply header dependent on boiler load. The OFA east and west headers each have a manual damper to balance flows and monitored based on header pressure. Particular details are provided in attached detailed specifications.

Other drawing details reflect the MdN FGR system and are described later.

WALLULA OFA MdN OFA system design consists of 23 custom port assemblies installed on the boiler sidewalls; 11 on one side and 12 on the other. This drawing illustrates the custom port assembly design, which consists of 3 nozzles locally grouped to distribute air over a broader zone in comparison to conventional designs. Port sizes and number of port assemblies are dependent on CFD model results and boiler waterwall construction.

\subsubsection{Wallula MdN Reburn Fuel Injection System}

Upon review, design deliberations concluded the most cost effective method for introduction of MdN reburn fuel (natural gas) was through the existing grate cleaning system. Stationary grate cleaning is achieved via dedicated steam jet nozzles installed in the grate to sweep the grate surface with 150 psig steam for removal of ash accumulations. The grate is divided into 4 zones 
associated with each bark feeder. A cleaning cycle sweeps one zone at a time sequentially. At periods when the zone cleaning cycle is off, MdN reburn fuel injection is on.

Injection of MdN reburn fuel is handled by combining natural gas with FGR with a gas sparger. The reburn fuel/FGR mixture is piped to the existing supply network feeding the grate's steam jet nozzles. The MdN reburn fuel system will have one (1) flow control skid for natural gas injection. The natural gas skid will supply four (4) injection headers. The supply for each injection header will have an isolation valve and the control scheme will allow for continued natural gas/FGR injection to the zones not in the grate cleaning process. The FGR supply to the steam jets will continue when the natural gas supply has been shutoff. The FGR will provide cooling to the steam jets and help to slow the erosion of the steam jets.

\section{Wallula:}

PID-2 MdN reburn fuel is supplied from the mill's natural gas header and is directed into a dedicated gas control skid sized to regulate and safely manage 75,000 scfh of reburn fuel. Control skid design consists of dual gas pressure reducing stations, main gas isolation and vent valves (double block and bleed valve arrangement), a flowmeter and control valve station. Two pressure reducing regulators provide redundancy and safety. Gas flow is measured with vortex flow technology; pressure and temperature compensation of the flow signal provides an accurate measurement of energy. Gas flow set point is dependent on boiler load.

INJ DETAIL The Wallula grate steam jet arrangement is illustrated showing spacing and distribution pattern planned for MdN reburn fuel/FGR injection.

\subsubsection{Wallula MdN FGR System}

In addition to providing a medium to create turbulent mixing for the natural gas, FGR is utilized as a replacement for any unnecessary air injected into the boiler. FGR's significantly lower oxygen content reduces the amount of oxygen available to form $\mathrm{NO}_{\mathrm{x}}$. Examples where air is replaced with FGR include cinder re-injection and pneumatic bark distributor services. Furthermore, addition of a small portion of FGR to the OFA system is expected to improve system $\mathrm{NO}_{\mathrm{x}}$ reduction performance..

Baseline data indicated limited spare capacity of the ID fan. Test data also showed low levels of carbon content in the fly ash. Consequently, an MdN design review recommended removing four (4) cinder re-injection lines connected with the systems dust collector. FGR requirements for this cinder re-injection can be more effectively utilized in other components of the MdN system and it reduces the expected ID fan load .

The MdN FGR fan takeoff in this preliminary design was selected after the ID Fan and before the wet scrubber to reduce horsepower requirements of the new FGR fan motor. Particulates in the flue gas are a concern because of potential plugging and erosion problems. It was assumed collection efficiency of the system's mechanical collector removed any excessive dust or particulate levels before this takeoff point. If FGR was taken after the wet scrubber, particulate problems would be less of a concern but the additional moisture in the flue gas would negatively impact design considerations by increasing system pressure losses and impact FGR fan sizing and possibly require a system for removing the additional moisture. 
In this design case, FGR system duct work was sized based on pressure drop loss through 600 feet of straight pipe with an elevation change of 25 feet from the FGR fan outlet. This length was chosen to account for pressure loss encountered with duct transition sections, elbows, and takeoffs in the installed duct work. 
Wallula:

PID-1 The MdN FGR system starts at a takeoff point located after the ID fan. The single line diagram shows the FGR fan inlet duct is equipped with an automated inlet damper to control a specified pressure within the FGR duct work. The 150 hp FGR fan construction consists of a radial blade design sized to handle $27,435 \mathrm{cfm}$ with a SP of 40 $\mathrm{inH}_{2} \mathrm{O}$. The MdN system includes a measurement of total FGR flow along with pressure, temperature and oxygen content at the fan discharge. A 24" diameter duct was selected to conveys FGR to the stoker furnace area where reburn fuel is added and the combined flow of MdN FGR and MdN reburn fuel is distributed and injected the grate region as described earlier. FGR branches are also routed to replace air to the ash re-injection system and to the bark pneumatic distributors. Another provision directs a portion of FGR to combine with OFA for optimization of system performance.

The FGR flow to the cinder reinjection and pneumatic distribution systems should remain constant throughout the boiler operating range and do not require automatic control. The mass flow of FGR mixing with reburn fuel is measured and compensated with pressure and temperature. The FGR flow is controlled at rates determined system commissioning work.

\subsubsection{Wallula MdN Controls}

The control philosophy for the MdN system makes every effort to minimize the amount of boiler operator interaction necessary to operate the system. The control system contains discrete and regulatory control algorithms to safely start, regulate and shutdown the system automatically in accordance with accepted NFPA standards. System various set points for flowrates and pressures are based on boiler steam load and adjusted dependent on changes in boiler operating conditions. Detailed instrument specifications are given in a later section.

For the purpose of the design, it was assumed the mill's current DCS hardware has adequate spare capacity for additional MdN system instrumentation, both analog and discrete signal points.

\section{Wallula}

LOGIC-1 An MdN system discrete logic diagram is given that oversees activation of the main reburn fuel supply. Before the main fuel safety shutoff valve is open, System Start permissive and System interlocks must be satisfied. Startup permissives focus on verifying the boiler is operating; a grate flame is detected and the MdN FGR flow and oxygen levels are within proper limits.

LOGIC-2 Discrete logic presented contains the permissives and interlocks for each of the four grate zones, which automatically shutoff MdN reburn fuel/FGR mixture during periods the grate cleaning cycle is in service. This scheme permits independent operation between MdN operation and grate cleaning. Permissive and interlocks are designed to monitor operation of the valves and the physical characteristics of the natural gas, such as pressure and flowrates.

LOGIC-3 Drawing contains a single line SAMA control diagram showing regulatory control requirements associated with MdN FGR services; services include FGR supply 
pressure, FGR flow to OFA and FGR flow to natural gas injection. Process set points are controlled and regulated with process PID controllers (proportional, integral \& derivative), which are configured into the mill's existing DCS. In automatic, controller set points are dependent on boiler load, which are characterized during system commissioning activities.

LOGIC-4 This drawing shows similar information as in LOGIC-3 except for the MdN OFA fan operation

LOGIC-5 MdN reburn fuel control scheme for regulation of natural gas injection is presented. In the SAMA control diagram, natural gas flow is compensated for flowing pressure and temperature. This signal is sent to a PID controller configured with proportional and integral modes to maintain proper flow set point. The controller receives a signal from during grate cleaning periods to proper manage natural gas injection. A calculation for heat input from natural gas injection is also included in order to maintain a desired input from natural gas.

\subsubsection{Wallula MdN System installation Cost Estimate}

The estimated cost to complete final design, procure and install equipment, and test and tune a MdN system for hog fuel boiler at the Wallula mill is One Million Dollars $\mathbf{( \$ 1 , 0 0 0 , 0 0 . 0 0 )}$. This estimate is on a plus/minus $30 \%$ basis. The major item with regards to uncertainty in the estimate is the cost of local labor and the unknowns related with installation.

The above quoted cost does not include the initial baseline testing, CFD model, and preliminary MdN design. The estimated cost to perform these tasks is One Hundred Seventy Five Thousand Dollars $\mathbf{( \$ 1 7 5 , 0 0 0 )}$.

\subsubsection{Wallula MdN Retrofit Design}

Detailed design information for the Wallula MdN retrofit are of preliminary nature and represent a best effort as based on data obtained during tests in 2000. An MdN retrofit at Wallula was not installed due to other priority capital projects; it continues to remain an interest with the mill staff, however. 


\subsubsection{Wallula MdN System Drawings - Preliminary}

Table 7-3 Wallula - MdN Design Drawing Index

\begin{tabular}{|l|l|}
\hline \multicolumn{1}{|c|}{ Drawing \# } & \multicolumn{1}{c|}{ Description } \\
\hline MdN-Overview & MdN System Overview \\
\hline MdN System Elements & Single Line Process Drawig \\
\hline PID-1 & FGR \& OFA Equipment P\&ID \\
\hline PID -2 & Natural Gas Control Skid P\&ID \\
\hline LOGIC-1 & MdN System Interlocks \& Permissives Logic \\
\hline LOGIC-2 & MdN System Interlocks \& Permissives Logic \\
\hline LOGIC-3 & FGR System Control Logic \\
\hline LOGIC-4 & OFA System Control Logic \\
\hline LOGIC-5 & MdN System Natural Gas Flow Control Logic \\
\hline WALLULA - OFA & OFA Nozzle Detail \\
\hline INJ Detail & Steam Jet Placement and Injector Details \\
\hline
\end{tabular}




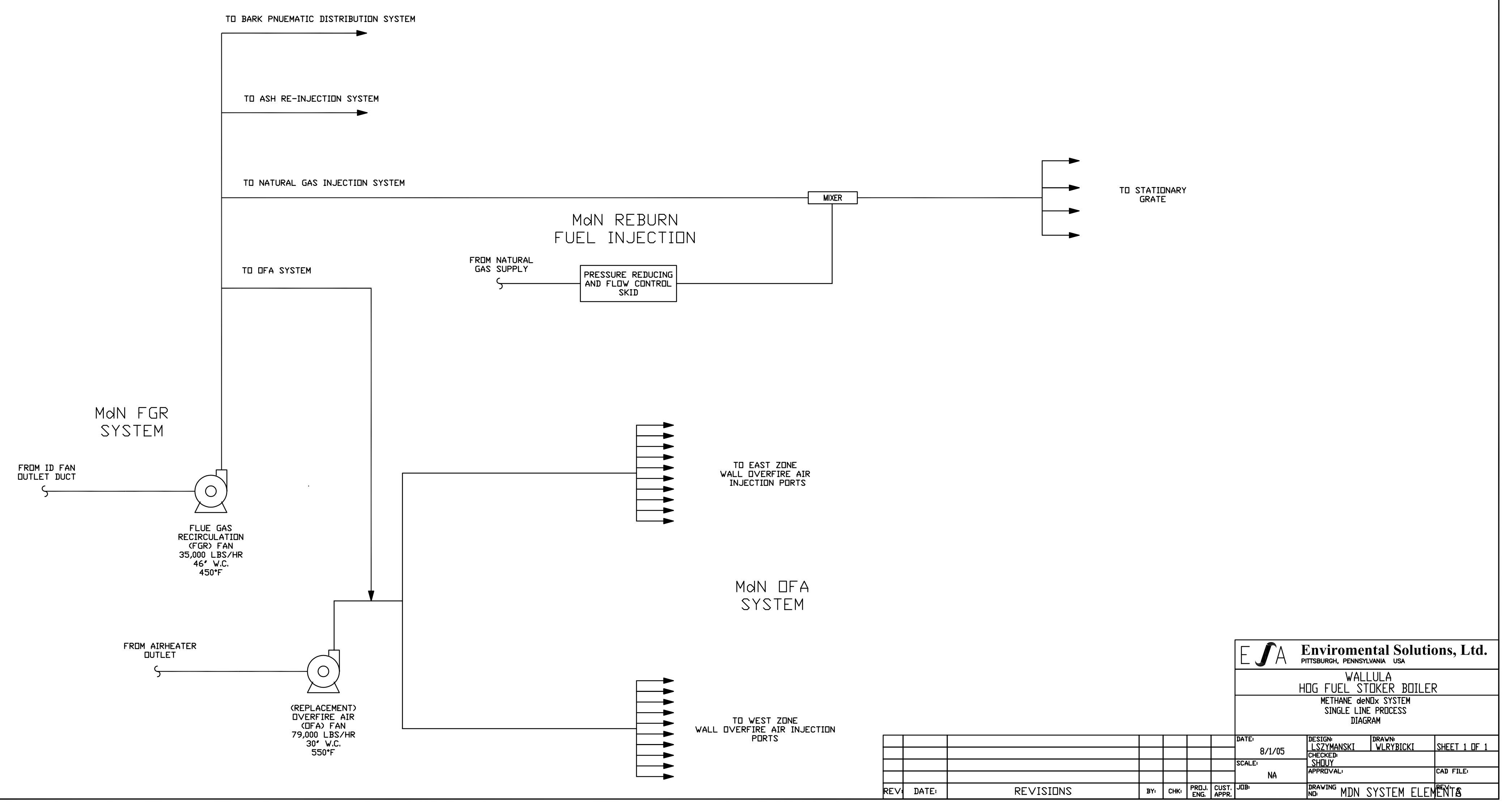




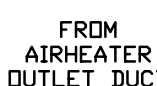<smiles>CC=CC=C(C)C</smiles>

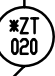

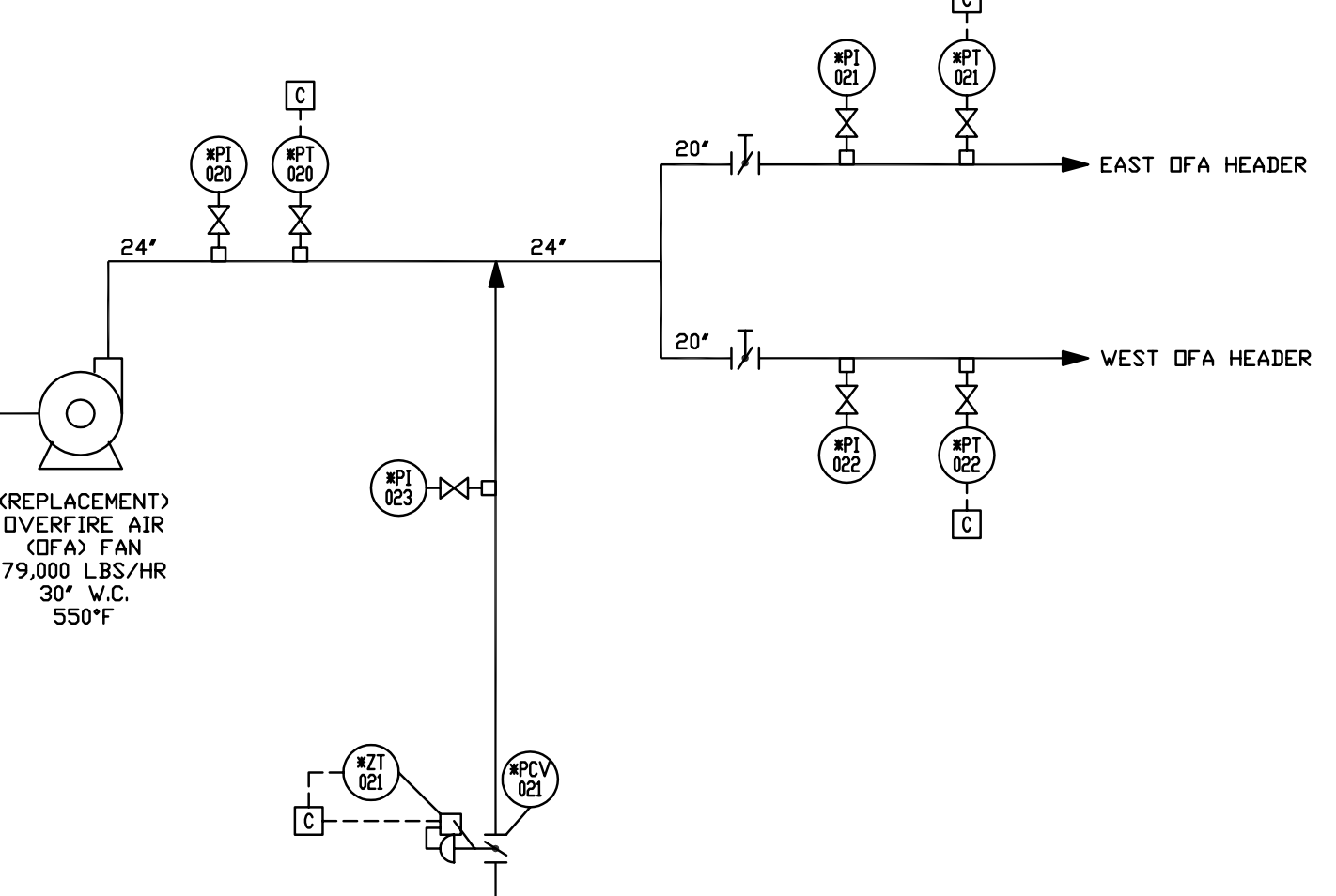

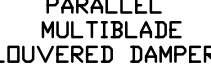

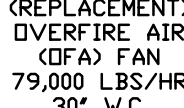

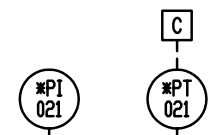

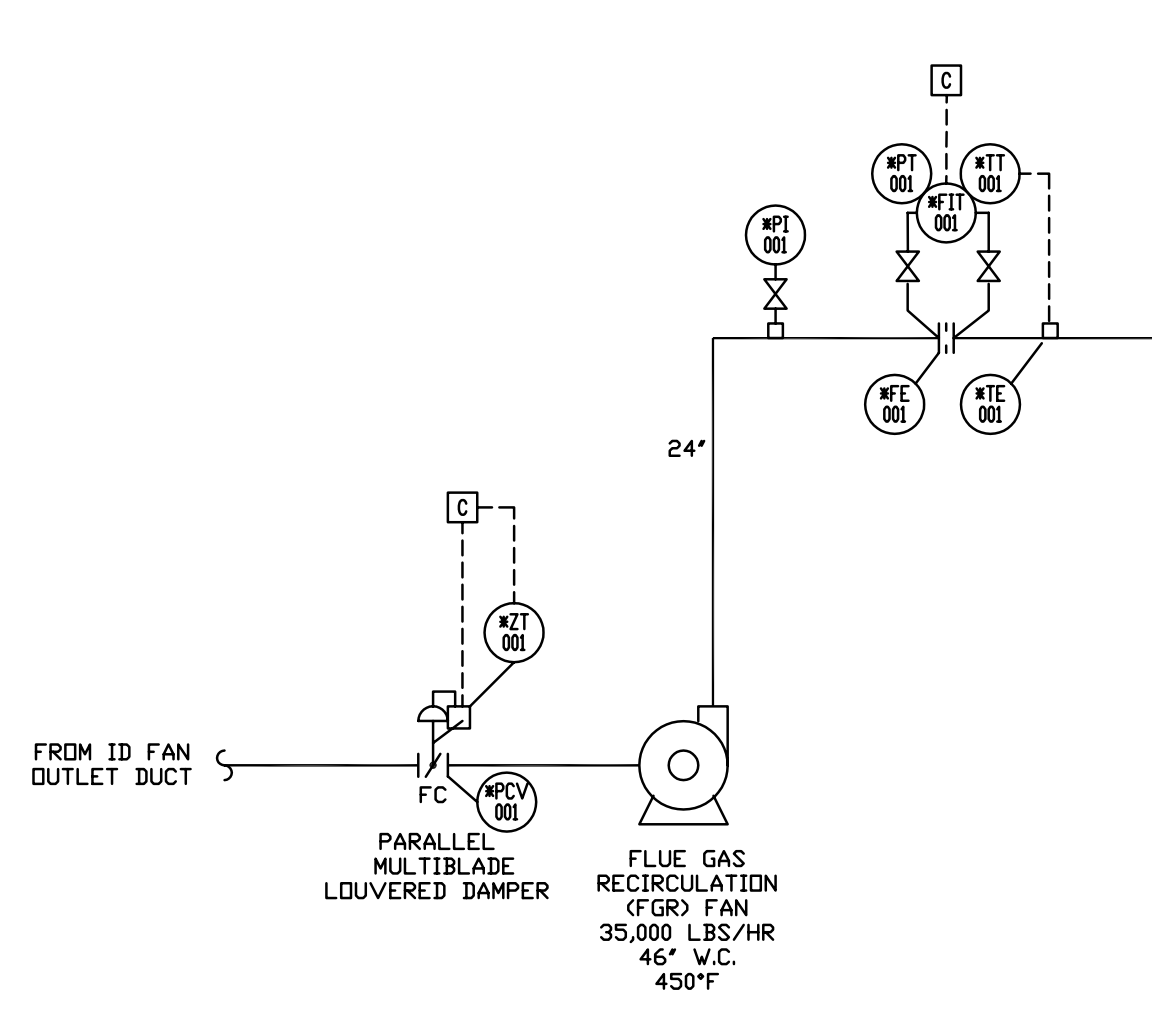

FRDM NATURAL GAS CONTROL SKID,
SEE DWG. \# PID-e $\square$

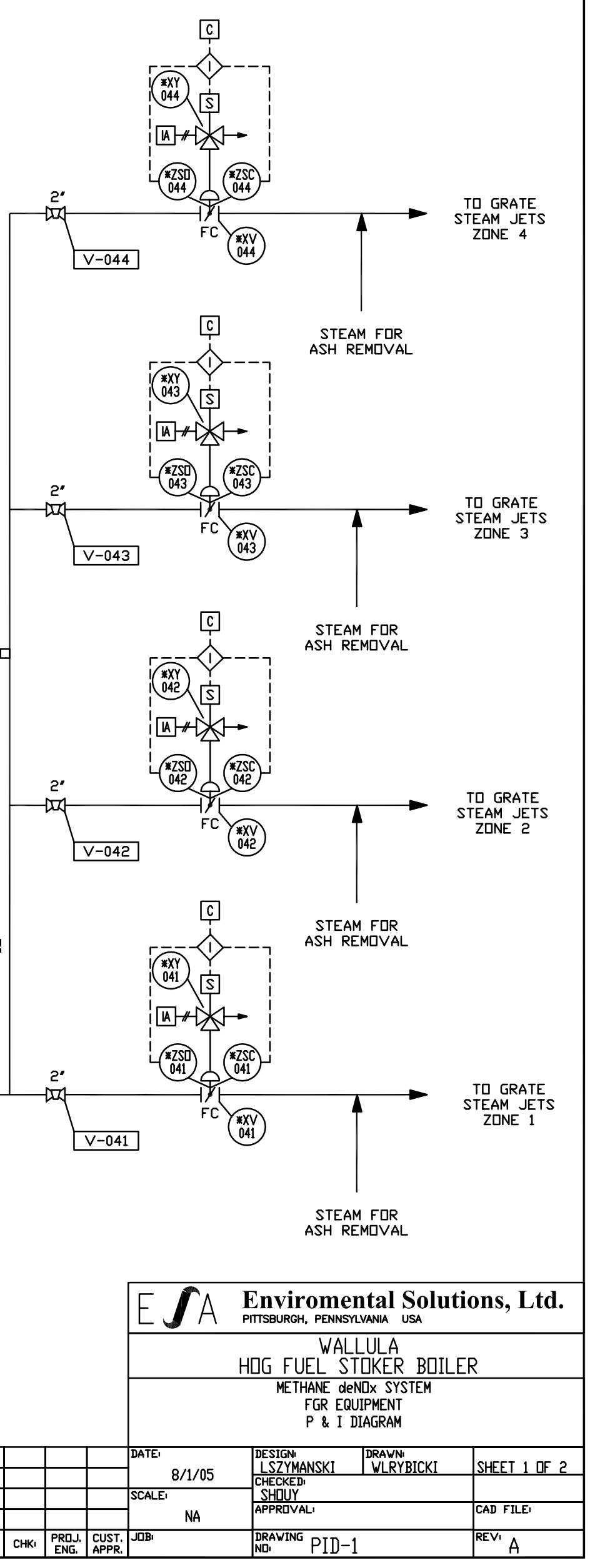




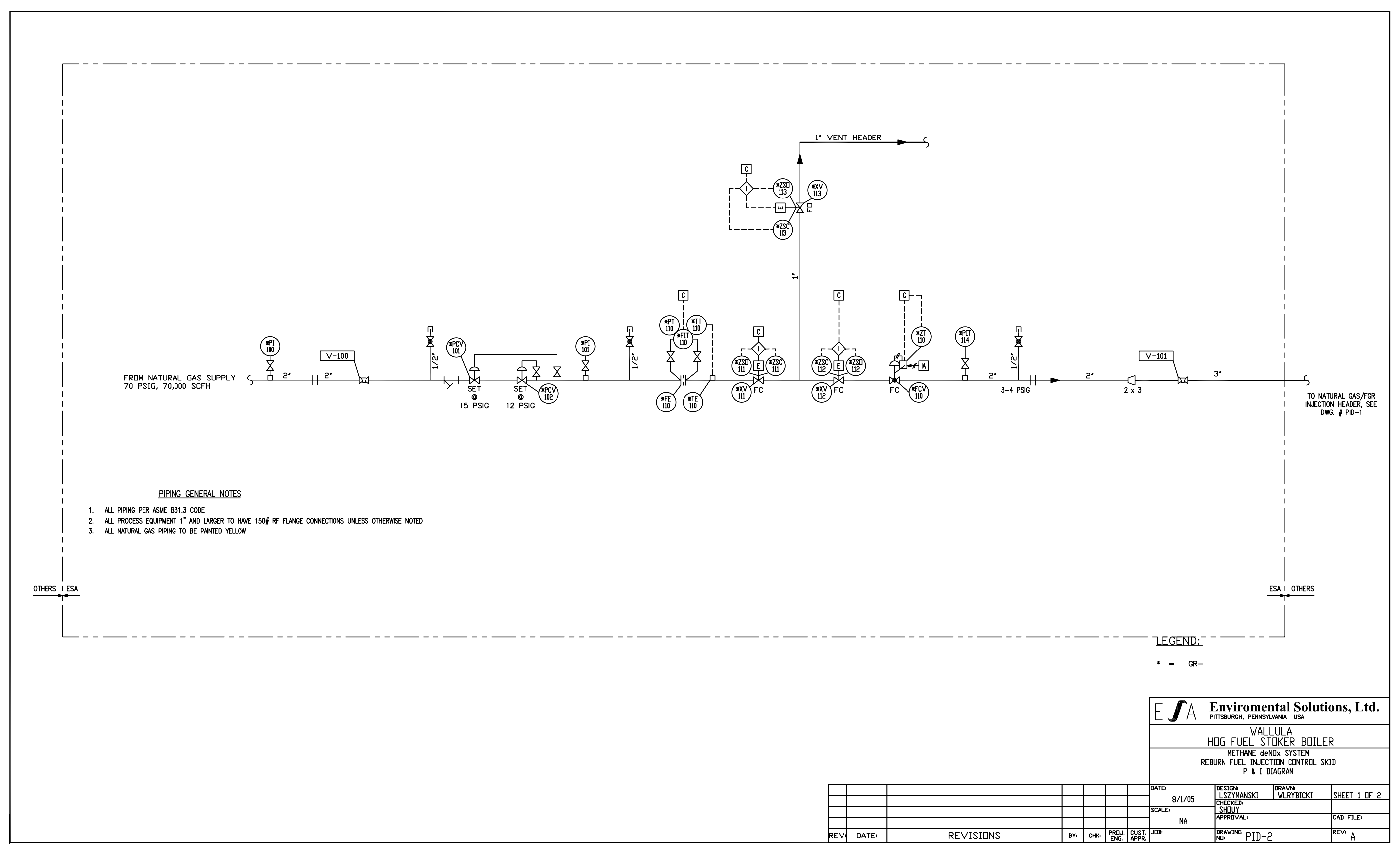



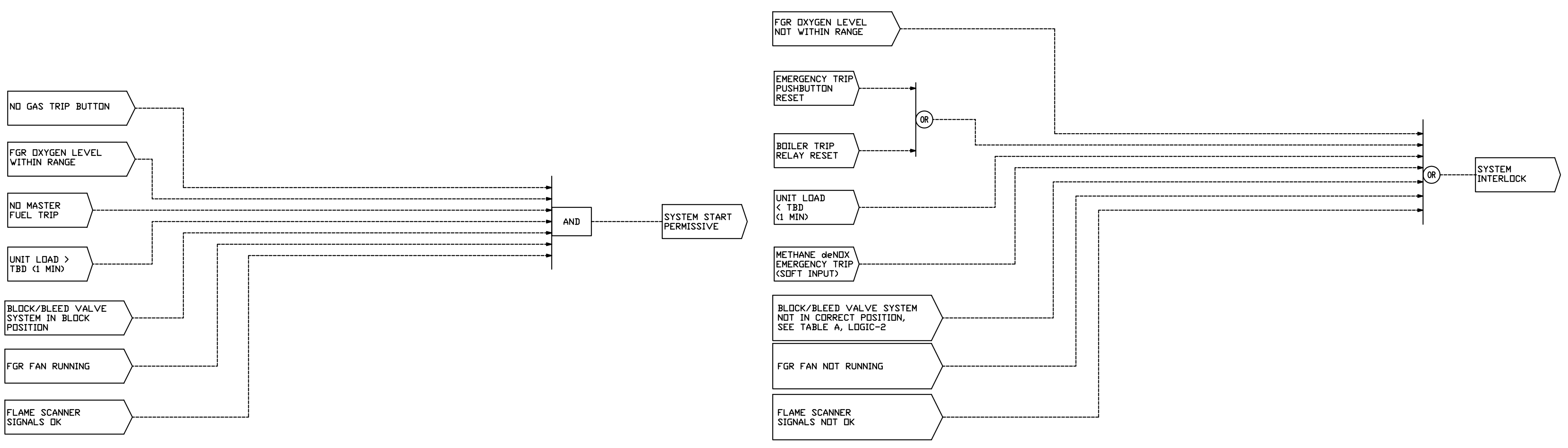

\begin{tabular}{|c|c|c|}
\hline $\int A$ & 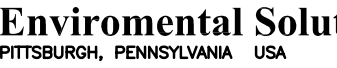 & ns, Ltd. \\
\hline REBUNN & 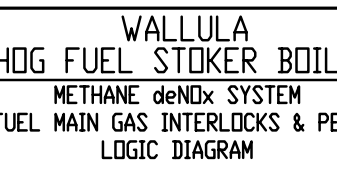 & \\
\hline $8 / 105$ & 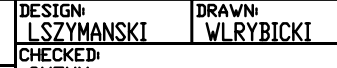 & SHEET 1 OF 5 \\
\hline NA & 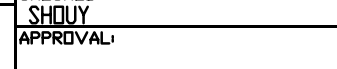 & taD Fille \\
\hline & 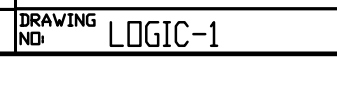 & ${ }^{R E V} A$ \\
\hline
\end{tabular}


FIELD

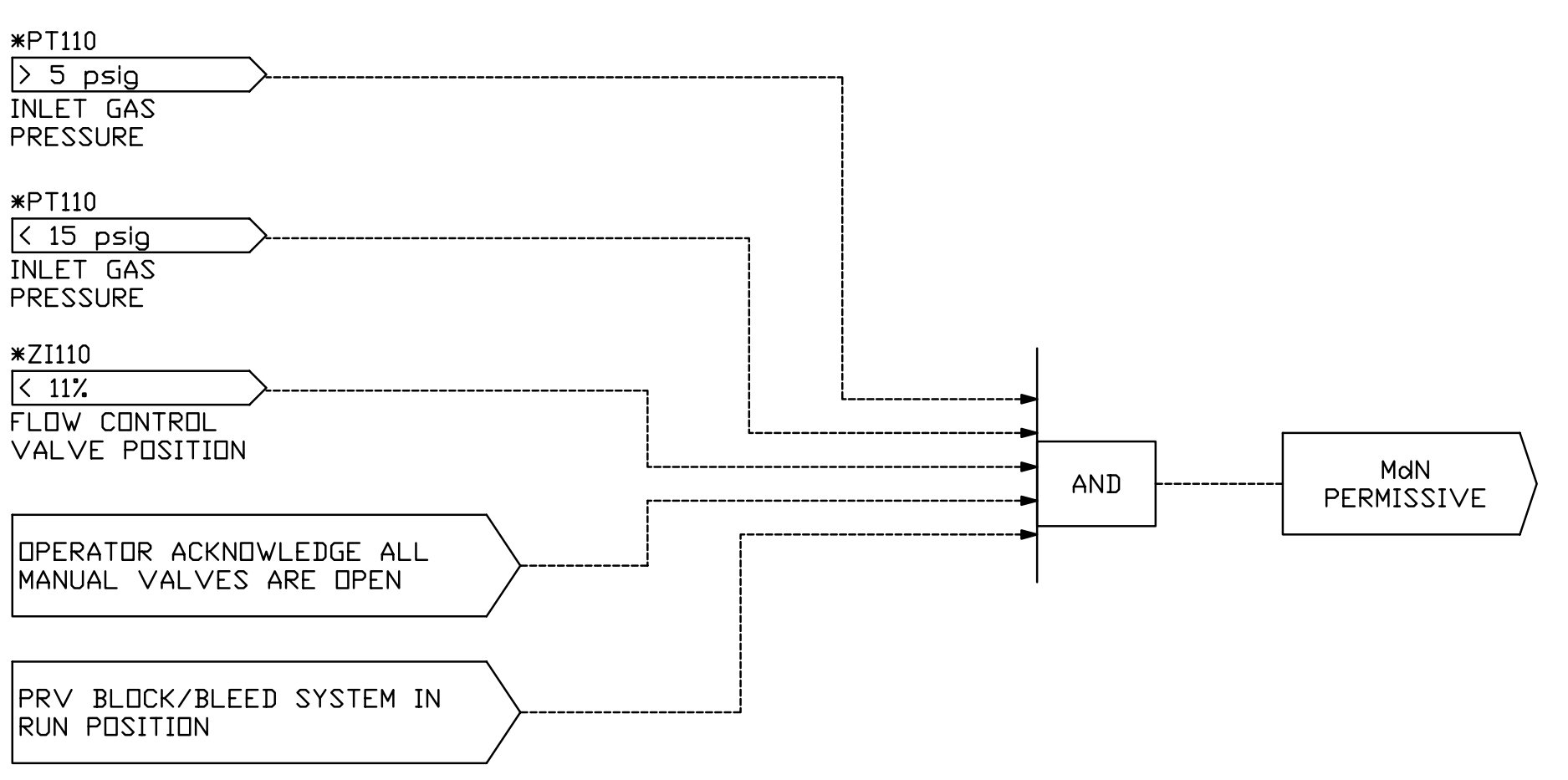

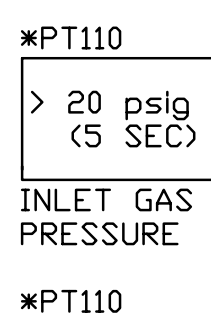

3 PSig
(5 SEC)

INLET GAS

*FIC110

GAS FLOW
DEVIATION

DEVIATIDN
$>$ X\% (1 MIN)

GAS FLOW
CDNTRDL

BLDCK/BLEED OR FLOW CONTRDL

VALVES NDT IN
(SEE TABLE A)

STEAM JET ISDLATIDN SUPPLY
VALVES NDT IN RUN PDSITIDN
VSEE TABLE B) (SEE TABLE B)

\begin{tabular}{|c|c|c|c|c|c|c|c|}
\hline \multicolumn{8}{|c|}{ TABLE A } \\
\hline EQUIPNENT ITEM/PPRRATING STATE & TAGNAMES & REBURN STOPPED & REBURN STARTING & REBURN RUNNING & REBURN STOPPING & REBRUN VENTING & REBRUN TRIP \\
\hline REBURN BLDCK VALVES & $\mathrm{xV} 111, \mathrm{xV} 112, \mathrm{x}$ V121, $\mathrm{xV} 122$ & CLOSED & DPEN & DPENED & CLDSE & CLOSED & CLOSE \\
\hline REBRUN BLEED VALVE & $\mathrm{xV} 113, \mathrm{xV} 123$ & DPENED & $\begin{array}{cl}\text { CLOSE } \\
\end{array}$ & CLOSED & DPEN & DPENED & DPEN \\
\hline FLOW CONTROL VALVE & FCV110, FCV120 & MIN & CONTROL & CONRROL & RAMP TO MIN & $\begin{array}{l}\text { MIN } \\
\end{array}$ & MIN \\
\hline
\end{tabular}

\begin{tabular}{|c|c|c|c|c|c|}
\hline \multicolumn{6}{|c|}{ TABLE B } \\
\hline EQUPPMENT ITEM/DPERATING STAAE & TAGNAMES & CLEANING STARTING & CLEANING RUNNING & CLEANING STDPPING & CLEANING STOPPED \\
\hline STEAM JET SUPPLYY ISOLATION VALVES & $\mathrm{xV} 041, \mathrm{xV} 042, \mathrm{xV043,} x \mathrm{x} 044$ & 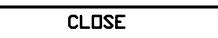 & $\begin{array}{l}\text { CLDSED } \\
\end{array}$ & $\begin{array}{l}\text { CLDSED } \\
\end{array}$ & DPEN \\
\hline
\end{tabular}

NDTE:

GRATE ASH REMUVAL IS A LOCAL OPERATIDN, DIVIDED INTO 4 ZONES.

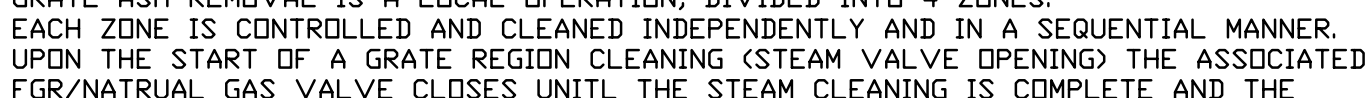

FGR/NATRUAL GAS VALVE
TABLE KEY:

CLDSED -VALVE CLDSED

OPENED -VALVE DPENED
CLDSE - VALVE CLDSING

$\begin{array}{ll}\text { CLDSE } & \text {-VALVE CLDSING } \\ \text { OPEN } & \text {-VALVE DPENING }\end{array}$

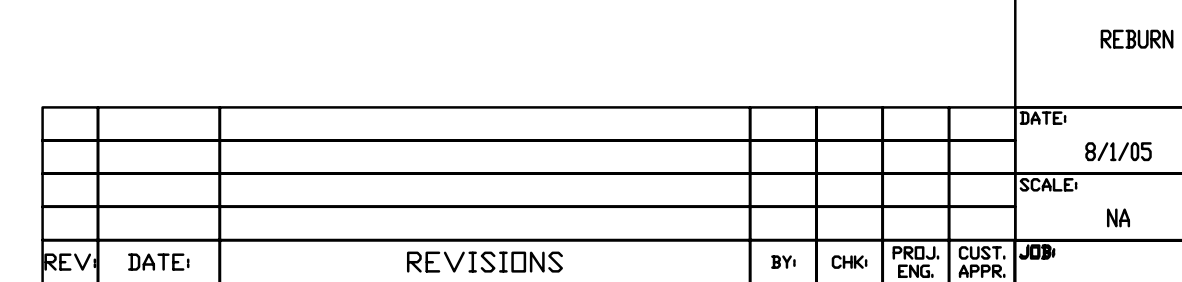

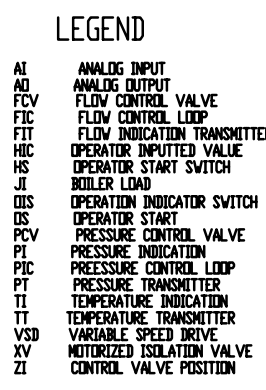

LEGEND:

$*$ GR-

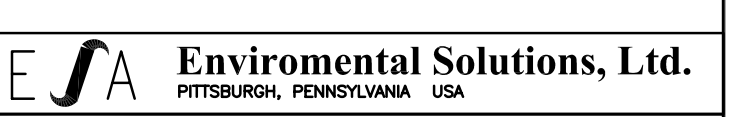
HIG FUEL WALULLA BTKER BDILER

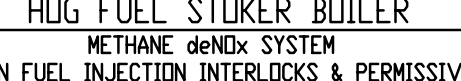

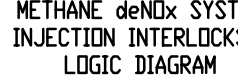

\begin{tabular}{|c|c|}
\hline 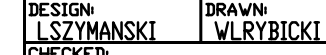 & SHEET 2 OF 5 \\
\hline $\begin{array}{l}\text { SHHOY } \\
\text { APPRPVAL } \\
\end{array}$ & \\
\hline NRaAving LDGIC-2 & $\mathrm{REVI}^{\mathrm{R}} \mathrm{A}$ \\
\hline
\end{tabular}




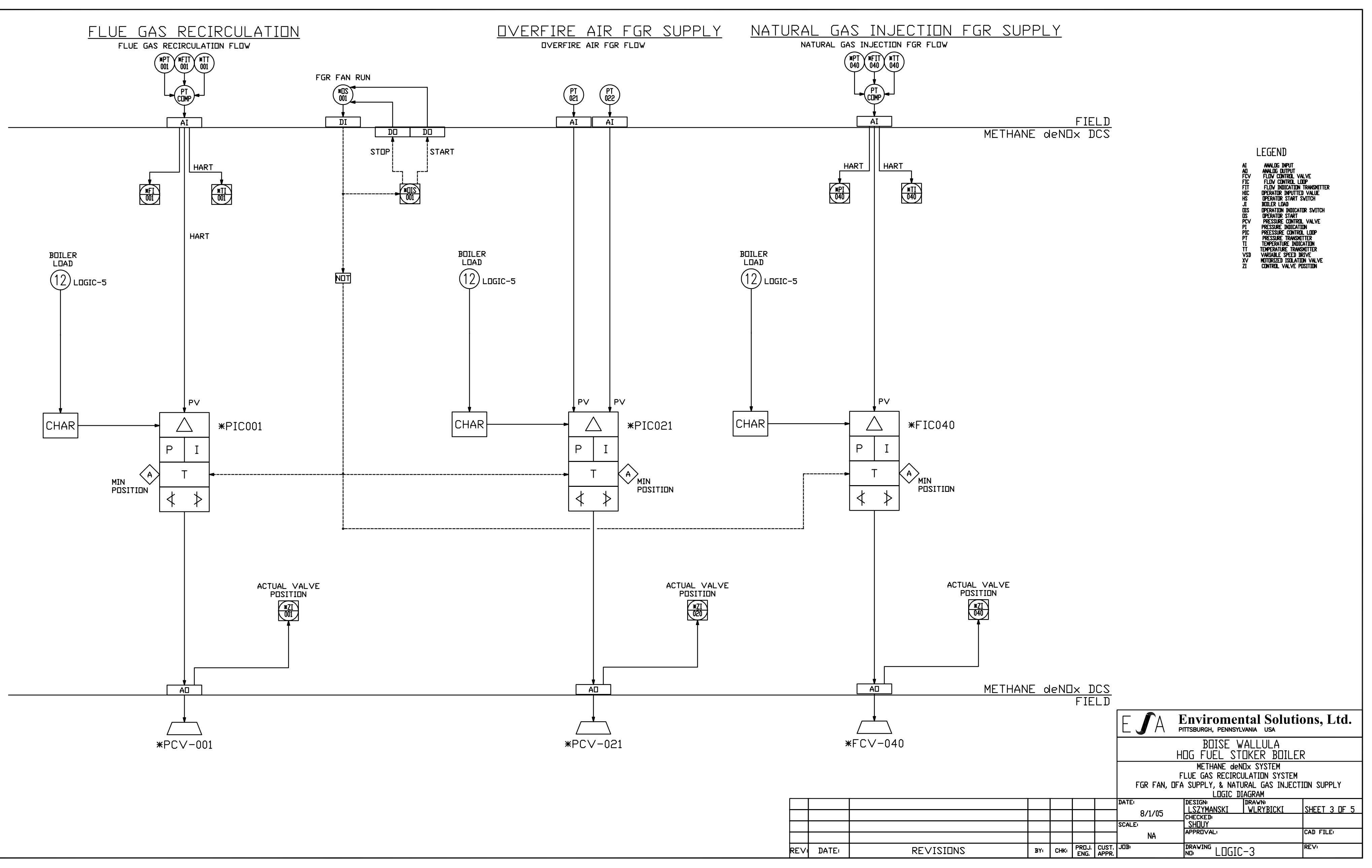


QVERFIRE AIR SUPPLY

OVERTIRE AIR FGR FLOW

(Pre)

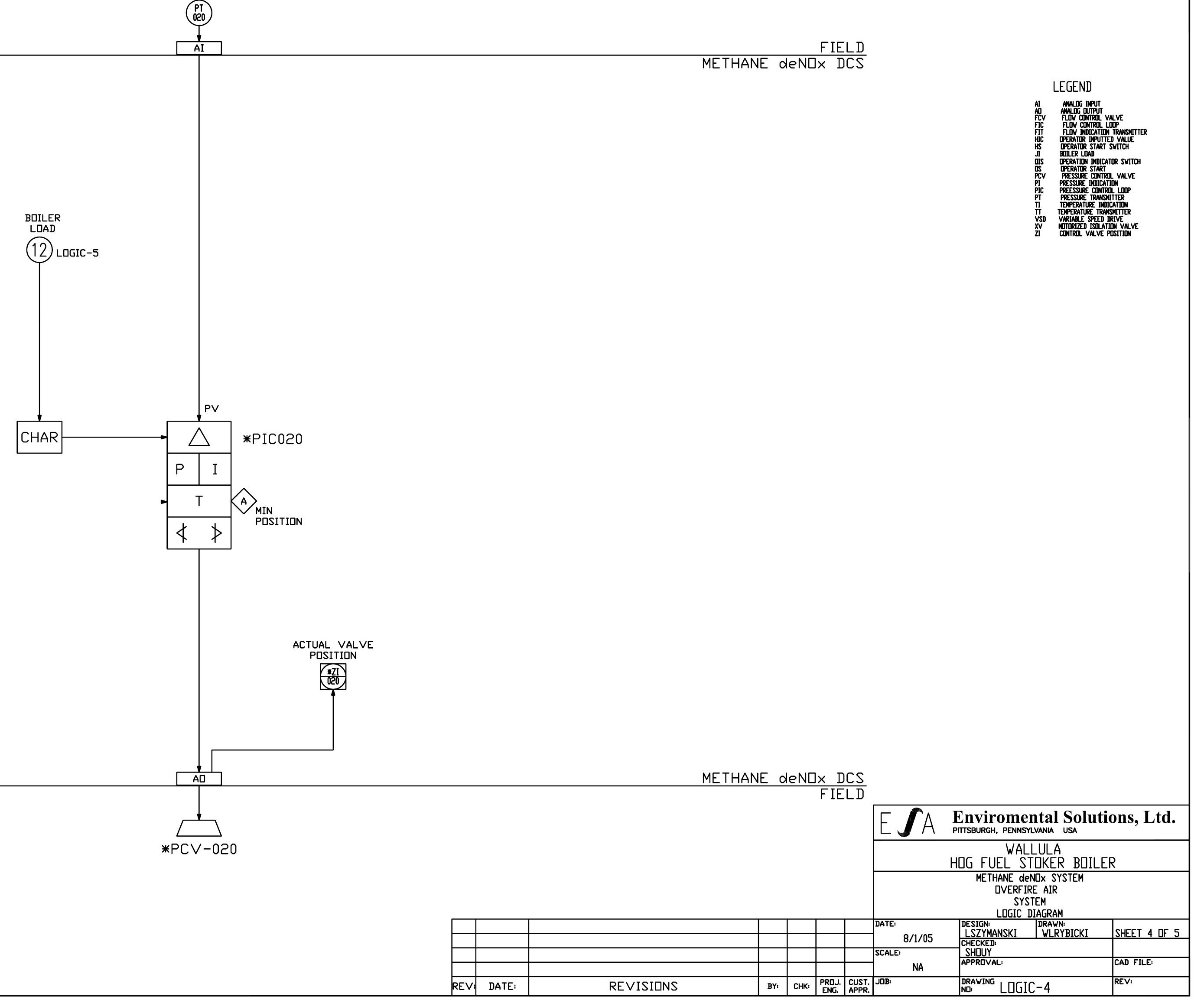


METHANEdeNDX GAS FLIW CDNTRDL

\begin{tabular}{l} 
REBURN \\
EERMISSIVES OK \\
\hline
\end{tabular}

RERRUN START

[ARS

\begin{tabular}{l} 
REREUN \\
INITRRLCK \\
\hline
\end{tabular}

\begin{tabular}{|l}
\hline RERRUN BLLCKNVENT \\
VALVES IN RUN POSITID
\end{tabular}

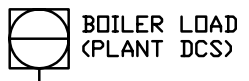

AI PEER TD PEER

m

$0-x \times X L B S / H R$.

TARGET

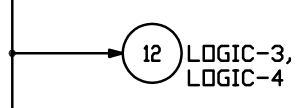

$0-10 \%$

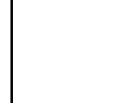

METHANE deNDX DCLS

SUPPLY GAS FLON

(ivi) (init) (iii)

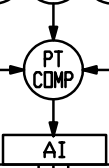

商

LEGEND

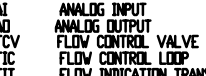

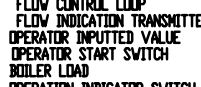

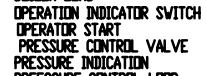

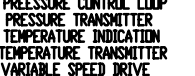

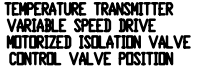
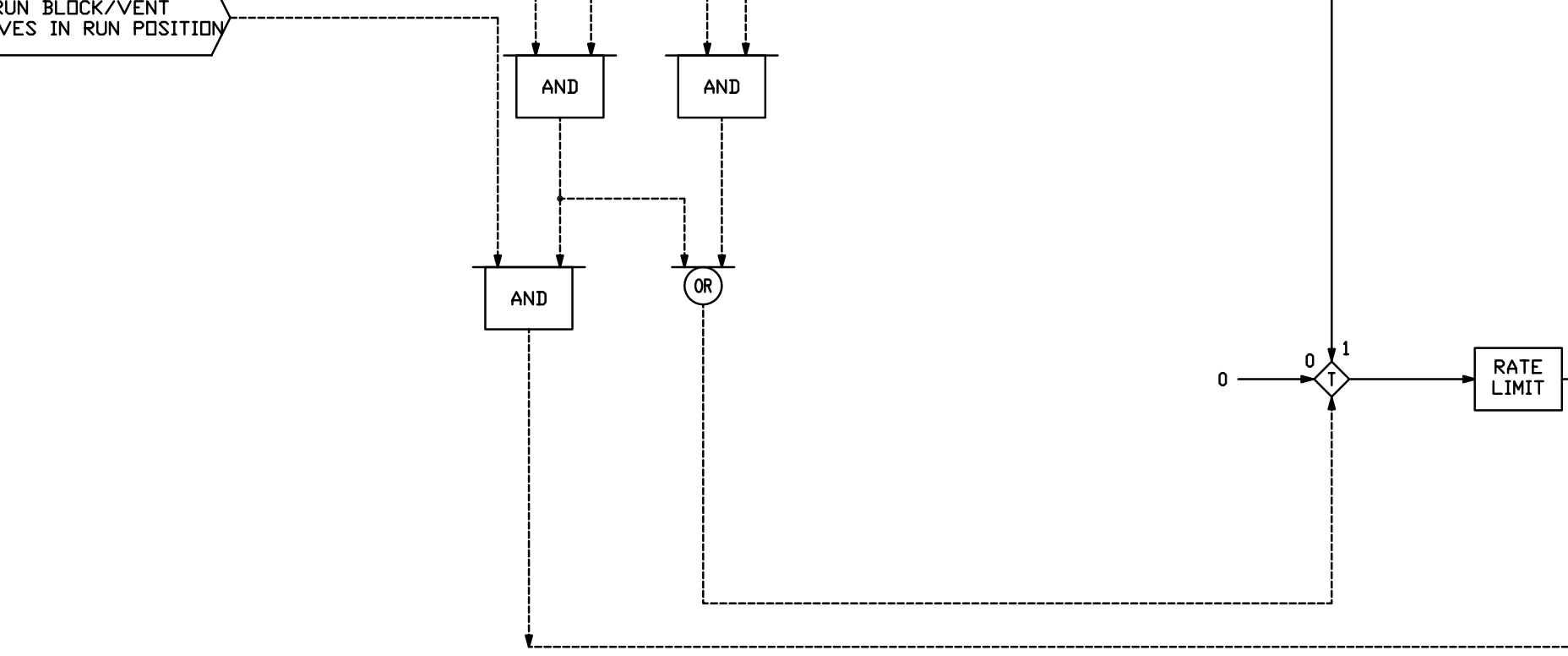

$\stackrel{b}{a} \frac{a \text { (LBS } / \text { HR.) }}{a \times \text { STEAMING RATE }} \times \frac{b}{1000 \times 1000}$

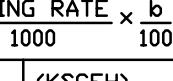

LEGEND:

METHANE deNDX DCS

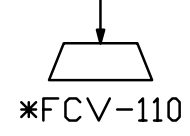

\section{E $\int A$ Enviromental Solutions, Ltd.} HIG FUEL STLUKER BDILER MEUTANEL STENDE SYSTEM BILER MaN METHANE D RENQX SYSTEM
REBURN FUEL FLLW CONTRDL
LOGIC DIAGGAM

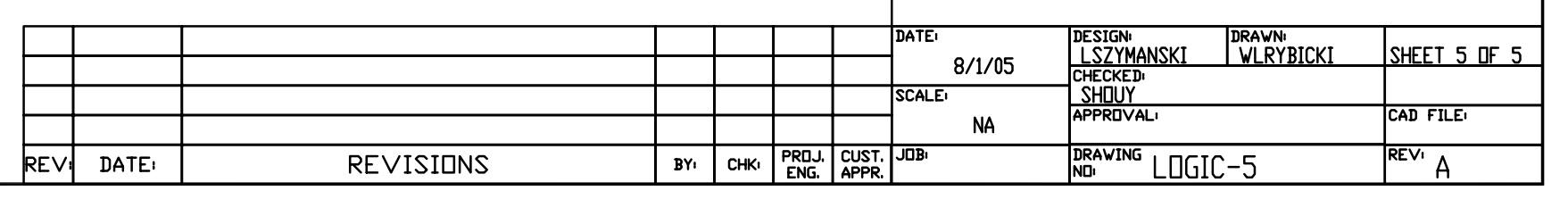



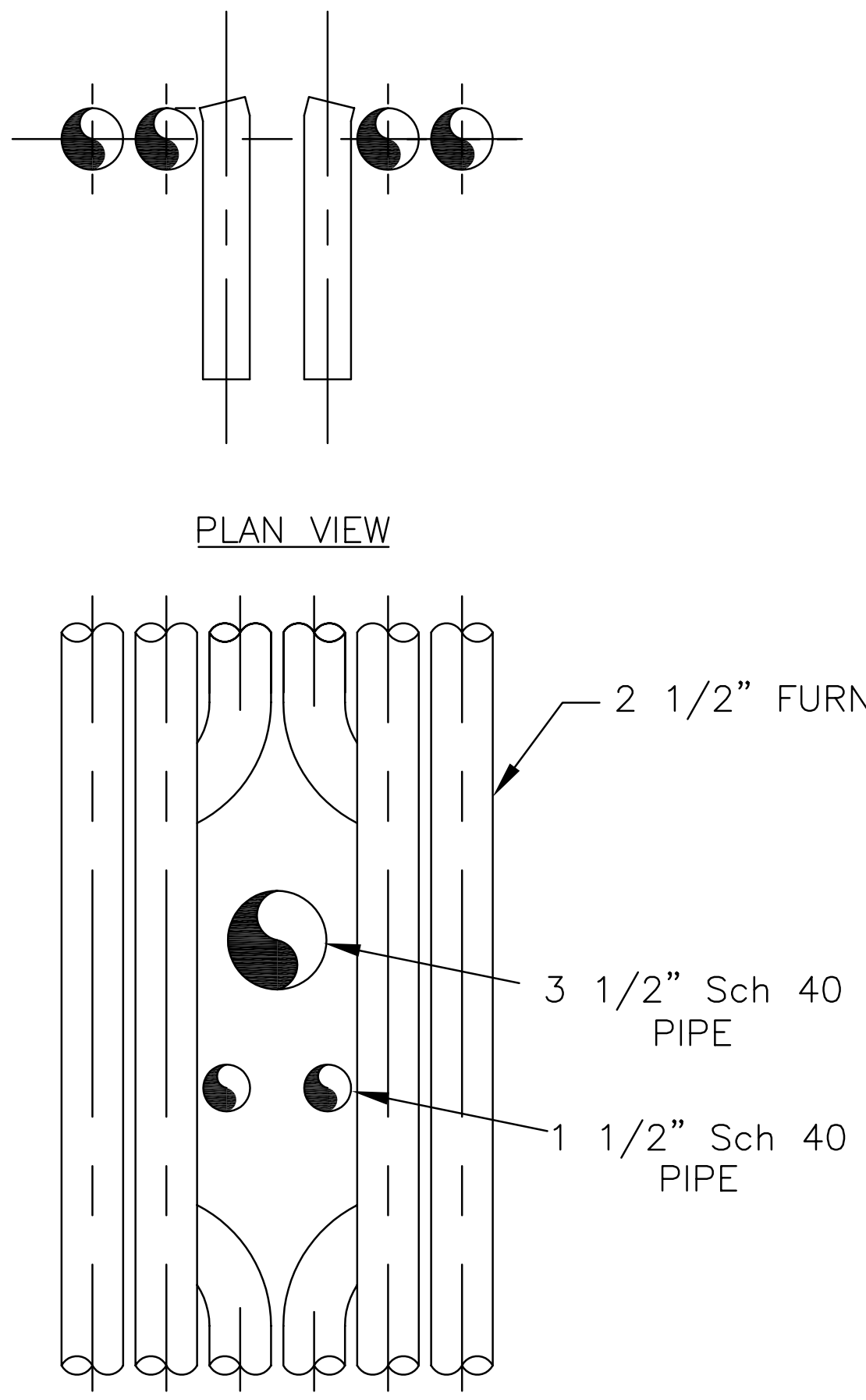

\section{ELEVATION VIEW}

@ OFA NOZZLE CONFIGURATION

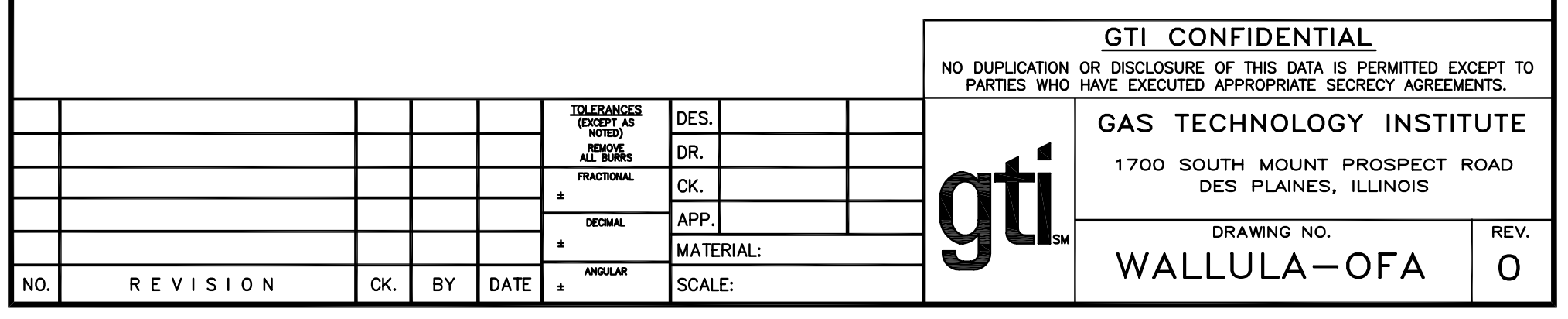




\subsubsection{Wallula MdN System Equipment Specifications}

\section{Table 7-4 Boise Wallula - MdN Design Specification Index}

\begin{tabular}{|c|c|c|}
\hline Service & Specification \# & Specification Description \\
\hline \multicolumn{3}{|c|}{ Rotating Equipment } \\
\hline & \multirow{2}{*}{$\begin{array}{l}\text { FGR-FAN } \\
\text { OFA FAN }\end{array}$} & FGR Supply Fan \\
\hline & & OFA Supply Fan \\
\hline \multicolumn{3}{|c|}{ Instrumentation: Flow Transmitters } \\
\hline \multicolumn{2}{|c|}{ FGR-FIT } & Mass Flow Transmitters for FGR System \\
\hline \multicolumn{2}{|r|}{ CH4-FIT } & Flow Transmitters for Methane Supply Zones \\
\hline \multicolumn{3}{|c|}{ Instrumentation: Pressure } \\
\hline \multicolumn{2}{|r|}{ FGR-PRESS } & Pressure Transmitters for FGR System \\
\hline \multicolumn{2}{|r|}{ CH4-PRESS-XMIT } & Pressure Transmitters for Methane Supply System \\
\hline \multicolumn{2}{|r|}{ FGR/OFA GAUGE } & Pressure Gauges for FGR/OFA System \\
\hline \multicolumn{2}{|r|}{ CH4-PRESS } & Pressure Gauges for Methane Supply System \\
\hline \multicolumn{3}{|c|}{ Instrumentation: Temperature } \\
\hline \multicolumn{2}{|r|}{ FIT-RTD } & RTD/Thermowell for FGR Flow Transmitters \\
\hline \multicolumn{2}{|r|}{ CH4-RTD } & RTD/Thermowell for Methane Flow Transmitters \\
\hline \multicolumn{2}{|r|}{ FGR-TEMP } & Temperature Transmitters for FGR System \\
\hline \multicolumn{2}{|r|}{ FGR-RTD } & RTD/Thermowell for Temperature Transmitters \\
\hline \multicolumn{3}{|c|}{ Instrumentation: Control Valve } \\
\hline \multicolumn{2}{|c|}{ PCV-001 } & FGR Fan Inlet Damper Actuator \\
\hline \multicolumn{2}{|r|}{ PCV-021 } & FGR Pressure Control Valve for OFA System \\
\hline \multicolumn{2}{|r|}{ FCV-040 } & FGR Flow Control Valve for Methane Injection \\
\hline \multicolumn{2}{|r|}{ PCV-020 } & OFA Fan Inlet Damper Actuator \\
\hline \multicolumn{2}{|r|}{ FCV-110 } & Flow Control Valves for Methane Supply \\
\hline \multicolumn{3}{|c|}{ Instrumentation: Dampers } \\
\hline \multicolumn{2}{|c|}{$\begin{array}{r}\text { DAMPERS } \\
\end{array}$} & Butterfly Dampers for FGR System \\
\hline \multicolumn{3}{|c|}{ Instrumentation: Isolation Valve } \\
\hline \multicolumn{2}{|c|}{ XV-111 \& -112} & Double Block \& Bleed Isolation Valve for Methane \\
\hline \multicolumn{2}{|r|}{ XV-041 } & Zone 1 Methane/FGR Injection Isolation Valve \\
\hline \multicolumn{2}{|r|}{ XV-042 } & Zone 2 Methane/FGR Injection Isolation Valve \\
\hline \multicolumn{2}{|r|}{ XV-043 } & Zone 3 Methane/FGR Injection Isolation Valve \\
\hline & XV-044 & Zone 4 Methane/FGR Injection Isolation Valve \\
\hline Instrum & Valve & \\
\hline & $\mathrm{XV}-113$ & Double Block \& Bleed Vent Valve \\
\hline Instrum & Valve & \\
\hline & PLUG-VLV & Manual Plug Valve for Methane Isolation \\
\hline Instrum & lator & \\
\hline & PRESS-REG & Pressure Regulators for Methane Supply \\
\hline Instrum & & \\
\hline & $\mathrm{O}_{2}$-INST & Oxygen Analyzer for FGR System \\
\hline & FLAME & Flame Scanner for MdN System \\
\hline
\end{tabular}




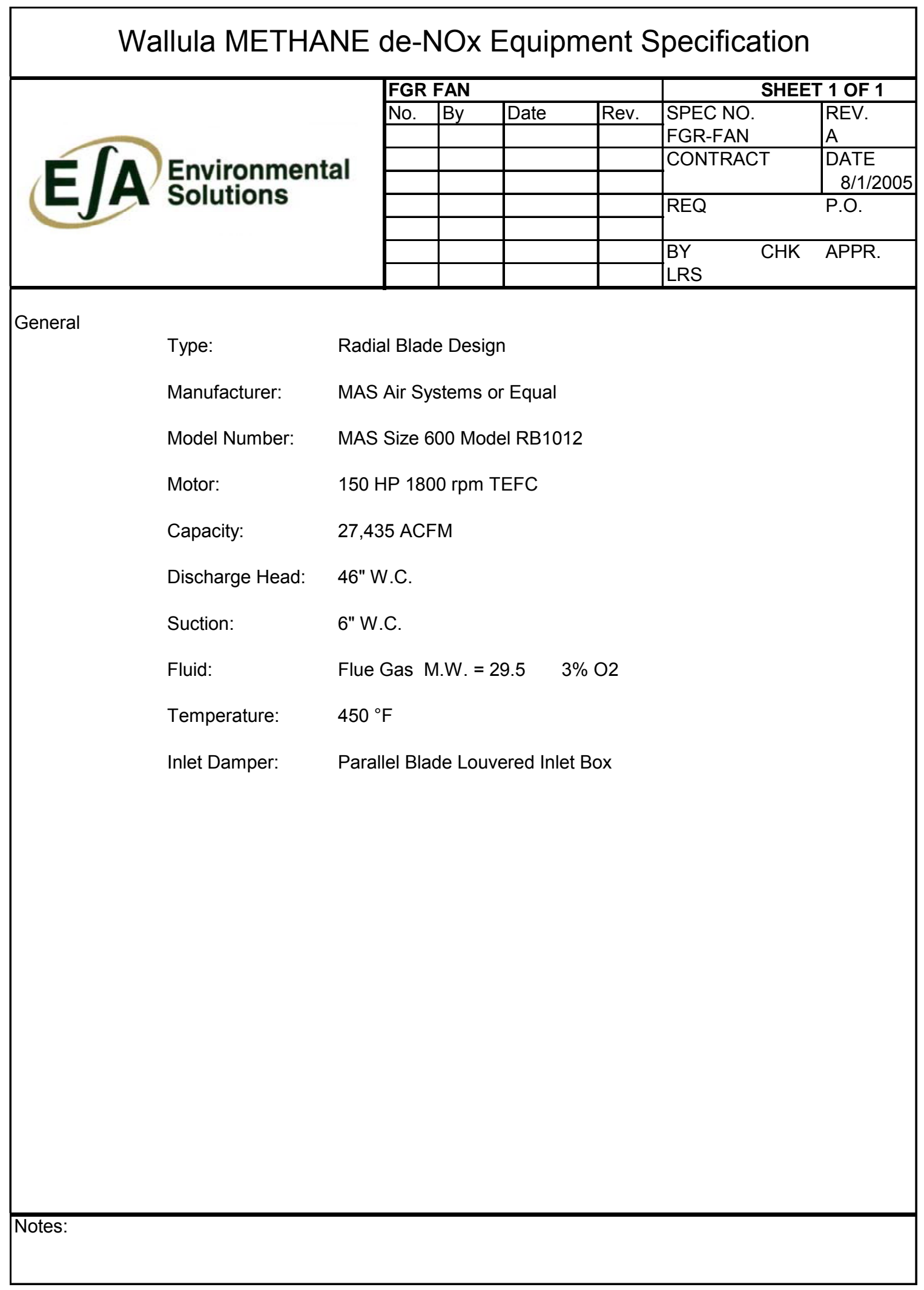




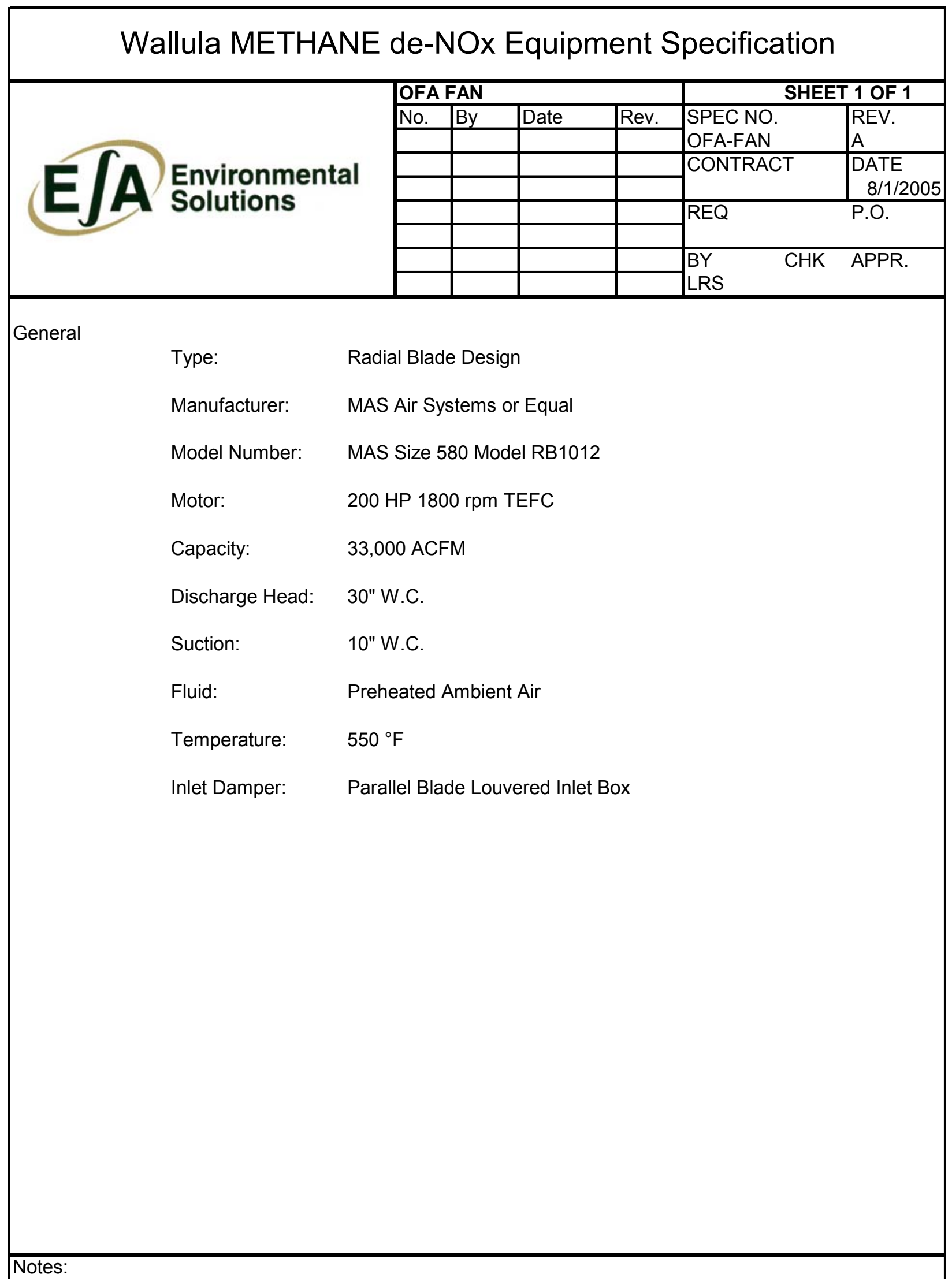




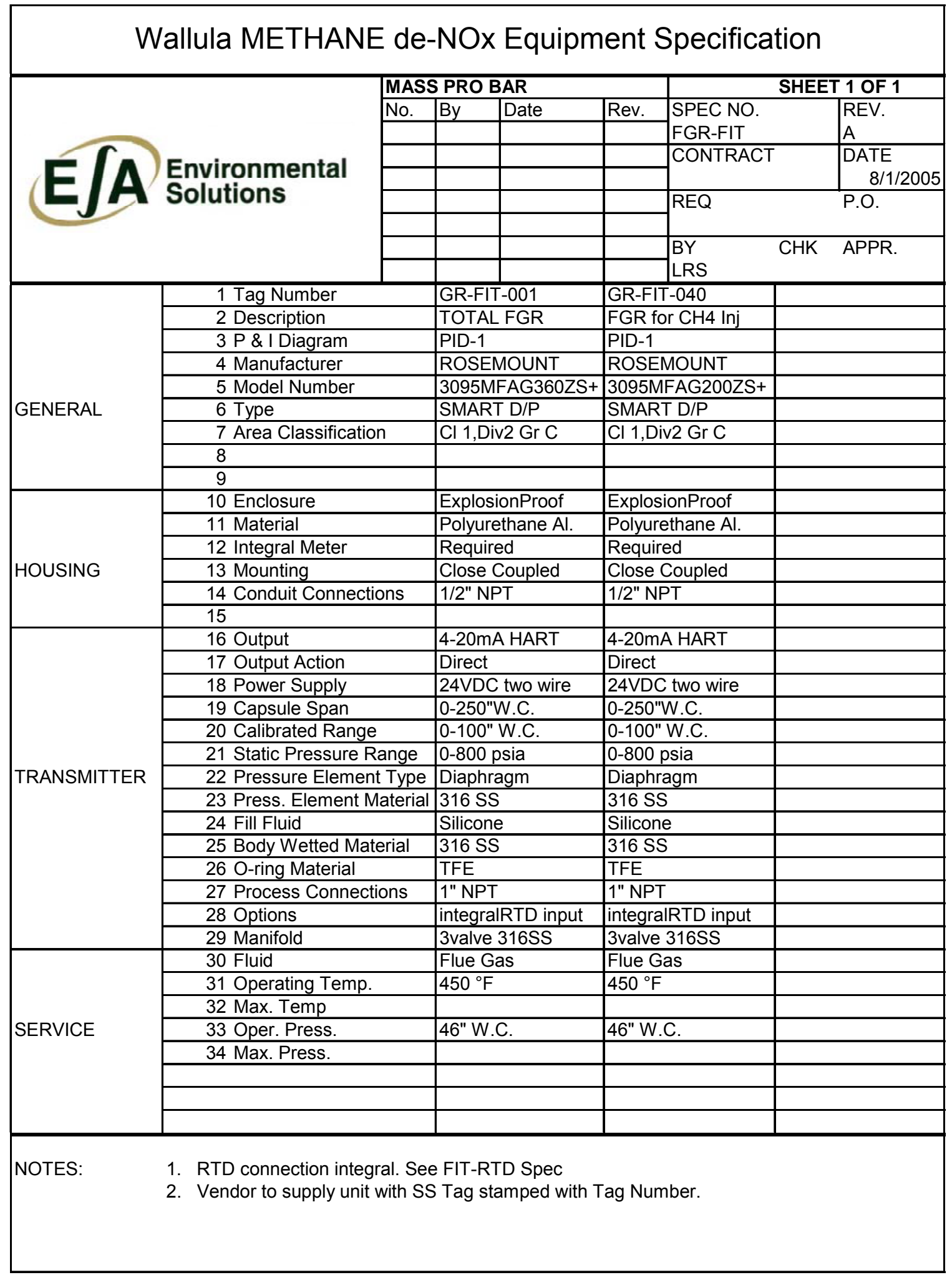




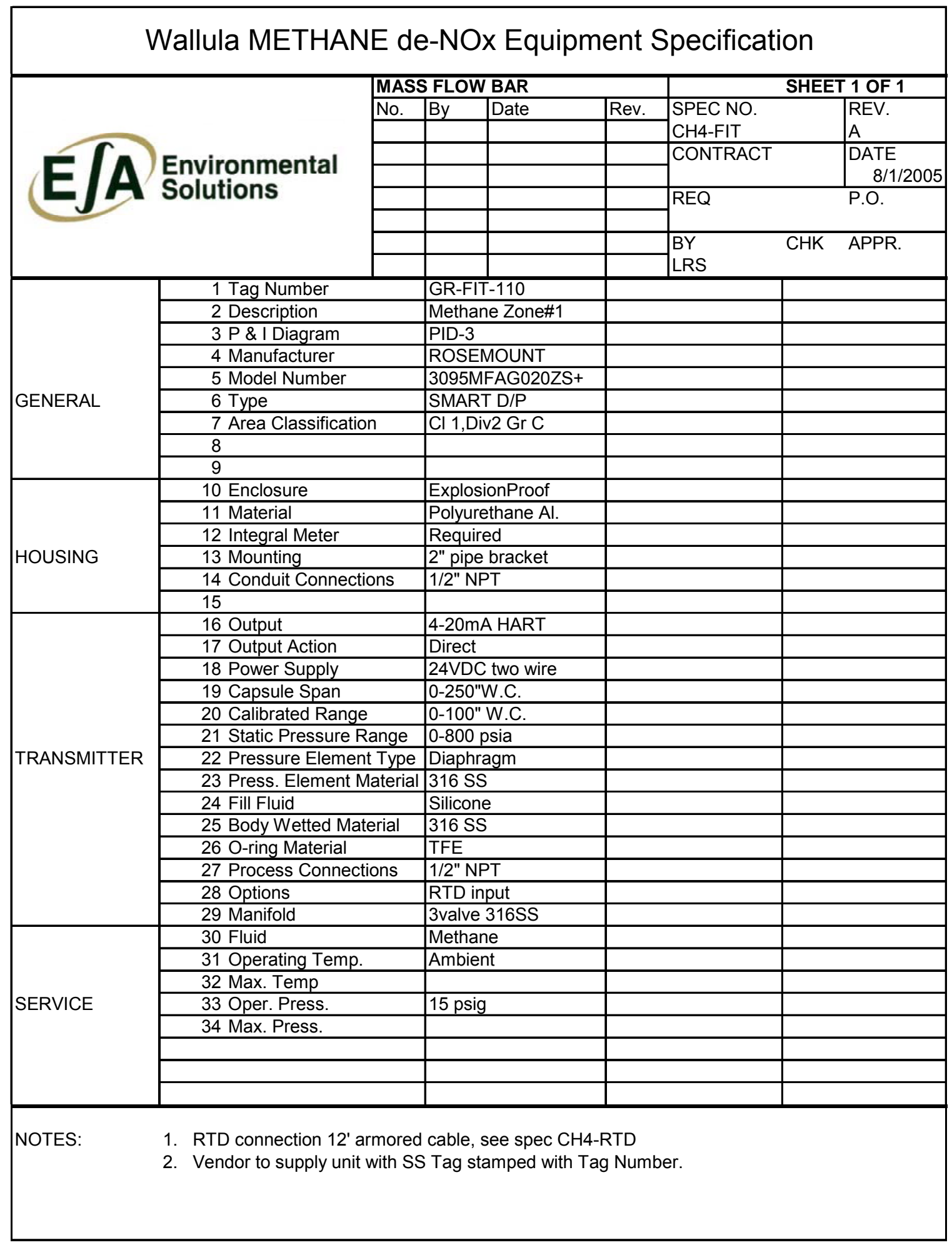




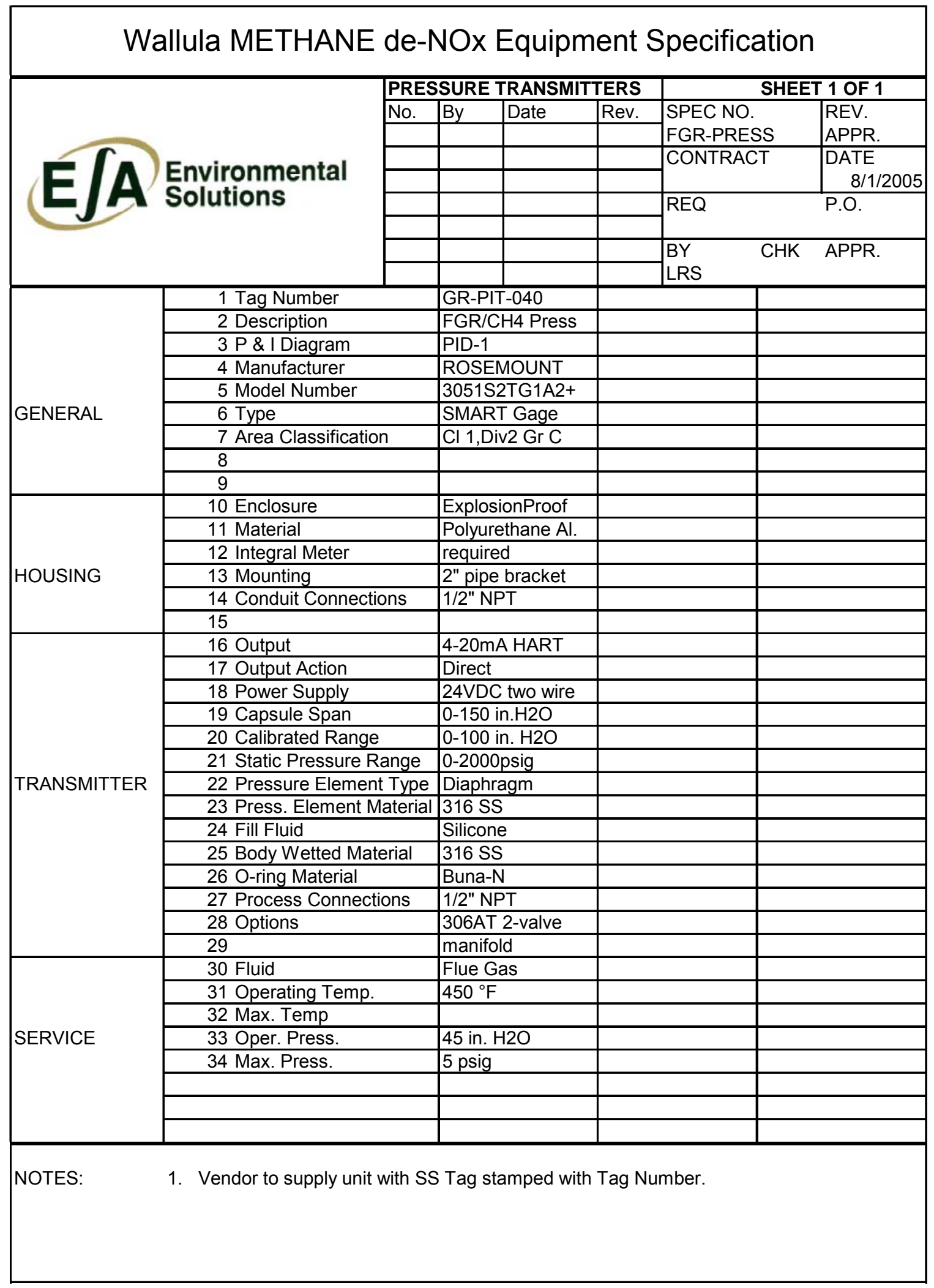




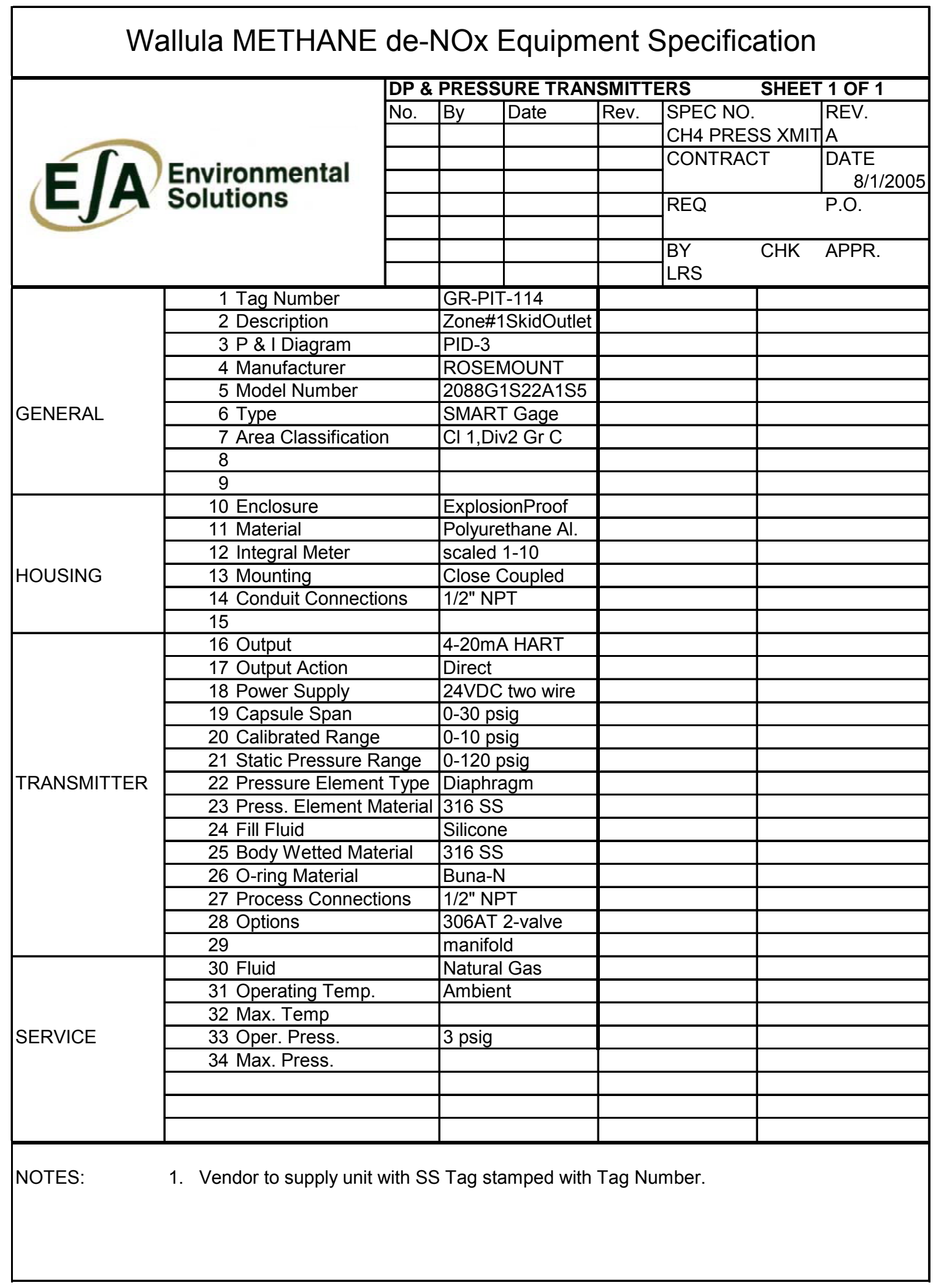




\section{Wallula METHANE de-NOx Equipment Specification}

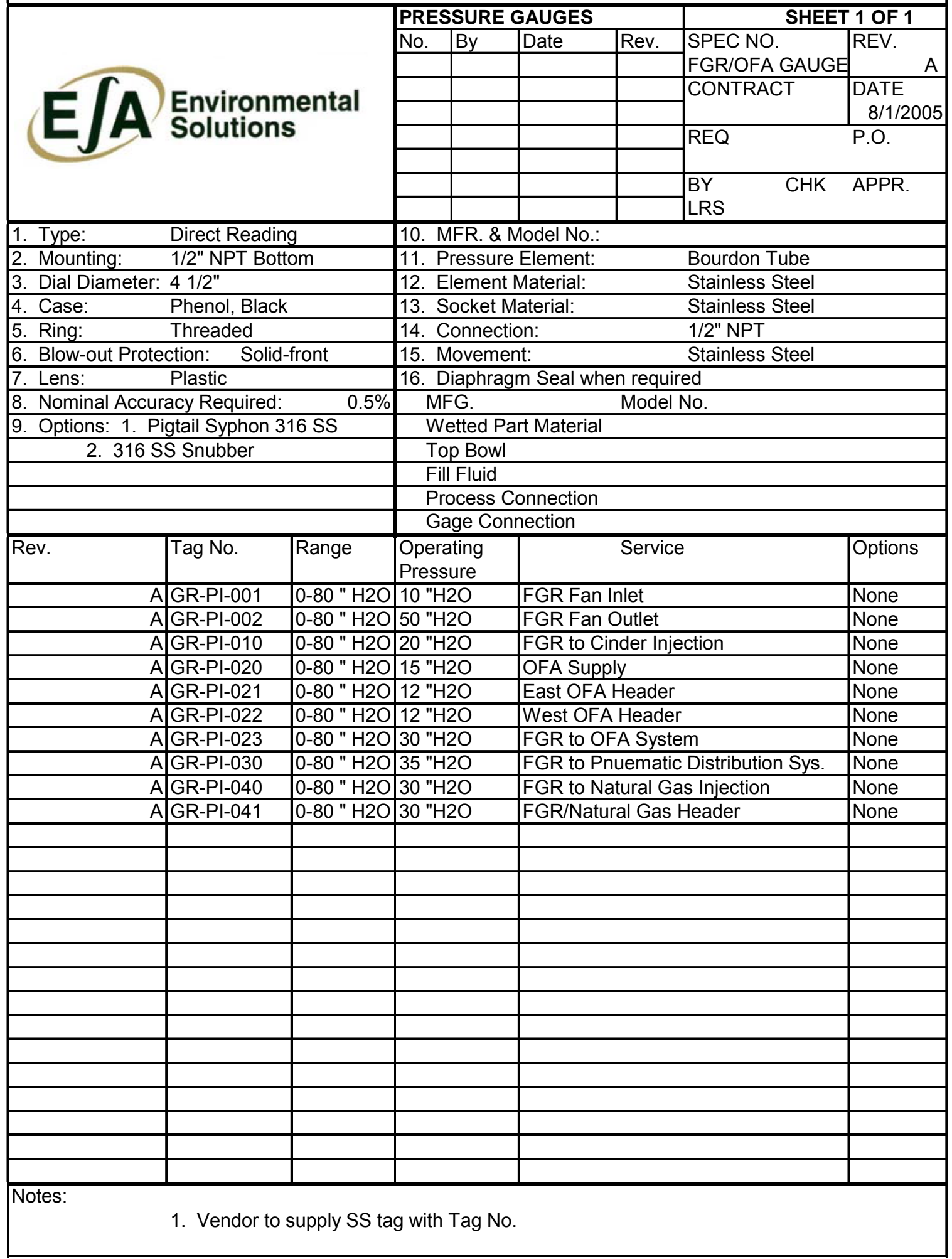




\section{Wallula METHANE de-NOx Equipment Specification}

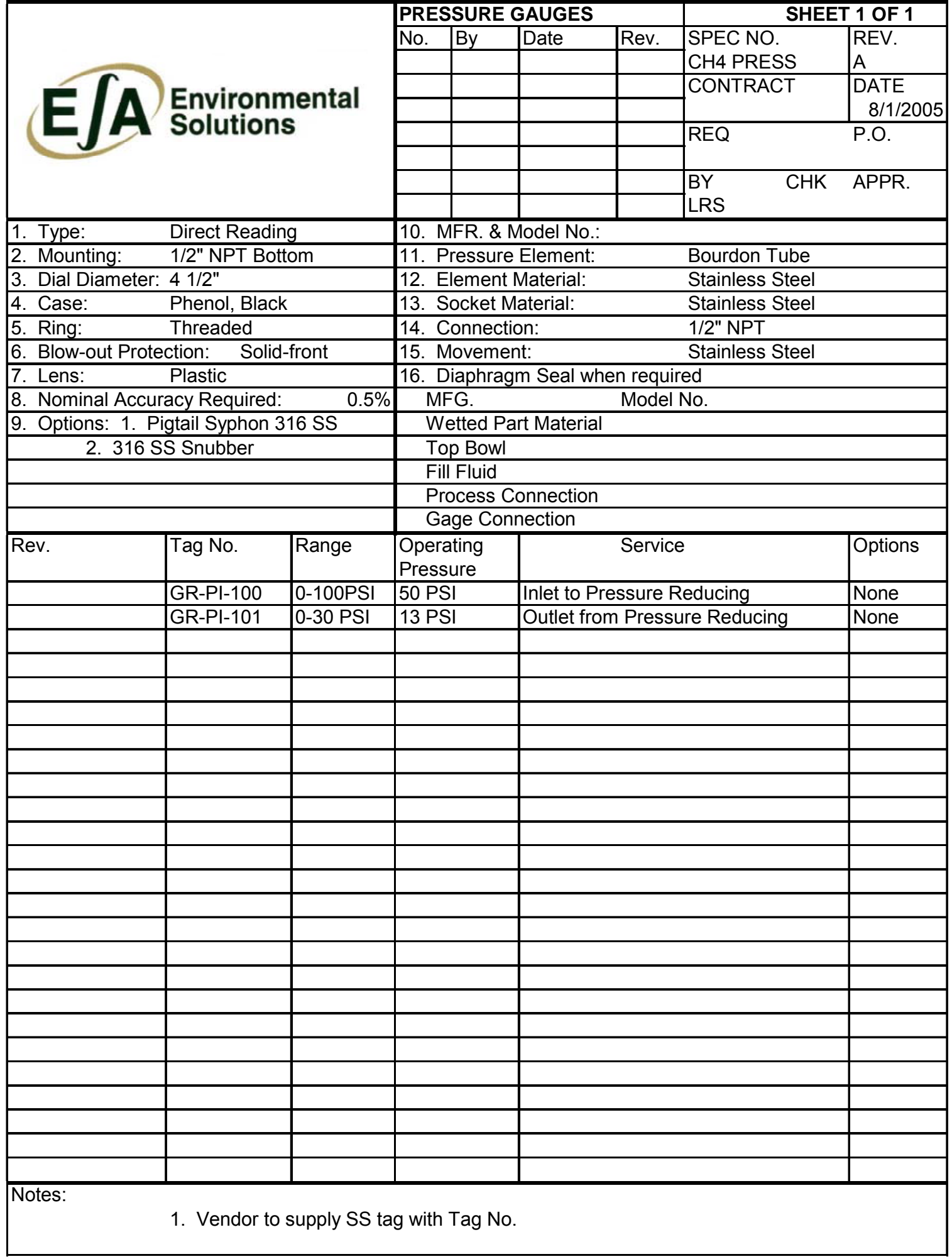




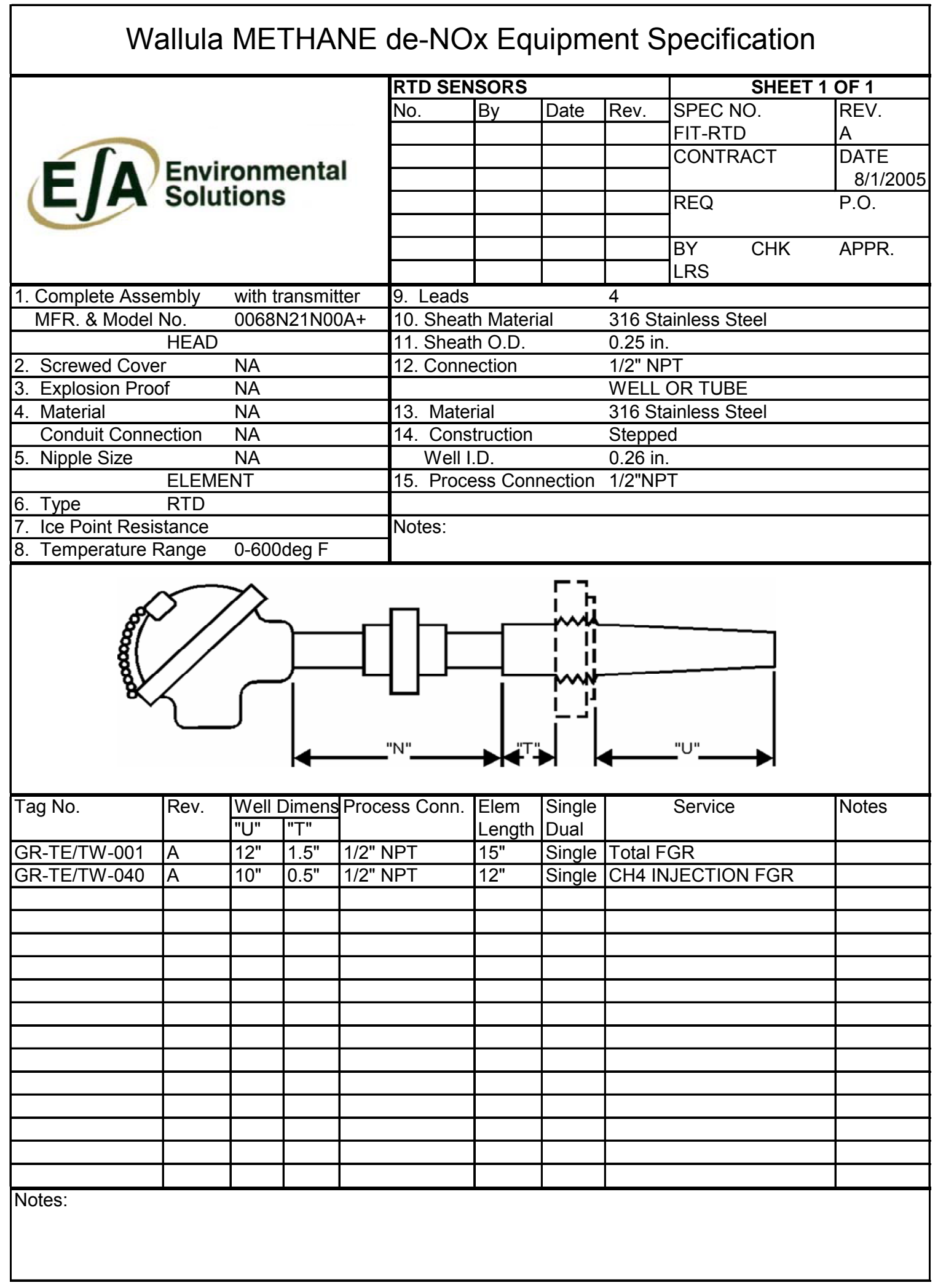




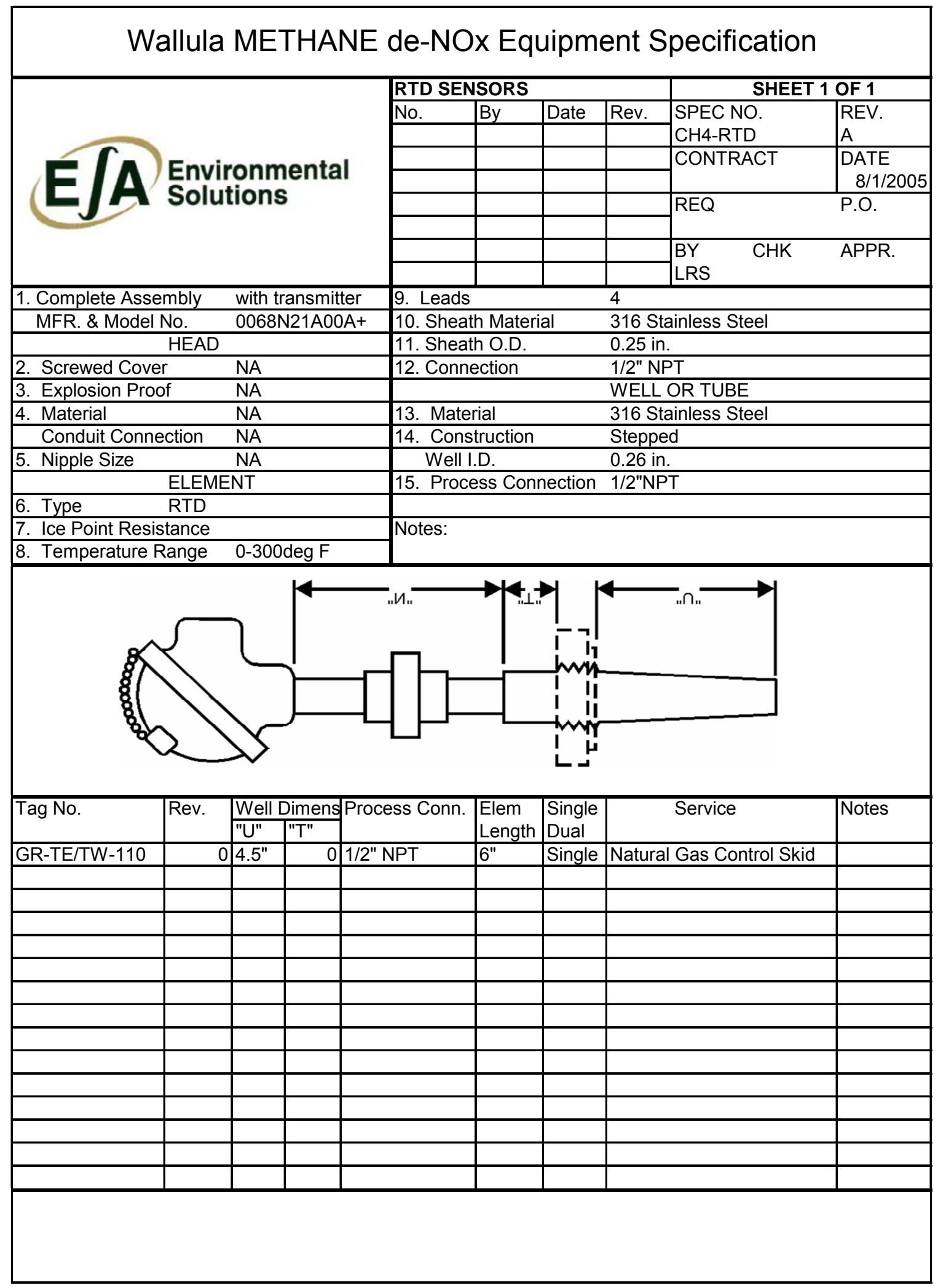




\section{Wallula METHANE de-NOx Equipment Specification}

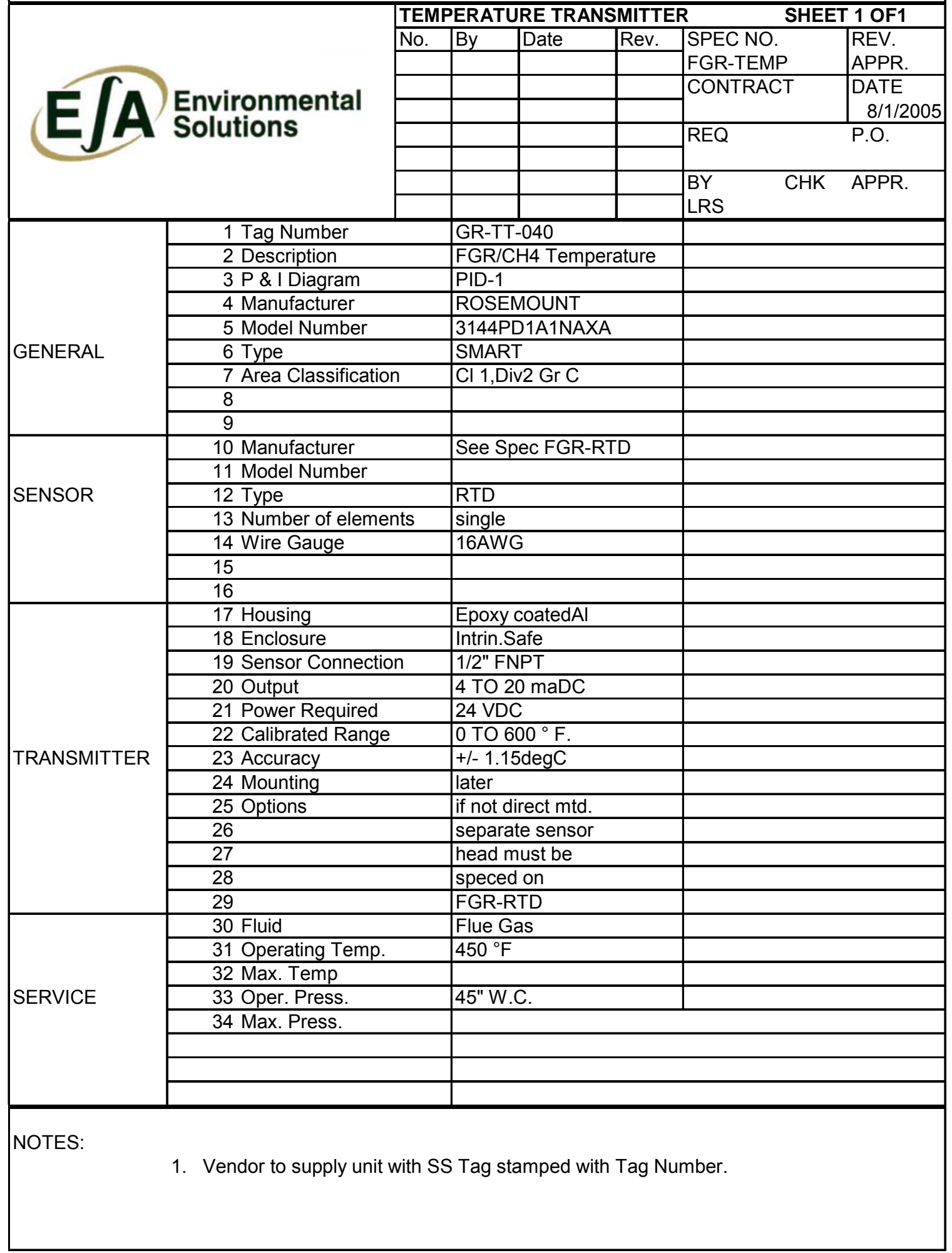




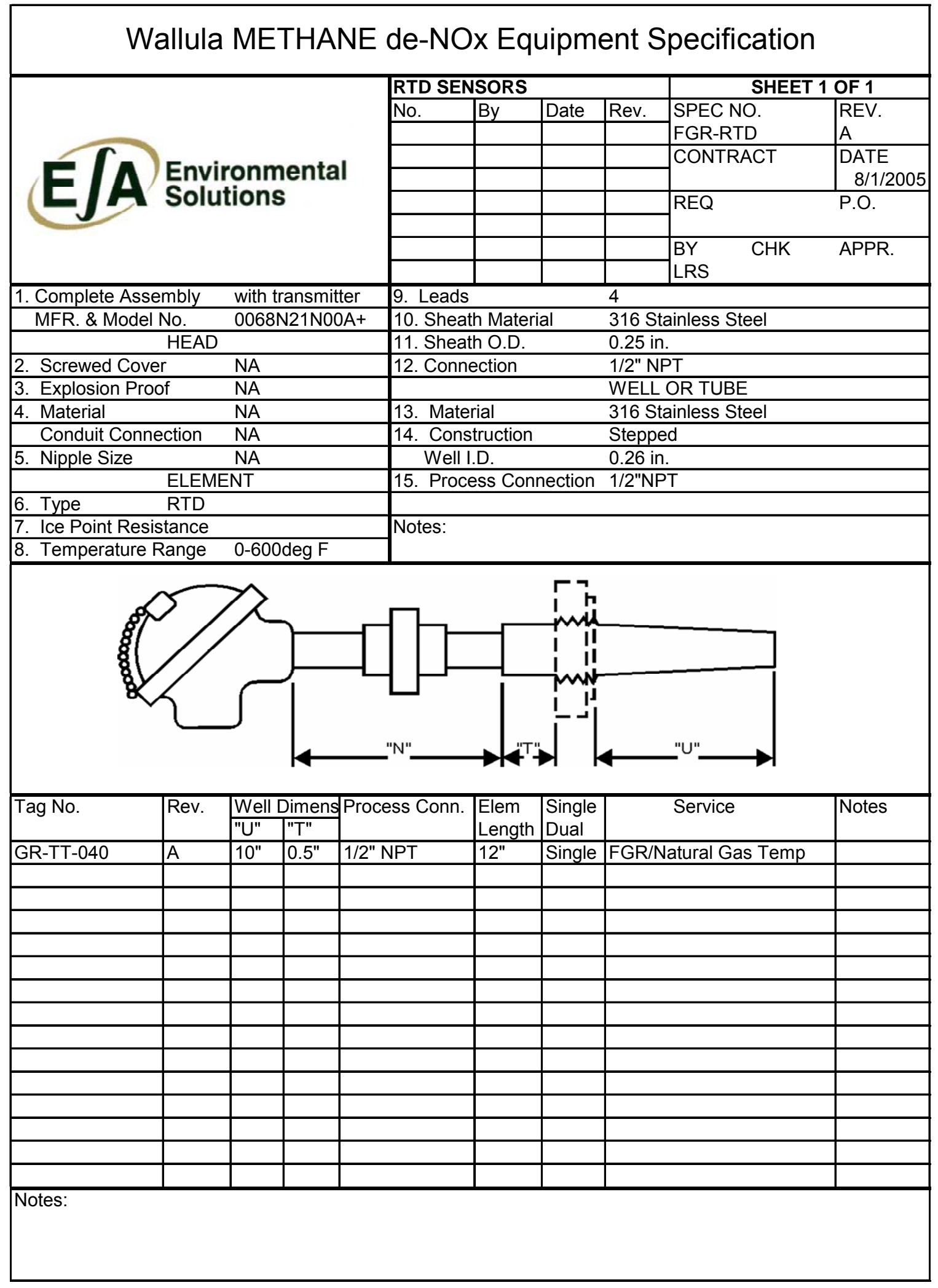




\begin{tabular}{|c|c|c|c|c|c|c|c|}
\hline \multicolumn{8}{|c|}{ Wallula METHANE de-NOx Equipment Specification } \\
\hline & \multirow{8}{*}{$\begin{array}{l}\text { Environmental } \\
\text { Solutions }\end{array}$} & \multicolumn{4}{|c|}{ DAMPER ACTUATOR } & \multicolumn{2}{|c|}{$\begin{array}{r}\text { SHEET } 1 \text { OF } 1 \\
\end{array}$} \\
\hline & & \begin{tabular}{|l|} 
No. \\
\end{tabular} & By & Date & Rev. & \multirow{2}{*}{$\begin{array}{l}\text { SPEC NO. } \\
\text { PCV-001 }\end{array}$} & \multirow{2}{*}{$\begin{array}{l}\text { REV. } \\
\text { A }\end{array}$} \\
\hline & & & & & & & \\
\hline & & & & & & \multirow[t]{2}{*}{ CONTRACT } & DATE \\
\hline & & & & & & & $8 / 1 / 2005$ \\
\hline & & & & & & REQ & P.O. \\
\hline & & & & & & \multirow{2}{*}{$\begin{array}{l}\text { BY } \\
\text { LRS }\end{array}$} & \multirow[t]{2}{*}{ APPR. } \\
\hline & & & & & & & \\
\hline \multirow{5}{*}{ GENERAL } & \multicolumn{3}{|c|}{ 1. Tag No.: PCV-001 } & \multicolumn{4}{|c|}{ 6. Type of Control: Throttling } \\
\hline & \multirow{2}{*}{\multicolumn{3}{|c|}{\begin{tabular}{|l} 
2. Service: Flue Gas Recirculation \\
3. Location: IDFan OutletDuct
\end{tabular}}} & \multicolumn{4}{|c|}{ 7. Inlet Connection: } \\
\hline & & & & \multicolumn{4}{|c|}{ 8. Outlet Connection: } \\
\hline & \multicolumn{3}{|c|}{ 4. Line Material: Carbon Steel } & \multicolumn{4}{|c|}{ 9. Noise dBA allowable: $<80$} \\
\hline & \multicolumn{3}{|c|}{ 5. Body Type: Parallel Blade } & 10. $\mathrm{Fa}$ & to Face: & & \\
\hline & 11. Fluid: Flue Gas & & & Units & MaxFlow & NormFloyMinFlow & Shut-off \\
\hline & 12. Flow Rate: & & & $\mathrm{lb} / \mathrm{hr}$ & 35,000 & & \\
\hline & 13. Inlet Pressure: & & & "W.C. & 7 & & \\
\hline SERVICE & 14. Outlet Pressure: & & & "W.C. & 6 & & \\
\hline CONDITIONS & 15. S.G. / M.W. & & & & & & \\
\hline & 16. Viscosity/Spec Heats & Ratio & & & & & \\
\hline & 17. Vapor Pressure & & & & & & \\
\hline & 18. Required Cv & & & $\mathrm{Cg}$ & & & \\
\hline & 19. Travel & & & & & & \\
\hline & $\begin{array}{r}\text { GLOBE } \\
\end{array}$ & & & & & ROTARY & \\
\hline & 20. Manufacturer: & & & 32. $M c$ & ufacturer: & TBD & \\
\hline & 21. Body Size \& Material & & & 33. Bo & S Size \& Mc & laterial: & \\
\hline & 22. Flow Characteristic: & & & 34. Flc & Character & ristic: & \\
\hline & 23. Plug Size: & & & 35. $\mathrm{Re}$ & uired Torqu & ue: & \\
\hline VALVE & 24. Trim Material: & & & 36. Sh & ft Diameter & & \\
\hline BODY & 25. Seat Material: & & & 37. Di & Material: & & \\
\hline & 26. Bonnet Material: & & & 38. Dis & Liner: & & \\
\hline & 27. Guiding: & & & 39. $\mathrm{Tr}$ & Material: & & \\
\hline & 28. Packing: & & & 40. Se & Material: & & \\
\hline & 29. Shutoff Class: & & & 41. Bo & net Materia & & \\
\hline & 30 & & & 42. $\mathrm{Pa}$ & king & & \\
\hline & 31 & & & 43. Sh & -off Class: & & \\
\hline & 44. Type: Spring and Die & phragm & & 49. Mi & Required & Pressure: & \\
\hline & 45. Model No.: Fisher 10 & & & 50. Air & ailure Valv & ve: Closes & \\
\hline ACTUATOR & 46. Operating Medium: 7 & psig Air & & 51. $\mathrm{Ac}$ & ator Orient & tation: NA & \\
\hline & 47. Max Allowable Press & & & 52. $\mathrm{Ha}$ & dwheel: $\mathrm{N}$ & & \\
\hline & 48 & & & 53 & & & \\
\hline & 54. Positioner: Fisher D & C6010 & & 60. Air & et: Require & & \\
\hline & 55. Input/Output: 3-15/3 & & & 61. Mc & el No. Fish & her 67FR & \\
\hline & 56. Bypass: yes Gauge & yes & & 62. $\mathrm{Se}$ & Pressure: & 20 psig & \\
\hline ACCESSORIES & 57. Limit Switches: NA & & & 63. Fil & r: yes Gat & auge: yes & \\
\hline & 58. Model No.: & & & 64. $\mathrm{Tr}$ & el Indicato & r: Std. Required & \\
\hline & 59. Type \& Rating: & & & 65 & & & \\
\hline $\begin{array}{l}\text { Notes: } \\
\text { 1. All tubing } \\
\text { 2. Actuator }\end{array}$ & $\begin{array}{l}\text { to be stainless steel. } \\
\text { to be provided with stainles }\end{array}$ & s steel na & ame & & & & \\
\hline
\end{tabular}




\begin{tabular}{|c|c|c|c|c|c|c|}
\hline \multicolumn{7}{|c|}{ Wallula METHANE de-NOx Equipment Specification } \\
\hline & \multirow{8}{*}{$\begin{array}{l}\text { Environmental } \\
\text { Solutions }\end{array}$} & \multicolumn{3}{|c|}{ CONTROL VALVE } & \multicolumn{2}{|c|}{$\begin{array}{r}\text { SHEET } 1 \text { OF } 1 \\
\end{array}$} \\
\hline & & \begin{tabular}{|l|l|} 
No. & By \\
\end{tabular} & Date & Rev. & \multirow{3}{*}{\begin{tabular}{|l|} 
SPEC NO. \\
PCV-021 \\
CONTRACT
\end{tabular}} & \multirow{2}{*}{$\begin{array}{l}\text { REV. } \\
\text { A }\end{array}$} \\
\hline & & & & & & \\
\hline & & & & & & DATE \\
\hline & & & & & CONTRACT & $8 / 1 / 2005$ \\
\hline & & & & & REQ & \multirow[t]{3}{*}{ P.O. } \\
\hline & & & & & \multirow{2}{*}{\begin{tabular}{|ll} 
BY & CHK \\
LRS & \\
\end{tabular}} & \\
\hline & & & & & & \\
\hline \multirow{5}{*}{ GENERAL } & \multicolumn{2}{|l|}{ 1. Tag No.: GR-PCV-021 } & \multicolumn{4}{|c|}{ 6. Type of Control: Pressure Damper } \\
\hline & \multicolumn{2}{|c|}{ 2. Service: OFA FGR Supply } & \multicolumn{4}{|c|}{ 7. Inlet Connection: 8" 150\#RF wafer style } \\
\hline & \multicolumn{2}{|c|}{ 3. Location: FGR Header } & \multicolumn{4}{|c|}{ 8. Outlet Connection: 8" 150\# R.F.wafer style } \\
\hline & \multicolumn{2}{|c|}{ 4. Line Material: Carbon Steel } & \multicolumn{4}{|c|}{ 9. Noise dBA allowable: $<80$} \\
\hline & \multicolumn{2}{|c|}{ 5. Body Type: Butterfly } & 10. Fac & to Face: & & \\
\hline & 11. Fluid: Flue Gas & & Units & MaxFlow & NormFloyMinFlow & Shut-off \\
\hline & 12. Flow Rate: & & Ibs/hr & 5000 & \begin{tabular}{|l|l|}
3000 & \\
\end{tabular} & \\
\hline & 13. Inlet Pressure: & & "W.C. & 45 & 46 & \\
\hline SERVICE & 14. Outlet Pressure: & & "W.C. & 37 & 38 & \\
\hline CONDITIONS & 15. S.G./M.W. & & & & & \\
\hline & 16. Viscosity/Spec Heats & Ratio & & & & \\
\hline & 17. Vapor Pressure & & & & & \\
\hline & 18. Required Cv & & & & & \\
\hline & 19. Travel & & & & & \\
\hline & \begin{tabular}{|l} 
RISING STEM \\
\end{tabular} & & & & ROTARY & \\
\hline & 20. Manufacturer: & & 32. Mal & iufacturer: & Fisher A41 & \\
\hline & 21. Body Size \& Material: & & 33. Boc & y Size \& M & laterial: $\quad$ 8" CS & \\
\hline & 22. Flow Characteristic: & & 34. Flo & Characte & equal $\%$ & \\
\hline & 23. Port Size: & & 35. Ball & Port Size: & & \\
\hline VALVE & 24. Trim Material: & & 36. Ball & Material: & & \\
\hline BODY & 25. Seat Material: & & 37. Dis & Material: & 316 SS & \\
\hline & 26. Bonnet Material: & & 38. Dis & Liner: & none & \\
\hline & 27. Guiding: & & 39. Trin & Material: & Stainless & Steel \\
\hline & 28. O-rings: & & 40. Sea & Material: & PTFE & \\
\hline & 29. Shutoff Class: & & 41. Bor & net Materia & Carbon S & Steel \\
\hline & 30 & & 42. $\mathrm{Pac}$ & king & PTFE & \\
\hline & 31 & & 43. Shu & t-off Class: & ANSI Cla & ass IV \\
\hline & 44. Type: Spring and Dia & phragm & 49. Min & Required & Pressure: & \\
\hline & 45. Model No.: Fisher 105 & & 50. Ele & tric/Air Fail & ilure Valve: Closes & \\
\hline ACTUATOR & 46. Operating Medium: In & strument Air 60ps & 51. Act & uator Orien & tation: & \\
\hline & 47. Max Allowable Pressu & ire $\quad 70 p s i$ & 52. $\mathrm{Har}$ & dwheel: $\mathrm{N}$ & & \\
\hline & 48 Enclosure: NEMA 4 & & 53 & & & \\
\hline & 54. Positioner: Fisher DV & C6010 & 60. Airs & et: Requir & & \\
\hline & 55. Input/Output: 3-15/3- & & 61. Mo & el No. Fish & her 67FR & \\
\hline & 56. Bypass: yes Gauges & yes & 62. Set & Pressure: & 20 psig & \\
\hline ACCESSORIES & 57. Limit Switches: NA & & 63. Filte & r: yes $\mathrm{Ga}$ & auge: yes & \\
\hline & 58. Model No.: & & 64. Tra & vel Indicato & r: Std. Required & \\
\hline & 59. Type \& Rating: & & 65 & & & \\
\hline $\begin{array}{l}\text { Notes: } \\
\text { 1. Valve to } \\
\text { 2. All tubing }\end{array}$ & $\begin{array}{l}\text { provided with stainless st } \\
\text { to be stainless steel. }\end{array}$ & teel nameplate. & & & & \\
\hline
\end{tabular}




\begin{tabular}{|c|c|c|c|c|c|c|}
\hline \multicolumn{7}{|c|}{ Wallula METHANE de-NOx Equipment Specification } \\
\hline & \multirow{8}{*}{$\begin{array}{l}\text { Environmental } \\
\text { Solutions }\end{array}$} & \multicolumn{3}{|c|}{ CONTROL VALVE } & \multicolumn{2}{|c|}{$\begin{array}{r}\text { SHEET } 1 \text { OF } 1 \\
\end{array}$} \\
\hline & & \begin{tabular}{|l|l|} 
No. & By \\
\end{tabular} & Date & Rev. & \multirow{2}{*}{$\begin{array}{l}\text { SPEC NO. } \\
\text { FCV-040 }\end{array}$} & \multirow{2}{*}{$\begin{array}{l}\text { REV. } \\
\text { A }\end{array}$} \\
\hline & & & & & & \\
\hline & & & & & \multirow[t]{2}{*}{ CONTRACT } & DATE \\
\hline & & & & & & $8 / 1 / 2005$ \\
\hline & & & & & REQ & \\
\hline & & & & & \multirow{2}{*}{\begin{tabular}{|ll} 
BY & CHK \\
LRS & \\
\end{tabular}} & \multirow[t]{2}{*}{ APPR. } \\
\hline & & & & & & \\
\hline \multirow{5}{*}{ GENERAL } & \multicolumn{2}{|l|}{ 1. Tag No.: GR-FCV-040 } & \multicolumn{4}{|c|}{ 6. Type of Control: Flow Damper } \\
\hline & \multicolumn{2}{|c|}{ 2. Service: $\mathrm{CH} 4$ Inj FGR Supply } & \multicolumn{4}{|c|}{ 7. Inlet Connection: 20" 150\#RF wafer style } \\
\hline & \multicolumn{2}{|c|}{ 3. Location: FGR Header } & \multicolumn{4}{|c|}{ 8. Outlet Connection: 20" 150\# R.F.wafer style } \\
\hline & \multirow{2}{*}{\multicolumn{2}{|c|}{\begin{tabular}{|ll} 
4. & Line Material: Carbon Steel \\
5. & Body Type: Butterfly
\end{tabular}}} & \multicolumn{4}{|c|}{ 9. Noise dBA allowable: $<80$} \\
\hline & & & 10. Fac & to Face: & & \\
\hline & 11. Fluid: Flue Gas & & Units & MaxFlow & NormFloyMinFlow & Shut-off \\
\hline & 12. Flow Rate: & & Ibs/hr & 20000 & \begin{tabular}{|l|l|}
17500 & \\
\end{tabular} & \\
\hline & 13. Inlet Pressure: & & "W.C. & 42 & 41 & \\
\hline SERVICE & 14. Outlet Pressure: & & "W.C. & 34 & 32 & \\
\hline CONDITIONS & 15. S.G./M.W. & & & & & \\
\hline & 16. Viscosity/Spec Heats & Ratio & & & & \\
\hline & 17. Vapor Pressure & & & & & \\
\hline & 18. Required Cv & & & & & \\
\hline & 19. Travel & & & & & \\
\hline & \begin{tabular}{|l} 
RISING STEM \\
\end{tabular} & & & & ROTARY & \\
\hline & 20. Manufacturer: & & 32. Mal & ufacturer: $\mathrm{F}$ & Fisher A41 & \\
\hline & 21. Body Size \& Material: & & 33. Boc & y Size \& Ma & aterial: $20 " \mathrm{CS}$ & \\
\hline & 22. Flow Characteristic: & & 34. Flo & Character & equal $\%$ & \\
\hline & 23. Port Size: & & 35. Ball & Port Size: & $20 "$ & \\
\hline VALVE & 24. Trim Material: & & 36. Ball & Material: & & \\
\hline BODY & 25. Seat Material: & & 37. Dis & Material: & 316 SS & \\
\hline & 26. Bonnet Material: & & 38. Dis & Liner: & none & \\
\hline & 27. Guiding: & & 39. Trin & Material: & Stainless & Steel \\
\hline & 28. O-rings: & & 40. Sea & Material: & PTFE & \\
\hline & 29. Shutoff Class: & & 41. Bor & net Materia & Carbon S & Steel \\
\hline & 30 & & 42. $\mathrm{Pac}$ & king & PTFE & \\
\hline & 31 & & 43. Shu & t-off Class: & ANSI Cla & ass IV \\
\hline & 44. Type: Spring and Dia & phragm & 49. Min & Required $\mathrm{F}$ & Pressure: & \\
\hline & 45. Model No.: Fisher 105 & & 50. Ele & tric/Air Fail & lure Valve: Closes & \\
\hline ACTUATOR & 46. Operating Medium: Ins & strument Air 60ps & 51. Act & uator Orient & tation: & \\
\hline & 47. Max Allowable Pressu & ire $\quad 70 p s i$ & 52. $\mathrm{Har}$ & dwheel: $\mathrm{N}$ & & \\
\hline & 48 Enclosure: NEMA 4 & & 53 & & & \\
\hline & 54. Positioner: Fisher DV & C6010 & 60. Airs & et: Require & & \\
\hline & 55. Input/Output: 3-15/3-1 & & 61. Mo & lel No. Fish & er 67FR & \\
\hline & 56. Bypass: yes Gauges & yes & 62. Set & Pressure: & 20 psig & \\
\hline ACCESSORIES & 57. Limit Switches: NA & & 63. Filte & r: yes Gal & uge: yes & \\
\hline & 58. Model No.: & & 64. Tra & vel Indicato & r: Std. Required & \\
\hline & 59. Type \& Rating: & & 65 & & & \\
\hline $\begin{array}{l}\text { Notes: } \\
\text { 1. Valve to } \\
\text { 2. All tubin }\end{array}$ & $\begin{array}{l}\text { pe provided with stainless st } \\
\text { to be stainless steel. }\end{array}$ & teel nameplate. & & & & \\
\hline
\end{tabular}




\begin{tabular}{|c|c|c|c|c|c|c|c|}
\hline \multicolumn{8}{|c|}{ Wallula METHANE de-NOx Equipment Specification } \\
\hline & \multirow{8}{*}{$\begin{array}{l}\text { Environmental } \\
\text { Solutions }\end{array}$} & \multicolumn{4}{|c|}{ DAMPER ACTUATOR } & \multicolumn{2}{|c|}{$\begin{array}{r}\text { SHEET } 1 \text { OF } 1 \\
\end{array}$} \\
\hline & & \begin{tabular}{|l|} 
No. \\
\end{tabular} & By & Date & Rev. & \multirow{2}{*}{$\begin{array}{l}\text { SPEC NO. } \\
\text { PCV-020 }\end{array}$} & \multirow{2}{*}{$\begin{array}{l}\text { REV. } \\
\text { A }\end{array}$} \\
\hline & & & & & & & \\
\hline & & & & & & \multirow[t]{2}{*}{ CONTRACT } & DATE \\
\hline & & & & & & & $8 / 1 / 2005$ \\
\hline & & & & & & REQ & P.O. \\
\hline & & & & & & \multirow{2}{*}{$\begin{array}{l}\text { BY } \\
\text { LRS }\end{array}$} & \multirow[t]{2}{*}{ APPR. } \\
\hline & & & & & & & \\
\hline \multirow{5}{*}{ GENERAL } & \multicolumn{3}{|l|}{ 1. Tag No.: PCV-020 } & \multicolumn{4}{|c|}{ 6. Type of Control: Throttling } \\
\hline & \multicolumn{3}{|l|}{ 2. Service: Overfire Air } & \multicolumn{4}{|c|}{ 7. Inlet Connection: } \\
\hline & \multicolumn{3}{|c|}{ 3. Location: AH OutletDuct } & \multicolumn{4}{|c|}{ 8. Outlet Connection: } \\
\hline & \multicolumn{3}{|c|}{ 4. Line Material: Carbon Steel } & \multicolumn{4}{|c|}{ 9. Noise dBA allowable: $<80$} \\
\hline & \multicolumn{3}{|c|}{ 5. Body Type: Parallel Blade } & 10. Fa & to Face: & & \\
\hline & 11. Fluid: Flue Gas & & & Units & MaxFlow & NormFloyMinFlow & Shut-off \\
\hline & 12. Flow Rate: & & & $\mathrm{lb} / \mathrm{hr}$ & 35,000 & & \\
\hline & 13. Inlet Pressure: & & & "W.C. & 7 & & \\
\hline SERVICE & 14. Outlet Pressure: & & & "W.C. & 6 & & \\
\hline CONDITIONS & 15. S.G. / M.W. & & & & & & \\
\hline & 16. Viscosity/Spec Heats & Ratio & & & & & \\
\hline & 17. Vapor Pressure & & & & & & \\
\hline & 18. Required Cv & & & $\mathrm{Cg}$ & & & \\
\hline & 19. Travel & & & & & & \\
\hline & $\begin{array}{r}\text { GLOBE } \\
\end{array}$ & & & & & ROTARY & \\
\hline & 20. Manufacturer: & & & 32. $\mathrm{M}$ & ufacturer: & TBD & \\
\hline & 21. Body Size \& Material & & & 33. $\mathrm{Bc}$ & S Size \& Mc & laterial: & \\
\hline & 22. Flow Characteristic: & & & 34. Fl & Character & ristic: & \\
\hline & 23. Plug Size: & & & 35. $\mathrm{R}$ & uired Torqu & ue: & \\
\hline VALVE & 24. Trim Material: & & & 36. Sl & ft Diameter & & \\
\hline BODY & 25. Seat Material: & & & 37. $\mathrm{Di}$ & Material: & & \\
\hline & 26. Bonnet Material: & & & 38. Di & Liner: & & \\
\hline & 27. Guiding: & & & 39. $\mathrm{Tr}$ & Material: & & \\
\hline & 28. Packing: & & & 40. Se & Material: & & \\
\hline & 29. Shutoff Class: & & & 41. $\mathrm{BC}$ & net Materia & & \\
\hline & 30 & & & 42. $\mathrm{Pc}$ & king & & \\
\hline & 31 & & & 43. $\mathrm{St}$ & -off Class: & & \\
\hline & 44. Type: Spring and Die & aphragm & & 49. M & Required & Pressure: & \\
\hline & 45. Model No.: Fisher 10 & & & 50. $\mathrm{Ai}$ & ailure Valv & ve: Closes & \\
\hline ACTUATOR & 46. Operating Medium: 7 & 0 psig Air & & 51. $\mathrm{Ac}$ & ator Orient & tation: NA & \\
\hline & 47. Max Allowable Press & & & 52. $\mathrm{H}$ & dwheel: $\mathrm{N}$ & & \\
\hline & 48 & & & 53 & & & \\
\hline & 54. Positioner: Fisher D & VC6010 & & 60. $\mathrm{Ai}$ & et: Require & & \\
\hline & 55. Input/Output: 3-15/3 & & & 61. M & el No. Fish & her 67FR & \\
\hline & 56. Bypass: yes Gauge & s: yes & & 62. $\mathrm{Se}$ & Pressure: & 20 psig & \\
\hline ACCESSORIES & 57. Limit Switches: NA & & & 63. $\mathrm{Fi}$ & r: yes Gat & auge: yes & \\
\hline & 58. Model No.: & & & 64. $\mathrm{Tr}$ & el Indicato & r: Std. Required & \\
\hline & 59. Type \& Rating: & & & 65 & & & \\
\hline $\begin{array}{l}\text { Notes: } \\
\text { 1. All tubing } \\
\text { 2. Actuator }\end{array}$ & $\begin{array}{l}\text { to be stainless steel. } \\
\text { to be provided with stainles }\end{array}$ & s steel na & amep & & & & \\
\hline
\end{tabular}




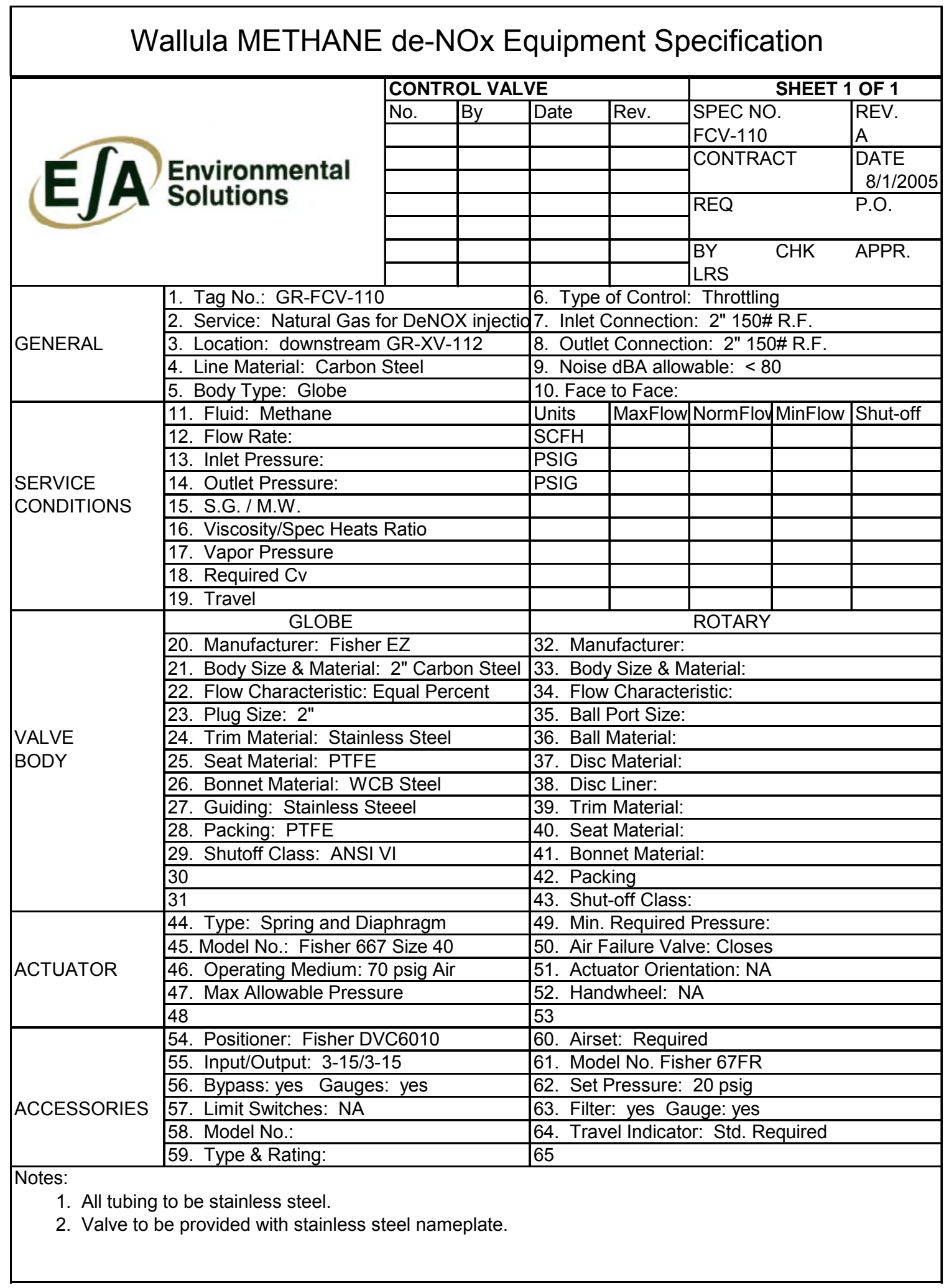




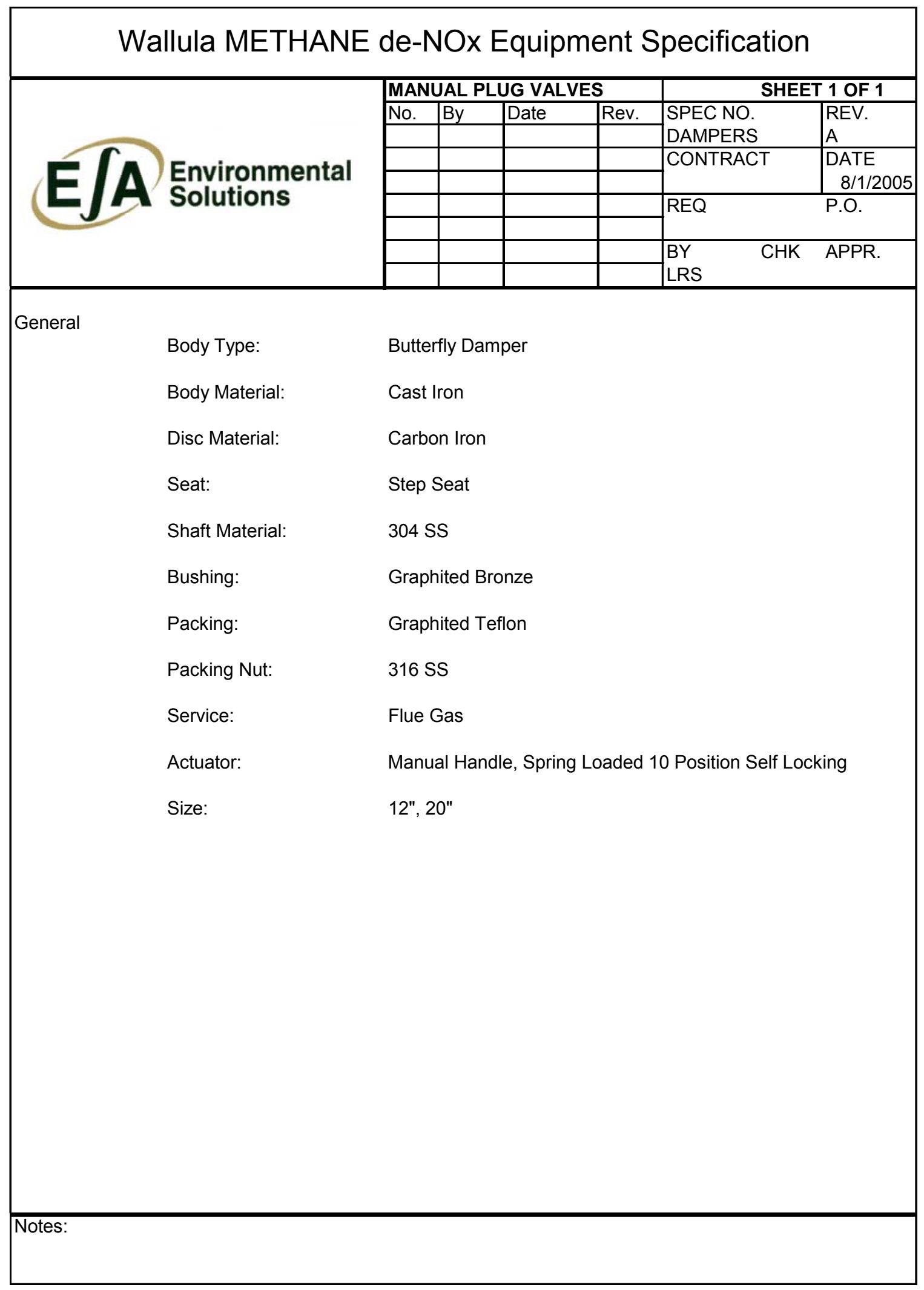




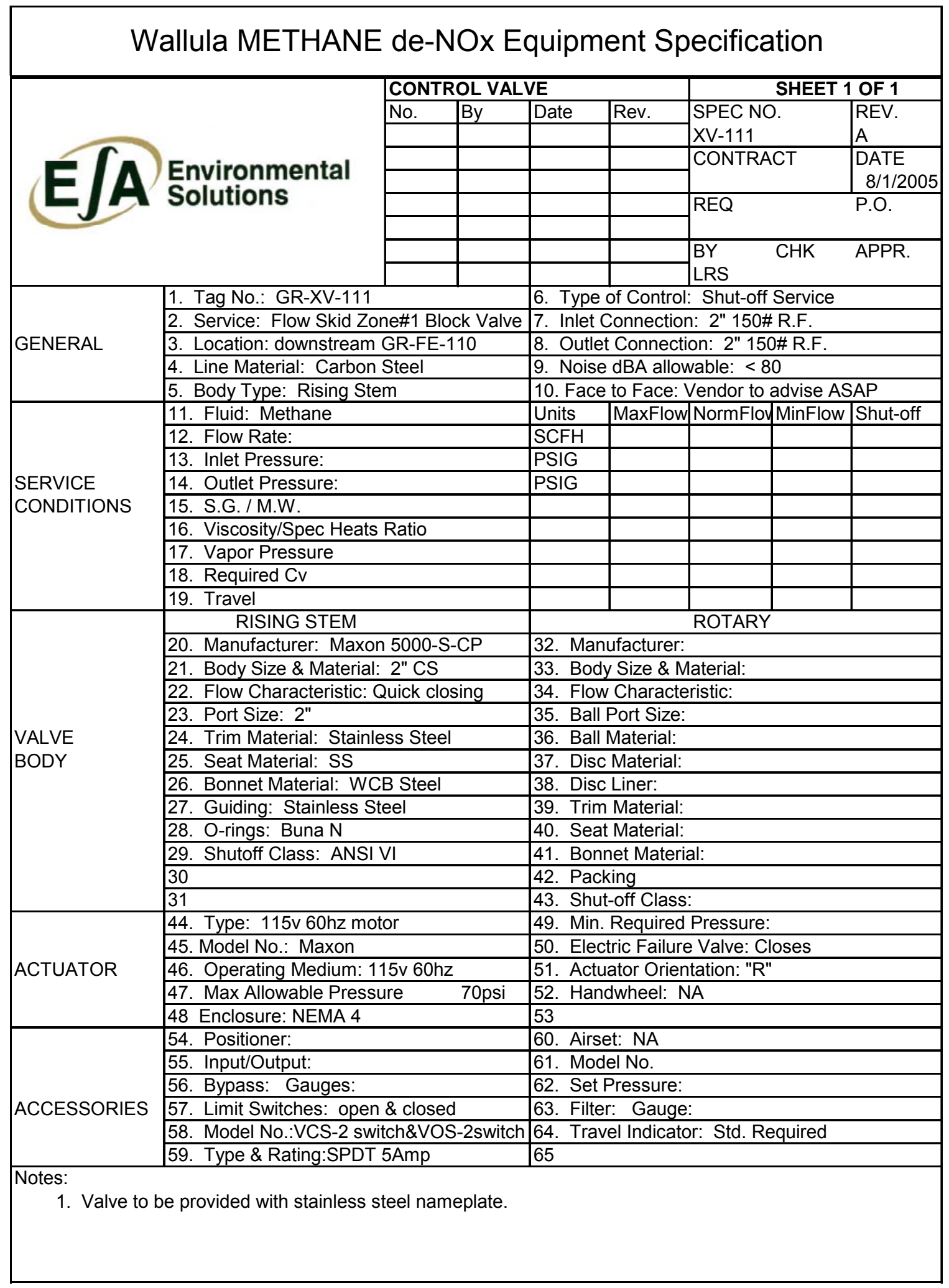




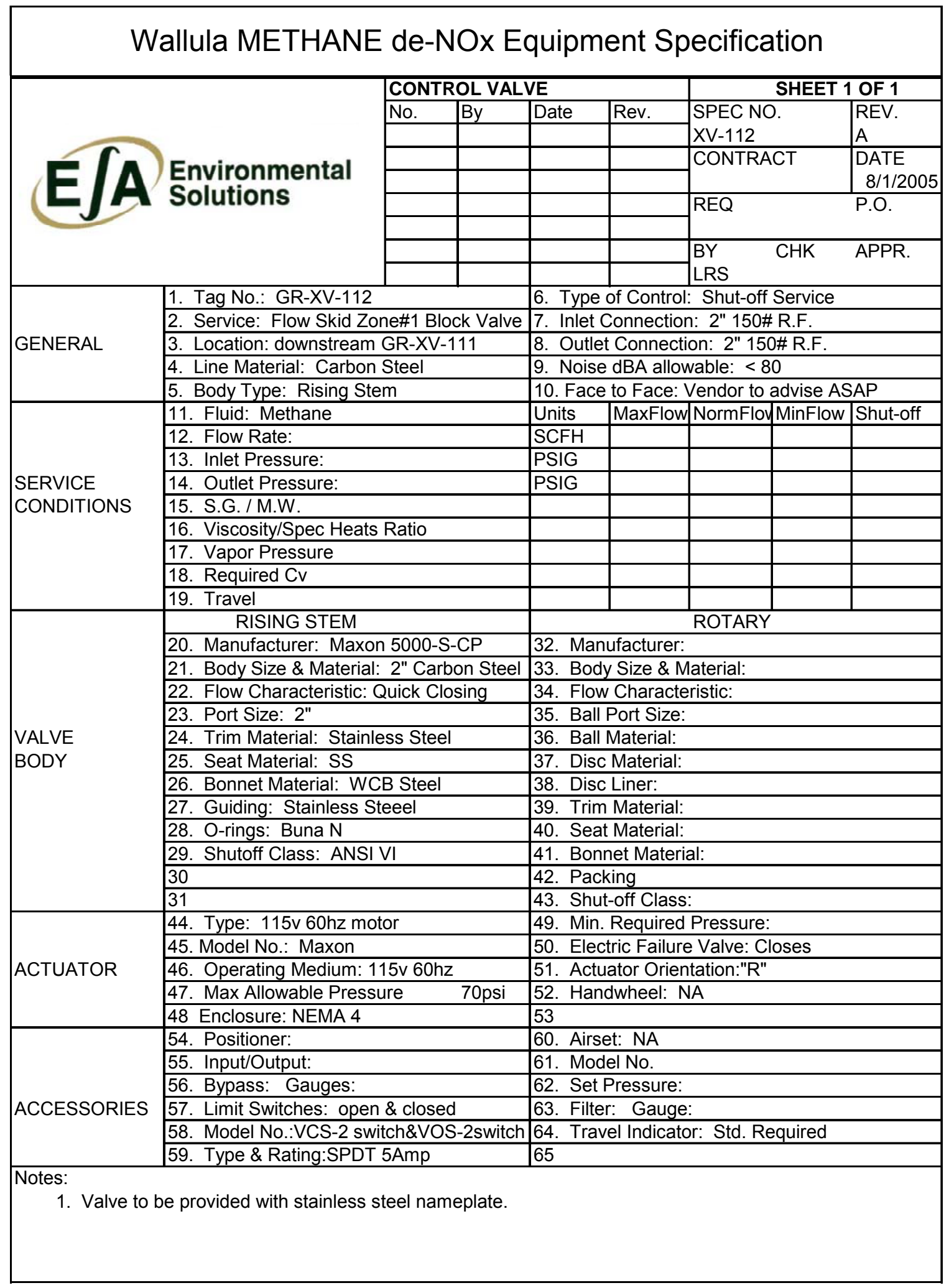




\begin{tabular}{|c|c|c|c|c|c|c|}
\hline \multicolumn{7}{|c|}{ Wallula METHANE de-NOx Equipment Specification } \\
\hline & \multirow{8}{*}{$\begin{array}{l}\text { Environmental } \\
\text { Solutions }\end{array}$} & \multicolumn{3}{|c|}{ CONTROL VALVE } & \multicolumn{2}{|c|}{$\begin{array}{r}\text { SHEET } 1 \text { OF } 1 \\
\end{array}$} \\
\hline & & \begin{tabular}{|l|l|} 
No. & By \\
\end{tabular} & Date & Rev. & \multirow{4}{*}{$\begin{array}{l}\text { SPEC NO. } \\
\text { XV-041 } \\
\text { CONTRACT }\end{array}$} & REV. \\
\hline & & & & & & \\
\hline & & & & & & DATE \\
\hline & & & & & & 8/1/2005 \\
\hline & & & & & REQ & P.O. \\
\hline & & & & & \multirow{2}{*}{\begin{tabular}{|ll} 
BY & CHK \\
LRS & \\
\end{tabular}} & \multirow[t]{2}{*}{ APPR. } \\
\hline & & & & & & \\
\hline \multirow{5}{*}{ GENERAL } & \multicolumn{2}{|l|}{ 1. Tag No.: GR-XV-041 } & \multicolumn{4}{|c|}{ 6. Type of Control: Shut-off Service } \\
\hline & \multicolumn{2}{|c|}{ 2. Service: Block Valve } & \multicolumn{4}{|c|}{ 7. Inlet Connection: 2" 150\# R.F. } \\
\hline & \multicolumn{2}{|c|}{ 3. Location: Inlet for Steam Zone 1} & \multicolumn{4}{|c|}{ 8. Outlet Connection: 2" 150\# R.F. } \\
\hline & \multicolumn{2}{|c|}{ 4. Line Material: Carbon Steel } & \multicolumn{4}{|c|}{ 9. Noise dBA allowable: $<80$} \\
\hline & \multicolumn{2}{|c|}{ 5. Body Type: Rising Stem } & \multicolumn{4}{|c|}{ 10. Face to Face: Vendor to advise ASAP } \\
\hline \multirow{9}{*}{$\begin{array}{l}\text { SERVICE } \\
\text { CONDITIONS }\end{array}$} & \multicolumn{2}{|l|}{ 11. Fluid: Methane } & Units & MaxFlow & NormFloyMinFlow & Shut-off \\
\hline & 12. Flow Rate: & & SCFH & & & \\
\hline & 13. Inlet Pressure: & & PSIG & & & \\
\hline & 14. Outlet Pressure: & & PSIG & & & \\
\hline & 15. S.G./M.W. & & & & & \\
\hline & 16. Viscosity/Spec Heats & Ratio & & & & \\
\hline & 17. Vapor Pressure & & & & & \\
\hline & 18. Required Cv & & & & & \\
\hline & 19. Travel & & & & & \\
\hline & \begin{tabular}{|c|} 
RISING STEM \\
\end{tabular} & & & & ROTARY & \\
\hline & 20. Manufacturer: Maxon & 5000-S-CP & 32. Ma & ufacturer: & & \\
\hline & 21. Body Size \& Material: & 2" CS & 33. Bo & y Size \& M & laterial: & \\
\hline & 22. Flow Characteristic: Q & Luick closing & 34. Flo & Characte & ristic: & \\
\hline & 23. Port Size: 2" & & 35. $\mathrm{Ba}$ & Port Size: & & \\
\hline VALVE & 24. Trim Material: Stainle & ss Steel & 36. $\mathrm{Ba}$ & Material: & & \\
\hline BODY & 25. Seat Material: SS & & 37. Dis & Material: & & \\
\hline & 26. Bonnet Material: WCE & B Steel & 38. Dis & Liner: & & \\
\hline & 27. Guiding: Stainless Ste & & 39. Tri & Material: & & \\
\hline & 28. O-rings: Buna N & & 40. Se & t Material: & & \\
\hline & 29. Shutoff Class: ANSIV & & 41. Bo & net Materi & & \\
\hline & 30 & & 42. $\mathrm{Pa}$ & king & & \\
\hline & 31 & & 43. Sh & t-off Class & & \\
\hline & 44. Type: $115 \mathrm{v} 60 \mathrm{hz}$ motc & & 49. Mir & Required & Pressure: & \\
\hline & 45. Model No.: Maxon & & 50. Ele & tric Failure & Valve: Closes & \\
\hline ACTUATOR & 46. Operating Medium: 11 & $15 \mathrm{v} 60 \mathrm{hz}$ & 51. Ac & jator Orien & tation: "R" & \\
\hline & 47. Max Allowable Pressu & are $\quad 70 p s i$ & 52. $\mathrm{Ha}$ & dwheel: $\Lambda$ & & \\
\hline & 48 Enclosure: NEMA 4 & & 53 & & & \\
\hline & 54. Positioner: & & 60. Air & et: NA & & \\
\hline & 55. Input/Output: & & 61. Mo & lel No. & & \\
\hline & 56. Bypass: Gauges: & & 62. Se & Pressure: & & \\
\hline ACCESSORIES & 57. Limit Switches: open & \& closed & 63. Filt & r: Gauge & & \\
\hline & 58. Model No.:VCS-2 swit & tch\&VOS-2switch & 64. Tre & vel Indicatc & r: Std. Required & \\
\hline & 59. Type \& Rating:SPDT & $5 \mathrm{Amp}$ & 65 & & & \\
\hline $\begin{array}{l}\text { Notes: } \\
\text { 1. Valve to }\end{array}$ & provided with stainless st & teel nameplate. & & & & \\
\hline
\end{tabular}




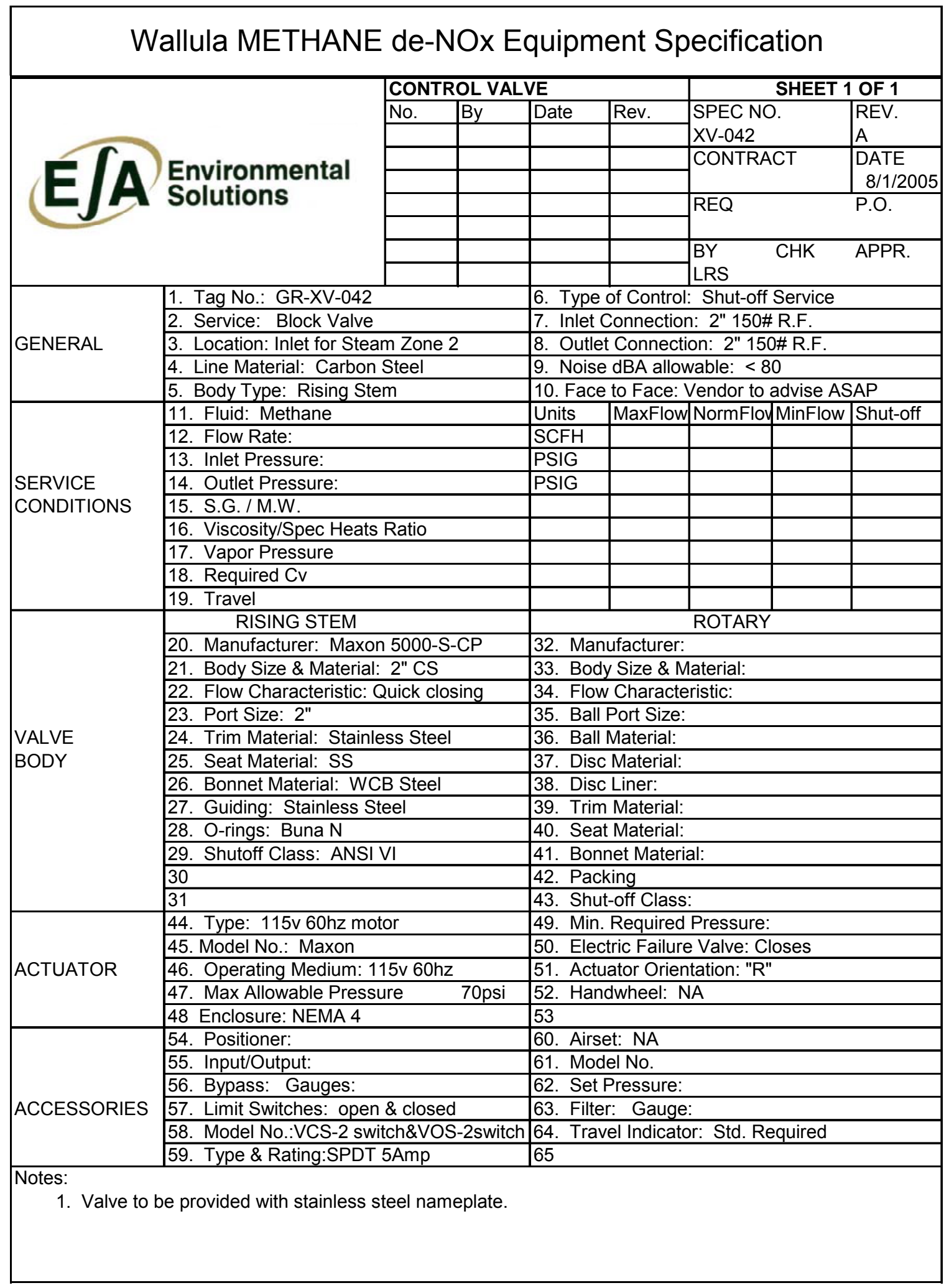




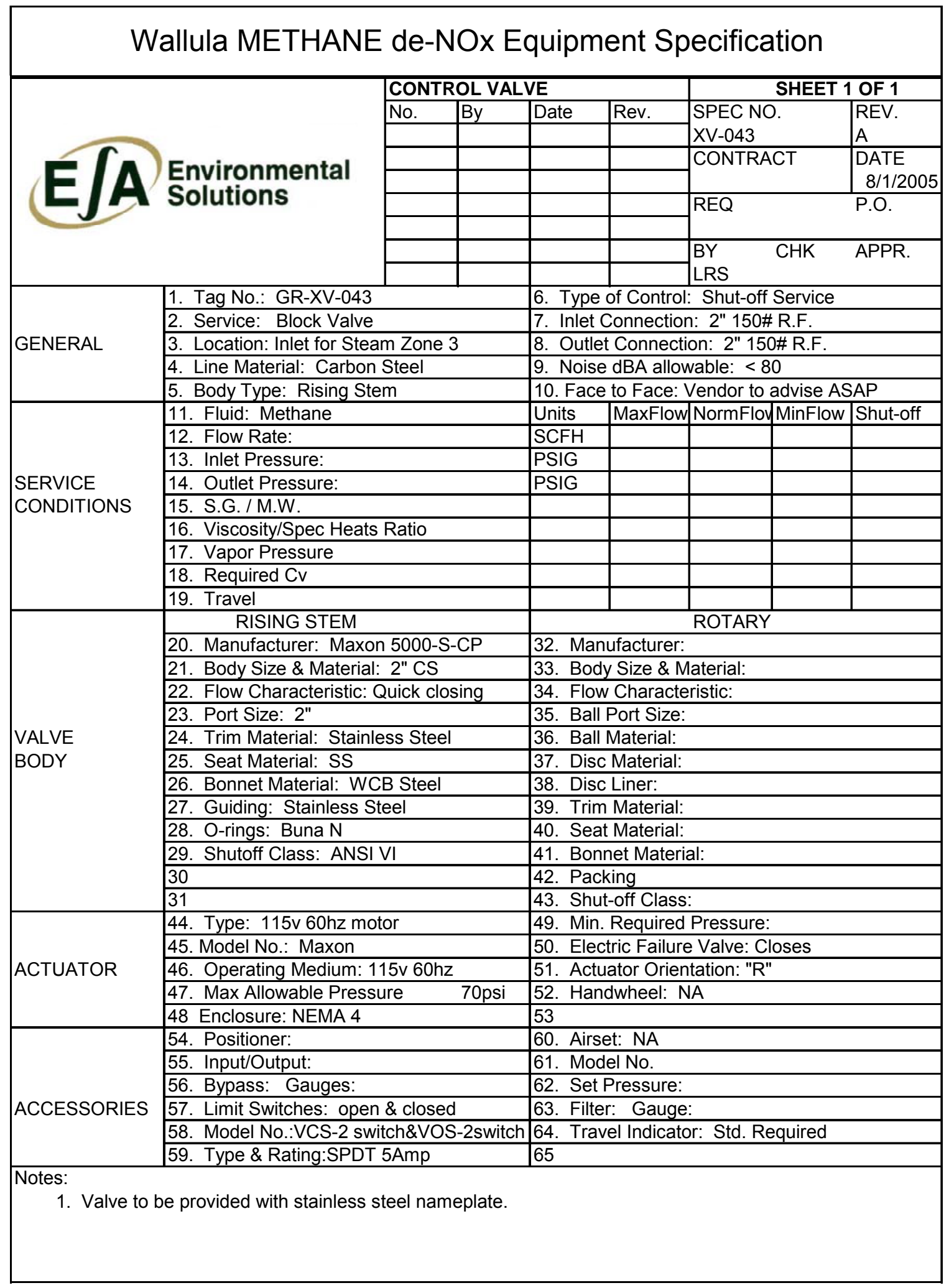




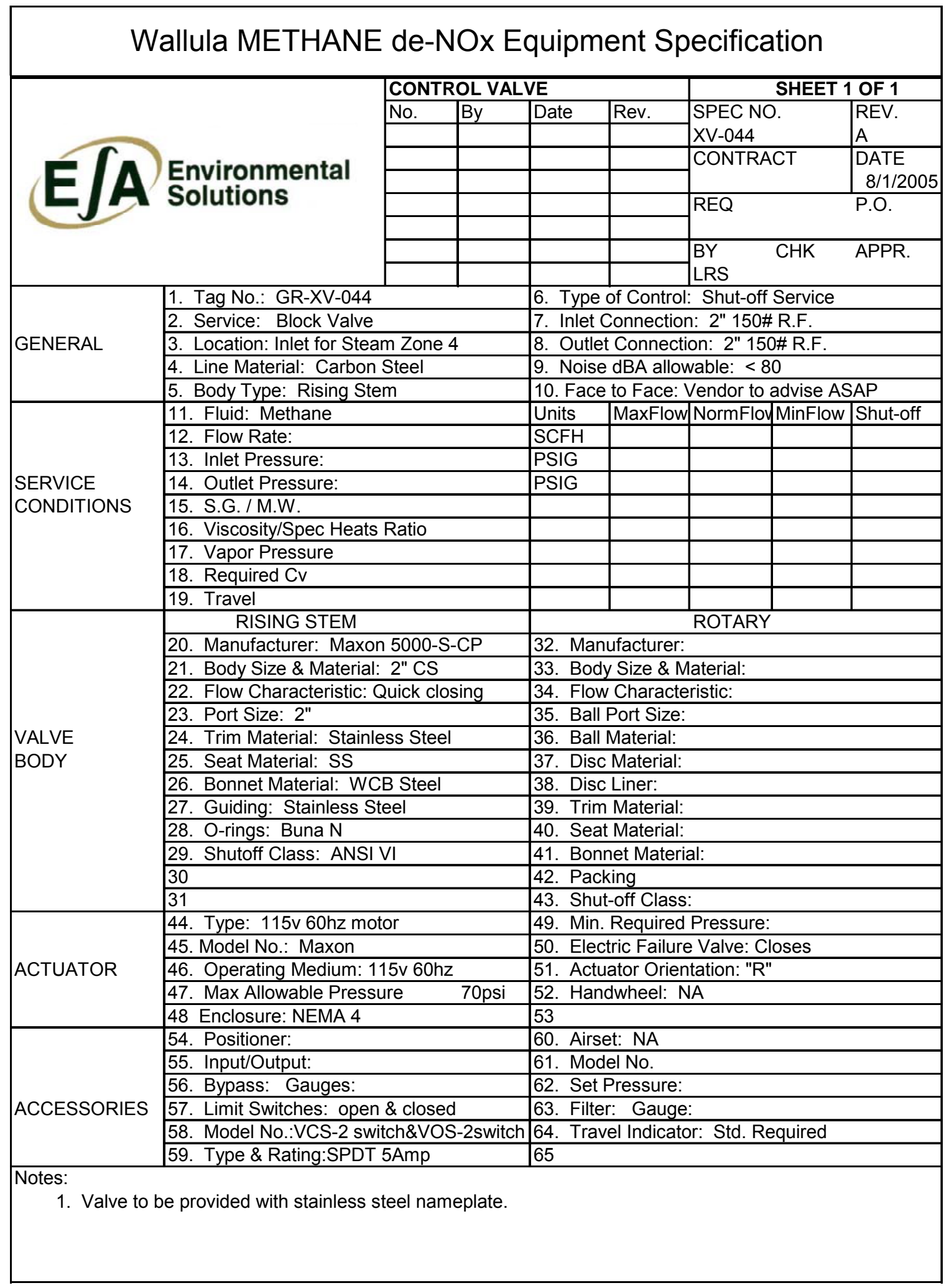




\begin{tabular}{|c|c|c|c|c|c|c|}
\hline \multicolumn{7}{|c|}{ Wallula METHANE de-NOx Equipment Specification } \\
\hline & \multirow{8}{*}{$\begin{array}{l}\text { Environmental } \\
\text { Solutions }\end{array}$} & \multicolumn{3}{|c|}{ CONTROL VALVE } & \multicolumn{2}{|c|}{$\begin{array}{r}\text { SHEET } 1 \text { OF } 1 \\
\end{array}$} \\
\hline & & \begin{tabular}{|l|l|} 
No. & By \\
\end{tabular} & Date & Rev. & \multirow{4}{*}{$\begin{array}{l}\text { SPEC NO. } \\
\text { XV-113 } \\
\text { CONTRACT }\end{array}$} & REV. \\
\hline & & & & & & \\
\hline & & & & & & DATE \\
\hline & & & & & & $8 / 1 / 2005$ \\
\hline & & & & & REQ & P.O. \\
\hline & & & & & \multirow{2}{*}{$\begin{array}{ll}\text { BY } & \text { CHK } \\
\text { LRS } & \\
\end{array}$} & \multirow[t]{2}{*}{ APPR. } \\
\hline & & & & & & \\
\hline \multirow{5}{*}{ GENERAL } & \multicolumn{2}{|l|}{ 1. Tag No.: GR- XV-113 } & \multicolumn{4}{|c|}{ 6. Type of Control: Vent Service } \\
\hline & \multicolumn{2}{|c|}{ 2. Service: Zone\#1 Bleed Valve } & \multicolumn{4}{|c|}{ 7. Inlet Connection: 1" 150\# R.F. } \\
\hline & \multicolumn{2}{|c|}{ 3. Location: downstream GR-XV-111 vent } & \multicolumn{4}{|c|}{ 8. Outlet Connection: 1" 150\# R.F. } \\
\hline & \multicolumn{2}{|c|}{ 4. Line Material: Carbon Steel } & \multicolumn{4}{|c|}{ 9. Noise dBA allowable: $<80$} \\
\hline & \multicolumn{2}{|c|}{ 5. Body Type: Rising Stem } & \multicolumn{4}{|c|}{ 10. Face to Face: Vendor to advise ASAP } \\
\hline \multirow{9}{*}{$\begin{array}{l}\text { SERVICE } \\
\text { CONDITIONS }\end{array}$} & \multicolumn{2}{|l|}{ 11. Fluid: Methane } & Units & MaxFlow & NormFloyMinFlow & Shut-off \\
\hline & 12. Flow Rate: & & SCFH & & & \\
\hline & 13. Inlet Pressure: & & PSIG & & & \\
\hline & 14. Outlet Pressure: & & PSIG & & & \\
\hline & 15. S.G./M.W. & & & & & \\
\hline & 16. Viscosity/Spec Heats & Ratio & & & & \\
\hline & 17. Vapor Pressure & & & & & \\
\hline & 18. Required Cv & & & & & \\
\hline & 19. Travel & & & & & \\
\hline & \begin{tabular}{|c|} 
RISING STEM \\
\end{tabular} & & & & ROTARY & \\
\hline & 20. Manufacturer: Maxon & STO-AS & 32. Ma & ufacturer: & & \\
\hline & 21. Body Size \& Material: & 1" Carbon Steel & 33. Bo & y Size \& M & laterial: & \\
\hline & 22. Flow Characteristic: Q & Luick opening & 34. Flo & Characte & ristic: & \\
\hline & 23. Port Size: 1" & & 35. $\mathrm{Ba}$ & Port Size: & & \\
\hline VALVE & 24. Trim Material: Stainle & ss Steel & 36. $\mathrm{Ba}$ & Material: & & \\
\hline BODY & 25. Seat Material: SS & & 37. Dis & Material: & & \\
\hline & 26. Bonnet Material: WCE & B Steel & 38. Dis & Liner: & & \\
\hline & 27. Guiding: Stainless Ste & eeel & 39. Tri & Material: & & \\
\hline & 28. O-rings: Buna N & & 40. Se & t Material: & & \\
\hline & 29. Shutoff Class: ANSIV & & 41. Bo & net Materi & & \\
\hline & 30 & & 42. $\mathrm{Pa}$ & king & & \\
\hline & 31 & & 43. Sh & t-off Class & & \\
\hline & 44. Type: $115 \mathrm{v} 60 \mathrm{hz}$ motc & & 49. Mir & Required & Pressure: & \\
\hline & 45. Model No.: Maxon & & 50. Ele & tric Failure & Valve: Closes & \\
\hline ACTUATOR & 46. Operating Medium: 11 & $15 \mathrm{v} 60 \mathrm{hz}$ & 51. Ac & jator Orien & tation: later & \\
\hline & 47. Max Allowable Pressu & Ire $\quad 125 p s i$ & 52. $\mathrm{Ha}$ & dwheel: $\Lambda$ & & \\
\hline & 48 Enclosure: NEMA 4 & & 53 & & & \\
\hline & 54. Positioner: & & 60. Air & et: NA & & \\
\hline & 55. Input/Output: & & 61. Mo & lel No. & & \\
\hline & 56. Bypass: Gauges: & & 62. Se & Pressure: & & \\
\hline ACCESSORIES & 57. Limit Switches: open & $\&$ closed & 63. Filt & r: Gauge & & \\
\hline & 58. Model No.:VCS-2 swit & tch\&VOS-2switch & 64. Tre & vel Indicatc & r: Std. Required & \\
\hline & 59. Type \& Rating:SPDT & $5 \mathrm{Amp}$ & 65 & & & \\
\hline $\begin{array}{l}\text { Notes: } \\
\text { 1. Valve to }\end{array}$ & provided with stainless st & teel nameplate. & & & & \\
\hline
\end{tabular}




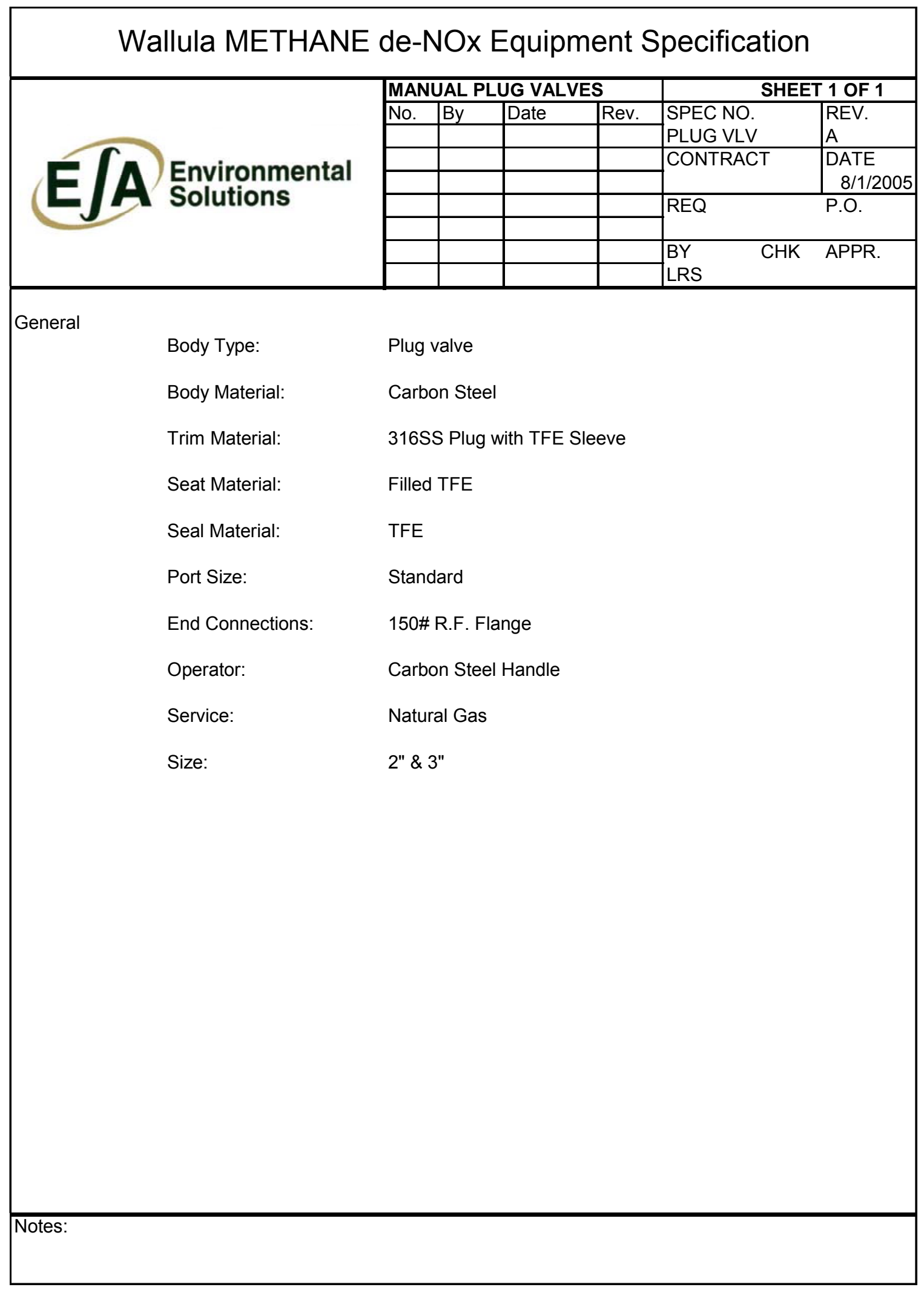




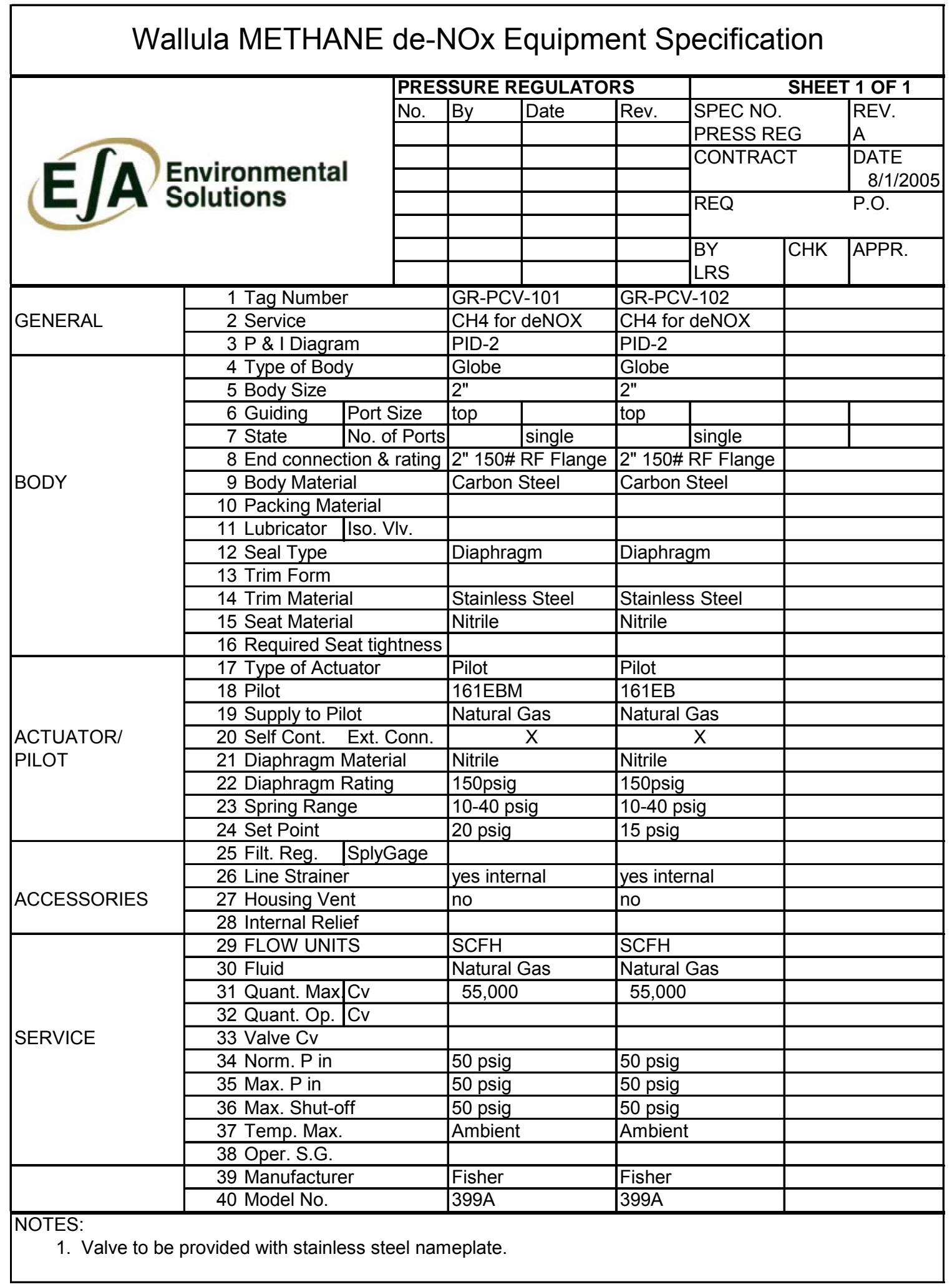




\begin{tabular}{|c|c|c|c|c|c|c|c|c|}
\hline & Ilula METH & NF & de- & JO> & Equip & ent & pecification & \\
\hline & & & 021 & VALY & & & $\begin{array}{r}\text { SHEE } \\
\end{array}$ & 1 OF 1 \\
\hline & & & No. & By & Date & Rev. & SPEC NO. & REV. \\
\hline & & & & & & & O2 INST & \\
\hline & Environmer & & & & & & CONTRACT & DATE \\
\hline & Solutions & & & & & & 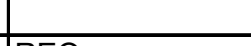 & \begin{tabular}{|r|} 
\\
\end{tabular} \\
\hline & & & & & & & & \\
\hline & & & & & & & $\mathrm{CHK}$ & APPR. \\
\hline & & & & & & & LRS & \\
\hline Genera & & & & & & & & \\
\hline & Type: & & tu $O x$ & $\operatorname{sen} A$ & lyzer & & & \\
\hline & Sensor: & & nium & xide & & & & \\
\hline & Manufacturer: & & emour & or ec & & & & \\
\hline & Model Number: & & $4 \mathrm{~A} 30^{-}$ & & & & & \\
\hline & Housing: & & coppe & Alun & & & & \\
\hline & Rating: & & IA 4X, & P66 & & & & \\
\hline & Temperature Rat & $y:-40$ & eg $\mathrm{Ft}$ & +185 & g F(elec & ics) & 1300deg $F$ senso & $\max$. \\
\hline & Mounting: & $\begin{array}{l}\mathrm{P} / \mathrm{N} \\
\text { hot }\end{array}$ & $\begin{array}{l}\text { 3D397 } \\
\text { luctwo }\end{array}$ & $\begin{array}{l}51 \mathrm{G} 0 \\
k\end{array}$ & pool pie & o offs & transmitter housin & from \\
\hline & Probe Type: & & beer D & Ifusio & Element & & & \\
\hline & Probe materials: & 316 & SS $\mathrm{n}$ & tted & & & & \\
\hline & Length: & $18 "$ & & & & & & \\
\hline & Range: & & $5 \%$ ox & gen & & & & \\
\hline & Accuracy: & & $.75 \%$ & f reac & g or 0.05 & $\mathrm{D} 2, \mathrm{wl}$ & chever is greater & \\
\hline & Analog Output: & & $0 \mathrm{~mA}$ & AART & & & & \\
\hline & Calibration: & sen & -autor & latic $c$ & atomati & ustom & to specify & \\
\hline Process & & & & & & & & \\
\hline & Fluid: & Flu & Gas & & & & & \\
\hline & Pressure Inlet: & 52 & W.C. & & & & & \\
\hline & Temperature: & 400 & & & & & & \\
\hline Notes: & 1. Vendor to sup & yS & lamep & ate $\mathrm{w}$ & Tag No. & R-AT- & & \\
\hline
\end{tabular}




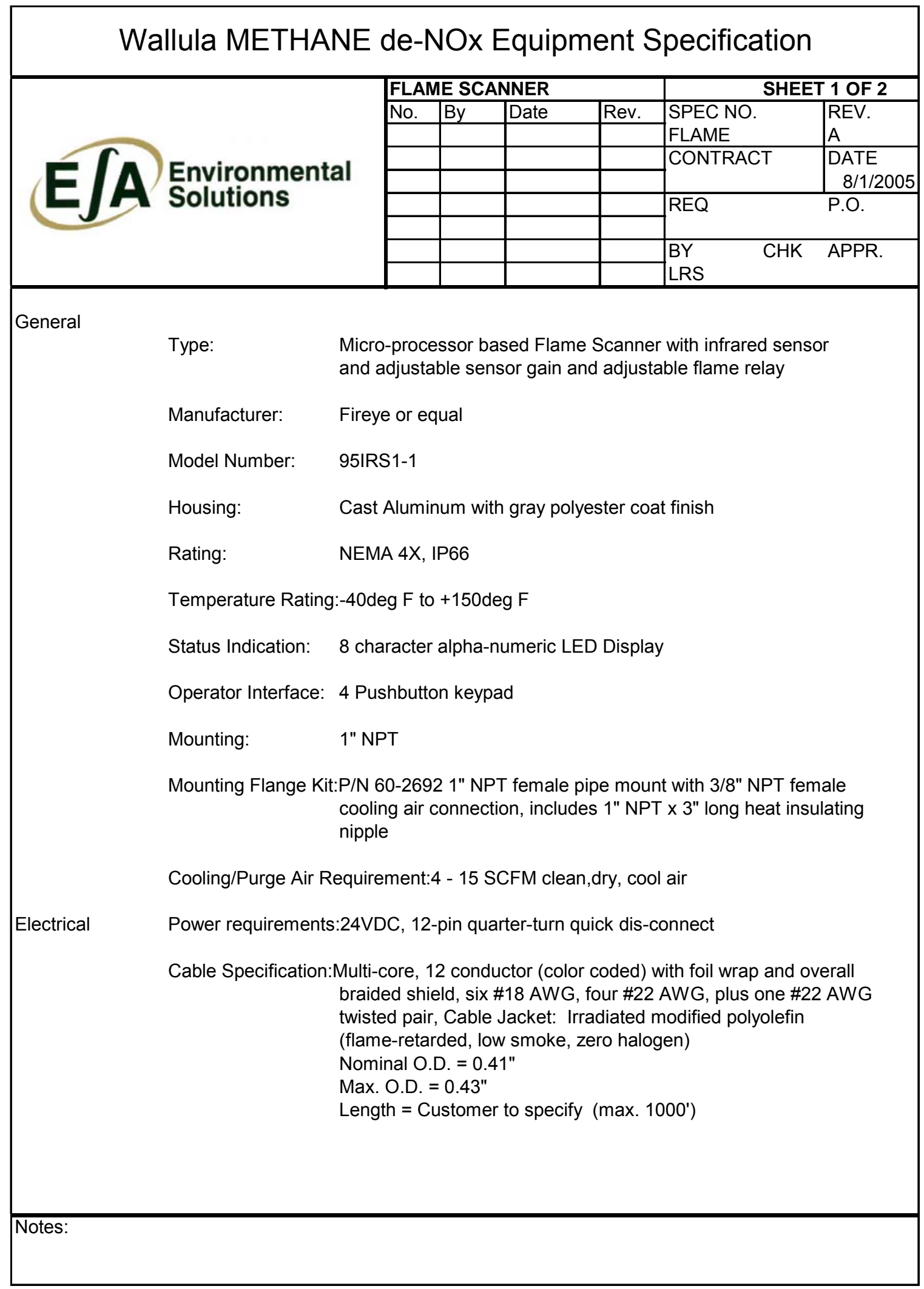




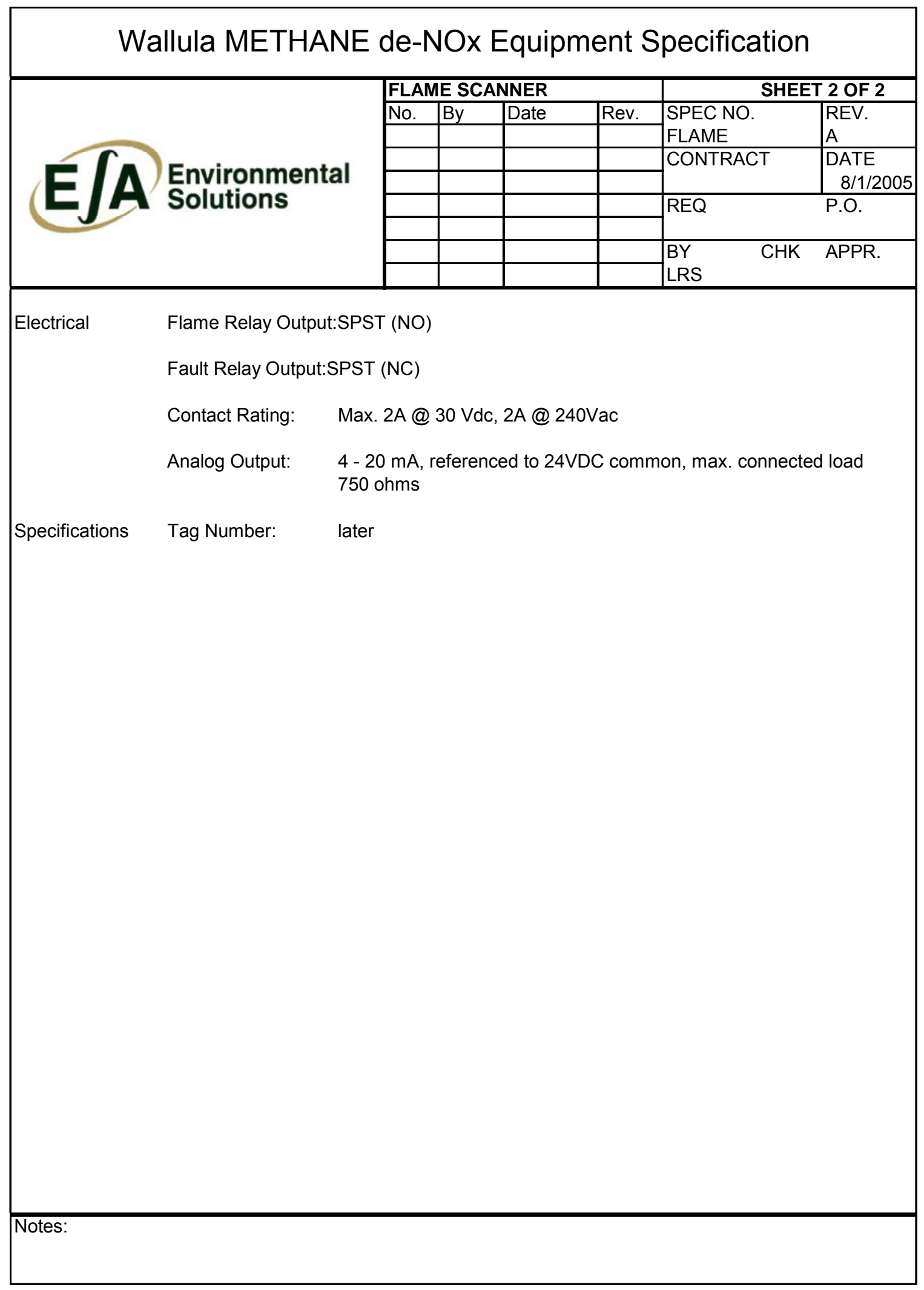




\subsection{Port Hudson MdN Retrofit Design- Preliminary}

\subsubsection{Port Hudson MdN Design Objectives}

The MdN design for the Port Hudson boiler has several expected benefits. The mill's primary objective was achieving a reduction in $\mathrm{NO}_{\mathrm{x}}$ emissions and maximizing stoker bark fuel. CFD studies indicated deep levels of $\mathrm{NO}_{\mathrm{x}}$ reduction is possible with $\mathrm{MdN}$ operation. A target of 0.14 pound $\mathrm{NO}_{\mathrm{x}}$ per million Btu was the system design basis based on a request from the mill. This is very deep and aggressive reduction level; baseline operation measured $\mathrm{NO}_{\mathrm{x}}$ at about 0.28 pound $\mathrm{NO}_{\mathrm{x}}$ per million Btu. The same CFD simulations indicated carbon monoxide emissions for this level of $\mathrm{NO}_{\mathrm{x}}$ reduction could be maintained within the permitted limits.

Baseline evaluation also projected a reduction in natural gas consumption of about $30 \%$ total heat input compared to conventional co-firing operations. With $\mathrm{MdN}$, the gas burners in the upper furnace are to be shutdown and used on an as-needed basis such as during fuel interruptions. The displacement of natural gas from the upper level gas burners to the MdN natural gas injection above the grate improves and stabilizes the grate combustion environment, which in turn reduces the negative impact of burning of high moisture content wood waste.

Increased temperatures at the grate improve combustion as evidence by lower carbon content in both bottom and fly ash. Increased grate temperatures along with reduction in total air is also projected to provide improvements in the boiler's overall efficiency of $1-2 \%$ at full load operation.

Based on favorable boiler baseline results, Port Hudson agreed to proceed with a MdN technology retrofit on its No. 1 Power Boiler. The retrofit installation was completed in November 2002 and is currently in full-scale continuous operation. This Port Hudson retrofit included the entire array of MdN technology components: MdN reburn fuel injection, MdN FGR and MdN OFA.

Initial performance of the system after commissioning activities provided a reduction in $\mathrm{NO}_{\mathrm{x}}$ emissions of about $30 \%$, a significant decrease; however this value was still short of the mill target level. Greater $\mathrm{NO}_{\mathrm{x}}$ reduction was achieved during trials but could not be maintained because of high carbon monoxide levels in the flue gas. Commissioning activities also discovered a problem; operations could not comply with the design basis of shutting down the gas burners. These auxiliary gas burners take air away and negatively impacted MdN system distribution plans for OFA and boiler total air flows; overall all system performance suffered. The reason these gas burners had to remain in service was a result of the small size of the boiler steam drum. With no economizer, steam load changes caused significant swings in steam drum water level, which could and did result in boiler trips. Operations configured the burner controls to quickly respond to such upsets, which prevented occurrences of boiler trips.

Mill interest in maximizing the boiler $\mathrm{NO}_{\mathrm{x}}$ reduction continued; further support was obtained and additional CFD studies conducted to optimize system performance. CFD analysis indicated potential improvements with a rework of the MdN system. System changes consisted of adding an FGR dilution flow to the OFA service and a reactivation of the previous existing furnace mid level OFA ports. These changes were implemented and system performance and operation 
stability improved; carbon monoxide levels were under control and a further reduction of $\mathrm{NO}_{\mathrm{x}}$ level between 0.18 to 0.20 pound $\mathrm{NO}_{\mathrm{x}}$ per million Btu was recorded. Based on this experience, MdN performance expectations below 0.18 pound $\mathrm{NO}_{\mathrm{x}}$ per million Btu is not a realistic design target.

\subsubsection{Port Hudson Boiler Description}

The Port Hudson paper mill No.1 Power Boiler is a hog fuel-fired stoker boiler co-fired with 4 natural gas burners arranged in two rows on the boiler rear wall. The stoker boiler manufacturer is Babcock \& Wilcox. The boiler design consists of a rectangular shape furnace, which was later retrofitted with a Detroit Stoker Company traveling grate and 3 windswept fuel (bark) distributors. The existing OFA system consisted of a total of 14, 5" diameter ports arranged in two rows, equally divided on both furnace front and rear walls. The boiler's maximum continuous rating (MCR) is $200,000 \mathrm{lb} / \mathrm{h}$ of $845 \mathrm{psig}$ superheated steam at $800{ }^{\circ} \mathrm{F}$. A sectional view of the furnace showing elevations from top of grate of major features is given in Figure 7-3. The remainder of the overall boiler system consists of a tubular air heater (no economizer), a multiclone dust collector and a high energy wet venturi flue gas scrubber.

Boiler operations at Port Hudson also handle proper disposal of a collected waste gas stream generated from the paper making process containing trace amounts of methanol and sulfur compounds classified as high volume low concentration (HVLC) non condensable waste gases (NCGs). These waste gases amount to approximately $9000 \mathrm{cfm}$ and are routed through dedicated ductwork into the furnace undergrate plenum where this HVLC waste gas combines with the undergrate air stream and participates in the primary combustion of wood waste at the grate.

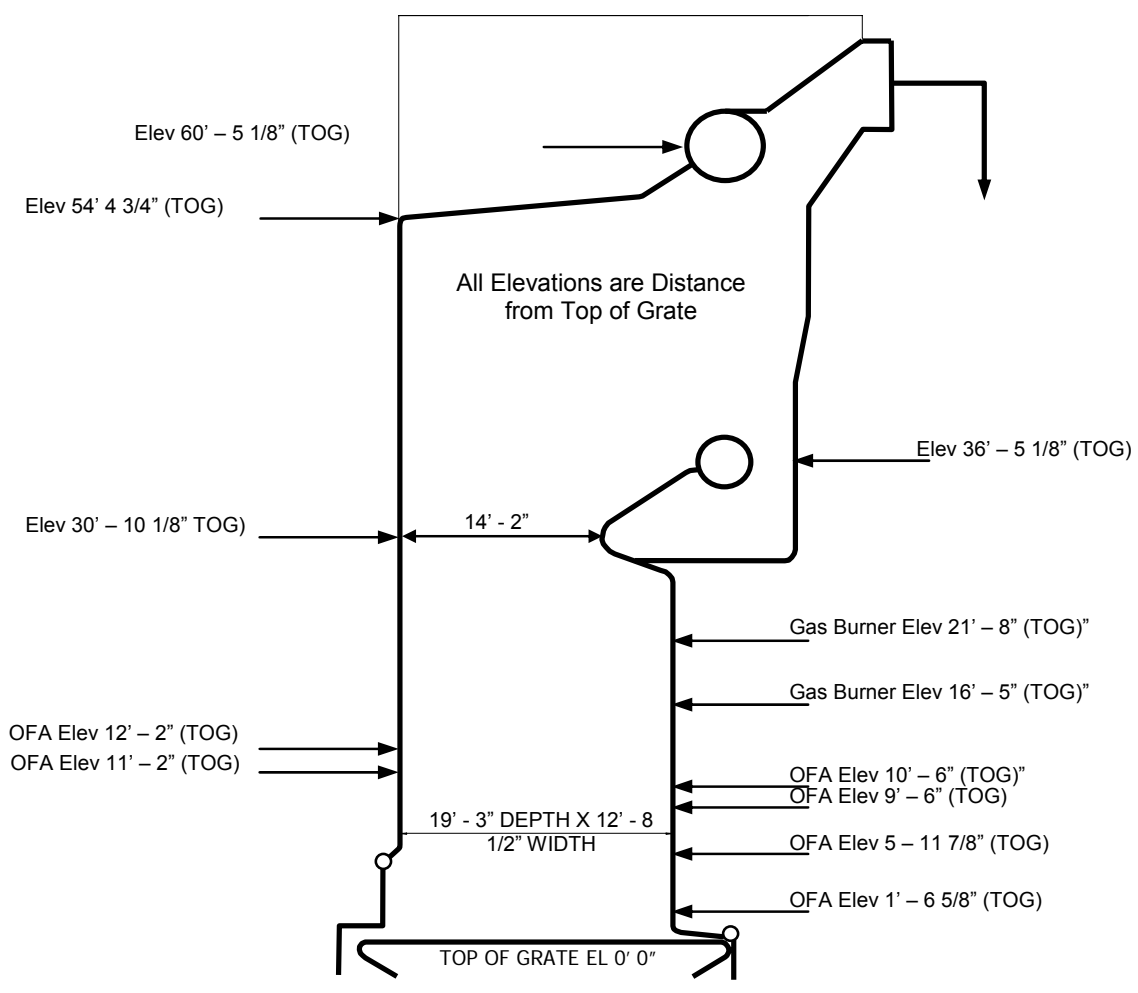

Figure 7-3 Port Hudson Boiler Elevation Data 


\subsubsection{Port Hudson MdN Design Overview}

Again, using data from baseline testing, test observations, and results from CFD simulations, MdN design information was assembled and through collaborated effort with a mill approved third party architectural and engineering firm, Ford Bacon \& Davis, a set of detailed MdN retrofit construction drawings and documentation were prepared. Mill personnel, similar to the I. Falls construction approach, provided field construction supervision.

An overview of the MdN commercial retrofit design for Port Hudson No. 1 Power Boiler is given in the following drawings: 1) a process diagram titled MdN Overview; 2) a detailed piping and instrument diagram titled MdN System P\&ID and 3) a single line process diagram titled MdN System Elements. Drawing descriptions are given below:

\section{Port Hudson:}

MdN OVERVIEW Design criteria recommended for the MdN retrofit system at Port Hudson's stoker boiler are presented. MdN system elements installed include an MdN reburn fuel injection system, an MdN FGR system and an MdN OFA system. Reburn fuel is natural gas and injection is through the front and rear walls of the furnace. Gas capacity was based on $25 \%$ of the boiler thermal input, estimated at 350 million Btu at full load, and mixing with FGR is achieved through a nozzle mix scheme at the injection ports. MdN FGR was sized to recirculate $15 \%$ of the flue with the boiler operation (without MdN) at full load. MdN OFA flow was based on a nominal UGA/OFA ratio of 50/50. Pressures noted in the supply headers for both OFA and FGR/gas injection provide for adequate penetration and mixing based on CFD evaluations. Major equipment consisted of one $250 \mathrm{hp}$ fan for FGR service.

MdN SYSTEM P\&ID A detailed piping and instrument giving actual Port Hudson installation features is given. System instrumentation is denoted for natural gas, FGR and OFA services. System interlock conditions are also listed.

MdN SYSTEM ELEMENTS A simplified single line schematic illustrates the major MdN retrofit subsystems to show how components of the retrofit system are related and function.

\subsubsection{Port Hudson MdN OFA System}

After a review of baseline test data, CFD model results and consideration of the mill's target for $\mathrm{NO}_{\mathrm{x}}$ reduction, it was concluded that the existing OFA system was not located to provide the best performance potential for an MdN system. The current OFA system has several deficiencies for MdN operation. The existing OFA fan supply is limited for MdN operation. The current OFA port elevation is too low to stage the combustion to the degree necessary for the MdN system. The rear lower level of the OFA system was found to have a significant contribution to the formation of $\mathrm{NO}_{\mathrm{x}}$.

\section{Port Hudson:}

PID-5 The OFA fan is fed from the airheater outlet duct at a temperature of $550^{\circ} \mathrm{F}$. The fan discharge includes a flow meter measuring total OFA before a tee for introduction of 
FGR. FGR addition provides an additional tool for optimization of system performance. The OFA ductwork is then split to supply two the OFA headers, located on the sidewalls of the furnace. If the location has available space, an optional automated inlet damper to maintain a specified pressure in the OFA supply header could be considered. Each header will is also equipped with a manual damper to balance flows and a pressure transmitter.

PORT HUDSON-OFA The installed MdN OFA system consisted of 22 custom port assemblies installed on the boiler sidewalls; 11 on one side and 11 on the other. The custom design was developed from CFD studies. The drawing illustrates the custom port design, which consists of a 3 nozzle assembly locally grouped to distribute air over a broader zone in comparison to conventional designs. The OFA assembly is constructed with one $3 \frac{1 / 2}{2}$ and two $1 \frac{11 / 2 ”}{2}$ schedule 40 pipe material.

\subsubsection{Port Hudson MdN Reburn Fuel Injection System}

The system will have two methane injection zones, one each along the front and rear wall. Each zone will have twelve (12) injection ports. The rear wall injection zone will utilize the bottom row of the existing lower zone OFA ports. The front wall zone will require new penetrations for the ports. The natural gas / FGR ports will continue to inject FGR to maintain a low oxygen environment along the grate when boiler conditions do not support natural gas injection.

\section{Port Hudson:}

PID-2 At Port Hudson, MdN reburn fuel is natural gas. Management of the system's main gas supply is detailed. Gas inlet pressure is 50 psig; a set of pressure reducing regulators maintain a stable gas pressure between 10 to 15 psig. A main safety shutoff valve and vent valve automatically prevent the introduction of natural gas until system interlocks are satisfied. Two pressure reducing valves provide redundancy and safety for natural gas supply should a fault occur with one of the regulators such as a ruptured diaphragm.

PID-3 \& $4 \quad$ Natural gas from the main supply is directed to two independent gas control trains. Each gas control train operates independently and regulates injection of reburn fuel to the furnace front and rear ports. Hardware provides for the safe introduction and flow metering and control of natural gas. Natural gas flowrate is measured with a vortex flow element; pressure and temperature sensors monitor flow conditions and also compensate the flow signal to provide a mass flow signal. The set point of natural gas is adjusted with a flow control valve until the desired flowrate is achieved. A safe shutoff and isolation of gas from the leaking into the boiler is achieved through a double block and bleed arrangement of safety shutoff solenoid valves. A small purge air fan and isolation valve provides a flow of purge air to clear the natural gas piping prevent pluggage in the gas injection quills.

INJ DETAIL Construction details and overall arrangement of the MdN FGR/natural gas injection ports are shown. In this design, gas is directed through a dedicated conduit and combined with FGR using a nozzle mix method. Nozzle mixing releases the reburn fuel at the FGR/gas injection port outlet, just before entering the furnace. 


\subsubsection{Port Hudson MdN FGR System}

At Port Hudson, the MdN Flue Gas Recirculation (FGR) system consisted of an arrangement which supplied FGR for reburn fuel injection and mixing of grate combustion gases; for replacement of bark feeder pneumatic air and for dilution of OFA's oxygen concentration. An earlier version also directed a portion of FGR to the undergrate air flow; this feature was eliminated after combustion tests showed little or no benefits. A reduction in OFA oxygen content provides a reduction in the amount of oxygen available to form $\mathrm{NO}_{\mathrm{x}}$. For the design, the MdN FGR fan takeoff point is after the ID fan and before the wet scrubber. The design assumed adequate collection efficiency from the mechanical collector and would not contain excessive dust or particulate content.

The FGR system duct work was sized and the design based on pressure loss through a length of 600 feet of straight pipe with an elevation change of 25 feet from the FGR fan outlet. This estimate gives adequate account for pressure loss encountered with duct transition sections, elbows, and takeoffs in the installed duct work.

\section{Port Hudson:}

PID-1 The MdN FGR system process takeoff is located after the boiler's ID fan. An isolation damper is installed in the inlet duct leading to the FGR fan. An optional scheme could also include a louvered damper or application of a variable speed drive to throttle total flow of FGR to satisfy the system flow and pressure requirements. After the fan, total FGR system flowrate is measured and other instrumentation monitors the FGR flowing pressure, temperature and oxygen content. Dedicated ductwork route FGR to other MdN system demands. FGR to OFA is set by a flow control station; regulation of FGR for natural gas injection is set by pressure to maintain adequate penetration and turbulence in grate combustion zone. FGR fan discharge pressure, as a minimum, must be maintained at greater than 20 ” in $\mathrm{H}_{2} \mathrm{O}$ to satisfy bark feeder pneumatic pressure requirements throughout the boiler operating range. Other FGR process set points are based on boiler load and operating objectives.

\subsubsection{Port Hudson MdN Controls}

The overall control philosophy for the MdN system is to minimize the amount of boiler operator interaction to operate the system. Integration of the controls, both discrete and regulatory requirements, were configured to automatically adjust various set points for FGR, OFA and natural gas flowrates and pressures based on boiler steam load or due to changes to the boiler operating conditions. A set of control drawings are provided; brief descriptions are given.

Reburn fuel injection (natural gas) controls follow guidance of industry standards and meet all safety requirements as recommended from the NFPA and boiler insurers.

For the purpose of this design, the unit DCS has adequate spare capacity for additional hardware and tagname points associated with the MdN system. 


\section{Port Hudson:}

LOGIC-1 This drawing contains the permissives and interlocks for the operation of the main natural gas supply isolation and vent valves. The logic is designed to insure that all the requirements for injecting natural gas are met. The permissive focus on the verifying the boiler is operating and a flame is present and the FGR system is functioning properly. The interlocks look at gas control equipment along with the same parameters monitored for the permissives.

LOGIC-2 This drawing contains the permissives and interlocks for the separate and independent operation of the front and rear natural gas injection control trains. The permissive and interlocks are specified; signals are designed to monitor operation of the valves and the flowing characteristics of natural gas, such as pressure and flowrates. Each zone has a dedicated set of permissives and interlocks.

LOGIC-3 This drawing contains regulatory control logic (proportional, integral, reset process control) for the MdN FGR system requirements. Control loop services include FGR fan pressure; FGR dilution flow to OFA and FGR header pressure for MdN gas injection ports. Control diagrams show system instrumentation; controller configuration and loop input and output signals (4-20 madc). Controller set points are determined through a characterization block dependent on boiler load.

LOGIC-4 \& 5 A regulatory control logic diagram for MdN reburn fuel injection (natural gas) to the furnace front and rear injection ports is given. The control logic includes a calculation for heat input from natural gas. The logic is designed to maintain a desired input from the various gas streams and minimizes the quantity of natural gas used. The logic also insures that the maximum allowable heat input from the multiple gas streams is not exceeded.

LOGIC-6 This drawing shows the regulatory control requirement for the OFA fan inlet damper. The OFA system is designed to maintain a specified header pressure; set point is adjusted automatically dependent on boiler load.

\subsubsection{Port Hudson MdN System installation Cost Estimate}

An estimated cost to complete construction ready drawings, procure and install equipment, and test and tune a MdN system for Power Boiler No. 1 at the Port Hudson mill based at current 2005 costs as represented by ESA drawings is One Million One Hundred Thousand Dollars $\mathbf{( \$ 1 , 1 0 0 , 0 0 . 0 0 )}$. Installed costs for the 2003 retrofit were unavailable from Port Hudson for inclusion. ESA's preliminary design drawings were developed specifically for this manual from baseline test data. The confidence of this estimate is rated at plus/minus $30 \%$ basis. The major item with regards to uncertainty in the estimate is the cost of local labor and the unknowns related with installation.

The above quoted cost does not include the initial baseline testing, CFD model, and preliminary MdN design. The estimated cost to perform these tasks is One Hundred Seventy Five Thousand Dollars $\mathbf{( \$ 1 7 5 , 0 0 0 )}$. 


\subsubsection{Port Hudson MdN Detailed Retrofit Design}

The design details contained in this manual for the DeRidder MdN system are preliminary details and are not approved for construction. A more comprehensive evaluation of the site and review of the preliminary design are required to finalize the MdN system design.

\subsubsection{Port Hudson MdN System Drawings - Preliminary}

Table 7-5 Port Hudson - MdN Design Drawing Index

\begin{tabular}{|l|l|}
\hline \multicolumn{1}{|c|}{ Drawing \# } & \multicolumn{1}{c|}{ Description } \\
\hline MdN Overview & MdN System Overview \\
\hline Port Hudson MdN P\&ID & MdN Overview P\&ID \\
\hline MdN System Elements & Single Line Process Drawing \\
\hline PID-1 & Flue Gas Recirculation Equipment P\&ID \\
\hline PID -2 & Methane Pressure Reducing Equipment P\&ID \\
\hline PID-3 & Front Zone Methane Injection Equipment P\&ID \\
\hline PID-4 & Rear Zone Methane Injection Equipment P\&ID \\
\hline PID-5 & Overfire Air Equipment P\&ID \\
\hline LOGIC-1 & MdN System Interlocks \& Permissives Logic \\
\hline LOGIC-2 & Front \& Rear Zone Interlocks \& Permissives Logic \\
\hline LOGIC-3 & FGR System Control Logic \\
\hline LOGIC-4 & FGR System Control Logic \\
\hline LOGIC-5 & Front Zone Gas Flow Control Logic \\
\hline LOGIC-6 & Rear Zone Gas Flow Control Logic \\
\hline PORT HUDSON - OFA & OFA Nozzle Design \\
\hline INJ DETAIL & Methane, NCG, \& SOG Injector Detail \\
\hline
\end{tabular}




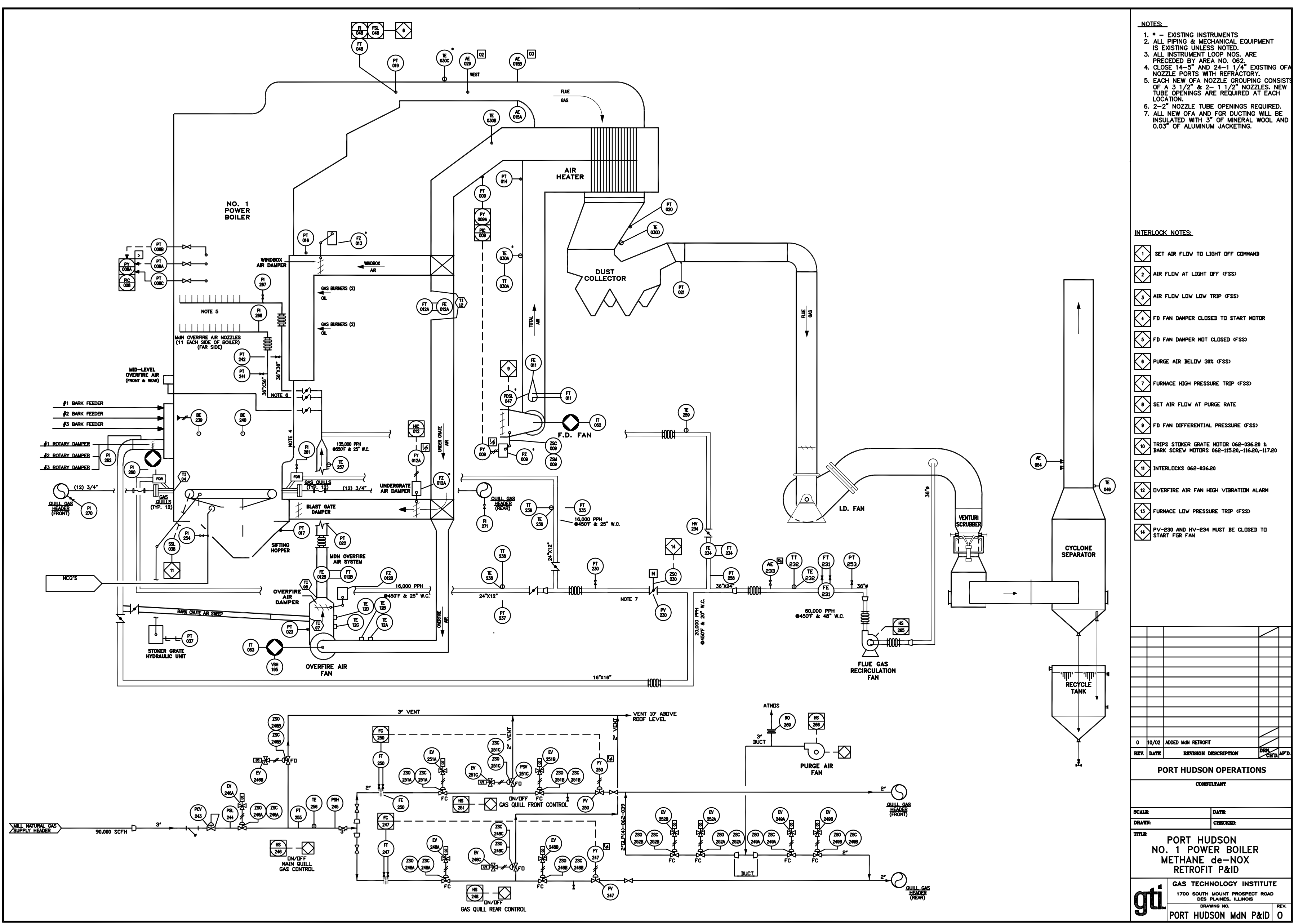




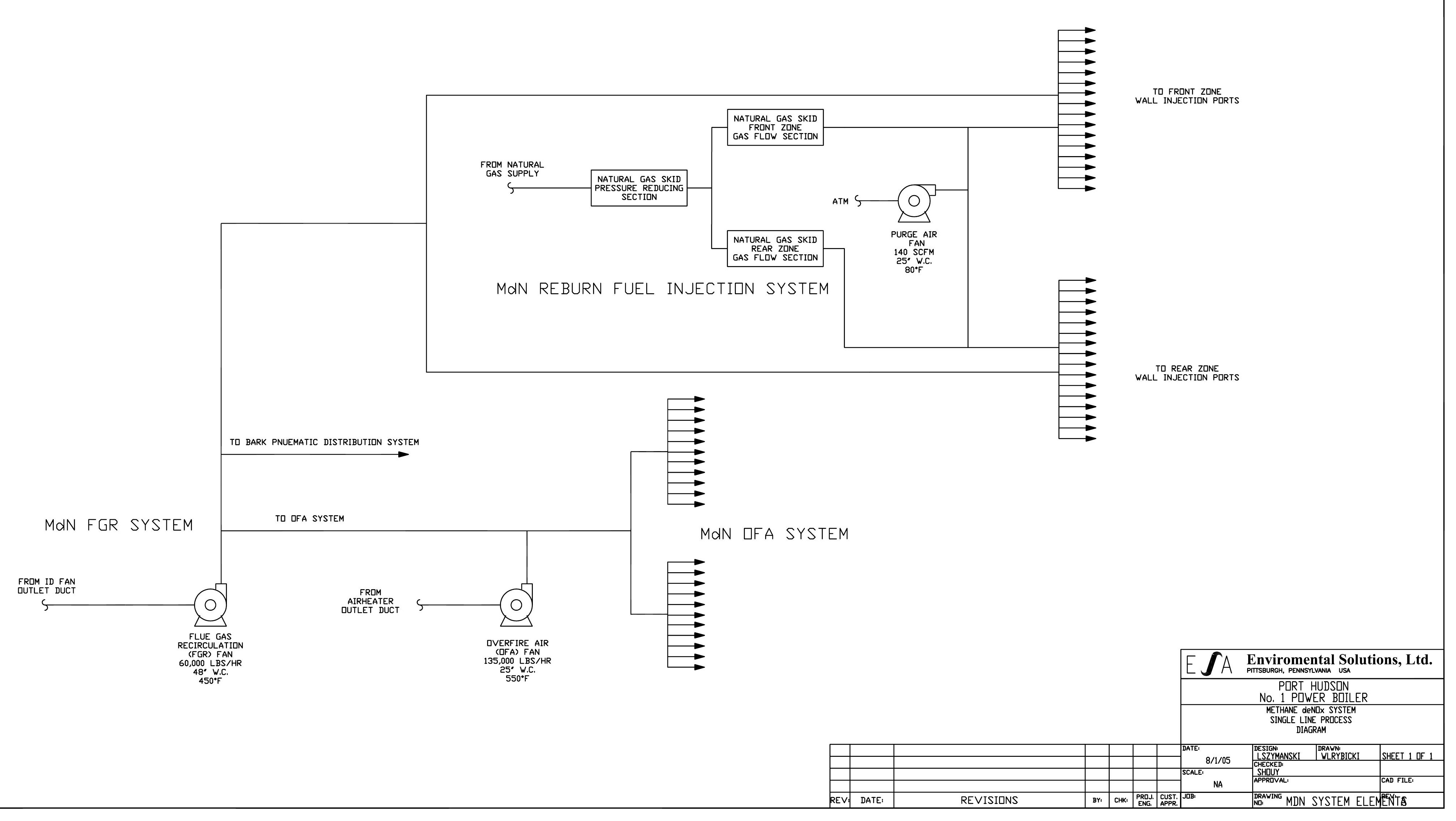




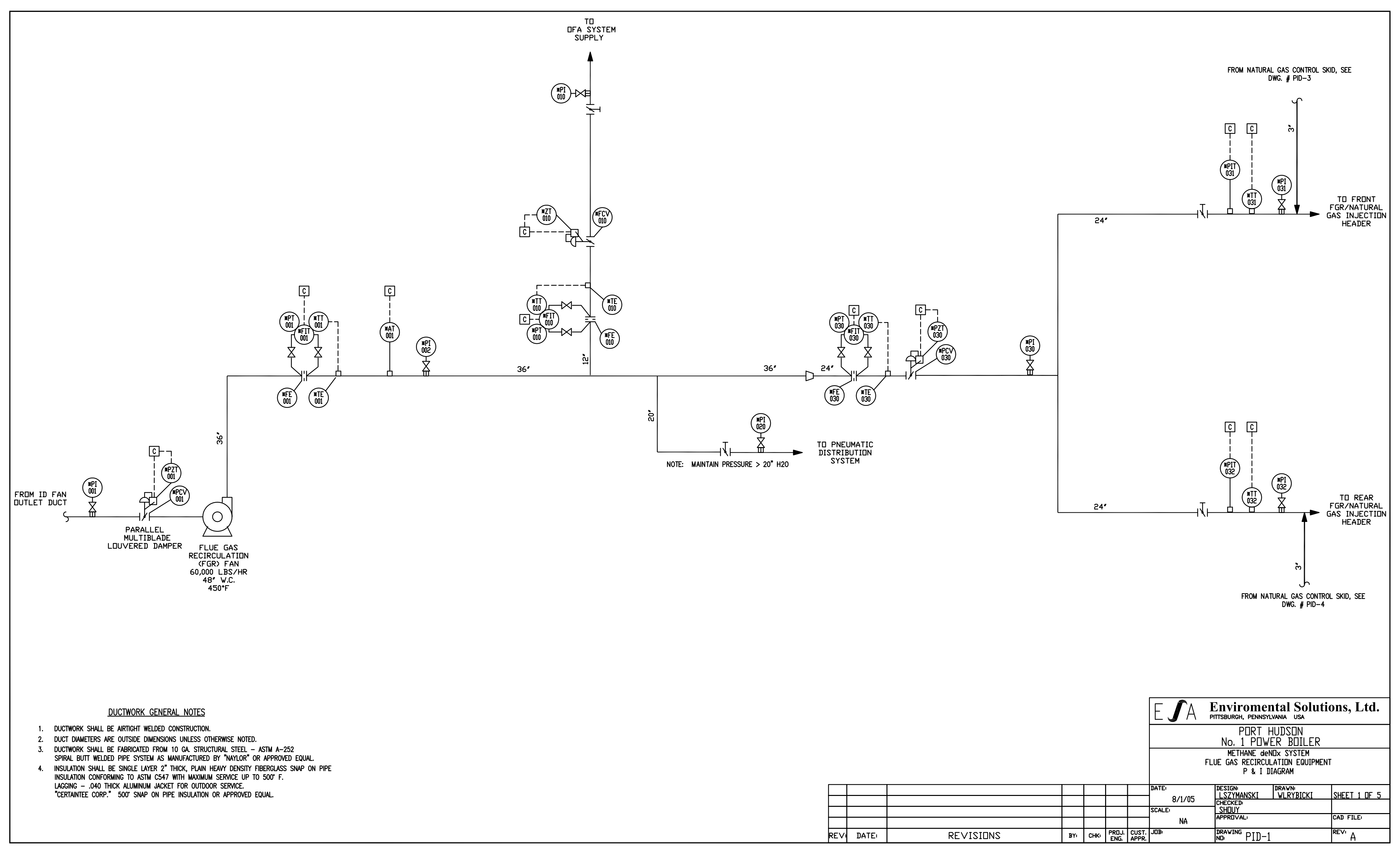




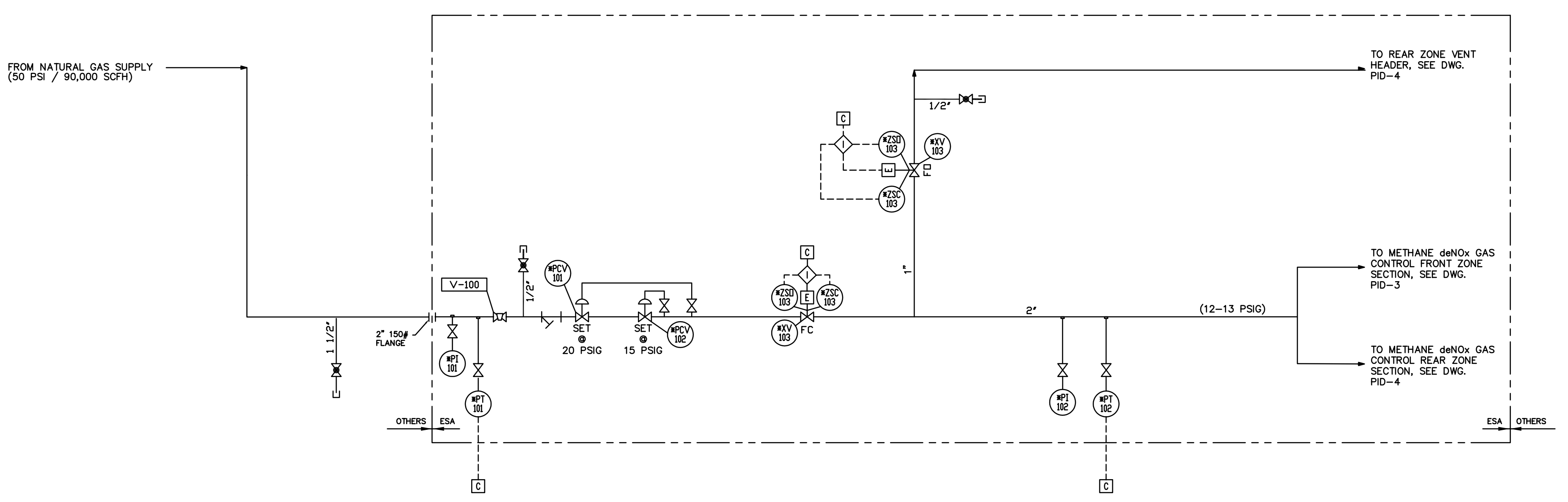




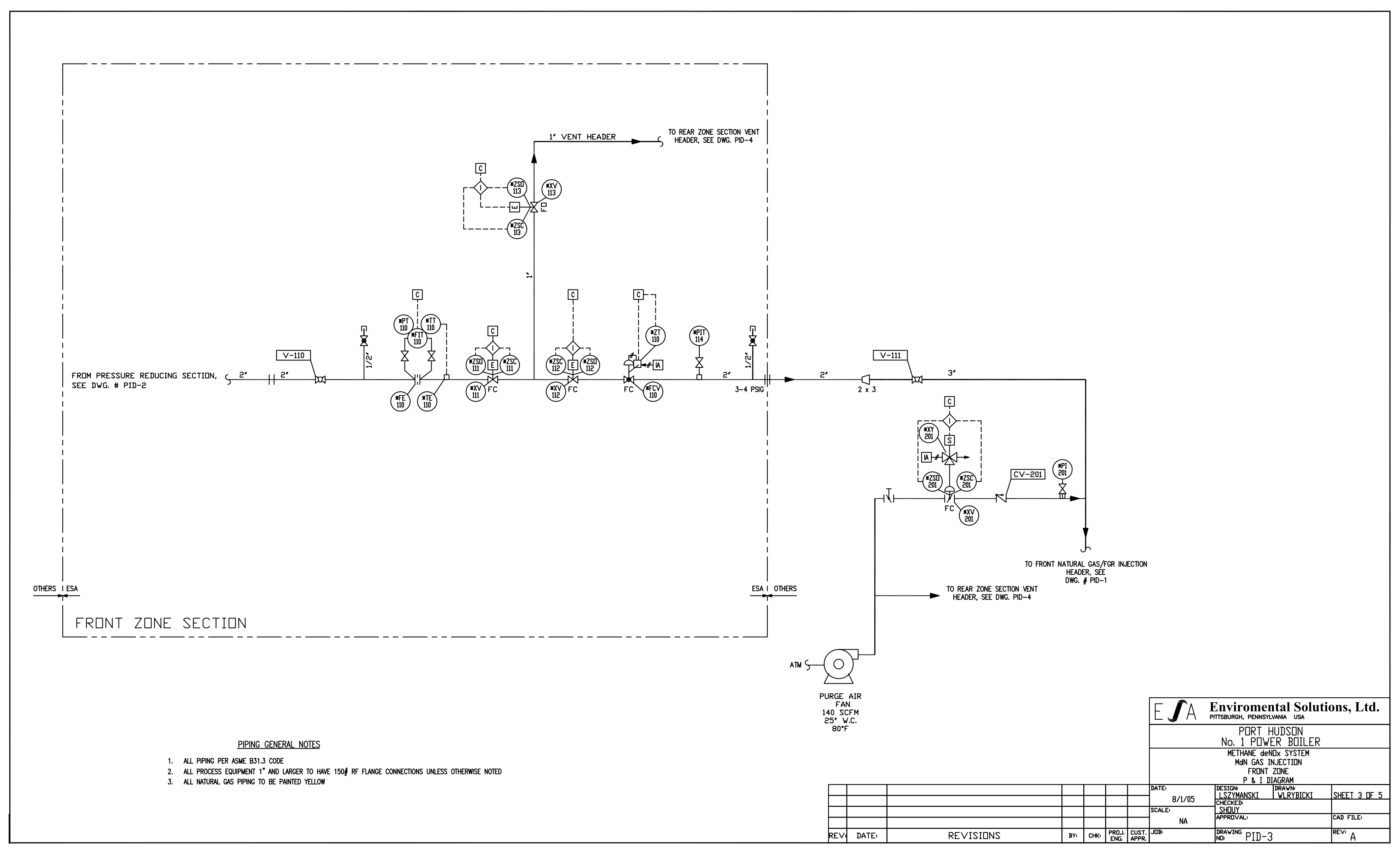




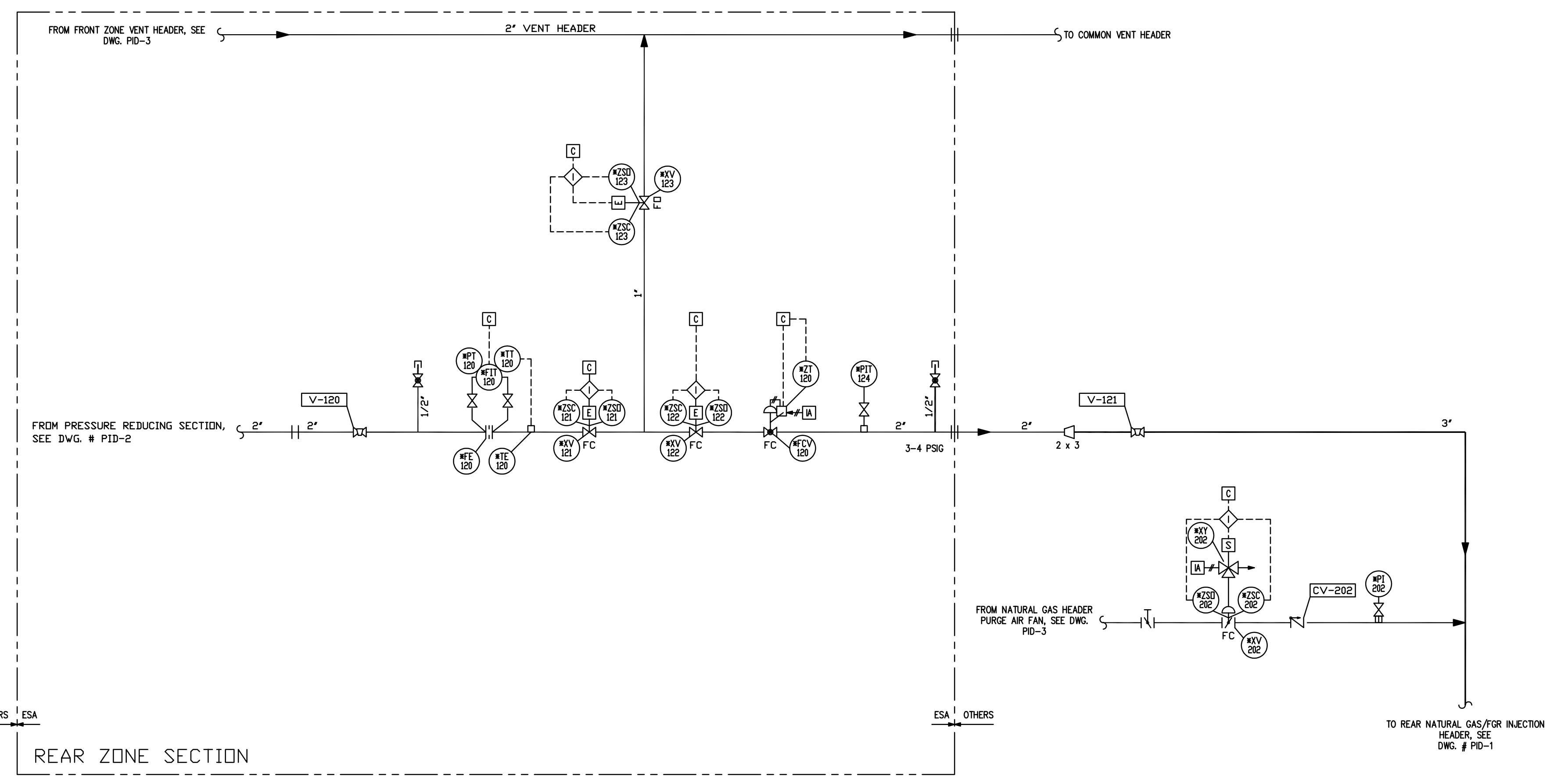

PIPING GENERAL NOTES

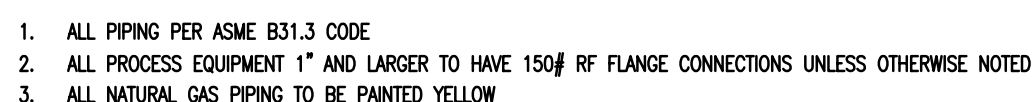

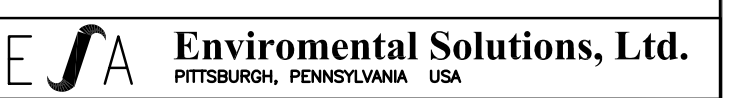

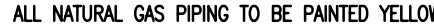

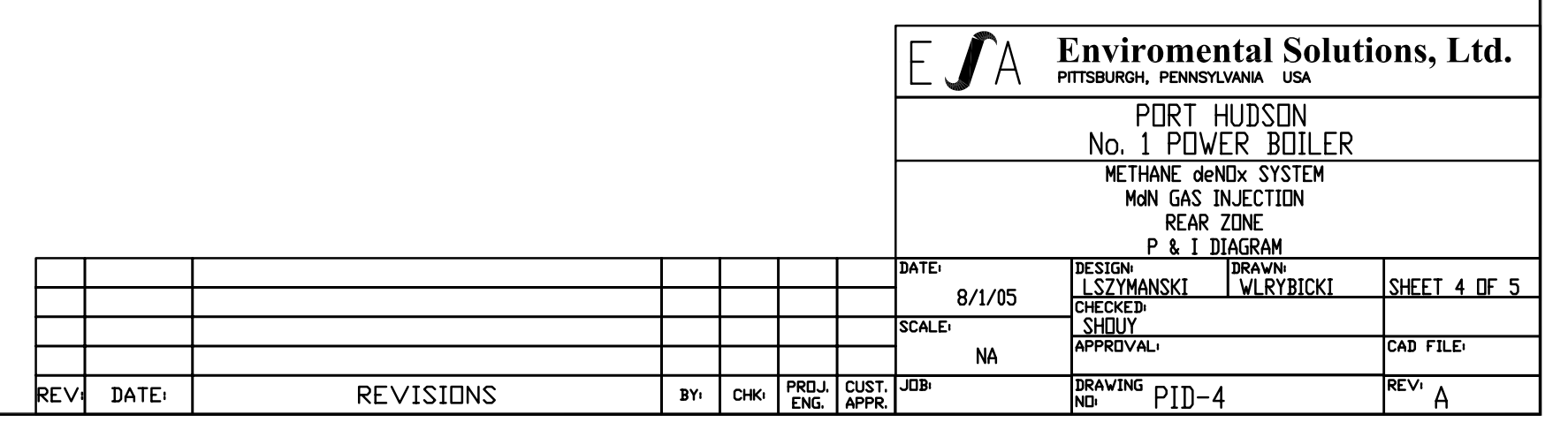




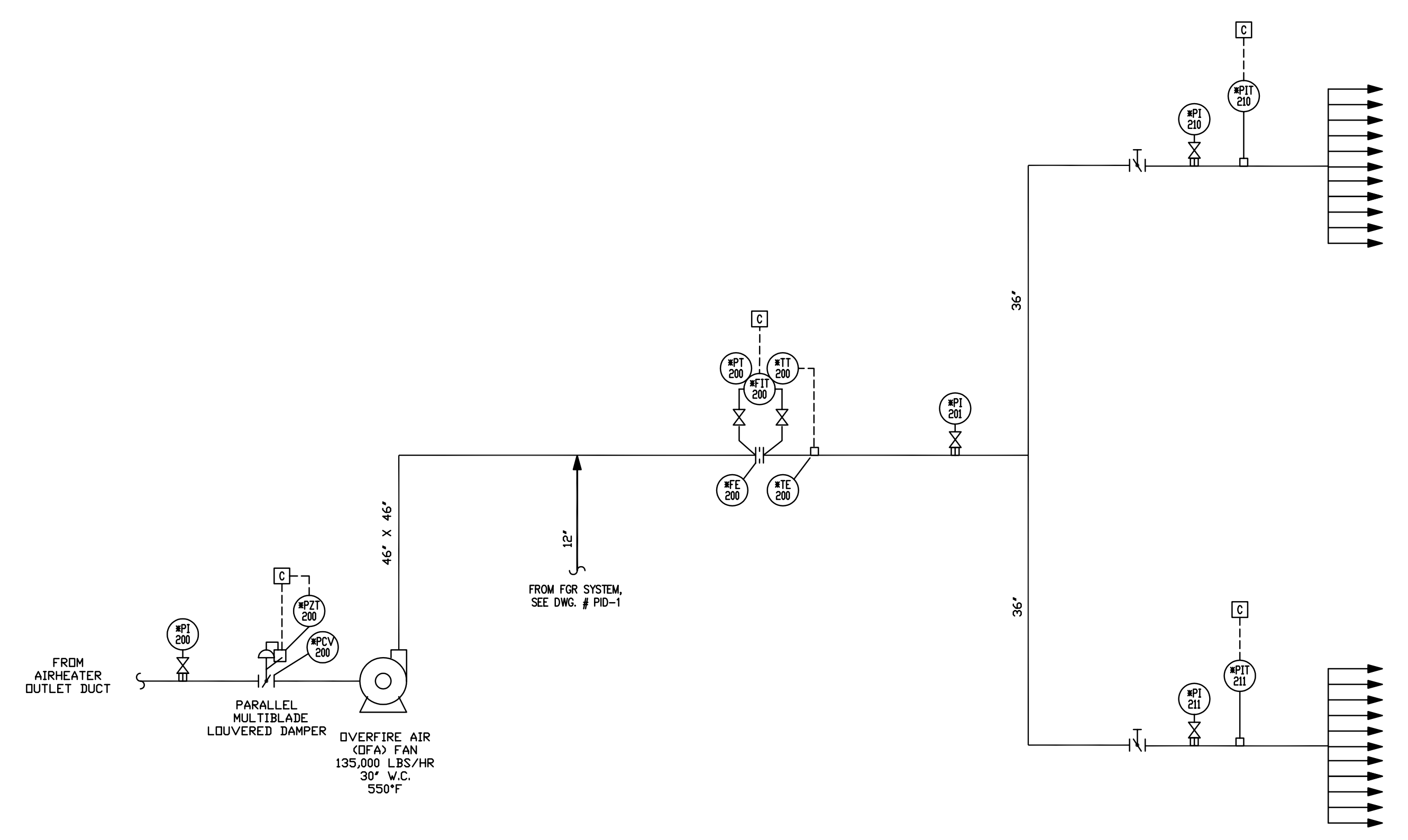

DUCTWORK GENERAL NOTES 

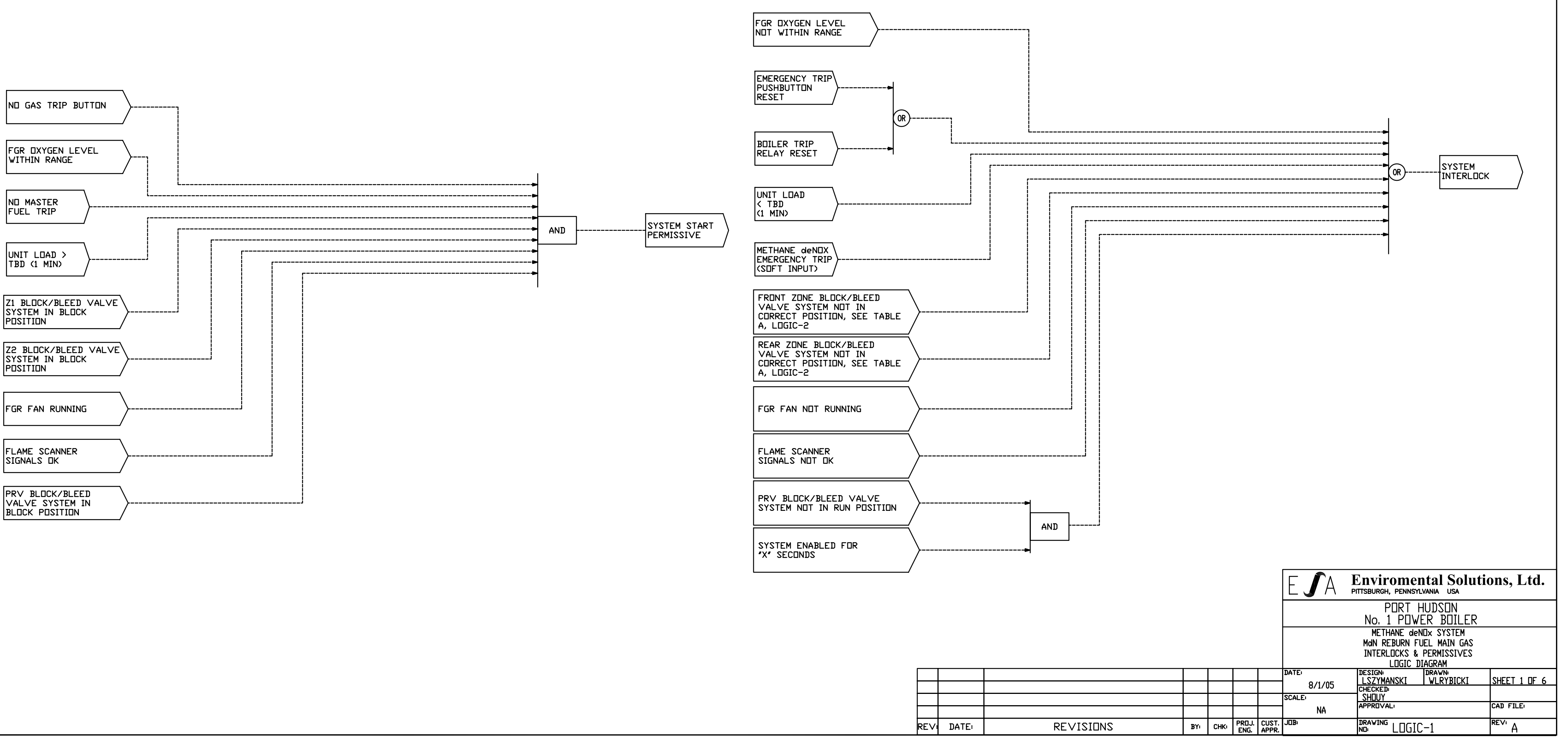

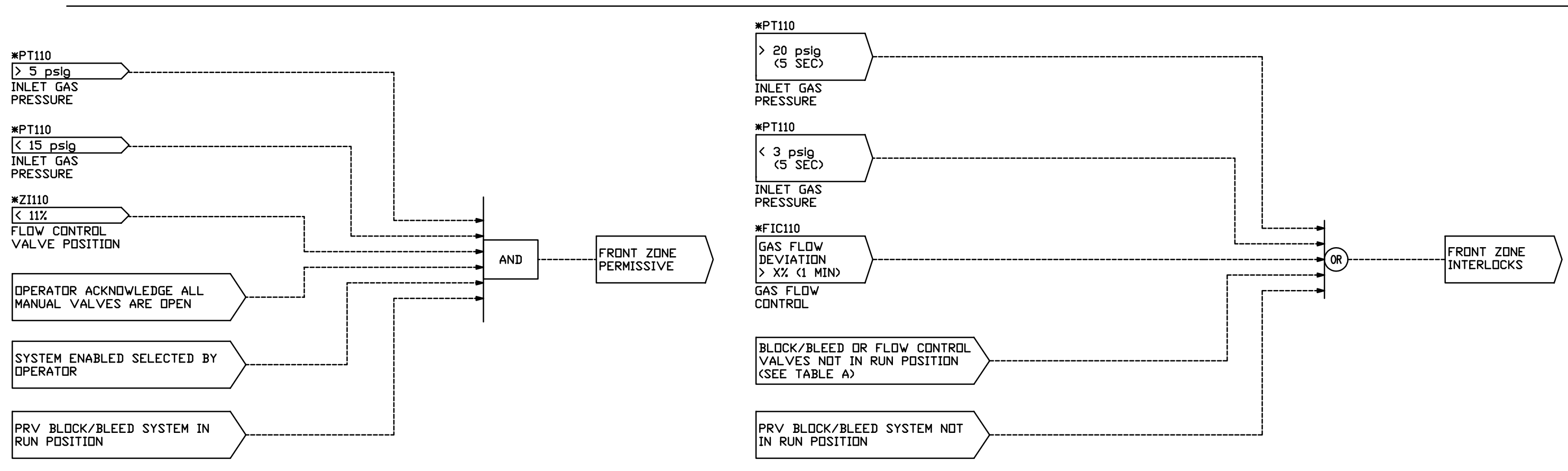

METHANE deNDX DCS
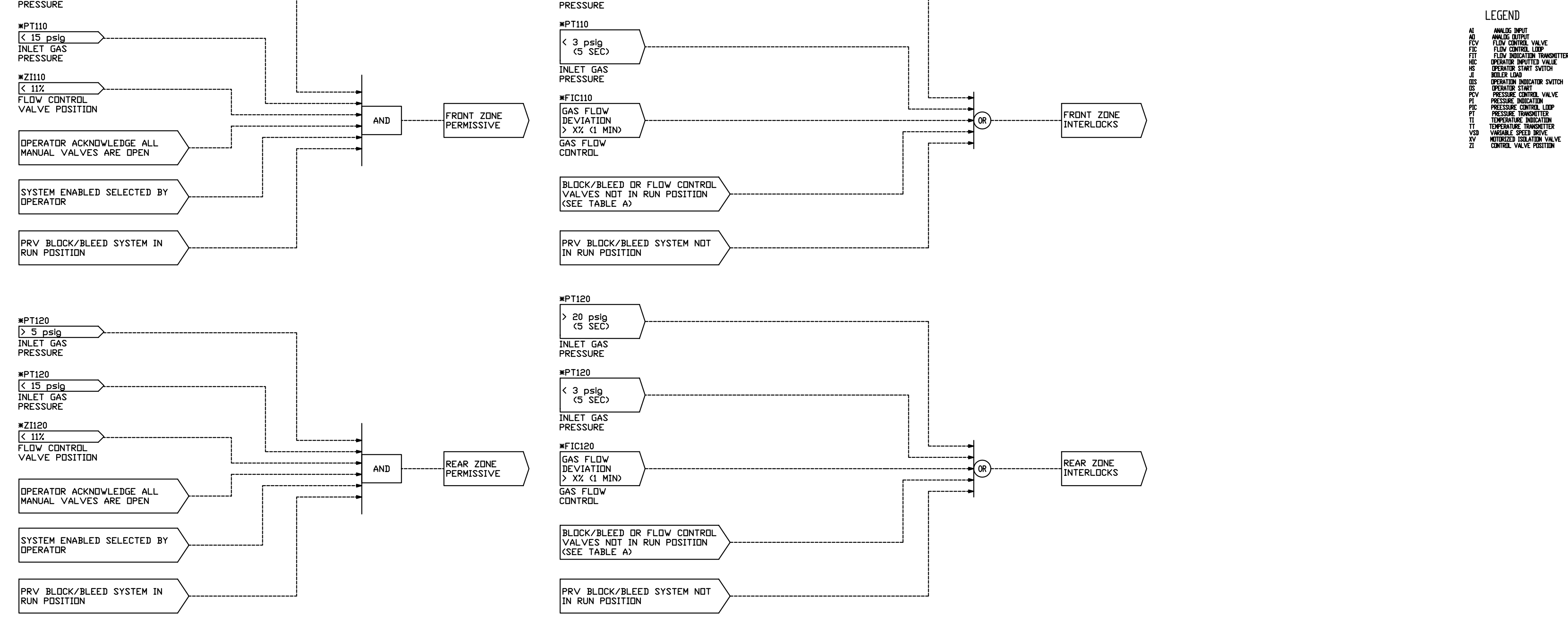

TABLE A

TABLE KEY:

CLOSED -VALVE CLOSED

DPENED -VALVE DPENED
CLOSE - VALVE CLDSING

DPEN -VALVE DPENING

\begin{tabular}{|c|c|c|c|c|c|c|}
\hline EQUIPME & ZQNE STOPPED & ZZNE STARTING & ZONE RUNNING & ZQNE STOPPING & ZQNE VENTING & ZZNE TRIR \\
\hline ZONE BLOC & CLDSED & OPEN & QPENED & CLDSE & CLOSED & \begin{tabular}{|l|l|} 
CLOSE \\
\end{tabular} \\
\hline ZONE BLEED VALVE & OPENED & CLOSE & CLOSED & DPEN & DPENED & DPEN \\
\hline FLOW CONTROL VALVE & MIN & CONTROL & CONTROL & RAMP TO MIN & MIN & MIN \\
\hline
\end{tabular}

FRENT \& REAR GAS INJECTIIN ZUNES

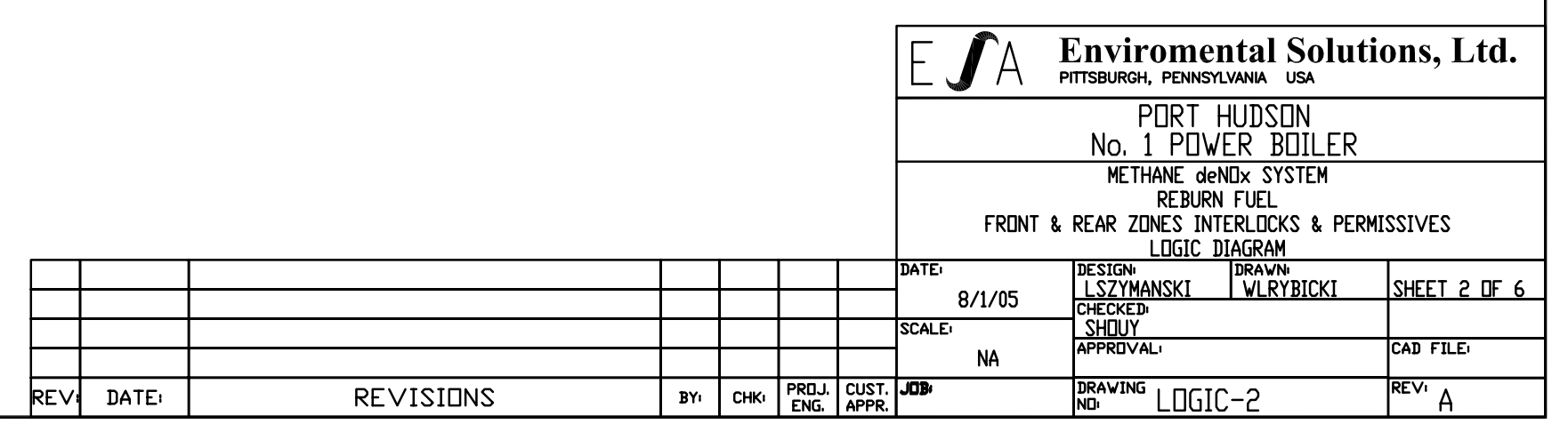




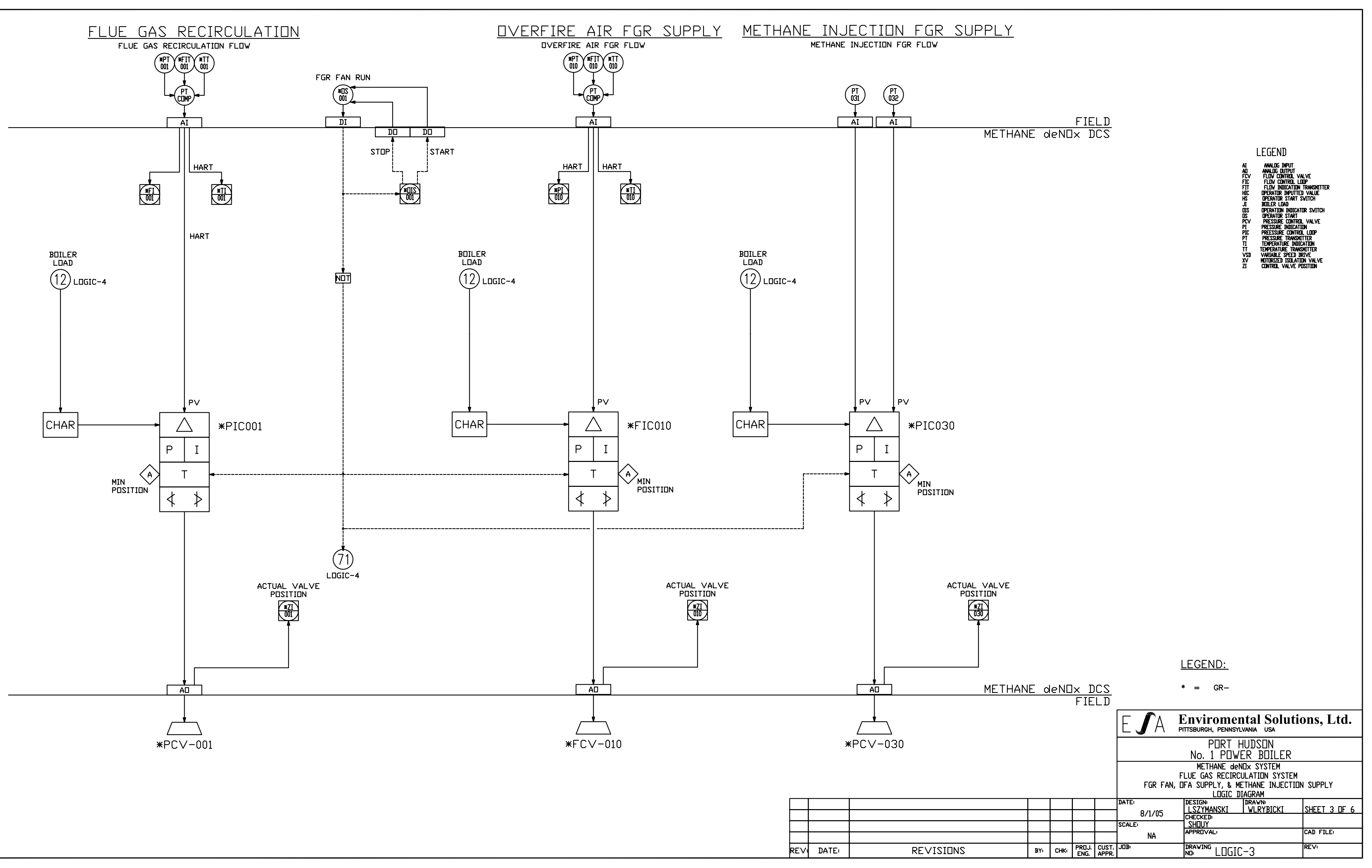




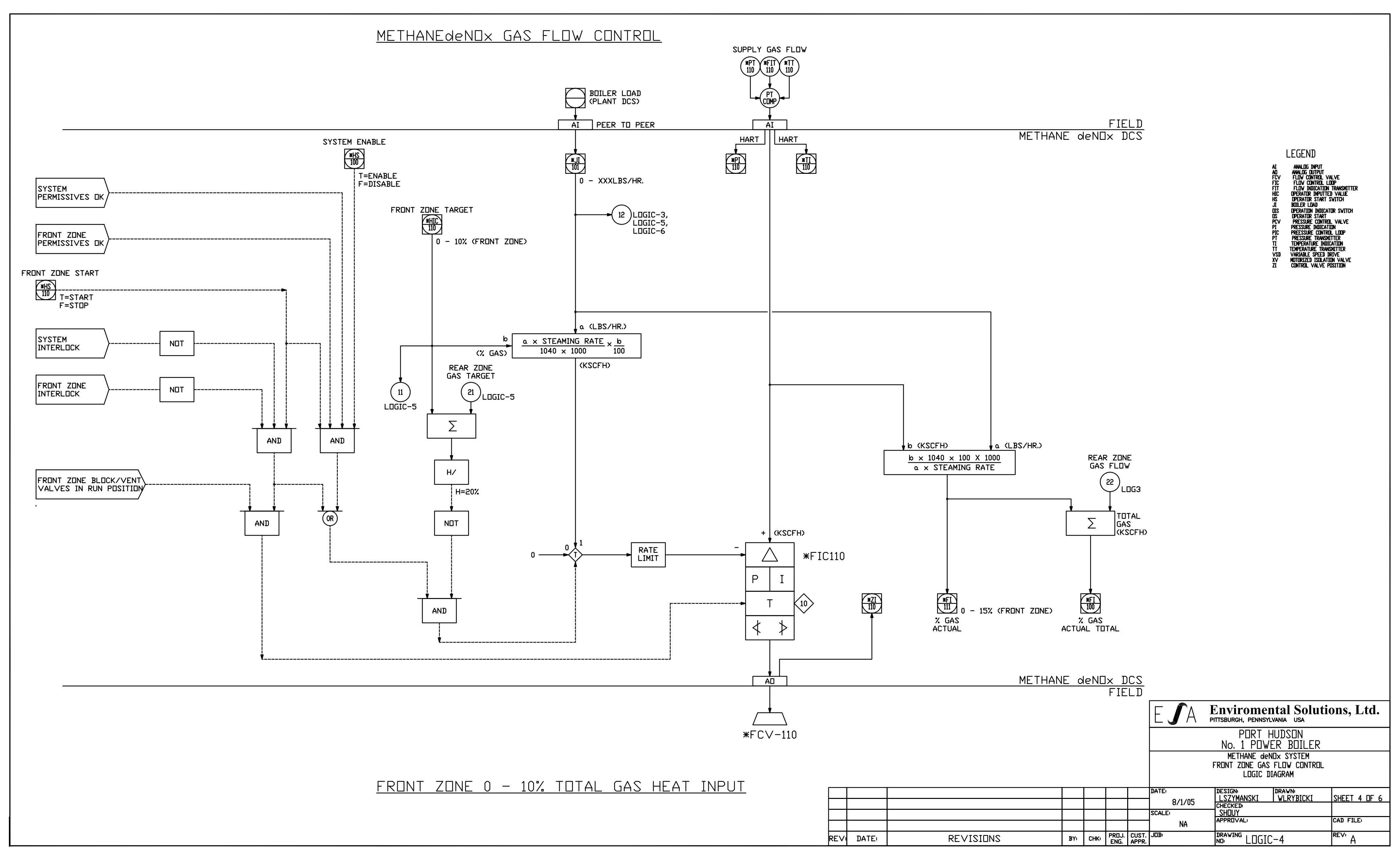




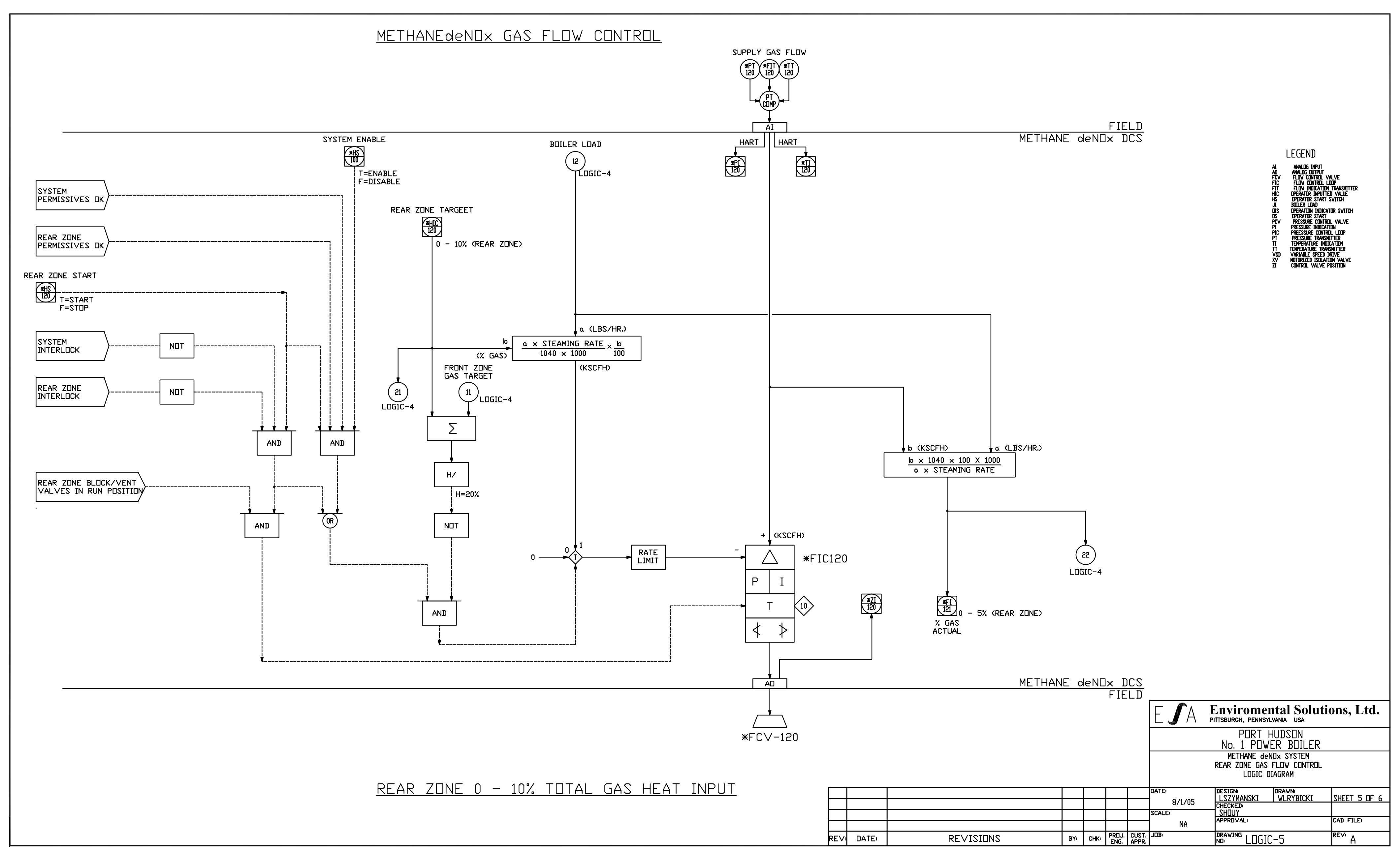




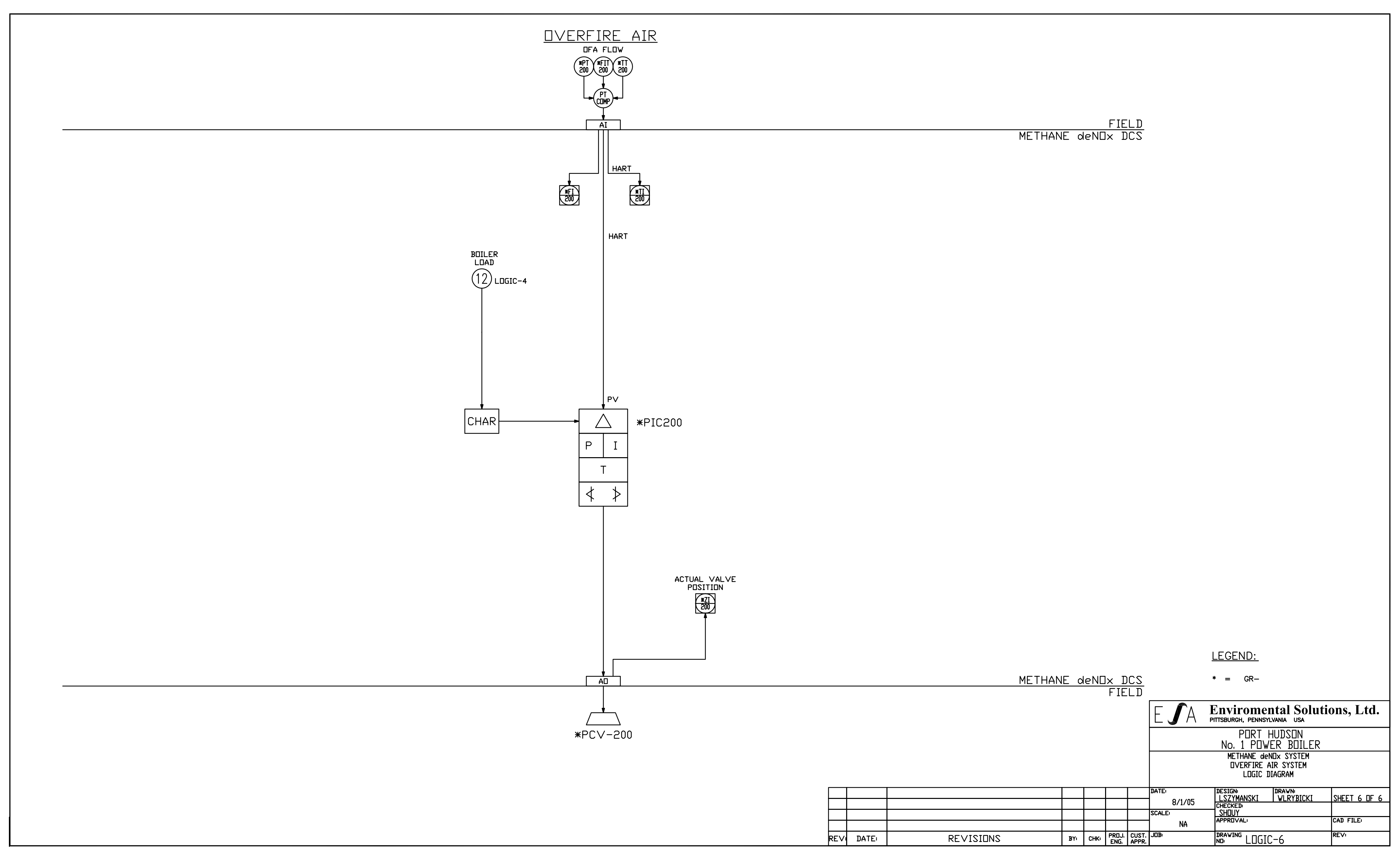




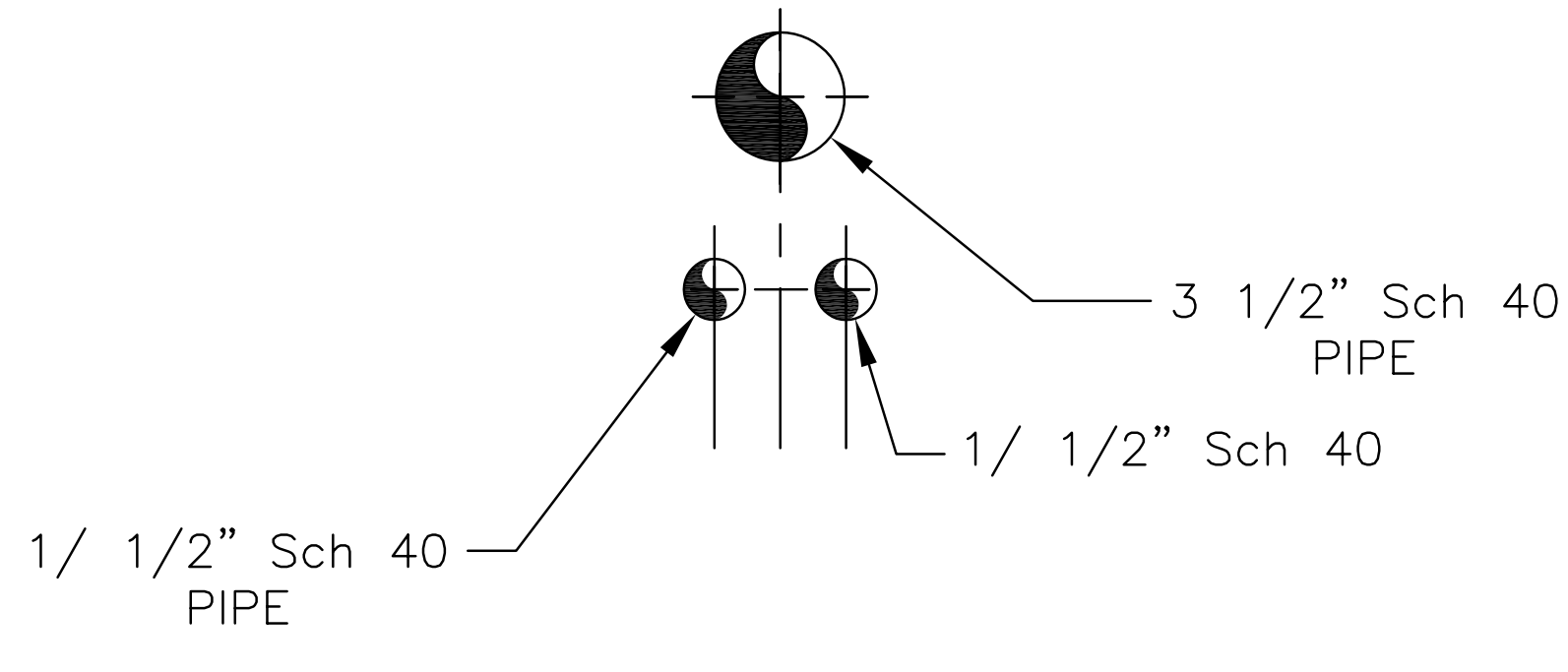

ELEVATION LOOKING EAST

(1) OFA NOZZLE CONFIGURATION

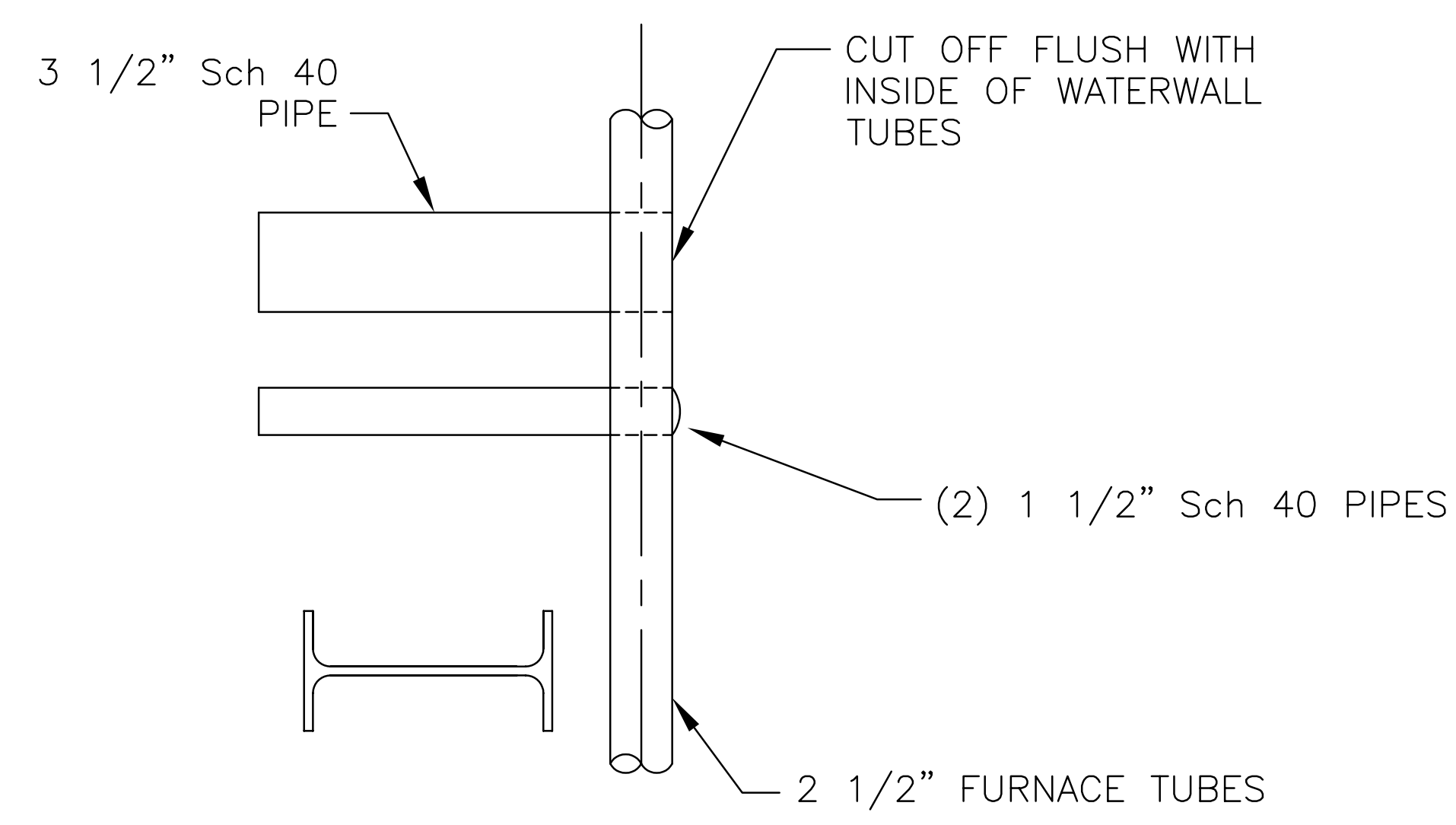

ELEVATION LOOKING NORTH @ ( OFA NOZZLE CONFIGURATION
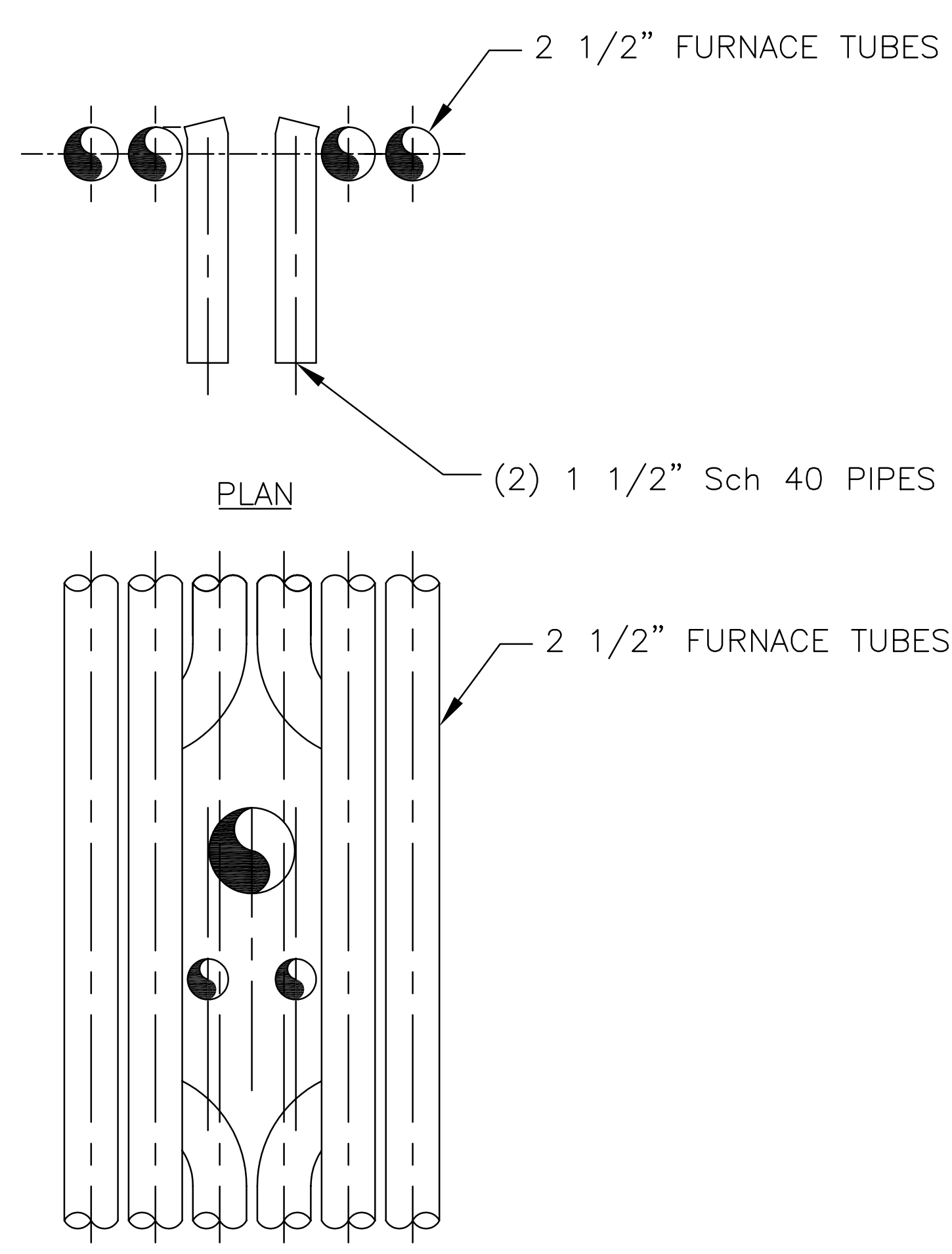

ELEVATION LOOKING EAST (@) OFA NOZZLE CONFIGURATION

FILE: PURT HUDSDN-GFARD.dwg GAS TECHNOLOGY INSTITUTE

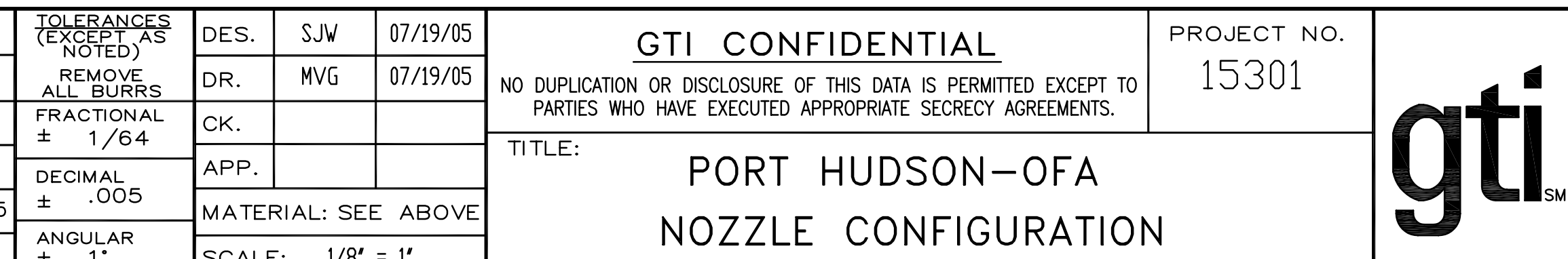

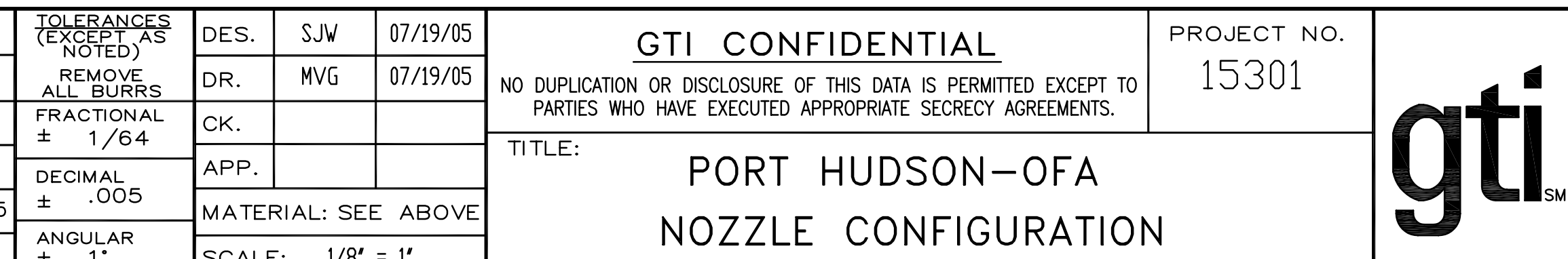
NOZZLE CONFIGURATION
1700 SOUTH MOUNT PROSPECT ROAD DES PLAINES, ILLINOIS 


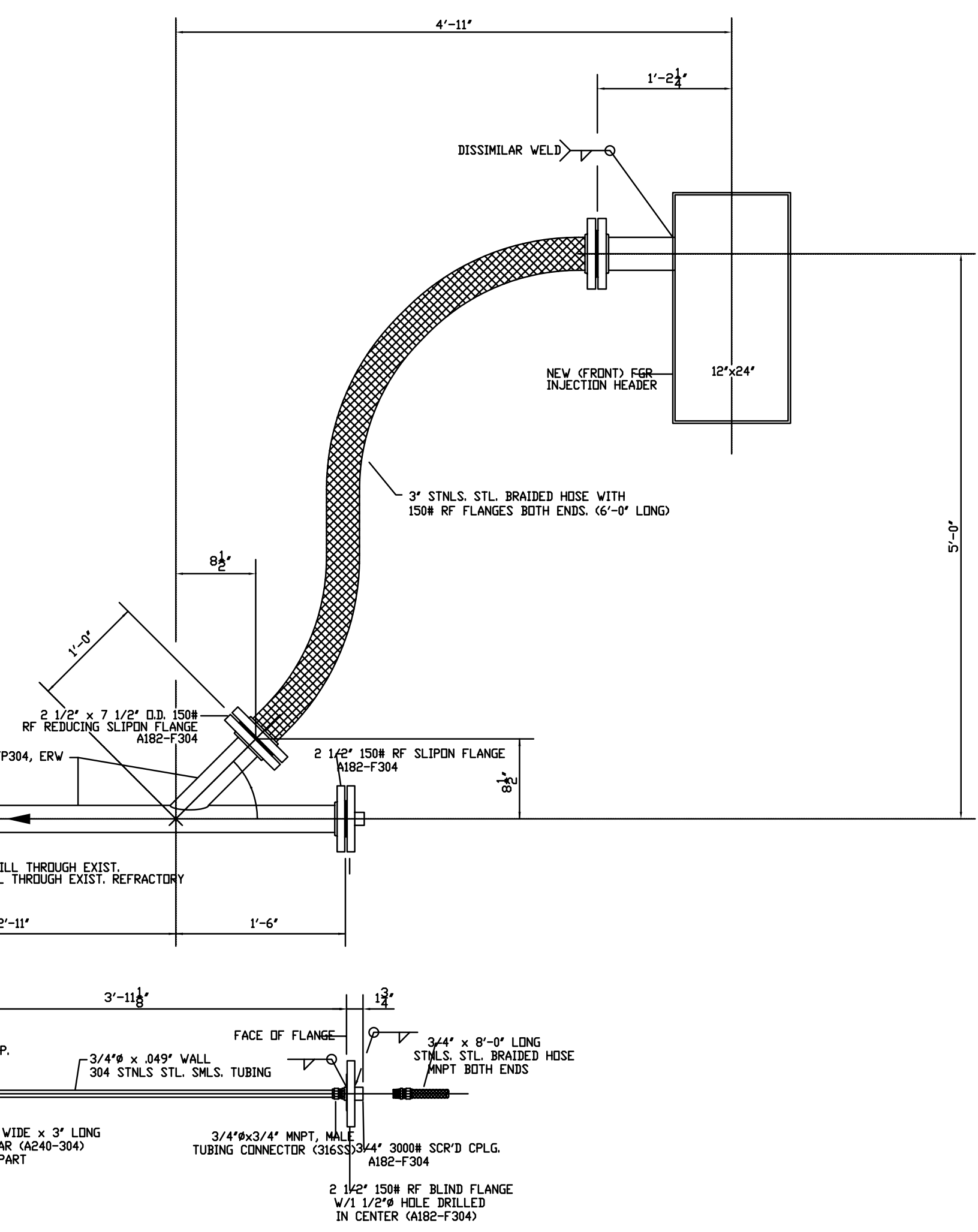

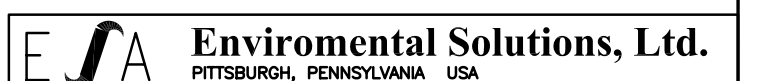 PRRT HUDSON FGR MEATURAL GAS INISECTRR DETAL

\begin{tabular}{|c|c|c|c|c|c|c|c|c|}
\hline & & & & & & $\left.\right|_{8 / 1 / 0} ^{\text {DATÉ }}$ & 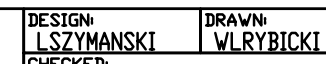 & SHEET 1 OF 1 \\
\hline & & & & & & SCCLLE! & 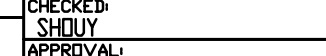 & CAD FILEE \\
\hline REV & DATE: & REVISIDNS & $\overline{B Y}$ & CHK: & $\begin{array}{c}\text { Cuss. } \\
\text { APP. }\end{array}$ & & PRAGING & $E_{v_{1}} \wedge$ \\
\hline
\end{tabular}




\subsubsection{Port Hudson MdN System Equipment Specifications}

\section{Table 7-6 Port Hudson - MdN Design Specification Index}

\begin{tabular}{|c|c|}
\hline Specification \# & Specification Description \\
\hline \multicolumn{2}{|l|}{ Rotating Equipment } \\
\hline \multirow{2}{*}{$\begin{array}{l}\text { FGR-FAN } \\
\text { OFA-FAN }\end{array}$} & FGR Supply Fan \\
\hline & OFA Supply Fan \\
\hline \multicolumn{2}{|l|}{ Instrumentation: Flow Transmitters } \\
\hline \multirow{3}{*}{$\begin{aligned} & \text { FGR-FIT } \text { CH4-FIT } \\
& \text { OFA-FIT } \\
&\end{aligned}$} & Mass Flow Transmitters for FGR System \\
\hline & Flow Transmitters for Methane Supply Zones \\
\hline & Mass Flow Transmitter for OFA System \\
\hline \multicolumn{2}{|l|}{ Instrumentation: Pressure } \\
\hline \multirow{5}{*}{$\begin{array}{r}\text { FGR-PRESS } \\
\text { OFA-PRESS } \\
\text { CH4-PRESS-XMIT } \\
\text { FGR-P-GAUGE } \\
\text { CH4-PRESS }\end{array}$} & Pressure Transmitters for FGR System \\
\hline & Pressure Transmitters for OFA System \\
\hline & Pressure Transmitters for Methane Supply System \\
\hline & Pressure Gauges for FGR System \\
\hline & Pressure Gauges for Methane Supply System \\
\hline \multicolumn{2}{|l|}{ Instrumentation: Temperature } \\
\hline \multirow{4}{*}{$\begin{array}{r}\text { FIT-RTD } \\
\text { CH4-RTD } \\
\text { FGR-TEMP } \\
\text { FGR-RTD }\end{array}$} & RTD/Thermowell for FGR Flow Transmitters \\
\hline & RTD/Thermowell for Methane Flow Transmitters \\
\hline & Temperature Transmitters for FGR System \\
\hline & RTD/Thermowell for Temperature Transmitters \\
\hline \multicolumn{2}{|l|}{ Instrumentation: Control Valve } \\
\hline \multirow{5}{*}{$\begin{array}{r}\text { PCV-001 } \\
\text { FCV }-010 \\
\text { PCV-030 } \\
\text { PCV-200 } \\
\text { FCV-110 \& }-120\end{array}$} & FGR Fan Inlet Damper Actuator \\
\hline & FGR Flow Control Valve for OFA System \\
\hline & FGR Pressure Control Valve for Methane Injection \\
\hline & OFA Fan Inlet Damper Actuator \\
\hline & Flow Control Valves for Methane Supply Zones \\
\hline \multicolumn{2}{|l|}{ Instrumentation: Dampers } \\
\hline DAMPERS & Butterfly Dampers for FGR System \\
\hline \multicolumn{2}{|l|}{ Instrumentation: Isolation Valve } \\
\hline XV-111 \& -112 & Double Block \& Bleed Isolation Valve (Front Zone) \\
\hline XV-121 \& -122 & Double Block \& Bleed Isolation Valve (Rear Zone) \\
\hline XV-201 \& -202 & Purge Air Isolation Valve \\
\hline XV-101 & Methane Supply Isolation Valve \\
\hline \multicolumn{2}{|l|}{ Instrumentation: Vent Valve } \\
\hline \multirow{2}{*}{$\begin{array}{r}\text { XV-113 \& }-123 \\
\text { XV-103 }\end{array}$} & Double Block \& Bleed Vent Valve for Zones \\
\hline & Methane Supply Vent Valve \\
\hline \multicolumn{2}{|l|}{ Instrumentation: Hand Valve } \\
\hline PLUG-VLV & Manual Plug Valve for Methane Isolation \\
\hline Instrumentation: Regulator & \\
\hline PRESS-REG & Pressure Regulators for Methane Supply \\
\hline \multirow[t]{3}{*}{ Instrumentation: Misc. } & \\
\hline & Oxygen Analyzer for FGR System \\
\hline & Flame Scanner for MdN System \\
\hline
\end{tabular}




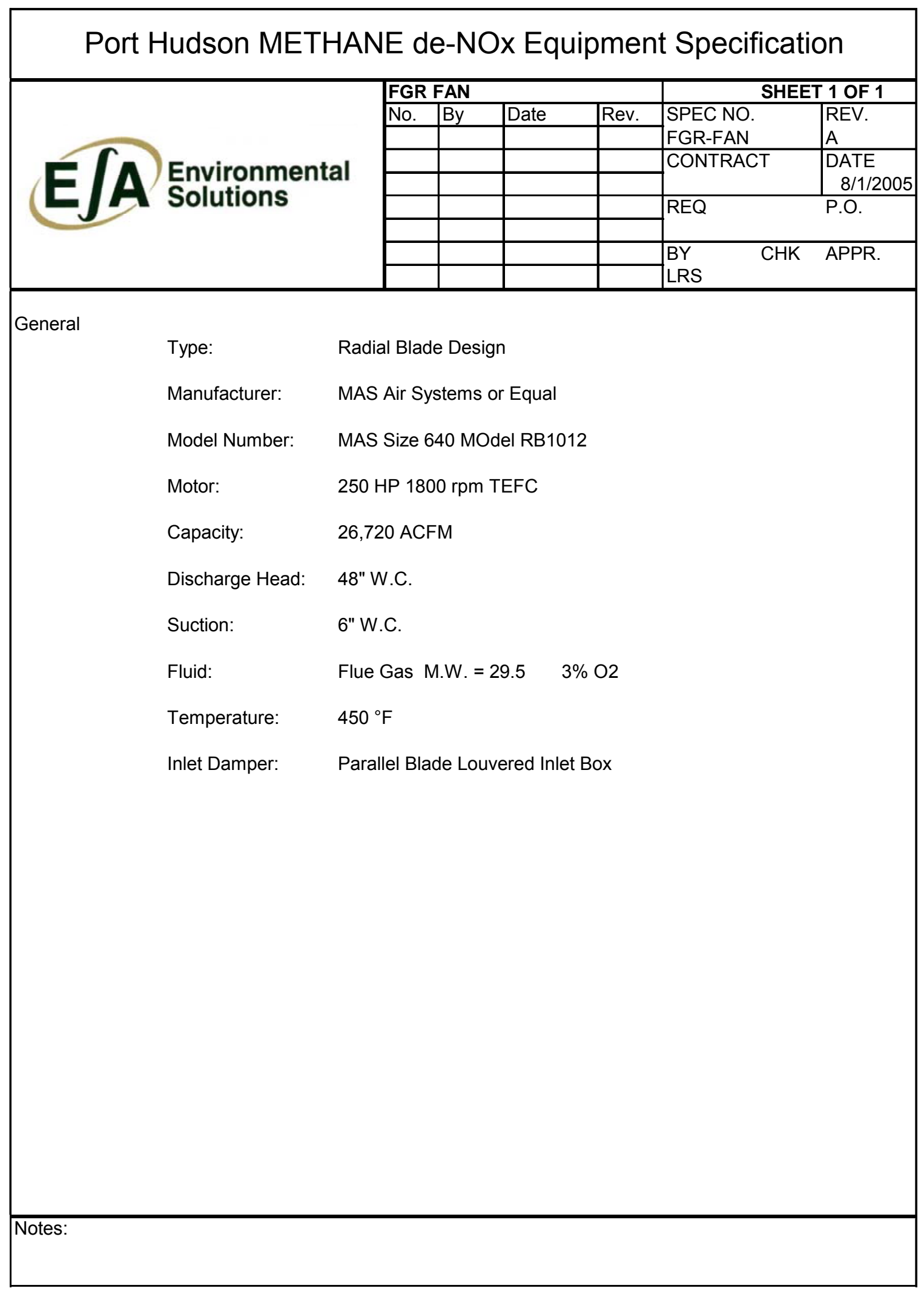




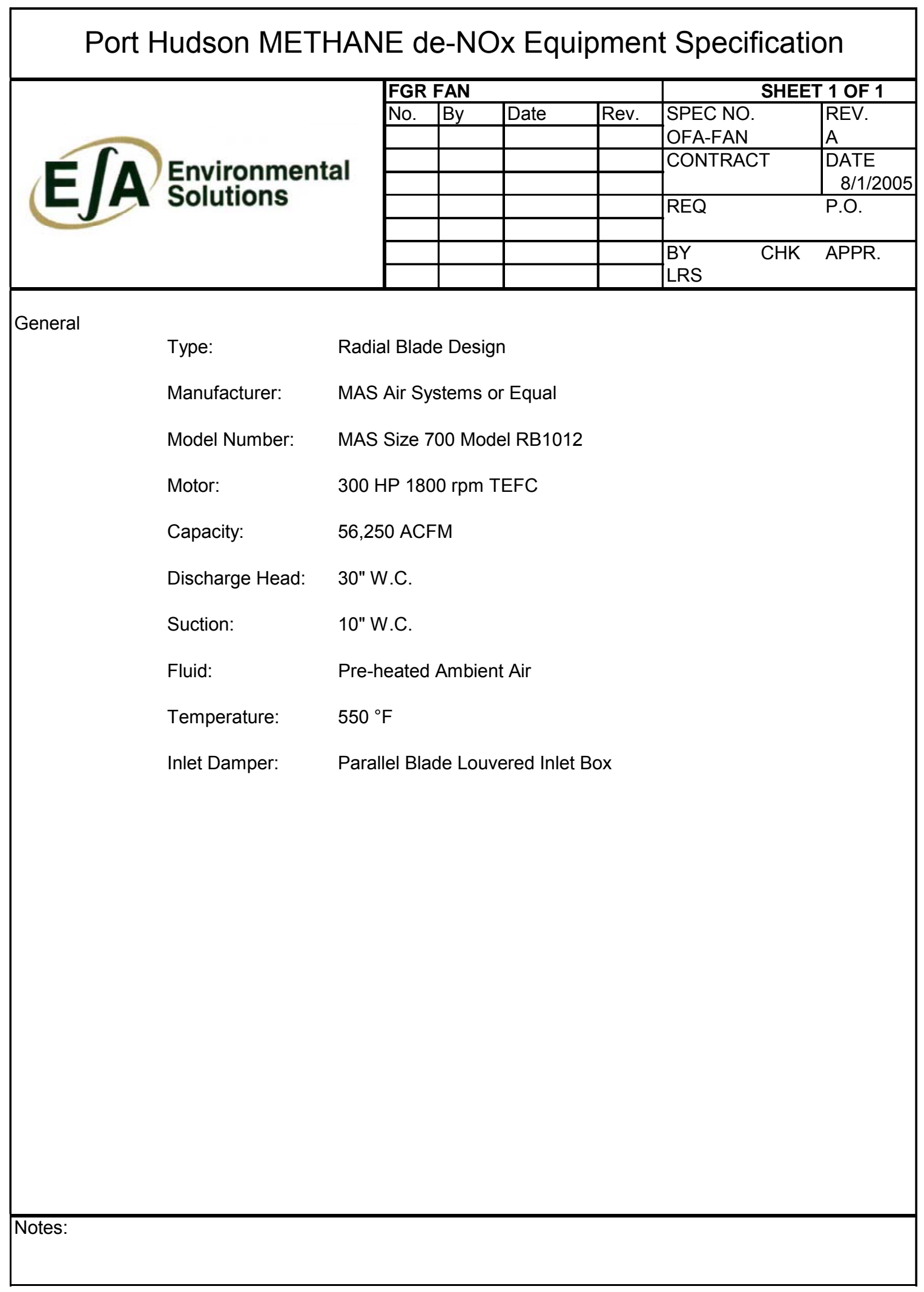




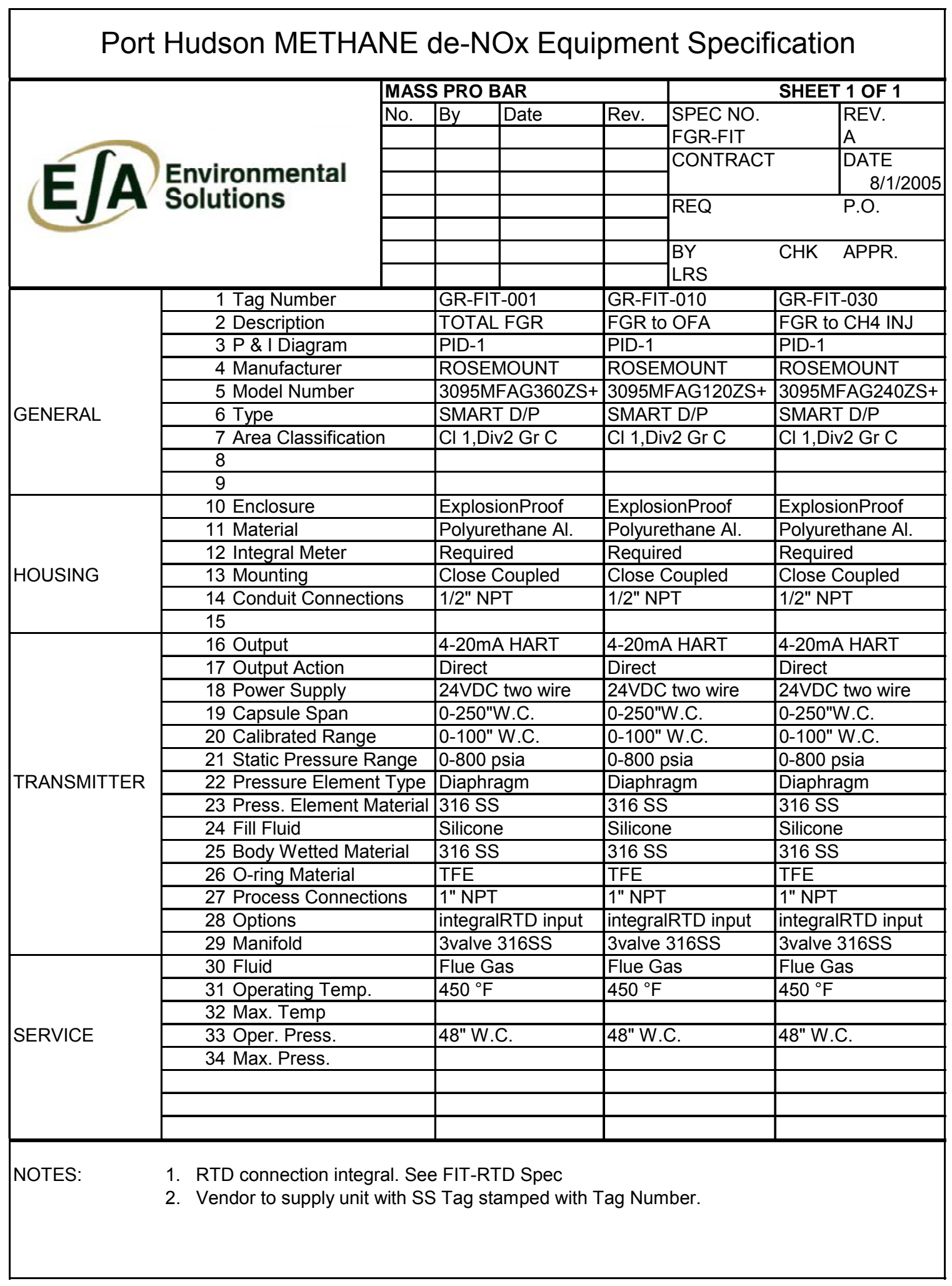




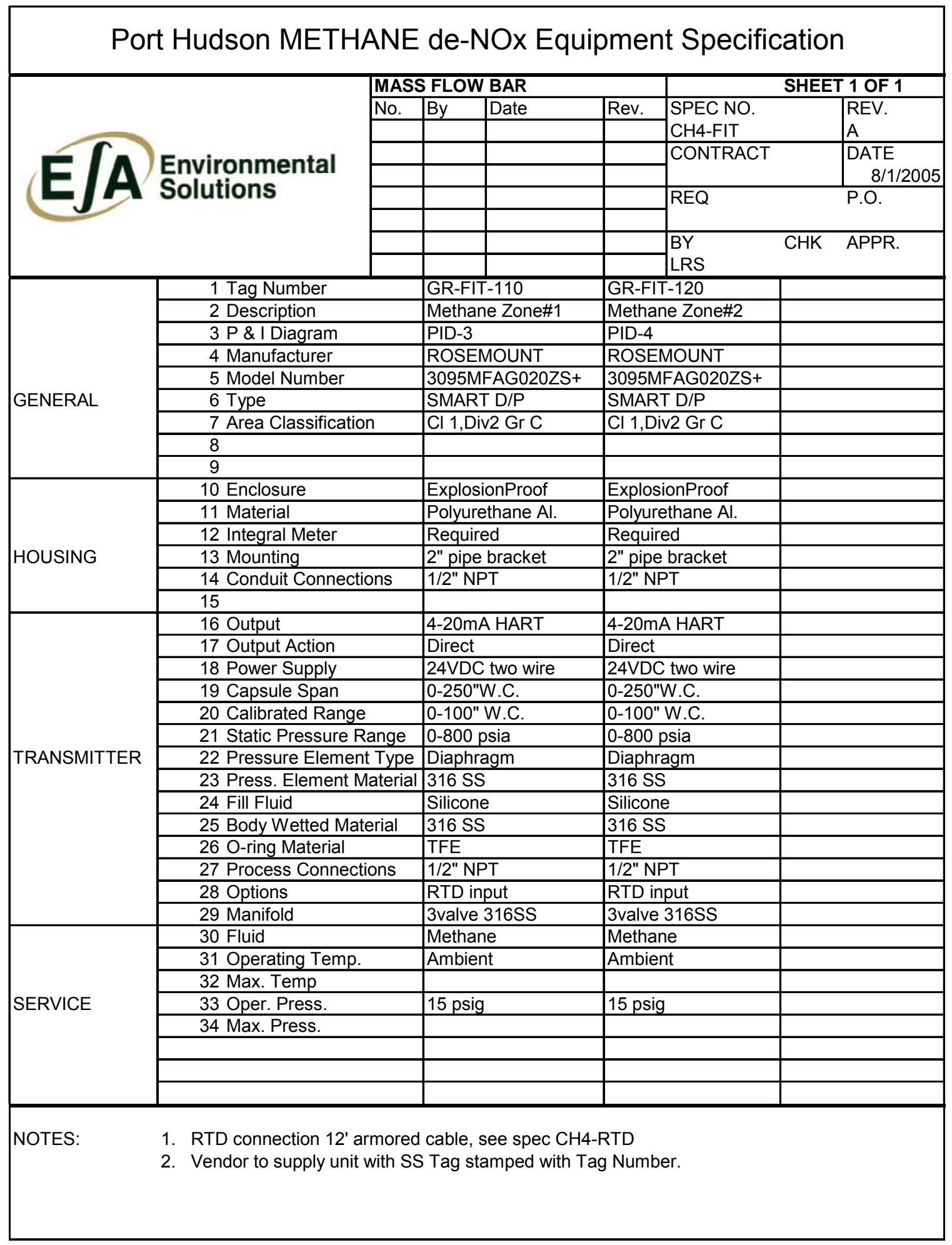




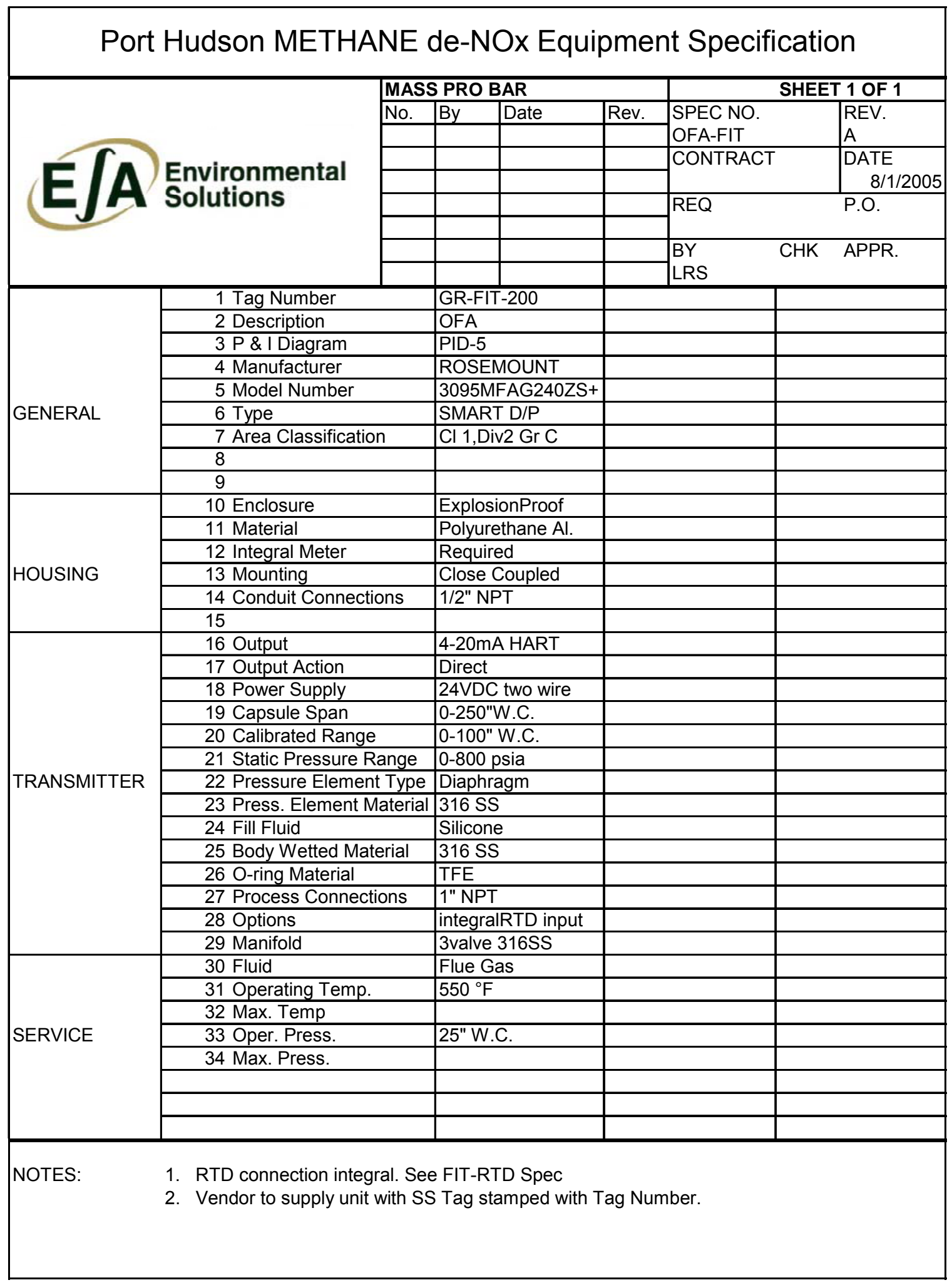




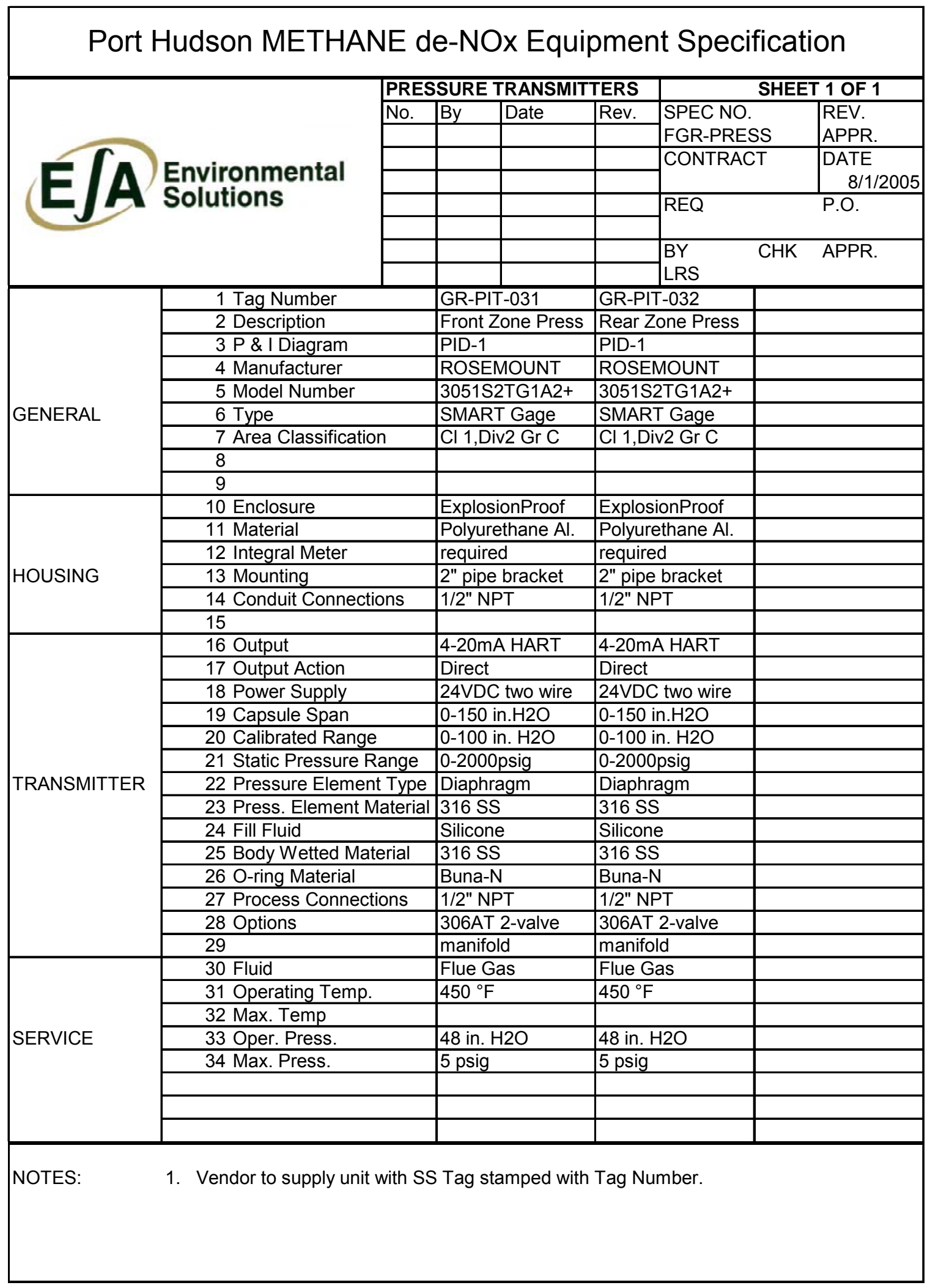




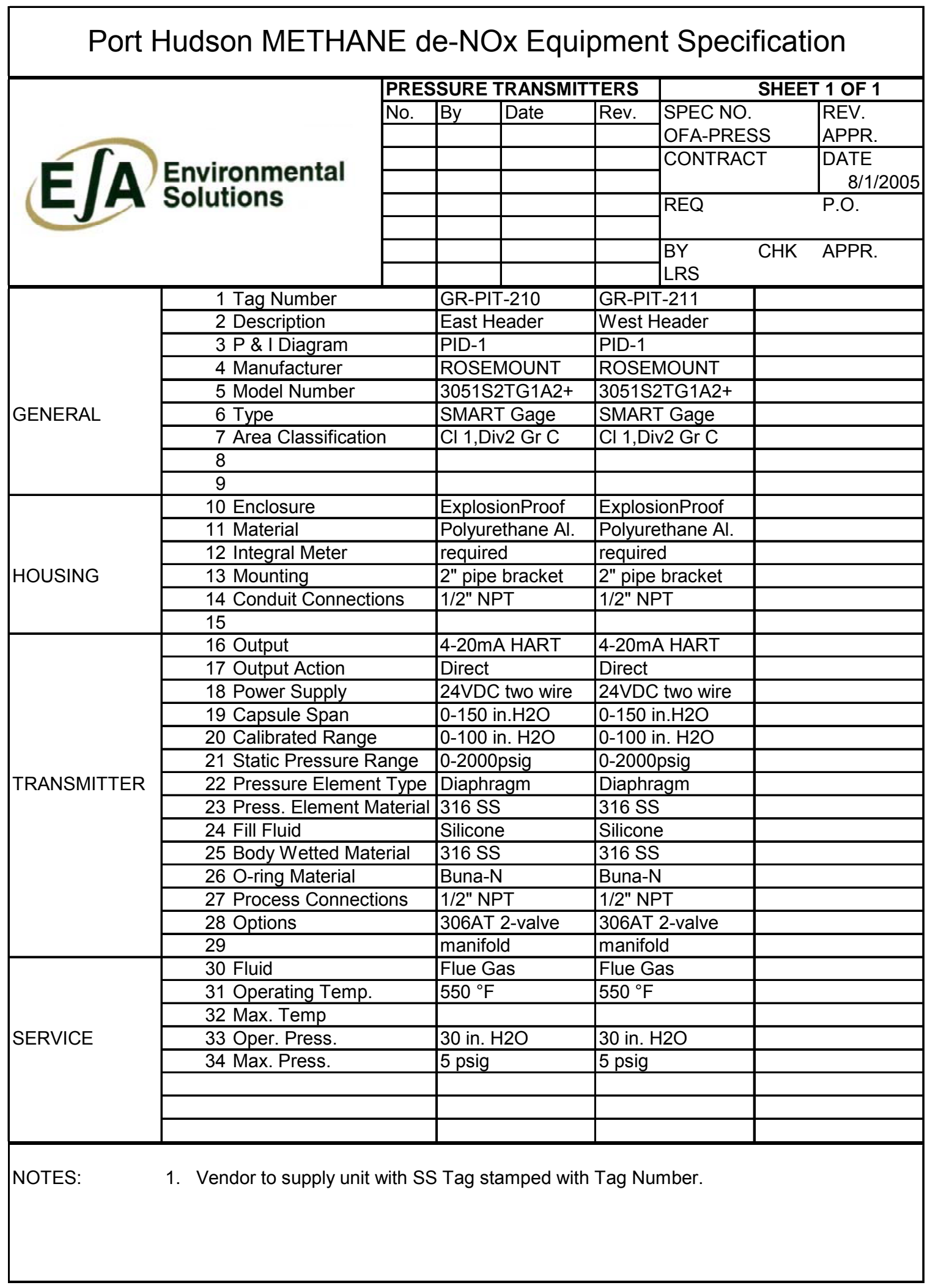




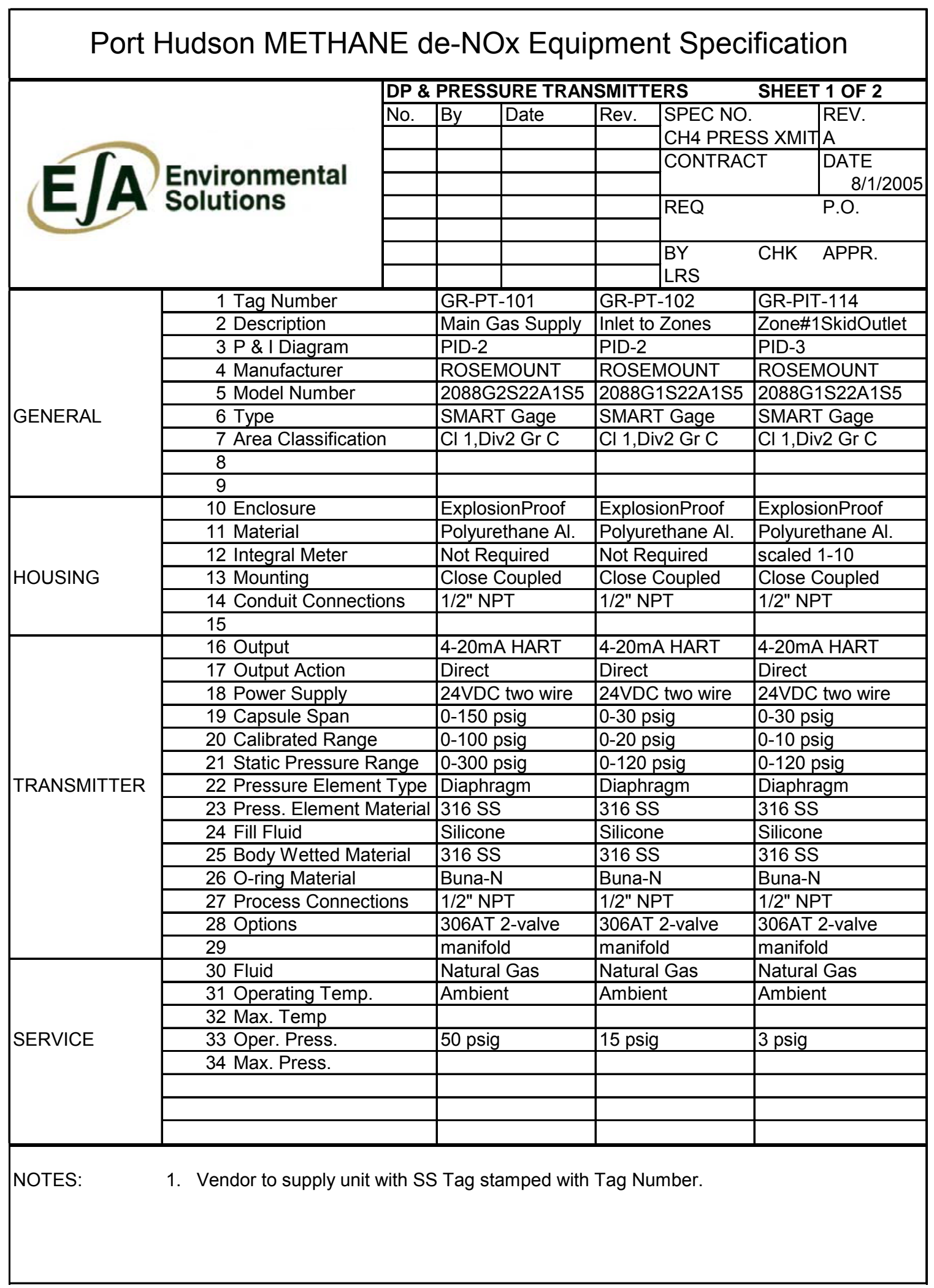




\section{Port Hudson METHANE de-NOx Equipment Specification}

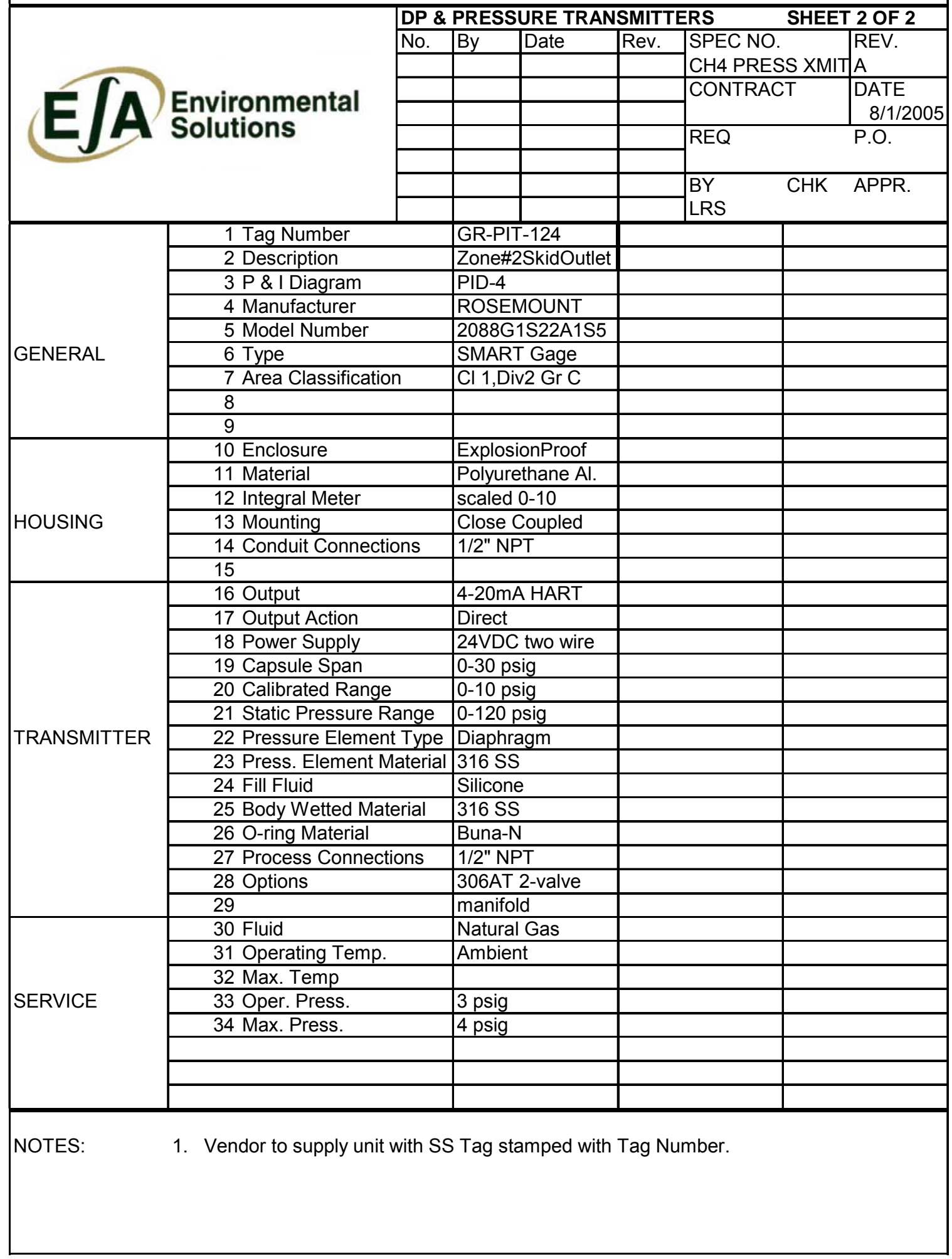




\section{Port Hudson METHANE de-NOx Equipment Specification}

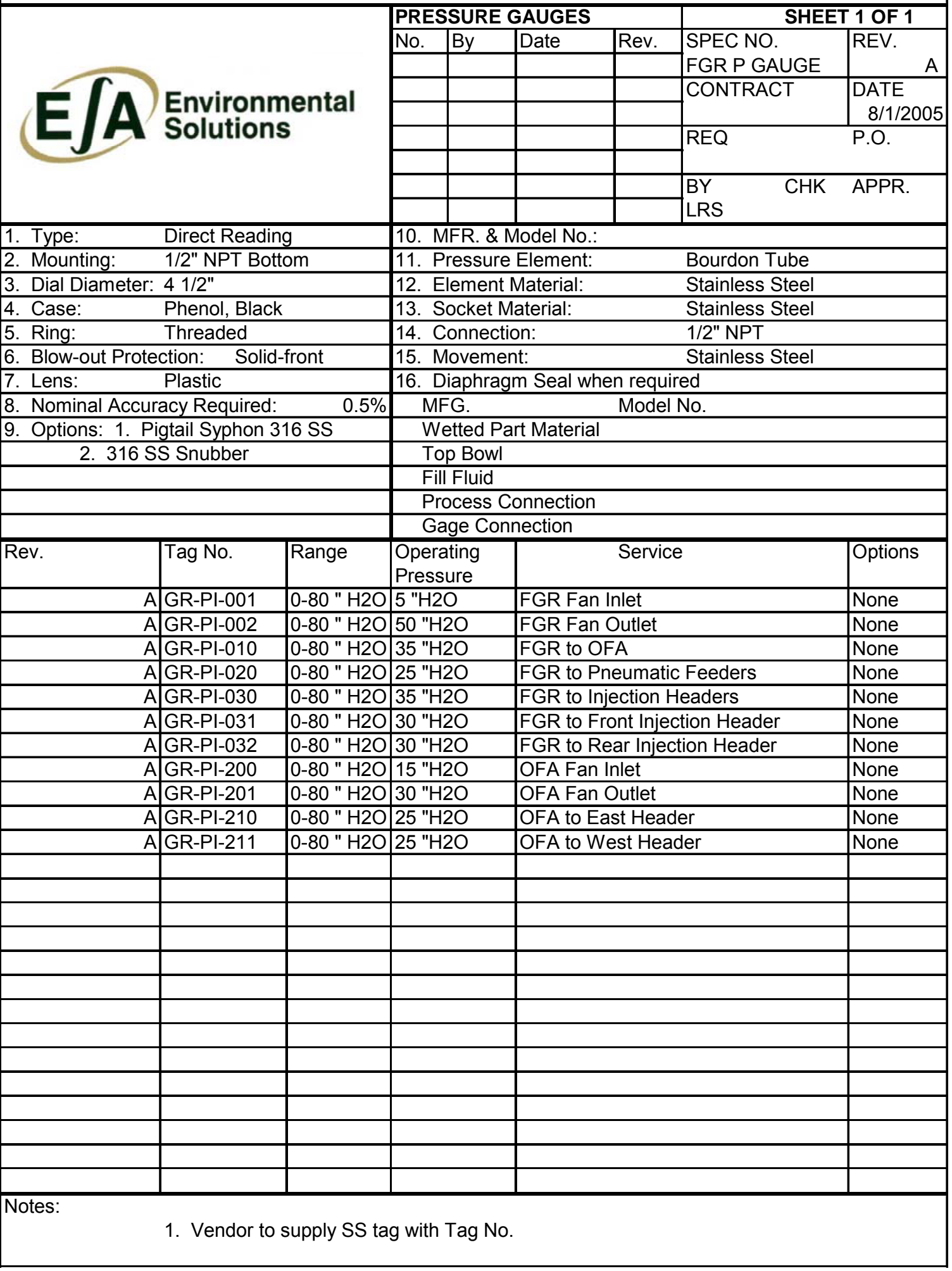




\section{Port Hudson METHANE de-NOx Equipment Specification}

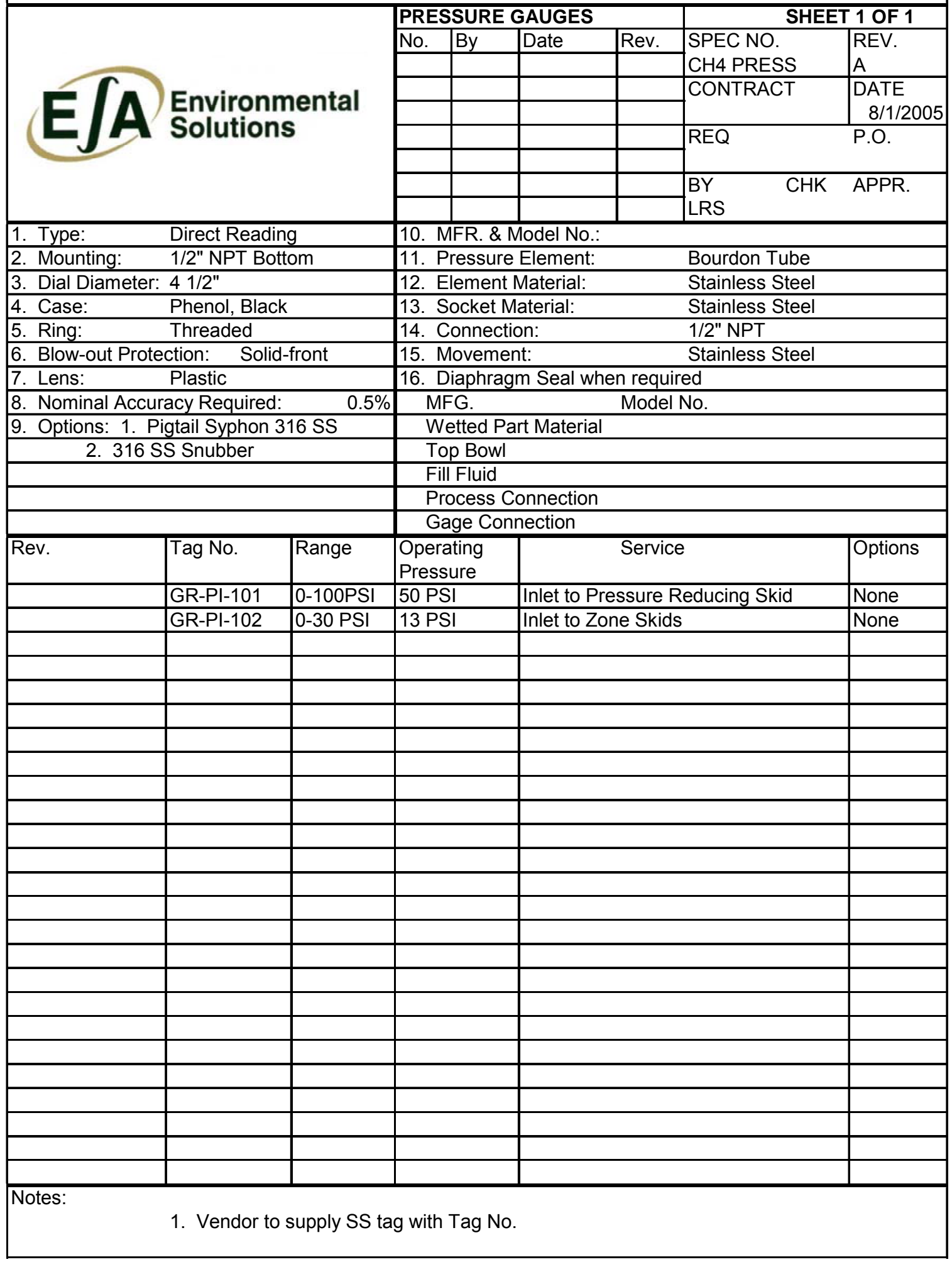




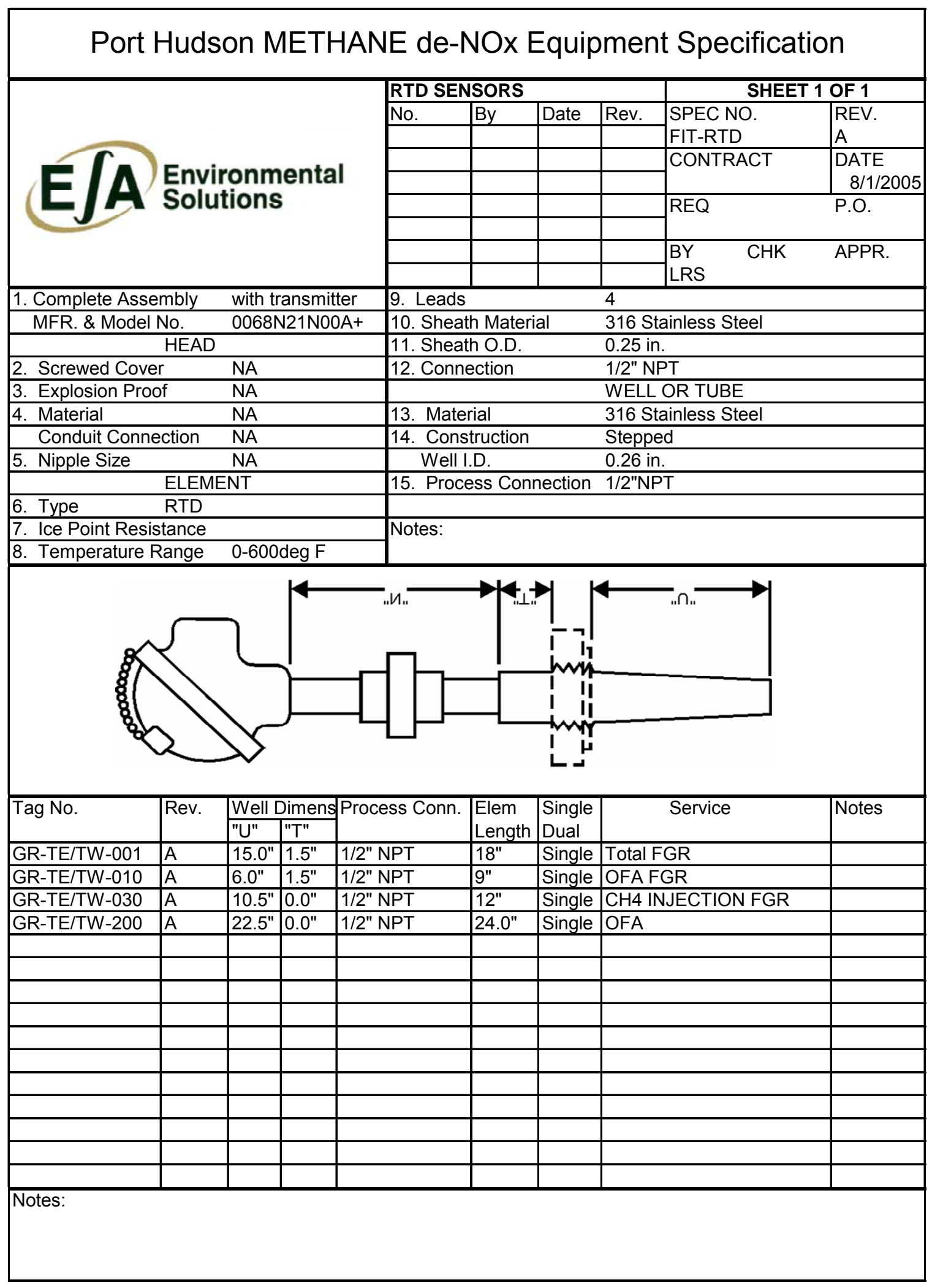




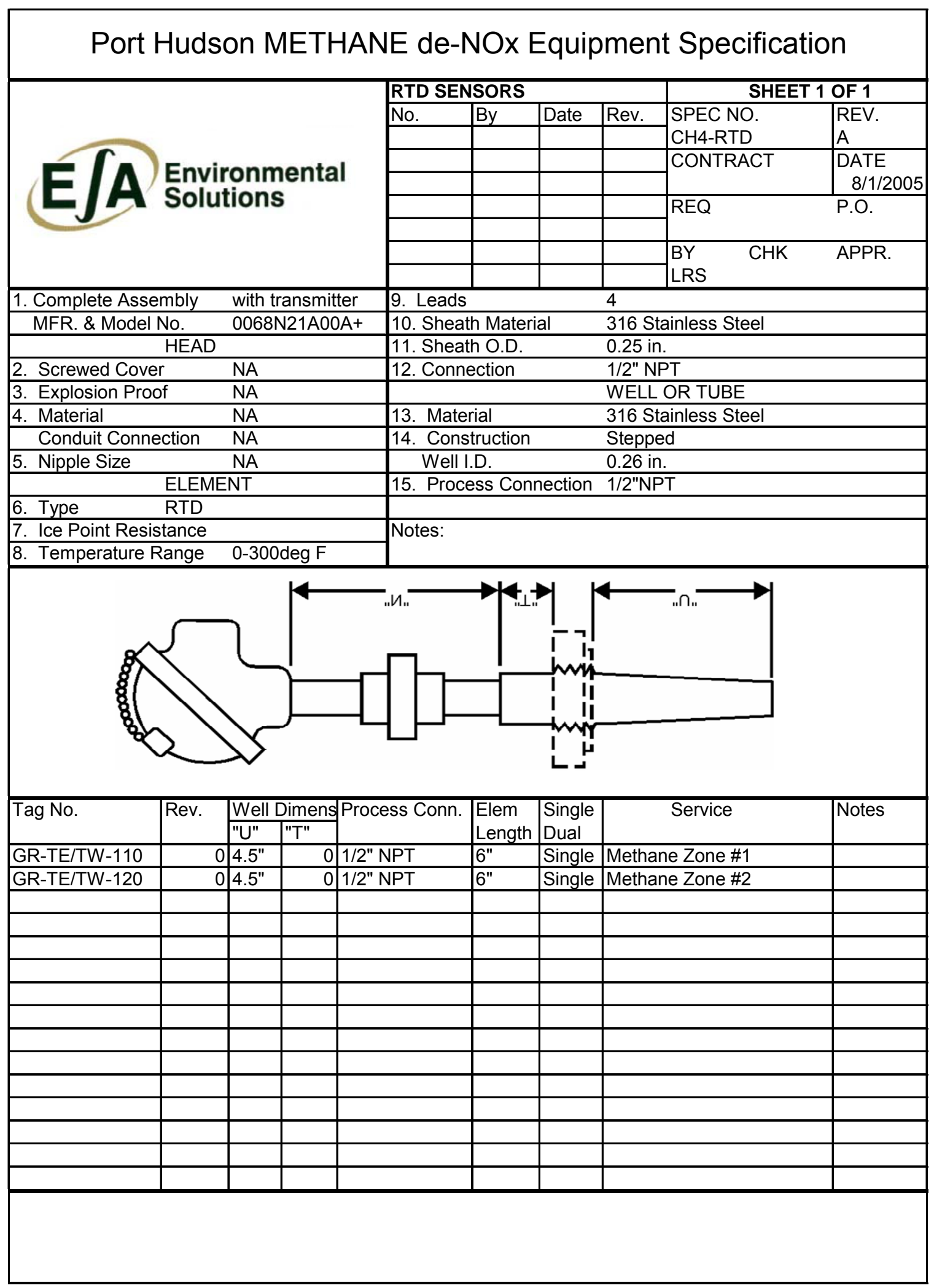




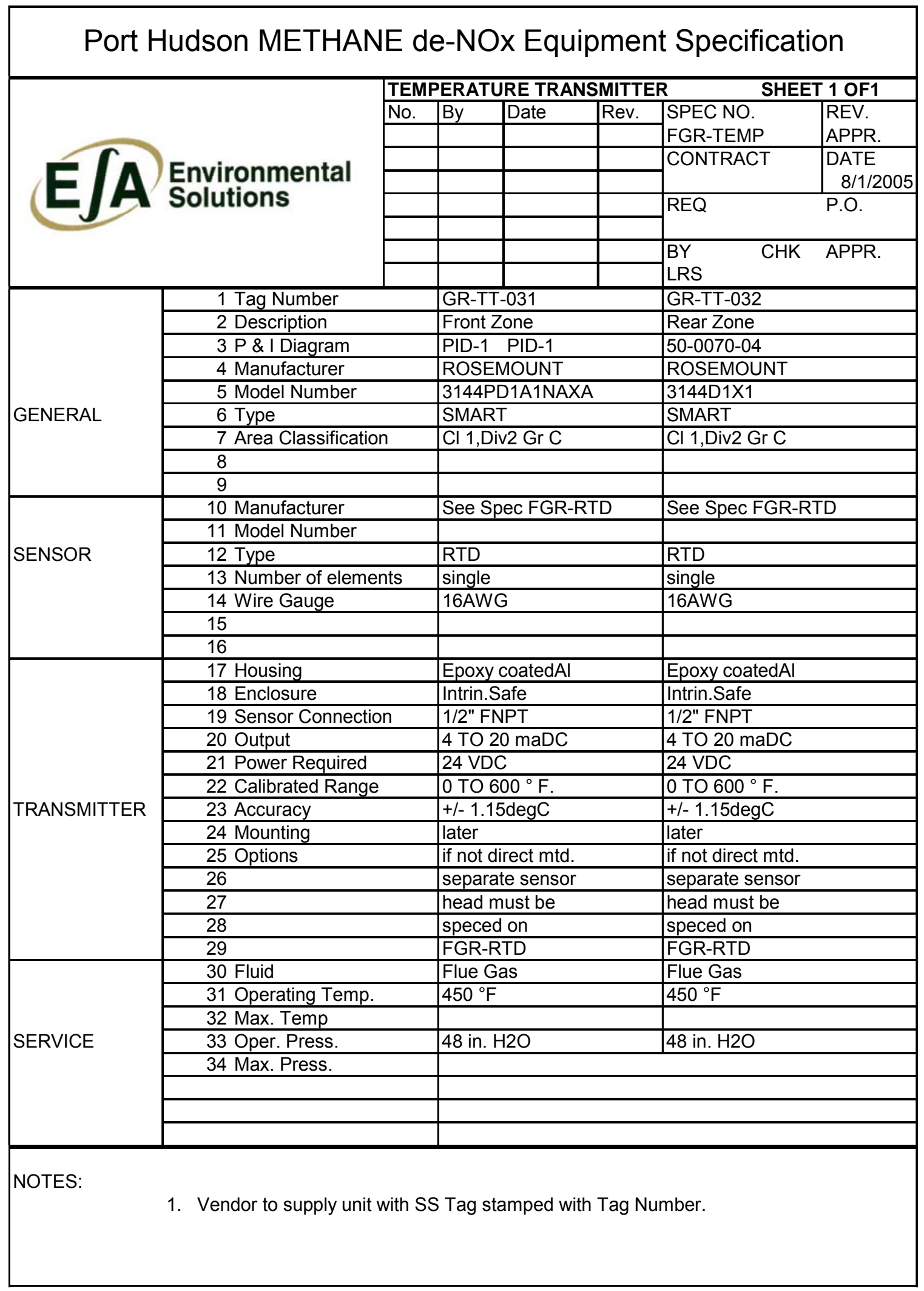




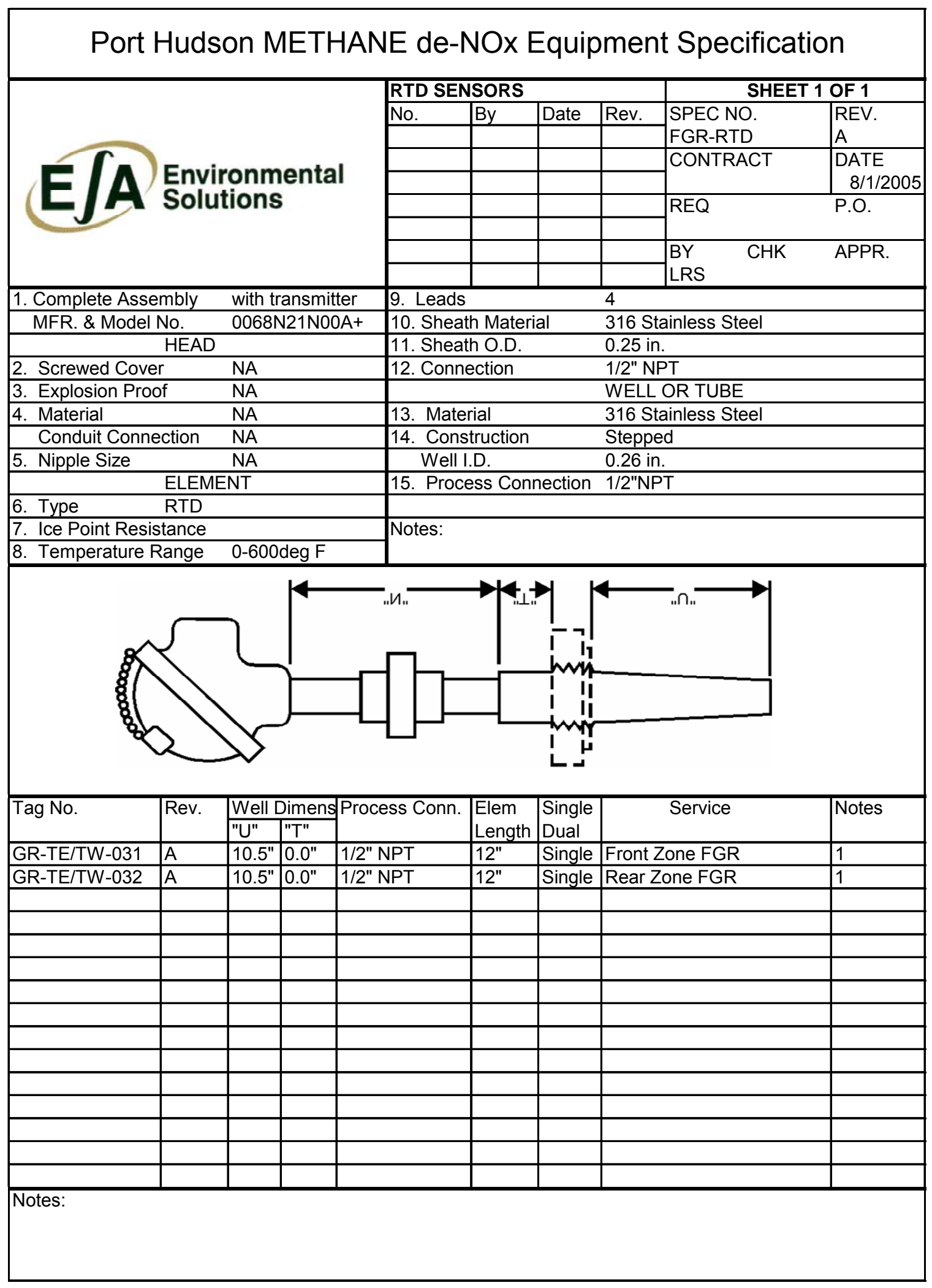




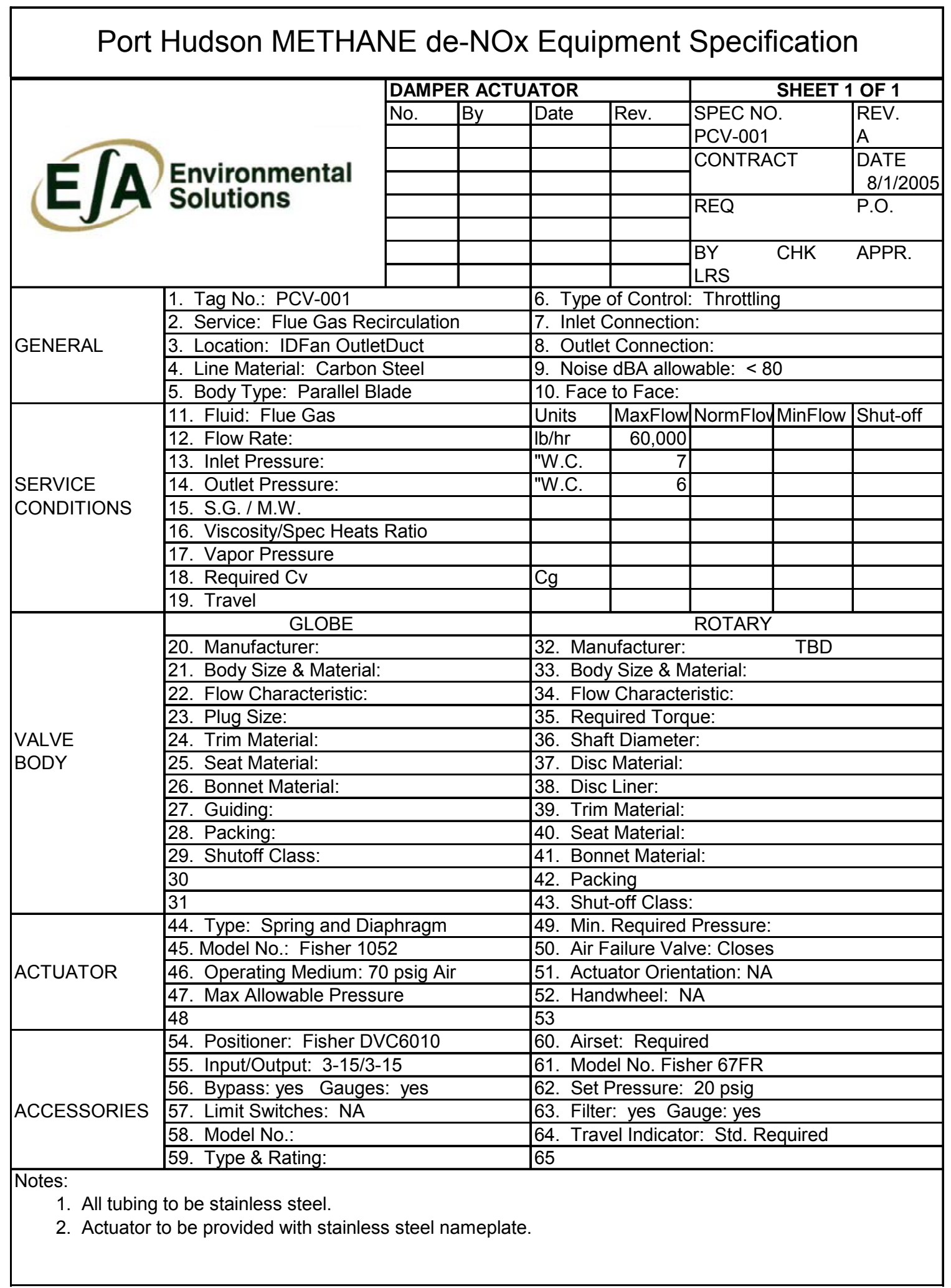




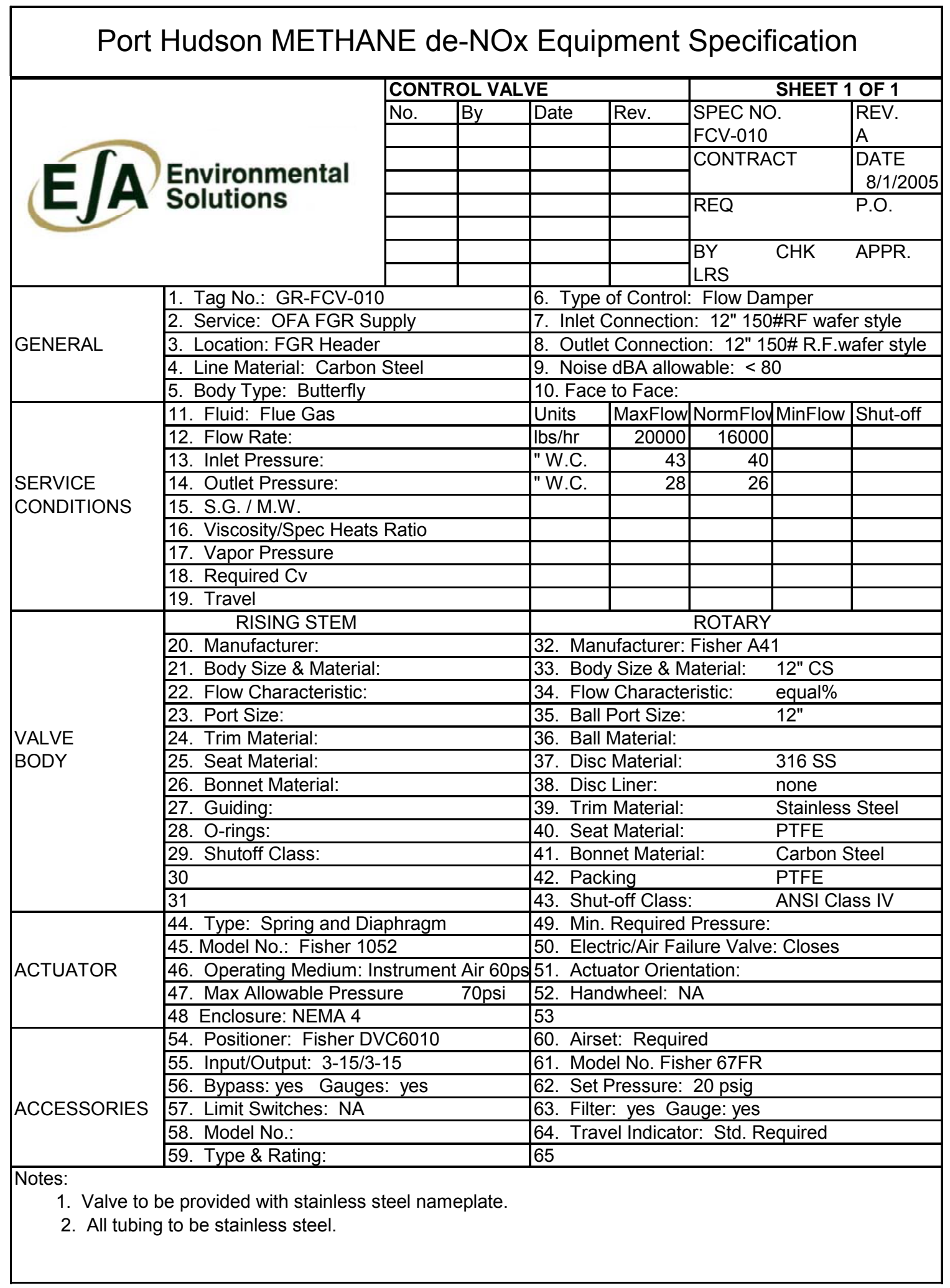




\begin{tabular}{|c|c|c|c|c|c|c|}
\hline \\
\hline & \multirow{8}{*}{$\begin{array}{l}\text { Environmental } \\
\text { Solutions }\end{array}$} & \multicolumn{3}{|c|}{ CONTROL VALVE } & \multicolumn{2}{|c|}{$\begin{array}{r}\text { SHEET } 1 \text { OF } 1 \\
\end{array}$} \\
\hline & & \begin{tabular}{|l|l|} 
No. & By \\
\end{tabular} & Date & Rev. & \multirow{2}{*}{$\begin{array}{l}\text { SPEC NO. } \\
\text { PCV-030 }\end{array}$} & \multirow{2}{*}{$\begin{array}{l}\text { REV. } \\
\text { A }\end{array}$} \\
\hline & & & & & & \\
\hline & & & & & \multirow[t]{2}{*}{ CONTRACT } & DATE \\
\hline & & & & & & $8 / 1 / 2005$ \\
\hline & & & & & REQ & P.O. \\
\hline & & & & & \multirow{2}{*}{$\begin{array}{l}\text { BY } \\
\text { LRS }\end{array}$} & \multirow{2}{*}{ APPR. } \\
\hline & & & & & & \\
\hline \multirow{5}{*}{ GENERAL } & \multicolumn{2}{|l|}{ 1. Tag No.: GR-PCV-030 } & \multicolumn{4}{|c|}{ 6. Type of Control: Pressure Damper } \\
\hline & \multirow{2}{*}{\multicolumn{2}{|c|}{\begin{tabular}{|l|} 
2. Service: Injection Header FGR Supply \\
3. Location: FGR Header
\end{tabular}}} & \multicolumn{4}{|c|}{ 7. Inlet Connection: 24" 150\#RF wafer style } \\
\hline & & & \multicolumn{4}{|c|}{ 8. Outlet Connection: 24" 150\# R.F.wafer style } \\
\hline & \multicolumn{2}{|c|}{ 4. Line Material: Carbon Steel } & \multicolumn{4}{|c|}{ 9. Noise dBA allowable: $<80$} \\
\hline & \multicolumn{2}{|c|}{ 5. Body Type: Butterfly } & \multicolumn{4}{|c|}{ 10. Face to Face: } \\
\hline \multirow{9}{*}{$\begin{array}{l}\text { SERVICE } \\
\text { CONDITIONS }\end{array}$} & 11. Fluid: Flue Gas & & Units & MaxFlow & NormFloyMinFlow & Shut-off \\
\hline & 12. Flow Rate: & & Ibs/hr & 15000 & \begin{tabular}{|l|l|}
8000 & \\
\end{tabular} & \\
\hline & 13. Inlet Pressure: & & "W.C. & 36 & 36 & \\
\hline & 14. Outlet Pressure: & & "W.C. & 30 & 31 & \\
\hline & 15. S.G. / M.W. & & & & & \\
\hline & 16. Viscosity/Spec Heats & Ratio & & & & \\
\hline & 17. Vapor Pressure & & & & & \\
\hline & 18. Required Cv & & & & & \\
\hline & 19. Travel & & & & & \\
\hline & \begin{tabular}{|l} 
RISING STEM \\
\end{tabular} & & & & ROTARY & \\
\hline & 20. Manufacturer: & & 32. Ma & ufacturer: F & Fisher A41 & \\
\hline & 21. Body Size \& Materia & & 33. Bo & Size \& Ma & aterial: $24 " \mathrm{CS}$ & \\
\hline & 22. Flow Characteristic: & & 34. Flo & Characteri & equal $\%$ & \\
\hline & 23. Port Size: & & 35. $\mathrm{Ba}$ & Port Size: & $24 "$ & \\
\hline VALVE & 24. Trim Material: & & 36. $\mathrm{Ba}$ & Material: & & \\
\hline BODY & 25. Seat Material: & & 37. Dis & Material: & 316 SS & \\
\hline & 26. Bonnet Material: & & 38. Dis & Liner: & none & \\
\hline & 27. Guiding: & & 39. Tril & Material: & Stainless & Steel \\
\hline & 28. O-rings: & & 40. $\mathrm{Se}$ & Material: & PTFE & \\
\hline & 29. Shutoff Class: & & 41. Bo & net Material & Carbon S & Steel \\
\hline & 30 & & 42. $\mathrm{Pa}$ & king & PTFE & \\
\hline & 31 & & 43. Sh & -off Class: & ANSI Cla & ass IV \\
\hline & 44. Type: Spring and Di & phragm & 49. Mir & Required P & Pressure: & \\
\hline & 45. Model No.: Fisher 10 & & 50. Ele & tric/Air Failu & lure Valve: Closes & \\
\hline ACTUATOR & 46. Operating Medium: I & strument Air 60ps & 51. Act & ator Orienta & tation: & \\
\hline & 47. Max Allowable Press & ire $\quad 70 p s i$ & 52. $\mathrm{Ha}$ & dwheel: NA & & \\
\hline & 48 Enclosure: NEMA 4 & & 53 & & & \\
\hline & 54. Positioner: Fisher D & $\mathrm{C} 6010$ & 60. Air & et: Require & & \\
\hline & 55. Input/Output: 3-15/3 & & 61. Mo & el No. Fishe & eer 67FR & \\
\hline & 56. Bypass: yes Gauge & yes & 62. Se & Pressure: 2 & 20 psig & \\
\hline ACCESSORIES & 57. Limit Switches: NA & & 63. Filt & r: yes Gau & uge: yes & \\
\hline & 58. Model No.: & & 64. Tra & el Indicator: & r: Std. Required & \\
\hline & 59. Type \& Rating: & & 65 & & & \\
\hline $\begin{array}{l}\text { Notes: } \\
\text { 1. Valve to } \\
\text { 2. All tubing }\end{array}$ & $\begin{array}{l}\text { be provided with stainless } \\
\text { g to be stainless steel. }\end{array}$ & teel nameplate. & & & & \\
\hline
\end{tabular}




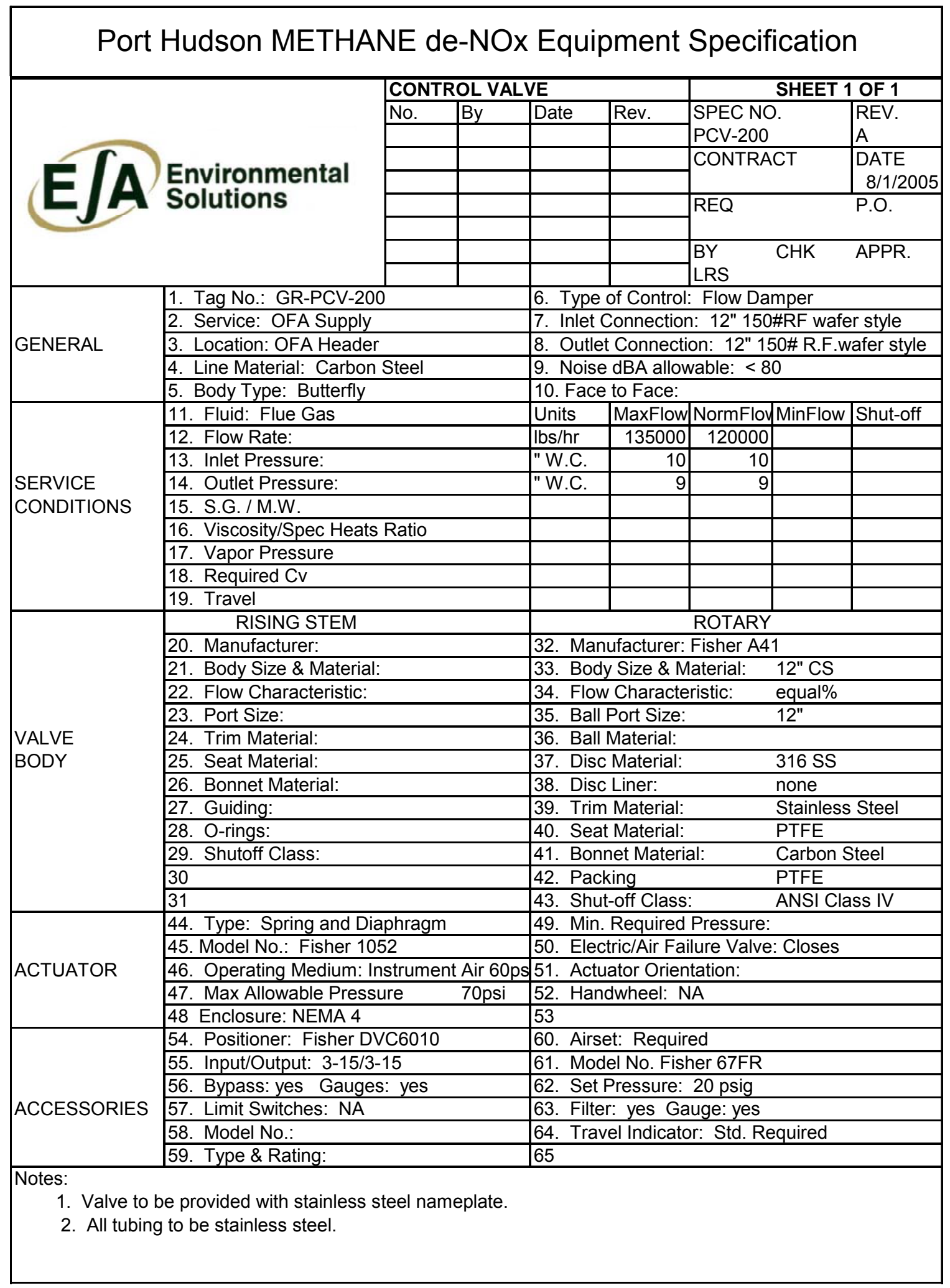




\begin{tabular}{|c|c|c|c|c|c|c|}
\hline Port & Hudson METHA & JE de-NOx & Equ & ment & Specification & \\
\hline & & CONTROL VALI & & & $\begin{array}{r}\text { SHEET } 1 \\
\end{array}$ & 1 OF 1 \\
\hline & & \begin{tabular}{|l|l|} 
No. & By \\
\end{tabular} & Date & Rev. & \begin{tabular}{|l|l} 
SPEC NO. &
\end{tabular} & REV. \\
\hline & & & & & FCV-110 & \\
\hline & & & & & CONTRACT & DATE \\
\hline & Convironimertal & & & & & $8 / 1 / 2005$ \\
\hline & & & & & REQ & P.O. \\
\hline & & & & & $\mathrm{CHK}$ & APPR \\
\hline & & & & & LRS & \\
\hline & 1. Tag No.: GR-FCV-11 & & 6. Тур & of Control: & : Throttling & \\
\hline & 2. Service: Natural Gas & or DeNOX injectio & 7. Inlet & Jonnection & : 2" 150\# R.F. & \\
\hline GENERAL & 3. Location: downstrean & GR-XV-112 & 8. Outl & Connectic & on: 2" 150\# R.F. & \\
\hline & 4. Line Material: Carbon & Steel & 9. Nois & dBA allon & vable: $<80$ & \\
\hline & 5. Body Type: Globe & & 10. Fac & to Face: & & \\
\hline & 11. Fluid: Methane & & Units & MaxFlow & NormFloy MinFlow & Shut-off \\
\hline & 12. Flow Rate: & & $\mathrm{SCFH}$ & & & \\
\hline & 13. Inlet Pressure: & & PSIG & & & \\
\hline SERVICE & 14. Outlet Pressure: & & PSIG & & & \\
\hline CONDITIONS & 15. S.G. / M.W. & & & & & \\
\hline & 16. Viscosity/Spec Heats & Ratio & & & & \\
\hline & 17. Vapor Pressure & & & & & \\
\hline & 18. Required Cv & & & & & \\
\hline & 19. Travel & & & & & \\
\hline & $\begin{array}{r}\text { GLOBE } \\
\end{array}$ & & & & ROTARY & \\
\hline & 20. Manufacturer: Fishe & $\mathrm{EZ}$ & 32. Ma & ufacturer: & & \\
\hline & 21. Body Size \& Material & 2" Carbon Steel & 33. Bo & Size \& M & laterial: & \\
\hline & 22. Flow Characteristic: & qual Percent & 34. Flo & Characte & ristic: & \\
\hline & 23. Plug Size: 2" & & 35. $\mathrm{Ba}$ & Port Size: & & \\
\hline VALVE & 24. Trim Material: Stainl & ss Steel & 36. $\mathrm{Ba}$ & Material: & & \\
\hline BODY & 25. Seat Material: PTFE & & 37. Dis & Material: & & \\
\hline & 26. Bonnet Material: WC & B Steel & 38. Dis & Liner: & & \\
\hline & 27. Guiding: Stainless S & eeel & 39. Tri & Material: & & \\
\hline & 28. Packing: PTFE & & 40. Se & Material: & & \\
\hline & 29. Shutoff Class: ANSI & & 41. Bo & het Materia & & \\
\hline & 30 & & 42. $\mathrm{Pa}$ & king & & \\
\hline & 31 & & 43. Sh & -off Class: & & \\
\hline & 44. Type: Spring and Di & phragm & 49. Mir & Required & Pressure: & \\
\hline & 45. Model No.: Fisher 66 & Size 40 & 50. Air & ailure Val & ve: Closes & \\
\hline ACTUATOR & 46. Operating Medium: 7 & psig Air & 51. Ac & ator Orien & tation: NA & \\
\hline & 47. Max Allowable Press & & 52. $\mathrm{Ha}$ & dwheel: $\mathrm{N}$ & & \\
\hline & 48 & & 53 & & & \\
\hline & 54. Positioner: Fisher D & $\mathrm{C} 6010$ & 60. Air & t: Requir & & \\
\hline & 55. Input/Output: 3-15/3 & & 61. Mo & el No. Fish & her 67FR & \\
\hline & 56. Bypass: yes Gauge & yes & 62. Se & Pressure: & 20 psig & \\
\hline ACCESSORIES & 57. Limit Switches: NA & & 63. Filt & $\mathrm{r}:$ yes $\mathrm{Ga}$ & auge: yes & \\
\hline & 58. Model No.: & & 64. Tra & el Indicato & r: Std. Required & \\
\hline & 59. Type \& Rating: & & 65 & & & \\
\hline $\begin{array}{l}\text { Notes: } \\
\text { 1. All tubing } \\
\text { 2. Valve to }\end{array}$ & $\begin{array}{l}\text { to be stainless steel. } \\
\text { be provided with stainless }\end{array}$ & teel nameplate. & & & & \\
\hline
\end{tabular}




\begin{tabular}{|c|c|c|c|c|c|c|c|}
\hline Port & Hudson METHA & JE de-NOx & Equip & oment & Specifi & ication & \\
\hline & & CONTROL VALI & & & & SHEET 1 & 1 OF 1 \\
\hline & & \begin{tabular}{|l|l|} 
No. & By \\
\end{tabular} & Date & Rev. & SPEC NO & & REV. \\
\hline & & & & & FCV-120 & & \\
\hline & & & & & CONTRAC & $\overline{\mathrm{CT}}$ & DATE \\
\hline & Envirominerital & & & & & & $8 / 1 / 2005$ \\
\hline & & & & & REQ & & P.O. \\
\hline & & & & & & $\mathrm{CHK}$ & APPR \\
\hline & & & & & LRS & & \\
\hline & 1. Tag No.: GR-FCV-12 & & 6. Type & of Control: & : Throttling & & \\
\hline & 2. Service: Natural Gas & or DeNOX injectio & 7. Inlet & Jonnection & ก: 2" 150\# & R.F. & \\
\hline GENERAL & 3. Location: downstrean & GR-XV-122 & 8. Outle & Connectic & on: 2" 150 & D\# R.F. & \\
\hline & 4. Line Material: Carbon & Steel & 9. Noise & dBA allon & Nable: $<80$ & & \\
\hline & 5. Body Type: Globe & & 10. Face & to Face: & & & \\
\hline & 11. Fluid: Methane & & Units & MaxFlow & NormFlov & MinFlow & Shut-off \\
\hline & 12. Flow Rate: & & $\mathrm{SCFH}$ & 37000 & 25000 & 18500 & \\
\hline & 13. Inlet Pressure: & & PSIG & 12 & 12 & 12 & 15 \\
\hline SERVICE & 14. Outlet Pressure: & & PSIG & 4 & 4 & 4 & ATM \\
\hline CONDITIONS & 15. S.G. / M.W. & & 0.599 & & & & \\
\hline & 16. Viscosity/Spec Heats & Ratio & $\mathrm{k}=1.3$ & & & & \\
\hline & 17. Vapor Pressure & & & & & & \\
\hline & 18. Required Cv & & $\mathrm{Cg}$ & 1436 & 970 & 718 & \\
\hline & 19. Travel & & & & & & \\
\hline & GLOBE & & & & ROTARY & & \\
\hline & 20. Manufacturer: Fishe & $\mathrm{EZ}$ & 32. Man & ufacturer: & & & \\
\hline & 21. Body Size \& Material & 2" Carbon Steel & 33. Bod & Size \& M & laterial: & & \\
\hline & 22. Flow Characteristic: & qual Percent & 34. Flon & Characte & ristic: & & \\
\hline & 23. Plug Size: 2" & & 35. Ball & Port Size: & & & \\
\hline VALVE & 24. Trim Material: Stainl & ss Steel & 36. Ball & Material: & & & \\
\hline BODY & 25. Seat Material: PTFE & & 37. Disc & Material: & & & \\
\hline & 26. Bonnet Material: WC & B Steel & 38. Disc & Liner: & & & \\
\hline & 27. Guiding: Stainless S & & 39. Trim & Material: & & & \\
\hline & 28. Packing: PTFE & & 40. Sea & Material: & & & \\
\hline & 29. Shutoff Class: ANSI & & 41. Bon & het Materia & & & \\
\hline & 30 & & 42. $\mathrm{Pac}$ & king & & & \\
\hline & 31 & & 43. Shu & -off Class: & & & \\
\hline & 44. Type: Spring and Di & phragm & 49. Min. & Required & Pressure: & & \\
\hline & 45. Model No.: Fisher 66 & Size 40 & 50. Air $\mathrm{F}$ & ailure Val & ve: Closes & & \\
\hline ACTUATOR & 46. Operating Medium: 7 & psig Air & 51. Actu & ator Orien & tation: NA & & \\
\hline & 47. Max Allowable Press & & 52. Han & dwheel: $\mathrm{N}$ & & & \\
\hline & 48 & & 53 & & & & \\
\hline & 54. Positioner: Fisher D & $\mathrm{C} 6010$ & 60. Airs & t: Requir & & & \\
\hline & 55. Input/Output: 3-15/3 & & 61. Mod & el No. Fish & her 67FR & & \\
\hline & 56. Bypass: yes Gauge & yes & 62. Set & Pressure: & 20 psig & & \\
\hline ACCESSORIES & 57. Limit Switches: NA & & 63. Filte & $\mathrm{r}:$ yes $\mathrm{Ga}$ & auge: yes & & \\
\hline & 58. Model No.: & & 64. Trav & el Indicato & r: Std. $\operatorname{Re}$ & equired & \\
\hline & 59. Type \& Rating: & & 65 & & & & \\
\hline $\begin{array}{l}\text { Notes: } \\
\text { 1. All tubing } \\
\text { 2. Valve to }\end{array}$ & $\begin{array}{l}\text { to be stainless steel. } \\
\text { be provided with stainless }\end{array}$ & teel nameplate. & & & & & \\
\hline
\end{tabular}




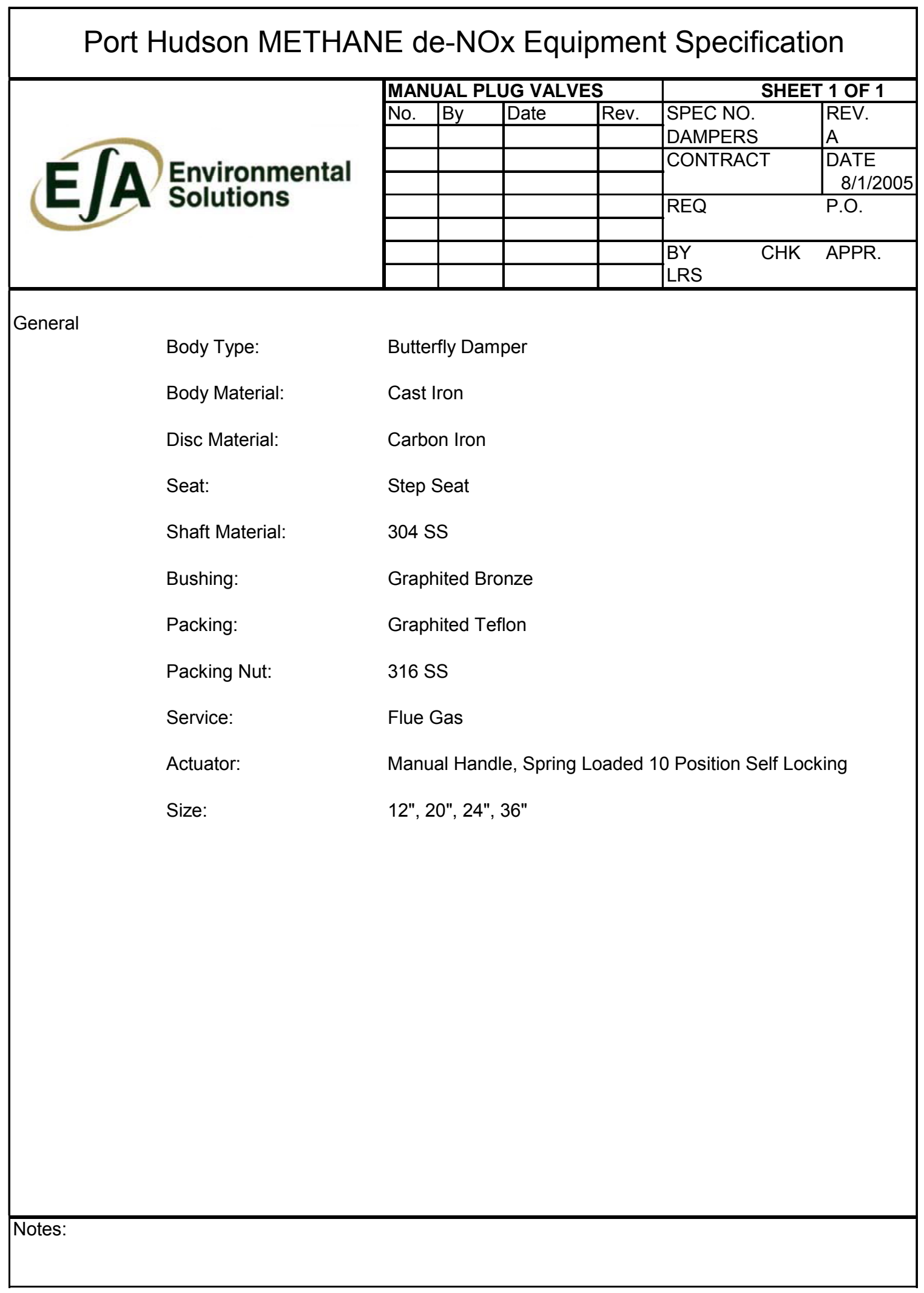




\begin{tabular}{|c|c|c|c|c|c|c|}
\hline Port & Hudson METHAN & NE de-NOx & Equ & ment & Specification & \\
\hline & & CONTROL VALI & & & $\begin{array}{r}\text { SHEET } 1 \\
\end{array}$ & $1 \mathrm{OF} 1$ \\
\hline & & \begin{tabular}{|l|l|} 
No. & By \\
\end{tabular} & Date & Rev. & \begin{tabular}{|l|} 
SPEC NO. \\
\end{tabular} & REV. \\
\hline & & & & & $\mathrm{XV}-111$ & \\
\hline & & & & & CONTRACT & DATE \\
\hline & & & & & & $8 / 1 / 2005$ \\
\hline & & & & & REQ & P.O. \\
\hline & & & & & $\mathrm{CHK}$ & APPR \\
\hline & & & & & LRS & \\
\hline & 1. Tag No.: GR-XV-111 & & 6. Тур & of Control: & : Shut-off Service & \\
\hline & 2. Service: Flow Skid Zone & ie\#1 Block Valve & 7. Inlet & Sonnection & n: 2" 150\# R.F. & \\
\hline GENERAL & 3. Location: downstream G & GR-FE-110 & 8. Outl & Connecti & ion: 2" 150\# R.F. & \\
\hline & 4. Line Material: Carbon S & Steel & 9. Nois & dBA allon & Nable: $<80$ & \\
\hline & 5. Body Type: Rising Stem & & 10. Fac & to Face: & Vendor to advise AS & SAP \\
\hline & 11. Fluid: Methane & & Units & MaxFlow & NormFloyMinFlow & Shut-off \\
\hline & 12. Flow Rate: & & SCFH & & & \\
\hline & 13. Inlet Pressure: & & PSIG & & & \\
\hline SERVICE & 14. Outlet Pressure: & & PSIG & & & \\
\hline CONDITIONS & 15. S.G. / M.W. & & & & & \\
\hline & 16. Viscosity/Spec Heats R & Ratio & & & & \\
\hline & 17. Vapor Pressure & & & & & \\
\hline & 18. Required Cv & & & & & \\
\hline & 19. Travel & & & & & \\
\hline & \begin{tabular}{|c|} 
RISING STEM \\
\end{tabular} & & & & ROTARY & \\
\hline & 20. Manufacturer: Maxon & $5000-\mathrm{S}-\mathrm{CP}$ & 32. Ma & ufacturer: & & \\
\hline & 21. Body Size \& Material: & 2" CS & 33. Bo & y Size \& M & laterial: & \\
\hline & 22. Flow Characteristic: Qu & uick closing & 34. Flo & Characte & ristic: & \\
\hline & 23. Port Size: 2" & & 35. $\mathrm{Ba}$ & Port Size: & & \\
\hline VALVE & 24. Trim Material: Stainles & ss Steel & 36. $\mathrm{Ba}$ & Material: & & \\
\hline BODY & 25. Seat Material: SS & & 37. Dis & Material: & & \\
\hline & 26. Bonnet Material: WCB & 3 Steel & 38. Dis & Liner: & & \\
\hline & 27. Guiding: Stainless Ste & & 39. Tri & Material: & & \\
\hline & 28. O-rings: Buna $\mathrm{N}$ & & 40. Se & Material: & & \\
\hline & 29. Shutoff Class: ANSI V & & 41. Bo & het Materia & & \\
\hline & 30 & & 42. $\mathrm{Pa}$ & king & & \\
\hline & 31 & & 43. Sh & -off Class: & & \\
\hline & 44. Type: $115 \mathrm{v} 60 \mathrm{hz}$ moto & & 49. Mir & Required & Pressure: & \\
\hline & 45. Model No.: Maxon & & 50. Ele & tric Failure & Valve: Closes & \\
\hline ACTUATOR & 46. Operating Medium: 115 & $5 v 60 h z$ & 51. Ac & ator Orien & tation: "R" & \\
\hline & 47. Max Allowable Pressur & re $\quad 70 p s i$ & 52. $\mathrm{Ha}$ & dwheel: $\mathrm{N}$ & & \\
\hline & 48 Enclosure: NEMA 4 & & 53 & & & \\
\hline & 54. Positioner: & & 60. Air & et: NA & & \\
\hline & 55. Input/Output: & & 61. Mo & el No. & & \\
\hline & 56. Bypass: Gauges: & & 62. Se & Pressure: & & \\
\hline ACCESSORIES & 57. Limit Switches: open 8 & \& closed & 63. Filt & r: Gauge: & & \\
\hline & 58. Model No.:VCS-2 switc & ch\&VOS-2switch & 64. Tra & el Indicato & r: Std. Required & \\
\hline & 59. Type \& Rating:SPDT 5 & Amp & 65 & & & \\
\hline $\begin{array}{l}\text { Notes: } \\
\text { 1. Valve to }\end{array}$ & provided with stainless ste & eel nameplate. & & & & \\
\hline
\end{tabular}




\begin{tabular}{|c|c|c|c|c|c|c|}
\hline Port & Hudson METHAN & NE de-NOx & Equ & ment & Specification & \\
\hline & & CONTROL VALI & & & $\begin{array}{r}\text { SHEET } 1 \\
\end{array}$ & $1 \mathrm{OF} 1$ \\
\hline & & \begin{tabular}{|l|l|} 
No. & By \\
\end{tabular} & Date & Rev. & \begin{tabular}{|l|} 
SPEC NO. \\
\end{tabular} & REV. \\
\hline & & & & & $\mathrm{XV}-112$ & \\
\hline & & & & & CONTRACT & DATE \\
\hline & & & & & & $8 / 1 / 2005$ \\
\hline & & & & & REQ & P.O. \\
\hline & & & & & $\mathrm{CHK}$ & APPR \\
\hline & & & & & LRS & \\
\hline & 1. Tag No.: GR-XV-112 & & 6. Тур & of Control: & Shut-off Service & \\
\hline & 2. Service: Flow Skid Zon & ie\#1 Block Valve & 7. Inlet & Sonnection & n: 2" 150\# R.F. & \\
\hline GENERAL & 3. Location: downstream G & GR-XV-111 & 8. Outl & Connecti & ion: 2" 150\# R.F. & \\
\hline & 4. Line Material: Carbon S & Steel & 9. Nois & dBA allon & Nable: $<80$ & \\
\hline & 5. Body Type: Rising Sten & & 10. Fac & to Face: & Vendor to advise AS & SAP \\
\hline & 11. Fluid: Methane & & Units & MaxFlow & NormFloyMinFlow & Shut-off \\
\hline & 12. Flow Rate: & & SCFH & & & \\
\hline & 13. Inlet Pressure: & & PSIG & & & \\
\hline SERVICE & 14. Outlet Pressure: & & PSIG & & & \\
\hline CONDITIONS & 15. S.G. / M.W. & & & & & \\
\hline & 16. Viscosity/Spec Heats & Ratio & & & & \\
\hline & 17. Vapor Pressure & & & & & \\
\hline & 18. Required Cv & & & & & \\
\hline & 19. Travel & & & & & \\
\hline & \begin{tabular}{|c|} 
RISING STEM \\
\end{tabular} & & & & ROTARY & \\
\hline & 20. Manufacturer: Maxon & 5000-S-CP & 32. Ma & ufacturer: & & \\
\hline & 21. Body Size \& Material: & 2" Carbon Steel & 33. Bo & y Size \& M & laterial: & \\
\hline & 22. Flow Characteristic: Q & uick Closing & 34. $\mathrm{Flo}$ & Characte & ristic: & \\
\hline & 23. Port Size: 2" & & 35. $\mathrm{Ba}$ & Port Size: & & \\
\hline VALVE & 24. Trim Material: Stainles & ss Steel & 36. $\mathrm{Ba}$ & Material: & & \\
\hline BODY & 25. Seat Material: SS & & 37. Dis & Material: & & \\
\hline & 26. Bonnet Material: WCB & 3 Steel & 38. Dis & Liner: & & \\
\hline & 27. Guiding: Stainless Ste & eeel & 39. Tri & Material: & & \\
\hline & 28. O-rings: Buna $\mathrm{N}$ & & 40. Se & Material: & & \\
\hline & 29. Shutoff Class: ANSI V & & 41. Bo & het Materia & & \\
\hline & 30 & & 42. $\mathrm{Pa}$ & king & & \\
\hline & 31 & & 43. Sh & -off Class: & & \\
\hline & 44. Type: $115 \mathrm{v} 60 \mathrm{hz}$ moto & & 49. Mir & Required & Pressure: & \\
\hline & 45. Model No.: Maxon & & 50. Ele & tric Failure & Valve: Closes & \\
\hline ACTUATOR & 46. Operating Medium: 11 & $5 v 60 h z$ & 51. Ac & ator Orien & tation:"R" & \\
\hline & 47. Max Allowable Pressur & re $\quad 70 p s i$ & 52. $\mathrm{Ha}$ & dwheel: $\mathrm{N}$ & & \\
\hline & 48 Enclosure: NEMA 4 & & 53 & & & \\
\hline & 54. Positioner: & & 60. Air & et: NA & & \\
\hline & 55. Input/Output: & & 61. Mo & el No. & & \\
\hline & 56. Bypass: Gauges: & & 62. Se & Pressure: & & \\
\hline ACCESSORIES & 57. Limit Switches: open 8 & \& closed & 63. Filt & r: Gauge: & & \\
\hline & 58. Model No.:VCS-2 switc & ch\&VOS-2switch & 64. Tra & el Indicato & r: Std. Required & \\
\hline & 59. Type \& Rating:SPDT 5 & Amp & 65 & & & \\
\hline $\begin{array}{l}\text { Notes: } \\
\text { 1. Valve to }\end{array}$ & provided with stainless ste & eel nameplate. & & & & \\
\hline
\end{tabular}




\begin{tabular}{|c|c|c|c|c|c|c|}
\hline Port & Hudson METHAN & JE de-NOx & Equ & ment & Specification & \\
\hline & & CONTROL VALI & & & $\begin{array}{r}\text { SHEET } 1 \\
\end{array}$ & 1 OF 1 \\
\hline & & \begin{tabular}{|l|l|} 
No. & By \\
\end{tabular} & Date & Rev. & \begin{tabular}{|l|l} 
SPEC NO. &
\end{tabular} & REV. \\
\hline & & & & & $\mathrm{XV}-121$ & \\
\hline & & & & & CONTRACT & DATE \\
\hline & & & & & & $8 / 1 / 2005$ \\
\hline & Solutions & & & & REQ & P.O. \\
\hline & & & & & $\mathrm{CHK}$ & APPR \\
\hline & & & & & LRS & \\
\hline & 1. Tag No.: GR-XV-121 & & 6. Typ & of Control: & : Shut-off Service & \\
\hline & 2. Service: Flow Skid Zone & e\#2 Block Valve & 7. Inlet & Jonnection & n: 2" 150\# R.F. & \\
\hline GENERAL & 3. Location: downstream G & R-FE-120 & 8. Outl & Connectic & on: 2" 150\# R.F. & \\
\hline & 4. Line Material: Carbon St & Steel & 9. Nois & dBA allon & Nable: $<80$ & \\
\hline & 5. Body Type: Rising Stem & & 10. Fac & to Face: & Vendor to advise AS & SAP \\
\hline & 11. Fluid: Methane & & Units & MaxFlow & NormFloy MinFlow & Shut-off \\
\hline & 12. Flow Rate: & & $\mathrm{SCFH}$ & & & \\
\hline & 13. Inlet Pressure: & & PSIG & & & \\
\hline SERVICE & 14. Outlet Pressure: & & PSIG & & & \\
\hline CONDITIONS & 15. S.G. / M.W. & & & & & \\
\hline & 16. Viscosity/Spec Heats R & Ratio & & & & \\
\hline & 17. Vapor Pressure & & & & & \\
\hline & 18. Required Cv & & & & & \\
\hline & 19. Travel & & & & & \\
\hline & \begin{tabular}{|l} 
RISING STEM \\
\end{tabular} & & & & ROTARY & \\
\hline & 20. Manufacturer: Maxon 5 & $5000-\mathrm{S}-\mathrm{CP}$ & 32. Ma & ufacturer: & & \\
\hline & 21. Body Size \& Material: 2 & $2 " \mathrm{CS}$ & 33. Bo & Size \& M & laterial: & \\
\hline & 22. Flow Characteristic: Qu & uick closing & 34. Flo & Characte & ristic: & \\
\hline & 23. Port Size: 2" & & 35. $\mathrm{Ba}$ & Port Size: & & \\
\hline VALVE & 24. Trim Material: Stainless & ss Steel & 36. $\mathrm{Ba}$ & Material: & & \\
\hline BODY & 25. Seat Material: SS & & 37. Dis & Material: & & \\
\hline & 26. Bonnet Material: WCB & Steel & 38. Dis & Liner: & & \\
\hline & 27. Guiding: Stainless Ste & & 39. Tri & Material: & & \\
\hline & 28. O-rings: Buna N & & 40. Se & Material: & & \\
\hline & 29. Shutoff Class: ANSI VI & & 41. Bo & het Materia & & \\
\hline & 30 & & 42. $\mathrm{Pa}$ & king & & \\
\hline & 31 & & 43. Sh & -off Class: & & \\
\hline & 44. Type: $115 \mathrm{v} 60 \mathrm{hz}$ motor & & 49. Mir & Required & Pressure: & \\
\hline & 45. Model No.: Maxon & & 50. Ele & tric Failure & Valve: Closes & \\
\hline ACTUATOR & 46. Operating Medium: 115 & $5 \mathrm{v} 60 \mathrm{hz}$ & 51. Ac & ator Orien & tation:"R" & \\
\hline & 47. Max Allowable Pressure & e $\quad 70 p s i$ & 52. $\mathrm{Ha}$ & dwheel: $\mathrm{N}$ & & \\
\hline & 48 Enclosure: NEMA 4 & & 53 & & & \\
\hline & 54. Positioner: & & 60. Air & t: NA & & \\
\hline & 55. Input/Output: & & 61. Mo & el No. & & \\
\hline & 56. Bypass: Gauges: & & 62. Se & Pressure: & & \\
\hline ACCESSORIES & 57. Limit Switches: open \& & closed & 63. Filt & r: Gauge: & & \\
\hline & 58. Model No.:VCS-2 switcl & ch\&VOS-2switch & 64. Tra & el Indicato & r: Std. Required & \\
\hline & 59. Type \& Rating:SPDT 5f & Amp & 65 & & & \\
\hline $\begin{array}{l}\text { Notes: } \\
\text { 1. Valve to }\end{array}$ & provided with stainless ste & eel nameplate. & & & & \\
\hline
\end{tabular}




\begin{tabular}{|c|c|c|c|c|c|c|}
\hline Port & Hudson METHAN & NE de-NOx & Equ & ment & Specification & \\
\hline & & CONTROL VALI & & & $\begin{array}{r}\text { SHEET } 1 \\
\end{array}$ & $1 \mathrm{OF} 1$ \\
\hline & & \begin{tabular}{|l|l|} 
No. & By \\
\end{tabular} & Date & Rev. & \begin{tabular}{|l|} 
SPEC NO. \\
\end{tabular} & REV. \\
\hline & & & & & $\mathrm{XV}-122$ & 0 \\
\hline & & & & & CONTRACT & DATE \\
\hline & & & & & & 8/1/2005 \\
\hline & & & & & REQ & P.O. \\
\hline & & & & & $\mathrm{CHK}$ & APPR \\
\hline & & & & & LRS & \\
\hline & 1. Tag No.: GR-XV-122 & & 6. Тур & of Control: & Shut-off Service & \\
\hline & 2. Service: Flow Skid Zon & ie\#2 Block Valve & 7. Inlet & Sonnection & n: 2" 150\# R.F. & \\
\hline GENERAL & 3. Location: downstream G & GR-XV-121 & 8. Outl & Connecti & ion: 2" 150\# R.F. & \\
\hline & 4. Line Material: Carbon S & Steel & 9. Nois & dBA allon & Nable: $<80$ & \\
\hline & 5. Body Type: Rising Sten & & 10. Fac & to Face: & Vendor to advise AS & SAP \\
\hline & 11. Fluid: Methane & & Units & MaxFlow & NormFloyMinFlow & Shut-off \\
\hline & 12. Flow Rate: & & SCFH & & & \\
\hline & 13. Inlet Pressure: & & PSIG & & & \\
\hline SERVICE & 14. Outlet Pressure: & & PSIG & & & \\
\hline CONDITIONS & 15. S.G. / M.W. & & & & & \\
\hline & 16. Viscosity/Spec Heats & Ratio & & & & \\
\hline & 17. Vapor Pressure & & & & & \\
\hline & 18. Required Cv & & & & & \\
\hline & 19. Travel & & & & & \\
\hline & \begin{tabular}{|c|} 
RISING STEM \\
\end{tabular} & & & & ROTARY & \\
\hline & 20. Manufacturer: Maxon & 5000-S-CP & 32. Ma & ufacturer: & & \\
\hline & 21. Body Size \& Material: & 2" Carbon Steel & 33. Bo & y Size \& M & laterial: & \\
\hline & 22. Flow Characteristic: Q & uick closing & 34. $\mathrm{Flo}$ & Characte & ristic: & \\
\hline & 23. Port Size: 2" & & 35. $\mathrm{Ba}$ & Port Size: & & \\
\hline VALVE & 24. Trim Material: Stainles & ss Steel & 36. $\mathrm{Ba}$ & Material: & & \\
\hline BODY & 25. Seat Material: SS & & 37. Dis & Material: & & \\
\hline & 26. Bonnet Material: WCB & 3 Steel & 38. Dis & Liner: & & \\
\hline & 27. Guiding: Stainless Ste & eeel & 39. Tri & Material: & & \\
\hline & 28. O-rings: Buna $\mathrm{N}$ & & 40. Se & Material: & & \\
\hline & 29. Shutoff Class: ANSI V & & 41. Bo & het Materia & & \\
\hline & 30 & & 42. $\mathrm{Pa}$ & king & & \\
\hline & 31 & & 43. Sh & -off Class: & & \\
\hline & 44. Type: $115 \mathrm{v} 60 \mathrm{hz}$ moto & & 49. Mir & Required & Pressure: & \\
\hline & 45. Model No.: Maxon & & 50. Ele & tric Failure & Valve: Closes & \\
\hline ACTUATOR & 46. Operating Medium: 11 & $5 v 60 h z$ & 51. Ac & ator Orien & tation:"R" & \\
\hline & 47. Max Allowable Pressur & re $\quad 70 p s i$ & 52. $\mathrm{Ha}$ & dwheel: $\mathrm{N}$ & & \\
\hline & 48 Enclosure: NEMA 4 & & 53 & & & \\
\hline & 54. Positioner: & & 60. Air & et: NA & & \\
\hline & 55. Input/Output: & & 61. Mo & el No. & & \\
\hline & 56. Bypass: Gauges: & & 28. O-1 & ggs: Buna & & \\
\hline ACCESSORIES & 57. Limit Switches: open 8 & \& closed & 63. Filt & r: Gauge: & & \\
\hline & 58. Model No.:VCS-2 switc & ch\&VOS-2switch & 64. Tra & el Indicato & r: Std. Required & \\
\hline & 59. Type \& Rating:SPDT 5 & Amp & 65 & & & \\
\hline $\begin{array}{l}\text { Notes: } \\
\text { 1. Valve to }\end{array}$ & provided with stainless ste & eel nameplate. & & & & \\
\hline
\end{tabular}




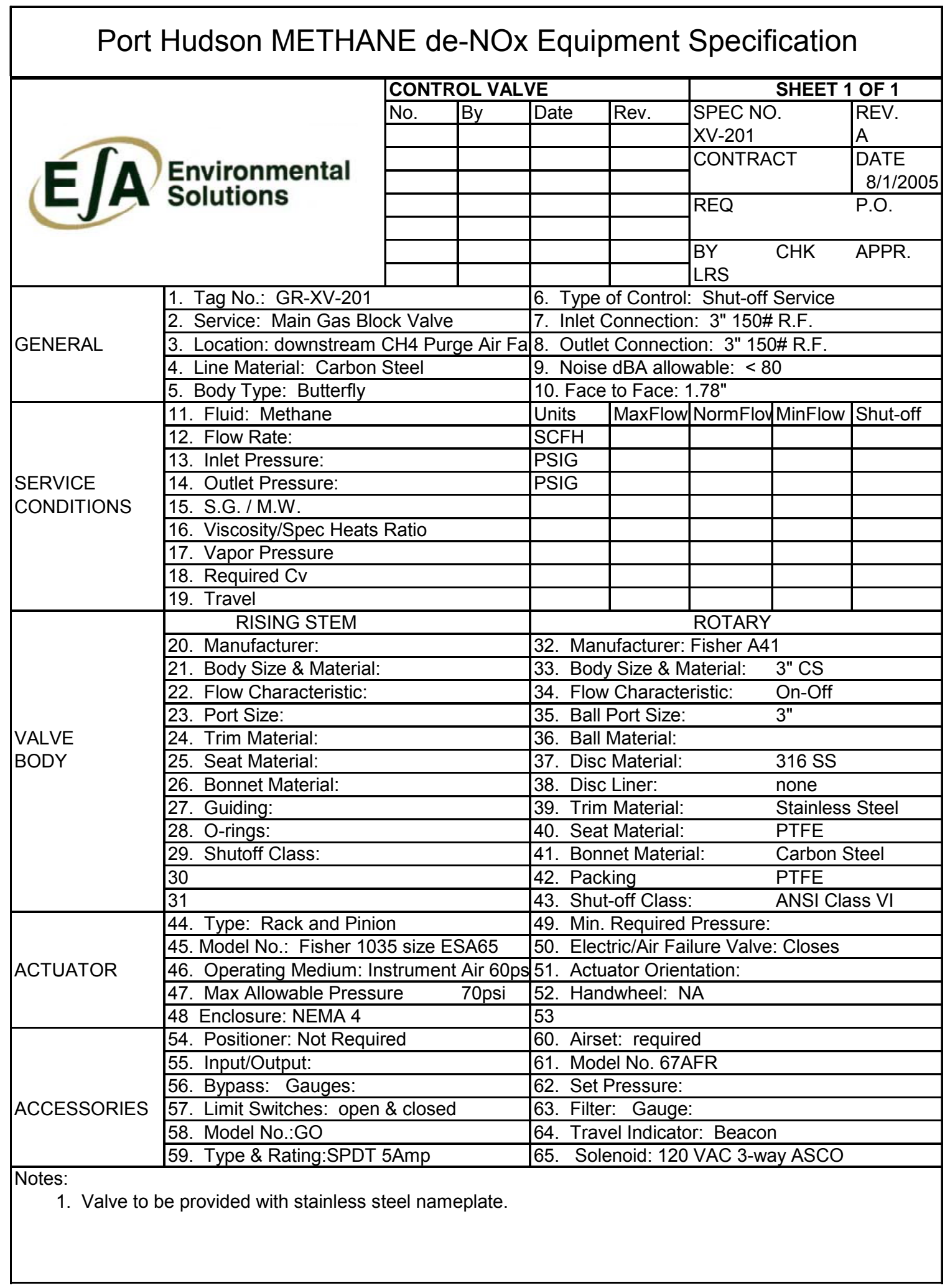




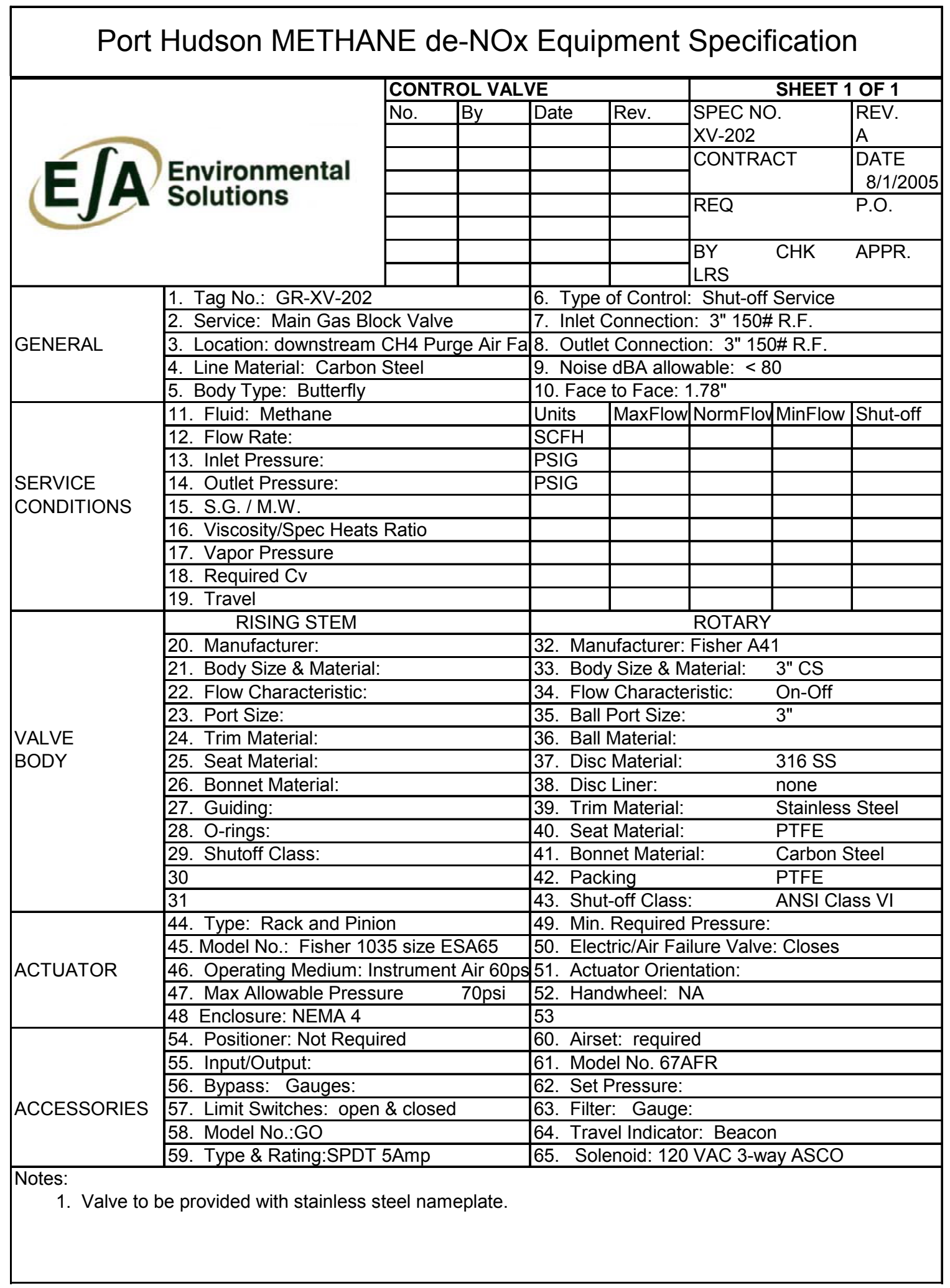




\begin{tabular}{|c|c|c|c|c|c|c|}
\hline Port & Hudson METHAN & NE de-NOx & Equ & ment & Specification & \\
\hline & & CONTROL VALI & & & $\begin{array}{r}\text { SHEET } 1 \\
\end{array}$ & $1 \mathrm{OF} 1$ \\
\hline & & \begin{tabular}{|l|l|} 
No. & By \\
\end{tabular} & Date & Rev. & \begin{tabular}{|l|} 
SPEC NO. \\
\end{tabular} & REV. \\
\hline & & & & & $\mathrm{XV}-101$ & \\
\hline & & & & & CONTRACT & DATE \\
\hline & & & & & & $8 / 1 / 2005$ \\
\hline & & & & & REQ & P.O. \\
\hline & & & & & $\mathrm{CHK}$ & APPR \\
\hline & & & & & LRS & \\
\hline & 1. Tag No.: GR-XV-101 & & 6. Typ & of Control: & : Shut-off Service & \\
\hline & 2. Service: MdN System Is & solation Valve & 7. Inlet & Connection & n: 2" 150\# R.F. & \\
\hline GENERAL & 3. Location: Downstream o & of GR-PCV-102 & 8. Outl & Connecti & ion: 2" 150\# R.F. & \\
\hline & 4. Line Material: Carbon S & Steel & 9. Nois & dBA allon & Nable: $<80$ & \\
\hline & 5. Body Type: Rising Stem & & 10. Fac & to Face: 1 & Vendor to advise AS & SAP \\
\hline & 11. Fluid: Methane & & Units & MaxFlow & NormFloyMinFlow & Shut-off \\
\hline & 12. Flow Rate: & & SCFH & & & \\
\hline & 13. Inlet Pressure: & & PSIG & & & \\
\hline SERVICE & 14. Outlet Pressure: & & PSIG & & & \\
\hline CONDITIONS & 15. S.G. / M.W. & & & & & \\
\hline & 16. Viscosity/Spec Heats R & Ratio & & & & \\
\hline & 17. Vapor Pressure & & & & & \\
\hline & 18. Required Cv & & & & & \\
\hline & 19. Travel & & & & & \\
\hline & \begin{tabular}{|c|} 
RISING STEM \\
\end{tabular} & & & & ROTARY & \\
\hline & 20. Manufacturer: Maxon & $5000-\mathrm{S}-\mathrm{CP}$ & 32. Ma & iufacturer: & & \\
\hline & 21. Body Size \& Material: & 2" CS & 33. Bo & y Size \& M & laterial: & \\
\hline & 22. Flow Characteristic: Qu & uick closing & 34. Flo & v Characte & ristic: & \\
\hline & 23. Port Size: 2" & & 35. $\mathrm{Ba}$ & Port Size: & & \\
\hline VALVE & 24. Trim Material: Stainles & ss Steel & 36. $\mathrm{Ba}$ & Material: & & \\
\hline BODY & 25. Seat Material: SS & & 37. Dis & Material: & & \\
\hline & 26. Bonnet Material: WCB & 3 Steel & 38. Dis & Liner: & & \\
\hline & 27. Guiding: Stainless Ste & & 39. Tri & Material: & & \\
\hline & 28. O-rings: Buna $\mathrm{N}$ & & 40. Se & t Material: & & \\
\hline & 29. Shutoff Class: ANSI V & & 41. Bo & net Materia & & \\
\hline & 30 & & 42. $\mathrm{Pa}$ & king & & \\
\hline & 31 & & 43. Sh & t-off Class: & & \\
\hline & 44. Type: $115 \mathrm{v} 60 \mathrm{hz}$ moto & & 49. Mir & Required & Pressure: & \\
\hline & 45. Model No.: Maxon & & 50. Ele & tric Failure & Valve: Closes & \\
\hline ACTUATOR & 46. Operating Medium: 115 & $5 v 60 h z$ & 51. Ac & Iator Orien & tation: "R" & \\
\hline & 47. Max Allowable Pressur & re $\quad 70 p s i$ & 52. $\mathrm{Ha}$ & dwheel: $\mathrm{N}$ & & \\
\hline & 48 Enclosure: NEMA 4 & & 53 & & & \\
\hline & 54. Positioner: & & 60. Air & et: NA & & \\
\hline & 55. Input/Output: & & 61. Mo & lel No. & & \\
\hline & 56. Bypass: Gauges: & & 62. Se & Pressure: & & \\
\hline ACCESSORIES & 57. Limit Switches: open 8 & \& closed & 63. Filt & r: Gauge: & & \\
\hline & 58. Model No.:VCS-2 switc & ch\&VOS-2switch & 64. Tra & vel Indicato & r: Std. Required & \\
\hline & 59. Type \& Rating:SPDT 5 & Amp & 65 & & & \\
\hline $\begin{array}{l}\text { Notes: } \\
\text { 1. Valve to }\end{array}$ & provided with stainless ste & eel nameplate. & & & & \\
\hline
\end{tabular}




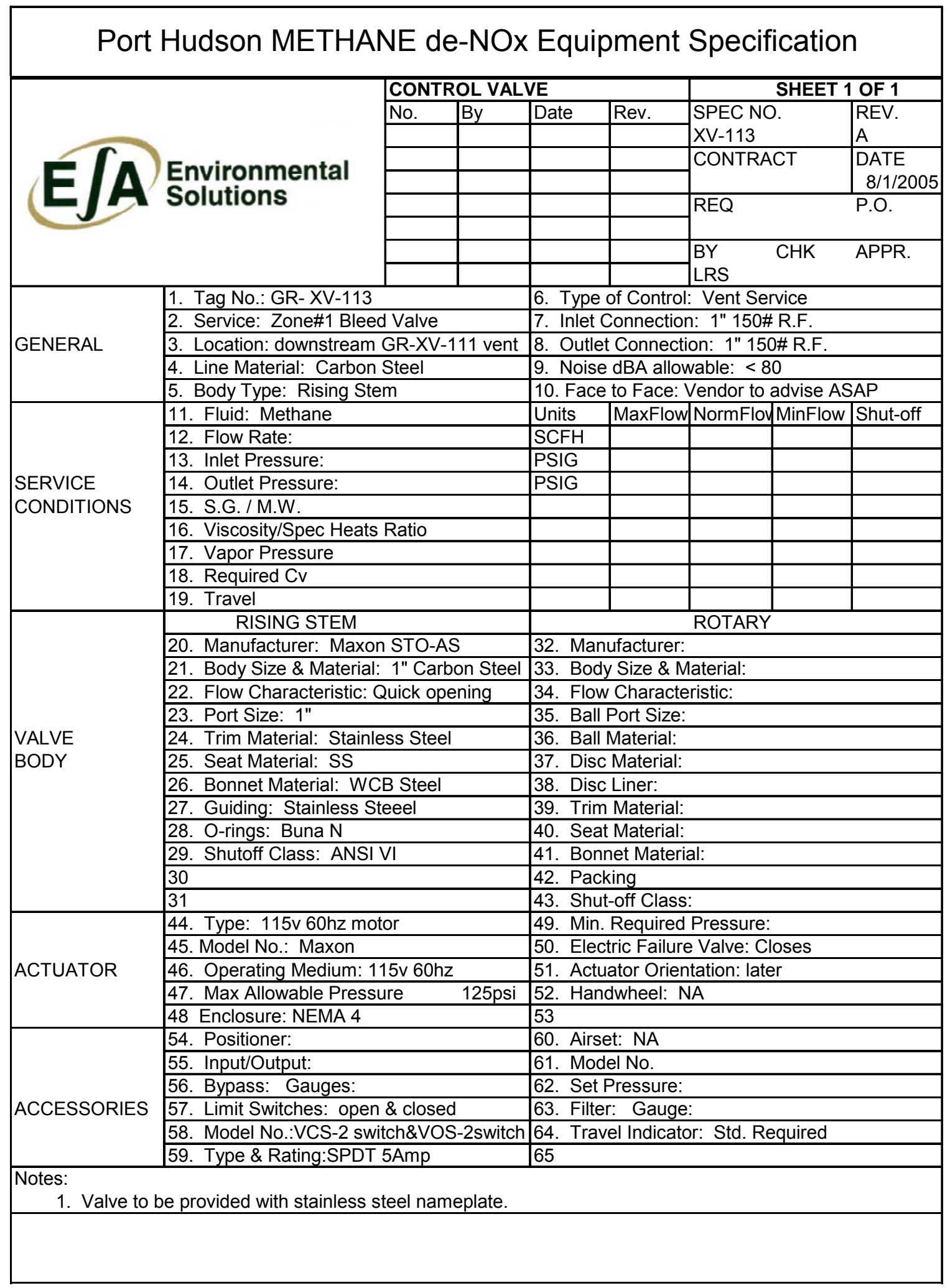




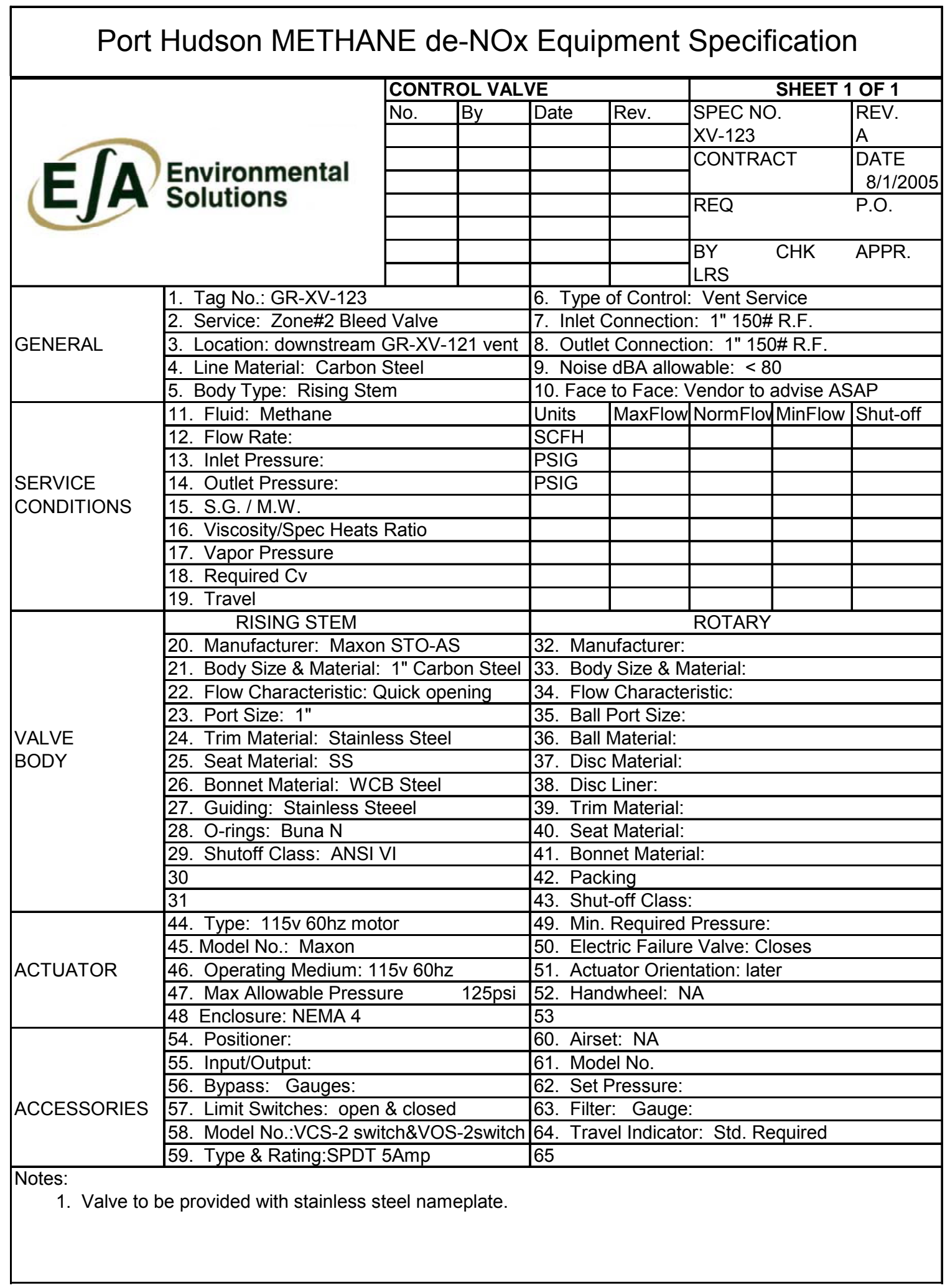




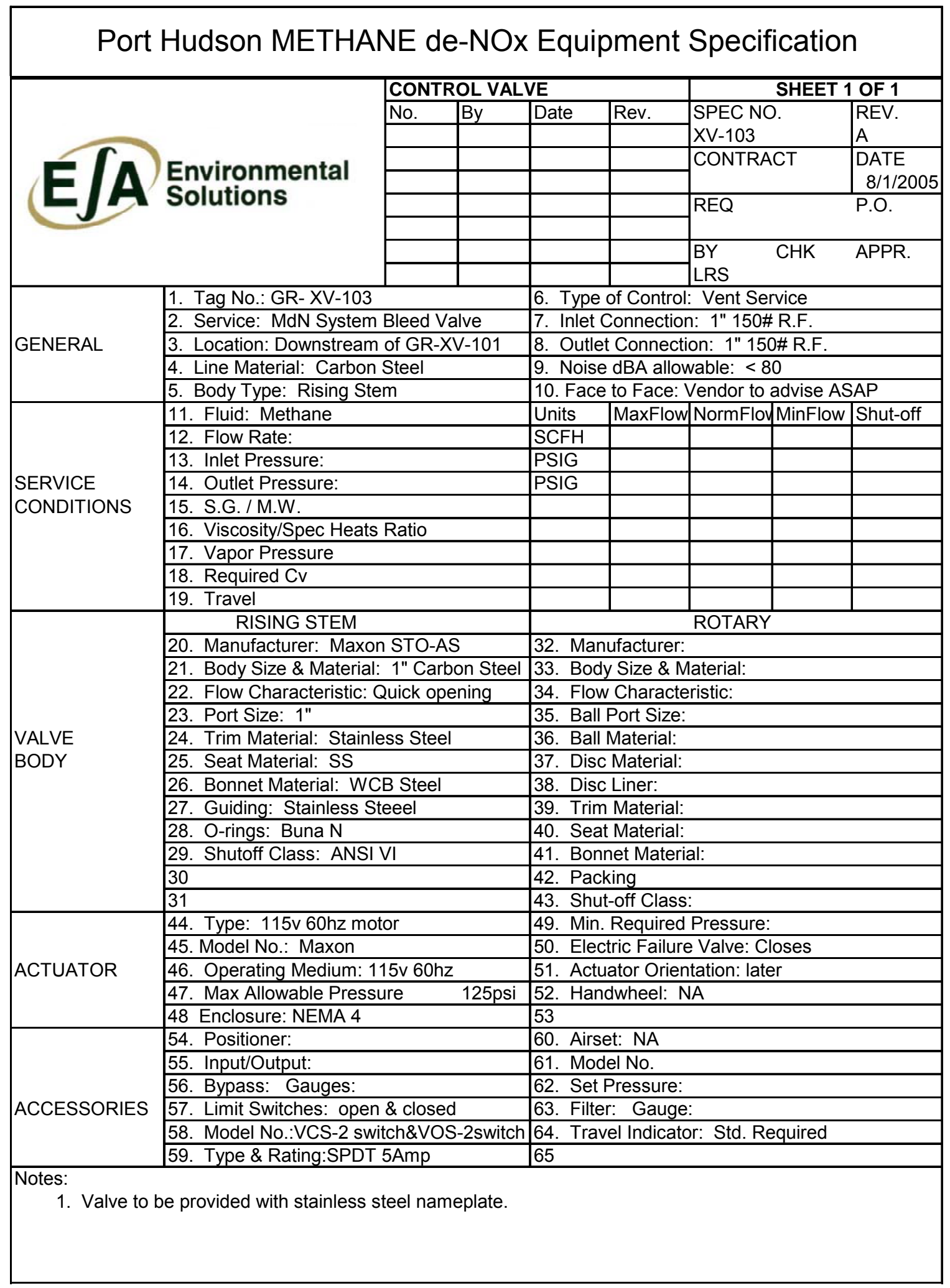




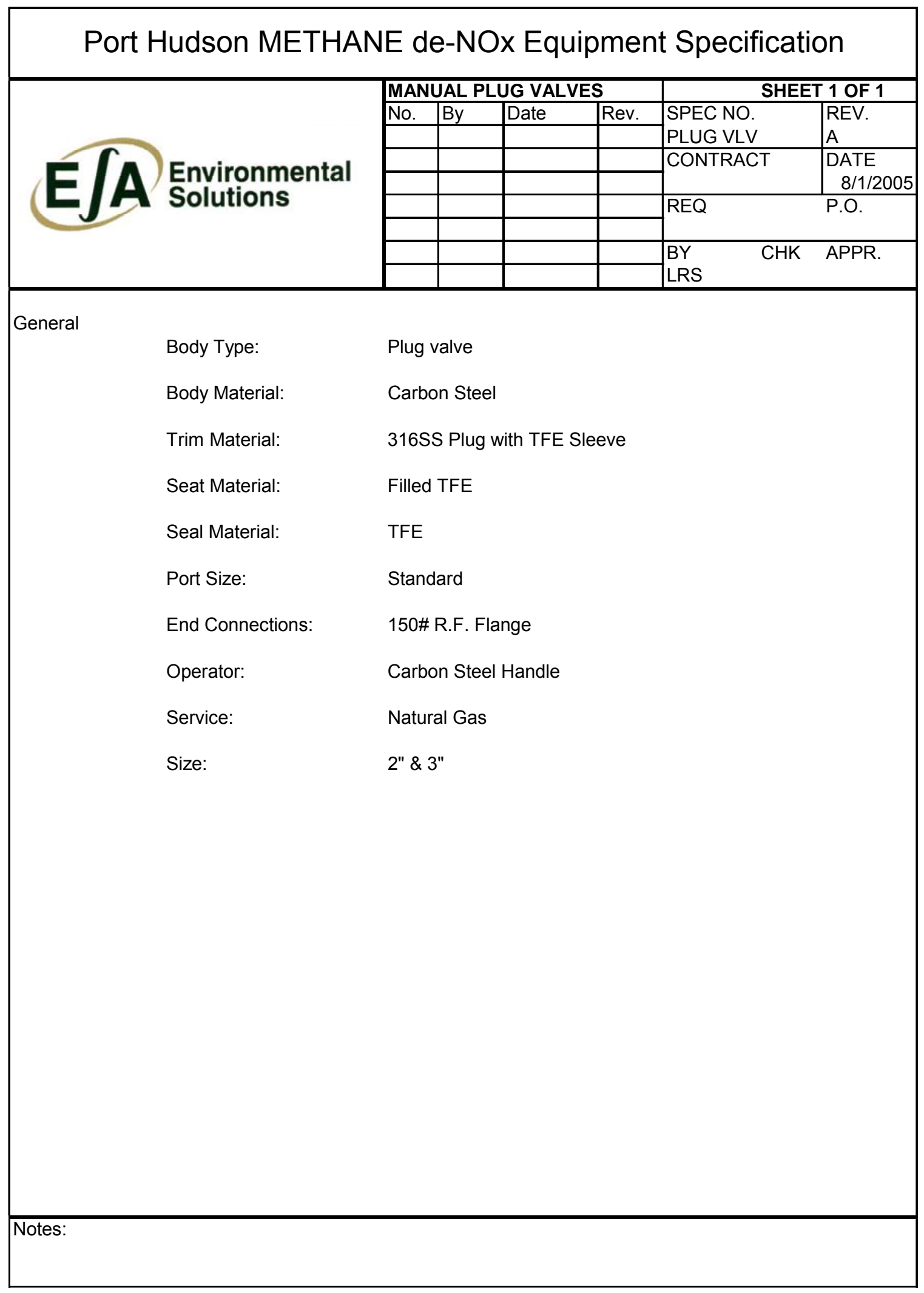




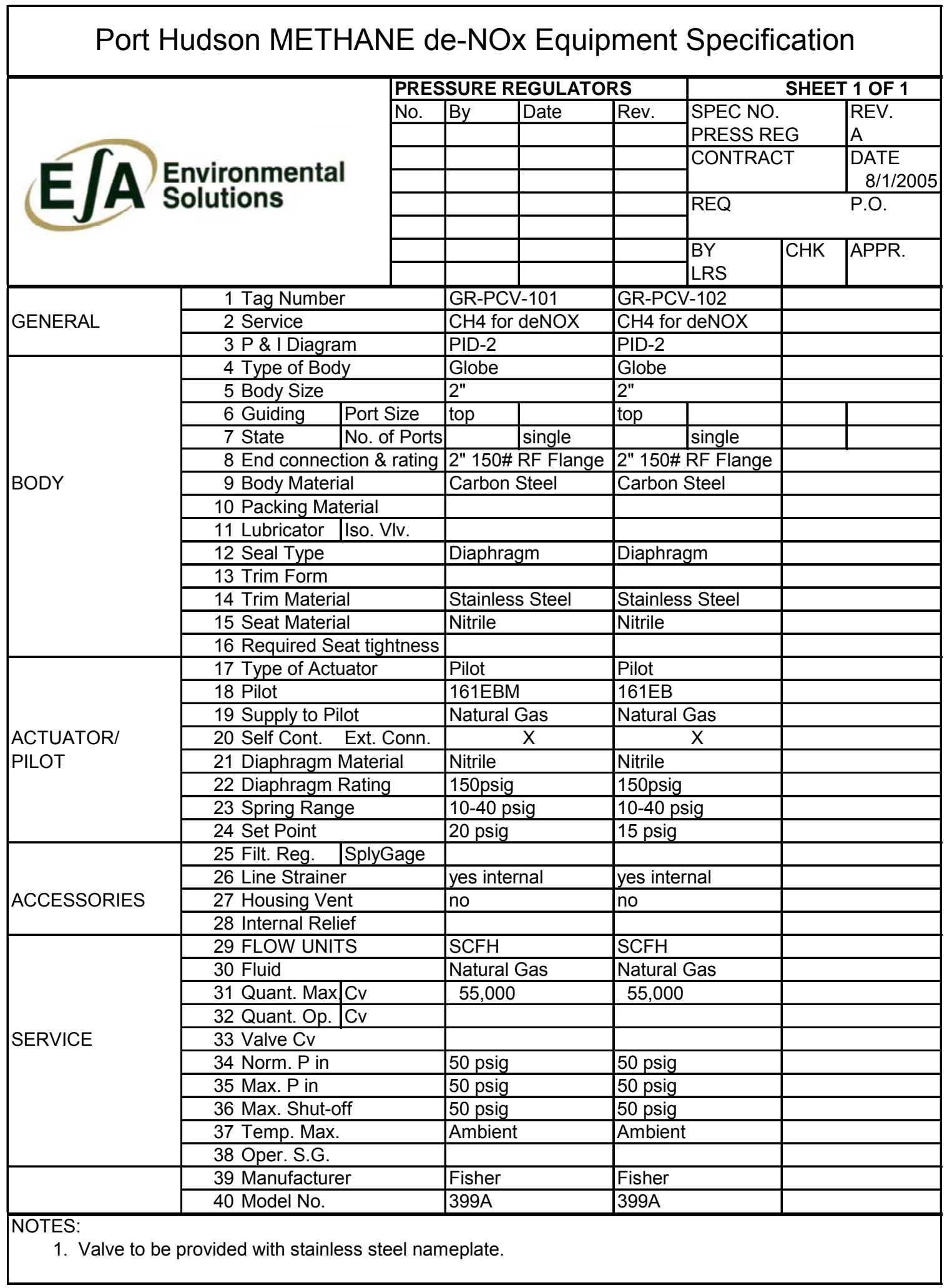




\begin{tabular}{|c|c|c|c|c|c|c|c|c|}
\hline & ludson ME & -A & JE C & $2-N$ & $x \mathrm{Eq}$ & ome & t Specificat & ion \\
\hline & & & 02 & VAL & & & \begin{tabular}{|r|} 
SHEI \\
\end{tabular} & T 1 OF 1 \\
\hline & & & No. & By & Date & Rev. & SPEC NO. & REV. \\
\hline & & & & & & & O2 INST & A \\
\hline & Environmer & & & & & & CONTRACT & DATE \\
\hline & Solutio & & & & & & & 8/1/2005 \\
\hline & & & & & & & & \\
\hline & & & & & & & $\mathrm{CHK}$ & APPR. \\
\hline & & & & & & & LRS & \\
\hline Genera & & & & & & & & \\
\hline & Type: & & tu Ox & $\operatorname{sen} A$ & lyzer & & & \\
\hline & Sensor: & & nium & xide & & & & \\
\hline & Manufacturer: & & mour & or $\mathrm{e}$ & & & & \\
\hline & Model Number: & & $4 \mathrm{~A} 30$ & & & & & \\
\hline & Housing: & & copp & Alur & & & & \\
\hline & Rating: & & A $4 X$ & P66 & & & & \\
\hline & Temperature Rat & $g:-40$ & eg $\mathrm{Ft}$ & +18 & $\mathrm{~F}(\mathrm{ele}$ & nics) & 1300deg $F$ sens & $r \max$ \\
\hline & Mounting: & & $\begin{array}{l}3 D 39 \\
\text { luctwc }\end{array}$ & & pool pi€ & to offs & transmitter housir & $\mathrm{g}$ from \\
\hline & Probe Type: & & ber $\mathrm{L}$ & fusic & Element & & & \\
\hline & Probe materials: & & SS v & tted & & & & \\
\hline & Length: & $18^{\prime}$ & & & & & & \\
\hline & Range: & & $5 \%$ ox & gen & & & & \\
\hline & Accuracy: & & $.75 \%$ & rea & g or 0.0 & $\mathrm{O} 2, \mathrm{wl}$ & chever is greater & \\
\hline & Analog Output: & & $0 \mathrm{~mA}$ & ART & & & & \\
\hline & Calibration: & & -auto & atic & gutomat & zustom & to specify & \\
\hline Process & & & & & & & & \\
\hline & Fluid: & & Gas & & & & & \\
\hline & Pressure Inlet: & 48 & W.C. & & & & & \\
\hline & Temperature: & 45 & & & & & & \\
\hline Notes: & 1. Vendor to sup & $\overline{S S}$ & lamer & $\overline{\text { ate } n}$ & $\overline{\text { Tag No }}$ & R-AT- & & \\
\hline
\end{tabular}




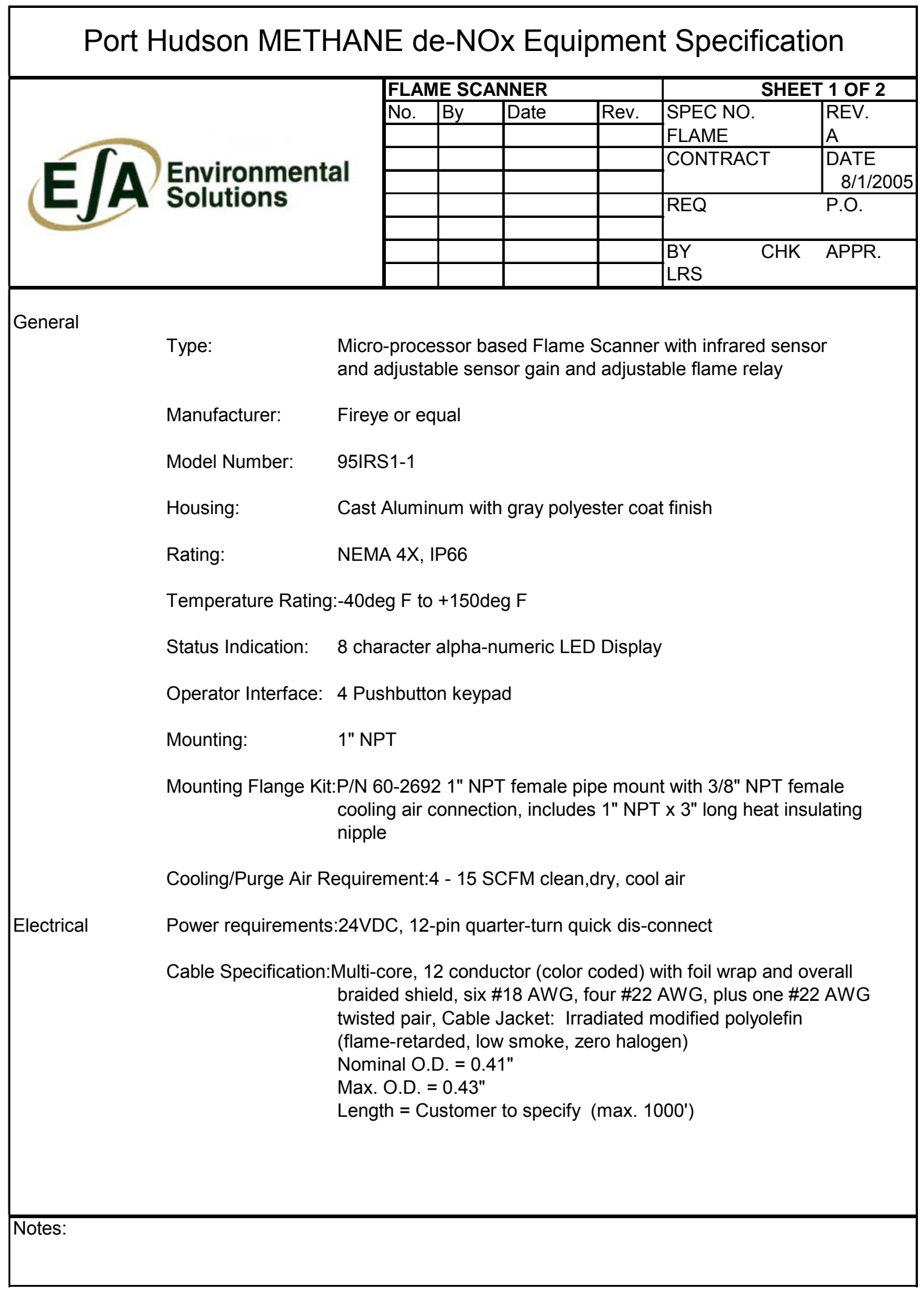




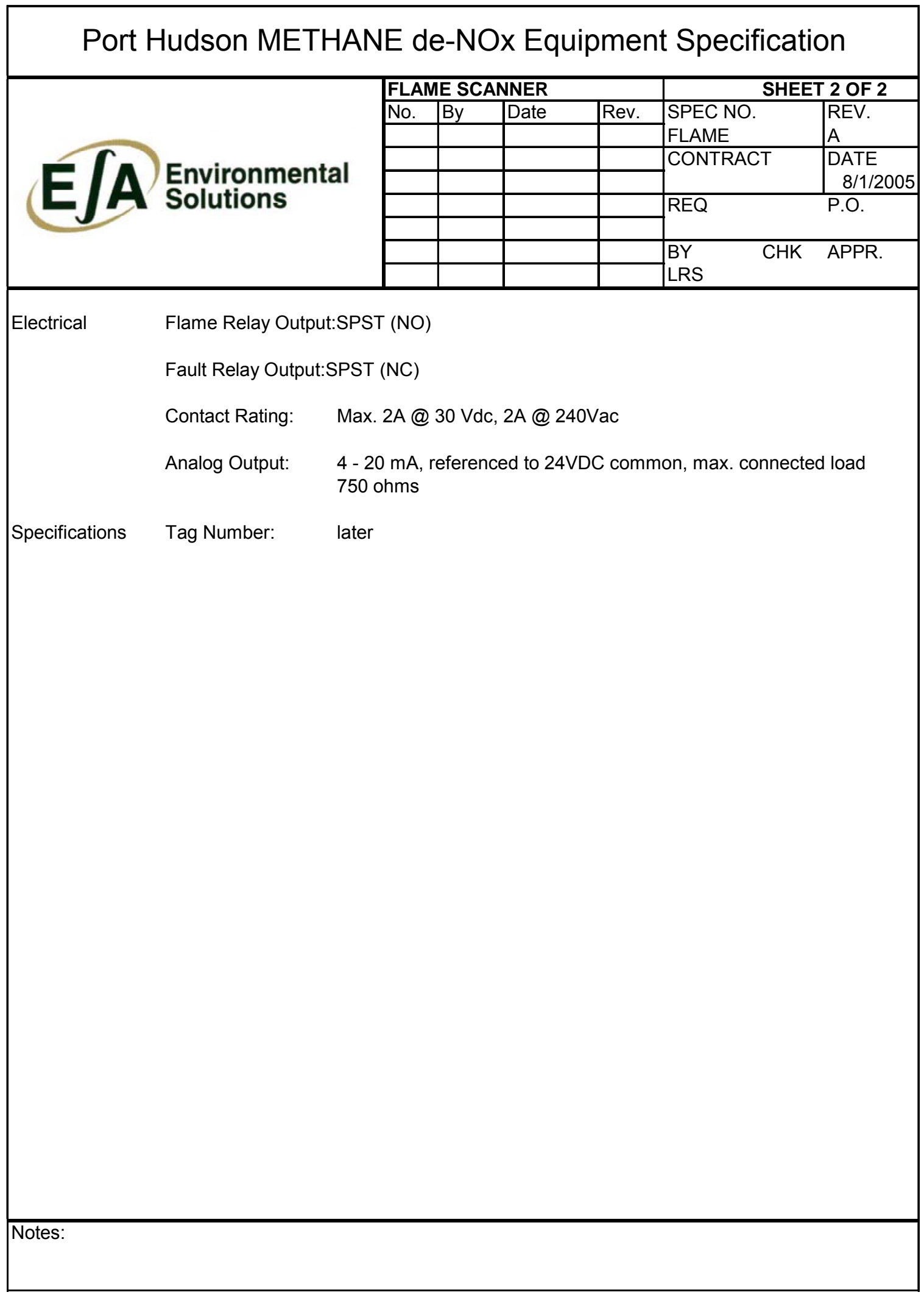




\section{4. $\quad$ DeRidder Power Boiler No. 2 - Preliminary Retrofit Design}

\subsubsection{DeRidder MdN Design Objectives}

The MdN retrofit design for the DeRidder boiler was targeted at demonstrating an extension to the technology. At DeRidder, a modification of the MdN process was planned to utilize mill generated waste gases from making paper which consisted of a low volume high concentration waste gas (LVHC) from its foul condensate stripper and a stream from a mill collection system of noncondensable gas wastes (NCGs). These waste gas streams are to be directed into the reburn zone and replace a portion of the reburn fuel requirements from natural gas. This scheme effectively utilizes the combustible content in the waste gases to assist in creation of an oxygen deficient environment for reburn reactions and by substitution for reburn fuel provides a means for further cost savings through a reduction in natural gas consumption. With basic MdN, system benefits expected a reduction in natural gas usage by approximately 25\%; at DeRidder this converts to about 25,000 scfh. With extended MdN, system projections indicate a potential for an additional reduction of natural gas usage by 4,000 to 6,000 scfh for a total savings of about 30,000 scfh. An extended MdN system also provides for the proper disposal of these waste gases, thereby giving the mill another flexible alternative for environmental compliance.

Measurement of $\mathrm{NO}_{\mathrm{x}}$ during boiler baseline tests measured a moderate emission level of 0.23 pound $\mathrm{NO}_{\mathrm{x}}$ per million Btu (corrected at $3 \% \mathrm{O}_{2}$ ). With $\mathrm{MdN}$, best system performance expectations look to a reduction in $\mathrm{NO}_{\mathrm{x}}$ emissions to 0.18 to 0.20 pound per million Btu. The reduction in $\mathrm{NO}_{\mathrm{x}}$ achieved with $\mathrm{MdN}$ in operation is intended to help offset a portion of the expected $\mathrm{NO}_{\mathrm{x}}$ increase from a planned future boiler upgrade.

The MdN system is also expected to improve the thermal efficiency of the boiler by 1-2\% at full load and maintain emissions of carbon monoxide at or below permitted limits.

\subsubsection{DeRidder Boiler Description}

DeRidder's Power Boiler No. 2 is a hog fuel-fired stoker boiler manufactured by Combustion Engineering and constructed in 1979 with a traveling grate and four (4) air swept bark distributors. The boiler is co-fired with two natural gas burners to stabilize and augment the combustion of the bark on the grate. The stoker furnace shape is square and was recently equipped with a new OFA system. A cinder re-injection system returns oversize ash particulates separated from sand classifiers at the outlet of a multiclone dust collector back into the lower furnace. The boiler exhaust system contains an economizer, tubular air heater, a mechanical dust collector and high energy wet venturi scrubber. The boiler contains an FD Fan and ID Fan but does not include a OFA fan as compared with other baseline tested boilers.

The original boiler design conditions for the unit at 100\% MCR were 225,000 lb/h steam flow at $825^{\circ} \mathrm{F}$ and 859 psig while burning 4500 Btu/lb HHV bark fuel with 50\% moisture by weight. The boiler fire side was upgraded in 2001 to provide $300,000 \mathrm{lb} / \mathrm{h}$ steam flow at $825^{\circ} \mathrm{F}$ and 850 psig at full capacity while burning 4526 Btu/lb HHV bark fuel with 52.5\% moisture by weight. 
At the time of the steam upgrade, the boiler was retrofitted with a High Mixing Zone (HMZ) overfire air system. The HMZ system has a total of twelve (12) overfire air nozzles. The new overfire air nozzles are located on the front and rear wall with six (6) nozzles on each wall.

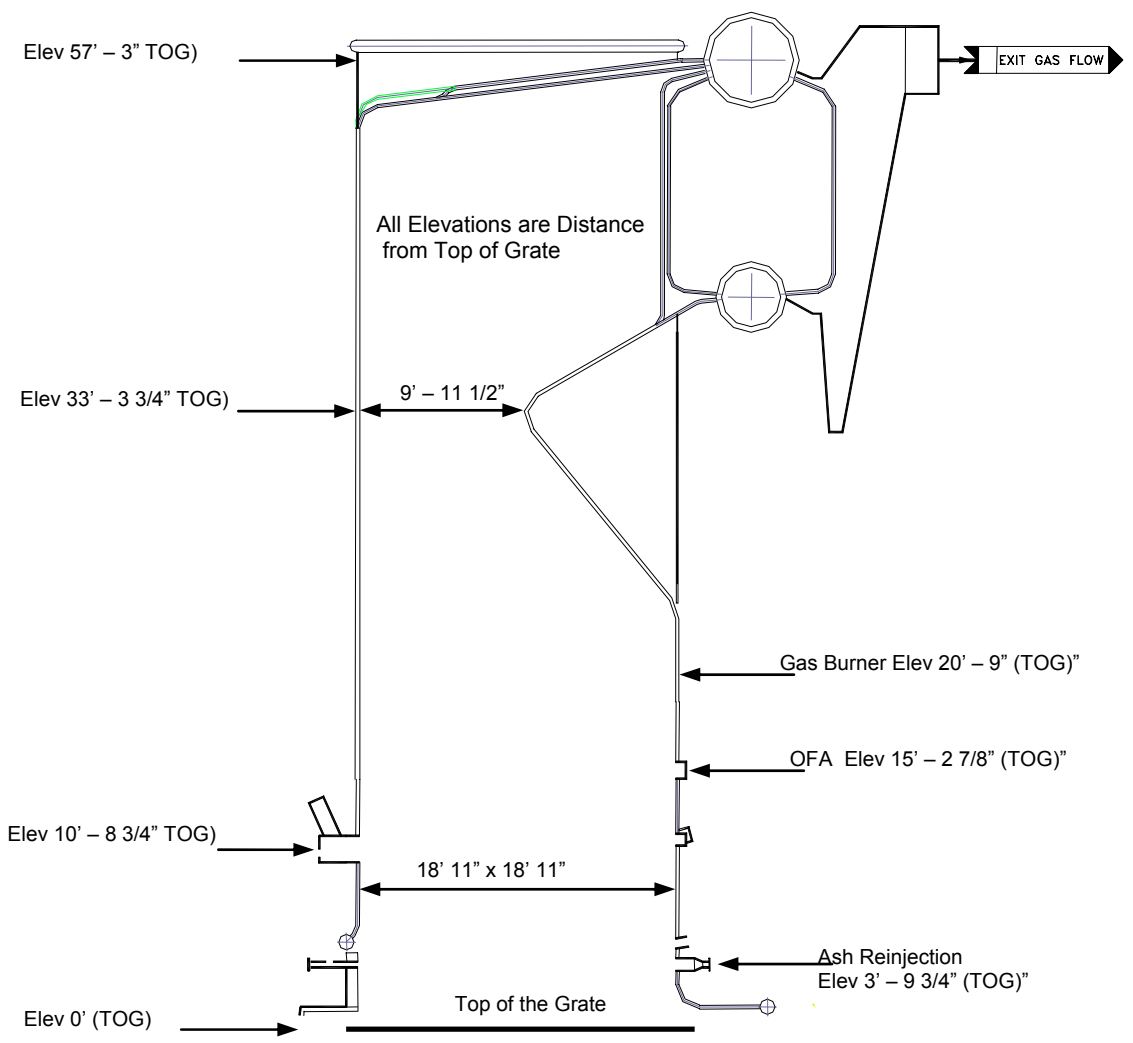

Figure 7-4 DeRidder Boiler Elevation Data

\subsubsection{DeRidder MdN with NCGs Design Overview}

The preliminary MdN system design for DeRidder is based on the baseline test data, boiler observations during baseline testing, and CFD model results. Certain engineering assumptions were made to develop the preliminary design. Characterization of the mill's NCG and SOG streams required added effort. Injection of NCG and SOG steams were planned for the primary grate combustion zone through dedicated ports in the boiler rear wall. Proper and safe handling of these waste gas streams are an important design consideration.

\section{DeRidder:}

MdN OVERVIEW MdN with NCGs system design information and guidance for DeRidder's No. 2 Power Boiler is shown. The boiler retrofit consists of MdN reburn fuel injection and an MdN FGR system. The existing OFA arrangement, while not at an optimum placement is adequate to control emissions of $\mathrm{NO}_{\mathrm{x}}$. The FGR take-off will likely be located after the ID Fan and before the wet venturi scrubber because of the excess vapor content problem if extracted after the wet scrubber. FGR distribution will go to: cinder re-injection service; MdN reburn fuel injection; OFA dilution service; bark pneumatic distributor service and NCG and SOG injection service. 
MdN reburn fuel injection is planned for the boiler front and rear walls just above the grate. Injection of natural gas uses a nozzle mix approach through a gas quill installed in the FGR nozzle. A total of 32 FGR/reburn fuel injection nozzles, 16 on each wall, disperse the mixture into the grate combustion zone creating additional turbulence and a oxygen deficient environment. FGR replaces air for cinder injection and is used to convey SOG and NCG streams into the grate combustion zone as well. MdN reburn fuel, natural gas, supply equipment is sized for about 90,000 scfh, which is approximately 25\% of the boiler estimated thermal heat input at 100\% MCR. SOG and NCG injection will be coordinated with existing mill instrumentation and diverted to the No. 2 Boiler at proper boiler conditions and safely monitored. An SOG/NCG injection trip will automatically divert flow of these gases to an operation to achieve proper disposal. SOG injection consists of two dedicated nozzles at the rear wall; FGR combines with SOG in the nozzle and is dispersed into the grate primary combustion zone. The same handling method is used for NCG injection. When SOG/NCG injection is activated, steam production is expected to increase and in response the control configuration will regulate the natural gas flow to maintain a steady boiler heat input.

Another design element incorporates a small MdN Air Fan. This feature increases system operational flexibility; it provides a mechanism to fine tune the grate stoichiometric ration and reduce oxygen content in the OFA or upper furnace for the intent of achieving optimum system performance. This fan was required to overcome the FGR system supply pressure.

System target parameters for the DeRidder MdN with NCGs retrofit are tabulated at the bottom of the drawing; data includes system design pressures and flowrates.

MdN SYSTEM ELEMENTS This drawing shows a simplified single line process diagram of the MdN retrofit with NCG system. The objective is to show how components of the system are related and function.

\subsubsection{DeRidder MdN OFA System}

A review of baseline test data and CFD modeling simulations determined the MdN retrofit for Power Boiler No.2 did not require a MdN OFA system mod. An MdN OFA system would allow a greater degree of air staging and consequently provide a performance improvement over the current OFA system, however, based on the boiler having an already moderate level for $\mathrm{NO}_{\mathrm{x}}$ emissions, the additional cost to install a MdN OFA system could not be justified at this time.

\subsubsection{DeRidder MdN Reburn Fuel Injection System}

The MdN reburn injection system uses natural gas and will have two zones of injection; one each along the front and rear wall slightly above the grates. The front and rear injection zones will each have sixteen (16) 2" schedule 40 pipe nozzles. The rear wall injection zone will utilize eight (8) existing ports from a past cinder re-injection system that are no longer in service. The remaining eight (8) ports will require water wall modifications on the rear wall to accommodate system injection requirements. These new boiler penetrations are to be placed along the same elevation plane as the cinder re-injection ports. Placement of MdN nozzles at the furnace front 
are located in a refractory section of the furnace front wall at the same elevation as the rear wall ports; no front water wall modifications are required.

The MdN with NCGs design for DeRidder enhance the system benefits by incorporation of a flexible alternative method for the disposal of the mill's NCG and SOG waste streams. Retrofit design plans for the NCG and SOG gas streams to be combined with FGR and injected through dedicated ports located a few feet above the grate at the rear wall. Ports from a previous OFA system, which are currently out of service, are to be modified to accept injection of the NCG and SOG streams. Four ports are provide to handle the NCG flow and two ports allocated for SOG injection. During time intervals with NCG and SOG injection the amount of natural gas injected will be reduced and controlled to reflect the heat input of the NCG and SOG streams.

A modular, preassembled natural gas control skid is planned that would contain the majority of components and hardware for the safe management and control of the MdN natural gas injection. This control skid is pre-tested for functionality and structural integrity before being shipped and installed at the boiler. Various sections of the natural gas control skid are illustrated in piping and instrumentation drawings PID-2, PID-3, and PID-4; drawing descriptions are given below.

The equipment for control and management of the mill's waste gases already exist at the boiler. Some amount of piping is required to make the final interconnections to the injection ports, however. Management and control interlocks for switching the SOG and NCG streams into the No. 2 Boiler exist and are to be integrated with the MdN with NCG system control during retrofit activities.

\section{DeRidder:}

PID-2 Management and control of the MdN system's main natural gas supply is detailed. Mill natural gas header pressure is 50 psig; branch piping connects to modular control skid where a set of pressure reducing regulators maintain a stable gas pressure between 10 to 15 psig. Electrically operated main safety shutoff valve and vent valve automatically manage the safe introduction of MdN natural gas. Two pressure reducing valves provide redundancy and safety for natural gas supply should a fault occur with one of the regulators such as a ruptured diaphragm.

PID-3 \& 4 Natural gas from the main isolation valve is directed to two independent gas control trains. Each gas control train operates independently and regulates injection of reburn fuel to the furnace front and rear ports. Hardware provides for the safe introduction and flow metering and control of natural gas. Natural gas flowrate is measured with a vortex flow element; pressure and temperature sensors monitor flow conditions and also compensate the flow signal to provide a mass flow measurement. The set point of natural gas is adjusted through a flow control station until the desired flowrate is achieved. Upon a system shutdown, the safe shutdown and isolation of natural gas from leaking into the boiler is achieved through a double block and bleed solenoid valve arrangement (an NFPA requirement). A small purge air fan and isolation valve provides a flow of purge air to clear the natural gas piping and prevent pluggage in the gas injection quills when gas is out of service. 
INJ DETAIL A construction scheme for the overall arrangement of the MdN $\mathrm{FGR} /$ natural gas injection ports is given. In this design, gas is directed through a dedicated central tube and combined with FGR using a nozzle mix method. Nozzle mixing releases the reburn fuel at the FGR/gas injection port outlet, just before entering the furnace.

\subsubsection{DeRidder MdN FGR System}

Flue Gas Recirculation (FGR) is a critical system in the overall operation and performance of $\mathrm{MdN}$ technology. It is essential in natural gas injection and provides a carrier medium for NCG and SOG injection. When the various injection gases are not in-service, FGR will continue to flow providing combustion NOx control benefits. A portion of the total FGR will replace the sweep air for the bark distributors as well as the air required for the cinder re-injection section. FGR will also be added to the existing OFA supply to reduce the amount of oxygen available to form NOx. For the preliminary design, the MdN FGR fan takeoff point is after the ID fan and before the wet scrubber. It was assumed the flue gas stream does not contain excessive dust or particulate at this point.

The FGR system duct work was sized and design based on the pressure drop loss through 600 feet of straight pipe with an elevation change of 25 feet from the FGR fan outlet. The actual duct work should be much shorter in length than 600 feet, but the additional length accounts for pressure loss encountered with duct transition sections, elbows, and takeoffs in the installed duct work. Drawing PID-1 shows the process equipment for the FGR system. The drawing details the measurement and control of the various uses of the FGR.

The preliminary design specifies circular duct made from 10 gauge structural steel with 2" heavy density fiberglass insulation. The insulation should conform to ASTM C547 and have an aluminum jacket covering the insulation. The detailed FGR design will depend final routing of the duct work.

\section{DeRidder:}

PID-1 This drawing shows the process equipment and instrumentation for the FGR system. The MdN FGR system starts with a takeoff point located after the ID fan. Ductwork is routed to the FGR Fan inlet; the fan inlet duct contains a motorized multilouvered damper unit to provide system isolation and regulatory control of the FGR supply header pressure. After the fan, total FGR flow is measured and compensated to give mass flow with flowing pressure and temperature. In addition an in-situ oxygen sensor monitors the FGR oxygen content and triggers an alarm should the level exceed $10 \%$. The FGR is then distributed to supply the various components of the system. FGR flow to some components is automated to allow for adjustment. FGR flow to the OFA, NCG, and SOG injection system is measured and automatically adjusted with a motorized damper to achieve proper set points at different operating objectives. The FGR flow to the cinder re-injection and pneumatic distribution systems should remain constant throughout the boiler operating range and do not require automatic control. The final FGR distribution point is the natural gas injection system. The FGR flow is measured along with pressure and temperature. The FGR flow is controlled to maintain a specified header pressure. FGR for natural gas injection has the provision to mix with 
preheated air for adjustments to the reburn zone stoichiometric ratio and improve the MdN overall system performance.

\subsubsection{DeRidder MdN Controls}

The control philosophy for the MdN system is to minimize the amount of boiler operator interaction in the system operation. System control logic utilizes both discrete and regulatory methods to safely run the system and make changes in various set points for flowrates and pressures based on boiler steam load and adjust with any change to the boiler operating conditions.

The control logic for the DeRidder MdN system was designed to account for the heat input from the waste gas streams and allow for further reduction in natural gas consumption. The control logic for the injection of natural gas is designed to meet or exceed the requirements of the NFPA and boiler insurers.

For the purpose of the preliminary design, the unit DCS was assumed to have adequate spare capacity for additional hardware and tagname points associated with the MdN system.

\section{DeRidder:}

LOGIC-1 Discrete logic (interlocks) governs the safe management of the MdN main supply of natural gas. MdN logic is designed to insure that all the requirements for safely injecting natural gas are met. Logic elements monitor and confirm stable boiler operation; detect and prove flame at the grate and verify a properly functioning FGR system. Instrumentation also monitors the operation of installed hardware on the natural gas supply skid. Should an abnormal state occur, control automatically shuts off gas supply to the system.

LOGIC-2 This drawing contains the permissives and interlocks for the operation of the front and rear zone natural gas injection control train equipment. The permissive and interlocks are designed to monitor operation of the valves and the physical characteristics of the natural gas, such as pressure and flowrates. Each zone has a set of permissives and interlocks allowing for independent operation between the two injection zones.

LOGIC-3 \& 4 This drawing contains regulatory control logic for the MdN FGR system, which includes FGR fan discharge pressure; FGR dilution flow to OFA; FGR NCG injection flow; FGR SOG injection flow and MdN reburn fuel injection. Control diagrams show system instrumentation; controller configuration and loop input and output signals (4-20 madc). Controller set points are determined through a characterization block dependent on boiler load.

\section{LOGIC-5 \& 6}

Regulatory control logic diagrams for MdN reburn fuel injection (natural gas) to the furnace front and rear injection ports are given. The control logic includes a calculation for heat input from natural gas, SOG, and NCG injection. The logic is designed to maintain a desired input from the various gas streams and minimizes the quantity of natural gas used. The logic also insures that the maximum allowable heat input from the multiple gas streams is not exceeded. 


\subsubsection{MdN System Installation Cost Estimate}

The estimated cost to complete the final design, procure and install equipment, and test and tune a MdN system for Power Boiler No. 2 at the DeRidder mill is One Million Fifty Thousand Dollars (\$1,050,00.00). This estimate is on a plus/minus 30\% basis. The major item with regards to uncertainty in the estimate is the cost of local labor and the unknowns related with installation.

The above quoted cost does not include the initial baseline testing, CFD model, and preliminary MdN design. The estimated cost to perform these tasks is One Hundred Seventy Five Thousand Dollars $\mathbf{( \$ 1 7 5 , 0 0 0 )}$.

\subsubsection{DeRidder Detailed Retrofit Design}

The design details contained in this manual for the DeRidder MdN system are preliminary details and are not approved for construction. A more comprehensive evaluation of the site and review of the preliminary design are required to finalize the MdN system design

\subsubsection{DeRidder MdN System Drawings - Preliminary}

Table 7-7 DeRidder - MdN Design Drawing Index

\begin{tabular}{|l|l|}
\hline \multicolumn{1}{|c|}{ Drawing\# } & \multicolumn{1}{c|}{ Description } \\
\hline MdN Overview & MdN System Overview \\
\hline MdN System Elements & Single Line Process Drawing \\
\hline PID-1 & Flue Gas Recirculation Equipment P\&ID \\
\hline PID-2 & Methane Pressure Reducing Equipment P\&ID \\
\hline PID-3 & Front Zone Methane Injection Equipment P\&ID \\
\hline PID-4 & Rear Zone Methane Injection Equipment P\&ID \\
\hline LOGIC-1 & MdN System Interlocks \& Permissives Logic \\
\hline LOGIC-2 & Front \& Rear Zone Interlocks \& Permissives Logic \\
\hline LOGIC-3 & FGR System Control Logic \\
\hline LOGIC-4 & FGR System Control Logic \\
\hline LOGIC-5 & Front Zone Gas Flow Control Logic \\
\hline LOGIC-6 & Rear Zone Gas Flow Control Logic \\
\hline INJ DETAIL & Methane, NCG, \& SOG Injector Detail \\
\hline
\end{tabular}




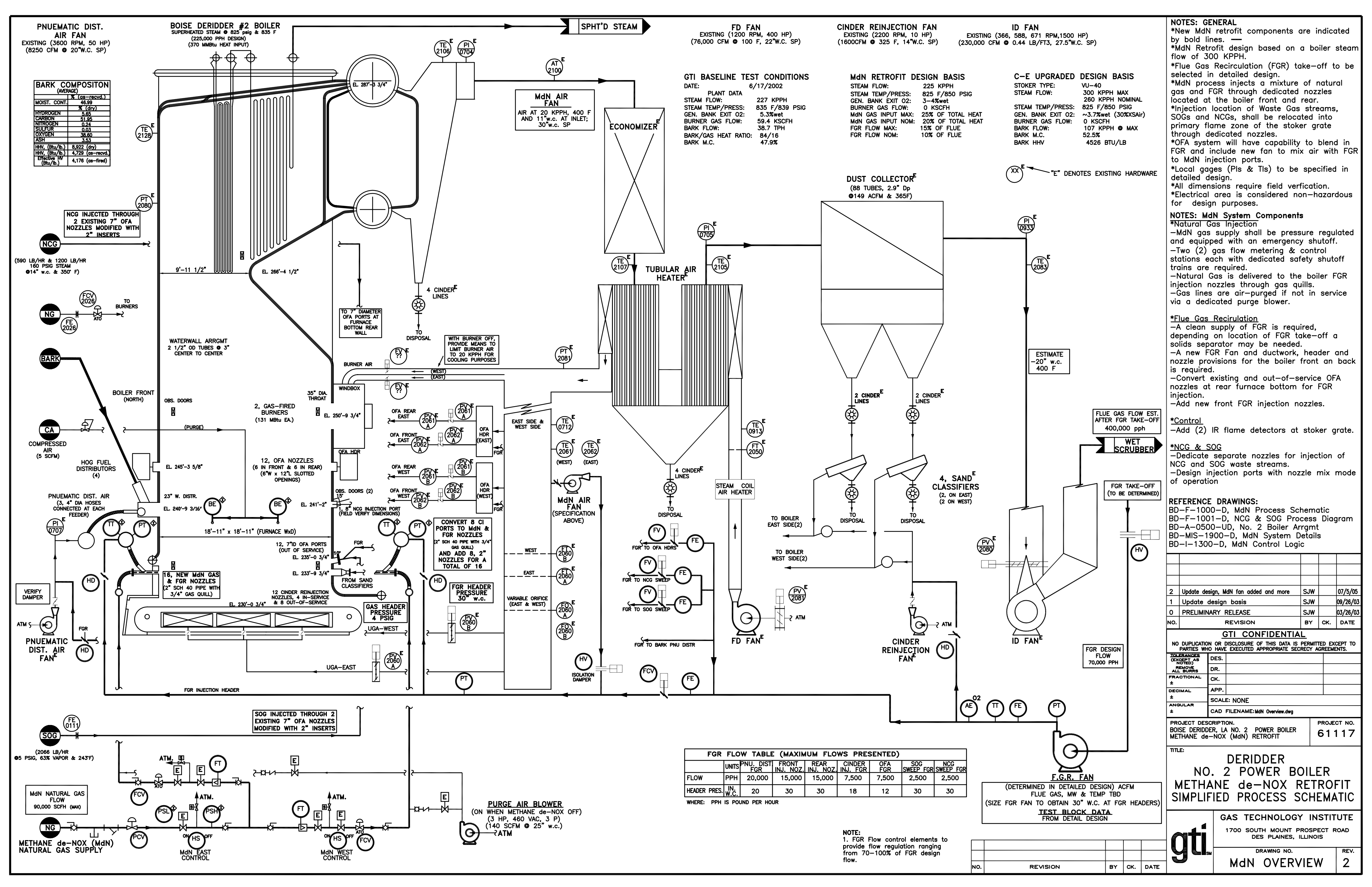




\section{No. 2 PQWER BDILER METHANE dENDX SYSTEM}

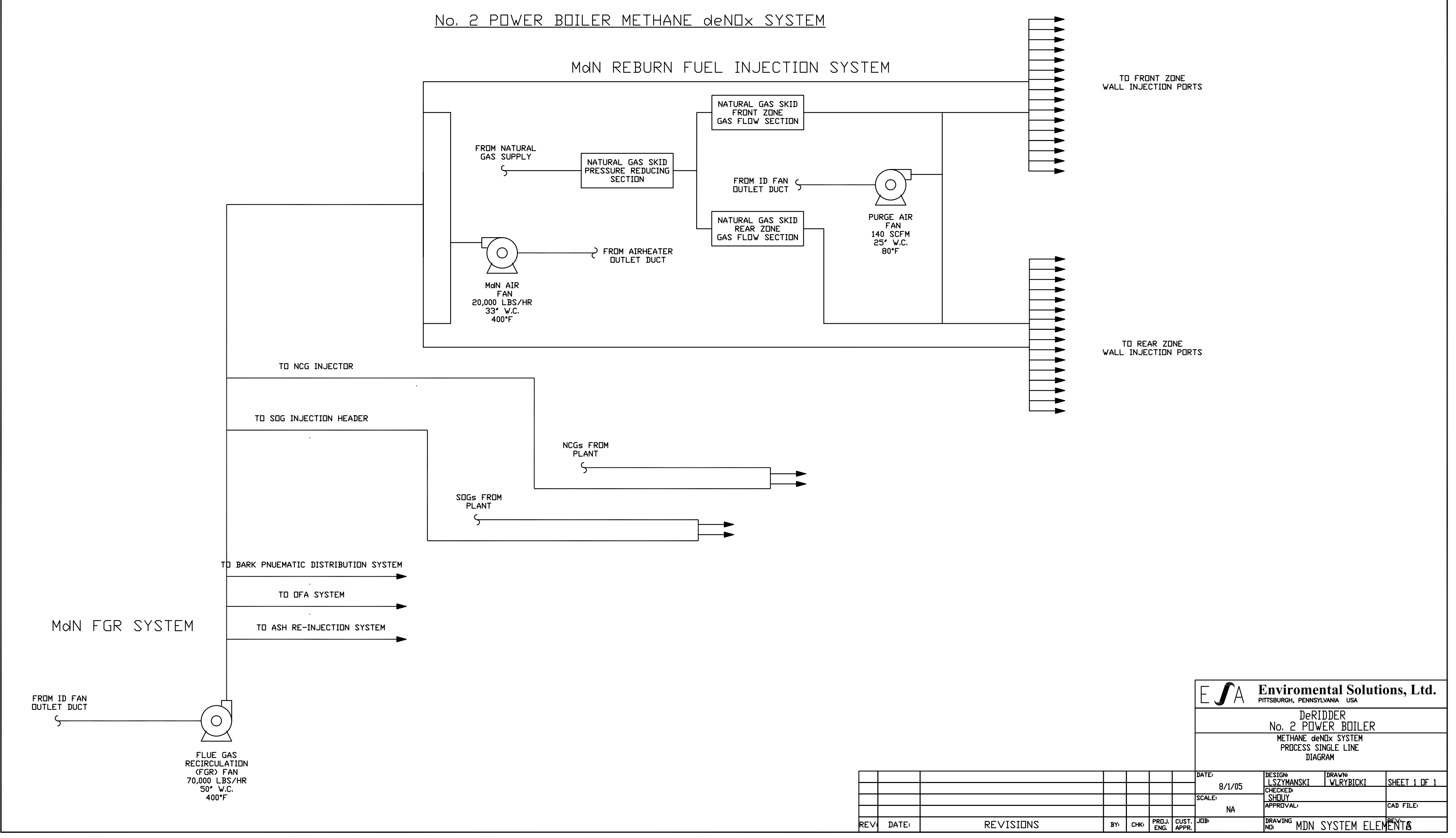



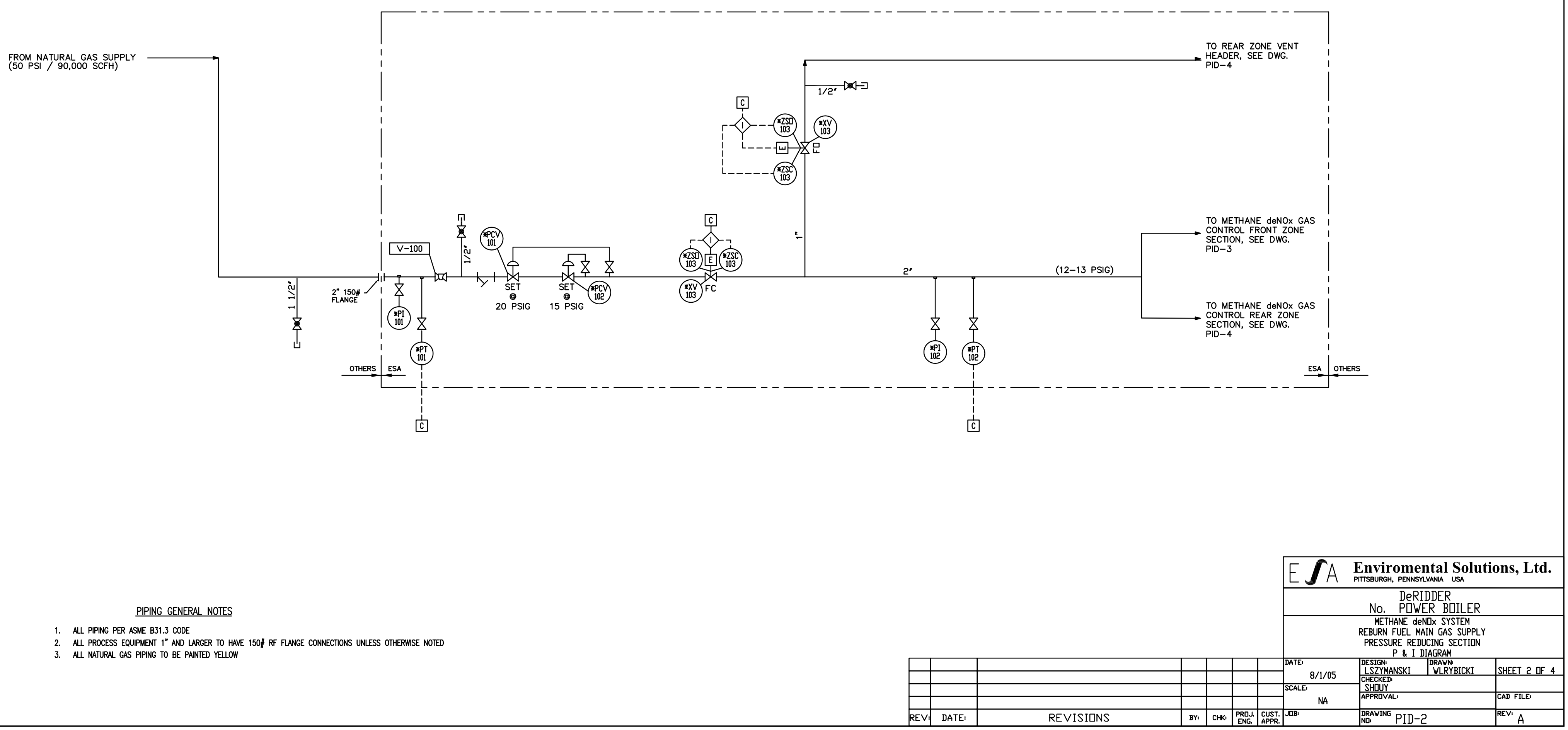


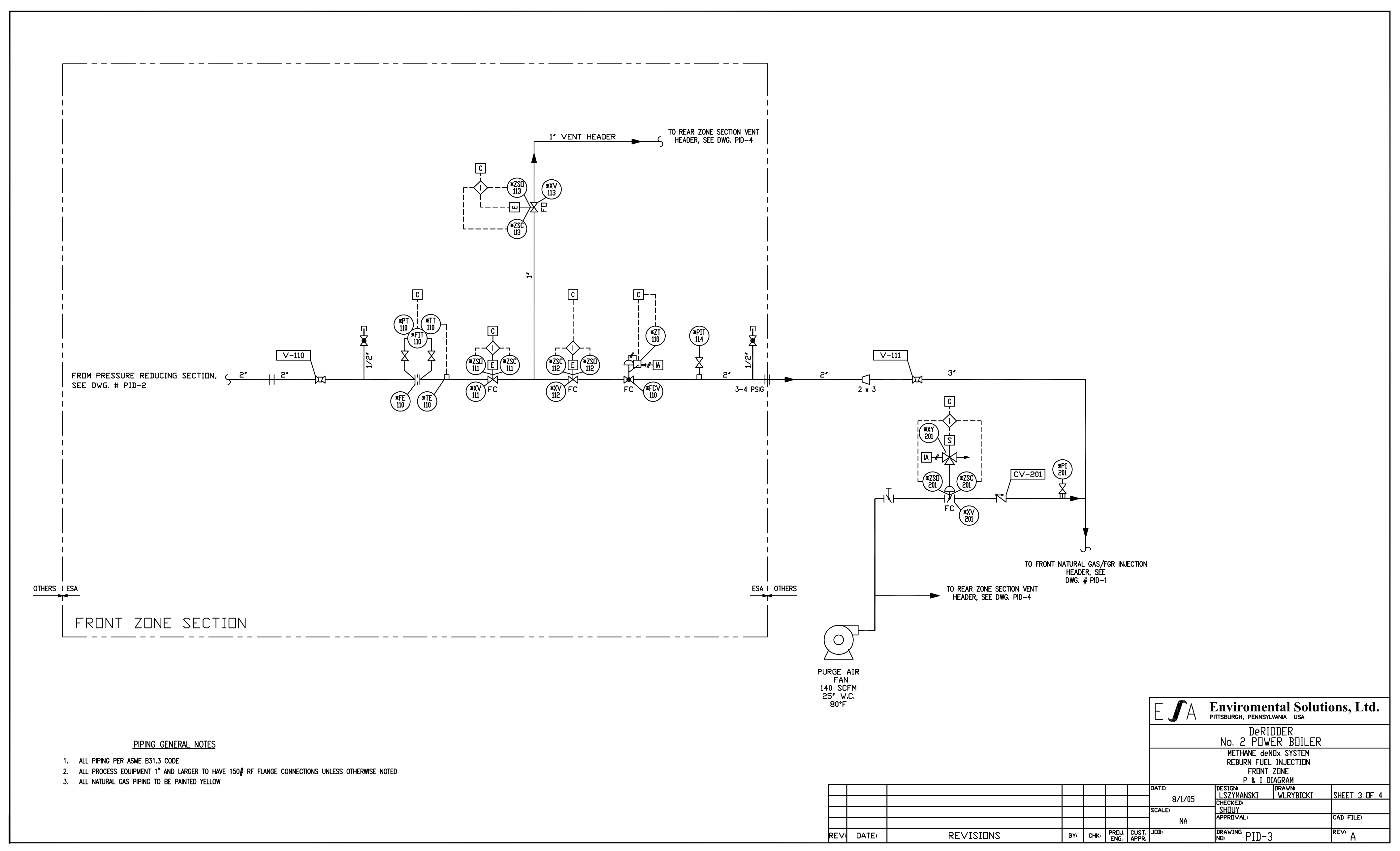




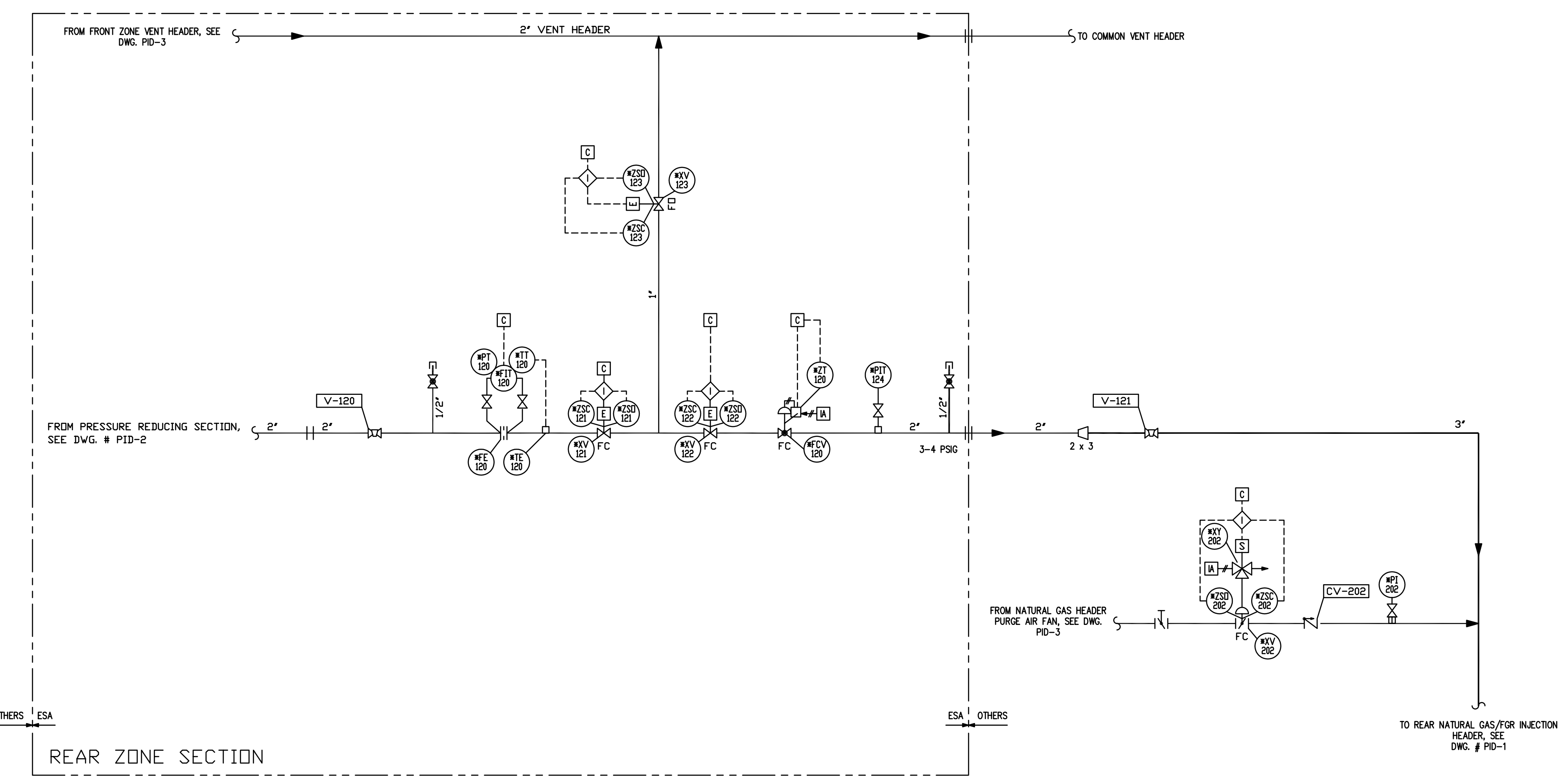

PIPING GENERAL NOTES

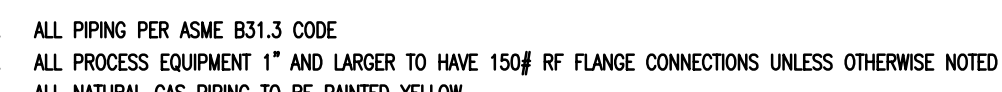

E $\int A$ Enviromental Solutions, Ltd.

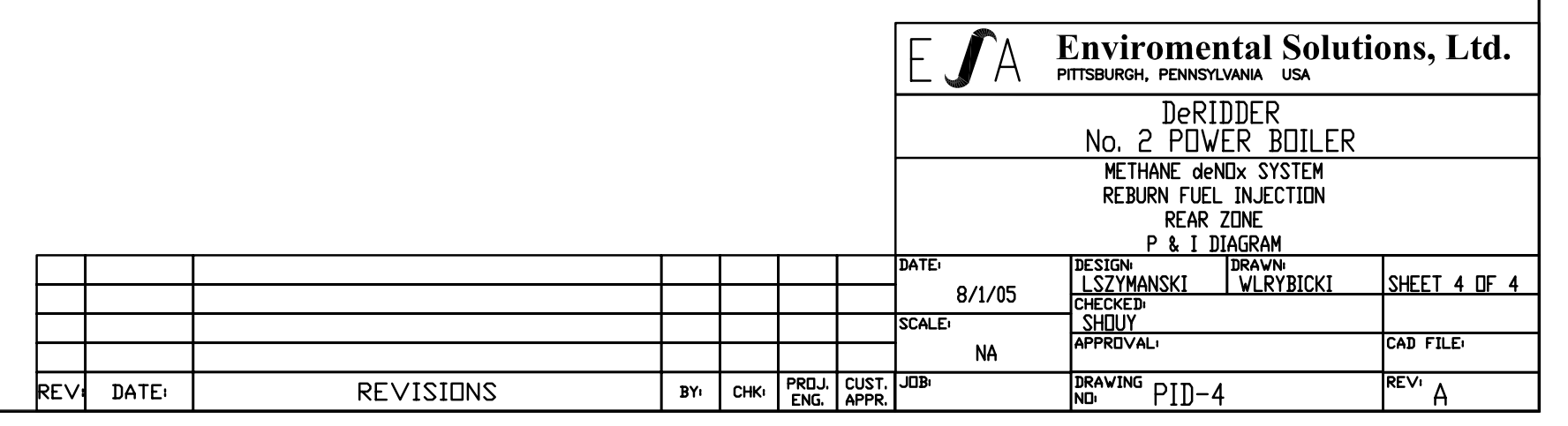




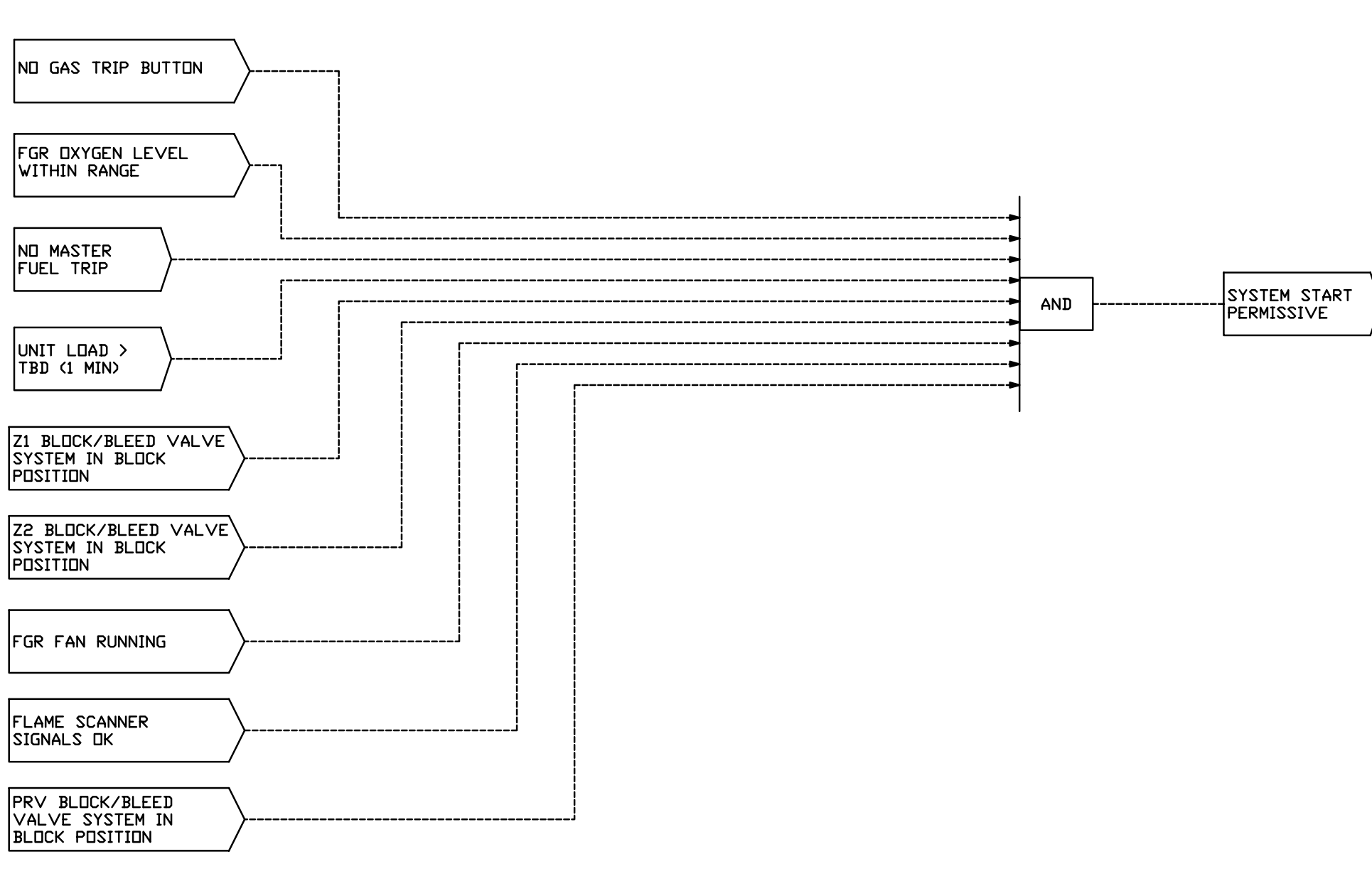
NDTE: PERMISSIVES AND INTERLDCKS FUR NCG AND SDG INJECTION ARE THE
RESPGNSIBLILTY GF THE MILL

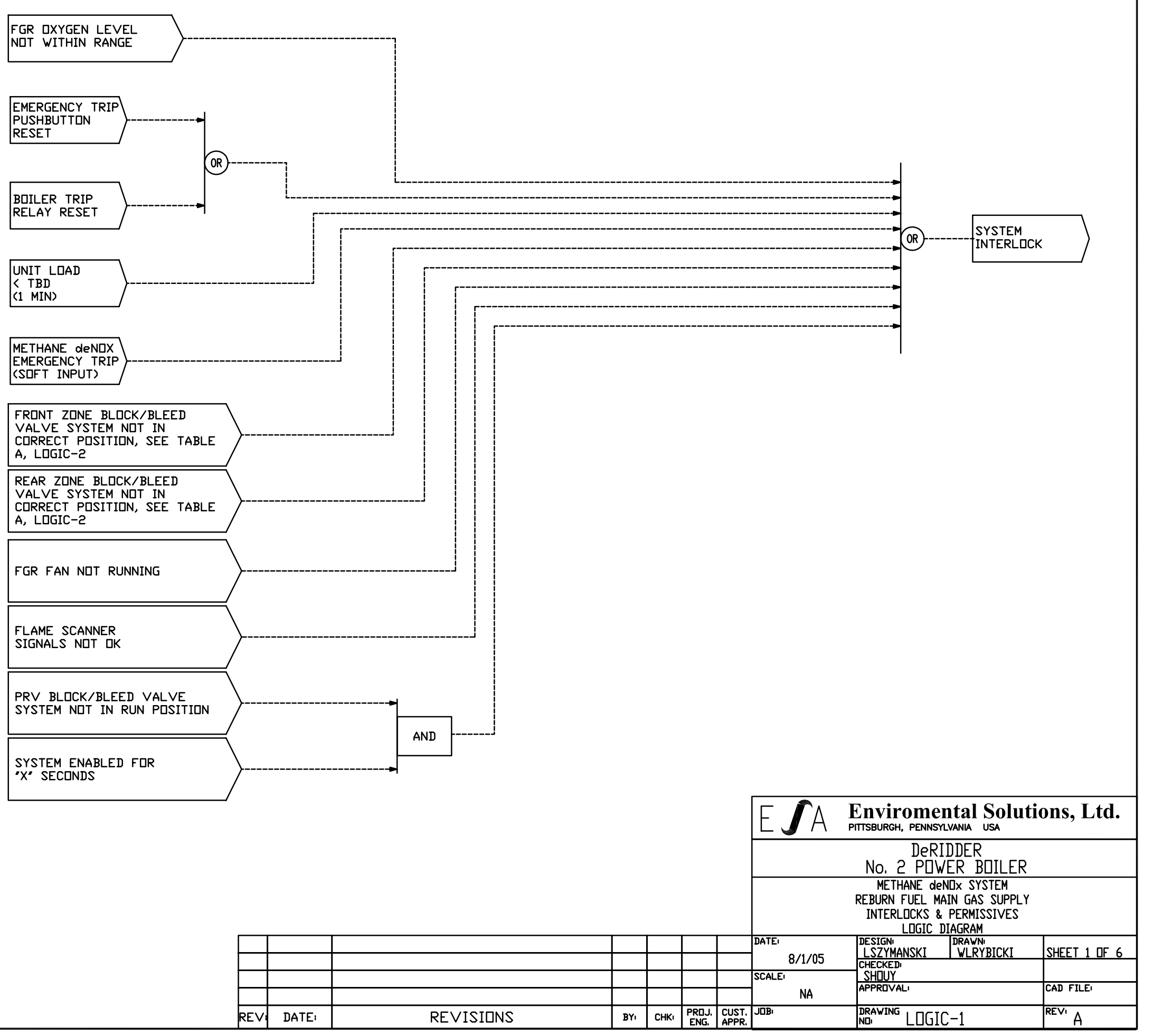



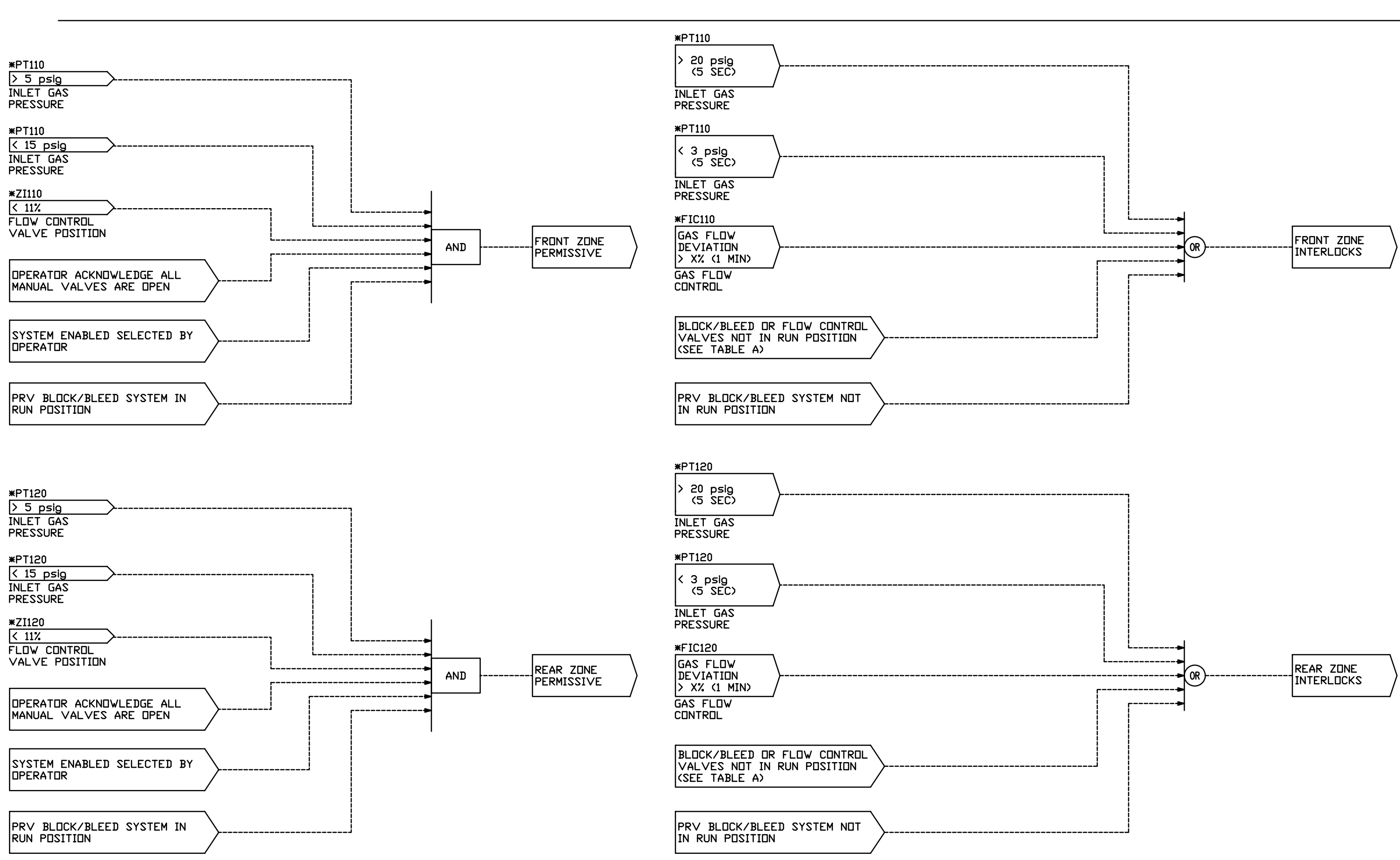

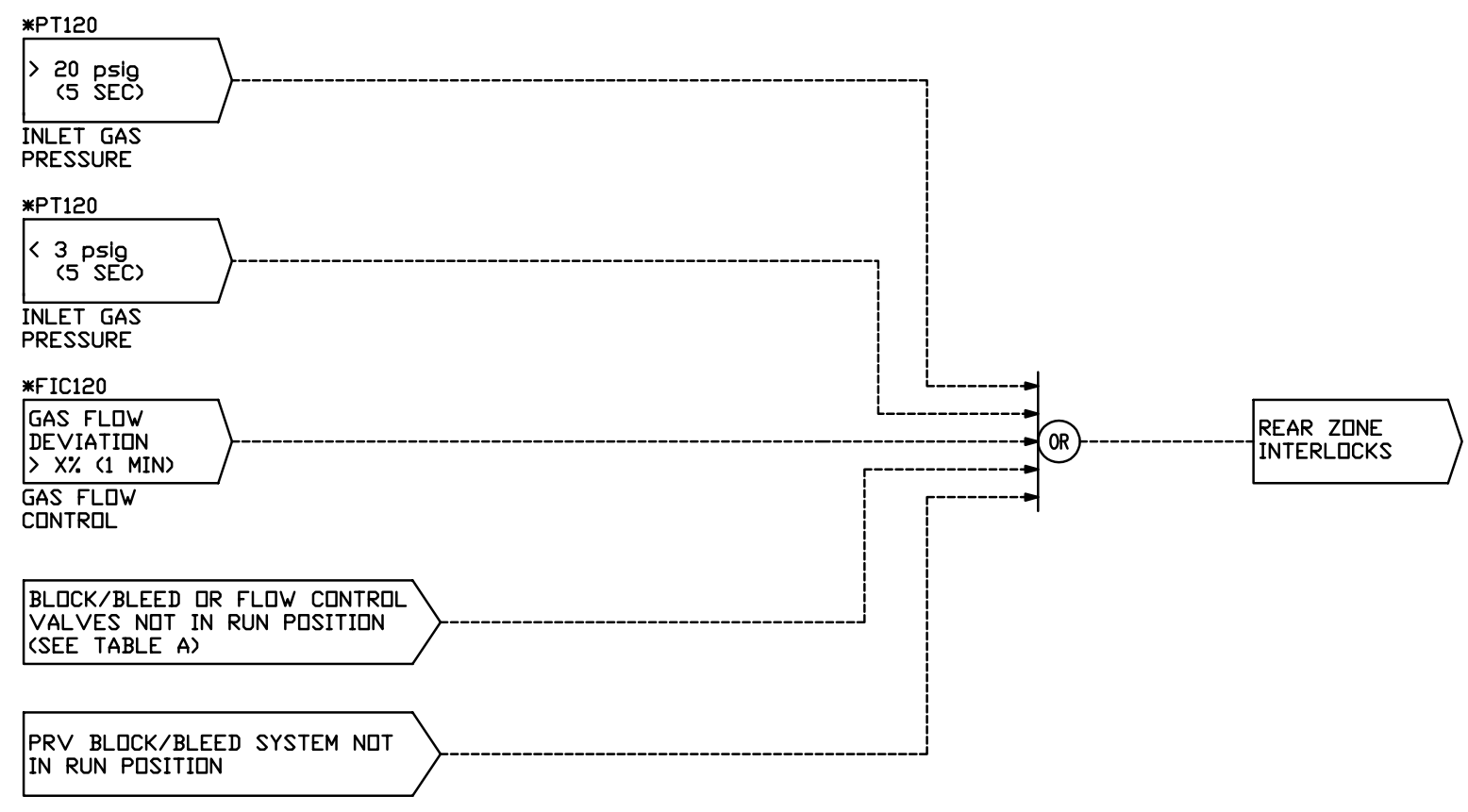

TABLE KEY:

CLOSED -VALVE CLDSED DPENED - VALVE OPENED CLDSE
DPEN
DALVE CLLSING
NDTE

SIVES AND INTERLDCKS FUR NCG AND SEG INJEC FUR ARE THE MILL

\begin{tabular}{|c|c|c|c|c|c|c|c|}
\hline \multicolumn{8}{|c|}{ TABLE A } \\
\hline EQUIPMENT ITEM/PPERATING STATE & TAGNAMES & ZUNE STAPPED & ZONE STARTING & ZONE RUNNINC & ZQNE STIPPING & $\begin{array}{l}\text { ZONE VENTING } \\
\end{array}$ & ZONE TRIP \\
\hline ZONE BLOCK VALVES & $\mathrm{xV} 111, \mathrm{xV} 112, \mathrm{xV} 121, \mathrm{xV} 122$ & CLISED & DPEN & QPENED & CLOSE & CLOSED & \begin{tabular}{|l|l|} 
CLOSE \\
\end{tabular} \\
\hline ZONE BLEED VALVE & XV113, XV123 & OPENED & CLOSE & CLOSED & DPEN & OPENED & OPEN \\
\hline FLOW CDNTRIL VALVE & FCV110, FCV120 & MIN & CONTROL & $\begin{array}{l}\text { CONTROL } \\
\end{array}$ & RAMP TO MIN & MIN & MIN \\
\hline
\end{tabular}

FRDNT \& REAR ZUNES

\begin{tabular}{|c|c|c|c|c|c|c|c|c|c|}
\hline & \multicolumn{3}{|c|}{ 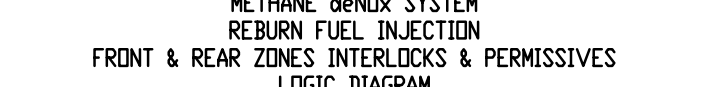 } \\
\hline & & & & & & & $8 / 105$ & 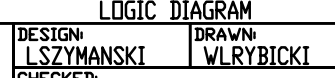 & SHEET 2 QF 6 \\
\hline & & & & & & & 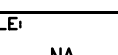 & 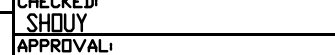 & CAD FILE! \\
\hline REV: & DATE: & REVISIONS & Brit & CHK: & 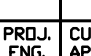 & 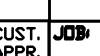 & & 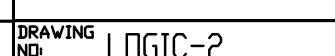 & $\mathrm{REV}_{\mathrm{REV}} A$ \\
\hline
\end{tabular}




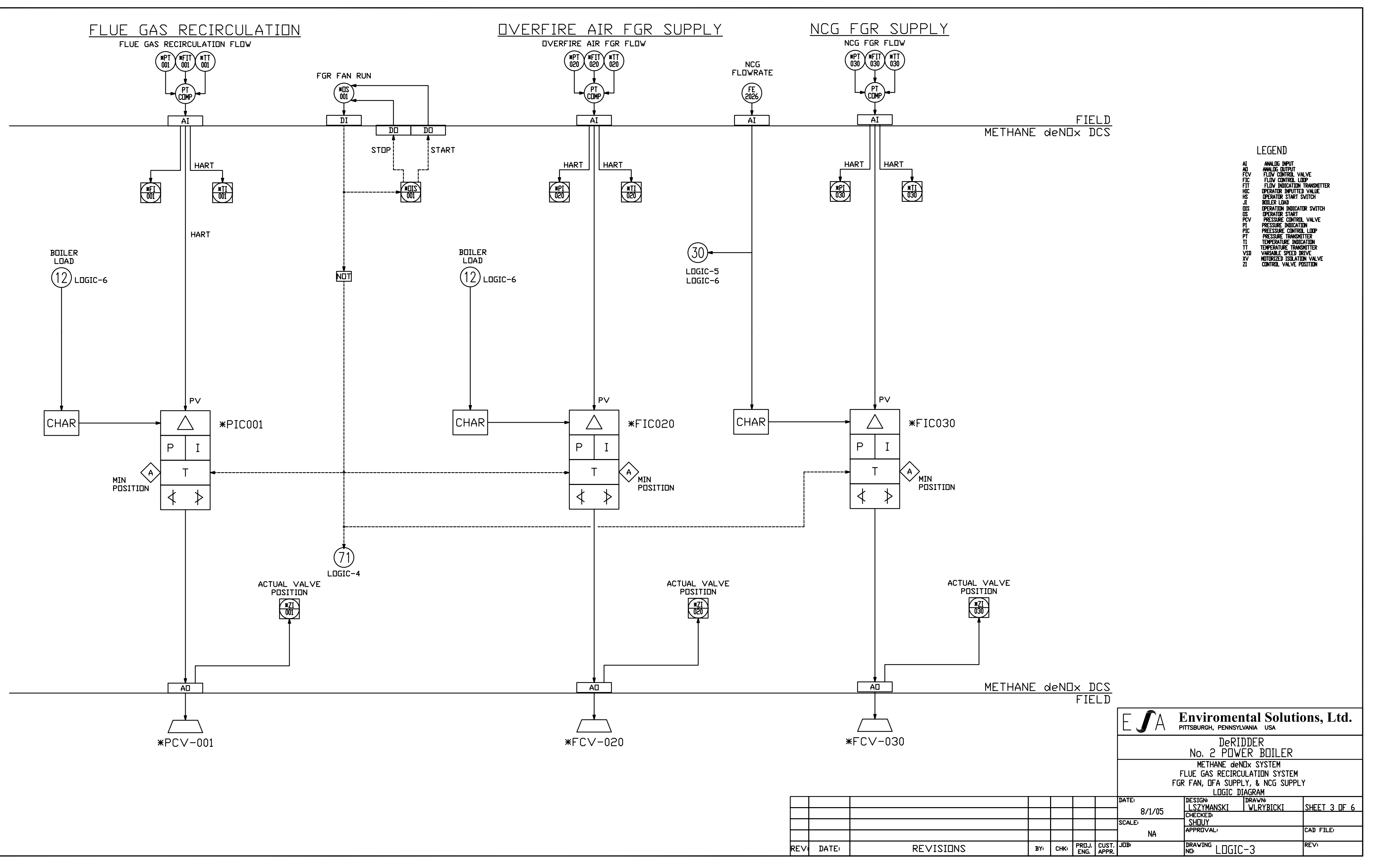


$\frac{\text { FRDNT \& REAR INJECTIDN ZDNE FGR SUPPLY }}{\text { FRDNT \& REAR INJECTIIN HEADER MaN FGR FLOW }}$

$\frac{\text { SEG FGR SUPPLY }}{\text { SOG FGR FLOW }}$

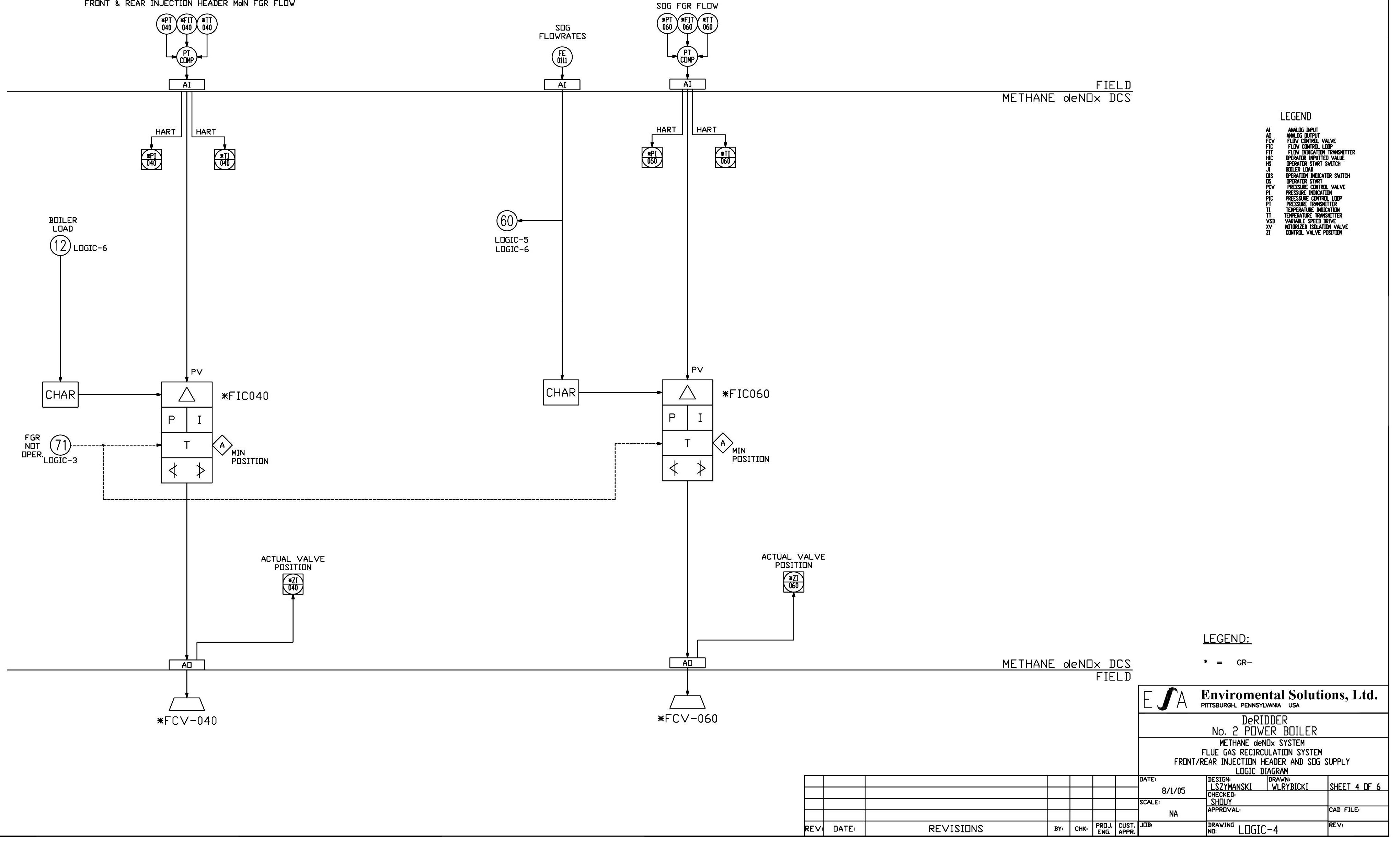




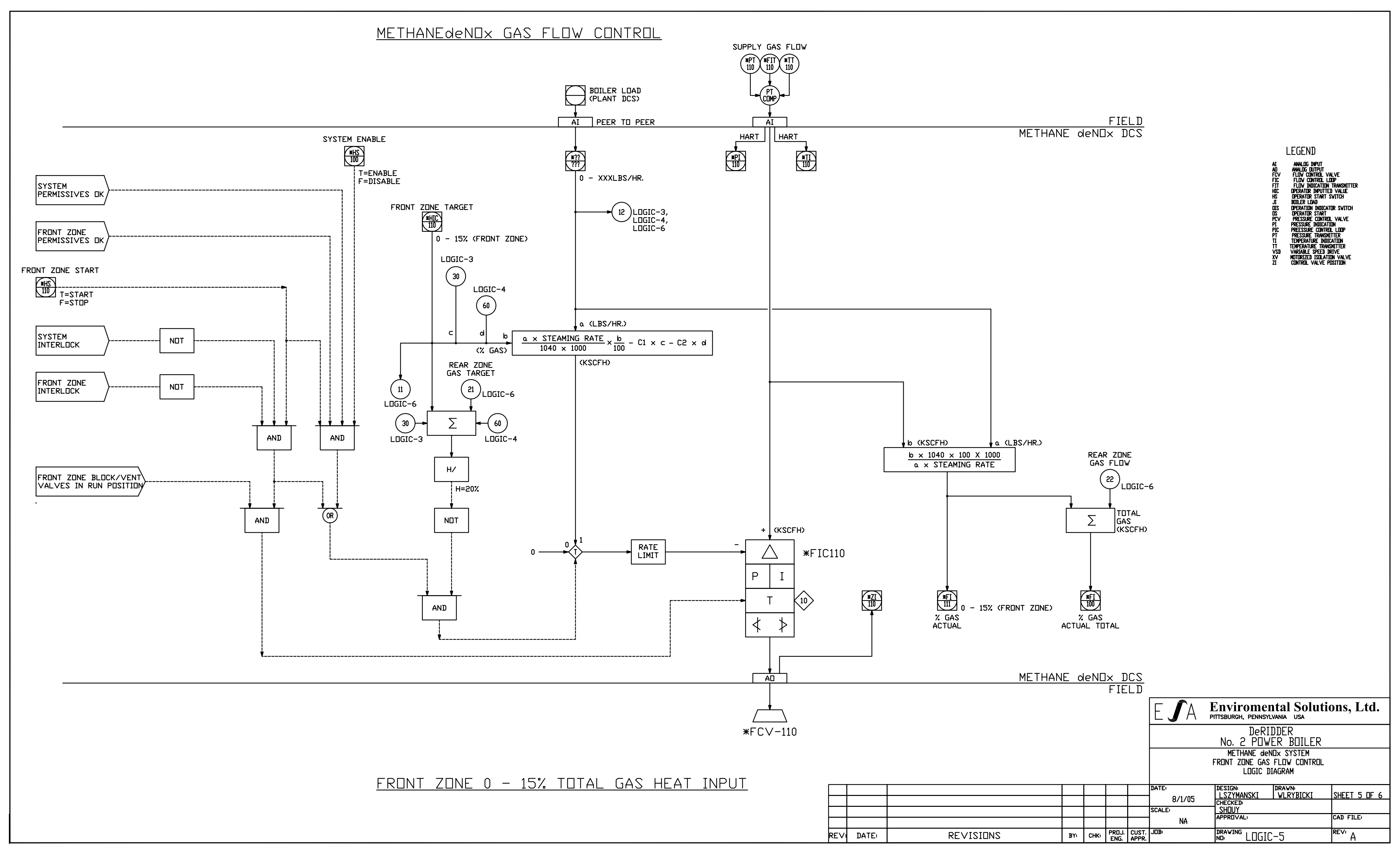




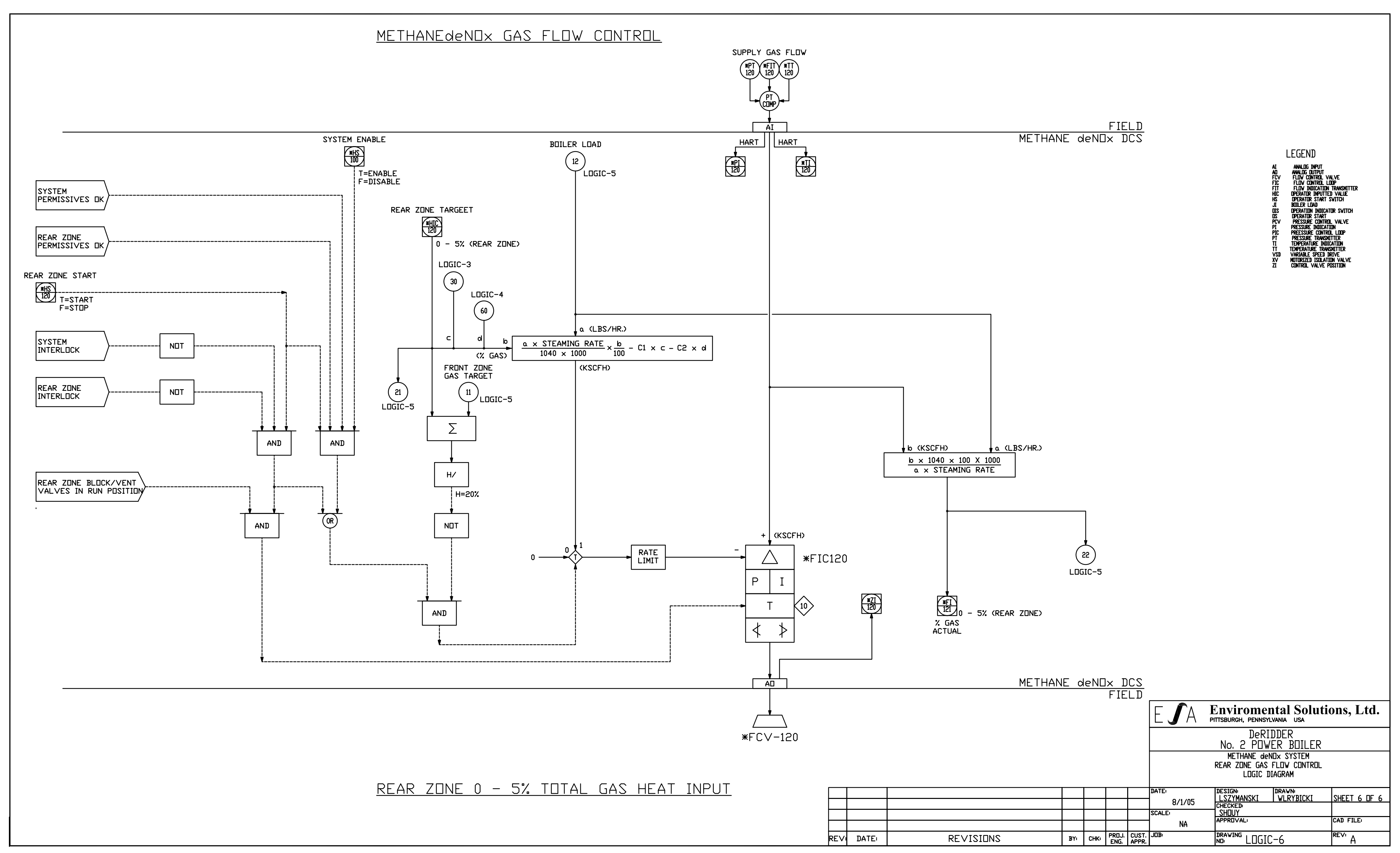




\section{IYPICAL NOZZLE DETAll}

1. NOZZLE DESIGN USED FOR NATURAL GAS, NCG, AND SOG INJECTION WITH FGR

2. ACTUAL DUCT HEADER DESIGN AND DIMENSIONS TO BE DETERMINED

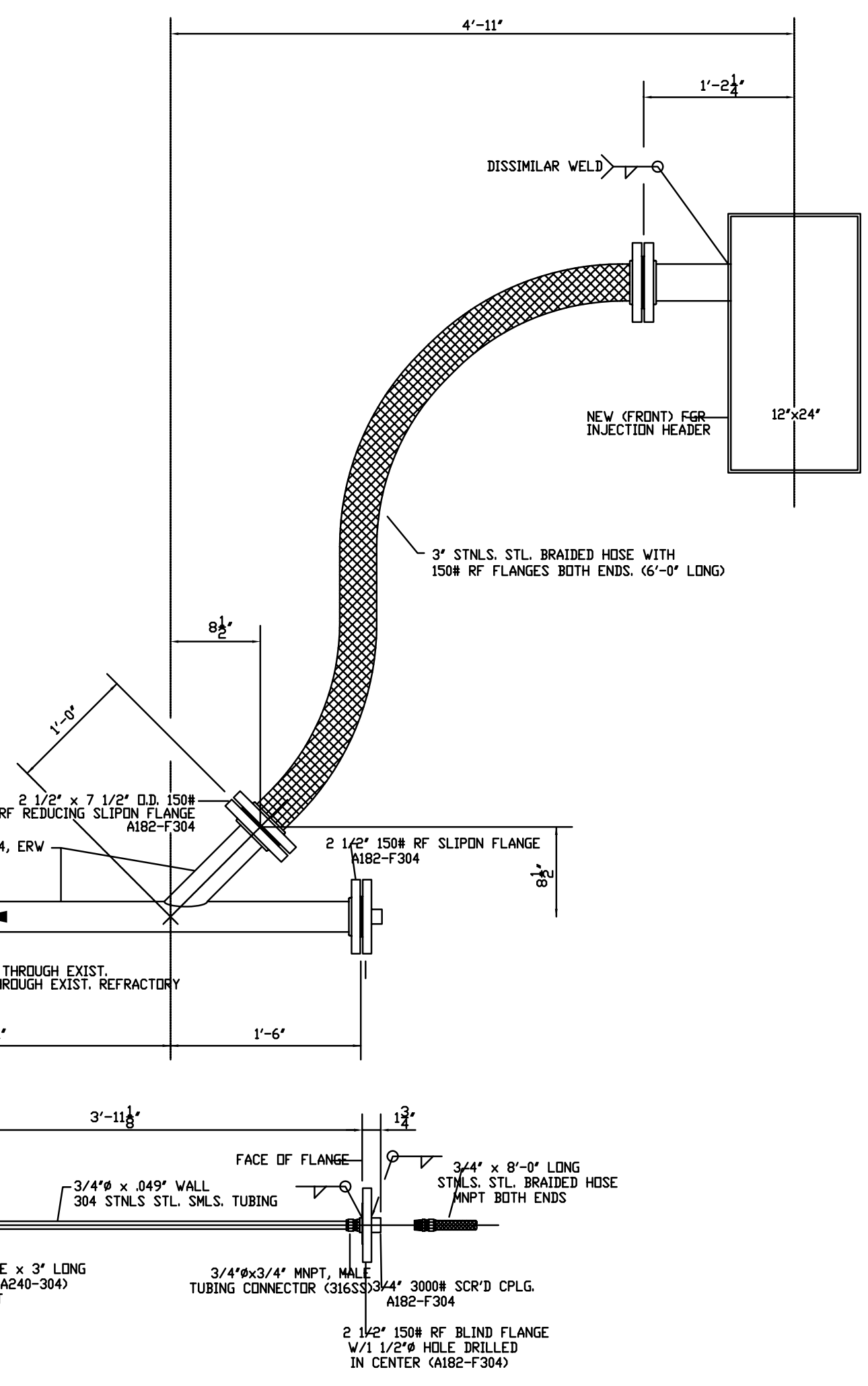

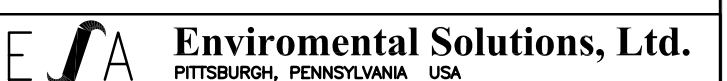 DeRIDDER

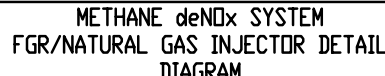

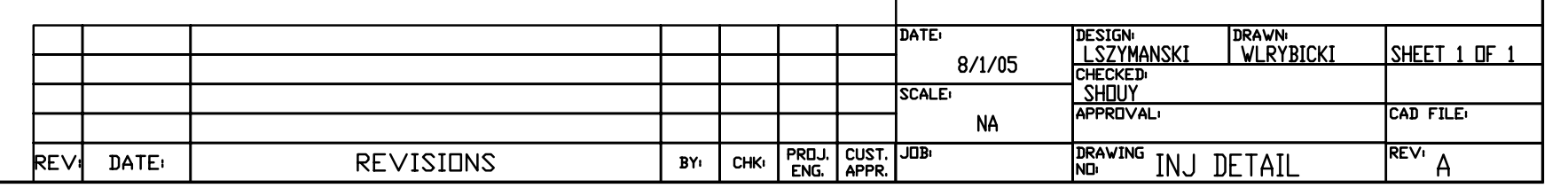




\subsubsection{DeRidder MdN System Equipment Specifications}

Table 7-8 Boise DeRidder - MdN Design Specification Index

\begin{tabular}{|c|c|}
\hline Specification \# & Specification Description \\
\hline \multicolumn{2}{|l|}{ Rotating Equipment } \\
\hline \multirow{2}{*}{$\begin{array}{r}\text { FGR-FAN } \\
\text { MdN AIR FAN }\end{array}$} & FGR Supply Fan \\
\hline & Air Supply Fan for Methane Injection \\
\hline \multicolumn{2}{|l|}{ Instrumentation: Flow Transmitters } \\
\hline \multirow{2}{*}{$\begin{aligned} \text { FGR-FIT } \\
\text { CH4-FIT }\end{aligned}$} & Mass Flow Transmitters for FGR System \\
\hline & Flow Transmitters for Methane Supply Zones \\
\hline \multicolumn{2}{|l|}{ Instrumentation: Pressure } \\
\hline \multirow{4}{*}{$\begin{array}{r}\text { FGR-PRESS } \\
\text { CH4-PRESS-XMIT } \\
\text { FGR-P-GAUGE } \\
\text { CH4-PRESS }\end{array}$} & Pressure Transmitters for FGR System \\
\hline & Pressure Transmitters for Methane Supply System \\
\hline & Pressure Gauges for FGR System \\
\hline & Pressure Gauges for Methane Supply System \\
\hline \multicolumn{2}{|l|}{ Instrumentation: Temperature } \\
\hline \multirow{4}{*}{$\begin{array}{r}\text { FIT-RTD } \\
\text { CH4-RTD } \\
\text { FGR-TEMP } \\
\text { FGR-RTD }\end{array}$} & RTD/Thermowell for FGR Flow Transmitters \\
\hline & RTD/Thermowell for Methane Flow Transmitters \\
\hline & Temperature Transmitters for FGR System \\
\hline & RTD/Thermowell for Temperature Transmitters \\
\hline \multicolumn{2}{|l|}{ Instrumentation: Control Valve } \\
\hline \multirow{6}{*}{$\begin{array}{r}\text { PCV-001 } \\
\text { FCV-020 } \\
\text { FCV-030 } \\
\text { PCV-040 } \\
\text { FCV-060 } \\
\text { FCV-110 \& }-120\end{array}$} & FGR Fan Inlet Damper Actuator \\
\hline & FGR Flow Control Valve for OFA System \\
\hline & FGR Flow Control Valve for NCG Injection \\
\hline & Pressure Control Valve for Methane Injection \\
\hline & Flow Control Valve for SOG Injection \\
\hline & Flow Control Valves for Methane Supply Zones \\
\hline \multicolumn{2}{|l|}{ Instrumentation: Dampers } \\
\hline DAMPERS & Butterfly Dampers for FGR System \\
\hline \multicolumn{2}{|l|}{ Instrumentation: Isolation Valve } \\
\hline \multirow{5}{*}{$\begin{array}{r}\text { XV-111 \& }-112 \\
\text { XV-121 \& }-122 \\
\text { XV-201 \& }-202 \\
\text { XV-101 } \\
\text { XV-090 }\end{array}$} & Double Block \& Bleed Isolation Valve (Front Zone) \\
\hline & Double Block \& Bleed Isolation Valve (Rear Zone) \\
\hline & Purge Air Isolation Valve \\
\hline & Methane Supply Isolation Valve \\
\hline & Isolation Damper for MdN Air Fan Supply \\
\hline \multicolumn{2}{|l|}{ Instrumentation: Vent Valve } \\
\hline \multirow{2}{*}{$\begin{array}{r}\text { XV-113 \& }-123 \\
\text { XV-103 }\end{array}$} & Double Block \& Bleed Vent Valve for Zones \\
\hline & Methane Supply Vent Valve \\
\hline \multicolumn{2}{|l|}{ Instrumentation: Hand Valve } \\
\hline PLUG-VLV & Manual Plug Valve for Methane Isolation \\
\hline \multicolumn{2}{|l|}{ Instrumentation: Regulator } \\
\hline PRESS-REG & Pressure Regulators for Methane Supply \\
\hline \multirow[t]{3}{*}{ Instrumentation: Misc. } & \\
\hline & Oxygen Analyzer for FGR System \\
\hline & Flame Scanner for MdN System \\
\hline
\end{tabular}




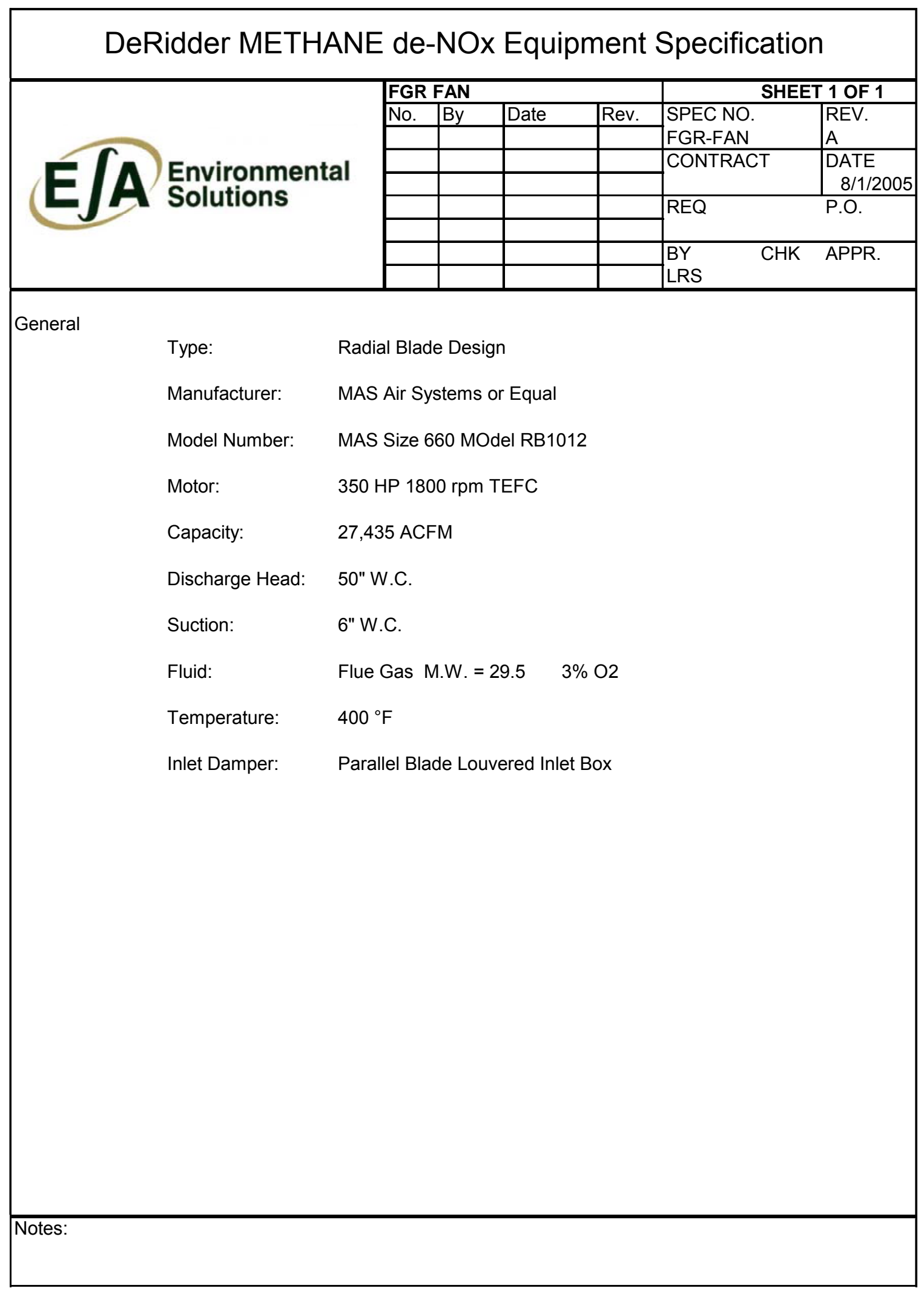




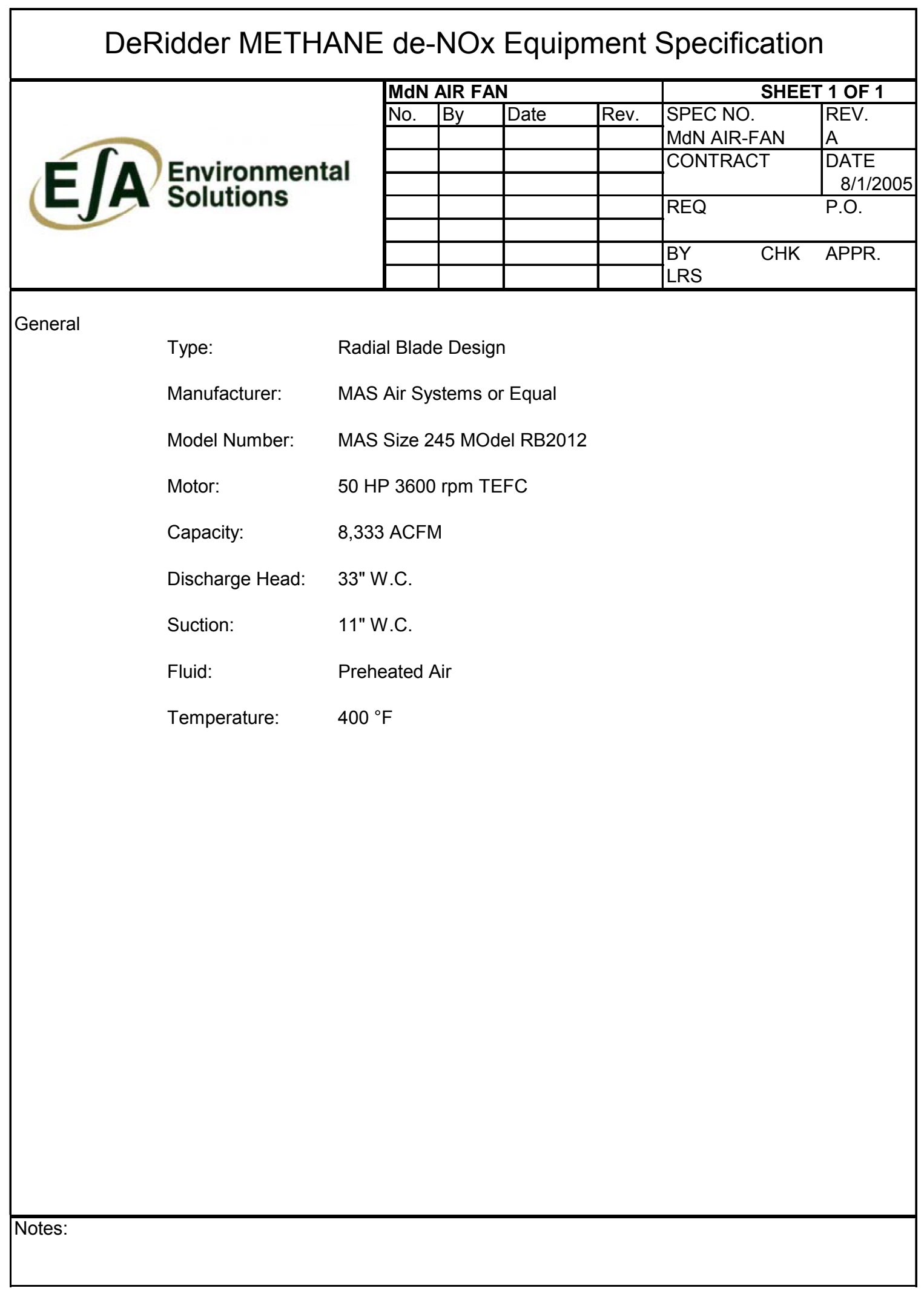




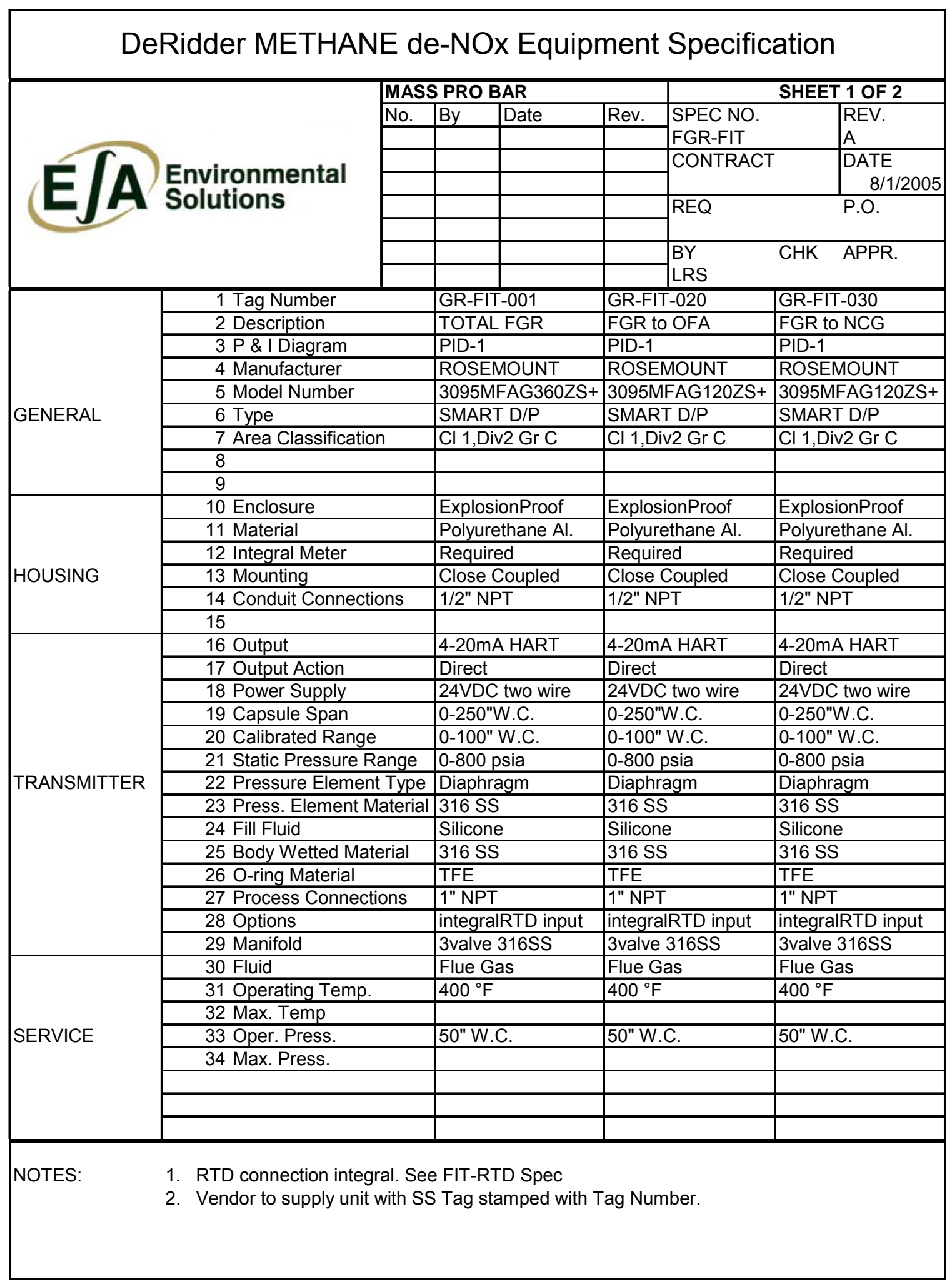




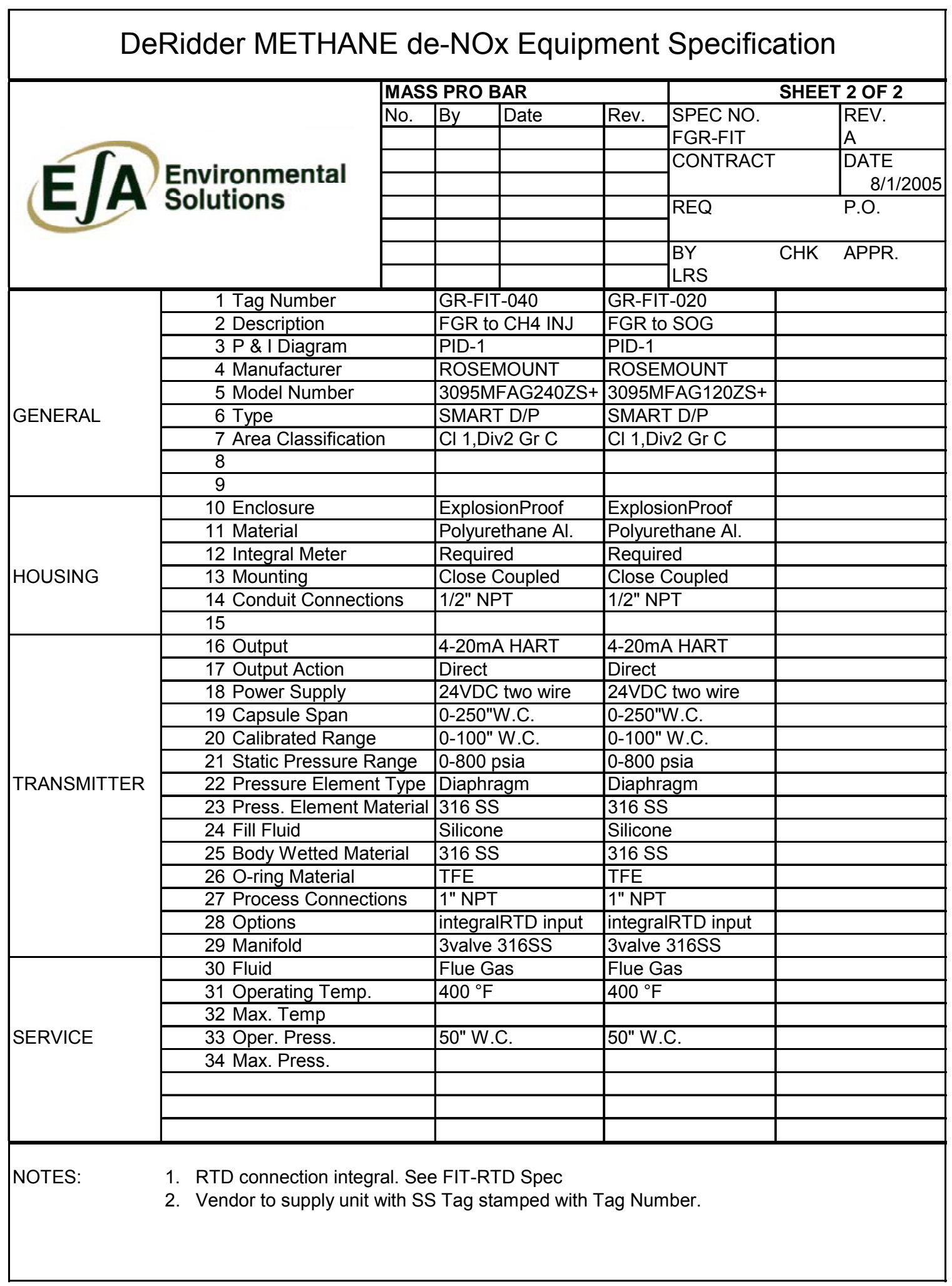




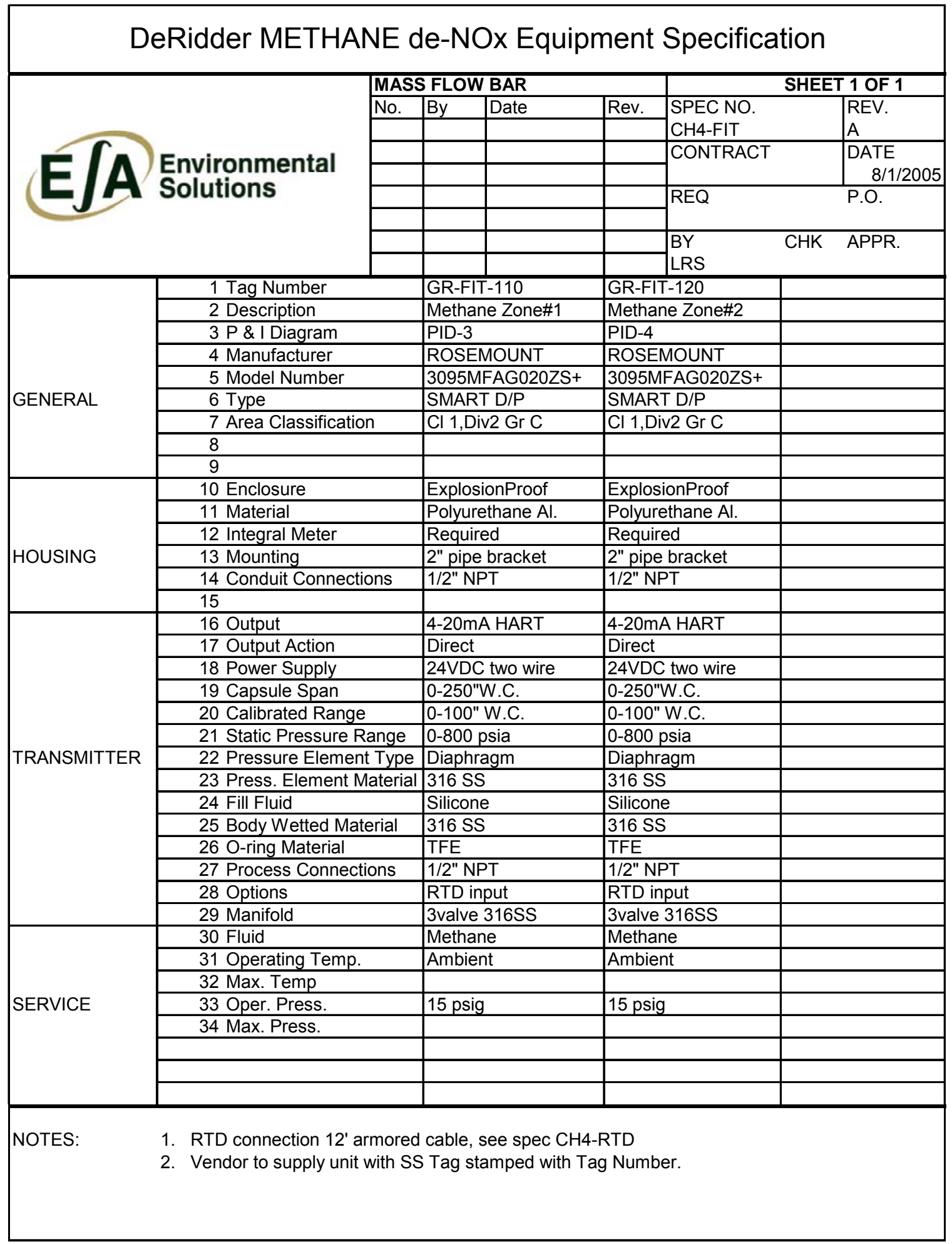




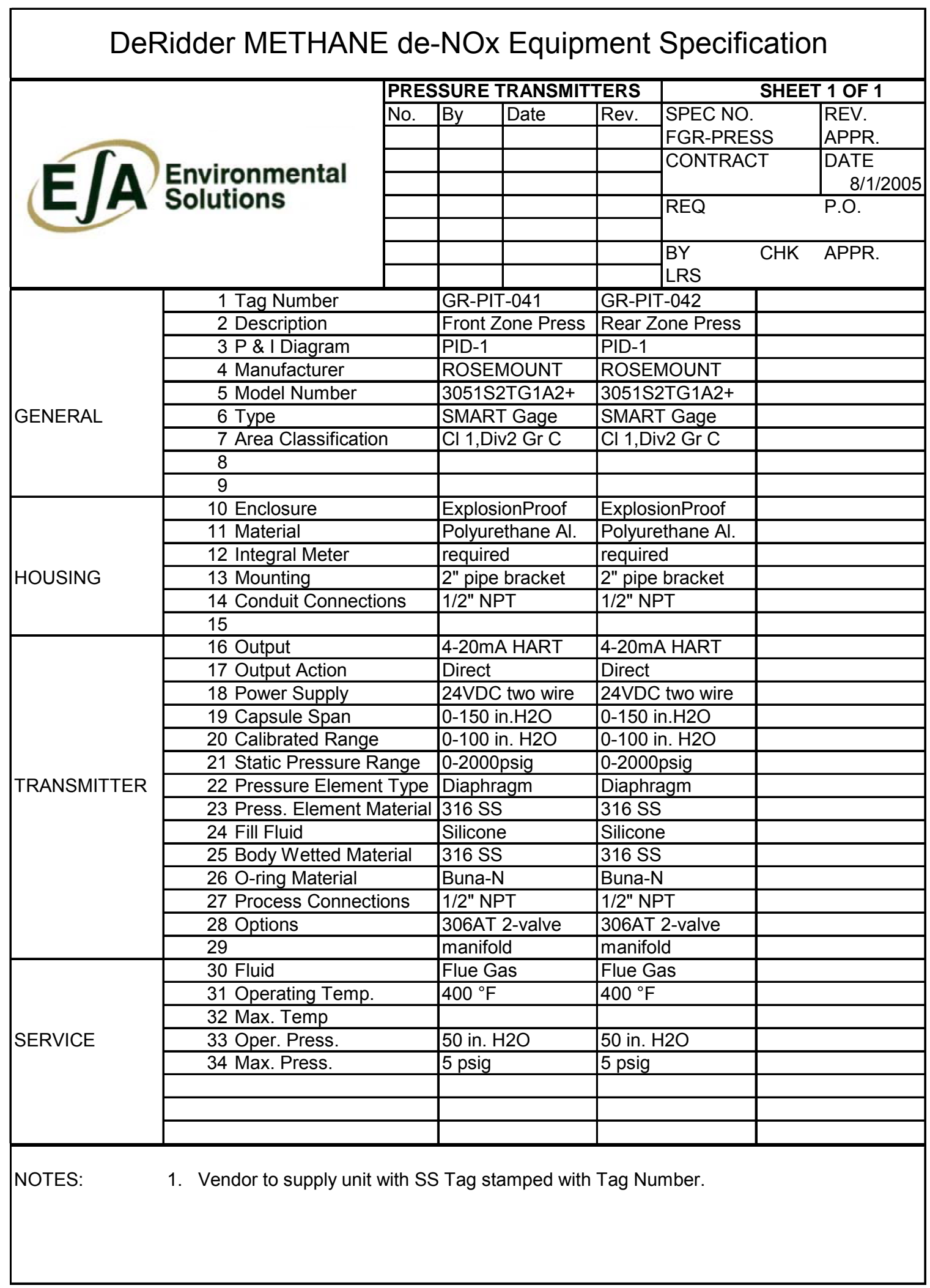




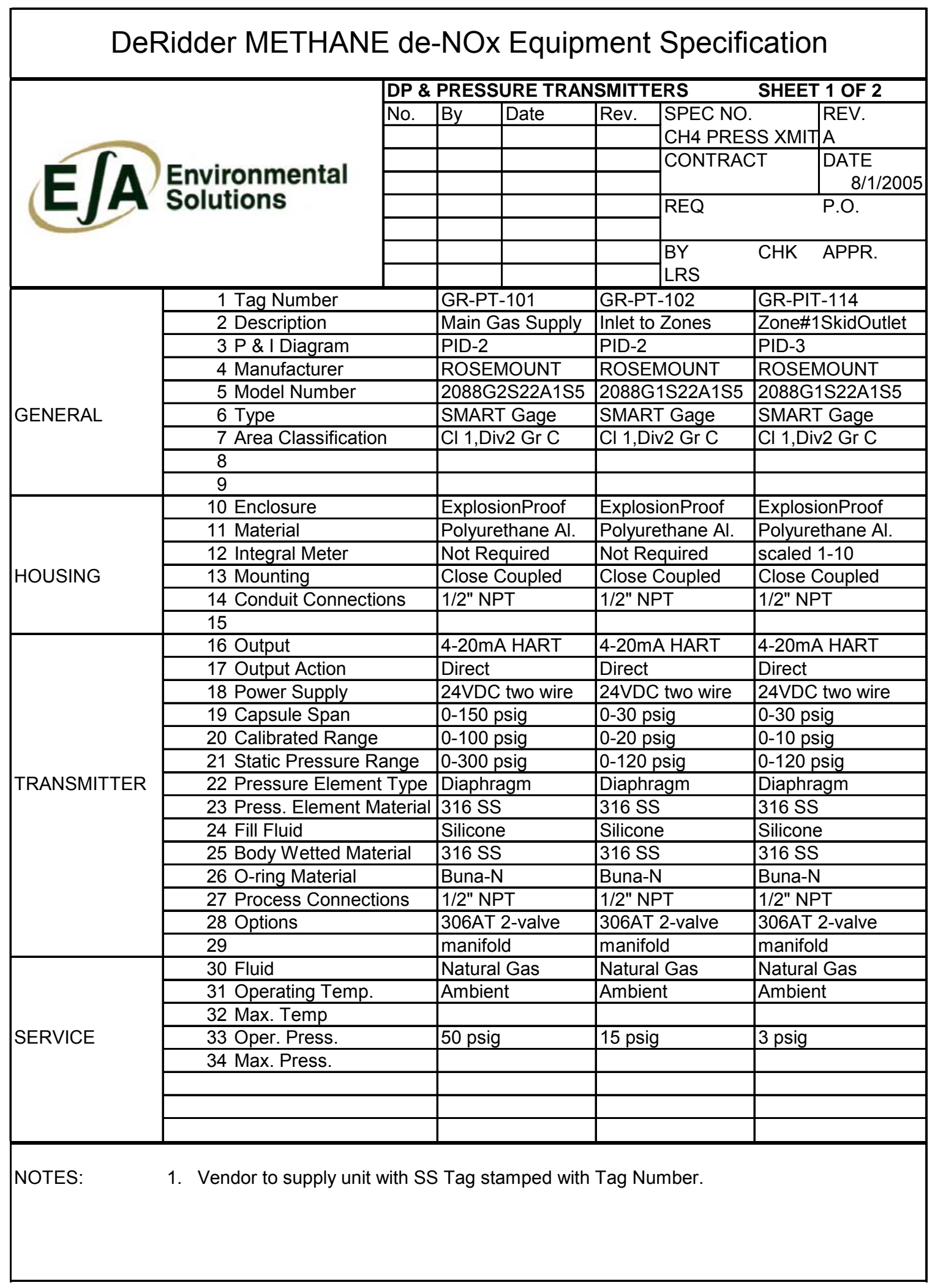




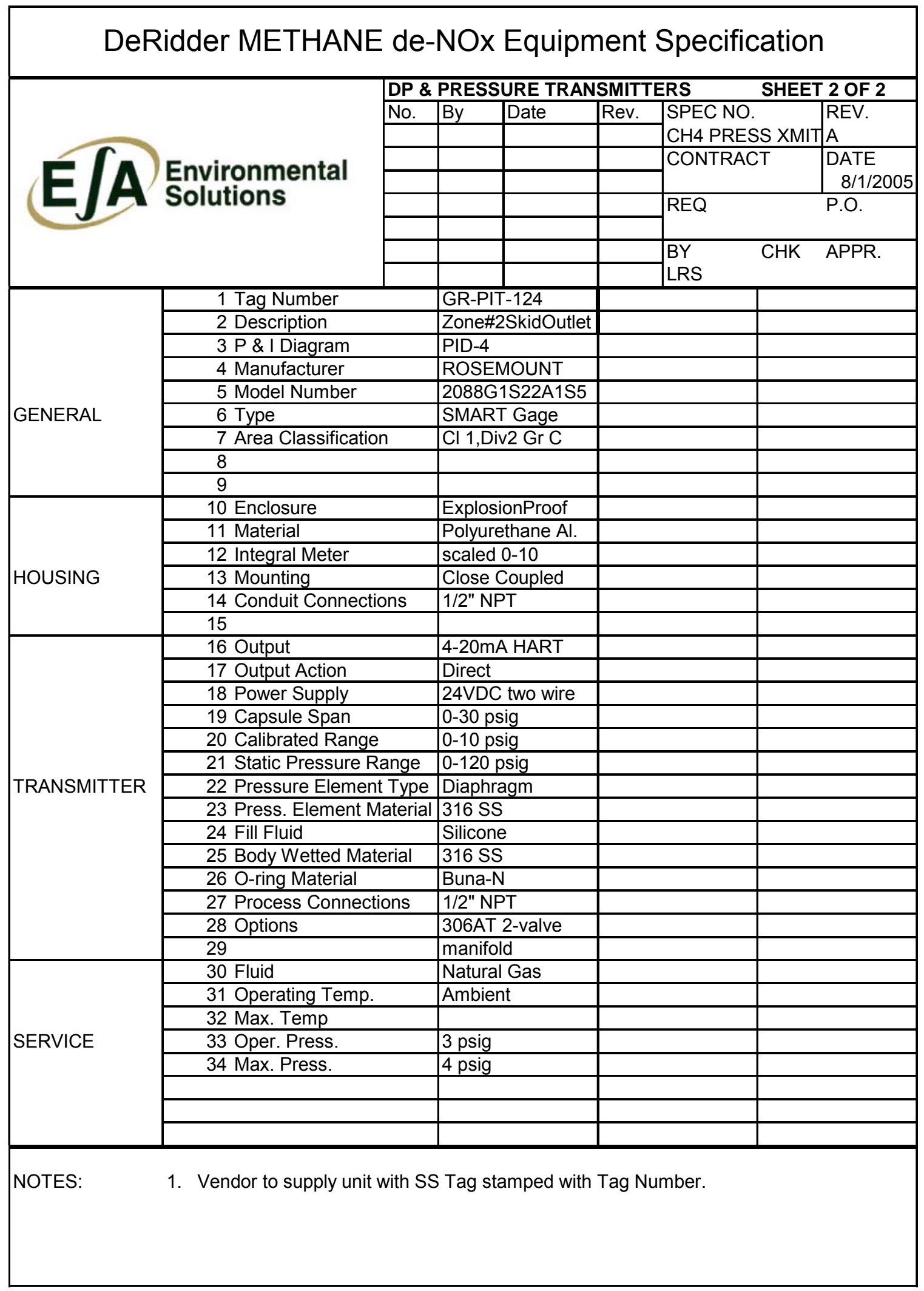




\section{DeRidder METHANE de-NOx Equipment Specification}

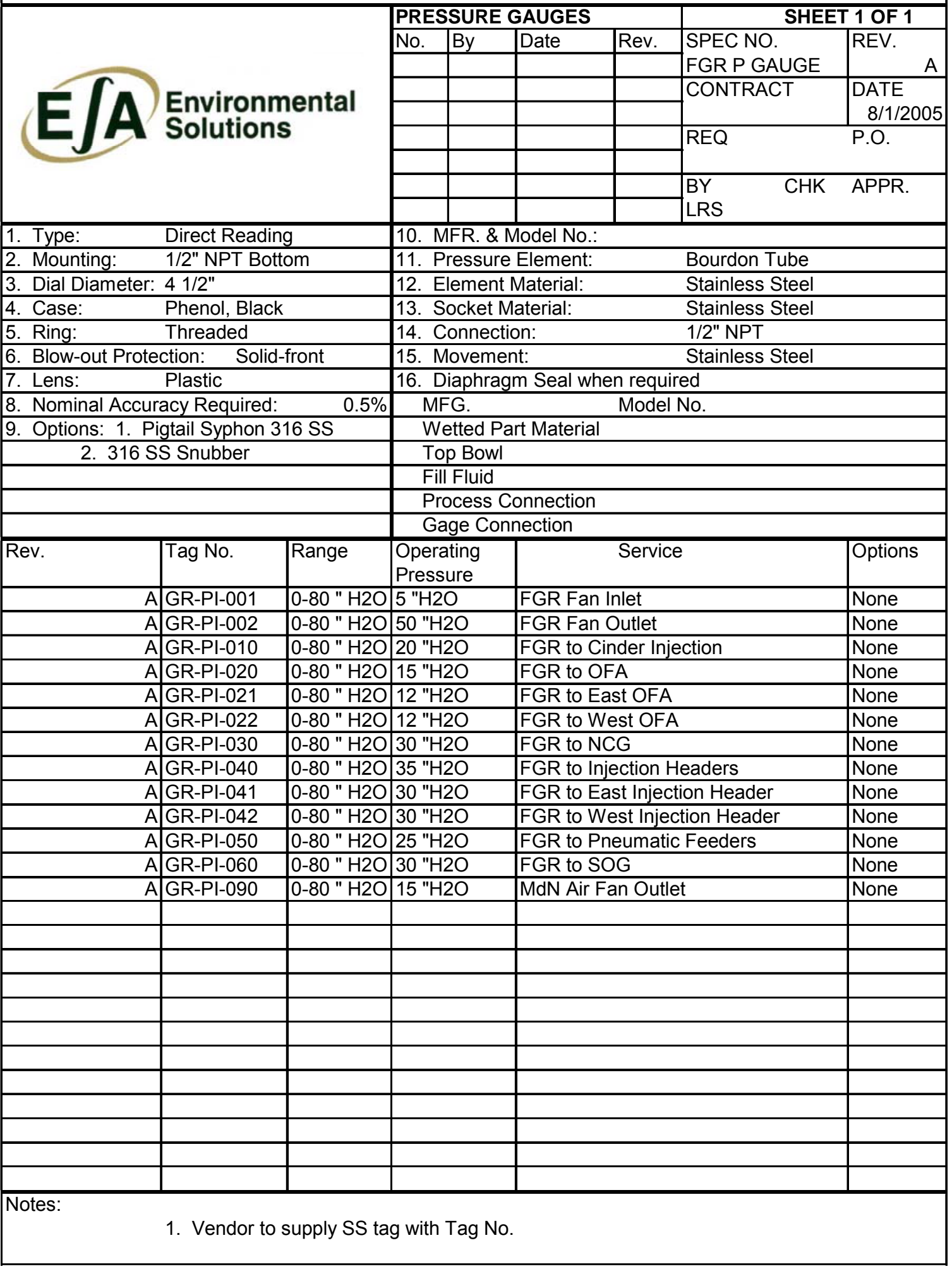




\section{DeRidder METHANE de-NOx Equipment Specification}

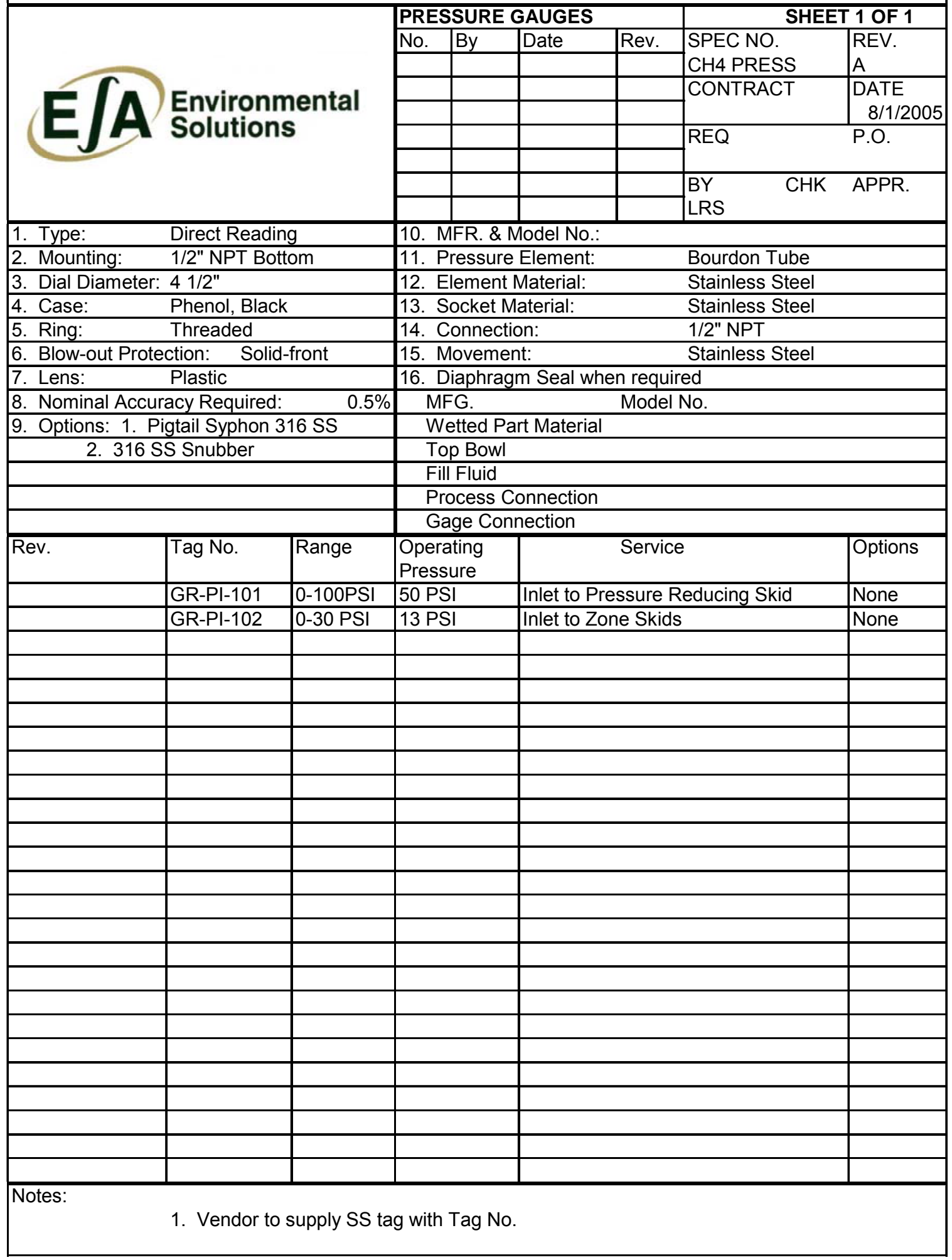




\section{DeRidder METHANE de-NOx Equipment Specification}

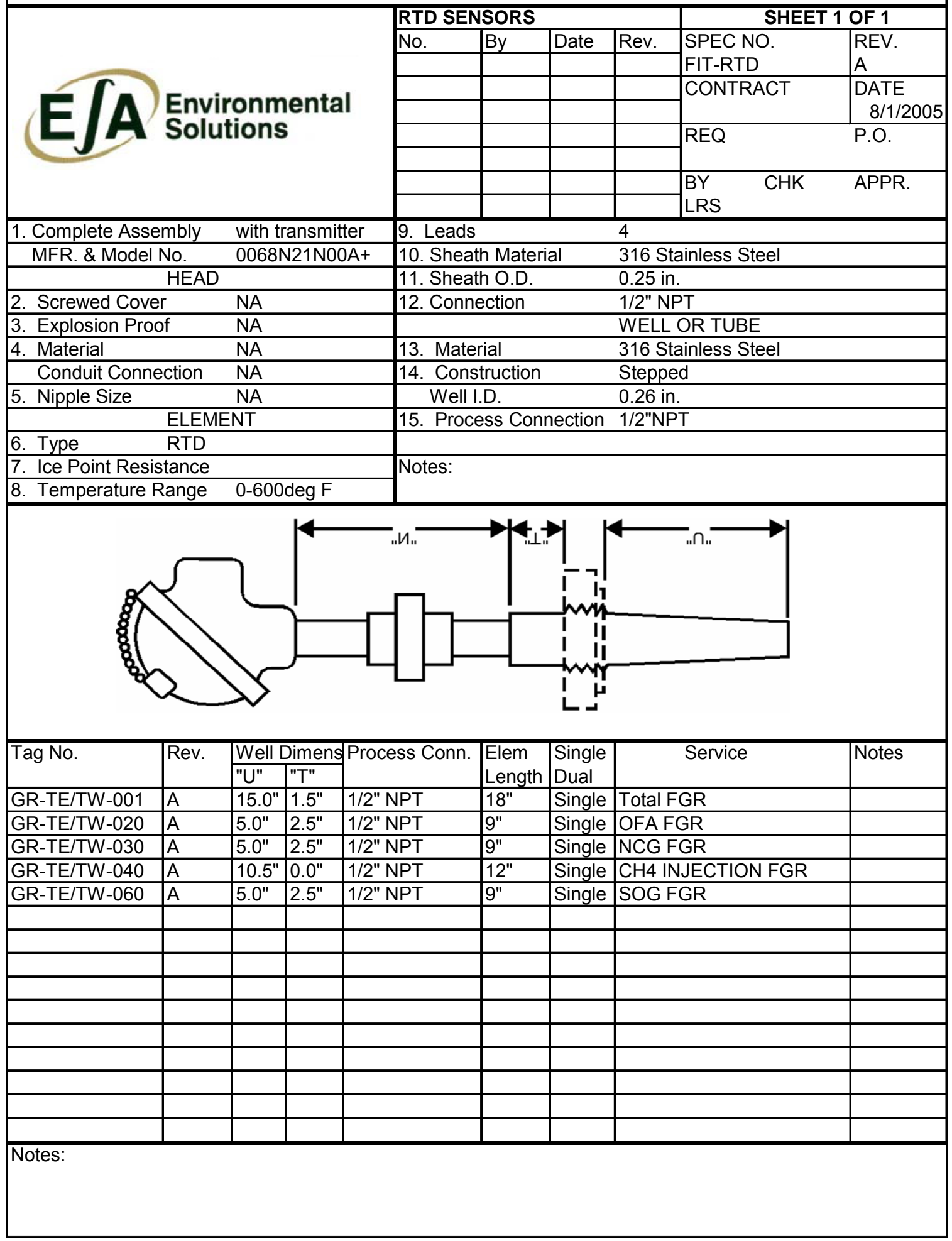




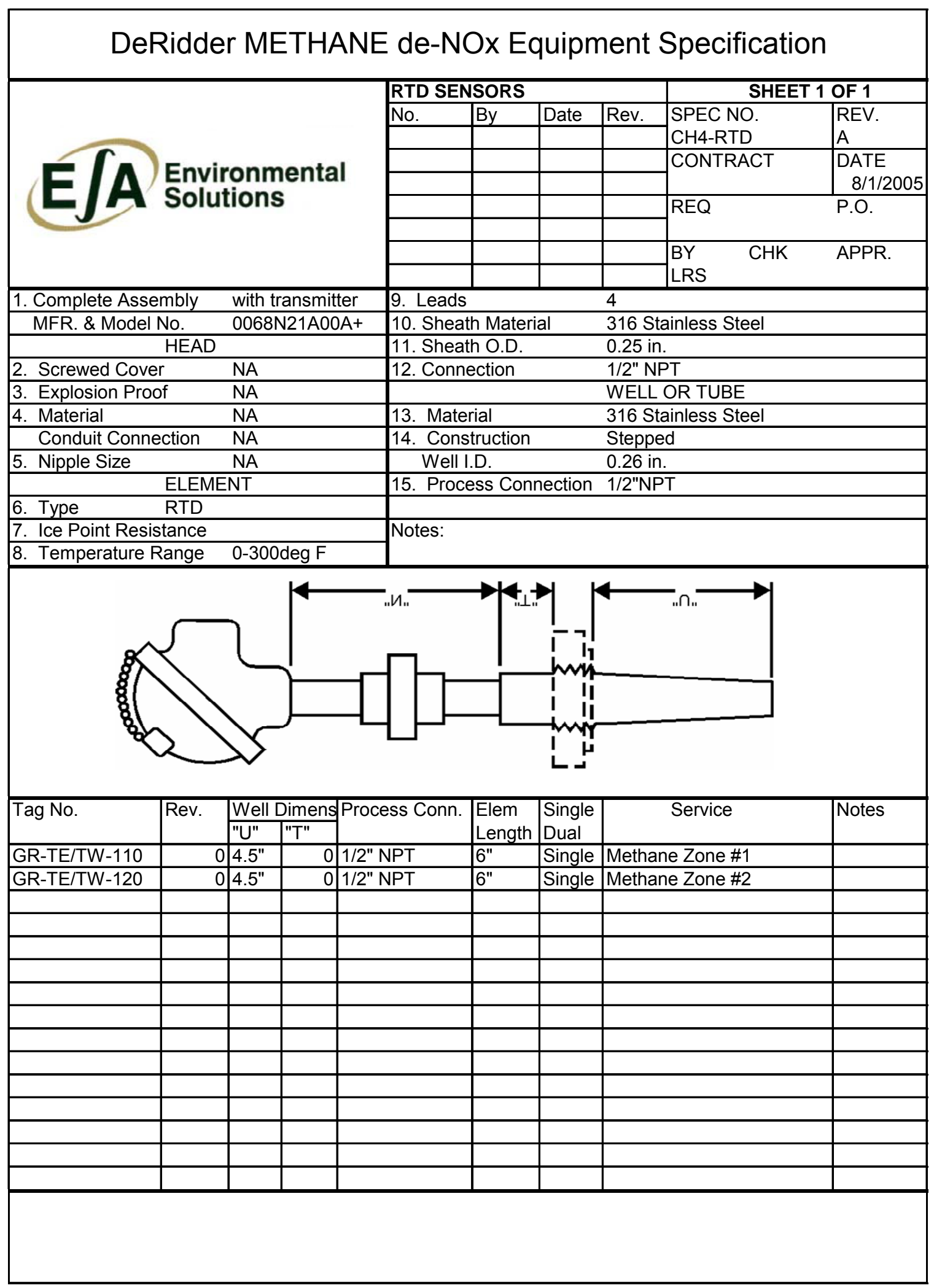




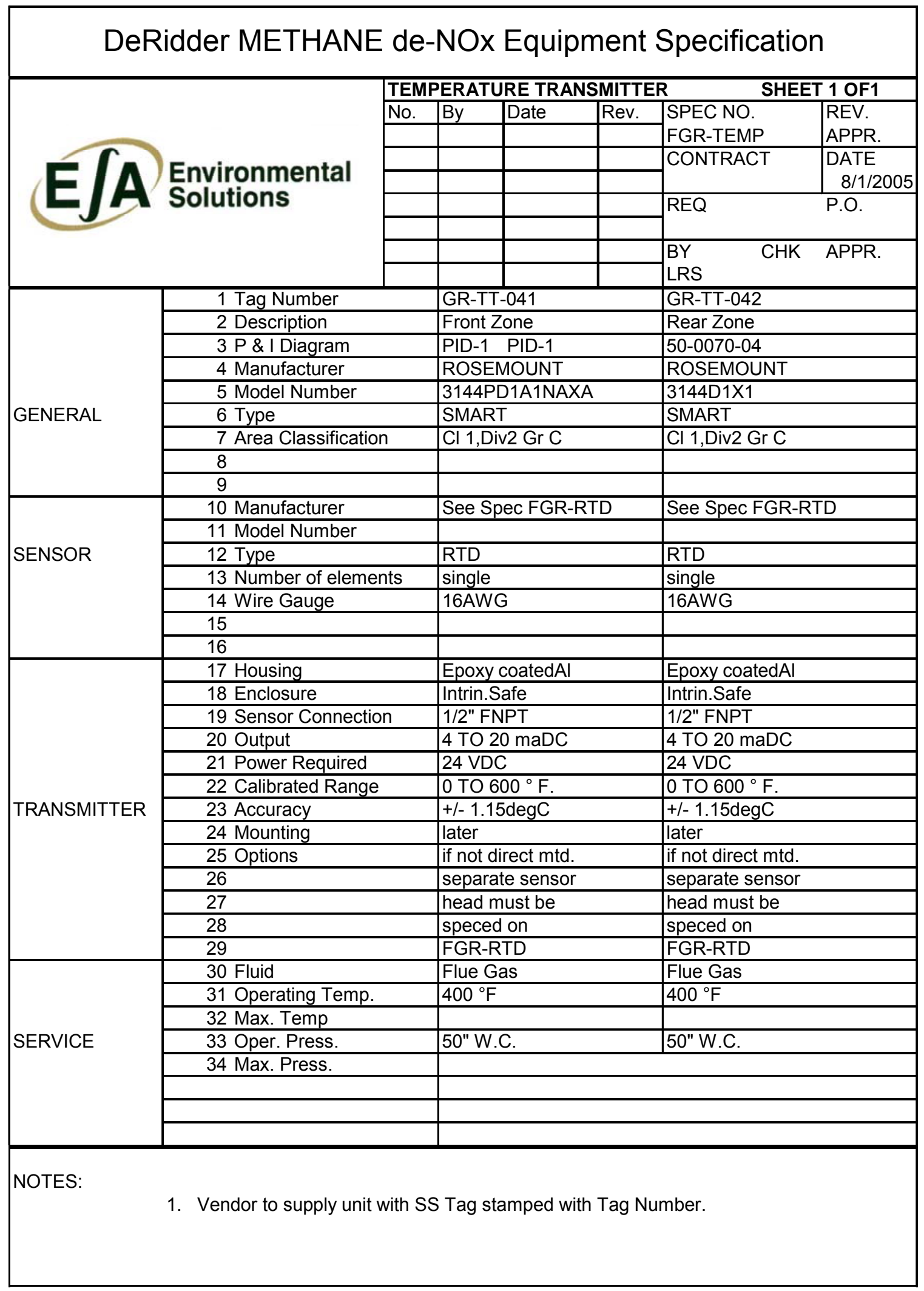




\section{DeRidder METHANE de-NOx Equipment Specification}

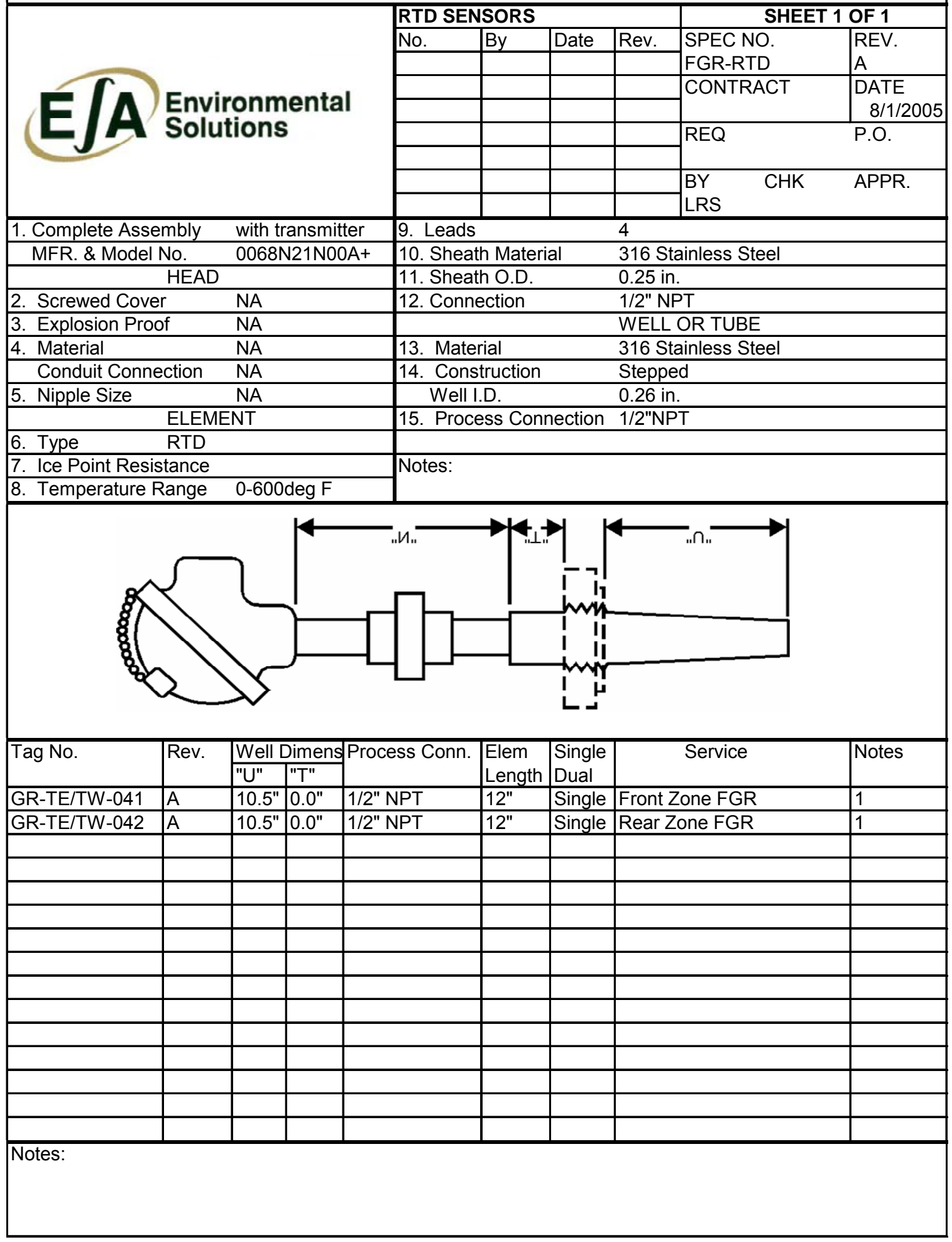




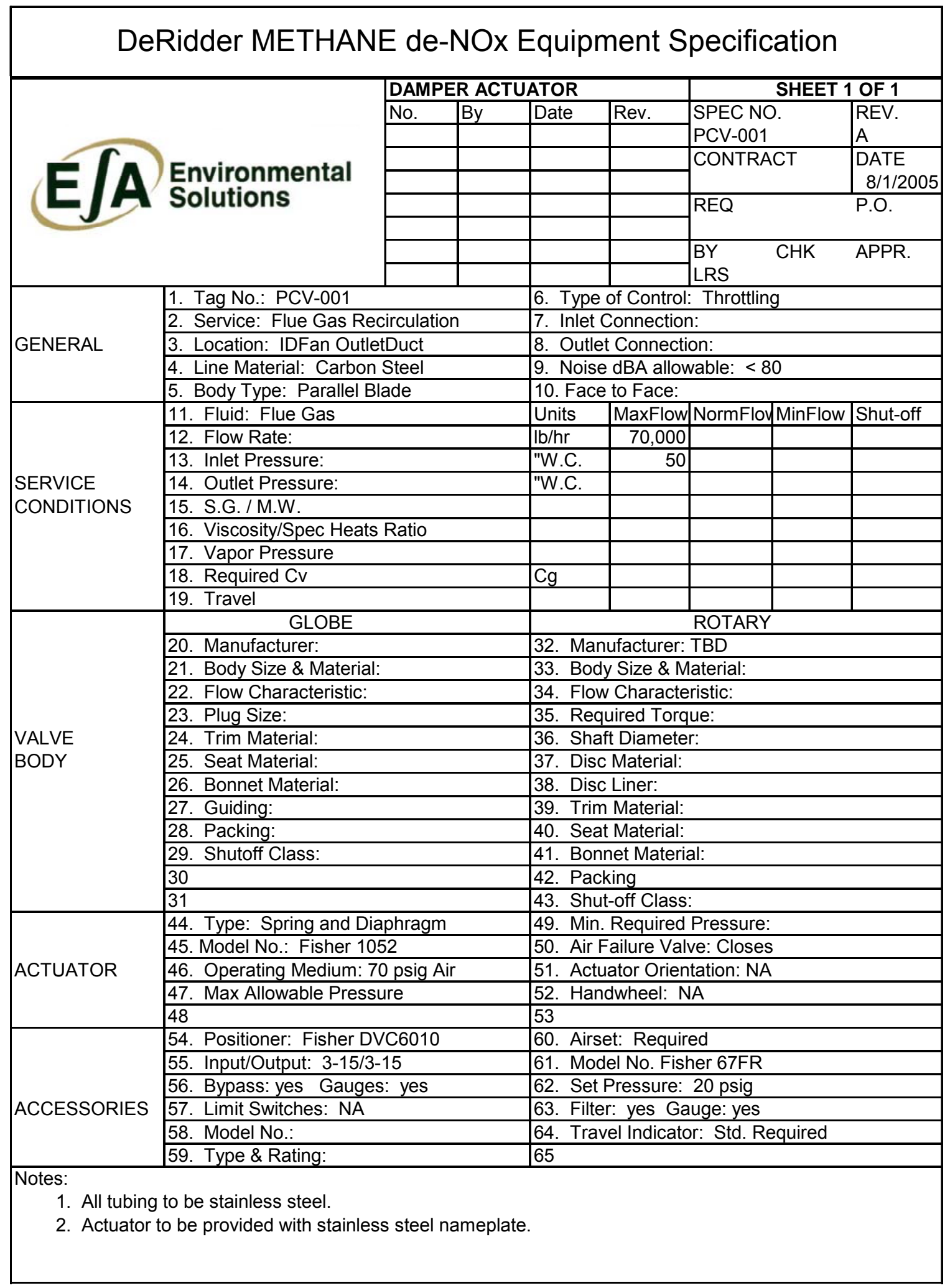




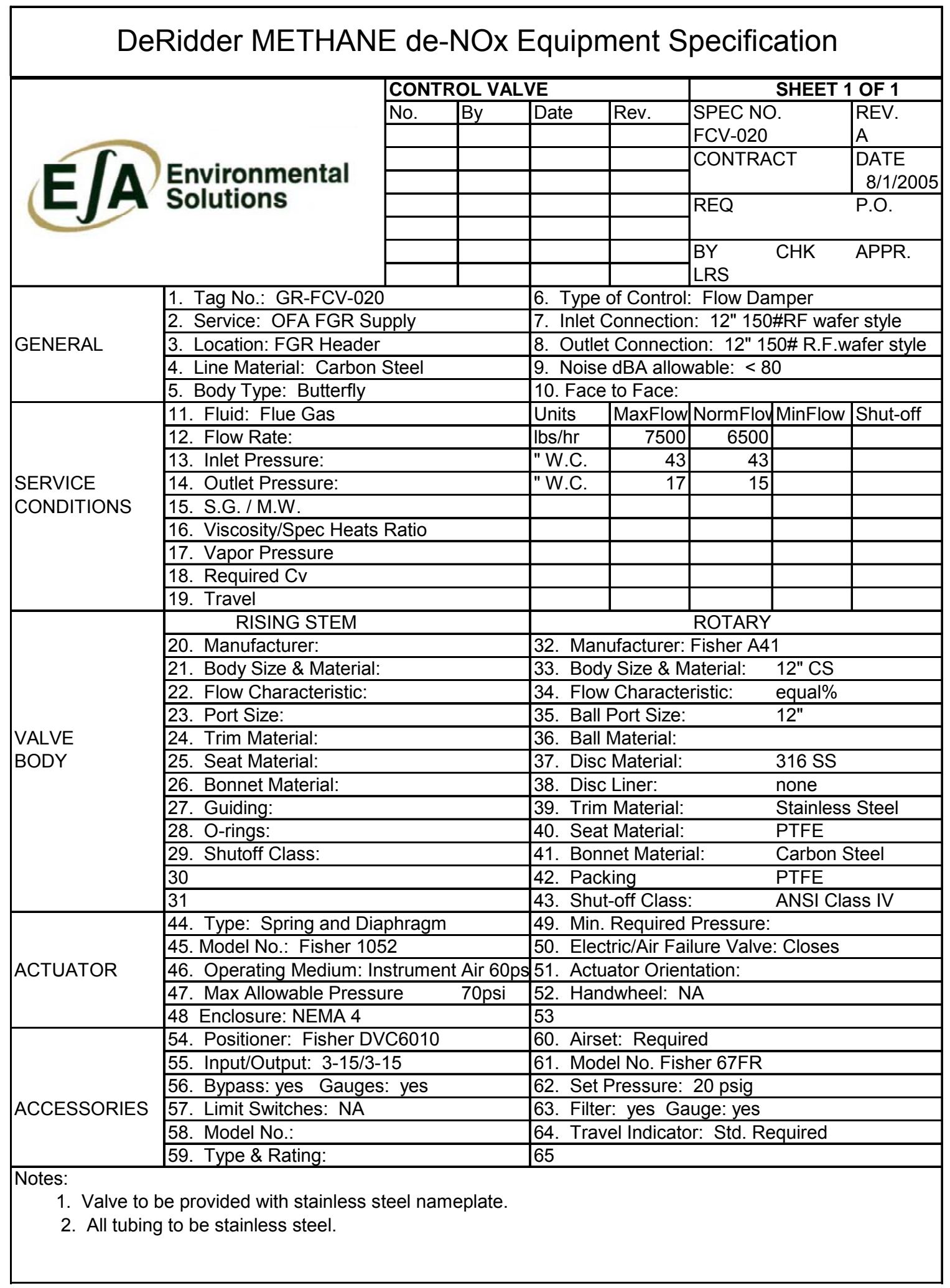




\begin{tabular}{|c|c|c|c|c|c|c|}
\hline \\
\hline & \multirow{8}{*}{$\begin{array}{l}\text { Environmental } \\
\text { Solutions }\end{array}$} & \multicolumn{3}{|c|}{ CONTROL VALVE } & \multicolumn{2}{|c|}{$\begin{array}{r}\text { SHEET } 1 \text { OF } 1 \\
\end{array}$} \\
\hline & & \begin{tabular}{|l|l|} 
No. & By \\
\end{tabular} & Date & Rev. & \multirow{2}{*}{$\begin{array}{l}\text { SPEC NO. } \\
\text { FCV-030 }\end{array}$} & \multirow{2}{*}{$\begin{array}{l}\text { REV. } \\
\text { A }\end{array}$} \\
\hline & & & & & & \\
\hline & & & & & \multirow[t]{2}{*}{ CONTRACT } & DATE \\
\hline & & & & & & $8 / 1 / 2005$ \\
\hline & & & & & REQ & \\
\hline & & & & & \multirow{2}{*}{$\begin{array}{ll}\text { BY } & \text { CHK } \\
\text { LRS } & \\
\end{array}$} & \multirow{2}{*}{ APPR. } \\
\hline & & & & & & \\
\hline \multirow{5}{*}{ GENERAL } & \multicolumn{2}{|l|}{ 1. Tag No.: GR-FCV-030 } & \multicolumn{4}{|c|}{ 6. Type of Control: Flow Damper } \\
\hline & \multicolumn{2}{|c|}{ 2. Service: NCG FGR Supply } & \multicolumn{4}{|c|}{ 7. Inlet Connection: 12" 150\#RF wafer style } \\
\hline & \multicolumn{2}{|c|}{ 3. Location: FGR Header } & \multicolumn{4}{|c|}{ 8. Outlet Connection: 12" 150\# R.F.wafer style } \\
\hline & \multicolumn{2}{|c|}{ 4. Line Material: Carbon Steel } & \multicolumn{4}{|c|}{ 9. Noise dBA allowable: $<80$} \\
\hline & \multicolumn{2}{|c|}{ 5. Body Type: Butterfly } & \multicolumn{4}{|c|}{ 10. Face to Face: } \\
\hline & 11. Fluid: Flue Gas & & Units & MaxFlow & NormFloyMinFlow & Shut-off \\
\hline & 12. Flow Rate: & & Ibs/hr & 2500 & \begin{tabular}{|l|l|}
2000 & \\
\end{tabular} & \\
\hline & 13. Inlet Pressure: & & "W.C. & 43 & 43 & \\
\hline SERVICE & 14. Outlet Pressure: & & "W.C. & 30 & 32 & \\
\hline CONDITIONS & 15. S.G. / M.W. & & & & & \\
\hline & 16. Viscosity/Spec Heats & Ratio & & & & \\
\hline & 17. Vapor Pressure & & & & & \\
\hline & 18. Required Cv & & & & & \\
\hline & 19. Travel & & & & & \\
\hline & \begin{tabular}{|l} 
RISING STEM \\
\end{tabular} & & & & ROTARY & \\
\hline & 20. Manufacturer: & & 32. Ma & ufacturer: F & Fisher A41 & \\
\hline & 21. Body Size \& Material: & & 33. Bor & y Size \& Mr & aterial: $12 " \mathrm{CS}$ & \\
\hline & 22. Flow Characteristic: & & 34. Flo & Character & equal $\%$ & \\
\hline & 23. Port Size: & & 35. Bal & Port Size: & $12^{\prime \prime}$ & \\
\hline VALVE & 24. Trim Material: & & 36. Bal & Material: & & \\
\hline BODY & 25. Seat Material: & & 37. Dis & Material: & 316 SS & \\
\hline & 26. Bonnet Material: & & 38. Dis & Liner: & none & \\
\hline & 27. Guiding: & & 39. Trir & Material: & Stainless & Steel \\
\hline & 28. O-rings: & & 40. Sec & Material: & PTFE & \\
\hline & 29. Shutoff Class: & & 41. Bor & net Materia & Carbon S & Steel \\
\hline & 30 & & 42. $\mathrm{Pac}$ & king & PTFE & \\
\hline & 31 & & 43. Shi & t-off Class: & ANSI Cla & ass IV \\
\hline & 44. Type: Spring and Dia & phragm & 49. Min & Required $\mathrm{F}$ & Pressure: & \\
\hline & 45. Model No.: Fisher 105 & & 50. Ele & tric/Air Fail & lure Valve: Closes & \\
\hline ACTUATOR & 46. Operating Medium: Ins & strument Air 60ps & 51. Act & uator Orient & tation: & \\
\hline & 47. Max Allowable Pressu & ire $\quad 70 p s i$ & 52. Hal & dwheel: $\mathrm{N}$ & & \\
\hline & 48 Enclosure: NEMA 4 & & 53 & & & \\
\hline & 54. Positioner: Fisher DV & $\mathrm{C} 6010$ & 60. Airs & et: Require & & \\
\hline & 55. Input/Output: 3-15/3-1 & & 61. Mo & lel No. Fish & eer 67FR & \\
\hline & 56. Bypass: yes Gauges & yes & 62. Set & Pressure: & 20 psig & \\
\hline ACCESSORIES & 57. Limit Switches: NA & & 63. Filt & r: yes Gal & uge: yes & \\
\hline & 58. Model No.: & & 64. Tra & vel Indicato & r: Std. Required & \\
\hline & 59. Type \& Rating: & & 65 & & & \\
\hline $\begin{array}{l}\text { Notes: } \\
\text { 1. Valve to } \\
\text { 2. All tubing }\end{array}$ & $\begin{array}{l}\text { pe provided with stainless st } \\
\text { to be stainless steel. }\end{array}$ & teel nameplate. & & & & \\
\hline
\end{tabular}




\begin{tabular}{|c|c|c|c|c|c|c|}
\hline \\
\hline & \multirow{8}{*}{$\begin{array}{l}\text { Environmental } \\
\text { Solutions }\end{array}$} & \multicolumn{3}{|c|}{ CONTROL VALVE } & \multicolumn{2}{|c|}{$\begin{array}{r}\text { SHEET } 1 \text { OF } 1 \\
\end{array}$} \\
\hline & & \begin{tabular}{|l|l|} 
No. & By \\
\end{tabular} & Date & Rev. & \multirow{2}{*}{$\begin{array}{l}\text { SPEC NO. } \\
\text { PCV-040 }\end{array}$} & \multirow{2}{*}{$\begin{array}{l}\text { REV. } \\
\text { A }\end{array}$} \\
\hline & & & & & & \\
\hline & & & & & \multirow[t]{2}{*}{ CONTRACT } & DATE \\
\hline & & & & & & $8 / 1 / 2005$ \\
\hline & & & & & REQ & \multirow{3}{*}{ APPR. } \\
\hline & & & & & \multirow{2}{*}{$\begin{array}{l}\text { BY } \\
\text { LRS }\end{array}$} & \\
\hline & & & & & & \\
\hline \multirow{5}{*}{ GENERAL } & \multicolumn{2}{|l|}{ 1. Tag No.: GR-PCV-040 } & \multicolumn{4}{|c|}{ 6. Type of Control: Pressure Damper } \\
\hline & \multirow{2}{*}{\multicolumn{2}{|c|}{\begin{tabular}{|l|} 
2. Service: Injection Header FGR Supply \\
3. Location: FGR Header
\end{tabular}}} & \multicolumn{4}{|c|}{ 7. Inlet Connection: 24" 150\#RF wafer style } \\
\hline & & & \multicolumn{4}{|c|}{ 8. Outlet Connection: $24 "$ 150\# R.F.wafer style } \\
\hline & \multicolumn{2}{|c|}{ 4. Line Material: Carbon Steel } & \multicolumn{4}{|c|}{ 9. Noise dBA allowable: $<80$} \\
\hline & \multicolumn{2}{|c|}{ 5. Body Type: Butterfly } & \multicolumn{4}{|c|}{ 10. Face to Face: } \\
\hline \multirow{9}{*}{$\begin{array}{l}\text { SERVICE } \\
\text { CONDITIONS }\end{array}$} & 11. Fluid: Flue Gas & & Units & MaxFlow & NormFloyMinFlow & Shut-off \\
\hline & 12. Flow Rate: & & Ibs/hr & 30000 & \begin{tabular}{|l|l|}
25000 & \\
\end{tabular} & \\
\hline & 13. Inlet Pressure: & & "W.C. & 36 & 36 & \\
\hline & 14. Outlet Pressure: & & "W.C. & 30 & 31 & \\
\hline & 15. S.G. / M.W. & & & & & \\
\hline & 16. Viscosity/Spec Heats & Ratio & & & & \\
\hline & 17. Vapor Pressure & & & & & \\
\hline & 18. Required Cv & & & & & \\
\hline & 19. Travel & & & & & \\
\hline & \begin{tabular}{|l} 
RISING STEM \\
\end{tabular} & & & & ROTARY & \\
\hline & 20. Manufacturer: & & 32. Ma & ufacturer: F & Fisher A41 & \\
\hline & 21. Body Size \& Material: & & 33. Bo & y Size \& Mr & aterial: $24 " \mathrm{CS}$ & \\
\hline & 22. Flow Characteristic: & & 34. Flo & Character & equal $\%$ & \\
\hline & 23. Port Size: & & 35. $\mathrm{Ba}$ & Port Size: & $24 "$ & \\
\hline VALVE & 24. Trim Material: & & 36. $\mathrm{Ba}$ & Material: & & \\
\hline BODY & 25. Seat Material: & & 37. Dis & Material: & 316 SS & \\
\hline & 26. Bonnet Material: & & 38. Dis & Liner: & none & \\
\hline & 27. Guiding: & & 39. Tril & Material: & Stainless & Steel \\
\hline & 28. O-rings: & & 40. $\mathrm{Se}$ & Material: & PTFE & \\
\hline & 29. Shutoff Class: & & 41. Bo & net Materia & Carbon S & Steel \\
\hline & 30 & & 42. $\mathrm{Pa}$ & king & PTFE & \\
\hline & 31 & & 43. Sh & t-off Class: & ANSI Cla & ass IV \\
\hline & 44. Type: Spring and Dia & phragm & 49. Mir & Required $\mathrm{F}$ & Pressure: & \\
\hline & 45. Model No.: Fisher 105 & & 50. Ele & tric/Air Fail & lure Valve: Closes & \\
\hline ACTUATOR & 46. Operating Medium: Ins & strument Air 60p & 51. Act & uator Orient & tation: & \\
\hline & 47. Max Allowable Pressu & ire $\quad 70 p s i$ & 52. $\mathrm{Ha}$ & dwheel: $\mathrm{N}$ & & \\
\hline & 48 Enclosure: NEMA 4 & & 53 & & & \\
\hline & 54. Positioner: Fisher DV & $\mathrm{C} 6010$ & 60. Air & et: Require & & \\
\hline & 55. Input/Output: 3-15/3-1 & & 61. Mo & lel No. Fish & eer 67FR & \\
\hline & 56. Bypass: yes Gauges & yes & 62. Se & Pressure: & 20 psig & \\
\hline ACCESSORIES & 57. Limit Switches: NA & & 63. Filt & r: yes Gal & uge: yes & \\
\hline & 58. Model No.: & & 64. Tra & vel Indicato & r: Std. Required & \\
\hline & 59. Type \& Rating: & & 65 & & & \\
\hline $\begin{array}{l}\text { Notes: } \\
\text { 1. Valve to } \\
\text { 2. All tubing }\end{array}$ & $\begin{array}{l}\text { pe provided with stainless st } \\
\text { to be stainless steel. }\end{array}$ & teel nameplate. & & & & \\
\hline
\end{tabular}




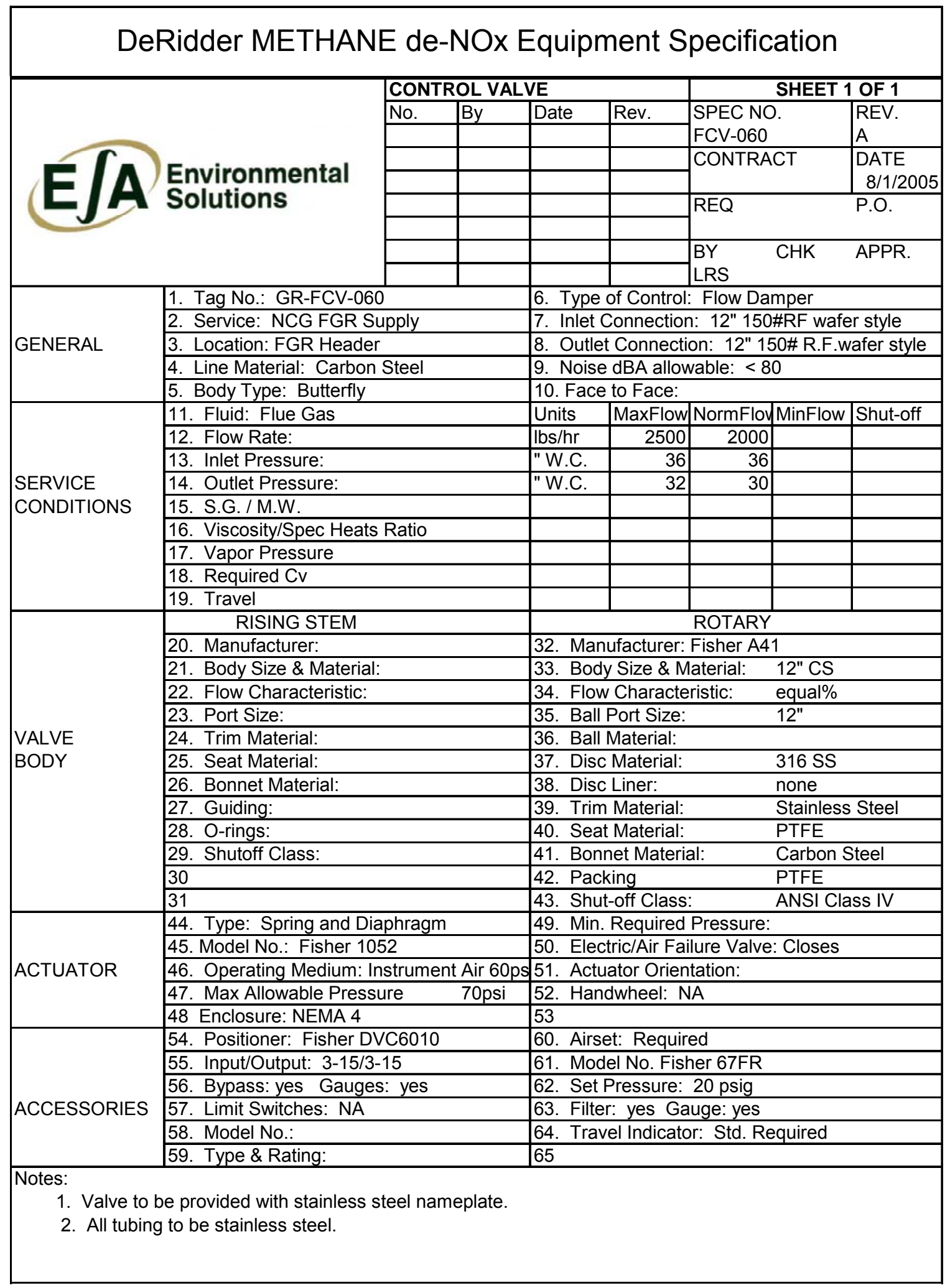




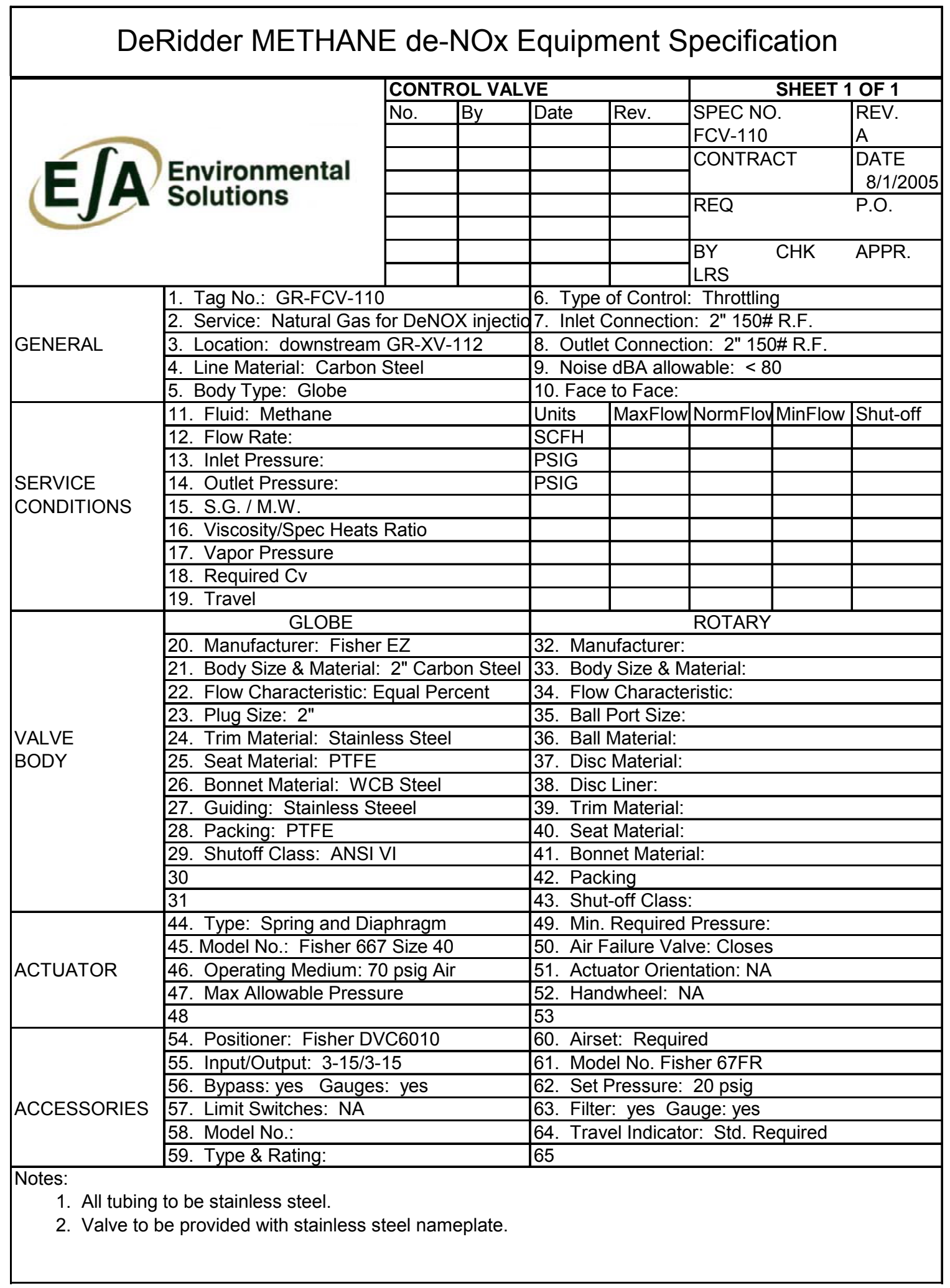




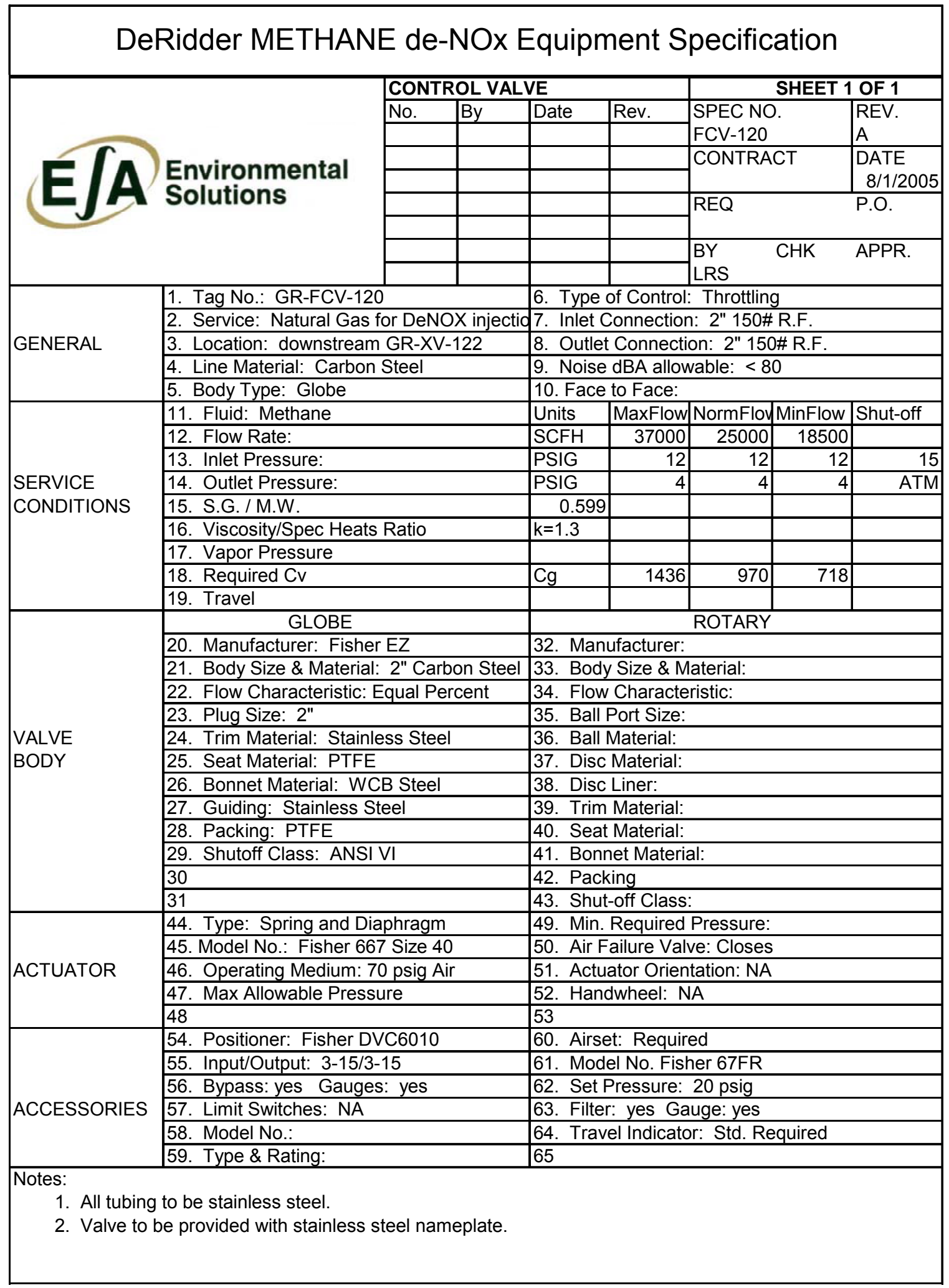




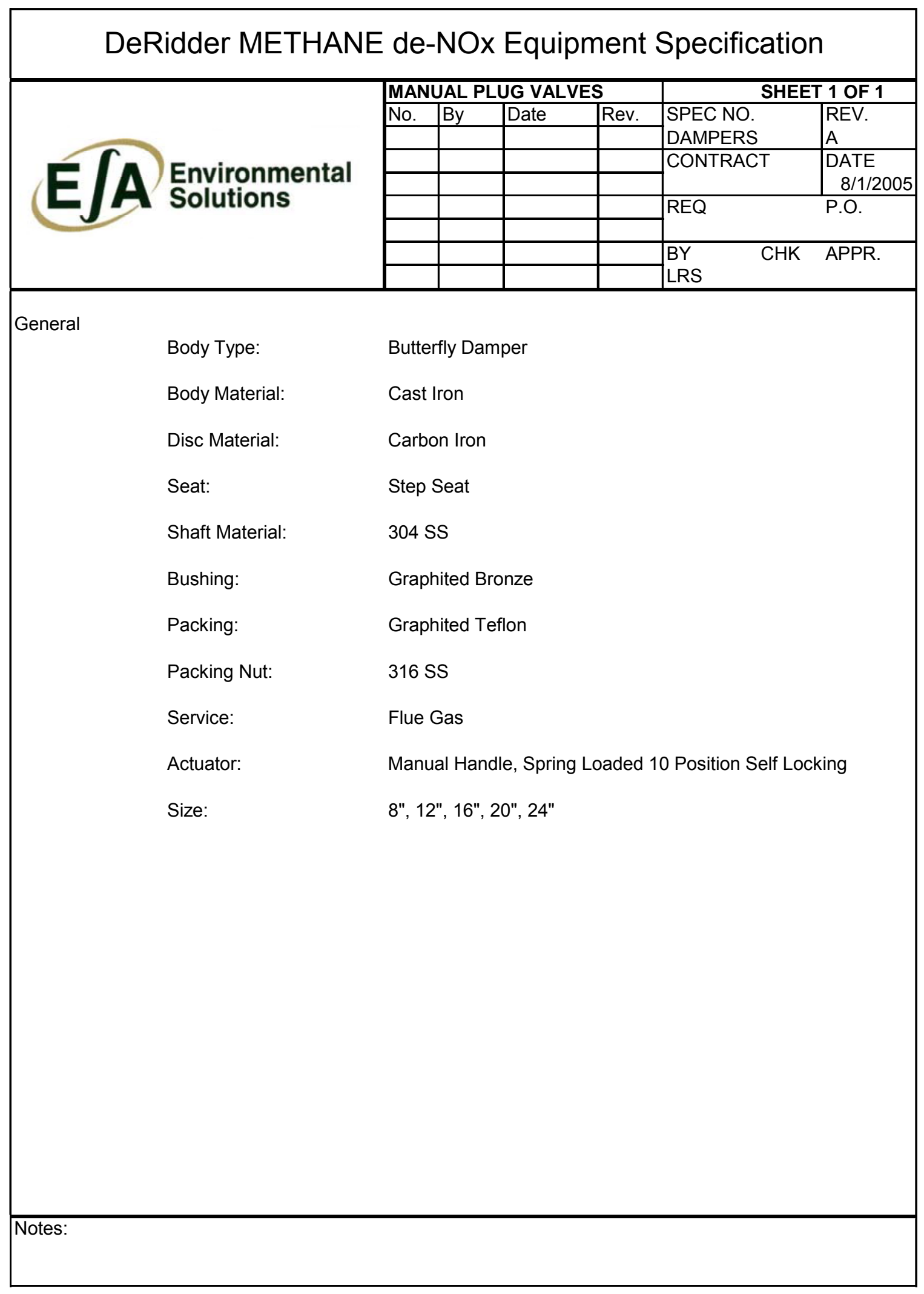




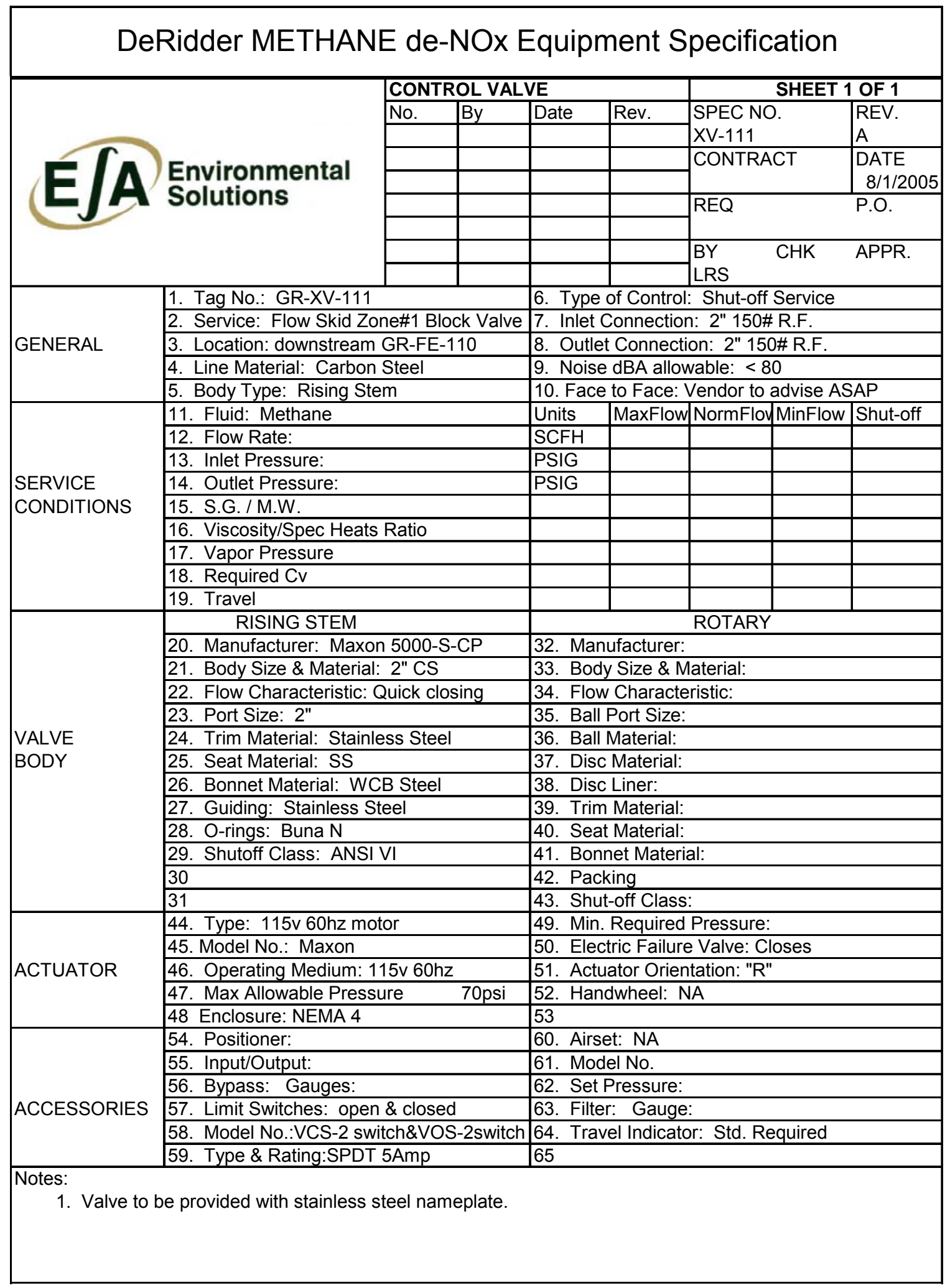




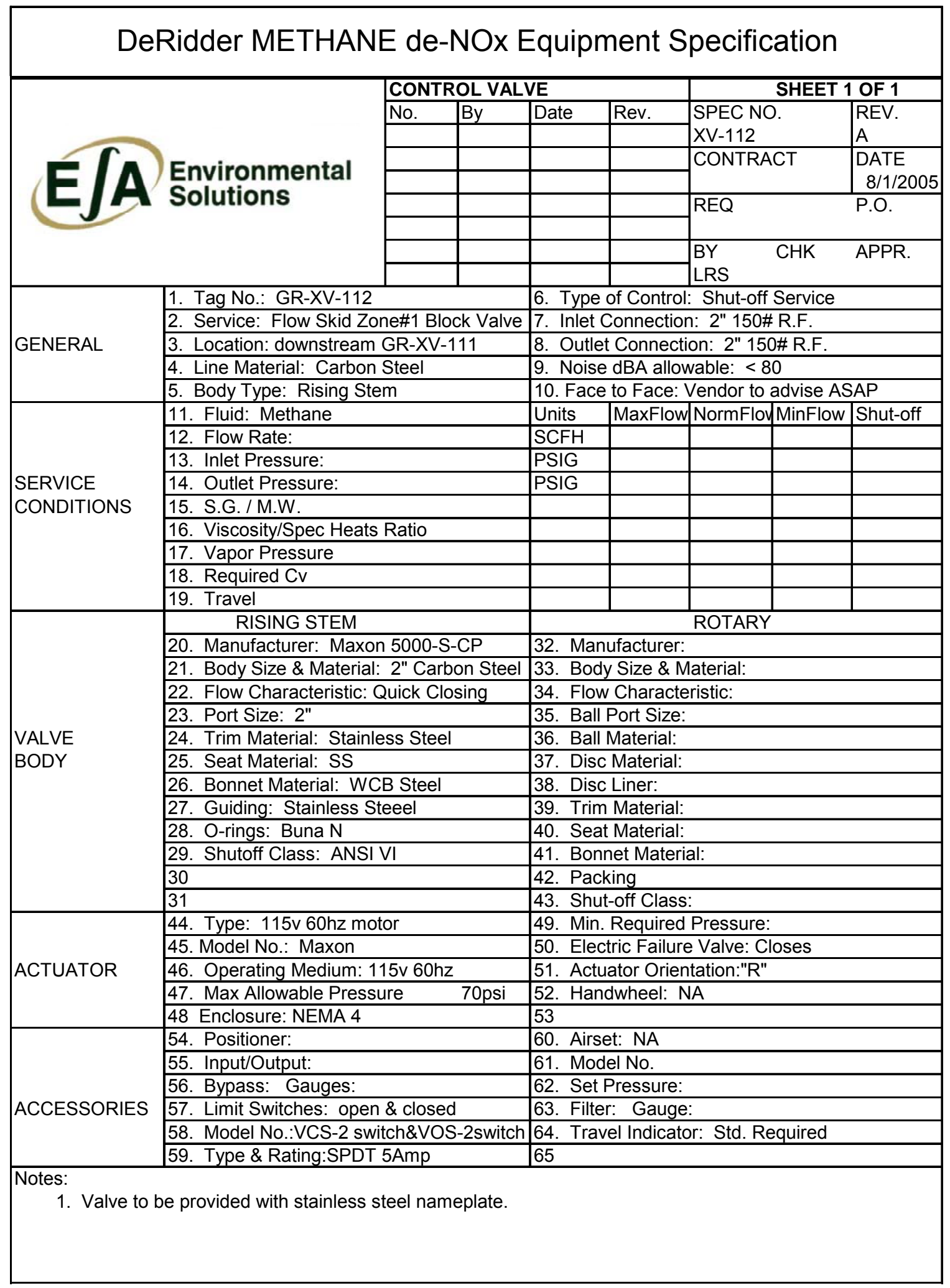




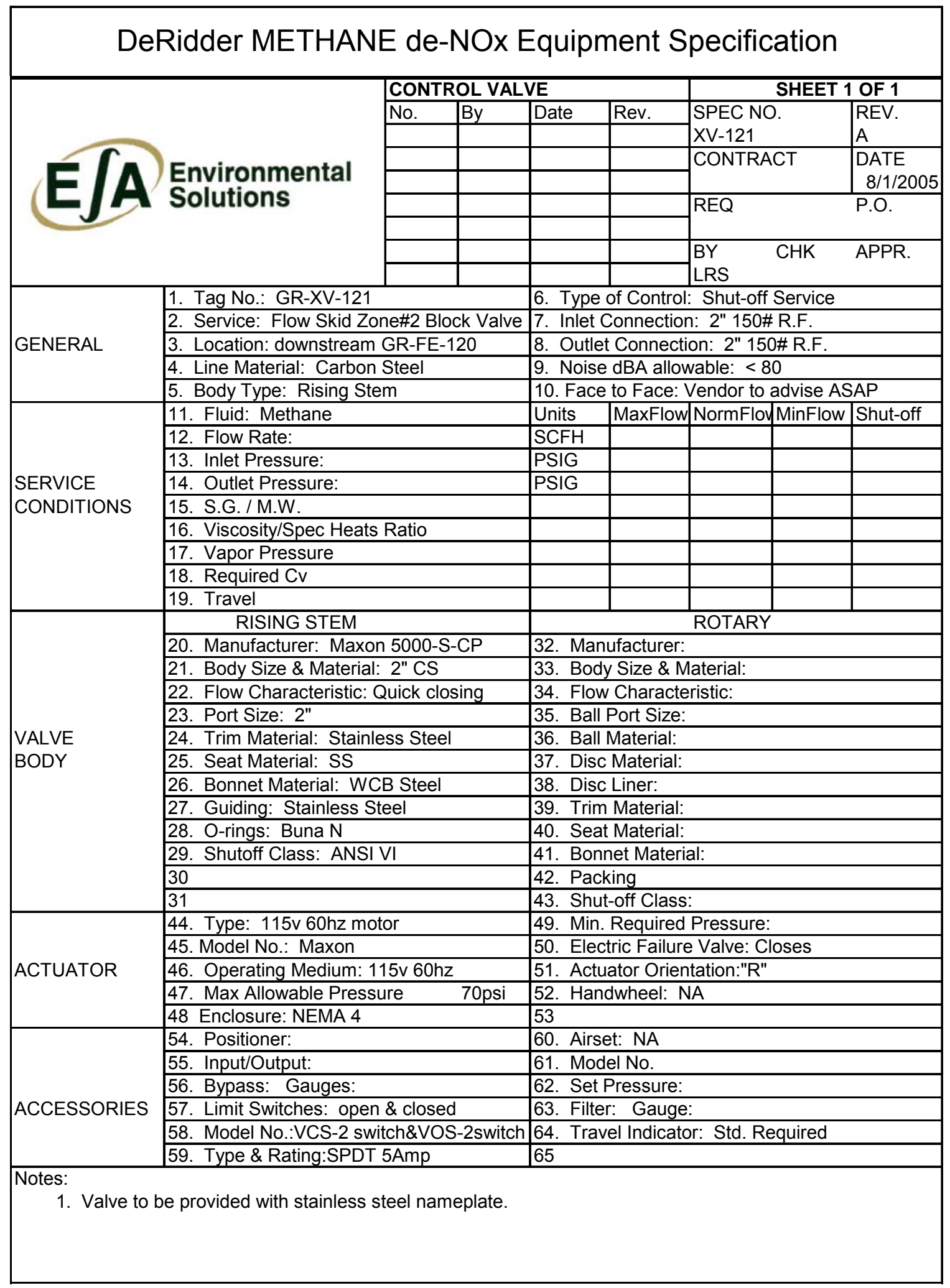




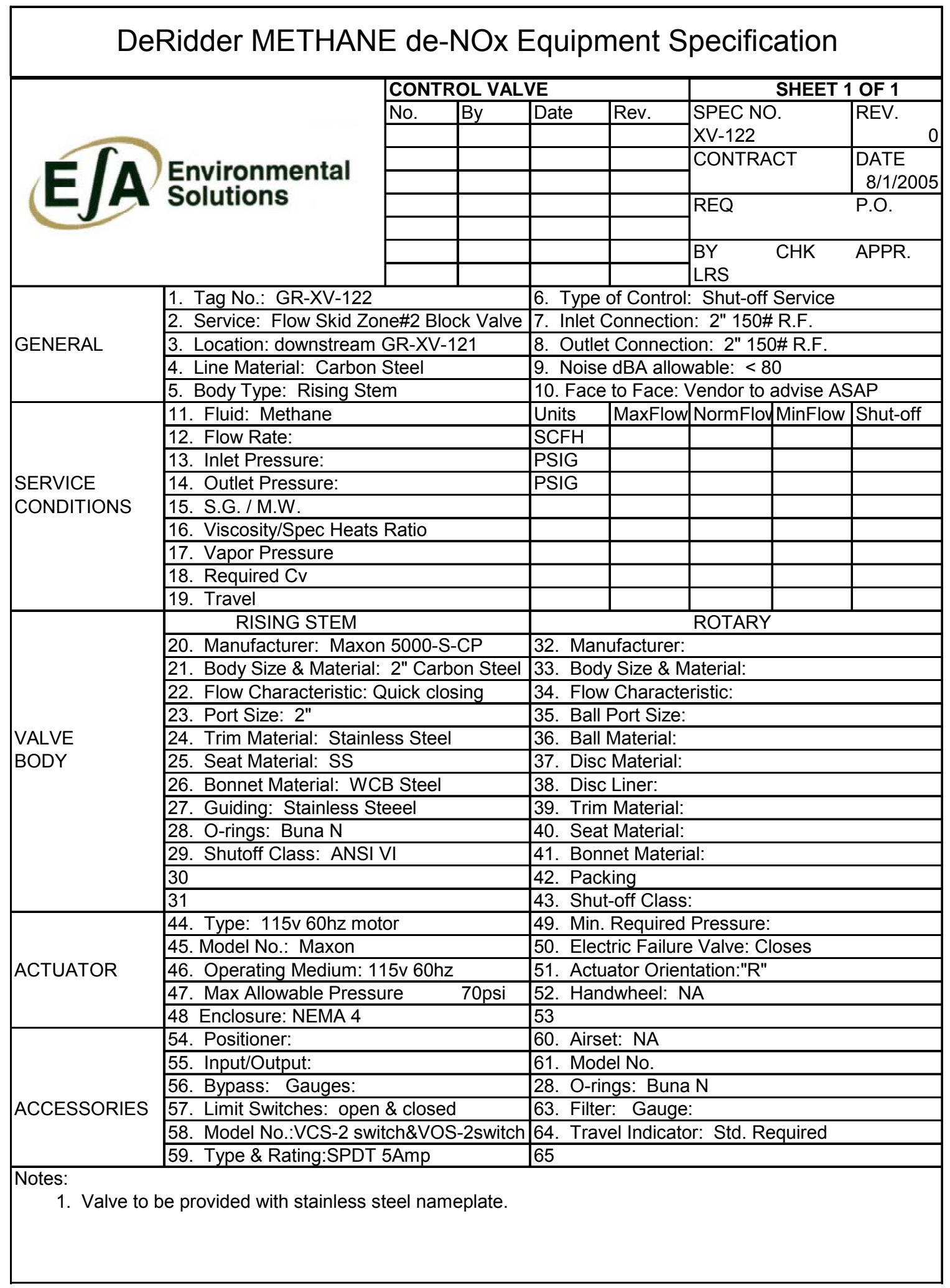




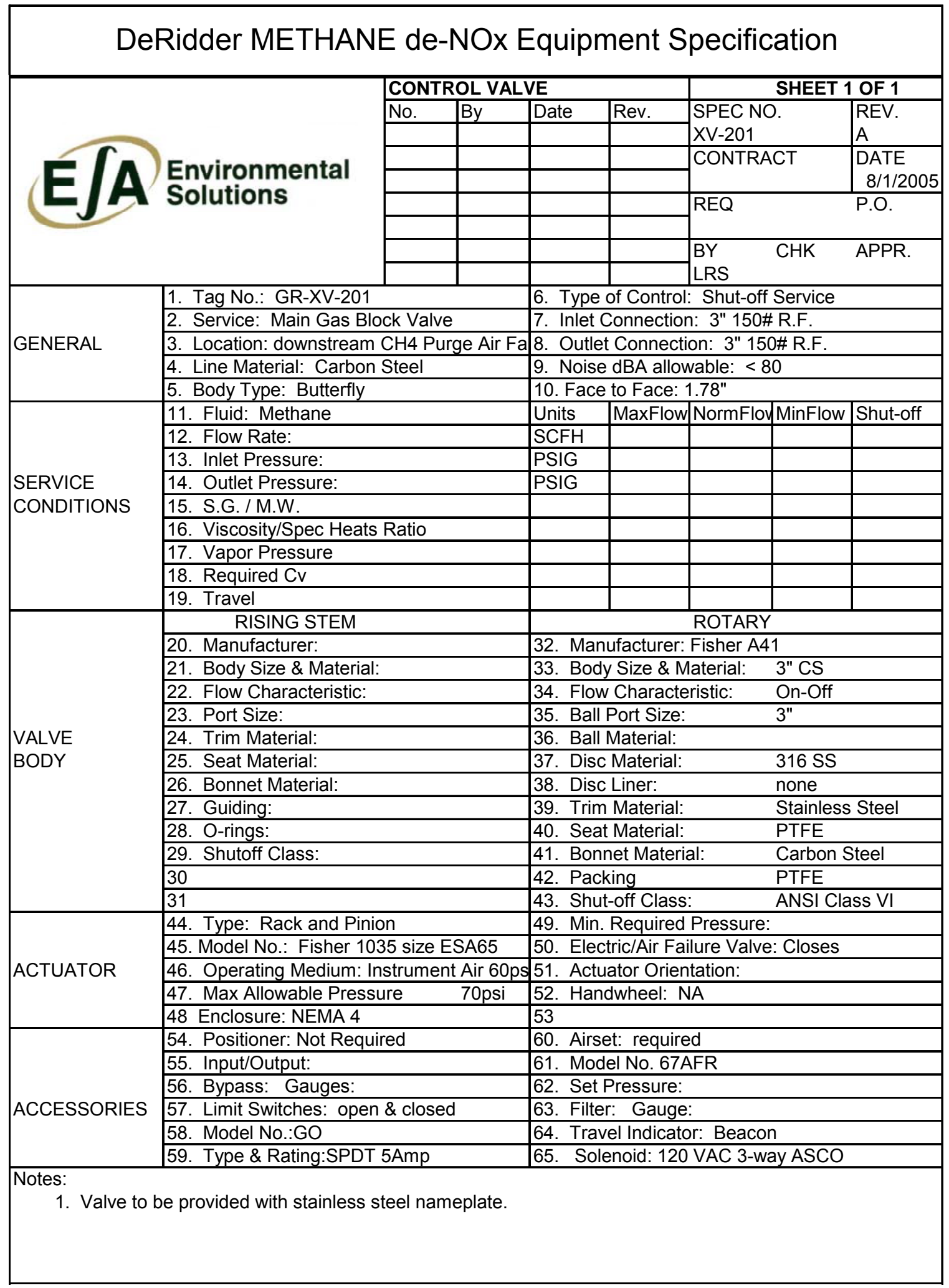




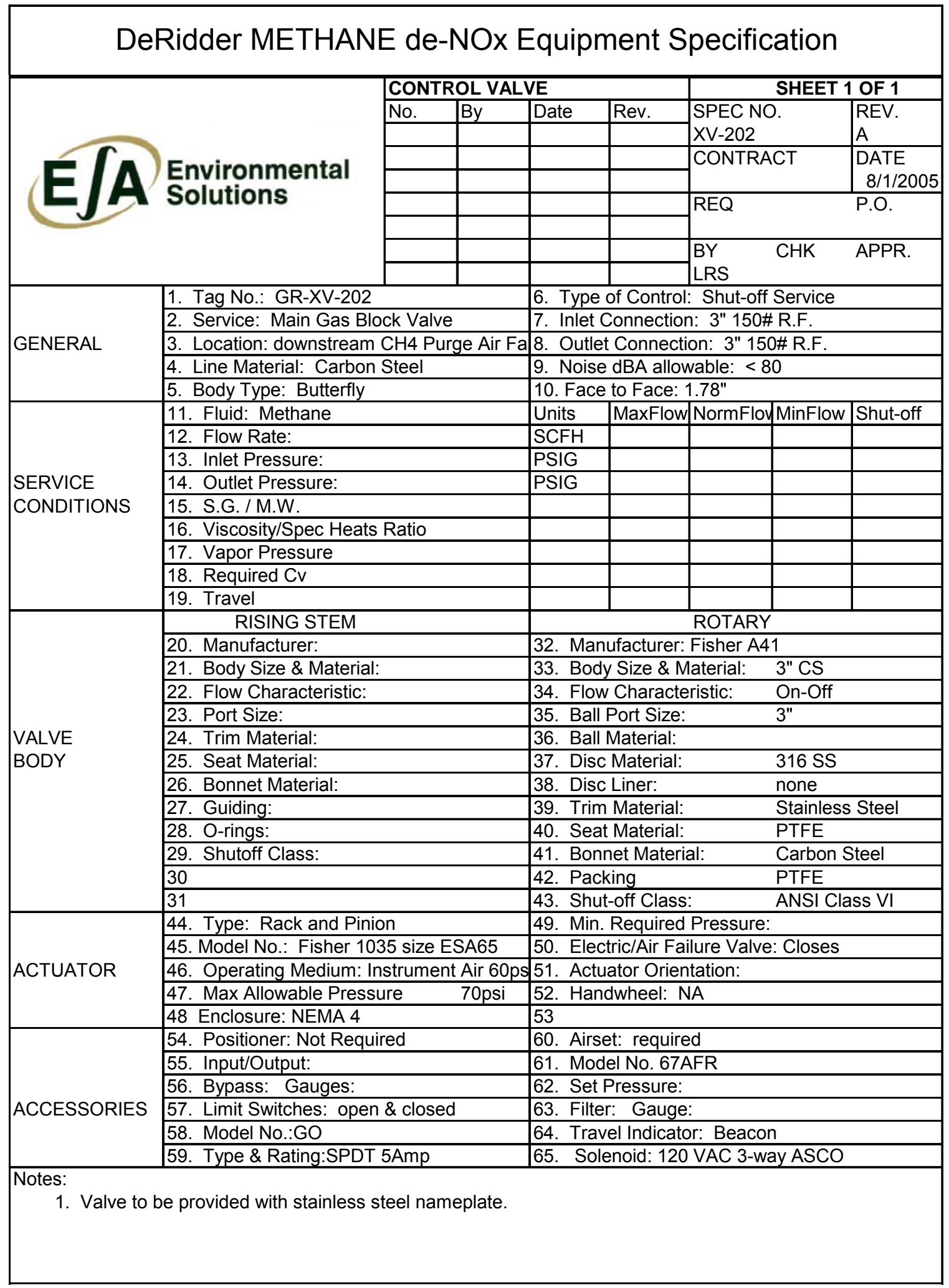




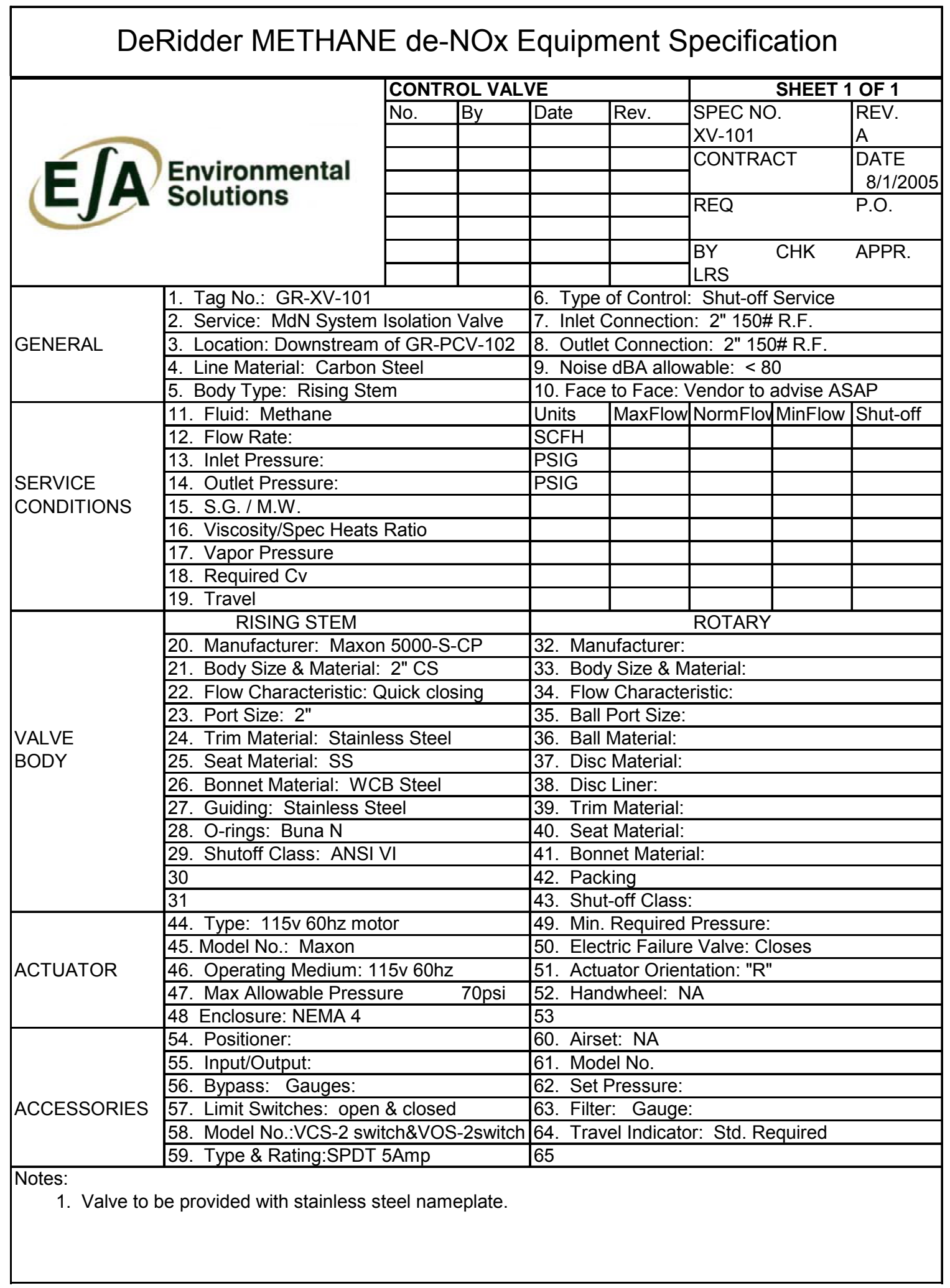




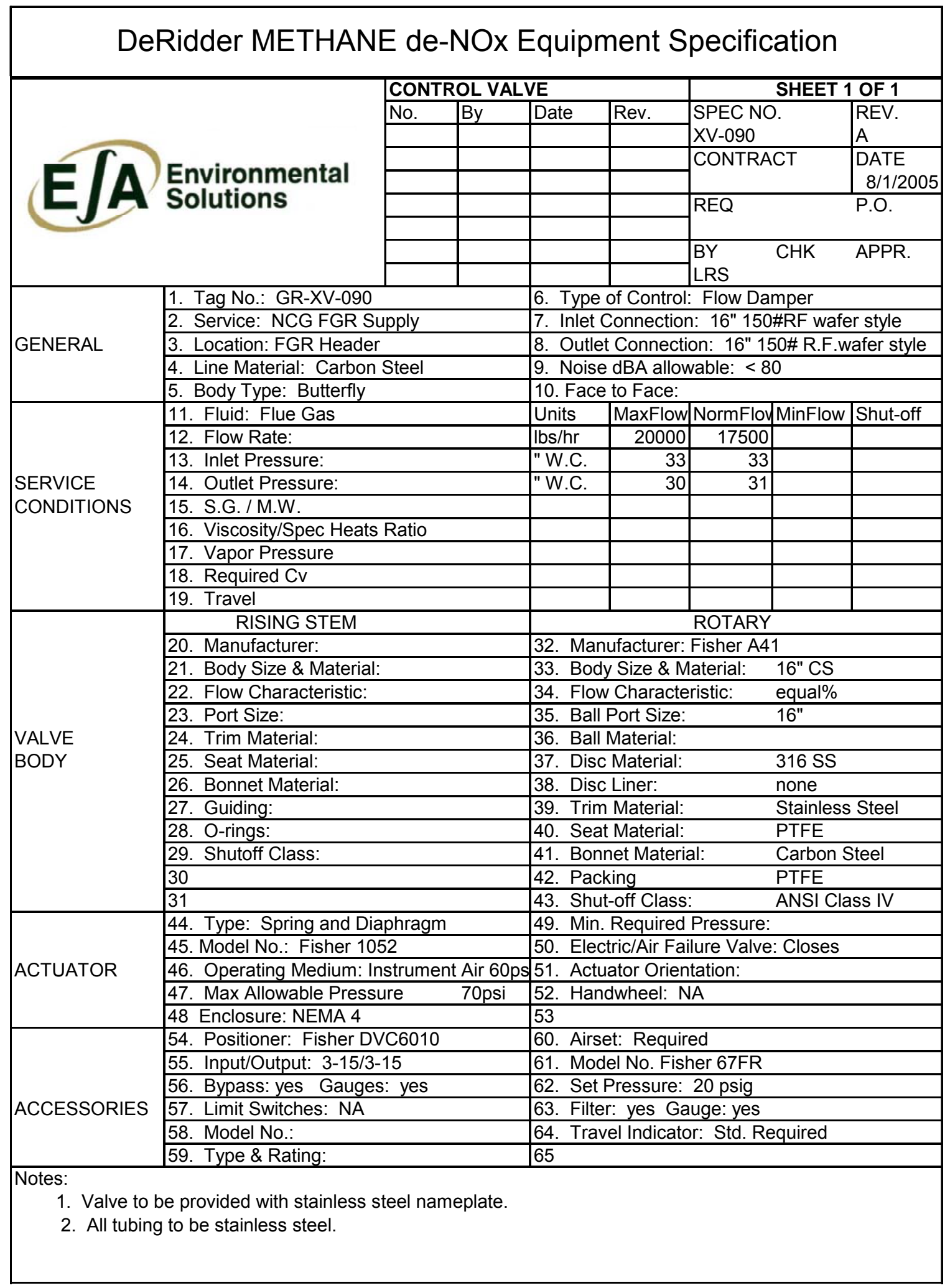




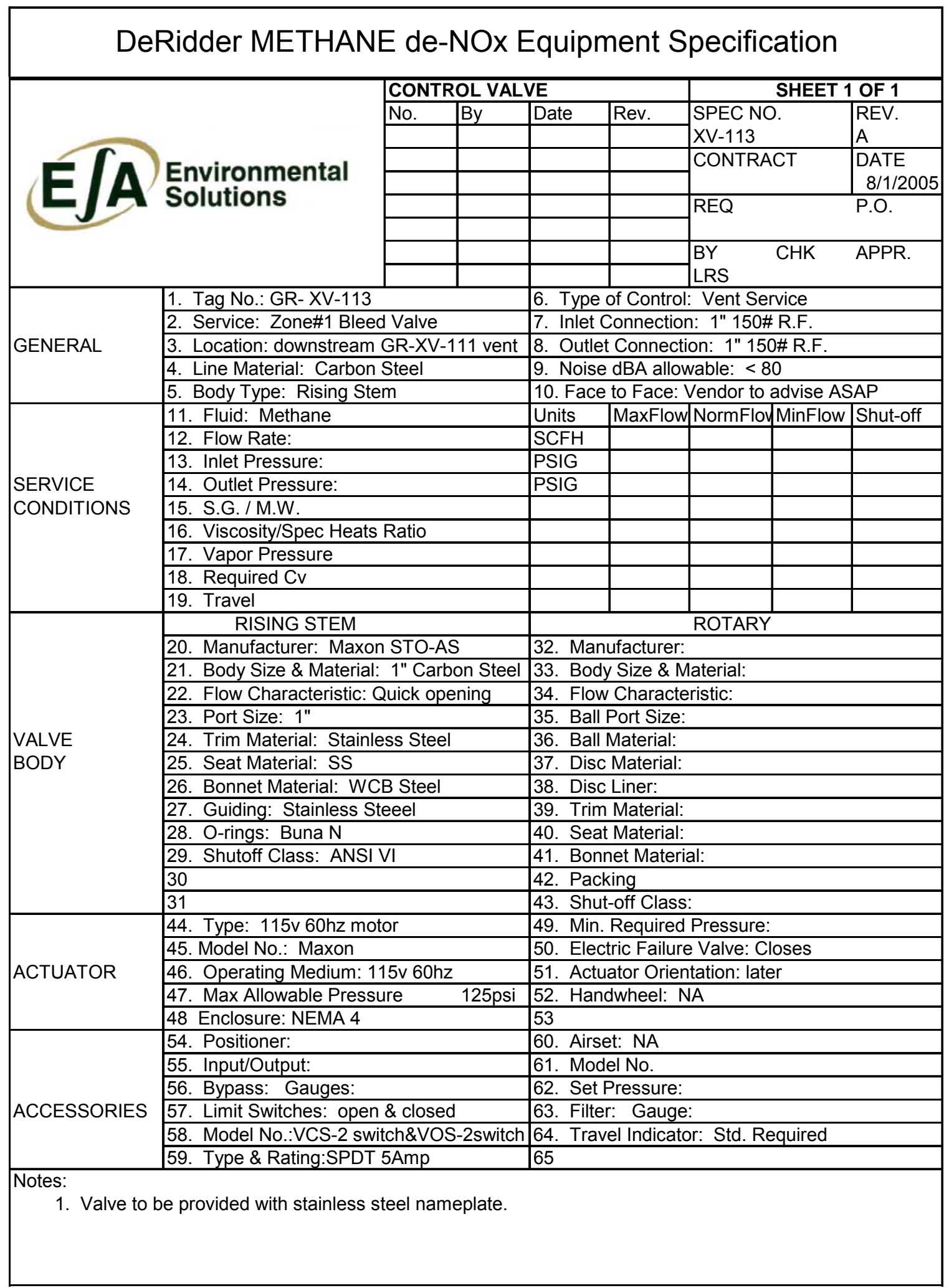




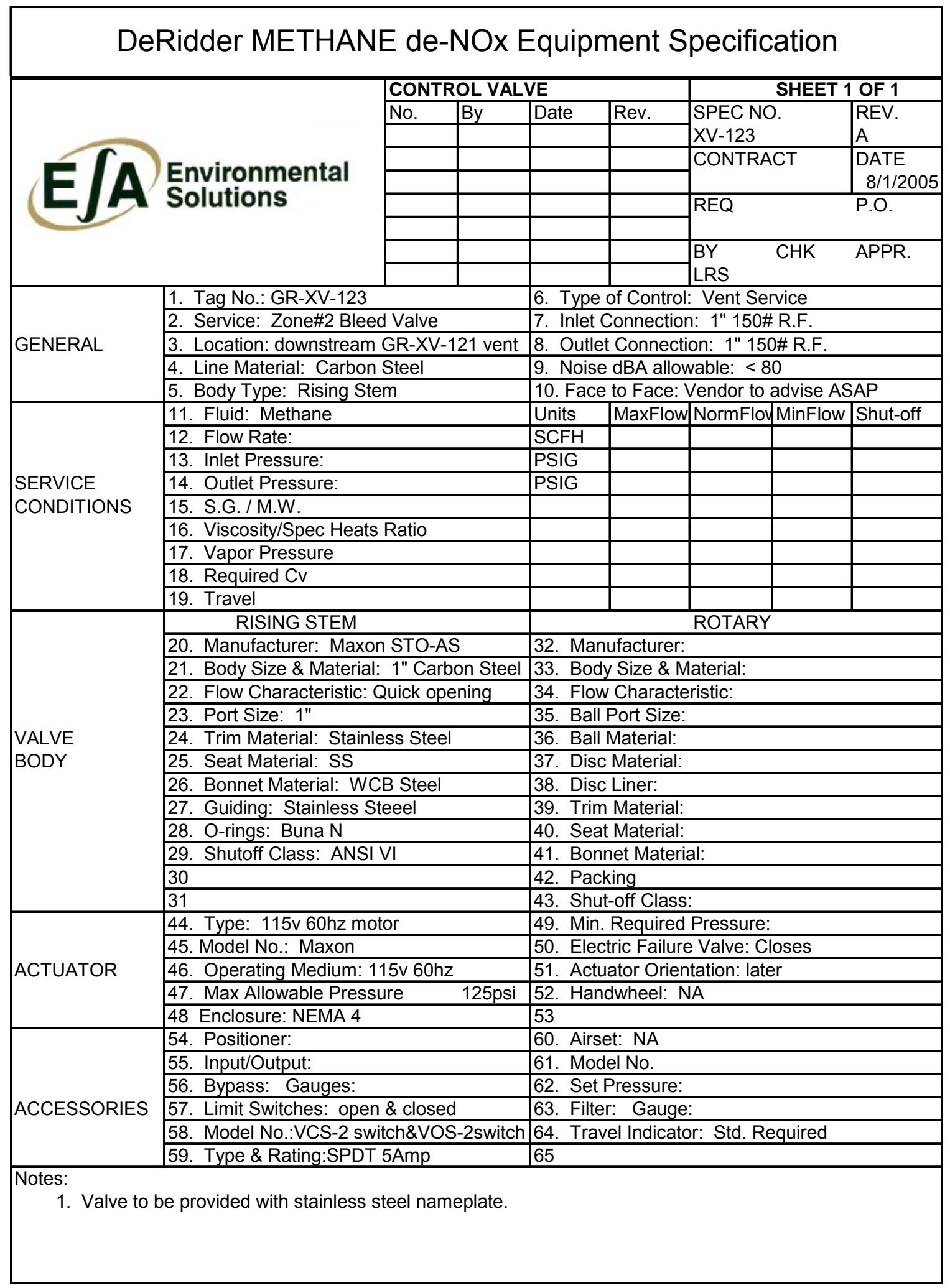




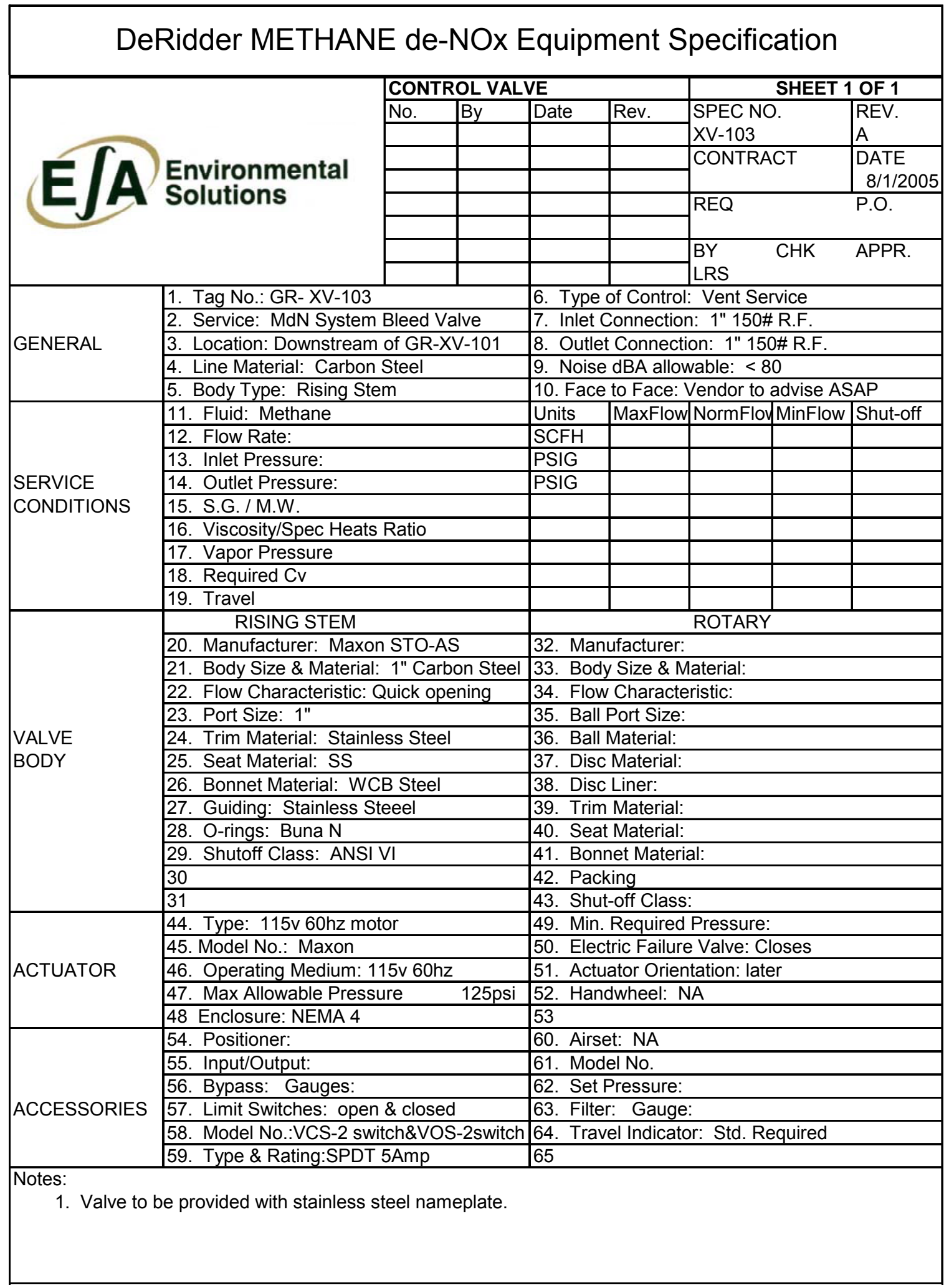




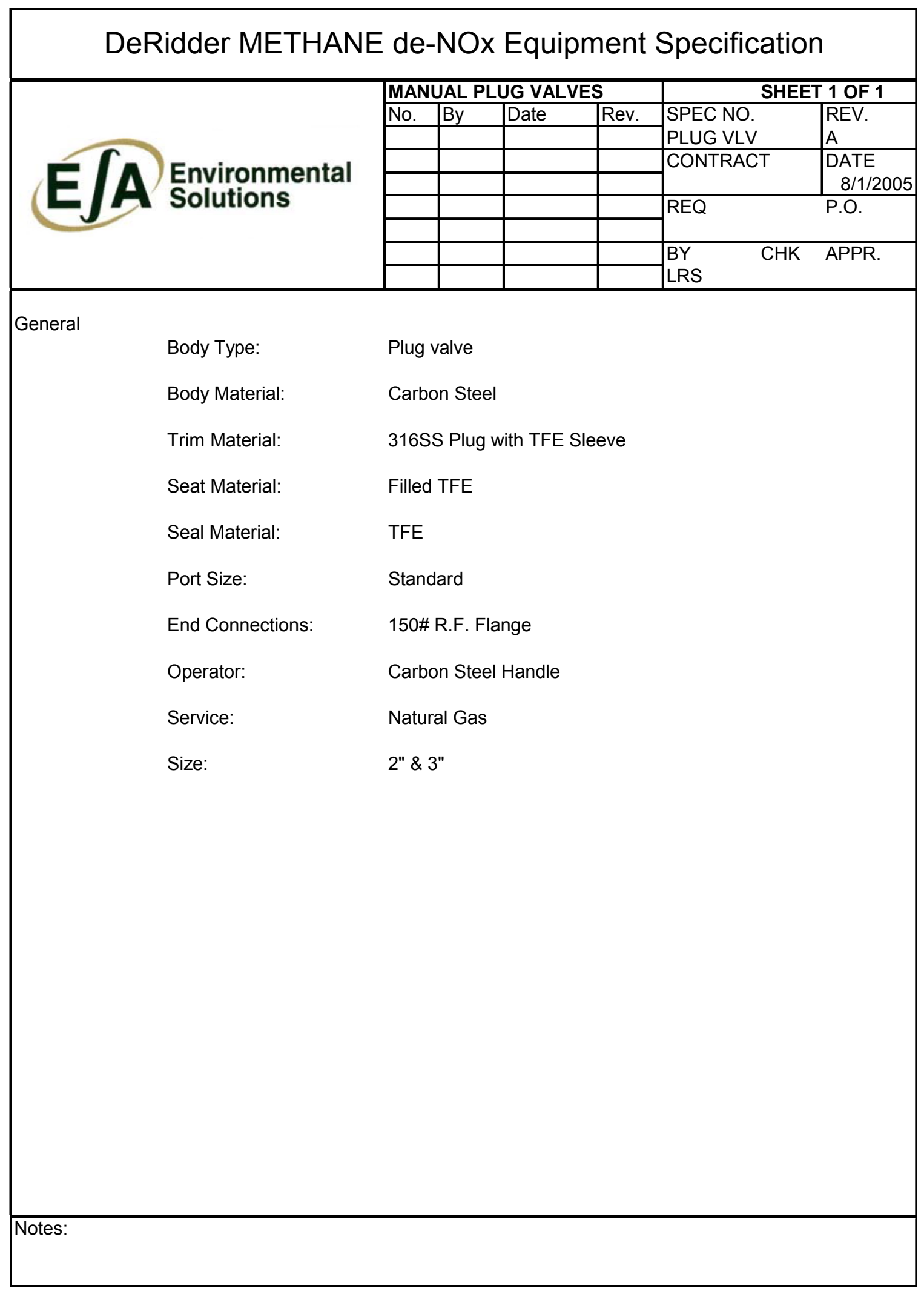




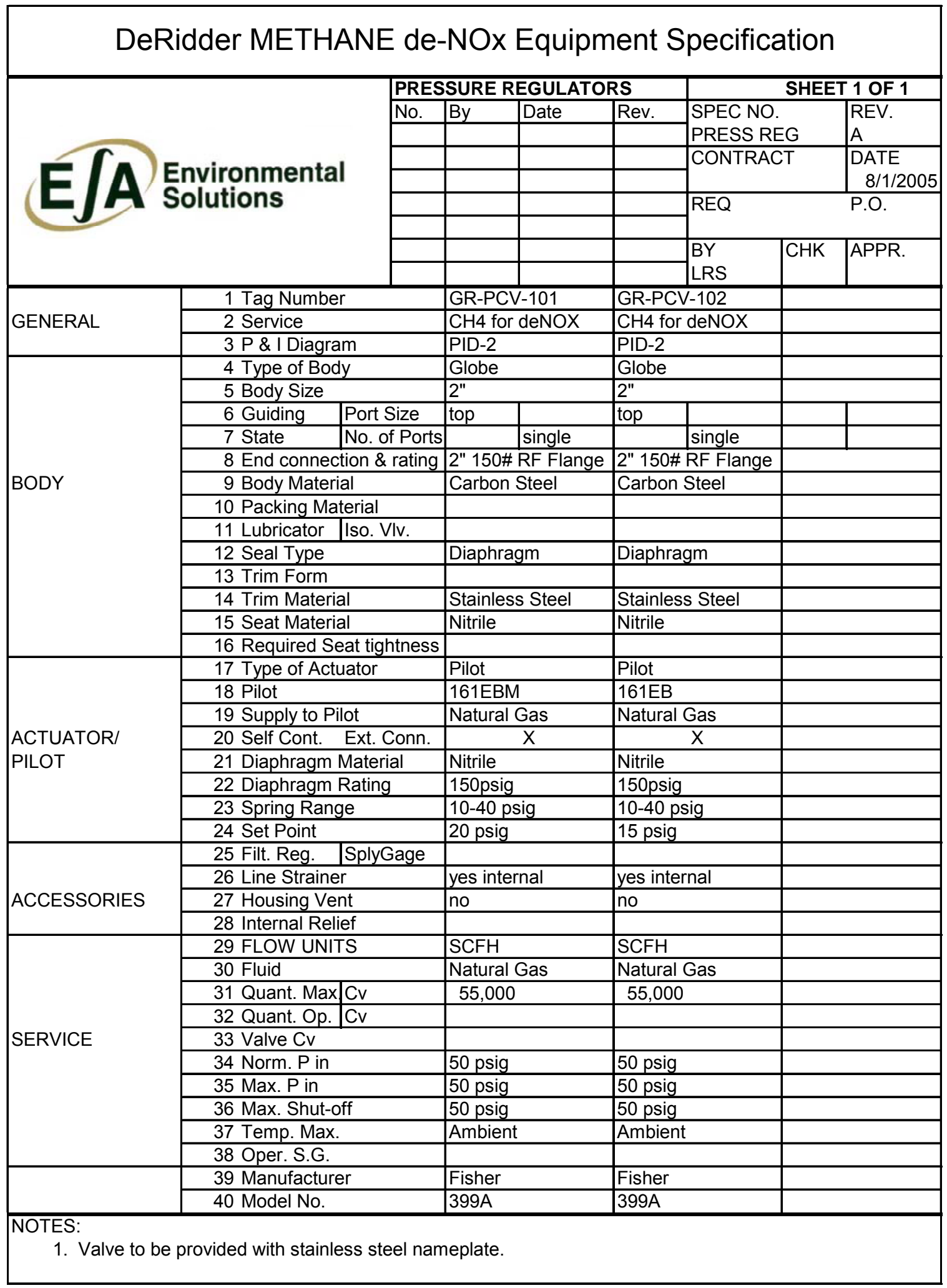




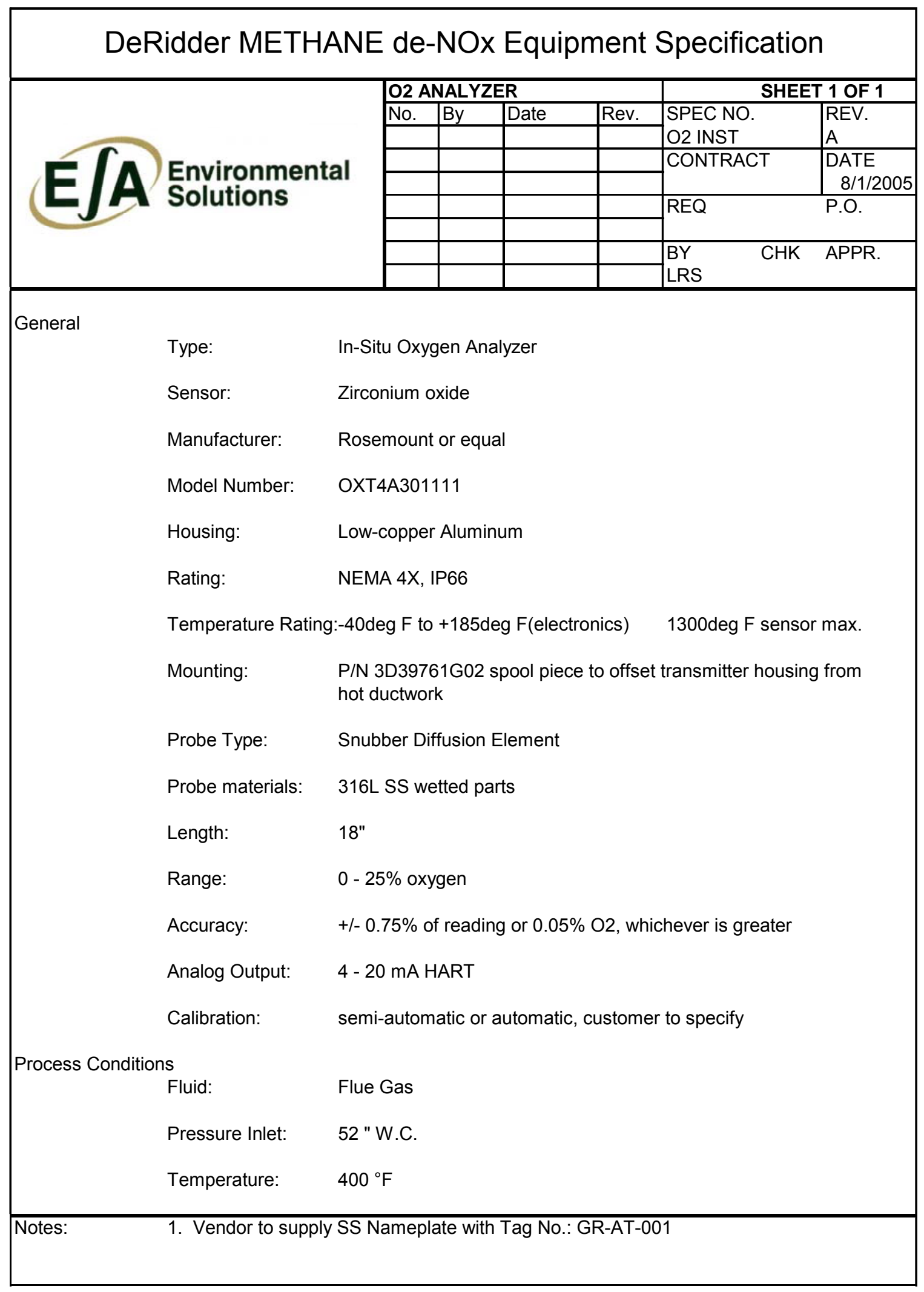




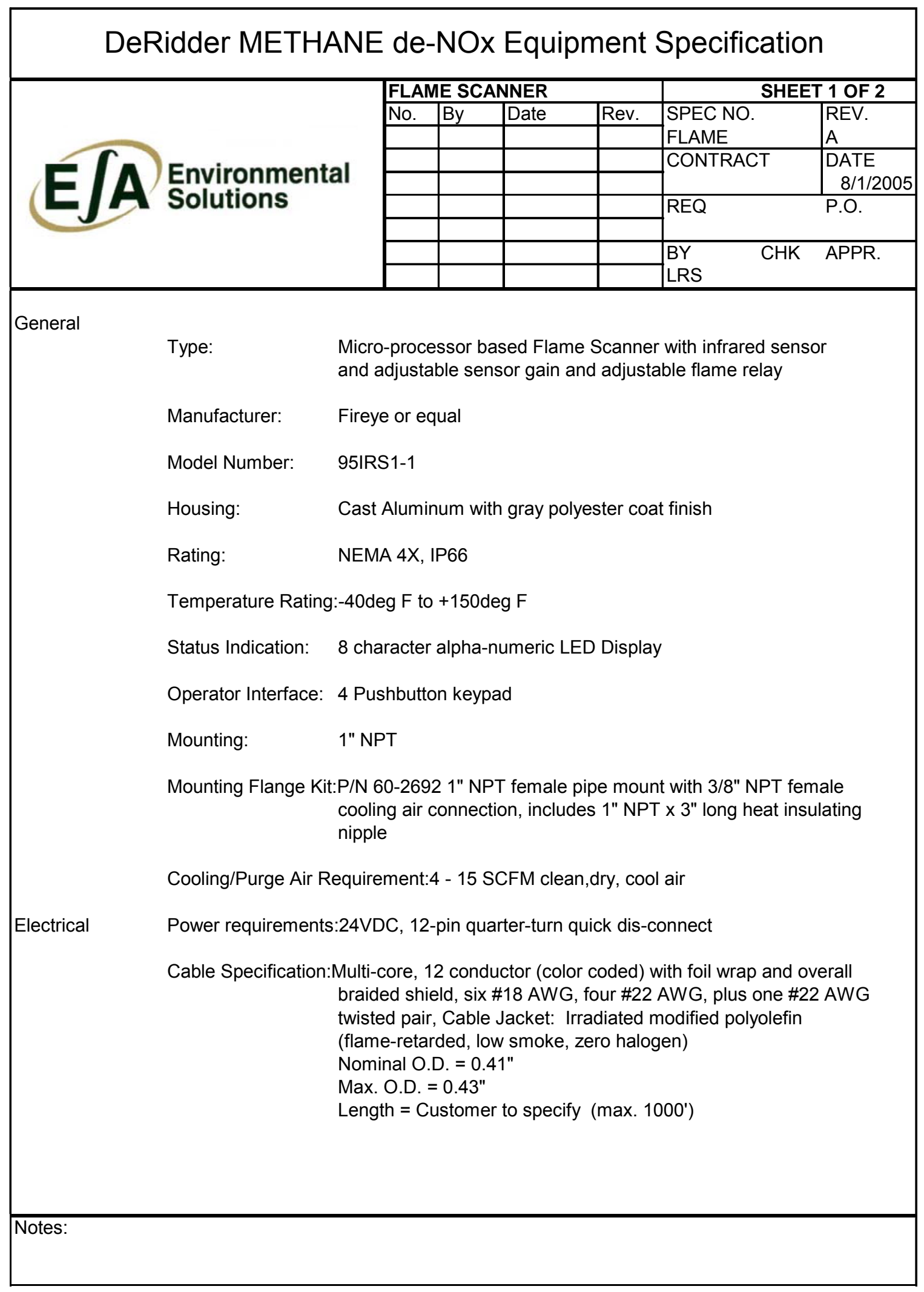




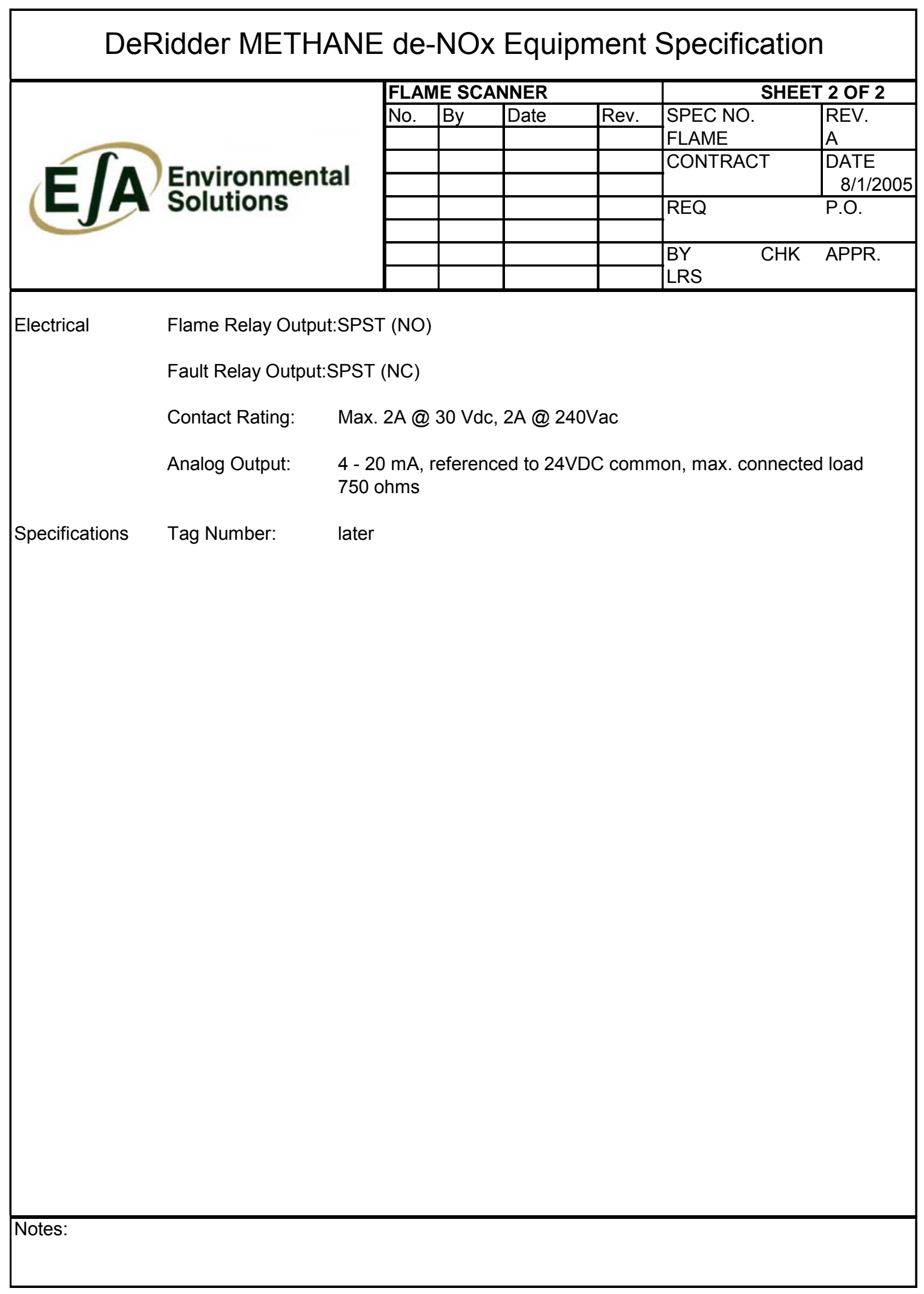




\section{Conclusions}

\subsection{International Falls MdN System}

The MdN construction was completed over a two month period with a short 5 day outage to make final tie-ins. The initial performance testing consistent of fifteen (15) tests and was conducted in December 1999. The parametric testing revealed several benefits in the operation of the boiler. The $\mathrm{NO}_{\mathrm{x}}$ emissions were reduced by $40 \%$ from baseline levels. The natural gas usage was decreased by $33 \%$ and the sludge feed rate increase by approximately $300 \%$. The general observations of the grate region indicated a more stable combustion environment and the carbon content in ash substantiated this observation. The bottom ash and fly ash carbon levels decreased by $52 \%$ and $25 \%$, respectively.

GTI and mill personnel inspected the boiler after thirty (30) days and six (6) months of MdN operation. The boiler equipment and MdN injection ports had no detrimental effects. A comparison of operating conditions from the eight months prior $\mathrm{MdN}$ installation and the first eight months of $\mathrm{MdN}$ showed a decrease of $55 \%$ in $\mathrm{NO}_{\mathrm{x}}$ emissions, a $1.4 \%$ increase in thermal efficiency, a $25 \%$ reduction in natural gas usage, and an increase of $120 \%$ in sludge feed rate.

After the MdN system had been in operation for one year, the mill personnel performed an economic and performance evaluation on the system. The quantity of sludge burned in the boiler doubled over the year prior to $\mathrm{MdN}$ operation. The $\mathrm{NO}_{\mathrm{x}}$ emissions were controlled to the state environmental limits, boiler efficiency increased over 1\%, and the quantity of natural gas used decreased by $50 \%$. The total savings for the first year of operation was $\$ 770,000$ with $\$ 100,000$ in avoided landfill cost and \$670,000 in natural gas savings. The natural gas savings was based on a $\$ 4$ per MMBtu gas cost.

\subsection{Wallula MdN System}

The MdN design for the Wallula boiler is predicted to reduce the $\mathrm{NO}_{\mathrm{x}}$ emissions approximately $50 \%$. The carbon monoxide emissions for this level of $\mathrm{NO}_{\mathrm{x}}$ reduction should be controlled to below $200 \mathrm{ppm}$. The mill is expected to see a 5-10\% reduction in natural gas consumption with the MdN system. Based on the baseline data collected the natural gas feed rate would decrease by 4,000-8,000 scfh and would result in an annual savings of $\$ 250,000-\$ 500,000$.. The displacement of natural gas from the burners to the grate region would stabilize the grate combustion conditions and reduce the impact of burning high moisture content bark. The MdN system is also expected to improve the thermal efficiency of the boiler by $1.5-2.0 \%$ by reducing total boiler airflow.

\subsection{Port Hudson MdN System}

The initial testing of the MdN system began in September 2002. At this time only the FGR and OFA systems were available for operation. The $\mathrm{NO}_{\mathrm{x}}$ emissions with only OFA and FGR 
injection were $0.17-0.18 \mathrm{lb} / \mathrm{MMBtu}$ or $40 \%$ below baseline levels. The CO emissions at this condition were higher than predicted. The testing resumed in November 2002 with natural gas injection. The $\mathrm{NO}_{\mathrm{x}}$ emissions were recorded as low as $0.14 \mathrm{lb} / \mathrm{MMBtu}$ but were inconsistent and high levels of CO (2000 ppmv) were documented. The CO emission could be controlled to plant limits by increasing OFA pressure and flow but the $\mathrm{NO}_{\mathrm{x}}$ emissions increased with this adjustment to the OFA system.

The test data collected by GTI was used to tune the CFD model and run additional model case studies to address the operational problems of the MdN system. At the conclusion of the CFD model study, GTI made recommendations to modify the MdN system. The first recommendation was to introduce FGR to the OFA supply. The target FGR concentration in the OFA supply was 35\%. By mixing FGR with the OFA, a higher OFA pressure can be used to improve mixing with the furnace without significantly increasing oxygen in the upper furnace. The better mixing helped to reduce the CO levels without severely impacting the $\mathrm{NO}_{\mathrm{x}}$ reduction. The second recommendation was to re-commission the mid-level OFA header. This recommendation was also designed to improve the mixing characteristics of the OFA system.

Once the recommendations were implemented GTI returned to continue the tuning effort on the $\mathrm{MdN}$ system. The modified $\mathrm{MdN}$ system achieved $\mathrm{NO}_{\mathrm{x}}$ emissions of $0.18 \mathrm{lb} / \mathrm{MMBtu}$ with $\mathrm{CO}$ levels within the permitted levels. At this condition the natural gas injection flow was about 6\% of boiler total heat input and the FGR flow was equivalent to about $10 \%$ of the total flue gas

flow. The natural gas injected for the MdN was displaced from the natural gas burners. The MdN system

GTI continues to monitor boiler performance and is working with the Port Hudson mill in trials that may further optimize the system's $\mathrm{NO}_{\mathrm{x}}$ reduction capability.

\subsection{DeRidder MdN System}

The MdN design for the DeRidder boiler is expected to reduce NOx emissions by $40 \%$ from the current operating levels. Another benefit of the $\mathrm{MdN}$ system would be the reduction in the natural gas consumption of the boiler. The projected natural gas usage would be decreased by approximately $25 \%$ or 25,000 scfh. The natural gas consumption could be further reduced by demonstrating an alternative method for the disposal of NCG and SOG gas streams. The MdN system was designed to utilize the NCG and SOG waste gas streams. An additional natural gas reduction of 4,000-6,000 scfh would be realized when the maximum flow of NCG and SOG is injected through the MdN system. The reduction in natural gas usage is projected to save more than $\$ 1,000,000$ per year. The MdN system is also expected to improve the thermal efficiency of the boiler by $1-2 \%$. The objectives of the MdN system would be achieve while maintaining carbon monoxide emissions within the regulatory limits. 